\title{
A PHYLOGENETIC ANALYSIS OF FASCIOLARIIDAE (GASTROPODA: BUCCINOIDEA)
}

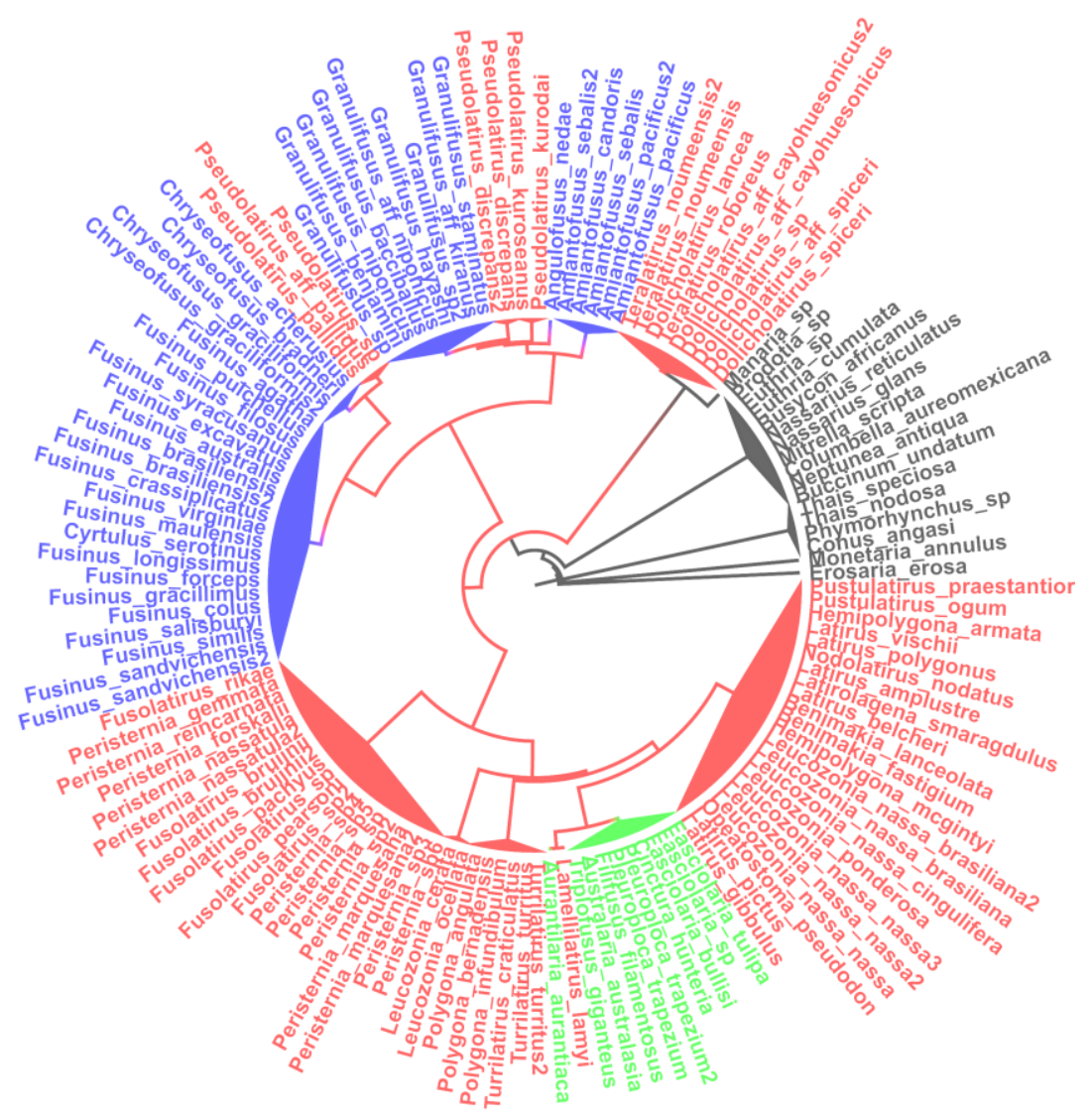

São Paulo, 2016 


\section{Diogo Ribeiro do Couto}

\section{A PHYLOGENETIC ANALYSIS OF FASCIOLARIIDAE (GASTROPODA: BUCCINOIDEA) ANÁliSe FILOGENÉTICA DE FASCIOLARIIDAE (GASTROPODA: BUCCINOIDEA)}

Dissertation presented to the post-graduate programme of the Museu de Zoologia da Universidade de São Paulo as a requirement for the aquisition of a Doctorate degree in Systematics, Animal Taxonomy and Biodiversity

Tese apresentada ao Programa de Pós Graduação do Museu de Zoologia da Universidade de São Paulo para obtenção do título de Doutor em Sistemática, Taxonomia Animal e Biodiversidade.

Supervisor/Orientador: Prof. Dr. Luiz Ricardo Lopes de Simone

São Paulo, 2016 


\section{Authorization/AutorizaÇÃo}

I authorize the reproduction and dissemination of this work in part or entirely by any electronic or conventional means, for study or research, provide the source is cited.

Autorizo a reprodução e divulgação total ou parcial deste trabalho, por qualquer meio convencional ou eletrônico, para fins de estudo e pesquisa, desde que citada a fonte. 


\section{Ficha CATALOGRÁfiCa}

Couto, Diogo Ribeiro

A phylogenetic analysis of Fasciolariidae (Gastropoda: Buccinoidea) / Análise filogenética de Fasciolariidae (Gastropoda: Buccinoidea) / Diogo Ribeiro do Couto; supervisor Luiz Ricardo Lopes de Simone - São Paulo, SP, 2016. Dissertation (doctorate) - Programa de Pós Graduação em Sistemática, Taxonomia Animal e Biodiversidade, Museu de Zoologia da Universidade de São Paulo..

1. Neogastropoda - phylogeny. 2. Morphology - Gastropod. 3. Totalevidence - analysis. I. Simone, Luiz Ricardo, orient. II. Título.

\section{Banca examinadora}

Prof. Dr. Instituição:

Julgamento: Assinatura:

Prof. Dr. Instituição:

Julgamento: Assinatura:

Prof. Dr. Instituição:

Julgamento: Assinatura:

Prof. Dr. Instituição:

Julgamento: Assinatura:

Prof. Dr. Instituição:

Julgamento: Assinatura: 


\section{ACKNOWLEDGMENTS}

First and foremost, I thank my family for the love and support I received throughout all my life: Martha, Lize, Anna and Edra Lee; Dilton Couto and D.C. Jr. Alexandre Selvatti and Maria Augusta and Terezinha Maria. My advisor, Luiz Simone, for the opportunity and aid in the fine craft of molluscan anatomy. To my friends and colleagues in the malacology lab of MZSP (and to those already departed), in which the daily life together brought much learning and maturing: Ana Paula Dornellas, Vanessa Simão, Daniel and Patícia Abbate, Jaime Jardim, Sérgio Mendonça, Hilton Galvão, Bárbara Louise, Rodrigo César Marques and Carlo Magenta. To all the technical staff and interns of the lab, that keep the wheels running: Daniel Cavallari, Isac Balbino, Natan Carvalho, Eugenio Melo, Cibele Carvalho, Fernanda Silva. Lara Guimarães for the SEM sessions, to the academic staff Marta Maria, Omair Filho and Sonia de Araújo for their help. To Dione Seripierri, for the immense help in the Reference section of this dissertation. I thank Gary Rosenberg (ANSP), Gustav Paulay (FMNH), Daniel Geiger (SBMNH) and Gregory Herbert (USF) for loan of additional specimens and sending of molecular samples for this work; Philippe Bouchet kindly loaned specimens from the Museum in Paris, and greatly helped in the taxonomy. Virginie Héros, Philippe Maestrati, Pierre Lozouet, Barbara Buge, Laurent Charles $(\mathrm{MNHN})$ and Ellen Strong (NMNH) for their role in specimen processing during the expeditions and curation. Martin Snyder, Paul Callomon (ANSP) and Yuri Kantor (SIEEM) for their help in species identification and other insights. Other friends, in different spheres of life, include, but are not limited to: Babies: Renata Novaes, Gabriel Costa and Andre Costa; Julia Castro, Gabi and Gisa Sobral, Fernanda Oliveira, Luiz Renato, Simeão Moraes, the [bio]family: Flavia Sant'Anna, Raíssa Rosa, Victor Santos, Veronica Slobodian, Eloísa Zanin; to my brothers in UFRJ: Daniel Paiva, Elias Viana and Filipe Alonso; Beta Graboski and Felipe Grazziotin, Jorge Calvimontes, Vanessa Pose, Barbara Vale, Paula Garcia, Felipe Bastos and Dudu Dvogt, Marina Avila; Nathalia Granado, Jesine Falcão and Luiza Gondin; Rafa Lumi and Andre Giroti; Rafaela Jorge Trad and Cristiano Sampaio; finally, Nathalia Machado and Leandro Grance. Gonzalo Giribet (MCZ) made the molecular part of this work possible, opening up his lab and allowing the most fruitful experience of my academic career. To all his team, Rosa Fernández, Sarah Lemer, David Combosch, Erin McIntyre, Tauana Cunha, Ana Tourinho and Beka Buckham, that helped with many aspects of bench work and analysis and Adam Baldinger (MCZ) for help in collection and 
management. Lee Ann Galindo (MNHN) and Patricia Álvarez (UAM) provided helpful insights during the early stages of the lab work; Alexander Fedosov and Nicolas Puillandre (MNHN) for sending useful sequence information; John Slapcinsky (FMNH) sent photographic material. Jeffrey Doucette, David Becker, Augustin (A.J.) Rodriguez and Bruna Palsen were essential friends during the making of this dissertation abroad. This work was funded by grant \#2012/14821-3, Fundação de Amparo à Pesquisa do Estado de São Paulo (FAPESP), Brazil. Funds abroad came from grant \#2014/10951-5 of FAPESP and by internal funds from the MCZ and the Faculty of Arts and Sciences, Harvard University. 


\section{AbStraCT}

The neogastropod family Fasciolariidae comprise of important representatives of tropical and subtropical molluscan assemblages, with over 500 species in the subfamilies Fasciolariinae, Fusininae and Peristerniinae. Fasciolariids - with many well-known species such as tulip shells, horse-conchs, spindles, among others - have a long complicated taxonomical history, with several genus names being used to group heterogeneous contingents of many unrelated species. Recently, however, taxonomical revisions have begun to set straight its taxonomy. The present work aims to resolve the phylogeny of the family Fasciolariidae, through: 1) a morphological phylogenetic parsimony analysis in TnT based on 95 characters and 53 taxa which revealed a monophyletic Fasciolariidae, with the genera Dolicholatirus and Teralatirus representing the first split in the family, followed by three splits that correspond to a fusinine grade, which also include the genus Pseudolatirus (Peristerniinae); a last split groups the peristerniine genera Peristernia and Fusolatirus, while the last group comprises of fasciolariines and the remaining peristerniines. None of these clades correspond to the present-day accepted circumscription of the three recognized subfamilies. 2) Complementing the work of Couto et al. (2016), which used a fivegene molecular dataset to analyze the phylogeny of the family. To this dataset, the previous morphological matrix was added, generating a total evidence dataset that was implemented in POY. This analysis revealed a non-monophyletic family with the genera Dolicholatirus and Teralatirus as non-fasciolariids; the remaining fasciolariids are well-supported, with the first split a monophyletic Fusininae and Pseudolatirus; a second split groups Peristernia and Fusolatirus; while the last, the remaining peristerniines and fasciolariines. Total evidence was congruent with the morphological data with the exception of the Fusininae that appeared as a crown-group and not as a grade; Lamellilatirus lamyi (Peristerniinae) nested within the fasciolariines. Finally, 3) supplement the phylogenetic analysis of Simone (2011), inserting the analyzed taxa from the morphological analysis in the same dataset. This resulted in a monophyletic Buccinoidea superfamily, a monophyletic Fasciolariidae, despite low resolution of relationship for internal taxa; Dolicholatirus nested within Fasciolariidae and the fusinines with Pseudolatirus appeared as a monophyletic crown-group.

Key-words: Neogastropoda, Fasciolariinae, Peristerniinae, Fusininae, Dolicholatirus, morphology, total-evidence 


\section{RESUMO}

A família de neogastrópodes Fasciolariidae é composta por representantes significativos da malacofauna em mares tropicais e subtropicais, com mais de 500 espécies descritas nas subfamílias Fasciolariinae, Fusininae e Peristerniinae. Os fasciolarídeos possuem um longo e confuso histórico taxonômico, com muitas espécies sendo alocados em gêneros claramente heterogêneos, resultando em agrupamentos que não refletem relação de parentesco. $\mathrm{O}$ presente estudo tem como objetico gerar hipóteses de filogenia da família Fasciolariidae; dessa maneira, foi realizada: 1) uma análise filogenética através de parcimonia no programa TnT, baseada em 95 caracteres morfológicos e 53 espécies, na qual demostrou a monofilia da família. Em relação aos arranjos internos dos fasciolarídeos, as subfamílias que compõem esse clado não são monofiléticas. Segundo a topologia obtida, observou-se que a primeira divergência separa um grupo com os gêneros Dolicholatirus e Teralatirus; a seguir, três divisões que correspondem a um grado de fusiníneos, que também inclui o gênero Pseudolatirus (Peristerniinae); uma última divisão, na qual se observa uma dicotomia que agrupa os gêneros de peristerníneos Peristernia e Fusolatirus, e os demais peristerníneos e fasciolaríneos. 2) Complementar o trabalho de Couto et al. (2016), que utilizaram dados moleculares de cinco genes para analisar a filogenia da família. A esses dados, foram incluídos também a matriz da análise morfológica, a fim de realizar uma análise de evidência total implementada no programa POY. O resultado dos dados concatenados corrobora com a análise molecular evidenciando a família Fasciolariidae como um clado não monofilético, uma vez que os gêneros Dolicholatirus e Teralatirus não estão incluídos na família; os demais fasciolarídeos formam um clado com uma primeira divisão que separa os fusiníneos e Pseudolatirus dos demais; uma segunda divisão compondo os peristerníneos Peristernia e Fusolatirus e a última agrupa os demais peristerníneos e fasciolaríneos. Dados de evidência total foram congruentes com a análise morfológica, com exceção dos fusiníneos, que apareceram como um grupo monofilético e Lamellilatirus lamyi (Peristerniinae) dentro dos fasciolaríneos. Finalmente, 3) inserir as espécies analisadas na análise morfológica, na matriz de dados de Simone (2011). Esta última análise resultou um uma superfamília Buccinoidea monofilética, a família Fasciolariidae sendo monofilético apesar de com uma topologia com pouca resolução interna para os táxons internos; Dolicholatirus e Teralatirus estão incluídos na família e os fusiníneos mais o gênero Pseudolatirus como um grupo monofilético.

Palavras-chave: Neogastropoda, Fasciolariinae, Peristerniinae, Fusininae, Dolicholatirus, morfologia, evidência-total 


\section{LIST OF FIGURES}

\section{Chapter I}

Figure 1A. Phylogenetic tree obtained through parsimonious analysis in TnT using prior, unweighted characters.

Figure 1B. Phylogenetic tree obtained through parsimonious analysis in TnT using prior, unweighted characters. 21

Figure 2. Phylogenetic tree (part one) indicating the synapomorphies that support them...........22

Figure 3. Phylogenetic tree (part two) indicating the synapomorphies that support them...........23

Figure 4. Phylogenetic tree (part three) indicating the synapomorphies that support them.........24

Figure 5. Phylogenetic tree (part four) indicating the synapomorphies that support them..........25

Figure 6. Phylogenetic tree obtained through parsimonious analysis in TnT with prior weighing.

Numbers in nodes indicate node numbers..............................................................26

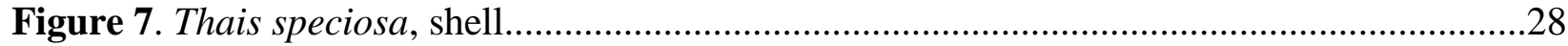

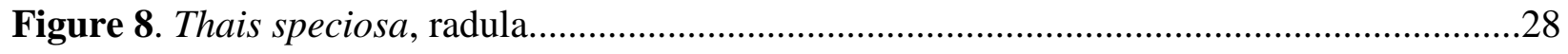

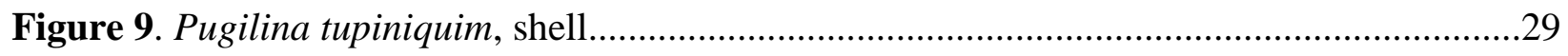

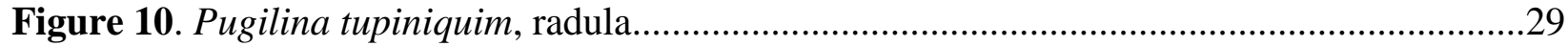

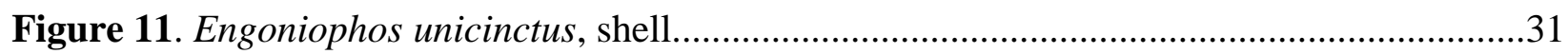

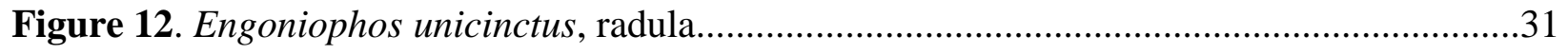

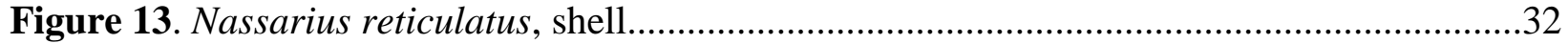

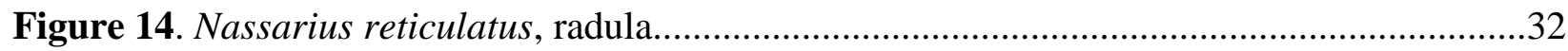

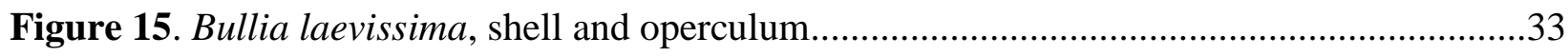

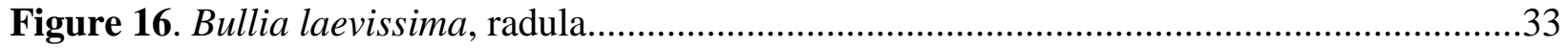

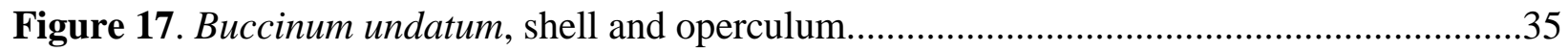

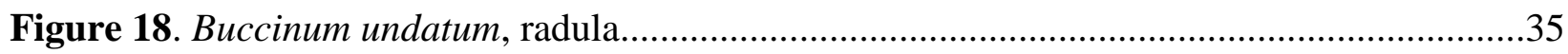

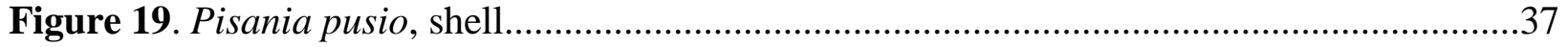

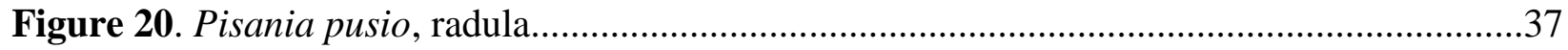

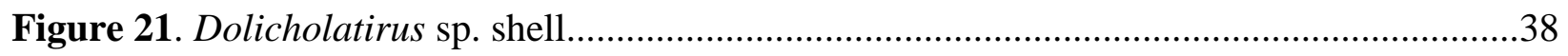

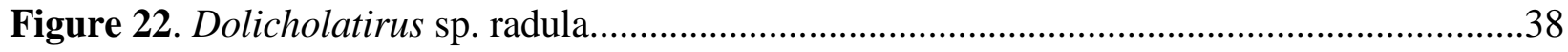

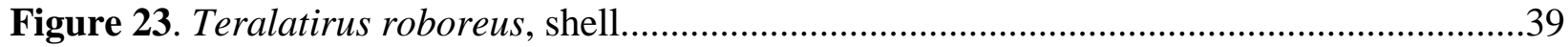

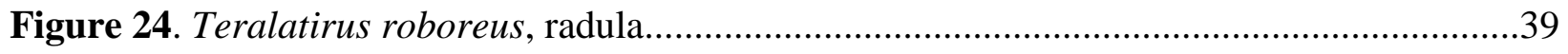


Figure 25. Dolicholatirus aff. cayohuesonicus, shell........................................................40

Figure 26. Dolicholatirus aff. cayohuesonicus, radula..........................................................40

Figure 27. Pseudolatirus kuroseanus, shell........................................................................42

Figure 28. Pseudolatirus kuroseanus, radula..................................................................42

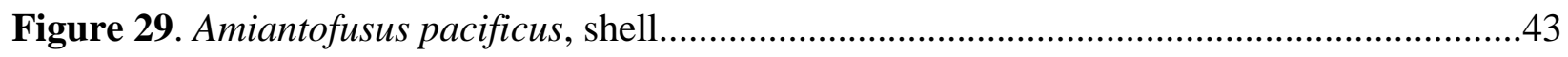

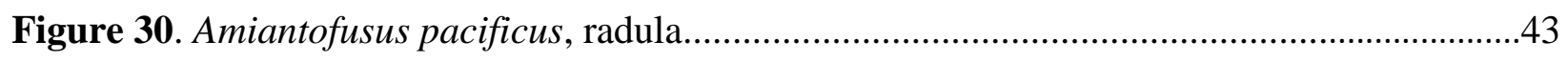

Figure 31. Amiantofusus candoris, shell.....................................................................4

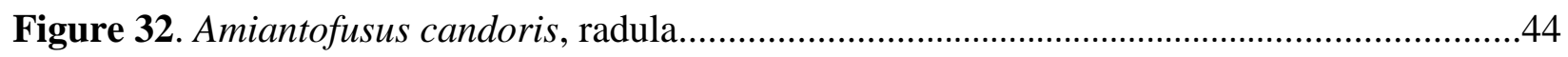

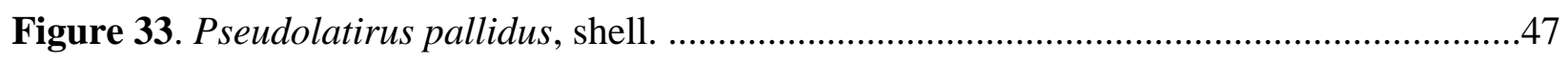

Figure 34. Pseudolatirus pallidus, radula....................................................................47

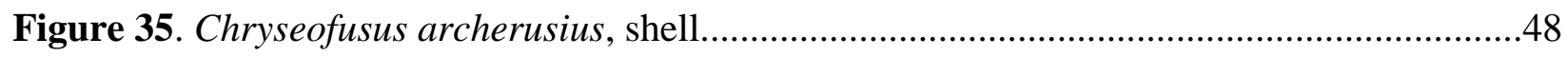

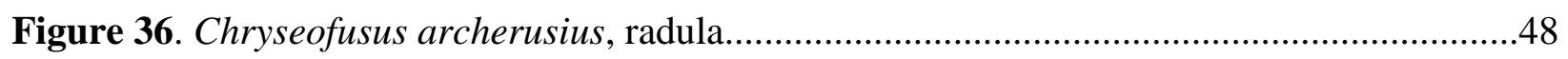

Figure 37. Chryseofusus graciliformis, shell................................................................50

Figure 38. Chryseofusus graciliformis, radula.................................................................50

Figure 39. Fusinus brasiliensis, shell and operculum.....................................................51

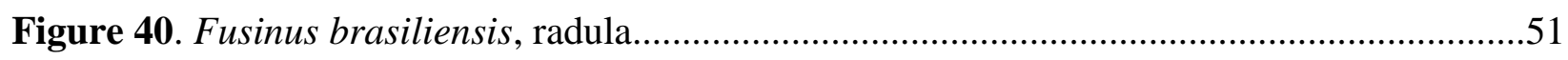

Figure 41. Fusinus marmoratus, shell and operculum.....................................................52

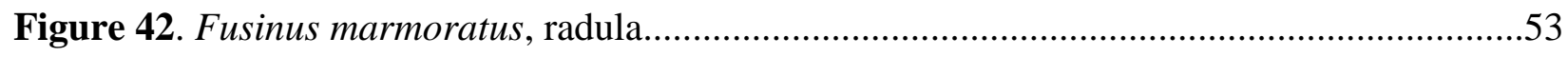

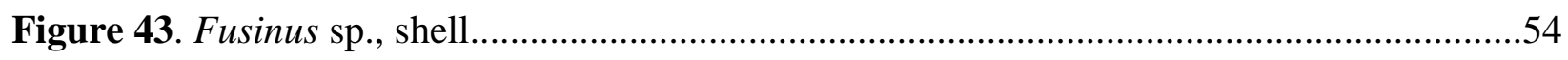

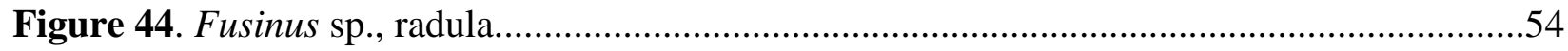

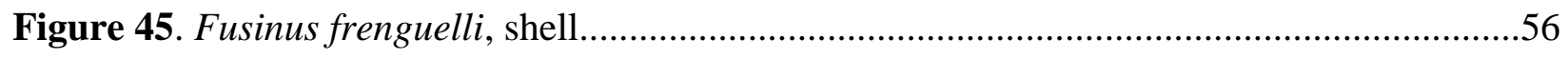

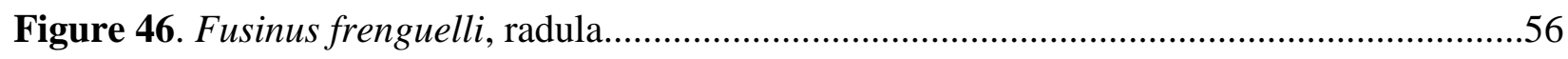

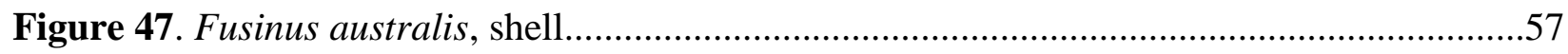

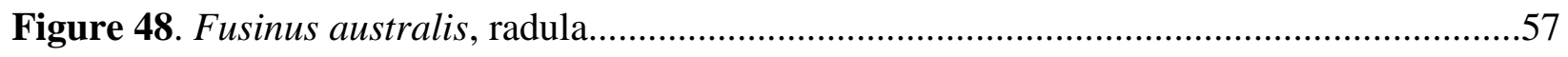

Figure 49. Cyrtulus serotinus, shell in growth series.......................................................58

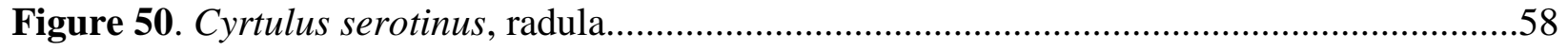

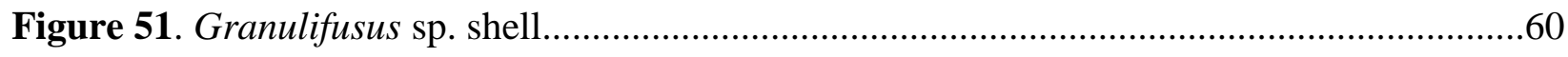

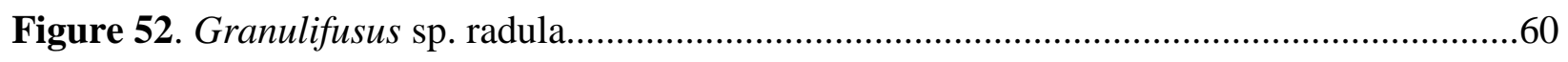

Figure 53. Granulifusus hayashi, shell......................................................................61

Figure 54. Granulifusus hayashi, radula......................................................................61

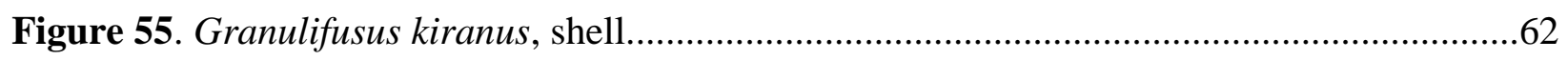




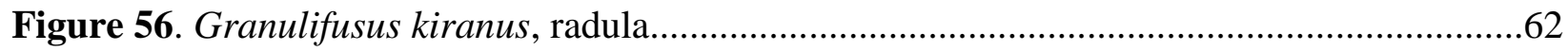

Figure 57. Pseudolatirus discrepans, shell......................................................................64

Figure 58. Pseudolatirus discrepans, radula..................................................................64

Figure 59. Fusolatirus bruijnii. shell and operculum......................................................66

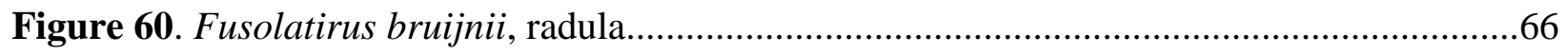

Figure 61. Peristernia nassatula, shell and operculum...................................................67

Figure 62. Peristernia nassatula, radula..........................................................................67

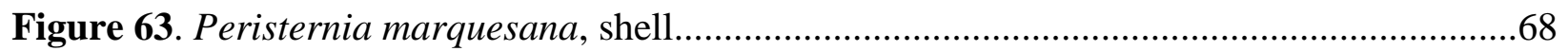

Figure 64. Peristernia marquesana, radula.......................................................................68

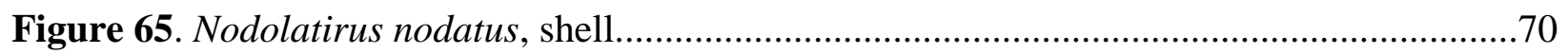

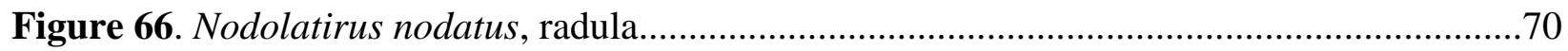

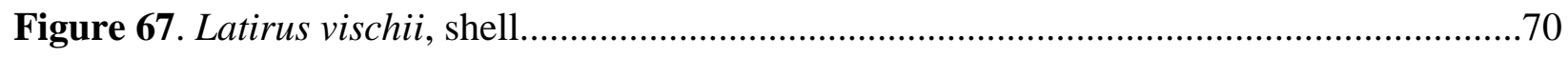

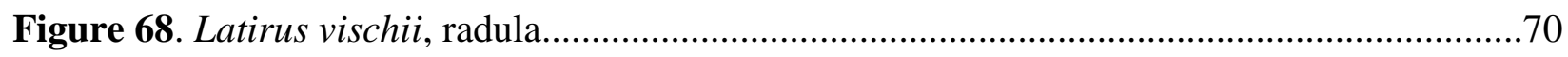

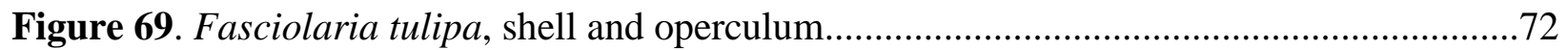

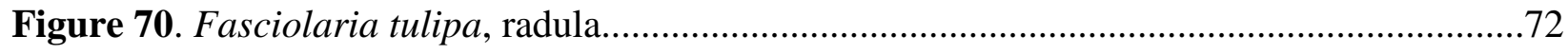

Figure 71. Aurantilaria aurantiaca, shell and operculum..................................................74

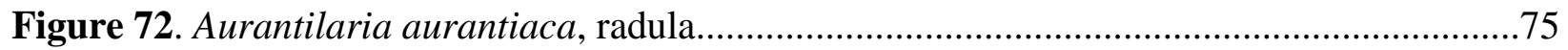

Figure 73. Filifusus filamentosus. shell and operculum....................................................76

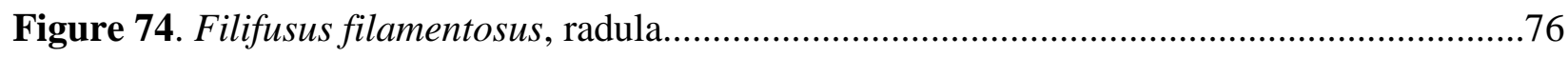

Figure 75. Australaria australasia, shell....................................................................... 77

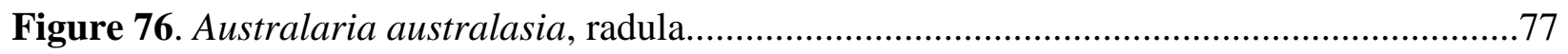

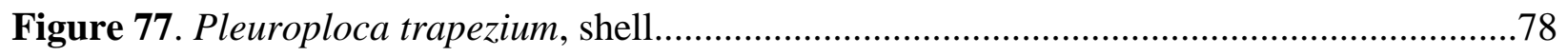

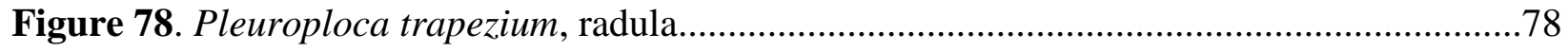

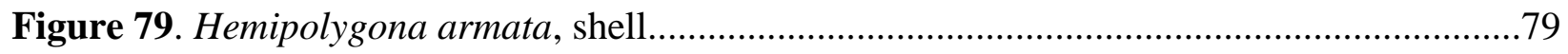

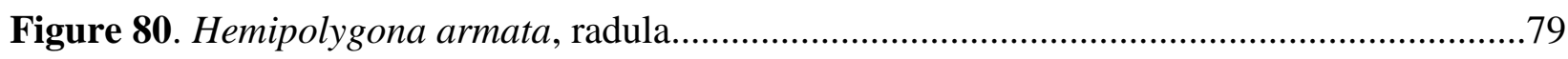

Figure 81. Pustulatirus mediamericanus, shell.................................................................80

Figure 82. Pustulatirus ogum, shell and operculum.........................................................81

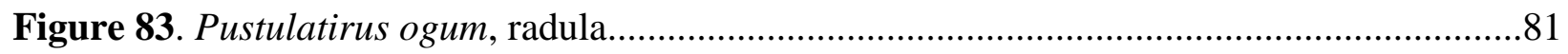

Figure 84. Polygona angulata, shell and operculum........................................................82

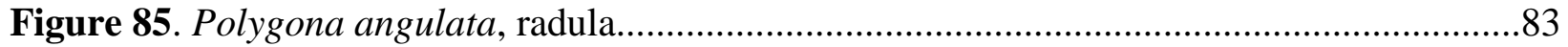

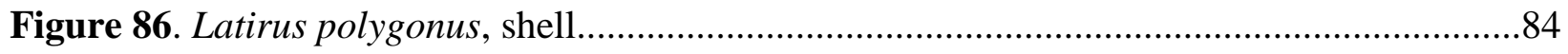




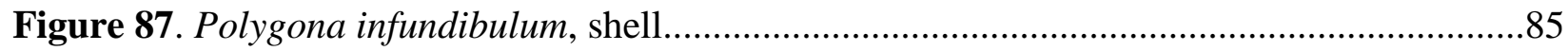

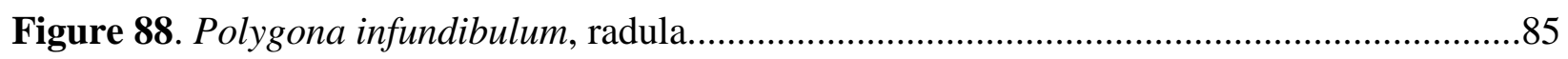

Figure 89. Hemipolygona beckyae, shell and operculum...................................................86

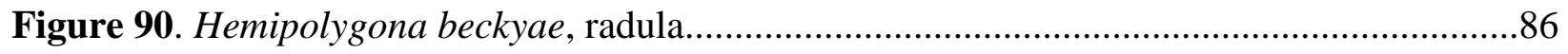

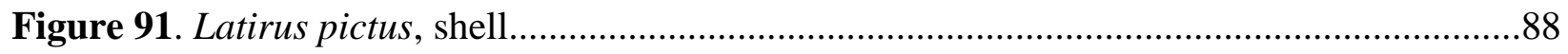

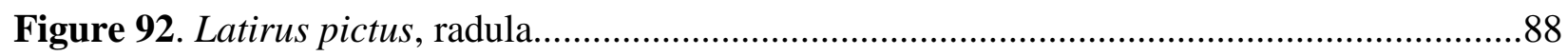

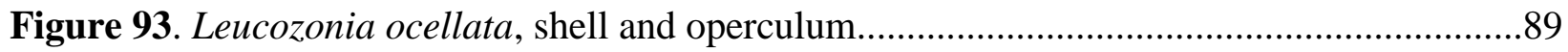

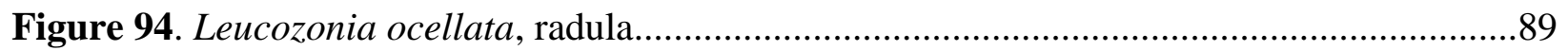

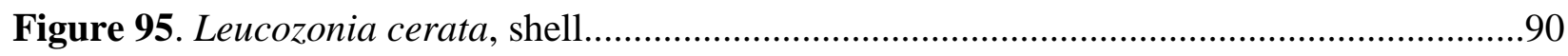

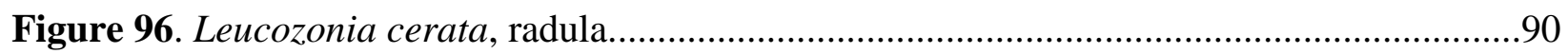

Figure 97. Opeatostoma pseudodon, shell and operculum.................................................92

Figure 98. Opeatostoma pseudodon, radula.....................................................................92

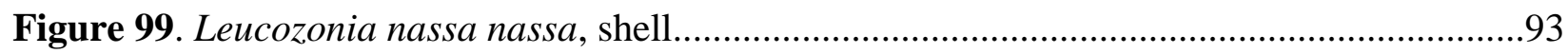

Figure 100. Leucozonia nassa cingulifera, shell.....................................................................94

Figure 101. Leucozonia nassa brasiliana, shell.................................................................95

Figure 102. Leucozonia nassa brasiliana, radula................................................................95

Figure 103. Leucozonia ponderosa, shell and operculum.....................................................96

Figure 104. Leucozonia ponderosa, radula..........................................................................96

Figure 105. Strict consensus of the obtained trees from Ponder \& Lindberg (1997).................99

Figure 106. Strict consensus tree of the analysis of Caenogastropoda based on morphological

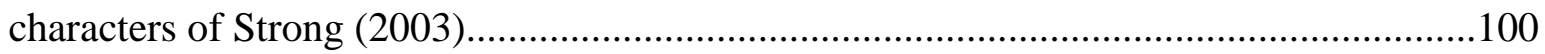

Figure 107. Strict consensus tree of the Caenogastropoda analysis of Simone (2011)..............101

Figure A. Shell in apertural and abapertural view. A1-2. Monetaria annulus (modified from Simone, 2004); A3. Opeatostoma pseudodon; 4A. Fusinus frenguelli.

Figure B. Shell in apertural view. B1. Aurantilaria aurantiaca; B2. Amiantofusus candoris; B3. Pseudolatirus sp.

Figure C. Shell in apertural view. C1. Dolicholatirus sp.; C2. Chryseofusus graciliformis; C3. Aurantilaria aurantiaca......

Figure D. Shell in apertural view and detail of aperture. D1. Pisania pusio; D2-3. Angulofusus nedae (modified from Fedosov \& Kantor, 2012). 
Figure E. Shell in apertural and lateral view. E1. Latirus vischii; E2-3. Leucozonia nassa cingulifera; E4-5. Opeatostoma pseudodon............................................................. 145

Figure F. Shell, lateral view. F1. Pisania pusio; F2. Hemipolygona beckyae ...........................146

Figure G. Apertural view of shell. G1. Pseudolatirus discrepans; G2. Pleuroploca trapezium;

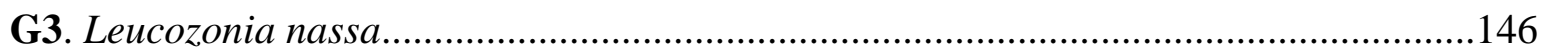

Figure H. Apertural view of shell. H1. Granulifusus sp.; H2. Filifusus filamentosus................147

Figure I. Shell in apertural view. I1. Buccinum undatum; I2. Leucozonia ocellata; I3. Fusinus

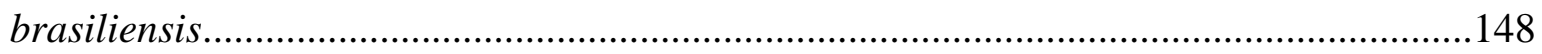

Figure J. Shell in apertural view 1J. Pseudolatirus pallidus; 2J. Fusolatirus bruijnii................148

Figure K. Live specimens with body extended. K1. Buccinum undatum, (0); K2. Fusinus brasiliensis; K3. Aurantiaca aurantiaca; K4.Leucozonia nassa brasiliana.......................149

Figure L. Head in ventral view. L1. Buccinum undatum; L2. Polygona angulata....................150

Figure M. Head in ventral view. M1. Pseudolatirus pallidus; M2. Fusinus brasiliensis; M3.

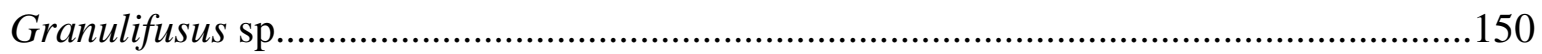

Figure N. Bullia laevissima (modified from Abbate \& Simone, 2016)...................................152

Figure O. Shell in apertural view. O1. Granulifusus kiranus; O2. Latirus polygonus................152

Figure P. Operculum in dorsal view. P1. Granulifusus poppei (modified from Preetha et al., 2014); P2. Fusinus frenguelli

Figure Q. Operculum in ventral view. Q1. Buccinum undatum; Q2. Fusinus marmoratus; Q3. Peristernia nassatula .153

Figure R. head-foot and visceral mass. R1.. Buccinum undatum (1); R2. Pisania pusio. .154

Figure S. Ventral view of the roof of the pallial cavity evidencing the osphradium. 1S. Dolicholatirus cayohuesonicus; 2S. Fusinus frenguelli; 3S. Amiantofusus candoris

Figure T. Ventral view of osphradium and transversal section of the roof of the pallial cavity, evidencing the osphradium. T1-2. Aurantilaria aurantiaca; T3-4. Opeatostoma pseudodon. .156

Figure U. Transversal section of the roof of the pallial cavity in the osphradium region. U1. Dolicholatirus cayohuesonicus; U2. Fusinus australis.

Figure V. Transversal section of the roof of the pallial cavity in the osphradium and ctenidium region. V1. Opeatostoma pseudodon; V2. Granulifusus sp. 
Figure W. Roof of the pallial cavity in the osphradium and ctenidium region. W1. Peristernia nassatula; W2. Dolicholatirus sp.; W3. Buccinum undatum........................................158

Figure X. Siphon X1. Granulifusus sp.; X2. Leucozonia cerata...........................................159

Figure Y. Siphon. Y1. Amiantofusus candoris; Y2. Fusinus marmoratus................................159

Figure Z. Kidney and pericardium. 1Z. Polygona angulata; 2Z. Granulifusus sp....................161

Figure AA. Kidney and pericardium. 1AA. Pustulatirus ogum; AA2. Aurantilaria

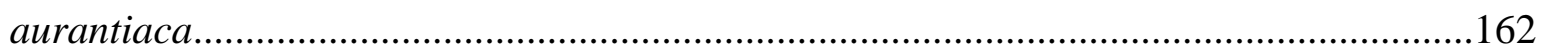

Figure AB. Head in ventral view. AB1. Granulifusus kiranus; AB2. Leucozonia cerata; AB3. Hemipolygona beckyae......

Figure AC. Head in ventral view. 1AC. Granulifusus sp.; 2AC. Dolicholatirus cayohuesonicus.

Figure AD. Proboscis opened laterally. AD1. Polygona angulata; AD2. Thais speciosa. 164

Figure AE. Proboscis opened laterally AE1. Thais speciosa; AE2. Granulifusus sp.; AE3. Fusinus brasiliensis. .165

Figure AF. Ventral view of odontophore cartilages and associated muscles AF1. Thais speciosa; AF2. Chryseofusus archerusius; AF3. Fusinus brasiliensis. 166

Figure AG. Odontophore in ventral view. AG1. Pustulatirus ogum; AG2. Fusinus sp. 167

Figure AH. Radula. HA1. Monetaria annulus (modified from Simone, 2004); AH2. Fusinus australis. 168

Figure AI. Radula, detail of rachidian. AI1. Fusinus frenguelli; AI2. Pseudolatirus kuroseanus.

Figure AJ. Radula. AJ1. Latirus pictus; AJ2. Fusolatirus bruijnii; AJ3. Cyrtulus serotinus.

Figure AK. Radula detail of rachidian. AK1. Latirus sp.; AK2. Pugilina tupiniquim, (modified from Abbate \& Simone, 2015); AK3. Nodolatirus nodatus; AK4. Pustulatirus ogum; AK5. Buccinum undatum..

Figure AL. Radula, detail of rachidian. AL1. Aurantilaria aurantiaca; AL2. Pustulatirus pallidus.

Figure AM. Radula. AM1. Dolicholatirus cayohuesonicus; AM2. Pisania pusio; AM3. Leucozonia nassa; AM4. Latirus vischii...... .172 
Figure AN. Radula. AN1. Dolicholatirus cayohuesonicus; AN2. Buccinum undatum; AN3. Amiantofusus candoris; AN4. Chryseofusus graciliformis; AN5. Peristernia marquesana.

Figure AO. Radula. AO1. Hemipolygona armata; AO2. Dolicholatirus cayohuesonicus.... 174

Figure AP. Radula, detail of lateral. AP1. Fusolatirus bruijnii; AP2. Latirus pictus..... 175

Figure AQ. Radula. AQ1. Dolicholatirus cayohuesonicus; AQ2. Amiantofusus pacificus; AQ3. Hemipolygona armata; AQ4. Pleuroploca trapezium. 175

Figure AR. Radula. AR1. Amiantofusus candoris; AR2. Polygona angulata. 176

Figure AS. Radula, detail of lateral. AS1. Pisania pusio; AS2. Pseudolatirus discrepans; AS3. Filifusus filamentosus; AS4. Leucozonia ocellata. 177

Figure AT. Radula. AT1. Cyrtulus serotinus; AT2. Pseudolatirus discrepans. 178

Figure AU. Radula. AU1. Peristernia nassatula; AU2. Leucozonia ponderosa.... 179

Figure AV. Proboscis. AV1. Granulifusus sp.; AV2. Fusinus frenguelli. 180

Figure AW. Proboscis. AW1. Pisania pusio; AW2. Pustulatirus ogum; AW3. Fusinus marmoratus.....

Figure AX. Proboscis. AX1. Dolicholatirus cayohuesonicus; AX2. Fusinus frenguelli. 183

Figure AY. Mid-esophagus. AY1. Fasciolaria tulipa; AY2. Fusinus sp. .184

Figure AZ. Section of the anterior esophagus immediately after valve of Leiblein. AZ1. Buccinum undatum; AZ2. Polygona infundibulum; AZ3. Fusinus australis. 184

Figure BA. Anterior and middle esophagus. BA1. Pugilina tupiniquim (modified from Abbate \& Simone, 2015); BA2. Aurantilaria aurantiaca; BA3. Fusinus frenguelli. 185

Figure BB. Anterior digestive system. BB1. Teralatirus roboreus (modified from Simone et al., 2013); BB2. Granulifusus sp.; BB3. Pugilina tupiniquim (modified from Abbate \& Simone, 2015) .188

Figure BC. Visceral mass. BC1. Polygona angulata; BC2. Aurantilaria aurantiaca. 189

Figure BD. Stomach in dorsal view and lumen. BD1. Monetaria annulus (modified from Simone, 2011); BD2. Pisania pusio; BD3. Fasciolaria tulipa 190

Figure BE. Roof of the pallial cavity in ventral view. BE1. Opeatostoma pseudodon; BE2. Amiantofusus candoris. 192

Figure BF. Pallial oviduct. BF1. Leucozonia ocellata; BF2. Opeatostoma pseudodon. 193 
Figure BG. Terminal portion of pallial oviduct. BG1. Granulifusus hayashi; BG2. Polygona angulata.

Figure BH. Longitudinal section of foot and columellar muscle, haemocoel removed. BH1.

Pseudolatirus discrepans; BH2. Filifusus filamentosus; BH3. Dolicholatirus cayohuesonicus.

Figure BI. Right side of roof of pallial cavity, male. BI1. Latirus vischii; BI2. Buccinum undatum.

Figure BJ. Penis and adjacent head-foot in dorsal view. BJ1. Pustulatirus ogum; BJ2. Pseudolatirus pallidus; BJ3. Dolicholatirus cayohuesonicus.

Figure BK. Penis. BK1. Leucozonia ocellata; BK2. Dolicholatirus cayohuesonicus; BK3.

Pisania pusio

Figure BL. Penis and section of tegument. BL1. Fusinus frenguelli; BL2. Opeatostoma pseudodon.

Figure BM. Nerve ring in dorsal view. BM1. Fusinus sp.; BM2. Filifusus filamentosus.

Figure BN. Nerve ring in dorsal view. BN1. Buccinum undatum; BN2. Hemipolygona beckyae.

Figure BO. Nerve ring in dorsal view. BO1. Leucozonia ponderosa; BO2. Pustulatirus ogum.

Figure BP. Nerve ring in dorsal view. BP1. Granulifusus sp.; BP2. Filifusus filamentosus......201

Figure BQ. Nerve ring. BQ1. Teralatirus roboreus (modified from Simone et al., 2013); BQ2.

Polygona angulata.... .203

\section{Chapter II}

Figure 1. Phylogenetic relationships based on a parsimonious analysis done in POY under parameter 3221

Figure 2. Phylogenetic relationships (part one) based on a parsimonious analysis done in POY under parameter 322. Navajo rugs indicate support for the given parameter.....

Figure 3. Phylogenetic relationships (part one) based on a parsimonious analysis done in POY under parameter 3221. Navajo rugs indicate support for the given parameter.

Figure 4. Phylogenetic relationships (part two) based on a parsimonious analysis done in POY under parameter 3221. Navajo rugs indicate support for the given parameter..... .235 
Figure 5. Phylogenetic relationships (part three) based on a parsimonious analysis done in POY under parameter 3221. Navajo rugs indicate support for the given parameter.

Figure 6. Phylogenetic relationships (part four) based on a parsimonious analysis done in POY under parameter 3221. Navajo rugs indicate support for the given parameter.

Figure 7. Phylogenetic relationships of Fasciolariidae for the total evidence analysis as

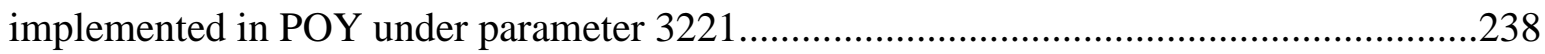

\section{Chapter III}

Figure 1. Phylogenetic tree obtained through parsimonious analysis in TnT using prior,

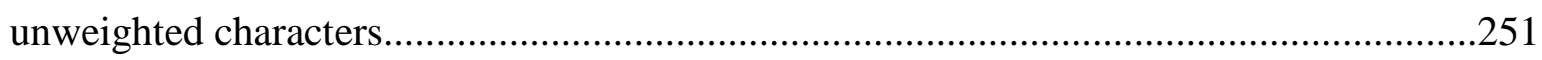

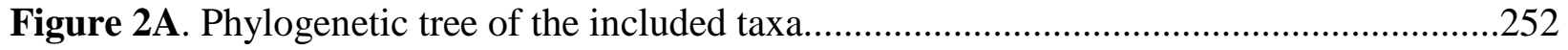

Figure 2B. Phylogenetic tree of the included taxa........................................................253 


\section{LIST OF TABLES}

\section{Chapter I}

Table 1. Species used for the morphological analysis, with voucher numbers, species count and locality. 11

\section{Chapter II}

Table 1. Number of taxa and fragments analyzed for each coding or non-coding loci.............228

Table 2. Taxa used for morphological (chapter I) and molecular analyses............................229 


\section{CONTENTS}

Chapter I__ 1

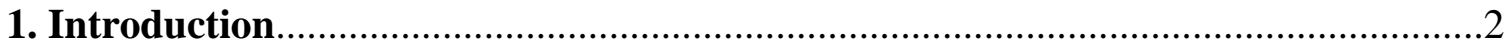

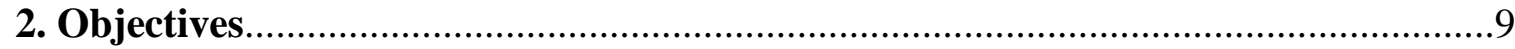

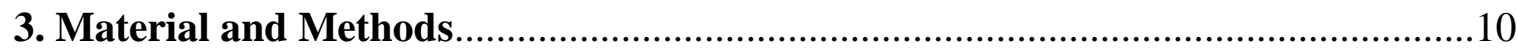

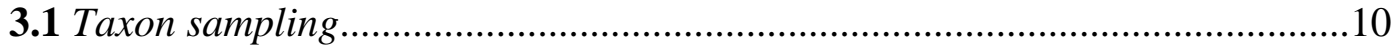

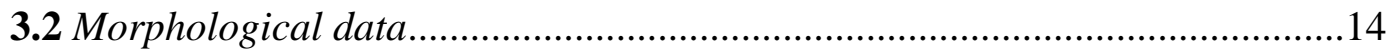

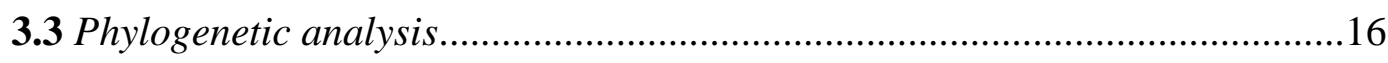

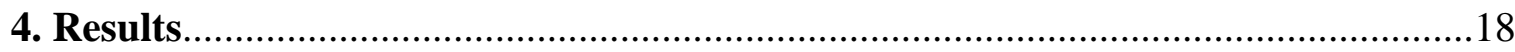

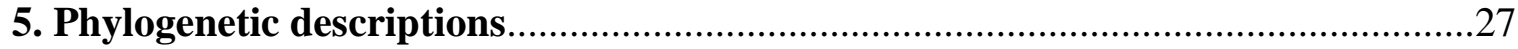

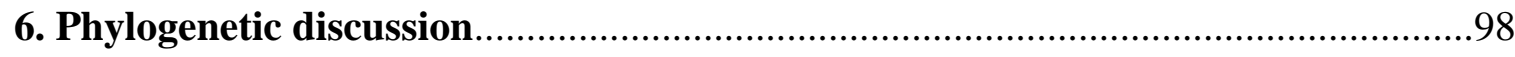

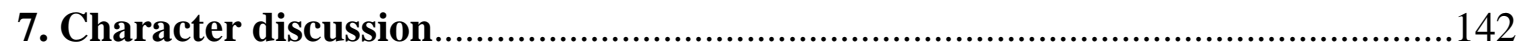

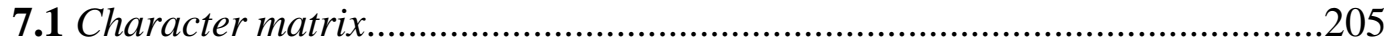

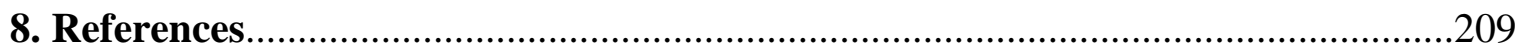

Chapter II__ 225

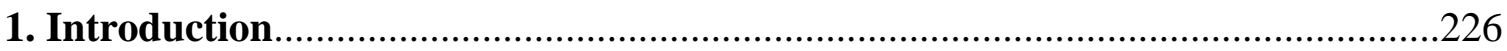

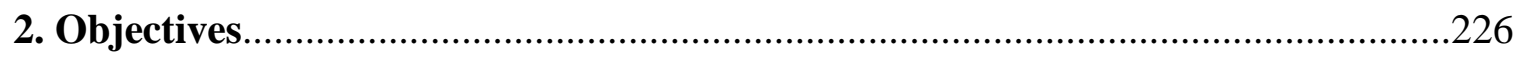

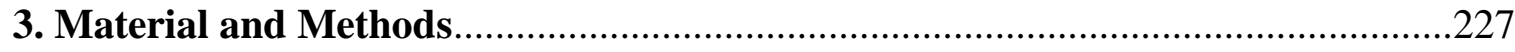

3.1 Parsimony analyses - molecular data......................................................22

3.2 Parsimony analyses - total evidence data.................................................228

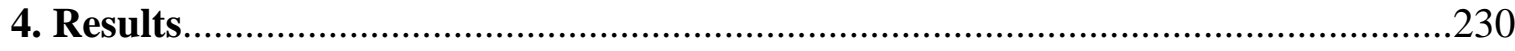

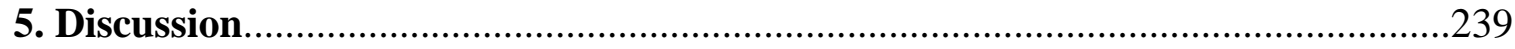

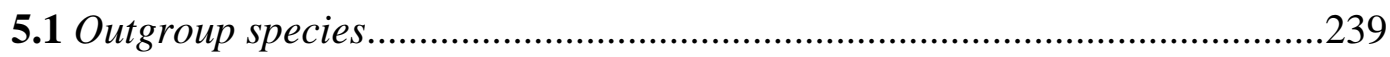

5.2 Dolicholatirus and Teralatirus clade ..............................................................239

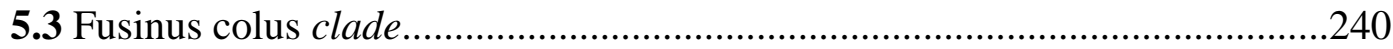

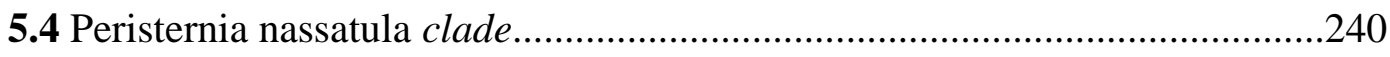

5.5 Fasciolaria tulipa clade ..........................................................................240

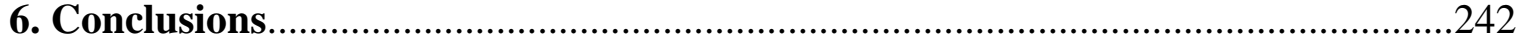

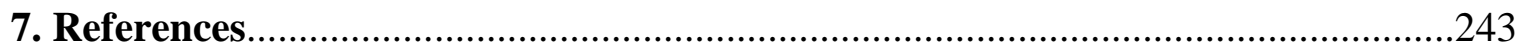


Chapter III

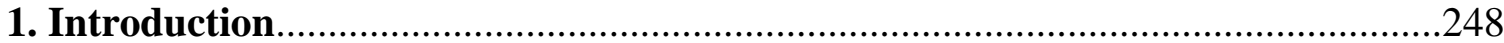

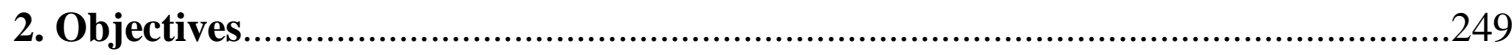

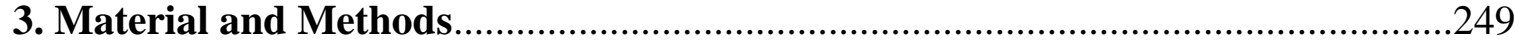

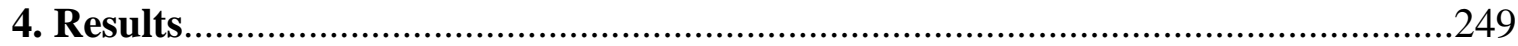

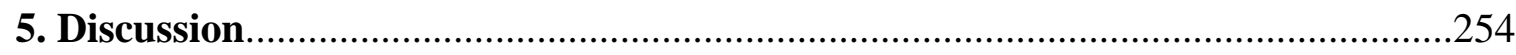

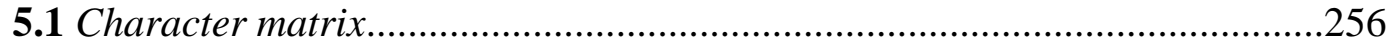

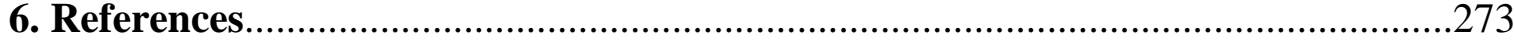


Phylogenetic analysis of Fasciolariidae based on comparative morphology (Gastropoda: Buccinoidea) 


\section{Introduction}

The phylum Mollusca, is one of the most important invertebrate group, second-most important according to species richness (topped only by the arthropods), with circa 130,000 extant species (WoRMS, 2016). Mollusks are extremely diverse biologically, not just in size and in anatomical structure, but also in behavior and in habitat, with great success in colonizing marine, terrestrial and freshwater environments. Gastropoda, the main class of the phylum and contributing to about $70 \%$ of the species, has achieved great success, particularly in marine environment. Gastropods are the main representatives in regards to biomass, ecological diversity and biogeographical patterns. They explore habitats from mangroves to hydrothermal vents to rocky coastal mesolittoral zone, have pelagic to epifaunal to infaunal lifestyles, occupying most ecological niches (Bronwen et al., 1998).

Despite the importance of the group, mollusks are likely sub-represented in areas with little or no collective and taxonomic effort, especially for deep-water species. In Brazil for example, only 1,776 taxa, including species and subspecies, occur according to Rios (2009), surely a portion of the real number. Trawling of economically important areas have only now been endeavored, as done by the REVIZEE program (Absalão et al., 2006) and this will most certainly increase the number of species reported for Brazilian waters.

The order Neogastropoda comprises the most diverse caenogastropod mollusk clade, and is currently divided in the superfamilies: Buccinoidea, Cancellarioidea, Conoidea, Muricoidea, Olivoidea and Pseudolivoidea (Bouchet \& Rocroi, 2005).

The monophyly of Neogastropoda is supported by recent morphology-based phylogenetic analyses (e.g., Ponder \& Lindberg, 1997; Strong, 2003; Simone, 2011). Ponder \& Lindberg (1997) analyzed 117 characters in 40 taxa of mainly prosobranch gastropods, and found that the Neogastropoda, included within the prosobranchs, are monophyletic; Caenogastropoda, a more inclusive group that encompasses neogastropods, mesogastropods and other small lineages, was also recovered monophyletic. Strong (2003) inferred the monophyly of Neogastropoda and Caenogastropoda utilizing 64 characters (mainly midgut) in 18 taxa, as well as establishing character homologies. The extensive Caenogastropoda phylogeny of Simone (2011) once again recovered a monophyletic Neogastropoda; this study sampled 676 characters in 305 species. All 
the above cited studies point to a well-supported Neogastropoda with several unambiguous synapomorphies corroborating it.

A Bayesian inference analysis of a combined morphological and molecular data was done by Ponder et al. (2008) with data from Colgan et al. (2007) and compiled morphological characters from the literature. Neogastropods appeared highly supported within a more inclusive 'siphonated' clade.

Several are the neogastropod synapomorphies that have been phylogenetically tested by Ponder \& Lindberg (1997) and Strong (2003): the presence of a pair of accessory salivary glands, a valve of Leiblein and an anal or rectal gland (the homology of the latter one was disputed by Kantor \& Fedosov, 2009). Based on these generally accepted morphological synapomorphies, Simone (2011) added: the pair of retractor muscles of the buccal mass passing through the nerve ring, the loss of jaws, the ducts of salivary glands free from the nerve ring and a high concentration of the ganglia, although this author retracted the synapomorphy of the valve of Leiblein to Muricoidea only. Ponder et al. (2008) stated that Neogastropoda tend to have higher chromosome numbers and larger cellular DNA content than other gastropods.

Most other analyses based solely in molecular data were not able to recover a monophyletic Neogastropoda (Harasewych et al., 1997; Colgan et al., 2000, 2003, 2007). Harasewych et al. (1997) based its molecular results in a two gene analysis of 18S rRNA and cytochrome $c$ oxidase subunit I (COI), and, although Caenogastropoda (including Neogastropoda and architaenioglossates) and heterobranchs were recovered, they were incapable of resolving relationships among neogastropod families, or between Neogastropoda and other higher Caenogastropoda.

Colgan et al. (2000) sampled partial 28S rRNA and Histone H3 and failed to recover a monophyletic Neogastropoda due to the low support of its branches. Colgan et al. (2003) used these same gene fragments plus 18S rRNA, COI and small nuclear U2 RNA (snU2 RNA) to infer the relationships of gastropods; neogastropod taxa appeared as several lineages in caenogastropods (also non-monophyletic), and also not well supported. Finally, Colgan et al. (2007) collected data from partial 18S rRNA, 28S rRNA, 12S rRNA, COI, histone H3 and elongation factor $1 \alpha$; despite a monophyletic Caenogastropoda, Neogastropoda was contradicted by their analyses. 
In their complete mitochondrial genome, Cunha et al. (2009) revisited the Neogastropoda concept with the inclusion of littoriniomorph lineages within the group. In another mitochondrial genome phylogeny, plus three nuclear genes, Osca et al. (2015), proposed the inclusion of Tonnoidea, or the exclusion of cancellarioids and possibly volutids from Neogastropoda; in the first case tonnoideans would have secondarily lost the traditional neogastropod synapomorphies, while in the latter these synapomorphies would be considered homoplastic, in this sense agreeing with Kantor and Fedosov (2009). Both of these studies prove the need to further increase gene sampling, as both mitochondrial genomes (circa 15-16k bp) were unable to achieve conclusive results regarding phylogenetic relationships within Neogastropoda, nevertheless, the rapid radiation at the Neogastropoda origin may not allow a fully resolution based only on such data. Another possible solution to these outcomes would be to include morphological data in these analyses.

Not all molecular-based analyses contest the monophyly of neogastropods. Zou et al. (2011), using data collected from entire nuclear 18S rRNA, histone H3, and three partial mitochondrial genes (COI, 16S rRNA and 12S rRNA) were able recover a monophyletic Neogastropoda. In their analyses, all neogastropod families were strongly supported except for the buccinids, turrids and cancellariids.

Despite these mentioned controversies, Neogastropoda has maintained its monophyletic status ('Archaeogastropoda' and 'Mesogastropoda' from Thiele [1925] proved to be artificial groups) until definitive conclusions prove otherwise (Bouchet \& Rocroi, 2005; WoRMS, 2016).

Within the Neogastropoda scheme, the superfamily Buccinoidea is considered highly derived due to several losses of typical neogastropod synapomorphies: mainly the accessory salivary glands and the rectal gland. The superfamily typically include the families Buccinidae, Belomitridae, Busyconidae, Colubrariidae, Columbellidae, Nassariidae, Melongenidae and Fasciolariidae (Bouchet \& Rocroi, 2005; WoRMS, 2016).

There is usually consensus among researchers that the superfamily is monophyletic and a crown group of Neogastropoda (e.g., Oliverio \& Modica, 2010; Fedosov et al., 2015). In the work of Simone (2011), the families included in Buccinoidea are present in the more inclusive clade Muricoidea.

Oliverio \& Modica (2010) included the first molecular analysis of Neogastropoda based on more than $50 \%$ of the recognized families. On their molecular dataset analyzing neogastropod 
families (28S rRNA, 16S rRNA, 12S rRNA and COI), Buccinoidea resulted in a monophyletic clade, with cancellariids the first offspring of the Neogastropoda (Rachiglossate) and the toxoglossate conoideans the sister group to it. On their second dataset (16S rRNA) that analyzed a more inclusive buccinoid ingroup, all families sampled except buccinids were recovered as monophyletic.

Fedosov et al. (2015) sequenced COI, 16S rRNA, 12S rRNA and Histone H3 for over 90 species in 20 genera and this molecular data set was supplemented by studies of radula morphology. Their results (which focused on mitriform gastropods) confirmed the monophyly of the neogastropod superfamilies Buccinoidea and Conoidea.

Phylogenetic studies are more common among more inclusive groups, especially those that have had a troubled taxonomic history, e.g., Buccinidae. WoRMS (2016) cites the family as accepted taxonomically; however, several works have refuted this hypothesis. Hayashi (2005) based its phylogeny on complete 16S rRNA sequences for buccinid species, and due to the intercalation by nassariid and fasciolariid species, the family was evidenced as polyphyletic. Kosyan et al. (2009) studied the phylogeny of buccinid species through a 16S rRNA dataset, partially from the sequences of Hayashi (2005), and the family was also reported as nonmonophyletic.

Kantor et al. (2013) endeavored in a phylogeny of deep-water buccinids based on COI, 12S rRNA and 28S rRNA genes, revealing that these taxa are closely related to taxa from vents. Although this study did not shed any lights into a more inclusive Buccinoidea, it shows a monophyletic Buccinidae family, despite a desired more extensive taxon sampling.

Galindo et al. (2016), through a five-gene phylogeny (COI, 16S rRNA, 12S rRNA, 28S rRNA and Histone H3) of 218 putative nassariid species, proved the monophyly of the family if one includes traditional buccinid species (e.g., Engoniophos Woodring, 1928, Nassaria Link, 1807). Their result confirmed the monophyletic families within Buccinoidea, with the exception of Buccinidae. Abbate (2016) has since confirmed the inclusion of the genus Engoniophos in Nassariidae.

The buccinoid family Fasciolariidae comprehends species that form a diverse element of the molluscan predatory fauna in shallow to deep coastal waters, especially on soft bottoms. With 540 extant species in 51 genera worldwide (WoRMS, 2016), fasciolariids are gonochoristic with internal fertilization and, usually, direct development (Leal, 1991), meaning that their distribution 
is more-or-less restricted to isolated geographical areas. They inhabit depths of up to $1900 \mathrm{~m}$ (Callomon \& Snyder, 2009) where they prey on polychaetes, sipunculans, bivalves and other gastropods (Rosenberg, 1992; Taylor \& Lewis, 1995).

Couto et al. (2016), in a study also related to this one, sampled 116 fasciolariid taxa and 17 outgroup species for its five-gene (COI, 18S rRNA, 28S rRNA, 16S rRNA and Histone H3) molecular phylogeny. These authors based their result on a maximum likelihood and a Bayesian inference analyses. All fasciolariids except Dolicholatirus Bellardi, 1884 and Teralatirus Coomans, 1965 were recovered within three subfamilies: Fusininae, Peristerniinae and Fasciolariinae; although with an extensively revised inclusion of species and genera. The subfamily Fusininae, includes the spindles (e.g., Fusinus Rafinesque, 1815, Chryseofusus Hadorn \& Fraussen, 2003 and related genera) including the genus Pseudolatirus Bellardi, 1884; Peristerniinae includes the genera Peristernia Mörch, 1852 and Fusolatirus Kuroda \& Habe, 1971; finally, Fasciolariinae includes the bulk of peristerniines sensu lato (e.g., Latirus Montfort, 1810, Polygona Schumacher, 1817) and fasciolariines, with the conspicuous and well-known tulips and horse-conchs (the only traditional clade that maintained its monophyly). The genera Teralatirus and Dolicholatirus formed a separate group from the remaining fasciolariids, although its position remains uncertain, as the statistic tests made were not able to correctly access its position.

The analysis of Couto et al. (2016) is so far the only extensive phylogenetic study of the family, since past works which included some fasciolariid taxa did not have the internal resolution to solve most internal clades (Hayashi, 2005; Kosyan et al., 2009; Zou et al., 2011). Other works in which fasciolariid taxa were present it was usually not possible to infer any phylogenetic position because of scarce taxon sampling and they lack the resolution and coverage to clarify its relationships or to test its monophyly, as the family was though to potentially comprise multiple paraphyletic groups (Fedosov \& Kantor, 2012), until the work of Couto et al. (2016) which clarified the relationships among major fasciolariid lineages.

Despite sub-familiar names being conserved in the current taxonomy of the family, Fusininae, Peristerniinae and Fasciolariinae have had a complicated history. For a long time, the name 'Fusus' has been used indiscriminately for numerous Cretaceous, Cenozoic and Recent spindle-shaped shells (Snyder, 2003), and likewise Latirus, Fasciolaria Lamarck, 1799 and Pleuroploca Fischer, 1884 were also used for evidently heterogeneous assemblages. More 
recently, however, the group has undergone extensive taxonomical revision (e.g., Vermeij \& Snyder, 2002: Leucozonia Gray, 1847; Vermeij \& Snyder, 2006: Latirus and related genera; Snyder et al., 2012: fasciolariines; Lyons \& Snyder, 2013: Pustulatirus Vermeij \& Snyder, 2006), elevating several subgenera to genus rank and establishing new ones. Of noteworthy reference is the genus Dolicholatirus that has had a confusing history in which its taxonomic position within Fasciolariidae is ambiguous, although currently generally accepted (e.g., Snyder, 2003; WoRMS, 2016), an issue unresolved by the analyses of Couto et al. (2016).

Fasciolariidae, Melongenidae, Cancellariidae and Buccinidae date back to the early Cretaceous (Valanginian, 140 Mya) (Benton, 1993), whereas other neogastropod families appeared between the late Cretaceous to early Paleogene, suggesting that the former families represent the first offshoots of Neogastropoda (Hayashi, 2005). While Fasciolariinae appeared during the Albian (Bandel, 1993), the fossil record indicates that the family - especially Fasciolariinae and Peristerniinae (Vermeij \& Snyder, 2006) - diversified extensively during the early Neogene (Aquitanian, 24 Mya). This rapid speciation endeavored by the group is evidenced by the many short branches of molecular analysis, because if speciation events are closely spaced in time, the amount of phylogenetic signal is often small, leading to short internal tree branches that are difficult to resolve (Philippe et al., 2011) such as those in Couto et al. (2016).

Like most gastropods, fasciolariids have a taxonomy based mostly on the shell and radula (e.g., Tryon, 1880; Thiele, 1929-1935; Vermeij \& Snyder, 2002; 2006), likewise, taxonomic and phylogenetic approaches based on soft-part anatomy are scarce. Even in the context of the superfamily, the anatomical framework of the buccinoideans is especially scant, for they are considered highly advanced Neogastropoda (Kantor, 1996), lacking accessory salivary glands, anal glands and ingesting gland in the oviduct (Harasewych 1998). Typical for fasciolariids is the orange-red color of the foot and head-foot mass. Fraussen et al. (2007) reported that a combination of traits is diagnostic for Fasciolariidae: multicuspidate lateral teeth and narrow rachidian teeth, proboscis retractor muscle as a single or paired tuft of fibers, ducts of the salivary glands immersed in the esophagus wall, and a stomach without a posterior caecum. Furthermore, Kosyan et al. (2009) studied the anatomy of fasciolariids based in eight species and seven genera arranged in all subfamilies. These authors distinguished fasciolariids from buccinids studied by them and by Kosyan \& Kantor (2009) based on stomach and proboscis retractor muscle characters, as appointed by Fraussen et al. (2007). 
The work of Simone (2011) is based on thorough anatomical analysis of caenogastropods, which was stemmed on several previous publications that were employed in his phylogeny of the subclass (e.g., Simone, 2004; Bieler \& Simone, 2005; Simone et al., 2009). Such detailed morphological studies are scarce. Kosyan et al. (2009) studied the anatomy of eight fasciolariids: Turrilatirus turritus (Gmelin, 1791), Pustulatirus mediamericanus (Hertlein \& Strong, 1951), Latirus polygonus (Gmelin, 1791), Peristernia nassatula (Lamarck, 1822), Peristernia ustulata (Reeve, 1847), Opeatostoma pseudodon (Burrow, 1815), Fusinus tenerifensis Hadorn \& Rolán, 1999 and Tarantinae lignaria (Linnaeus, 1758). Marcus \& Marcus (1962) made detailed anatomical descriptions of Leucozonia nassa (Gmelin, 1791) from Brazil, while Couto \& Pimenta (2012) studied the Brazilian Leucozonia species: L. nassa (Gmelin, 1791), L. ocellata (Gmelin, 1791) and L. ponderosa Vermeij \& Snyder, 1998. Couto et al. (2015a) investigated Pustulatirus ogum (Petuch, 1979) and Hemipolygona beckyae (Snyder, 2000) and Couto et al. (2015b) Fasciolaria tulipa (Linnaeus, 1758). Finally, Simone et al. (2013) described the anatomy of Teralatirus roboreus (Reeve, 1845).

Phylogenetic analyses of gastropods based on morphological data have greatly fallen in disuse, as molecular-based multi-gene or even next-generation sequencing (NGS), gains popularity. The work of Ponder \& Lindberg (1997), Strong (2003) and Simone (2011) were based solely on anatomical characters. Galindo et al. (2016), through an approach based on the reconstruction of the ancestral character, eight characters supposedly informative for taxonomy were coded in the final Nassariidae tree; this approach is relatively common. A phylogenetic approach, though parsimony or otherwise, that takes into consideration the transformation in morphological characters increasingly more infrequent; this is due to homology statements issues, the choice of higher taxa as terminals, and most importantly due to the cheapening of molecular analyses (Shendure \& Ji, 2008; McCormack et al., 2013; Giribet, 2015)

The use of morphology has traditionally been employed by phylogeneticists to infer the relationship of major groups since the first evolutionary biologists began to decipher the animal tree of life. The amount of molecular data has increased in a way that is unprecedented when compared to morphological ones (morphological or developmental data [e.g., patterns in egg cleavage, mesoderm formation, segmentation, etc.] are considered morphological characters and are treated as such), and that has enticed researchers into favoring the former over the latter. The 
amount of training required for a detailed anatomical study also greatly increases the cost of training morphologists over "molecular zoologists".

It is essential that morphological characters do not come into disuse for innumerous reasons. Giribet (2015) stressed that a zoologist's interest is to understand form and function, and how this evolved over its history; hence why morphology should not be left aside. It is pivotal that fossils be incorporated, not just in constraining a node, but as terminals, which proves to me a more realistic way of dating the evolution. Morphological characters prove useful in validating phylogenetic relationships and helps to resolve many internal clades, (e.g., as encountered in other groups such as butterflies by Wahlberg et al., 2005; arthropods by Giribet et al., 2001; Opiliones by Giribet et al., 2002).

Because of the difficulties in delimiting groups in fasciolariids especially those distinguished solely on shell features (Vermeij \& Snyder, 2006; Lyons \& Snyder, 2013), hence prone to issues regarding polymorphisms and convergence, it is essential that a morphology based phylogenetic analysis be implemented. In order to compare the morphological results obtained here with previous studies, the analysis of Couto et al. (2016) proves especially useful. The following work is, therefore, a comprehensive extensive phylogenetic study of the family Fasciolariidae.

\section{Objectives}

1. To provide a hypothesis, in hopes to further clarify the phylogeny of the family Fasciolariidae, based on a parsimonious analysis of morphological data.

2. To test the monophyly of the Fasciolariidae through inclusion of many outgroup.

3. To provide a comprehensive framework in morphological characters for a more inclusive Neogastropoda.

4. In light of the putative phylogeny, propose a tentative taxonomic scheme for the analyzed taxa. 


\section{Material and Methods}

\subsection{Taxon sampling}

Material for this study was obtained from deposited material in the Museum of Zoology, São Paulo University and foreign collections; through loan and/or visit to these institutions. A complete list of examined material is presented in table 1. The foreign institutions, abbreviated throughout the text, with their respective curators: ANSP - Academy of Natural Sciences, Drexel University, Philadelphia, PA, USA. Curator: Gary Rosenberg. CMPHRM - Federal University of Ceará, Brazil. Curator: Helena Matthews-Cascon. FMNH - Florida Museum of Natural History, Gainesville, FL, USA. Curator: Gustav Paulay. KZN - KwaZulu-Natal Museum, Pietermaritzburg, South Africa. MCZ - Museum of Comparative Zoology, Harvard University, Cambridge, MA, USA. Curator: Gonzalo Giribet. MNHN - National Museum of Natural History, University of Sorbonne, Paris, France. Curator: Philippe Bouchet. MNRJ - National Museum of Brazil, Federal University of Rio de Janeiro (UFRJ), Rio de Janeiro, RJ, Brazil. Curator: Alexandre Pimenta. MORG - Oceanografic Museum "Prof. Eliézer de Carvalho Rios", Federal University of Rio Grande (FURG), Rio Grande do Sul, Brazil. MZSP - Museum of Zoology, University of São Paulo (USP), São Paulo, SP, Brazil. Curator: Luiz R. L. Simone. NHMUK - National History Museum of London, England, UK. Curator: Andreia Salvador. SBMNH - Santa Barbara Museum of Natural History, Santa Barbara, CA, USA. Curator: Daniel Geiger.

In order to obtain a broad taxonomical sample of fasciolariids, 53 specimens in 21 genera were chosen: Amiantofusus Fraussen et al., 2007, Aurantilaria Snyder et al., 2012, Australaria Snyder et al., 2012, Chryseofusus, Cyrtulus Hinds, 1843, Dolicholatirus, Fasciolaria, Filifusus Snyder et al., 2012, Fusinus, Fusolatirus, Granulifusus Kuroda \& Habe, 1954, Hemipolygona Rovereto, 1899, Leucozonia, Latirus, Nodolatirus Bouchet \& Snyder, 2013, Peristernia, Pleuroploca, Polygona, Pseudolatirus, Pustulatirus and Teralatirus. Data from Angulofusus nedae Fedosov \& Kantor, 2012 and Teralatirus roboreus were taken from the literature; table 1 lists the origin of the morphological material, novel or excerpt from the literature.

Outgroup taxa were added in order to confirm the monophyly of Fasciolariidae, in particular, the positioning of Dolicholatirus and Teralatirus, in which doubt was raised by previous authors (Vermeij \& Snyder, 2006; Beu, 2011) and undetermined by Couto et al. (2016). 
Hence, species comprising of a broad taxonomic spectrum were chosen as outgroups, occurring in the families: Cypraeidae (Cypraeoidea), Rapaninae (Muricoidea), Melongenidae, Nassariidae and Buccinidae (Buccinoidea). In total, eight outgroup species were used.

Couto et al. (2016) is the culmination of the work endeavored in the MCZ (Appendix), and although only molecular data as used, it comprehends part of this dissertation. More on molecular data will be discussed on chapter II of the present dissertation. In order to compare the morphological results obtained here, most terminals also occur in Couto et al. (2016) providing a useful tool for comparison.

Table 1: Species used for the morphological analysis, with voucher numbers, species count and locality. Morphological data compiled from the literature is indicated after the species name, and highlighted in grey. For full voucher detail refer to Phylogenetic description section, following each species name. Cy: Cypraeidae. Me: Melongenidae. Na: Nassariidae. Th: Thaididae. Bu: Buccinidae. Fa: Fasciolariidae (continues in the next four pages).

\section{SPECIES}

Me Pugilina tupiniquim

Na Engoniophos unicinctus

Na Nassarius reticulatus

Na Bullia laevissima

Fa Dolicholatirus sp.

Fa Teralatirus roboreus

Fa Angulofusus nedae

Th Thais speciosa

Th Thais speciosa

Bu Buccinum undatum

Bu Buccinum undatum

Bu Pisania pusio

Bu Pisania pusio

Bu Pisania pusio

Bu Pisania pusio

Fa Dolicholatirus aff. Cayohuesonicus

Fa Dolicholatirus aff. Cayohuesonicus

Fa Dolicholatirus aff. Cayohuesonicus

Fa Pseudolatirus kuroseanus

Fa Amiantofusus pacificus

Fa Amiantofusus pacificus

Fa Amiantofusus candoris

Fa Pseudolatirus pallidus

Fa Pseudolatirus pallidus

Fa Pseudolatirus pallidus

Fa Pseudolatirus pallidus

Fa Pseudolatirus pallidus

Fa Pseudolatirus pallidus

Fa Chryseofusus archerusius
VOUCHER NUMBER \# LOCALITY

Abbate \& Simone (2015)

Abbate (2016)

Abbate (2016)

Abbate (2016)

Couto et al. (2016)

Simone et al. (2013)

Fedosov \& Kantor (2012)

MZSP 67772

MZSP 95270

MZSP 98217

MZSP 58732

MZSP 105583

MZSP 105690

MZSP 111471

MZSP 11290

ANSP A8131

ANSP 338609/A5642

ANSP A18293

MNHN IM-2013-14709

MNHN IM-2013-42508

MNHN IM-2013-44179

MNHN IM-2013-19759

MNHN IM-2013-19937

MNHN IM-2007-32537

MNHN IM-2013-19011

MNHN IM-2007-32913

MNHN IM-2013-44506

MNHN IM-2013-44495

MNHN IM-2013-44363
2

1 Ecuador

10 France

1 North Sea

18 Brazil, São Paulo state

2 Brazil, São Paulo state

6 Brazil, Espírito Santo state

6

2

Brazil, Fernando de Noronha

Archipelago

Cayman Islands

British Virgin Islands

Puerto Rico

Papua New Guinea

China Sea

China Sea

Papua New Guinea

Papua New Guinea

Salomon Islands

Papua New Guinea

Philippines

China Sea

China Sea

China Sea 
\begin{tabular}{|ll} 
Fa & Chryseofusus archerusius \\
Fa & Chryseofusus graciliformis \\
Fa & Chryseofusus graciliformis \\
Fa & Chryseofusus graciliformis \\
Fa & Fusinus brasiliensis \\
Fa & Fusinus brasiliensis \\
Fa & Fusinus brasiliensis \\
Fa & Fusinus marmoratus \\
Fa & Fusinus marmoratus \\
Fa & Fusinus marmoratus \\
Fa & Fusinus marmoratus \\
Fa & Fusinus sp. \\
Fa & Fusinus sp. \\
Fa & Fusinus frenguelli \\
Fa & Fusinus frenguelli \\
Fa & Fusinus frenguelli \\
Fa & Fusinus frenguelli \\
Fa & Fusinus frenguelli \\
Fa & Fusinus frenguelli \\
Fa & Fusinus australis \\
Fa & Fusinus australis \\
Fa & Cyrtulus serotinus \\
Fa & Cyrtulus serotinus \\
Fa & Cyrtulus serotinus \\
Fa & Cyrtulus serotinus
\end{tabular}

Fa Granulifusus sp.

Fa Granulifusus hayashi

Fa Granulifusus kiranus

Fa Granulifusus kiranus

Fa Granulifusus kiranus

Fa Pseudolatirus discrepans

Fa Pseudolatirus discrepans

Fa Fusolatirus bruijnii

Fa Fusolatirus bruijnii

Fa Peristernia nassatula

Fa Peristernia nassatula

Fa Peristernia nassatula

Fa Peristernia nassatula

Fa Peristernia nassatula

Fa Peristernia marquesana

Fa Peristernia marquesana

Fa Nodolatirus nodatus

Fa Nodolatirus nodatus

Fa Latirus vischii

Fa Fasciolaria tulipa

Fa Fasciolaria tulipa

Fa Fasciolaria tulipa

\begin{tabular}{|c|c|c|}
\hline MNHN IM-2013-44302 & 1 & China Sea \\
\hline MNHN IM-2007-32797 & 1 & Salomon Islands \\
\hline MNHN IM-2013-19921 & 1 & Salomon Islands \\
\hline MNHN IM-2013-19938 & 1 & Salomon Islands \\
\hline MZSP 70512 & $\sim 80$ & Brazil, Espírito Santo state \\
\hline MNRJ 8660 & 8 & Brazil, Espírito Santo state \\
\hline MNRJ 8960 & 1 & Brazil, Rio de Janeiro state \\
\hline MNRJ 14243 & 2 & Brazil, Rio de Janeiro state \\
\hline MNRJ 14489 & 2 & Brazil, Rio de Janeiro state \\
\hline MNRJ 14588 & 1 & Brazil, Rio de Janeiro state \\
\hline MZSP 77515 & 3 & Brazil, São Paulo state \\
\hline MNRJ 6258 & 1 & Brazil, Rio de Janeiro state \\
\hline MNRJ 6259 & 1 & Brazil, Rio de Janeiro state \\
\hline MNRJ 14414 & 3 & Brazil, Rio de Janeiro state \\
\hline MNRJ 7829 & 1 & Brazil, Rio de Janeiro state \\
\hline MNRJ 14595 & 5 & Brazil, Rio de Janeiro state \\
\hline MNRJ 14487 & 1 & Brazil, Rio de Janeiro state \\
\hline MNRJ 14709 & 1 & Brazil, Santa Catarina state \\
\hline MZSP 77531 & 17 & Brazil, Trindade Island \\
\hline MNHN IM-2013-42513 & 1 & Australia \\
\hline MNHN IM-2013-42517 & 1 & Australia \\
\hline MNHN IM-2013-42529 & 1 & Marchesas Archipelago \\
\hline MNHN IM-2013-42530 & 1 & Marchesas Archipelago \\
\hline MNHN IM-2013-42531 & 1 & Marchesas Archipelago \\
\hline MNHN IM-2013-42532 & 1 & Marchesas Archipelago \\
\hline MNHN IM-2013-19724 & 1 & $\begin{array}{l}\text { Bismarck Sea, Papua New } \\
\text { Guinea }\end{array}$ \\
\hline MNHN IM-2013-19210 & 1 & $\begin{array}{l}\text { Bismarck Sea, Papua New } \\
\text { Guinea }\end{array}$ \\
\hline MNHN IM-2013-44502 & 1 & China Sea \\
\hline MNHN IM-2013-19037 & 1 & $\begin{array}{l}\text { Bismarck Sea, Papua New } \\
\text { Guinea }\end{array}$ \\
\hline MNHN IM-2013-44449 & 1 & China Sea \\
\hline MNHN IM-2013-9777 & 1 & Papua New Guinea \\
\hline MNHN IM-2007-34604 & 1 & Philippines \\
\hline MNHN IM-2013-16671 & 1 & Papua New Guinea \\
\hline MNHN IM-2013-18013 & 1 & Papua New Guinea \\
\hline MNHN IM-2007-32487 & 1 & Vanuatu \\
\hline MNHN IM-2013-18061 & 1 & Papua New Guinea \\
\hline MZSP 71241 & 2 & Fiji \\
\hline MNHN IM-2007-32541 & 1 & Philippines \\
\hline MNHN IM-2013-10796, & 1 & Papua New Guinea \\
\hline MZSP 68507 & 2 & Japan \\
\hline MZSP 69249 & 2 & Japan \\
\hline MNHN IM-2013-42533 & 1 & Austral Islands \\
\hline MNHN IM-2013-42533 & 1 & Austral Islands \\
\hline MNHN IM-2009-15038 & 1 & Madagascar \\
\hline MZSP 69277 & 1 & Honduras \\
\hline MZSP 35530 & 2 & Venezuela \\
\hline MZSP 56870 & 2 & Venezuela \\
\hline
\end{tabular}




\begin{tabular}{|ll} 
Fa & Aurantilaria aurantiaca \\
Fa & Aurantilaria aurantiaca \\
Fa & Aurantilaria aurantiaca \\
Fa & Aurantilaria aurantiaca \\
Fa & Aurantilaria aurantiaca \\
Fa & Aurantilaria aurantiaca \\
Fa & Aurantilaria aurantiaca \\
Fa & Aurantilaria aurantiaca \\
Fa & Aurantilaria aurantiaca \\
Fa & Aurantilaria aurantiaca \\
Fa & Aurantilaria aurantiaca \\
Fa & Filifusus filamentosus \\
Fa & Filifusus filamentosus \\
Fa & Australaria australasia \\
Fa & Australaria australasia \\
Fa & Pleuroploca trapezium \\
Fa & Pleuroploca trapezium \\
Fa & Hemipolygona armata \\
Fa & Hemipolygona armata \\
Fa & Pustulatirus mediamericanus \\
Fa & Pustulatirus mediamericanus \\
Fa & Pustulatirus mediamericanus \\
Fa & Pustulatirus ogum \\
Fa & Pustulatirus ogum \\
Fa & Pustulatirus ogum \\
Fa & Polygona angulata \\
& \\
Fa & Leucozonia ocellata \\
Fa & Leucozonia ocellata \\
Fa & Leucozonia ocellata \\
Fa & Polygona angulata \\
& \\
Fa & Polygona angulata \\
& \\
Fa & Polygona angulata \\
Fa & Latirus polygonus \\
Fa & Latirus polygonus \\
Fa & Polygona infundibulum \\
Fa & Hemipolygona beckyae \\
Femipolygona beckyae \\
Femipolygona beckyae \\
\end{tabular}

CMPHRM 2765
MNRJ 8372
MNRJ 993
MNRJ 8304
MNRJ 15161
MNRJ 14346
MNRJ 8369
MNRJ 6678
MZSP 33005
MZSP 77496
MZSP 35976

MNHN IM-2013-13107

MNHN IM-2007-32592

MNHN IM-2013-42514

MNHN IM-2013-42516

MNHN IM-2009-15358

MNHN IM-2007-32591

MNHN IM-2013-42511

MNHN IM-2013-42509

MZSP 69500

MZSP 95273

MZSP 67752

MZSP 68475

MZSP 69477

MZSP 69301

MZSP 31125

MZSP 112907

MZSP 90774

MZSP 112826

MZSP 90047

MZSP 71428

MZSP 71869

MNHN IM-2013-19591

MNRJ 7696

MZSP 69482

MZSP 57053

MZSP 69764

MNRJ 11174

MNRJ 11200

MNRJ 4276

MNRJ 5357

MNRJ 12963
Brazil, Ceará state

Brazil, Ceará state

Brazil, Bahia state

Brazil, Bahia state

Brazil, Bahia state

Brazil, Espírito Santo state

Brazil, Espírito Santo state

Brazil, Paraíba state

Brazil, Paraíba state

Brazil, Alagoas state

Brazil, Bahia state

Papua New Guinea

Vanuatu

Australia

Australia

Madagascar

Vanuatu

Senegal

Senegal

Ecuador

15 Ecuador

1 Ecuador

16 Brazil, Espírito Santo state

5 Brazil, Bahia state

2 Brazil, Rio de Janeiro state

4 Brazil, Fernando de Noronha Archipelago

Brazil, Fernando de Noronha Archipelago

Brazil, Fernando de Noronha Archipelago

Brazil, Fernando de Noronha Archipelago

Brazil, Fernando de Noronha Archipelago

Fiji

Fiji

Guadeloupe

Brazil, Espírito Santo state

Brazil, Espírito Santo state

Brazil, Espírito Santo state

Brazil, Espírito Santo state

Brazil, Fernando de Noronha

Archipelago

Brazil, Fernando de Noronha

Archipelago

Brazil, Atol das Rocas

10

Archipelago

4 Brazil, Bahia state

35 Brazil, Abrolhos Archipelago 


\begin{tabular}{|ll} 
Fa & Leucozonia ocellata \\
Fa & Leucozonia ocellata \\
Fa & Leucozonia ocellata \\
Fa & Leucozonia cerata \\
Fa & Leucozonia cerata \\
Fa & Leucozonia cerata \\
Fa & Opeatostoma pseudodon \\
Fa & Opeatostoma pseudodon \\
Fa & Opeatostoma pseudodon \\
Fa & Leucozonia nassa nassa \\
Fa & Leucozonia nassa cingulifera \\
Fa & Leucozonia nassa cingulifera \\
Fa & Leucozonia nassa cingulifera \\
Fa & Leucozonia nassa cingulifera \\
Fa & Leucozonia nassa brasiliana \\
Fa & Leucozonia nassa brasiliana \\
Fa & Leucozonia nassa brasiliana \\
Fa & Leucozonia ponderosa \\
Fa & Leucozonia ponderosa \\
Fa & Leucozonia ponderosa \\
Fa & Leucozonia ponderosa \\
Fa & Leucozonia ponderosa \\
&
\end{tabular}

\subsection{Morphological data}

Novel morphological data was obtained through dissection of preserved animal immersed in ethanol $70 \%$ on a camera lucida attached to stereoscope microscope Zeiss SV6, through standard techniques (e.g., Simone, 2005; 2007). Whenever possible, individuals were removed from their shells through drilling of a whole in the spire, in order access the soft-parts and push the animal through the aperture. In this way it is possible to detach the animal when the columellar muscle is cut off. In some cases, whenever necessary, the shell was destroyed by use of a vise, if the number of individuals allowed for the destruction of one or some individuals. Most specimens from MNHN were removed through the use of a microwave oven (Galindo et al., 2014). The electromagnetic radiation very quickly heats both the animal and the water trapped inside the shell, resulting in separation of the muscles that anchor the animal to the shell, when done properly the body can be removed intact from the shell and the shell voucher is preserved undamaged (Galindo et al., 2014). Drilling or destruction of the shell on these individuals was not needed. 
Shells were photographed using a Canon PowerShot G1X camera, on a static photographical table, attached to stereoscope microscope, or in Auto-montage (image stacking) camera model Zeiss Axio Scope A1. Scanning electron microscopy (SEM) photography was done in a Leica model LEO 440; gold $(\mathrm{Au})$ was used for the ultra-thin coating of the radulae.

Dissections were done with the used of ophthalmological chirurgical material, fixed in place by entomological pins. As most gastropods, for the sake of dissections, animals herein have the body divided in the following regions: mantle cavity, visceral mass and head-foot mass. The mantle border was cut laterally in order to gain access to the pallial organs, following the section of the posterior esophagus and anterior aorta in order to separate the visceral mass from the adjacent head-foot mass. For the remainder of the head-foot mass, a longitudinal incision was made in order to separate the haemocoelic content from the foot mass.

Terminology for the anatomical study followed traditional studies (e.g., Simone, 2005, 2007; 2011), and modified by the author (e.g., Couto \& Pimenta, 2012; Couto et al., 2015a; 2015b). Imaging material was edited in Corel Photo-Paint X8 and Adobe Illustrator CC 2015.

Description for each analyzed taxa is present in a phylogenetic description model, in which the description of the clade is given (synapomorphy) and the included species (autapomorphy). Routinely, a through description of each species is endeavored, with anatomical observations and illustrations of all organs. Published articles containing species descriptions are found in the Appendix section, for the reader's perusal.

Delimiting characters and character states was based on personal observations of variation among species with respect to each other but also between individuals of the same species. With the exception of shell and radula (which have a terminology relatively well established e.g., Vermeij \& Snyder, 2002; Snyder et al., 2012 for shell; Bandel, 1984 for radula) anatomical characters were novel endeavors. Previous morphological analysis of related groups (e.g., Ponder \& Lindberg, 1997; Strong, 2003; Simone, 2011) were not helpful for most morphological data collected here because these were hierarchically more inclusive (order, suborder, etc.).

Qualitative characters were preferred, and whenever possible were expressed as so, despite no analytical difference between quantitative or qualitative characters. Ratios and measures, although useful for morphological characterizations, were not used for the analysis, even if they were present in non-overlapping intervals. 
Characters were analyzed as non-additive (unordered: cc -) except when there was a logical basis for doing so (Fitch, 1971); in this case the logical basis for additive characters (ordered: cc $+)$ this is present in the character description.

The character matrix was compiled in Mesquite v3.10 (build 765) (Maddison \& Maddison, 2010). Inapplicable characters scored '-'; unavailable or unknown scored '?' (Platnick et al., 1991).

\subsection{Phylogenetic analysis}

The character matrix from Mesquite v3.10 was analyzed in TNT, that runs via a parsimonious optimality criterion (Tree analysis using new technology: Goloboff et al., 2008), using heuristic algorithms to search off possible local optima into a global optimum. The algorithms of TNT are designed to deal with the problem of composite optima, (mixture of local optima of various heights, one of which is the global optimum, caused by large phylogenies having subtrees) in large datasets (Goloboff, 1999; Goloboff et al., 2008). The polarization of character states was done posteriorly, in which the plesiomorphic state is decided post rooting, i.e., simultaneously on ingoup and outgroup taxa (Nixon \& Carpenter, 1993).

All analyses were performed using equally weighted characters (prior weighting), initially through a traditional search engine using Tree bisection and reconnection (TBR). When using the TBR algorithm, a subtree is clipped from one portion of the tree and reattached at another node in the tree in any orientation, not necessarily maintaining sister group relationships within the subtree (Goloboff, 1999). A TBR search was performed on 1000 replicates (number of added sequences) saving 50 trees per TBR replication (10,000 trees retained in memory); in case of overflow (i.e., in at least some replicates, the TBR algorithm retained more trees than the designated number of trees retained in memory) an additional traditional search was done with the trees saved in memory. The trees were collapsed after each search. This method was repeated several times until the same TBR score and topology was conserved.

Another search was performed using an implied weighting method (Goloboff, 1993; Goloboff et al., 2008), using the same TBR search parameters cited above. Implied weighting is a method for attributing different weights during tree search, and is independent of previous analysis and weights (unlike successive weighting: Farris, 1969). This scheme utilizes a 
concavity constant $(k)$ (higher $k$ values weight more strongly against characters with homoplasy); in order to determine $k$ for the dataset, a TNT script (setk.run) (Goloboff et al., 2008) was used.

Bremer support for each node (decay index) was calculated using the Bremer algorithm implemented in the TNT script Bremer.run (this script and setk.run are freely available at http://phylo.wikidot.com/tntwiki, last access ix/08/2016).

ACCTRAN (accelerated transformation) or DELTRAN (delayed transformation) character optimization was done in WinClada ver 1.00.08 (Nixon, 1999), which allows visualization of each character transformation along branches. Tree files were exported in .emf format and edited in Adobe Illustrator CC 2015. Fasciolariidae clades were numbered 1 through $n$ for deeper nodes (-1 through $-n$ for outgroups) with subsequent inner clades numbered $n \mathrm{a}, n \mathrm{~b}, n \mathrm{c}$, etc. 


\section{Results}

The morphological analysis was based on 95 characters: ten relative to the shell; eight to the head-foot mass; 14 to the pallial cavity; four to the circulatory and excretory systems; 41 relative to the digestive system (18 of which were radular characters); seven based on female reproductive; six to male reproductive and finally; six based on the nervous system. All morphological character listings were novel acquisitions.

The traditional search through a TBR algorithm using prior weighting (best hit scored 98 times out of 1000 , best TBR $=369$ ) generated 20 equally parsimonious trees of 394 steps $(L)$, a consistency index of $33(\mathrm{Ci})$ and a retention index of $70(\mathrm{Ri})$. The resulting strict consensus generated a tree with $\mathrm{L}=407, \mathrm{Ci}=32$ and $\mathrm{Ri}=68$ (Fig. 1A). Implied weighing search using $k=$ 12.4 (determined by setk.run script) provided a tree with $\mathrm{L}=394, \mathrm{Ci}=33$ and $\mathrm{Ri}=70$ (Fig. 1B).

Goloboff (1993) argues in favor of the use of implied weighting because the 'fittest' tree is the one that explains the data most parsimoniously, i.e., with fewer number of steps. It has been argued that results based on characters properly weighted (e.g., implied, successive) are to be preferred to those with all characters given the same weight (Farris, 1969; Goloboff, 1993; Goloboff et al., 2008). There is some debate regarding down-weighing homoplasies in cladistic analyses, and this has been intensely criticized (e.g., Turner \& Zandee, 1995), also contributing to a lower Bremer support scores. The topologies between the strict consensus of the non-weighted analysis (Fig. 1A) and the weighed one (Fig. 1B) differ only slightly (mainly in resolving terminal polytomies); for this reason, because of the lower Bremer scores of the weighted tree, and the criticism of weighting, it seems logical that all optimizations and character discussion relate to the unweighted one.

The topology of the tree (Fig. 1A) revealed a monophyletic Fasciolariidae $($ Bremer $=3)$ consisting of roughly seven major groups: 1) the genera Dolicholatirus and Teralatirus; 2) Angulofusus nedae, Pseudolatirus kuroseanus (Okutani, 1975) and the genus Amiantofusus; 3) Pseudolatirus pallidus Kuroda \& Habe, 1961 with the genera Chryseofusus, Fusinus and Cyrtulus; 4) Pseudolatirus discrepans Kuroda \& Habe, 1961 and the genus Granulifusus; 5) the genera Peristernia and Fusolatirus; 6) Nodolatirus nodatus (Gmelin, 1791) and Latirus vischii Bozzetti, 2008 and all previously designated Fasciolariinae; and 7) the bulk of the previously 
designated Peristerniinae, including Leucozonia, Opeatostoma Berry, 1958, Polygona, Hemipolygona, Pustulatirus and Latirus polygonus.

A first split, group 1, separates the non-monophyletic Dolicholatirus and Teralatirus from the remaining fasciolariids $($ Clade $1 \mathrm{a}$, Bremer $=4)$. A highly supported clade (clade $2:$ Bremer $=$ 8) groups all non-Dolicholatirus or Teralatirus fasciolariids, with clade 2a, 3a and 4a (Bremer $=$ 2, 2 and 2, respectively) represented by the fusinines, that forms a stem paraphyletic group that also includes the genus Pseudolatirus. Group 5a $($ Bremer $=2)$ is the Peristerniine genera Fusolatirus and Peristernia (including the type of the subfamily, Peristernia nassatula). Groups 6a and 7 (Bremer $=2$ and 2, respectively) include the bulk of peristerniine species and all fasciolariines (including the type of the subfamily Fasciolaria tulipa). Bremer supports for all clades are indicated in Fig. 1A (unweighted) and Fig. 1B (weighted).

In order to evaluate the current taxonomical scheme, prior to this analysis, color scheme used for all terminals and branches in the trees correspond to each of the assigned subfamilies: black: outgroup species, non-fasciolariids; blue: fusinines; red: peristerniines; green: fasciolariines. This does not correspond to the natural subfamilies but the one previously assigned (pre-analysis).

The evolution of each of the 95 characters used for this analysis is seen in Figs. 3-6. Discussion of each character follows on the Character discussion section. 


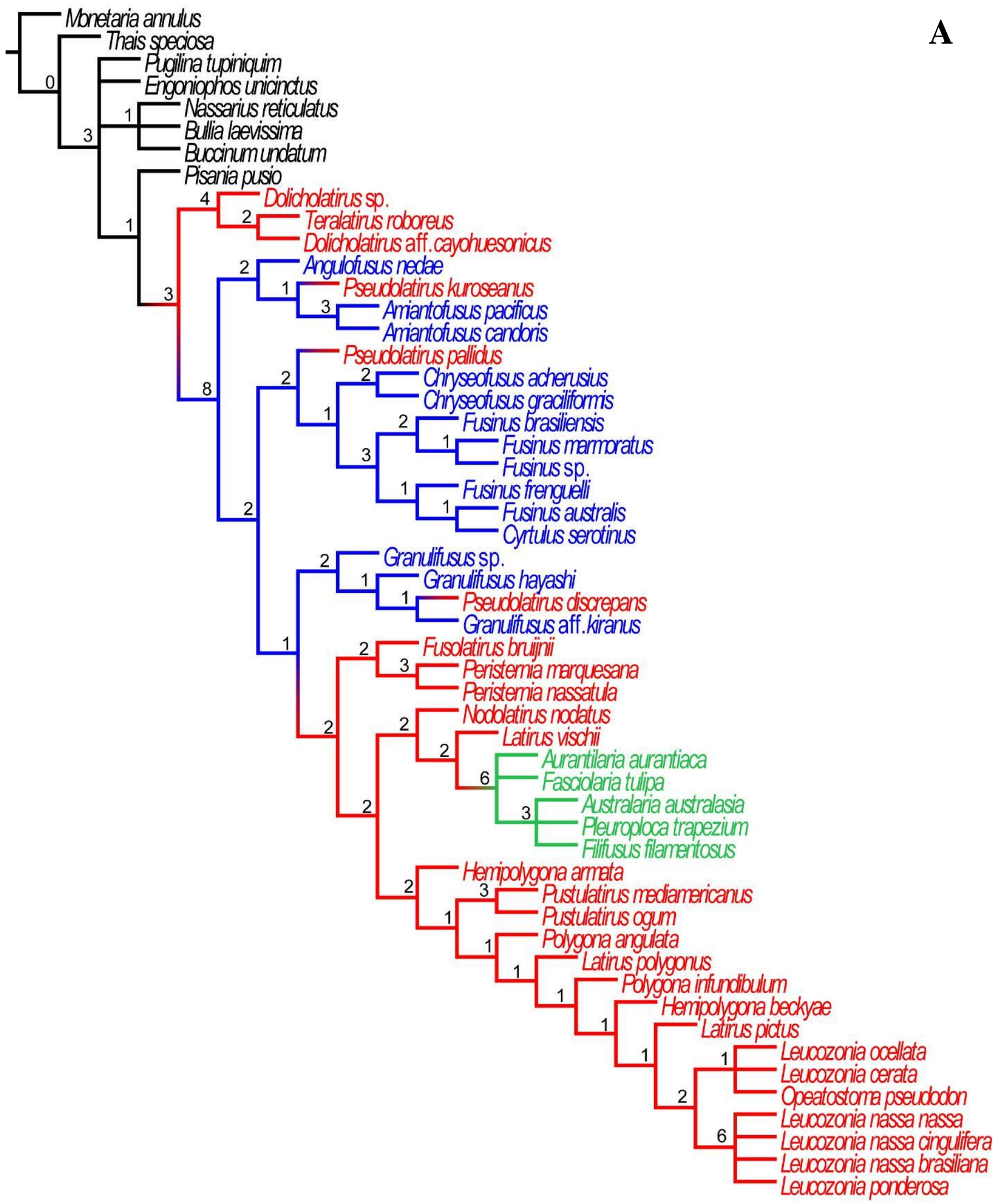

Figure 1. A: Phylogenetic tree obtained through parsimonious analysis in TnT using prior, unweighted characters. Numbers in nodes indicate Bremer support values. Color scheme: Black: non-fasciolariids. Blue: fusinines. Red: peristerniines. Green: fasciolariines. 


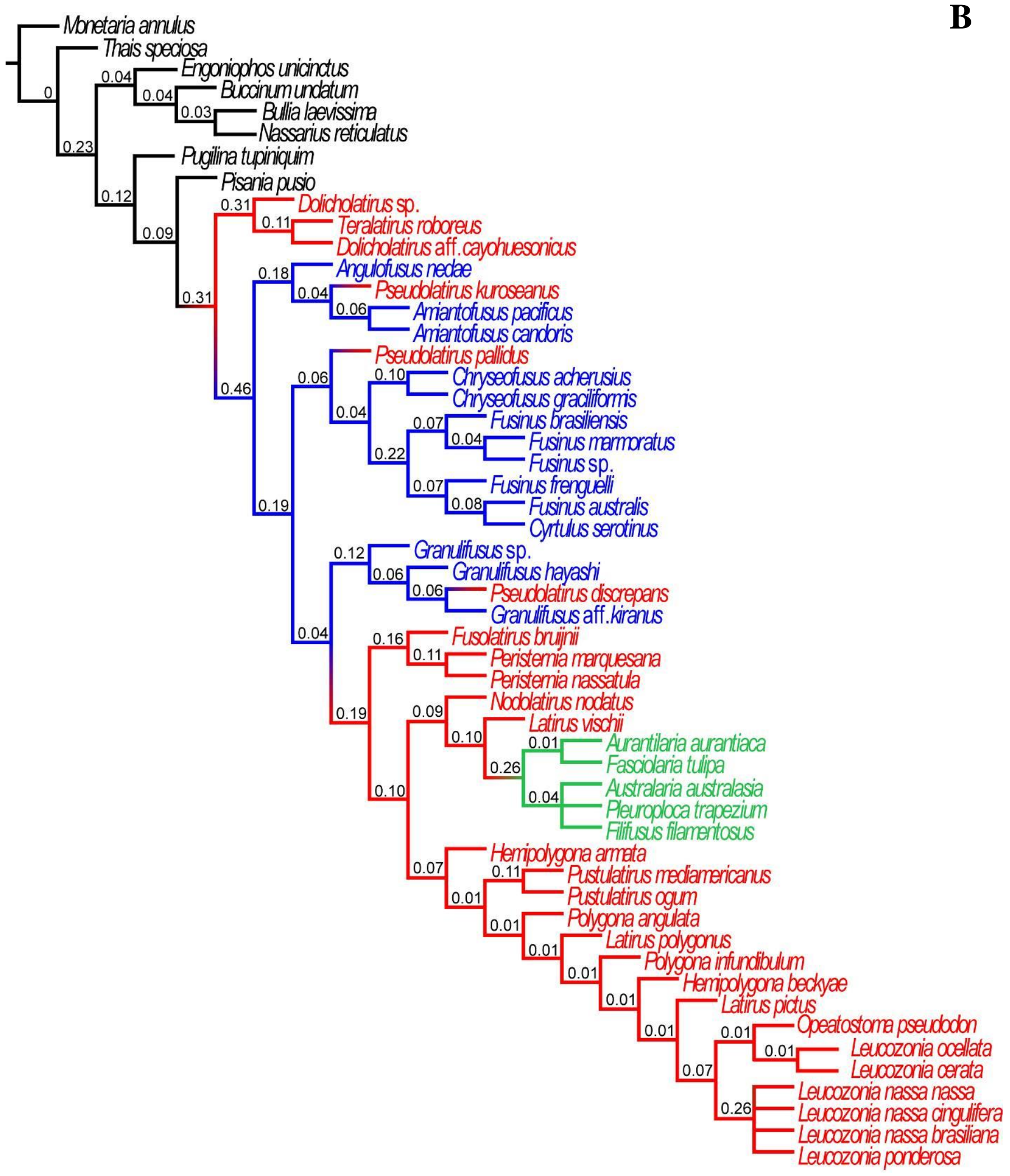

Figure 1 (cont.). B: Phylogenetic tree obtained through parsimonious analysis in TnT using implied weighing $(\mathrm{k}=12.4)$. Numbers in nodes indicate Bremer support values. Color scheme: Black: non-fasciolariids. Blue: fusinines. Red: peristerniines. Green: fasciolariines. 


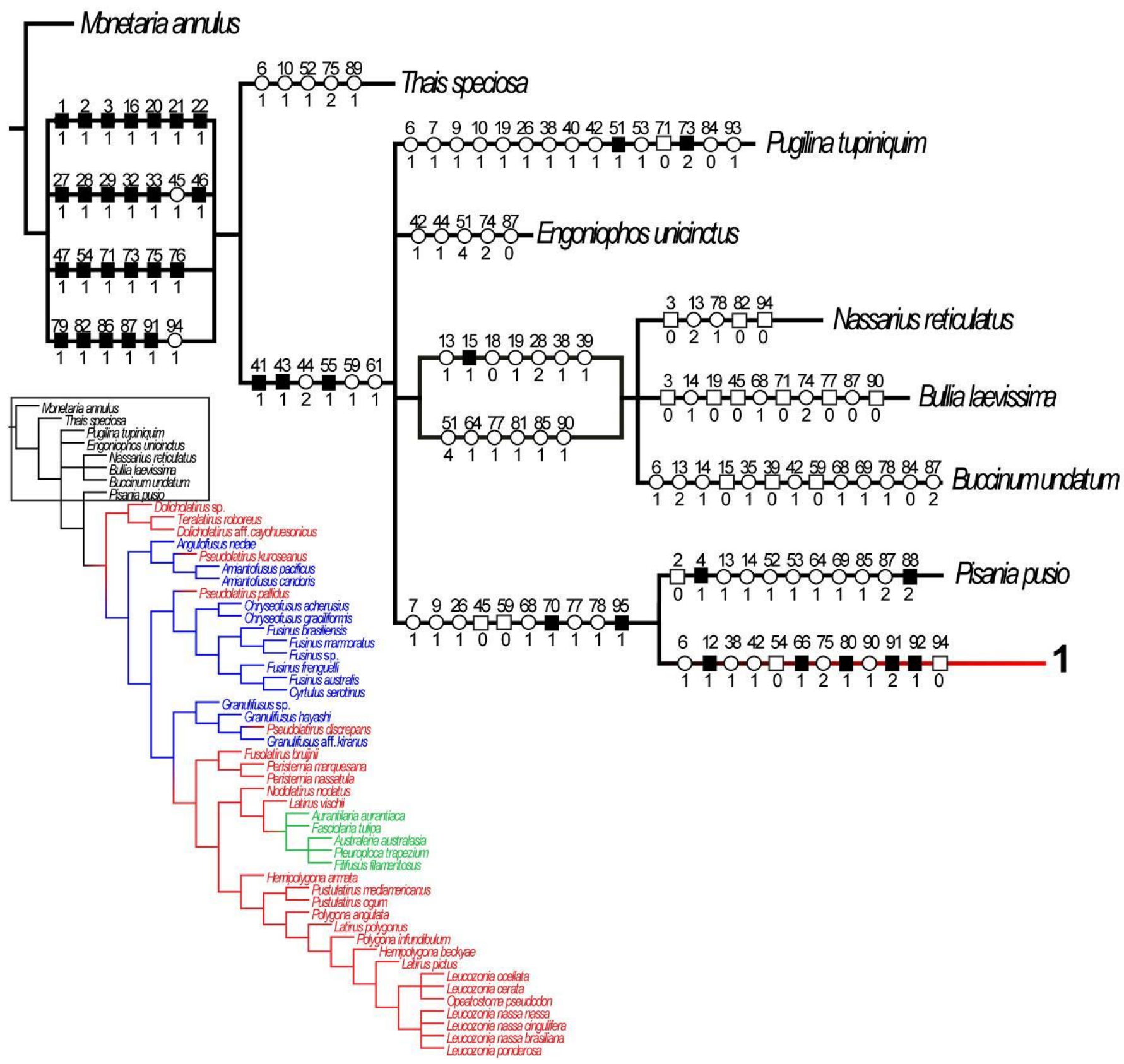

Figure 2. Phylogenetic tree (part one) indicating the synapomorphies that support them. The number above each symbol represents the character, while the number below indicates the character state. Dark squares: non-homoplastic synapomorphy. Empty square: reversion. Circle: convergence. Color scheme: Black: non-fasciolariids. Blue: fusinines. Red: peristerniines. Green: fasciolariines. 


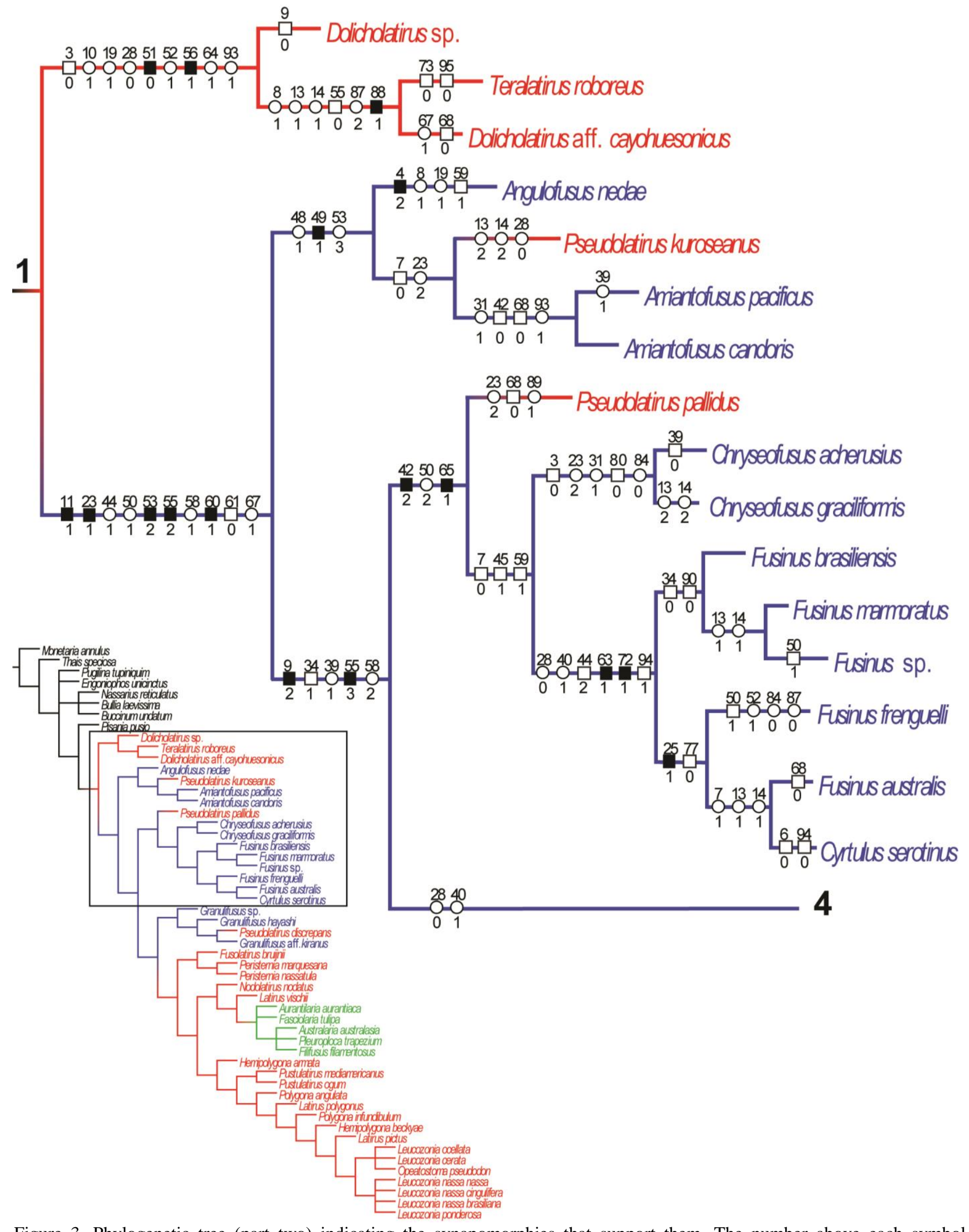

Figure 3. Phylogenetic tree (part two) indicating the synapomorphies that support them. The number above each symbol represents the character, while the number below indicates the character state. Dark squares: non-homoplastic synapomorphy. Empty square: reversion. Circle: convergence. Color scheme: Black: non-fasciolariids. Blue: fusinines. Red: peristerniines. Green: fasciolariines. 


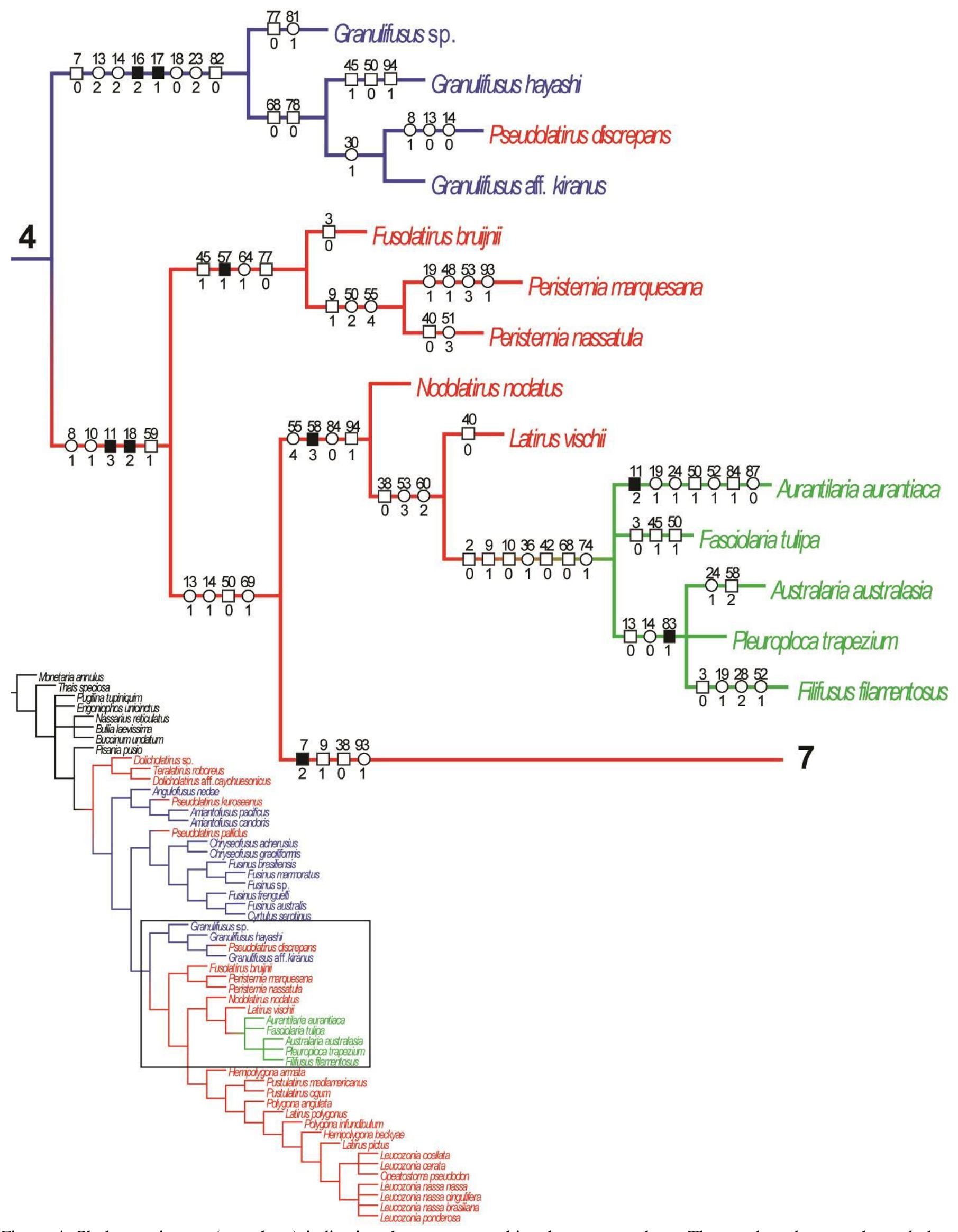

Figure 4. Phylogenetic tree (part three) indicating the synapomorphies that support them. The number above each symbol represents the character, while the number below indicates the character state. Dark squares: non-homoplastic synapomorphy. Empty square: reversion. Circle: convergence. Color scheme: Black: non-fasciolariids. Blue: fusinines. Red: peristerniines. Green: fasciolariines. 


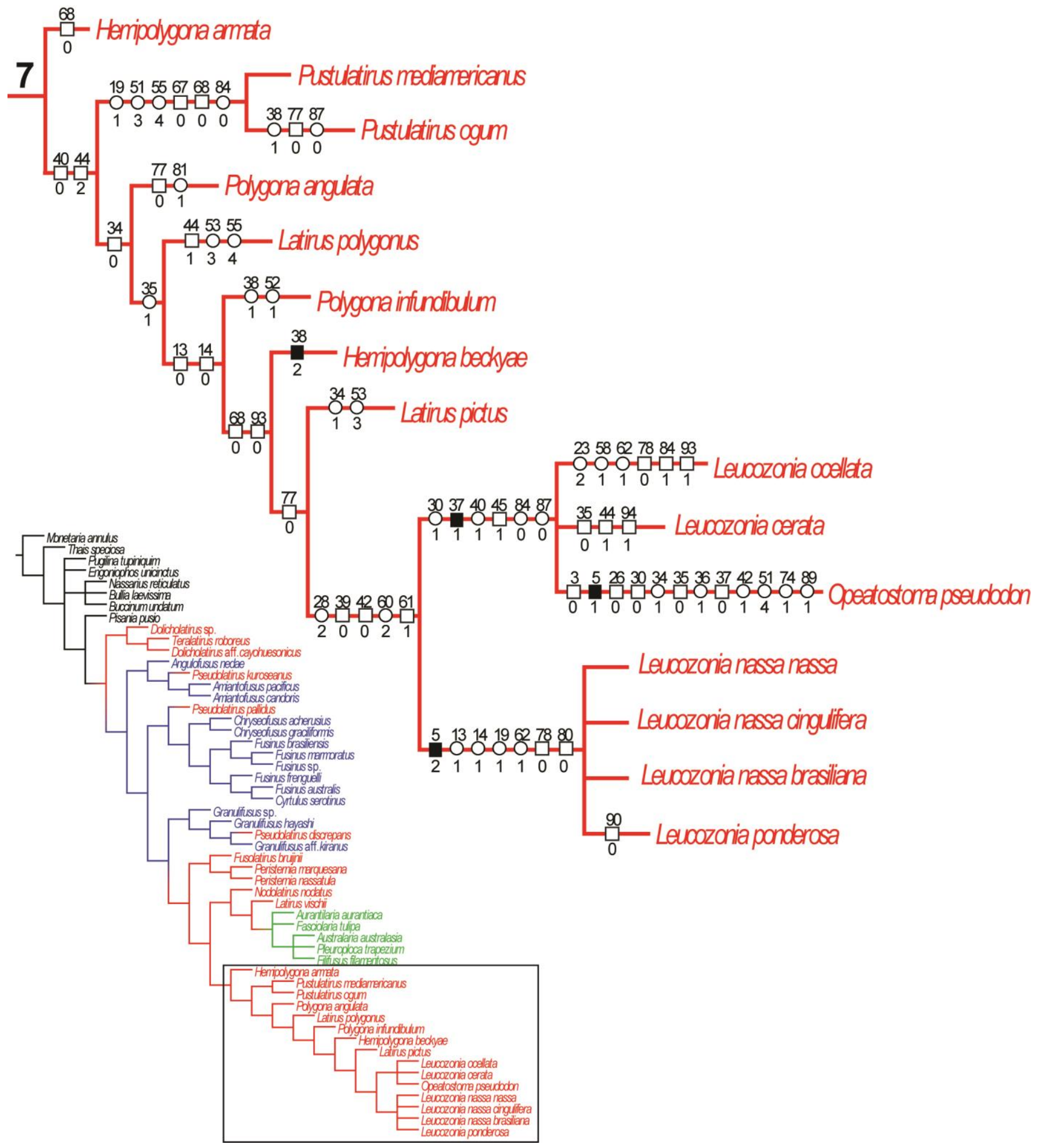

Figure 5. Phylogenetic tree (part four) indicating the synapomorphies that support them. The number above each symbol represents the character, while the number below indicates the character state. Dark squares: non-homoplastic synapomorphy. Empty square: reversion. Circle: convergence. Color scheme: Black: non-fasciolariids. Blue: fusinines. Red: peristerniines. Green: fasciolariines. 


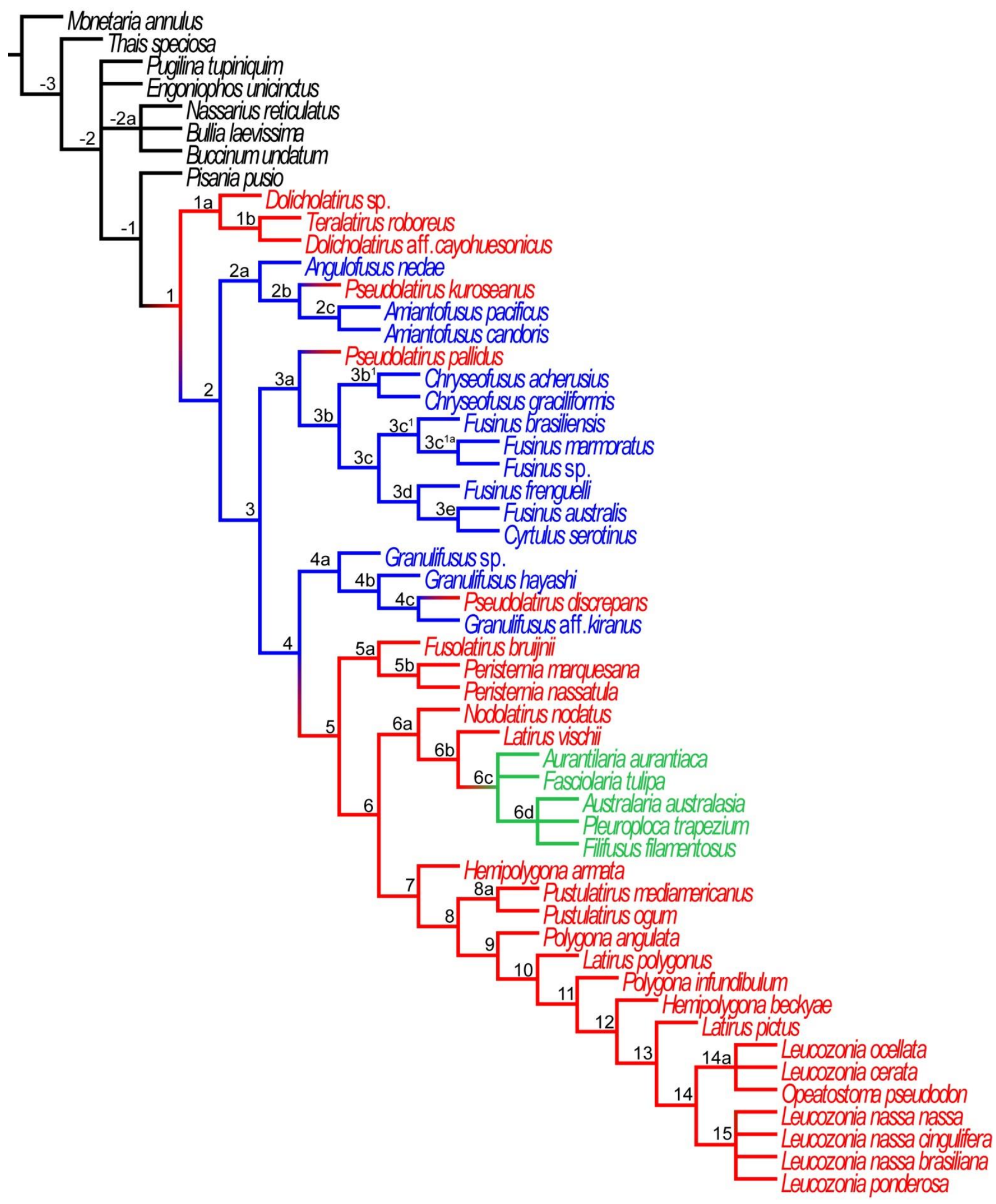

Figure 6. Phylogenetic tree obtained through parsimonious analysis in $\mathrm{TnT}$ with prior weighing. Numbers in nodes indicate node numbers (see text for reference and discussion of each number). Color scheme: Black: non-fasciolariids. Blue: fusinines. Red: peristerniines. Green: fasciolariines. 


\section{Phylogenetic descriptions}

The following discussion corresponds to the unweighted phylogenetic analysis, as specified in the Material and Methods section. For a reference to the following section see Figures 2-5.

\section{Outgroup taxa}

\section{Clade -3 Neogastropoda}

Shell spire visible (1:1), coloration absent or regularly spaced in spiral bands or axial nodes (2: 1); sculpture of spiral bands present (3: 1) throughout teleoconch. Operculum present, filling entire shell aperture (16:1). Mantle border with single lobe (20:1) without papilla (21:1) on its outer surface. Osphradium bearing two branches (anterior-posterior) (22: 1). Ctenidium adjacent to osphradium (27: 1), ctenidium width: osphradium width 1-1.5 (28: 1); its posterior tip directly adjacent to pericardium wall (29: 1). Anal (exhalant) siphon absent (32: 1). Kidney with interdigitating lamellae (pycnonephridial) (33: 1). Odontophore $\mathrm{m} 6$ muscle posterior free portion: odontophore length $\leq 1 / 6$ (45: 1); origin of m11 muscle posteriorly in odontophore cartilages (46: 1). Radula marginal teeth absent (47: 1); laterals not adjacent to rachidians (54:1). Valve of Leiblein present (71: 1). Esophageal gland as gland of Leiblein (73: 1). Stomach bearing posterior bulge with sorting area (caecum) (75: 1). Rectum enveloped with pallial gonoduct (76:1) by thin longitudinal membrane. Bursa copulatrix anterior (79: 1), terminally in pallial oviduct. Cement gland present (82: 1). Penis duct (vas deferens) closed (86: 1) throughout, its shape sinuous (87: 1). Buccal ganglia dorsally in nerve ring, connectives visible (91: 1); its commissure length: buccal ganglia length $\geq 1 / 2$ (94:1).

\section{Thais speciosa (Figs. 7-8)}

Examined material: MZSP 67772, Bajo Copé, off Ayangue, Guayas, Ecuador, Taken under rocks at 10-12m, by dive. Col. Femorale, vi/2006 [2 specimen]. MZSP 95270, Ecuador. Col. J. Coltro, 2009 [1 specimen].

Shell apical growth of outer lip absent (6: 1); pseudo-umbilicus (10: 1) as shallow slit. Radula rachidian bearing minute, secondary cusps (52:1). Stomach bearing posterior bulge without sorting area (75: 2). Penis ejaculatory duct long convoluted tube immersed in haemocoel (89: 1). 


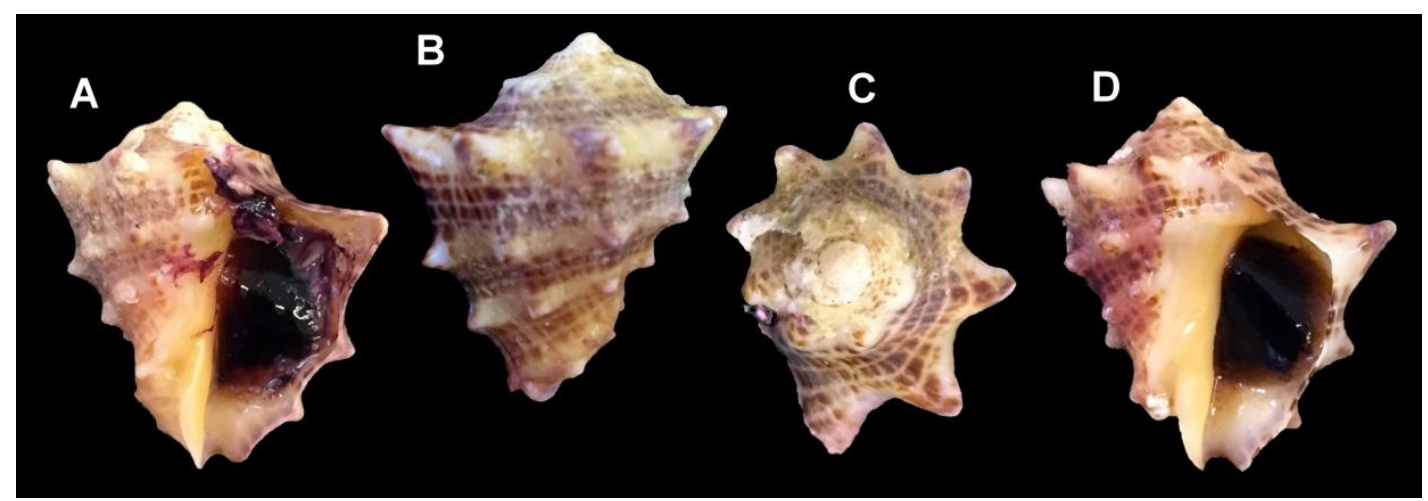

Figure 7. Thais speciosa, shell. A-C: MZSP 67772 (27.2mm). D: MZSP 97270 (23.5mm).

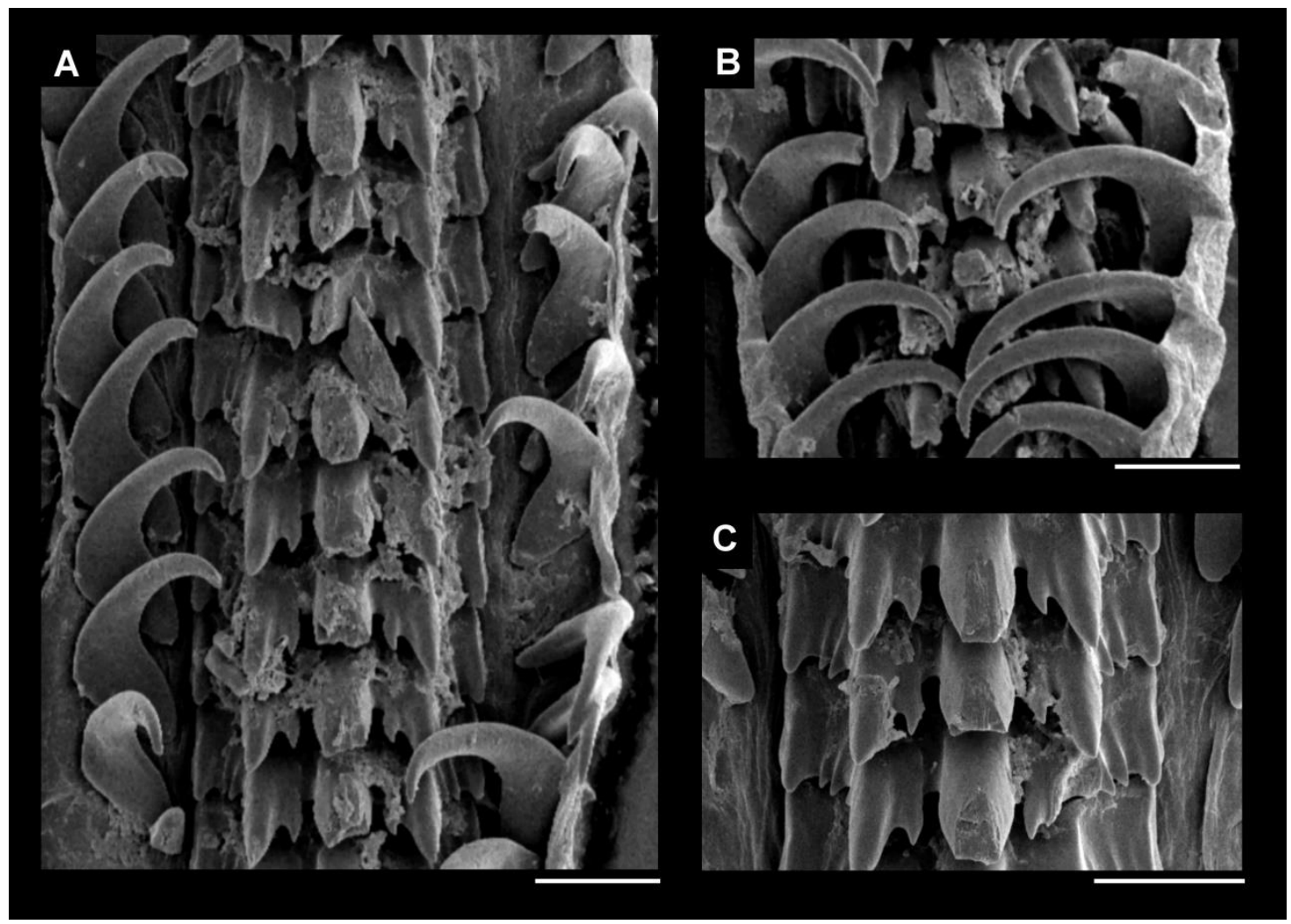

Figure 8. Thais speciosa, radula. A-C: MZSP 95270. A: panoramic view. B: detail of lateral tooth of radula. C. detail of rachidian tooth of radula. Scale bars $=50 \mu \mathrm{m}$. 


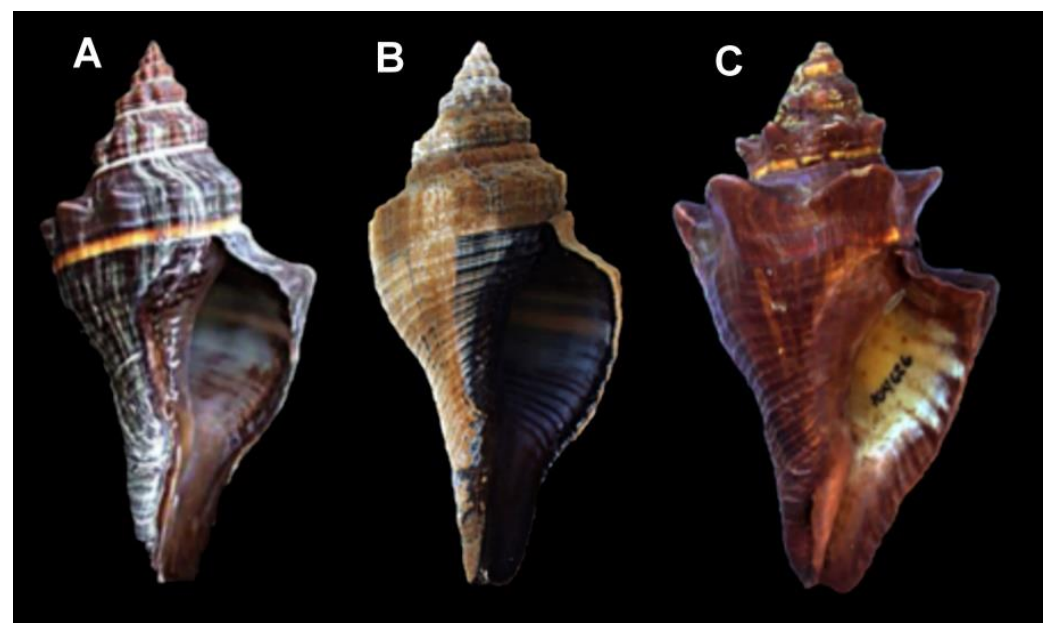

Figure 9. Pugilina tupiniquim, shell (modified from Abbate \& Simone, 2015). A: MZSP 73487 (120mm). B: MZSP 116299 (80mm). C: MZSP 116299 (110mm).

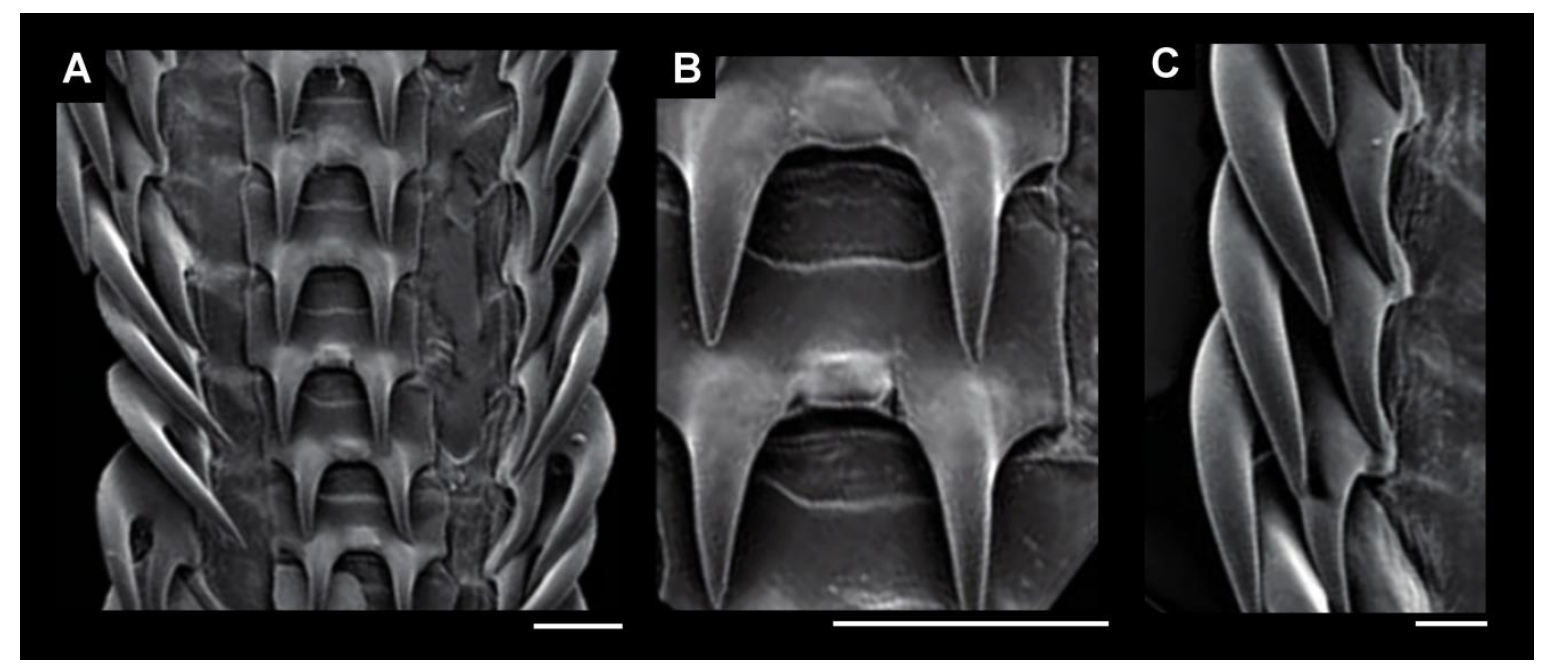

Figure 10. Pugilina tupiniquim, radula (modified from Abbate \& Simone, 2015). A-C: MZSP 91653. A: panoramic view. B: detail of rachidian tooth of radula. C. detail of lateral tooth of radula. Scale bars = $100 \mu \mathrm{m}$.

\section{Clade -2 Buccinoidea}

Odontophore radular sac contained within proboscis (41:1) not extending outwards; cartilages concave (43: 1) slender and elongated; fused anteriorly $\geq 15 \%$ of total odontophore length (44: 2 ). Lateral tooth of radula as long as wide, its length: width $~ 1$ (55: 1), its base curved (59: 1); length of cusp 2 of lateral $\sim$ twice as other cusps (61: 1). 


\section{Pugilina tupiniquim (Figs. 9-10)}

Examined material: data from Abbate \& Simone (2015).

Shell apical growth of outer lip present (6: 1); inner sculpture of outer lip bearing continuous spiral cord (7: 1); siphonal canal moderate-sized, its length: total shell length 1/6-1/4 (9: 1); pseudo-umbilicus present (10: 1) as shallow slit. Pallial cavity long, its extension $\geq 3 / 4$ whorls (19: 1). Osphradium leaflets high, its height: ctenidium height $\geq 1 / 2$ (26: 1). Rhynchostome as longitudinal (38: 1); simple (40: 1), slit. Odontophore medium-sized, its length: proboscis length 1-1/2 (42: 1). Rachidian tooth of radula bearing two principal cusps (51: 1), small, its width: lateral tooth width $1 / 2 \leq 1$ (53:1). Loss of valve of Leiblein (71:0) and esophageal gland (73:2). Cement gland opening centrally (84: 0 ) in foot sole. Commissure of buccal ganglia inconspicuous (93: 1).

\section{Engoniophos unicinctus (Figs. 11-12)}

Examined material: data from Abbate (2016).

Odontophore medium-sized, its length: proboscis length $1-1 / 2$ (42: 1), fused anteriorly $\leq 15 \%$ of total odontophore length (44: 1). Rachidian tooth of radula with $\geq 5$ cusps (51: 4). Posterior esophagus bearing sudden broadening in haemocoel region (74: 2), anterior to diaphragmatic septum. Duct of penis linear (87: 0).

\section{Clade -2a Clade Buccinidae + Nassariidae}

Head medium-sized, its width: head-foot mass width 1/4-1/2 (13: 1). Foot with metapodial 1 or 2 tentacles (15: 1) in posterior dorsal region of foot. Operculum eccentric, its lateral margin rounded (18: 0). Pallial cavity long, its extension $\geq 3 / 4$ whorls (19: 1 ). Ctenidium ample, its width: osphradium width $\geq 1.5$ (28: 2). Rhynchostome as longitudinal slit (38: 1), bearing longitudinal folds in its margin that extend inwards (39: 1). Rachidian tooth of radula with $\geq 5$ cusps (51:4); secondary cusps on lateral tooth present (64: 1). Anus far from mantle border, its distance from mantle border: total pallial cavity length $\geq 1 / 3$ (77: 1). Bursa copulatrix bearing anterior muscular bulb (81: 1) close to gonopore. Prostate as simple tube (85: 1). Pedal ganglia elongated, its length: nerve ring length $\geq 1 / 2$ (90:1). 


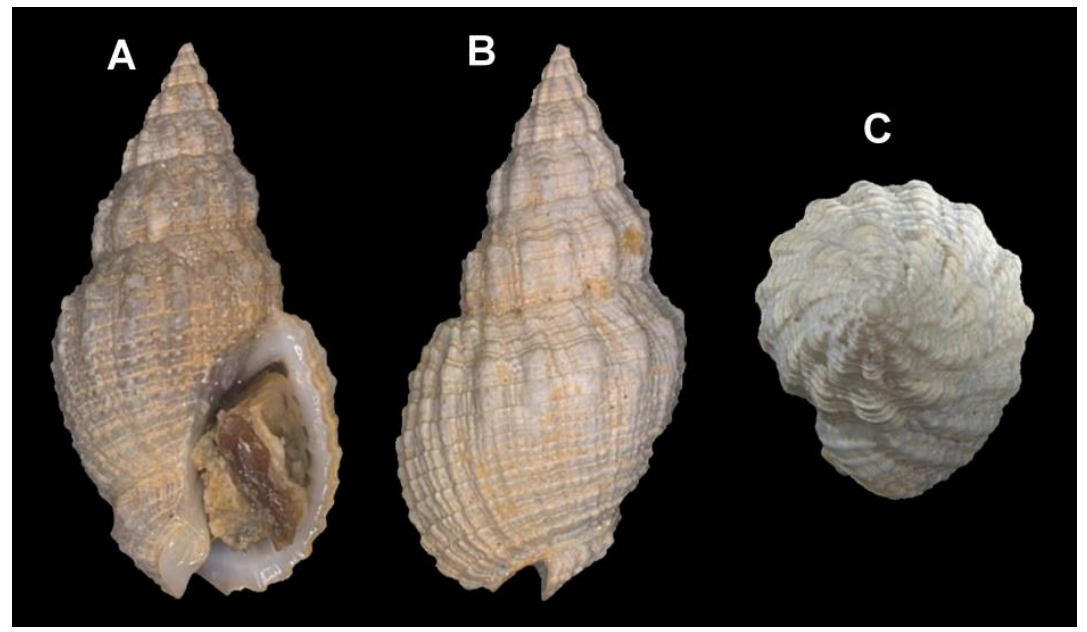

Figure 11. Engoniophos unicinctus, shell (modified from Abbate, 2016). A-B: MZSP 77798 (18.7mm). C: MZSP 77798.

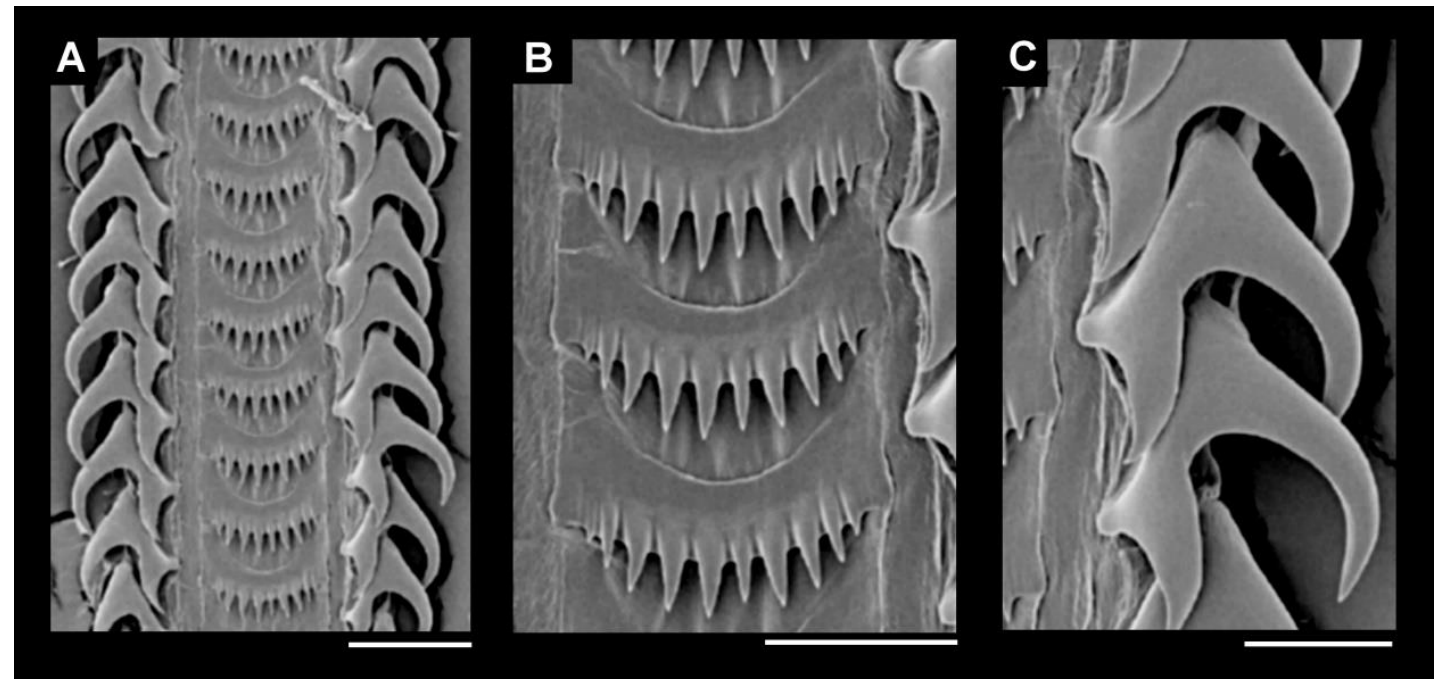

Figure 12. Engoniophos unicinctus. radula (modified from Abbate, 2015). A-C: MZSP 77798. A: panoramic view. B: detail of rachidian tooth of radula. C. detail of lateral tooth of radula. Scale bars $=50 \mu \mathrm{m}$.

\section{Nassarius reticulatus (Figs. 13-14)}

Examined material: data from Abbate (2016).

Loss of spiral sculpture of shell (3: 0). Head large, its width: head-foot mass width $\geq 1 / 2$ (13: 2). Seminal receptacle in pallial oviduct absent (78: 1). Loss of cement gland (82: 0). Buccal ganglia commissure diminute, its length: buccal ganglia length $\leq 1 / 2$ (94: 0 ). 


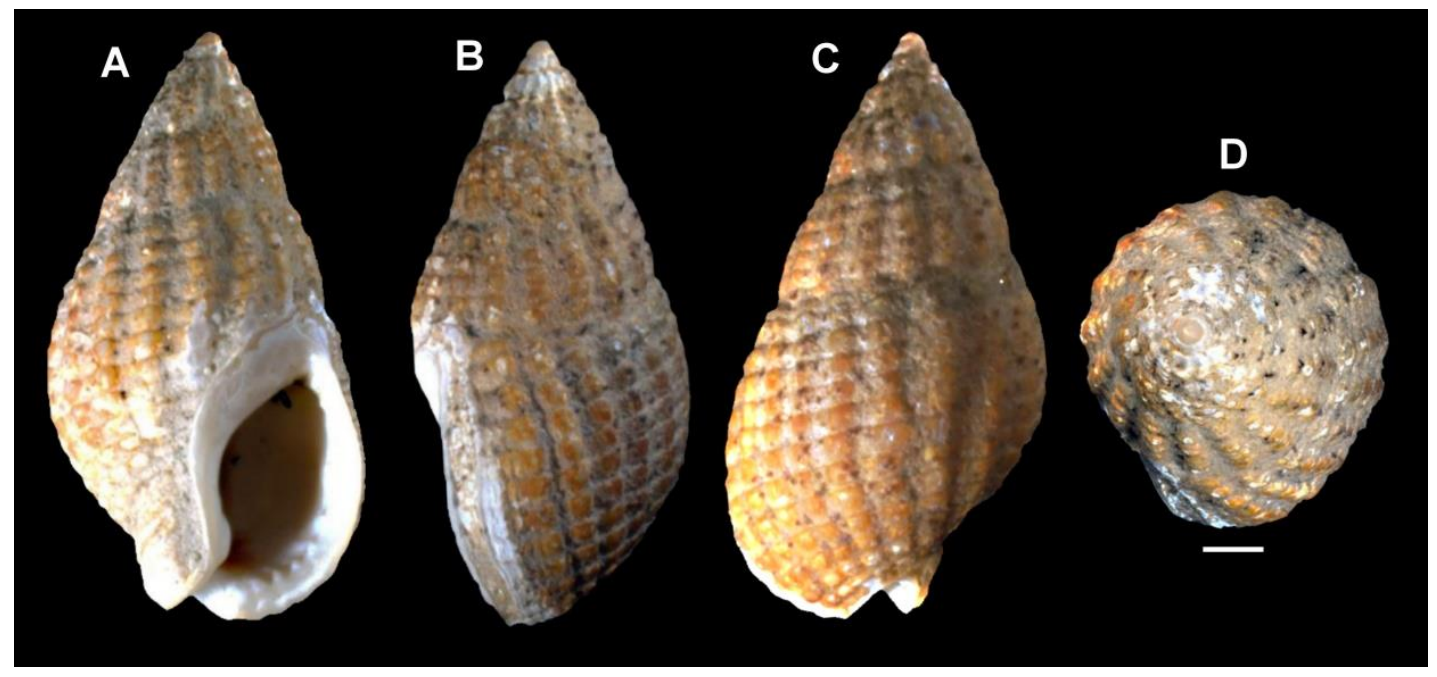

Figure 13. Nassarius reticulatus, shell (modified from Abbate, 2016). A-D: MZSP 92087. Scale bars $=2 \mathrm{~mm}$.

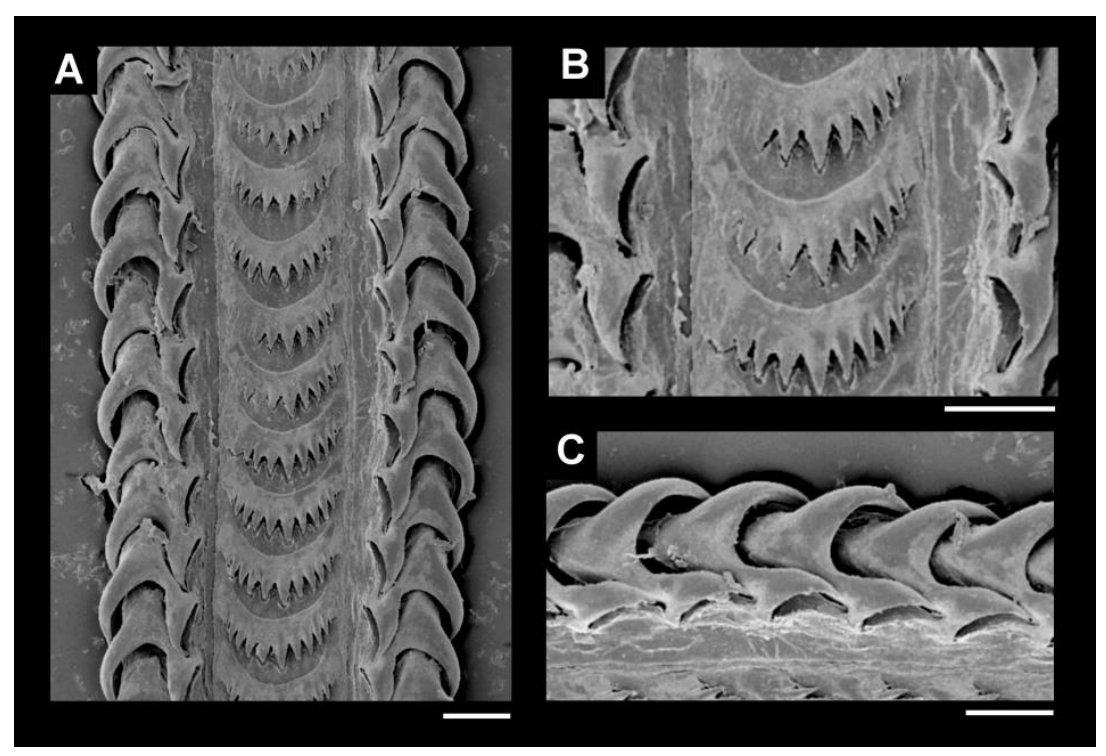

Figure 14. Nassarius reticulatus, radula (modified from Abbate, 2016). A-D: MZSP 92087. A: panoramic view. B: detail of rachidian tooth. C: detail of lateral tooth. Scale bars $=30 \mu \mathrm{m}$. 


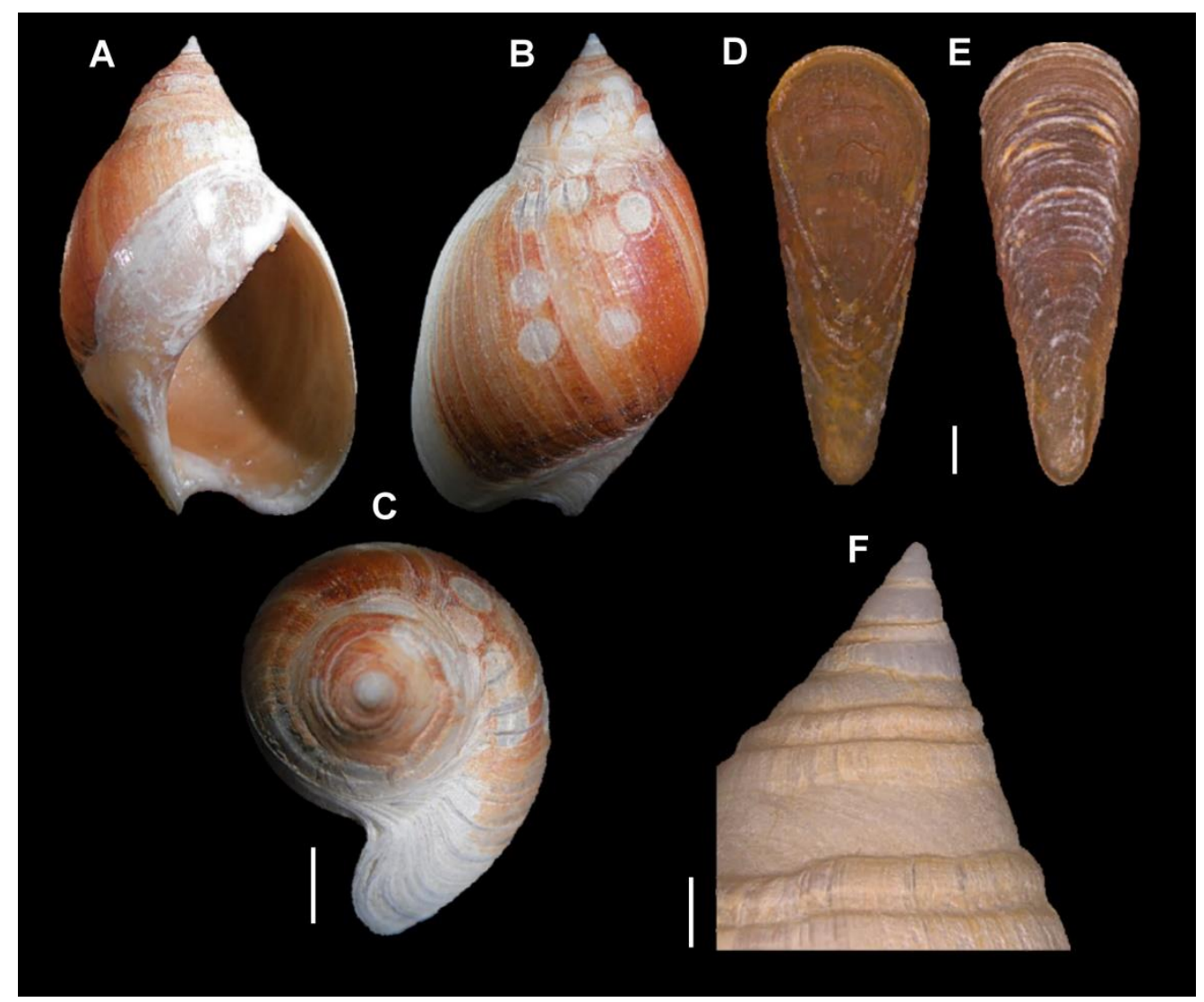

Figure 15. Bullia laevissima, shell and operculum (modified from Abbate \& Simone, 2016). A-F: KZN S3741. A-C: $(41.7 \mathrm{~mm})$. D-E: operculum ventral and dorsal view. F: detail of protoconch. Scale bars $=1 \mathrm{~mm}$.

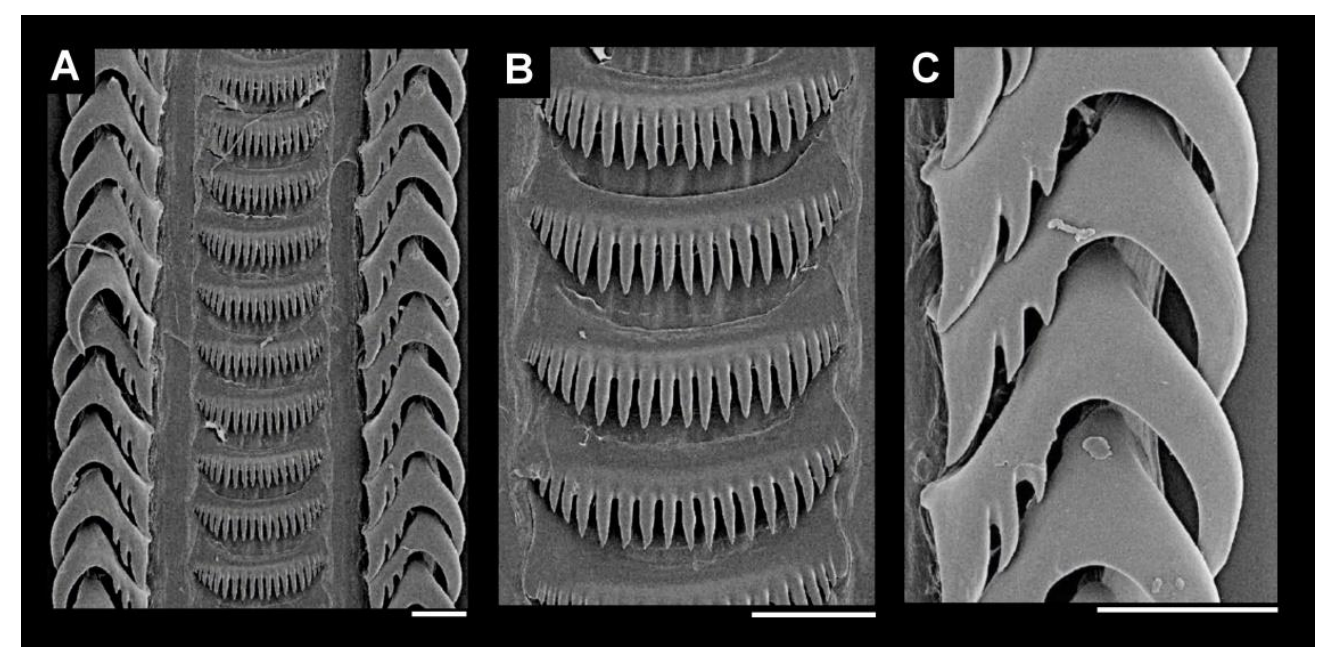

Figure 16. Bullia laevissima, radula (modified from Abbate \& Simone, 2016). A-C: KZN S3741. A: panoramic view. B: detail of rachidian tooth. C: detail of lateral tooth. Scale bars $=200 \mu \mathrm{m}$. 


\section{Bullia laevissima (Figs. 15-16)}

Examined material: data from Abbate (2016).

Loss of spiral sculpture of shell (3: 0). Head with short cephalic tentacles, its length: head width 1/2-2/3 (14: 1). Pallial cavity short, its extension $\leq 3 / 4$ whorls (19: 0). Odontophore m6 muscle posterior free portion: odontophore length >1/6 (45: 0). Proboscis retractor muscles originating mid-proboscis (68: 1). Loss of valve of Leiblein (71:0). Posterior esophagus constant in diameter (74: 2) throughout its extension. Anus close to mantle border, its distance from mantle border: total pallial cavity length <1/3 (77: 0). Duct of penis linear (87: 0). Pedal ganglia short, its length: nerve ring length <1/2 (90: 0$)$.

\section{Buccinum undatum (Figs. 17-18)}

Examined material: MZSP 98217, off Calais, North Sea, France, Taken by nets at 15-20 meters, bought at local market in Paris. xii/2010 [10 specimens]. MZSP 58732, Amrun Island, North Sea. L. Forneris col. vi/23/1960 [1 specimen].

Shell apical growth of outer lip absent (6: 1). Head large, its width: head-foot mass width $\geq 1 / 2$ (13: 2). Head with short cephalic tentacles, its length: head width 1/2-2/3 (14: 1). Loss of metapodial tentacles (15: 0). Nephridial gland present in membrane between renal cavity and pericardium (35: 1). Loss of longitudinal folds in margin of rhynchostome (39: 0). Odontophore medium-sized, its length: proboscis length 1-1/2 (42: 1). Base of lateral tooth of radula straight (59: 0). Proboscis retractor muscles originating mid-proboscis (68: 1). Salivary glands as free amorphous masses (69: 1) present in haemocoel. Seminal receptacle of oviduct absent (78: 1); cement gland opening centrally (84:0) in foot sole. Penis duct highly convoluted (87: 2). 


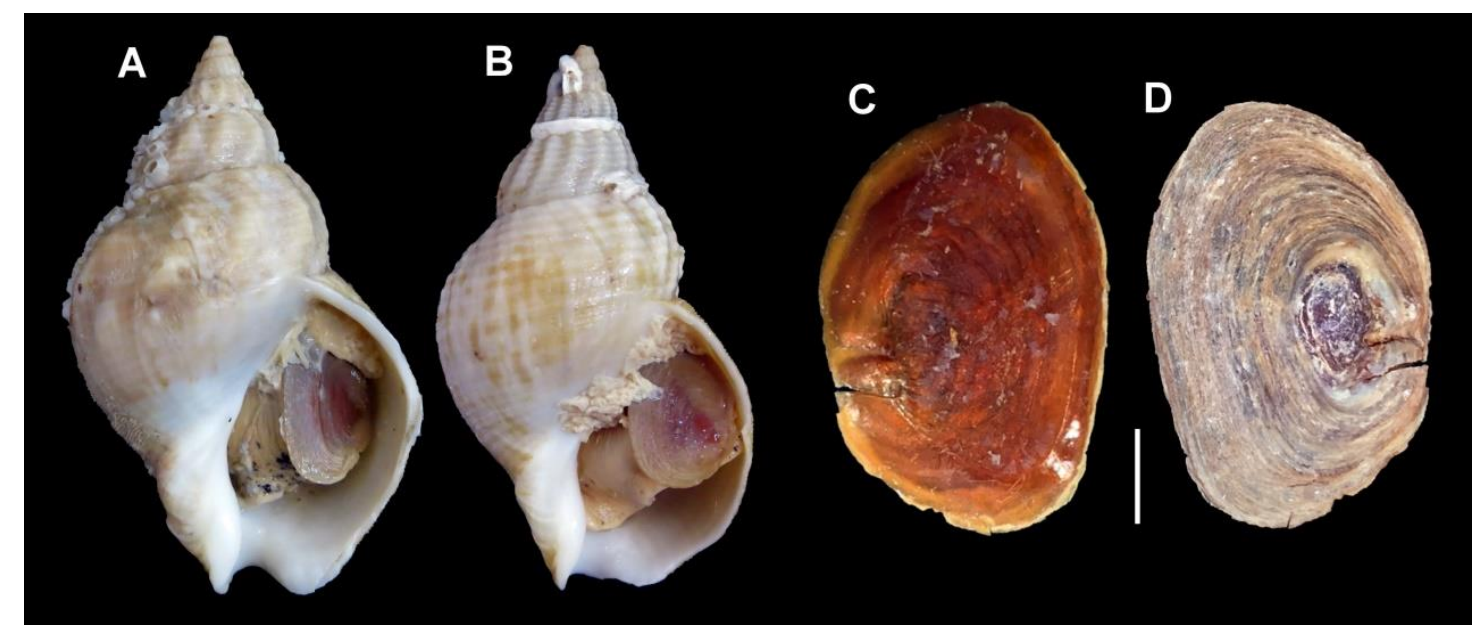

Figure 17. Buccinum undatum, shell and operculum. A-D: MZSP 98217. A: $67.7 \mathrm{~mm}$. B: 85.4mm. C: operculum, inner view. D. operculum, outer view. Scale bars $=10 \mathrm{~mm}$.

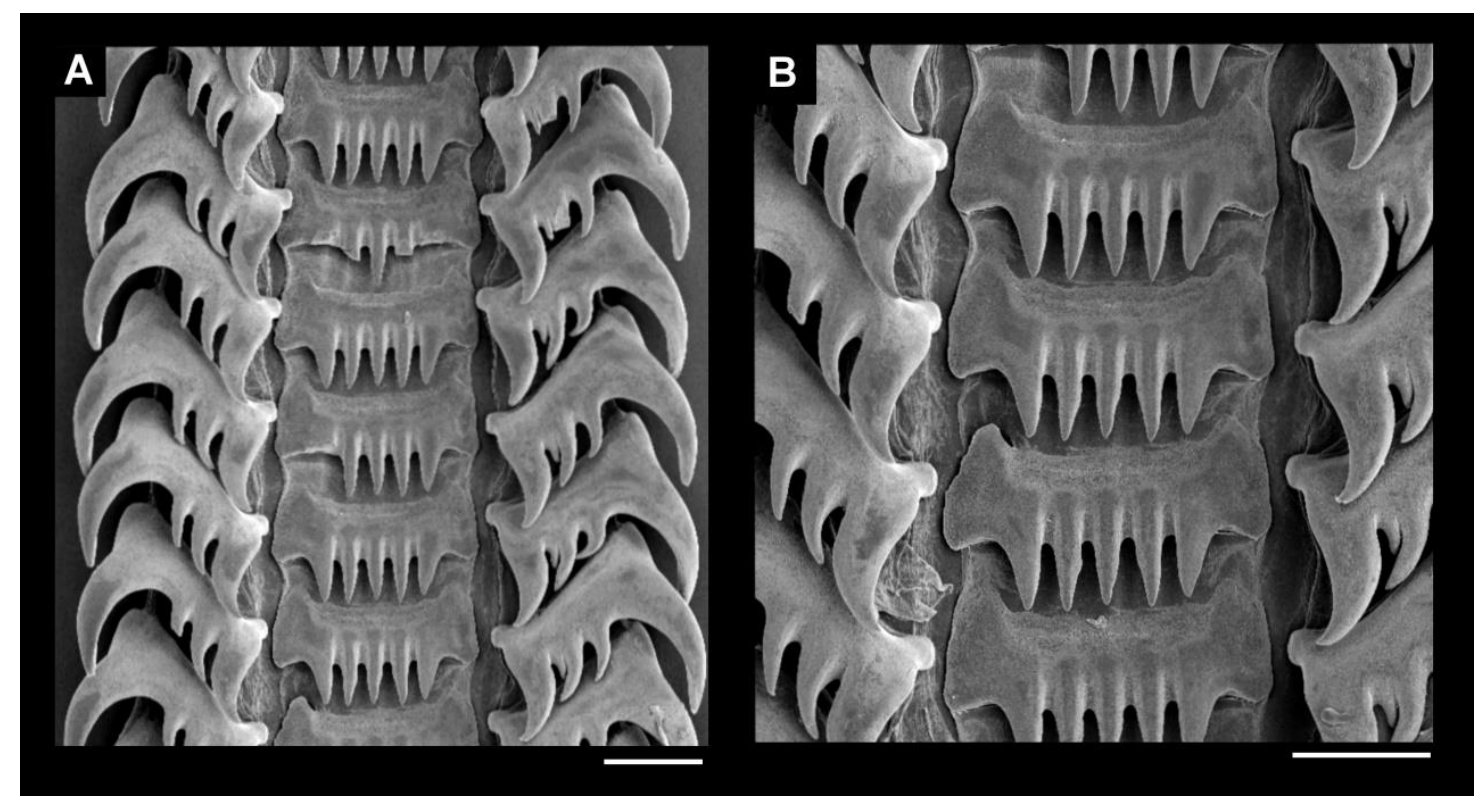

Figure 18. Buccinum undatum, radula. A-B: MZSP 98217. A: panoramic view. B: detail of rachidian tooth of radula. Scale bars $=200 \mu \mathrm{m}$.

\section{Clade -1 Pisaniinae + Fasciolariidae "salivary ducts immersed in esophagus wall"}

Shell outer lip bearing inner sculpture of continuous spiral cord (7: 1); siphonal canal of moderate size, its length: total shell length 1/6-1/4 (9: 1). Osphradium leaflets high, its height: ctenidium height $\geq 1 / 2$ (26: 1$)$. Odontophore $m 6$ muscle posterior free portion: odontophore length $>1 / 6$ (45: 0 ). Base of lateral tooth of radula straight (59: 0). Proboscis retractor muscles originating midproboscis (68: 1). Salivary ducts immersed in its ventral-laterally walls of anterior esophagus (70: 1), anteriorly to valve of Leiblein. Anus distance from mantle border: total pallial cavity length $\geq 1 / 3$ (77: 1). Seminal receptacle in pallial oviduct absent (78: 1). Statocysts in nerve ring asymmetrical, right anterior and left posterior (95: 1). 


\section{Pisania pusio (Figs. 19-20)}

Examined material: MZSP 105583, Búzios, Ilhabela, São Paulo state, 23ํำ.762'S $45^{\circ} 09.282^{\prime} \mathrm{W}, 10 \mathrm{~m}$ depth. Coltro col. vi/2003 [18 specimens]. MZSP 105690. São Paulo state, Brazil. v/15/2012 [6 specimens]. MZSP 111471 Guaraparí, Espírito Santo state, Brazil. ii/17/2013 [7 specimens]. MZSP 112908, Fernando de Noronha, Pernambuco state, Brazil. FAPESP col v/04/2013. [4 specimens].

Shell coloration blotchy spots, irregularly spaced (2: 0); anal notch in outer lip, ventral to aperture (4: 1). Head medium-sized, its width: head-foot mass width 1/4-1/2 (13: 1), with short cephalic tentacles, length: head width 1/2-2/3 (14: 1). Radula rachidian bearing minute, secondary cusps (52: 1), small, width: lateral tooth width $1 / 2 \leq 1$ (53:1); lateral tooth bearing secondary cusps (64: 1). Salivary glands as free amorphous masses (69:1). Prostate as simple tube (85: 1). Penis duct highly convoluted (87: 2), pre-copulatory chamber bearing long terminal papilla (88: 2).

\section{Ingroup taxa}

\section{Clade 1 Family Fasciolariidae}

Shell apical growth of outer lip absent (6:1). Head with cephalic tentacles positioned with its bases side by side (12: 1), lacking forehead. Rhynchostome as longitudinal slit (38: 1). Odontophore medium-sized, its length: proboscis length 1-1/2 (42: 1). Lateral tooth of radula directly adjacent to rachidian (54: 0). Single or paired proboscis retractor muscles originate in columellar muscle (66: 1). Stomach bearing posterior bulge without sorting area (75: 2). Bursa copulatrix long, its length: oviduct length $\geq 1 / 4$ (80: 1). Pedal ganglia elongated, its length: nerve ring length $\geq 1 / 2$ (90: 1); buccal ganglia immersed in nerve ring (91: 2), its connectives not visible, positioned dorsal to cerebro-pleural ganglia (92: 1); buccal ganglia commissure diminute, its length: buccal ganglia length $\leq 1 / 2$ (94: 0).

\section{Clade 1a Dolicholatirus + Teralatirus}

Loss of shell spiral sculpture (3: 0); pseudo-umbilicus (10: 1). Pallial with extension $\geq 3 / 4$ whorls (19: 1). Ctenidium width: osphradium width <1 (28: 0). radula rachidian tooth with 1 principal cusp (51: 0), bearing secondary cusps (52: 1); lateral tooth curved outward (56: 1), secondary cusps on lateral tooth absent (64: 1). Commissure of buccal ganglia inconspicuous (93: 1). 


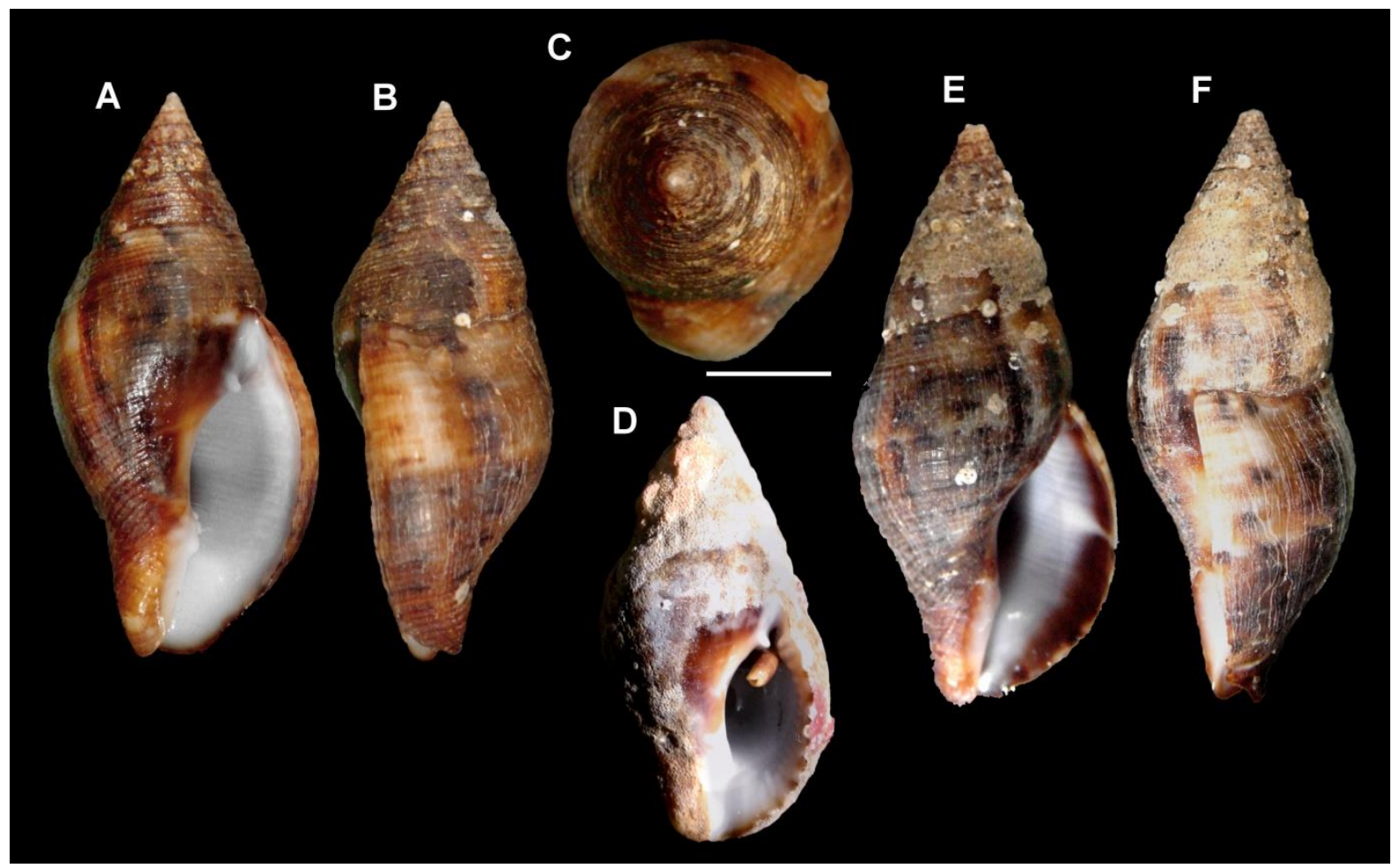

Figure 19. Pisania pusio, shell. A-C: MZSP 111471 (26,3mm). D: MZSP 105583 (38,0mm). E-F: MZSP $105690(35,2 \mathrm{~mm})$. Scale bars $=10 \mathrm{~mm}$.

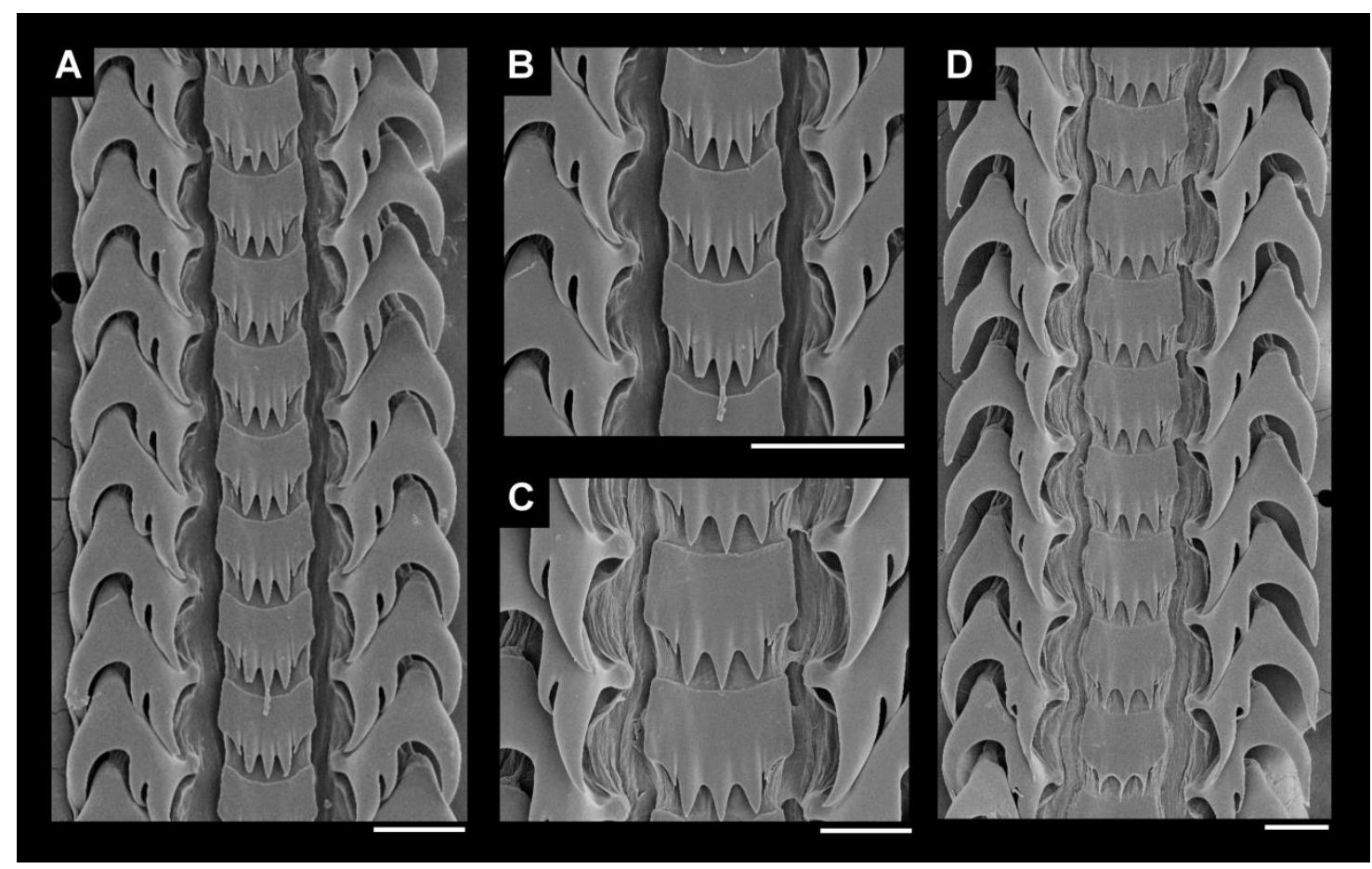

Figure 20. Pisania pusio, radula. A-B: MZSP 105690. A: panoramic view. B: detail of rachidian tooth of radula. C-D: MZSP 111471. C: radula. D: detail of rachidian tooth of radula. Scale bars = $50 \mu \mathrm{m}$. 


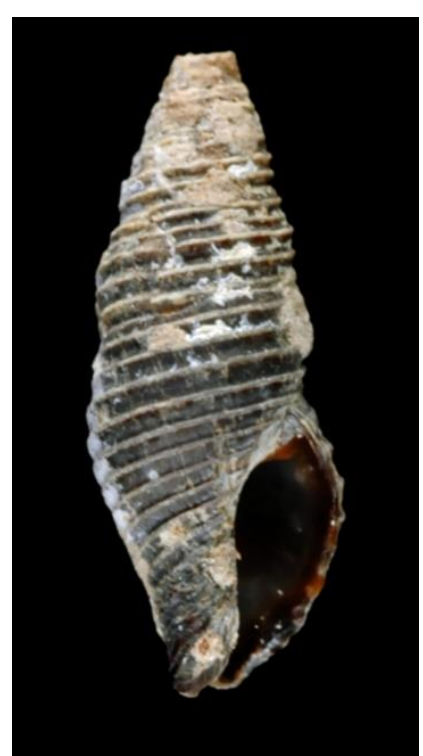

Figure 21. Dolicholatirus sp. shell (modified from Couto et al., 2016), MNHN IM-2009-29739.

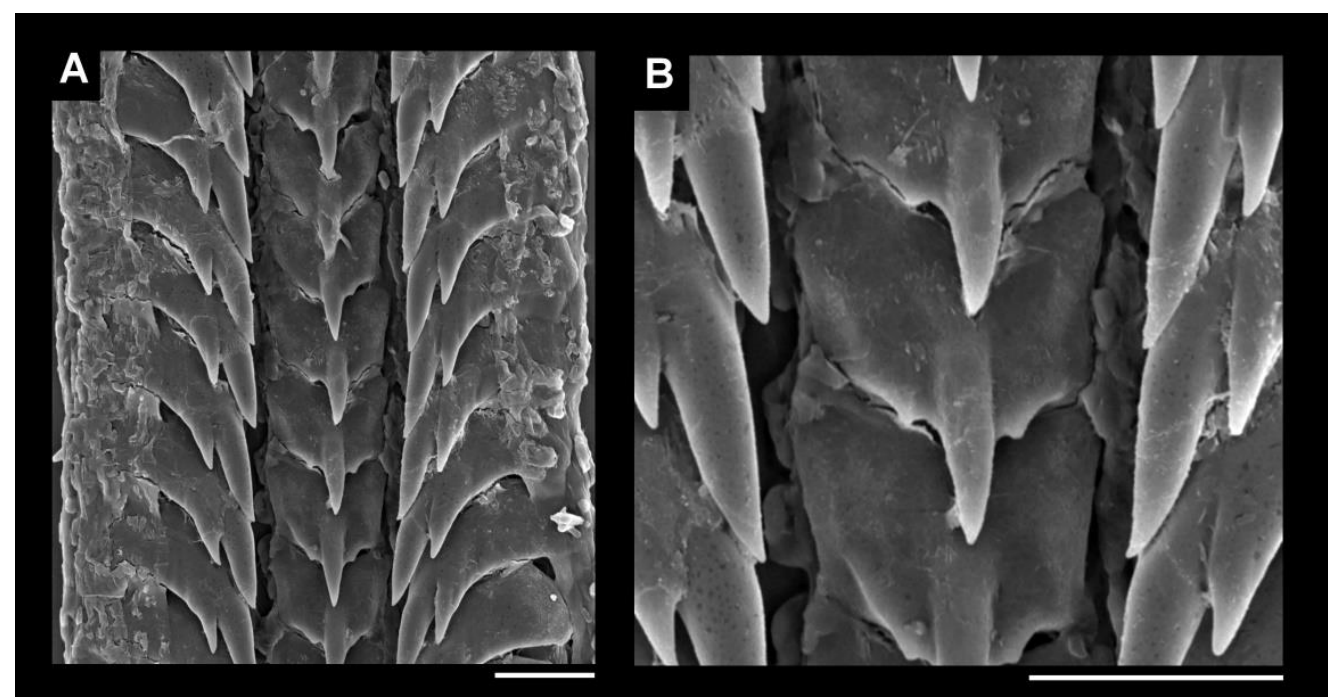

Figure 22. Dolicholatirus sp. radula (modified from Couto et al., 2016). A-B: MNHN IM2009-29739. A: panoramic view. B: detail of rachidian tooth. Scale bars $=10 \mu \mathrm{m}$.

Dolicholatirus sp. (Figs. 21-22)

Examined material: data from Couto et al. (2016).

Shell with short siphonal canal, its length: total shell length $\leq 1 / 6(9: 0)$.

\section{Clade 1b}

Shell with columellar folds (8: 1) present in mid-aperture. Head medium-sized, its width: headfoot mass width 1/4-1/2 (13: 1), bearing short cephalic tentacles, its length: head width 1/2-2/3 (14: 1). Radula lateral tooth longer than wide, its length: width >1 (55: 0). Penis duct highly convoluted (87: 2), pre-copulatory chamber bearing short terminal papilla (88: 1) contained within.

\section{Teralatirus roboreus (Figs. 23-24)}

Examined material: data from Simone et al. (2013).

Esophageal gland as ventral septated sac (73: 0). Statocysts in nerve ring symmetrical (95: 0), anterior in pedal ganglia. 


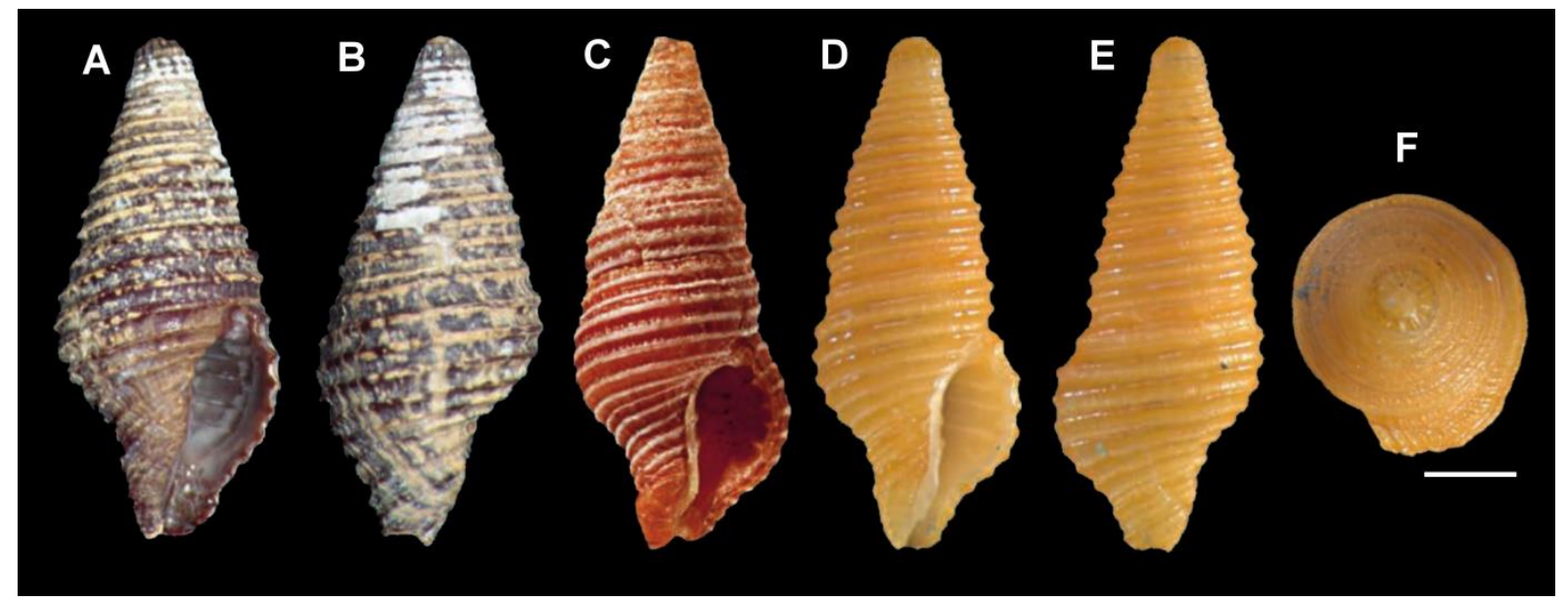

Figure 23. Teralatirus roboreus, shell (modified from Simone et al., 2013). A-B: MZSP 92195 (9mm). C: NHMUK 1854, holotype (9.3mm). D-F: MZSP $87285(10.2 \mathrm{~mm})$. Scale bars $=1 \mathrm{~mm}$.

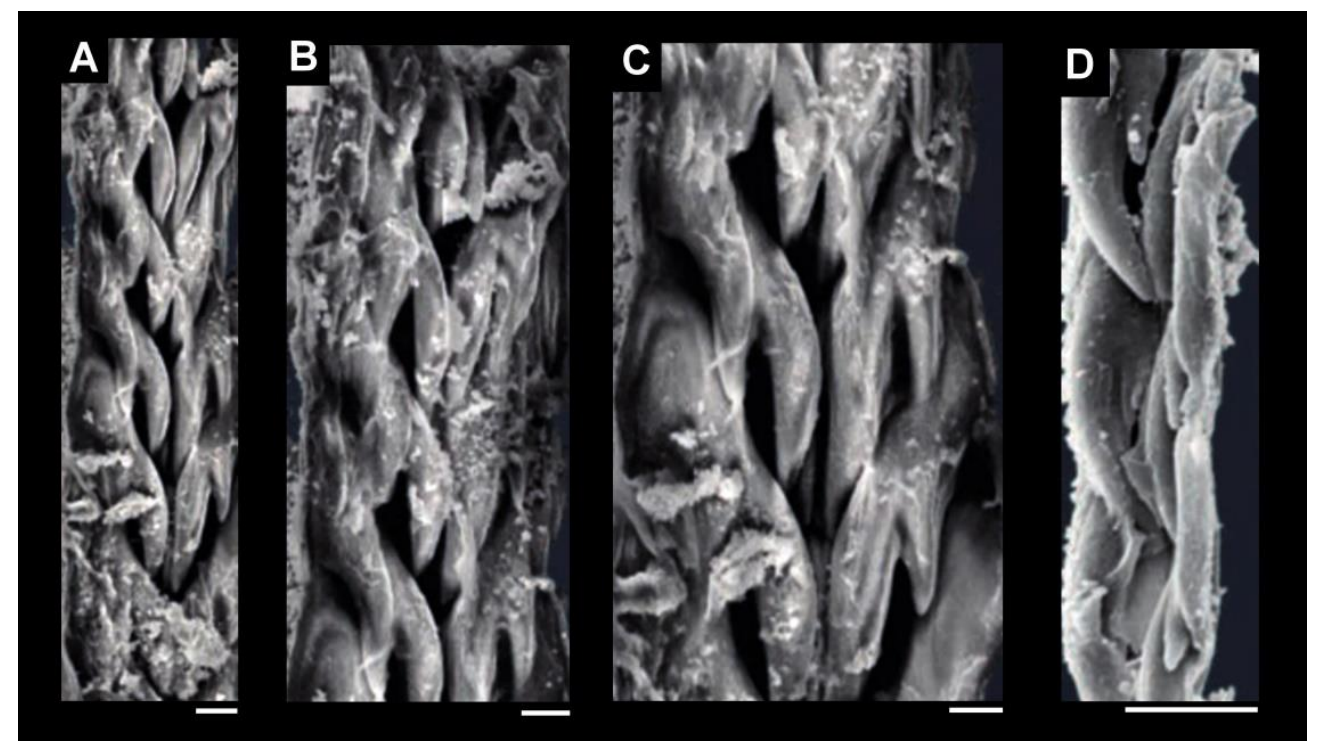

Figure 24. Teralatirus roboreus, radula (modified from Simone et al., 2013). A-D: MZSP 92195. Scale bars $=2 \mu \mathrm{m}$.

Dolicholatirus aff. cayohuesonicus (Figs. 25-26)

Examined material: ANSP A8131, Cayman Brac, Southwest Point, Cayman Islands. Maes, R. A. \& V. O col. ii/1968 [2 specimens]. ANSP 338609/A5642, White Bay, Guana Island, British Virgin Islands, in drifted sand on rocks, 2-3m depth. Maes, V. O. col. ii/15-28/1975 [9 specimens]. ANSP A18293, Reef, mouth of Puerto Yabucoa, Yabucoa, Puerto Rico. Loos, J. col. vii/22-23/1969. [1 specimen].

Proboscis retractor muscles as single bundle (67: 1), inserting posteriorly (68: 0). 


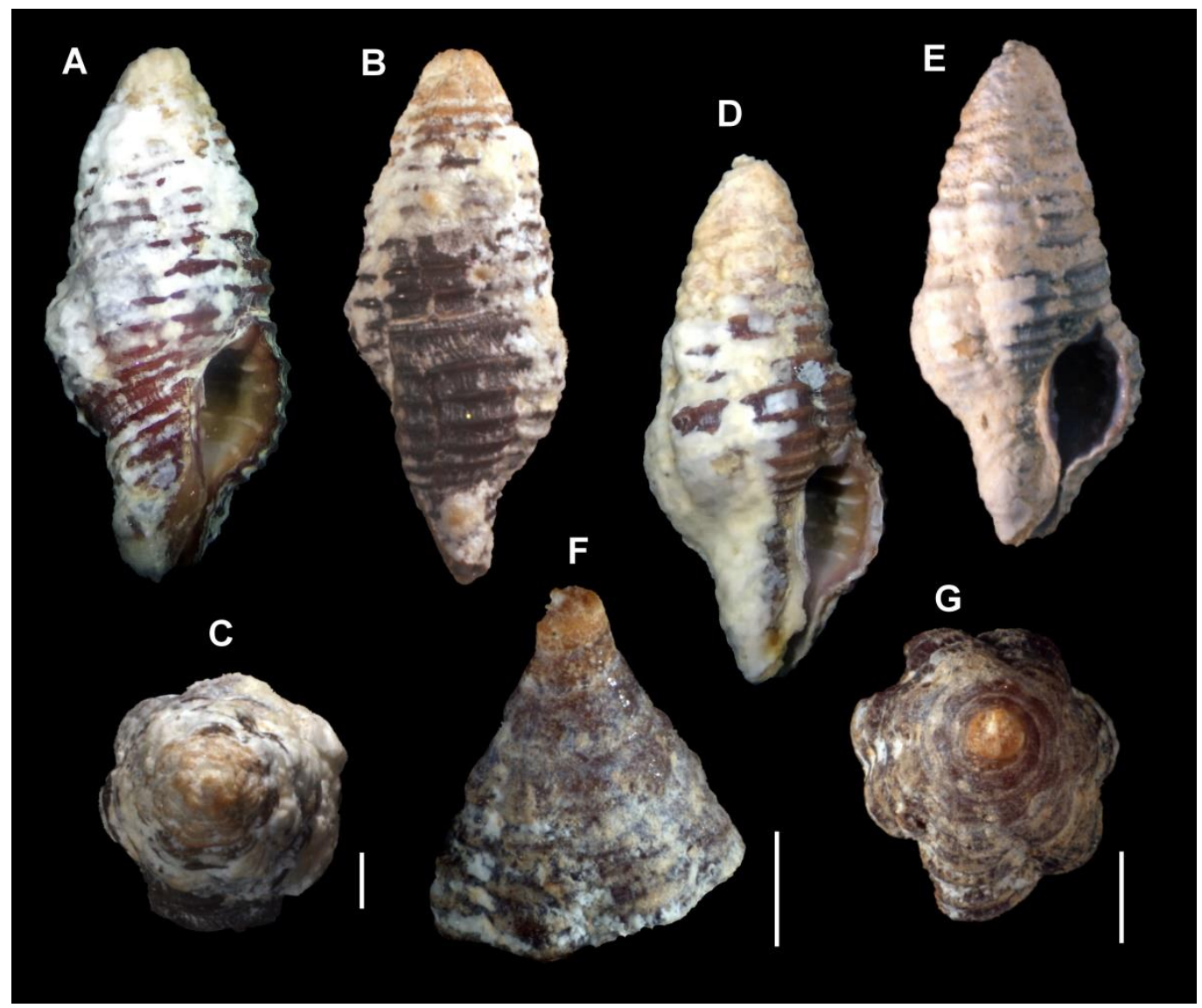

Figure 25. Dolicholatirus aff. cayohuesonicus, shell. A-C: ANSP 338609/A5642 (9.9mm). D-E: ANSP A18293. D: (13.2mm). E: (10.7mm). F-G: ANSP A8131. Scale bars $=1 \mathrm{~mm}$.

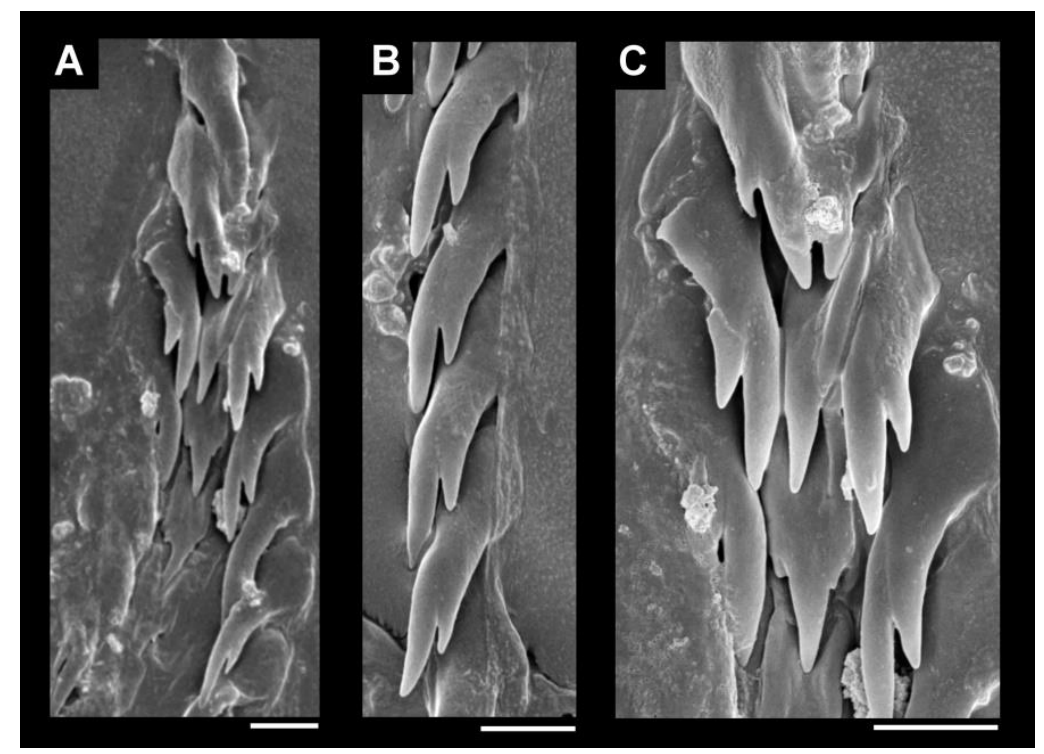

Figure 26. Dolicholatirus aff. cayohuesonicus, radula. A-C: ANSP 338609/A5642. A: panoramic view. B: detail of rachidian tooth. C: detail of lateral teeth. Scale bars $=10 \mu \mathrm{m}$. 


\section{Clade 2 Fasciolariidae non Dolicholatirus and Teralatirus}

Body pigmentation orange to light-red (11: 1), present in head-foot mass and mantle border. Osphradium slightly asymmetrical (23: 1), its right leaflets longer than left. Odontophore fused anteriorly $\leq 15 \%$ of total odontophore length (44: 1). Rachidian tooth of radula trapezoidalshaped, its base width: edge width 1/2-1 (50: 1), small, its width: lateral tooth width 1/4-1/2 (53: 2); lateral tooth wider than long, its length: width $1 / 2-1$ (55: 2), bearing 5-6 cusps (58: 1), the innermost one, cusp 1, is present in reduced size (60: 1), cusp 2 has same size or smaller than other cusps (61: 0). Proboscis retractor muscles as single bundle (67: 1).

\section{Clade 2a Angulofusus + Amiantofusus}

Rachidian tooth of radula triangle-shaped (48: 1), with sub-terminal cusps (49: 1), diminute, its width: lateral tooth width $<1 / 4(53: 3)$.

\section{Angulofusus nedae}

Examined material: data from Fedosov \& Kantor (2012).

Anal notch present in outer lip of shell, laterally in aperture (4: 1), inner side of aperture bearing distinct columellar folds (8: 1). Pallial cavity long, its extension $\geq 3 / 4$ whorls (19: 1). Base of lateral tooth of radula curved (59:1).

\section{Clade 2b Amiantofusus}

Loss of inner sculpture of outer lip (7: 0). Osphradium heavily asymmetrical (23: 2), its right leaflets longer than left.

Pseudolatirus kuroseanus (Figs. 27-28)

Examined material: MNHN IM-2013-14709, Rempi Area, Papua New Guinea, 5²'56.6592"S; 14549'5.6748"E. PAPUA NIUGINI expedition, ship Alis col. xi/22/2012 [1 specimen]. 

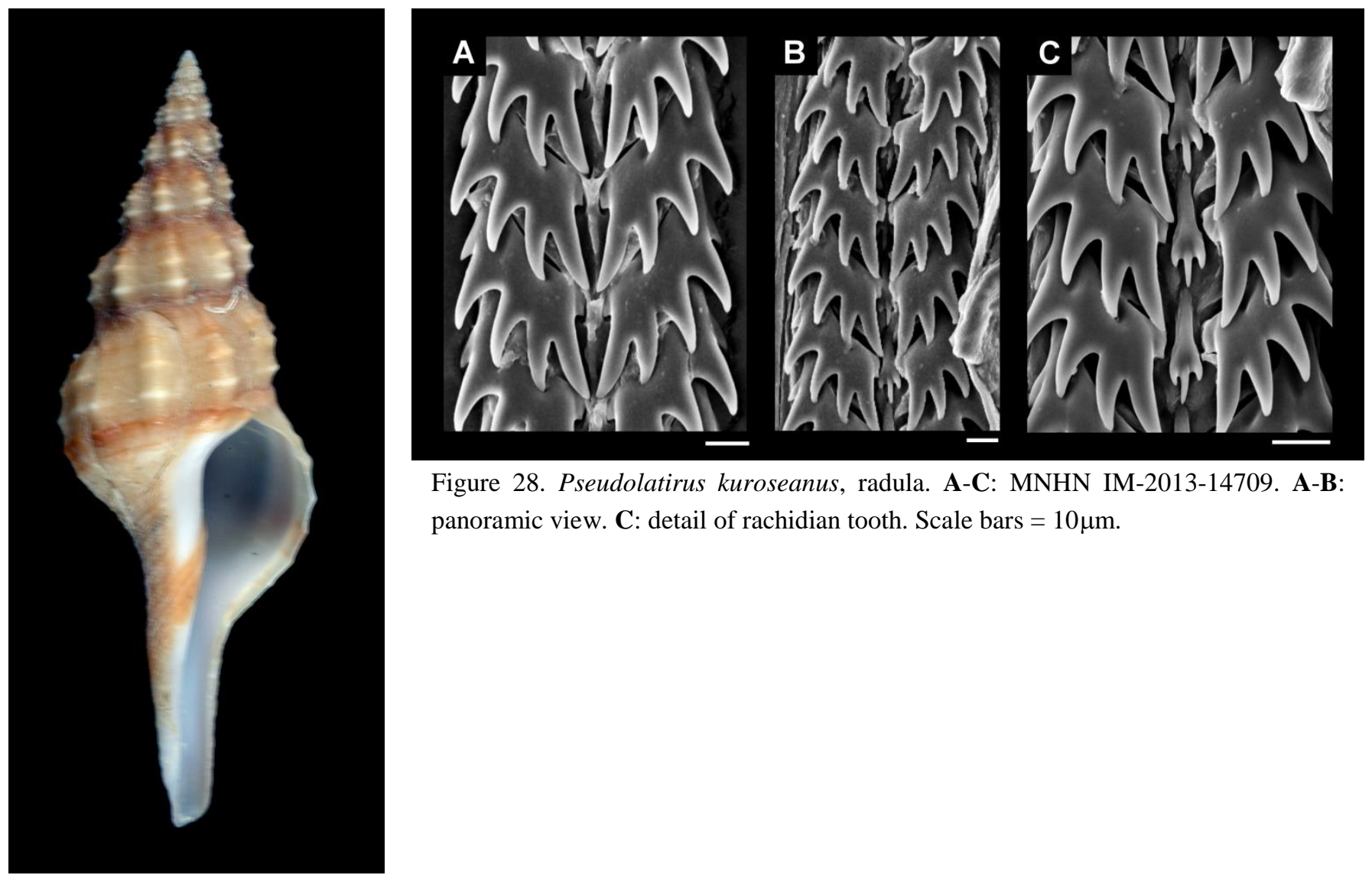

Figure 28. Pseudolatirus kuroseanus, radula. A-C: MNHN IM-2013-14709. A-B: panoramic view. $\mathbf{C}$ : detail of rachidian tooth. Scale bars $=10 \mu \mathrm{m}$.

Figure 27. Pseudolatirus

kuroseanus, shell. MNHN IM-

2013-14709 (41.3mm).

Head large, its width: head-foot mass width $\geq 1 / 2$ (13: 2), bearing long cephalic tentacles, its length: head width $\leq 2 / 3$ (14: 2). Ctenidium narrow, its width: osphradium width <1 (28: 0).

\section{Clade 2c Amiantofusus}

Ventral fold of siphon in pallial cavity with a wide base (31: 1). Odontophore long, its length: proboscis length $\sim 1$ (42: 0). Proboscis retractor muscles inserting posteriorly (68: 0). Commissure of buccal ganglia inconspicuous (93: 1).

Amiantofusus pacificus (Figs. 29-30)

Examined material: MNHN IM-2013-42508, China Sea, off An-Da Chiao, $10^{\circ} 24^{\prime} 52.398 " \mathrm{~N} ; 114^{\circ} 46^{\prime} 9.4872^{\prime \prime E}$. NanHai 2014 expedition, Ocean Researcher 5 ship, Chen Wei-jen col. i/07/2014 [1 specimen]. MNHN IM-2013-44179, China Sea, $\mathrm{V}$ bis (seamount), 15 $5^{\circ} 22.434^{\prime \prime} \mathrm{N} ; 1^{\prime} 16^{\circ} 29^{\prime} 39.84 " \mathrm{E}$. NanHai 2014 expedition, Ocean Researcher 5 ship, Chen Wei-jen col. i/02/2014. [1 specimen].

Rhynchostome bearing longitudinal folds in its margin that extend inwards (39: 1). 


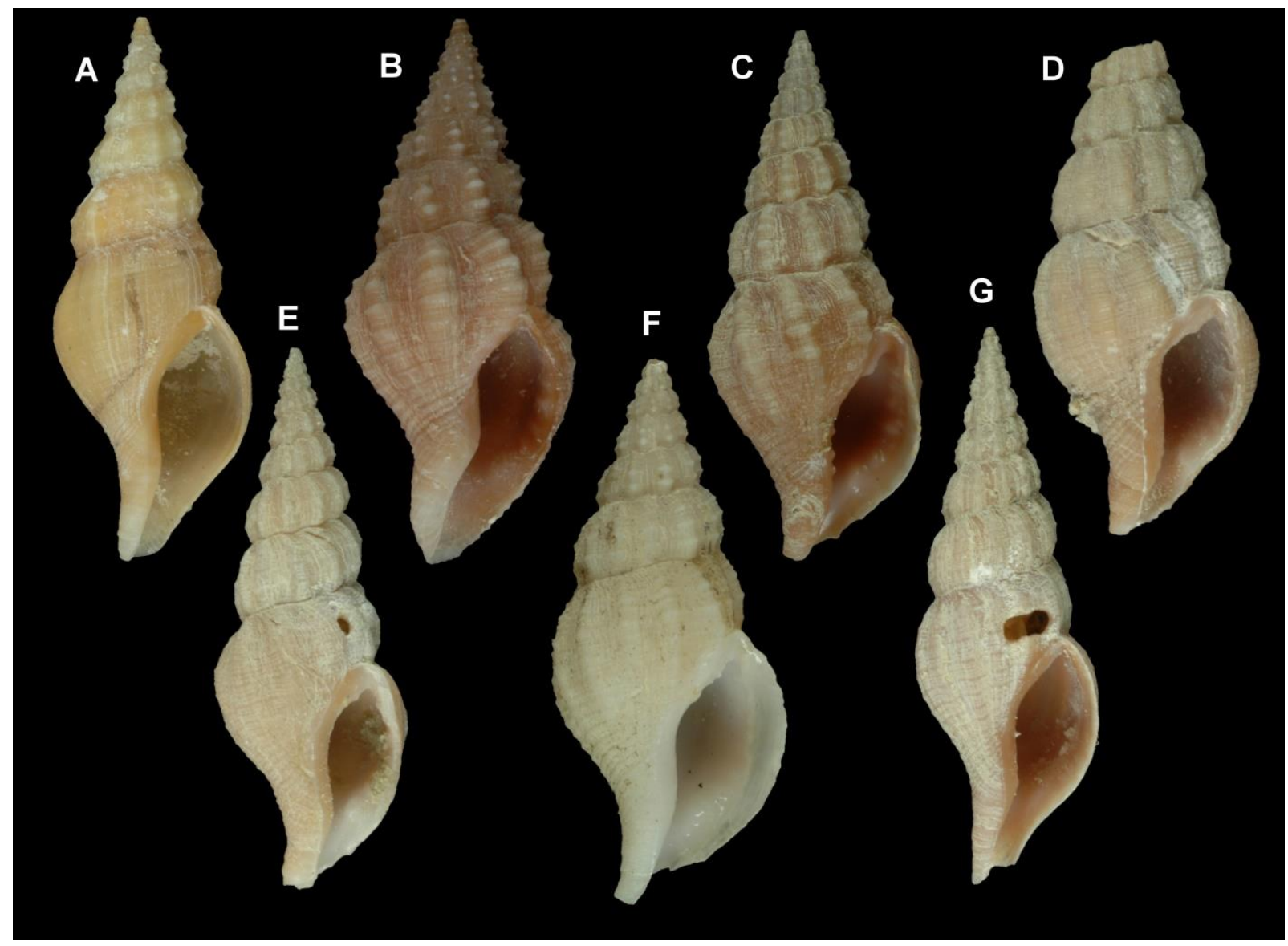

Figure 29. Amiantofusus pacificus, shell. A: MNHN IM-2009-13533 (28.1mm). B: MNHN IM-2013-41243 (23.2mm). C: MNHN IM-2013-44400 (29.3mm). D: MNHN IM-2013-42506 (30.3mm). E: MNHN IM-201342508 (36.9mm). F: MNHN IM-2013-44179 (28.8mm). G: MNHN IM-2013-42464 (37.1mm).

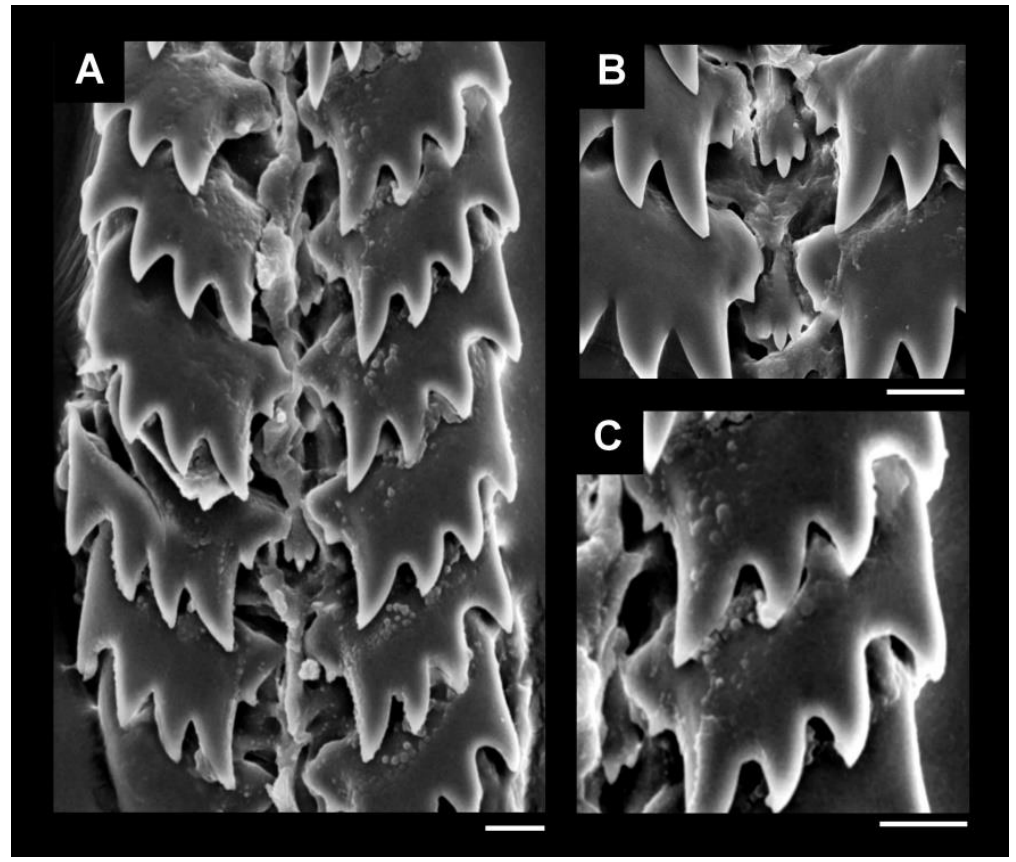

Figure 30. Amiantofusus pacificus, radula. A-C: MNHN IM-201344179. A: panoramic view. B: detail of rachidian tooth. C: detail of lateral tooth. Scale bars $=10 \mu \mathrm{m}$. 


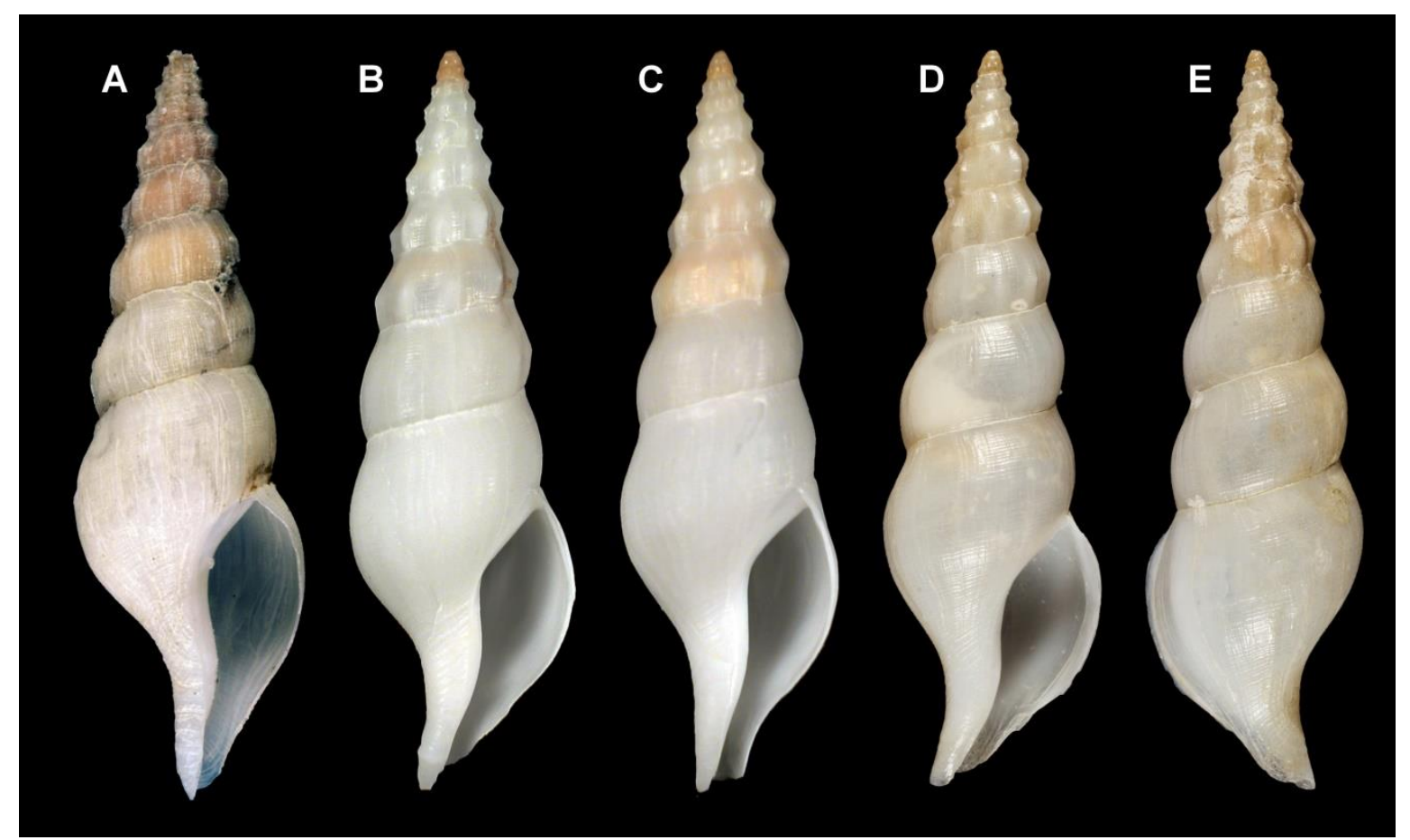

Figure 31. Amiantofusus candoris, shell. A: MNHN IM-2013-19759 (32.5mm). B: MNHN IM-200732813 (28mm). C: MNHN IM-2007-32814 (26.4mm). D-E: holotype MNHN-IM-2007-32814 (26.4mm).

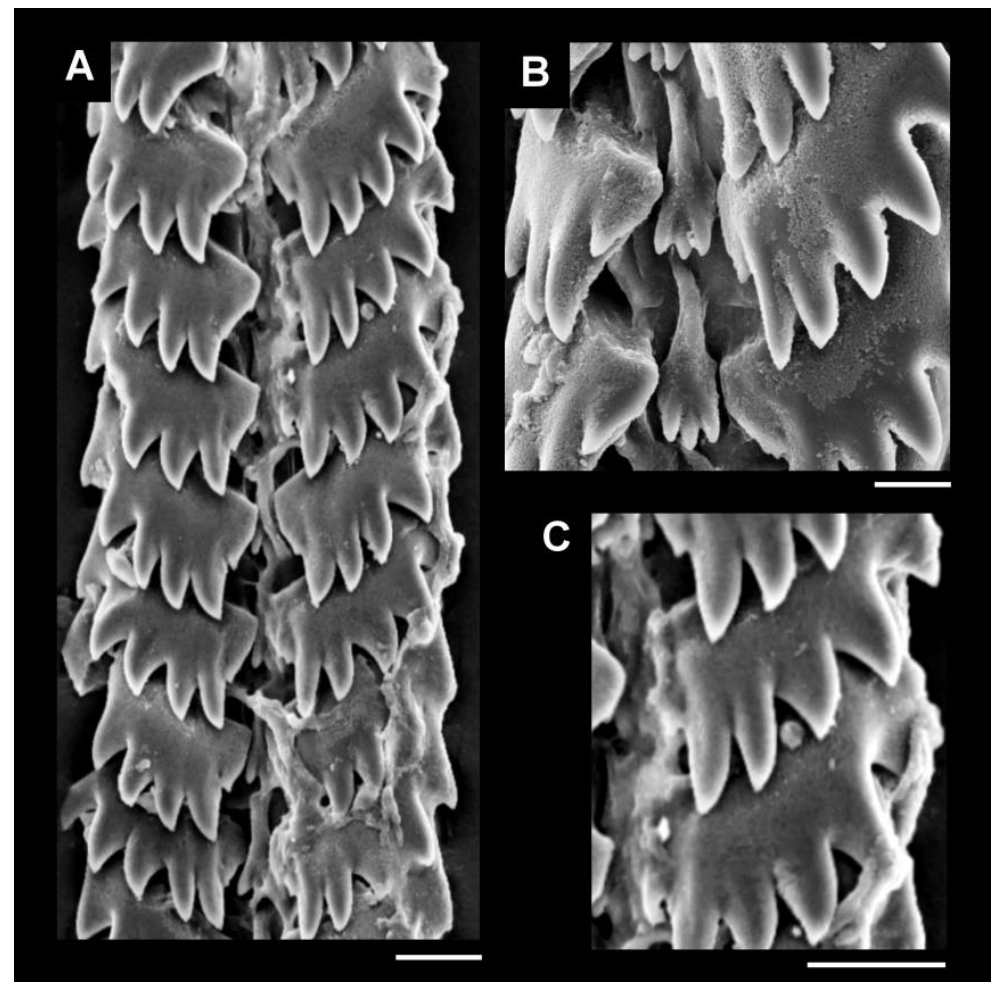

Figure 32. Amiantofusus candoris, radula. A-C: MNHN 201319759. A: panoramic view. B: detail of rachidian tooth. C: detail of lateral tooth. Scale bars $=10 \mu \mathrm{m}$. 


\section{Amiantofusus candoris (Figs. 31-32)}

Examined material: MNHN IM-2013-19759, N. Long Island, Bismarck Sea, 5¹0'27.84"S; 147²'53.8584"E. PAPUA NIUGINI expedition, ship Alis col. xii/06/2012 [1 specimen].

No known autapomorphies.

\section{Clade 3}

Siphonal canal of shell long, its length: total shell length >1/4 (9: 2). Margin of renal aperture lipped (34: 1). Rhynchostome bearing longitudinal folds in its margin (39: 1). Lateral tooth of radula much wider than long, its length: width 1/3-1/2 (55: 3), bearing 7-15 cusps (58: 2).

\section{Clade 3a}

Odontophore very short, length: proboscis length $\leq 1 / 2$ (42: 2). Rachidian tooth trapezoidalshaped, its base width: edge width $\leq 1 / 2$ (50: 2). Proboscis very long, coiled within sheath (65: 1).

\section{Pseudolatirus pallidus (Figs. 33-34)}

Examined material: MNHN IM-2013-19937, Dampier Strait, E Umboi Island, Salomon Sea, 5³6'18.2988"S; 148¹2'38.4408"E. PAPUA NIUGINI expedition, ship Alis col. xii/12/2012 [1 specimen]. MNHN IM-2007-32537, Tetepare, Salomon

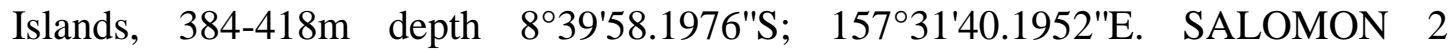
expedition, Alis ship col. xi/07/2004. [1 specimen]. MNHN IM-2013-19011, Bismarck Sea, NE Sissano, 255'19.6212"S; 142¹0'41.8764"E. PAPUA NIUGINI expedition, ship Alis col. xii/20/2012 [1 specimen]. MNHN IM-2007-32913, Bohol Sea, Maribojoc Bay, Philippines, 382-434m depth, 9³6'11.9988"N; 12343'48.0108"E. PANGLAO 2005 expedition, DA-BFAR ship col. v/31/2005 [1 specimen]. MNHN IM-2013-44506, China Sea, Continental slop, 333-421m depth, 20¹'52.3704"N; 1149'21.3192"E. NanHai 2014 expedition, Ocean Researcher 5 ship, Chen Wei-jen col. i/11/2014 [1 specimen]. MNHN IM-2013-44495, China Sea, continental slop, 333-421m depth, 20¹'52.3704"N; 1149'21.3192"E. NanHai 2014 expedition, Ocean Researcher 5 ship, Chen Wei-jen col. i/11/2014 [1 specimen]. 
Osphradium heavily asymmetrical (23: 2), its right leaflets longer than left. Proboscis retractor muscles inserting posteriorly (68: 0). Penis ejaculatory duct as long convoluted tube immersed in haemocoel (89: 1).

\section{Clade 3b Chryseofusus + Fusinus}

Loss of inner sculpture of outer lip (7: 0). Odontophore m6 muscle posterior free portion: odontophore length $\leq 1 / 6$ (45: 1). Base of lateral tooth of radula curved (59: 1).

\section{Clade $3 b^{1}$ Chryseofusus}

Loss of spiral sculpture of shell (3: 0). Osphradium heavily asymmetrical (23: 2), its right leaflets longer than left. Ventral fold of siphon in pallial cavity with a wide base (31: 1). Bursa copulatrix short, its length: oviduct length <1/4 (80: 0). Female cement gland opening centrally (84: 0$)$ in foot sole.

\section{Chryseofusus acherusius (Figs. 35-36)}

Examined material: MNHN IM-2013-44302, China Sea, off Taiping Island, 1707$1799 \mathrm{~m}$ depth, $10^{\circ} 25^{\prime} 37.056^{\prime \prime N} ; 114^{\circ} 14^{\prime} 20.5044^{\prime E}$. NanHai 2014 expedition, Ocean Researcher 5 ship, Chen Wei-jen col. i/06/2014 [1 specimen]. MNHN IM-201344363, China Sea, off An-Da Chiao, 464-1076m depth, 10²4'52.398"N; 11446'9.4872"E. NanHai 2014 expedition, Ocean Researcher 5 ship, Chen Wei-jen col. i/07/2014 [1 specimen].

Loss of longitudinal folds in margin of rhynchostome (39: 0). 


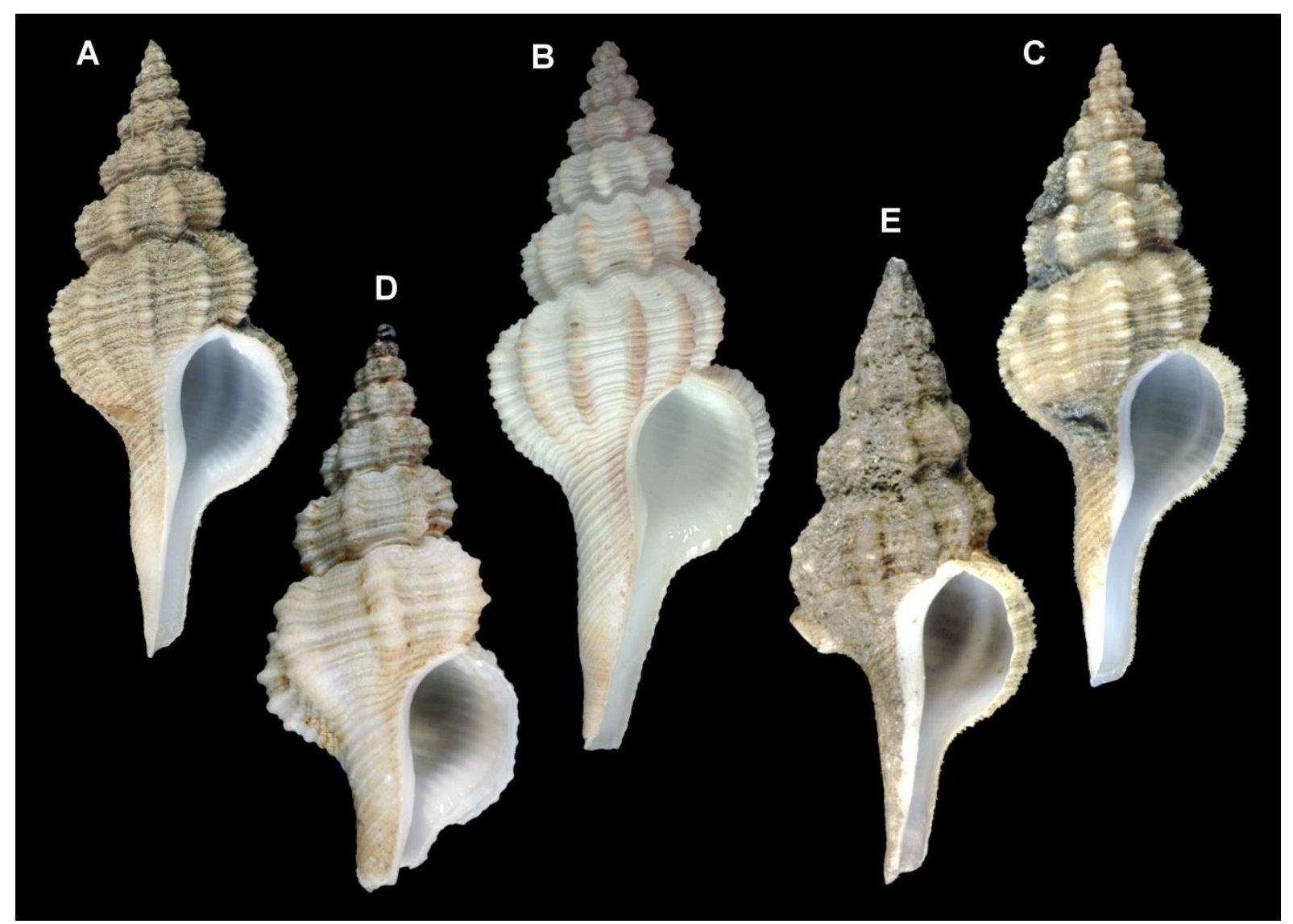

Figure 33. Pseudolatirus pallidus, shell. A: MNHN IM-2013-19937 (49.3mm). B-E: modified from Muséum national d'Histoire naturelle, Paris (France) Collection: Molluscs (IM). B: MNHN IM-2007-32537 (63.5mm). C: MNHN IM-2013-19011 (56.7mm). D: MNHN IM-2007-32913 (24.3mm). E: MNHN IM2013-44506 (39.8mm).

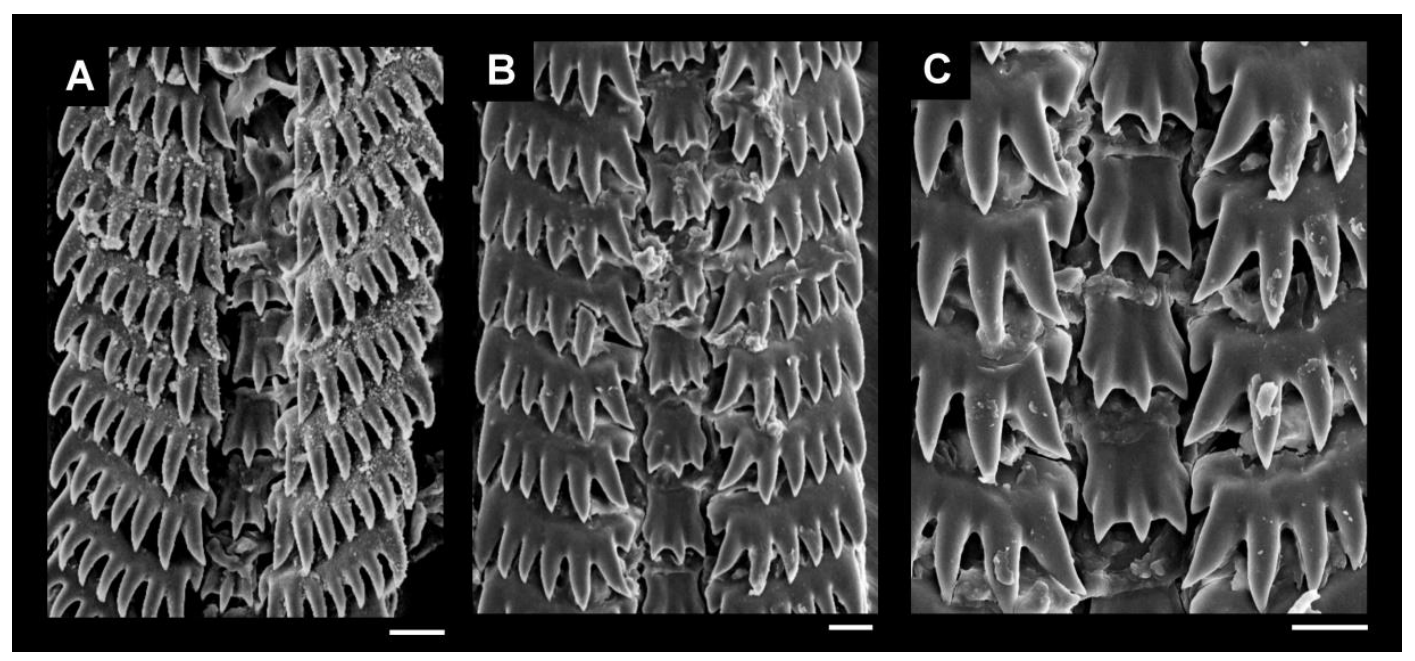

Figure 34. Pseudolatirus pallidus, radula. A: MNHN IM-2013-19937, panoramic view. B-C: MNHN IM-2013-44506. B: panoramic view. C: detail of rachidian tooth. Scale bars $=20 \mu \mathrm{m}$. 


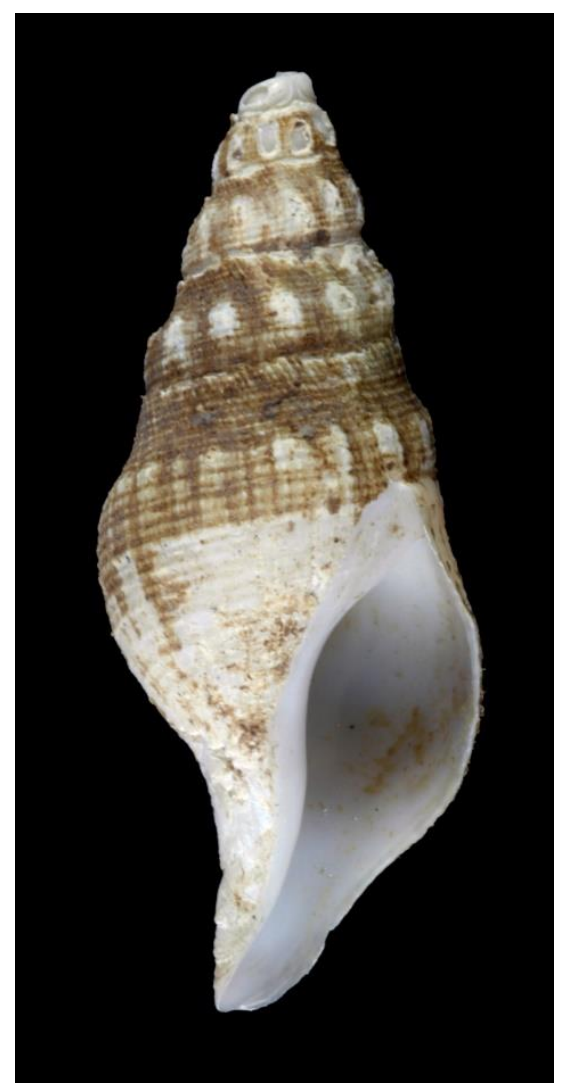

Figure 35. Chryseofusus

archerusius, shell. MNHN IM-

2013-44302 (56.2mm).

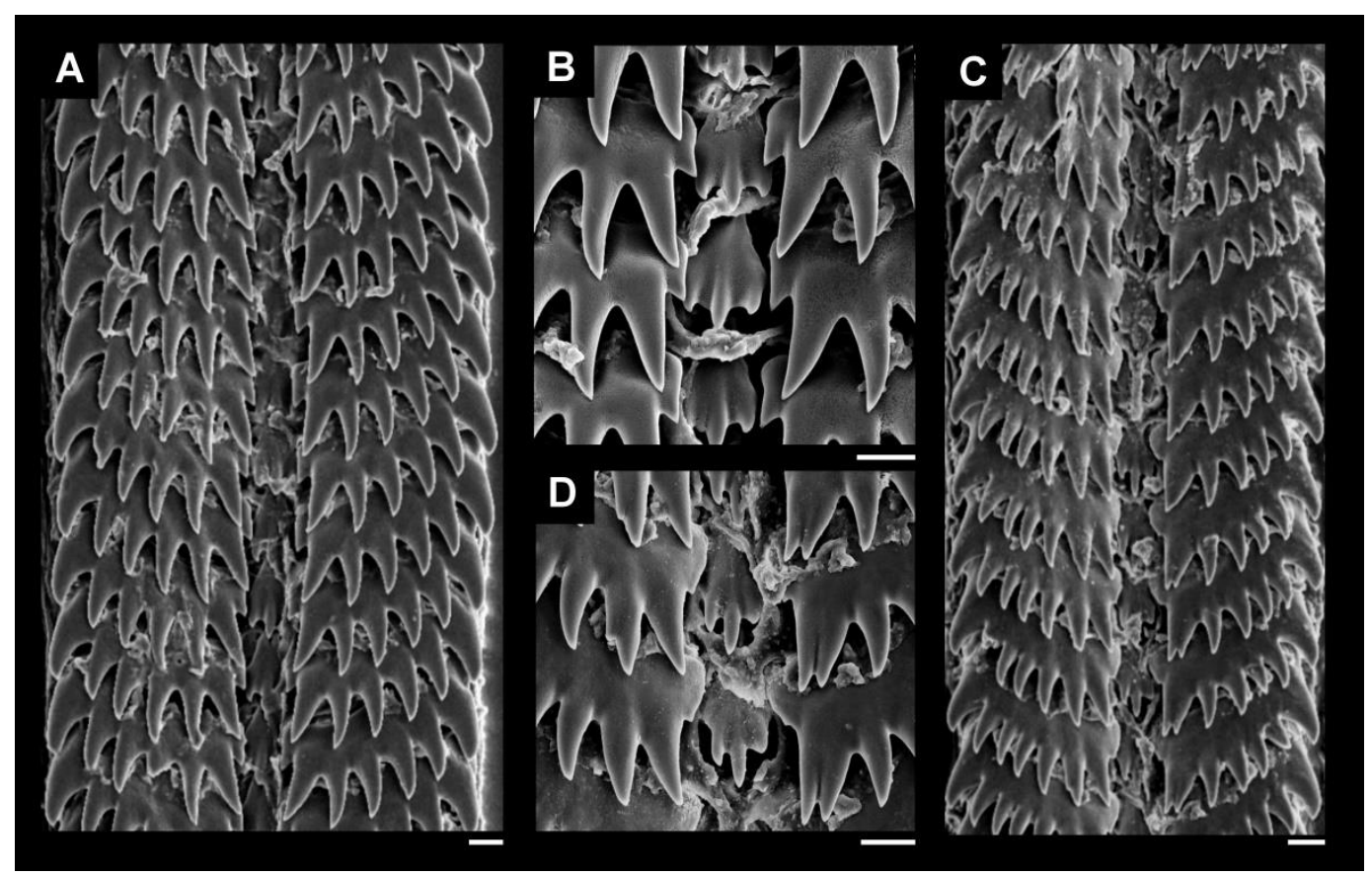

Figure 36. Chryseofusus archerusius, radula. A-B: MNHN IM-2013-44302. A: panoramic view. B: detail of rachidian tooth. C-D: MNHN IM-2013-44363. C: panoramic view. D: detail of rachidian tooth. Scale bars $=20 \mu \mathrm{m}$. 


\section{Chryseofusus graciliformis (Figs. 37-38)}

Examined material: MNHN IM-2007-32797, Salomon Islands, 650-673m depth, $7^{\circ}$ 42'30.5388"S; 156²4'50.076"E. SALOMON 2 expedition, Alis ship col. xi/01/2004. [1 specimen]. MNHN IM-2013-19921, SE Tuam Island, Salomon Sea, 500-555m depth, 6²'15.1788"S; $148^{\circ} 10^{\prime} 25.3416$ "E. PAPUA NIUGINI expedition, ship Alis col. xii/11/2012 [1 specimen]. MNHN IM-2013-19938, Dampier Strait, E Umboi Island, Salomon Sea, 500-640m depth, 5³6'18.2988"S; 148¹2'38.4408"E. PAPUA NIUGINI expedition, ship Alis col. xii/12/2012 [1 specimen].

Head large, its width: head-foot mass width $\geq 1 / 2$ (13: 2), bearing long cephalic tentacles, its length: head width $\leq 2 / 3$ (14: 2).

\section{Clade 3c Fusinus + Cyrtulus}

Ctenidium narrow, its width: osphradium width <1 (28: 0). Rhynchostome as simple, not lipped, slit (40: 1). Odontophore cartilages fused anteriorly $\geq 15 \%$ of total odontophore length (44: 2). Radula bearing lateral tooth with progressive increase in innermost cusps 1-3 length (63: 1). Medium esophagus with posterior ventral glandular region (72:1) posterior to valve of Leiblein and anterior to nerve ring. Buccal ganglia commissure length: buccal ganglia length $\geq 1 / 2$ (94:1).

\section{Clade $3 \mathrm{c}^{1}$}

Loss of lipped margin of renal aperture (34: 0). Pedal ganglia short, its length: nerve ring length $<1 / 2$ (90: 0).

\section{Fusinus brasiliensis (Figs. 39-40)}

Examined material: MZSP 70512, off Vitoria, Espírito Santo State, Brazil, trawled by shrimp boats, 30-40m depth. xii/2003 [ $\sim 80$ specimens]. MNRJ 8660, off Vitoria, Espírito Santo State, Brazil. 2001 [8 specimens]. MNRJ 8960, northern Rio de Janeiro state, Brazil. x/15/1963 [1 specimen].

No known autapomorphies. 


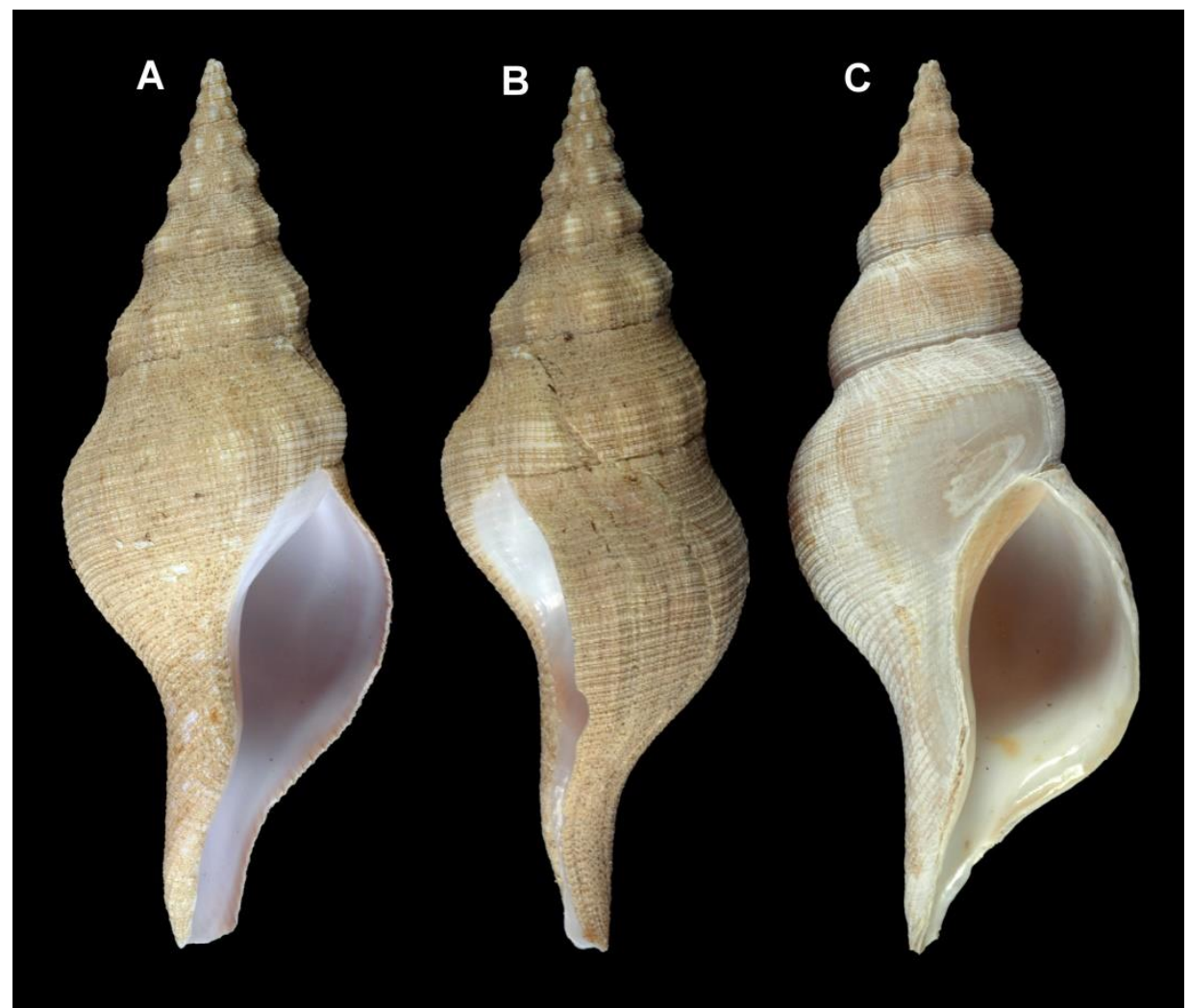

Figure 37. Chryseofusus graciliformis, shell. A-B: MNHN IM-2013-19921 (88.4mm). C: MNHN IM-2007-32797 (84mm).

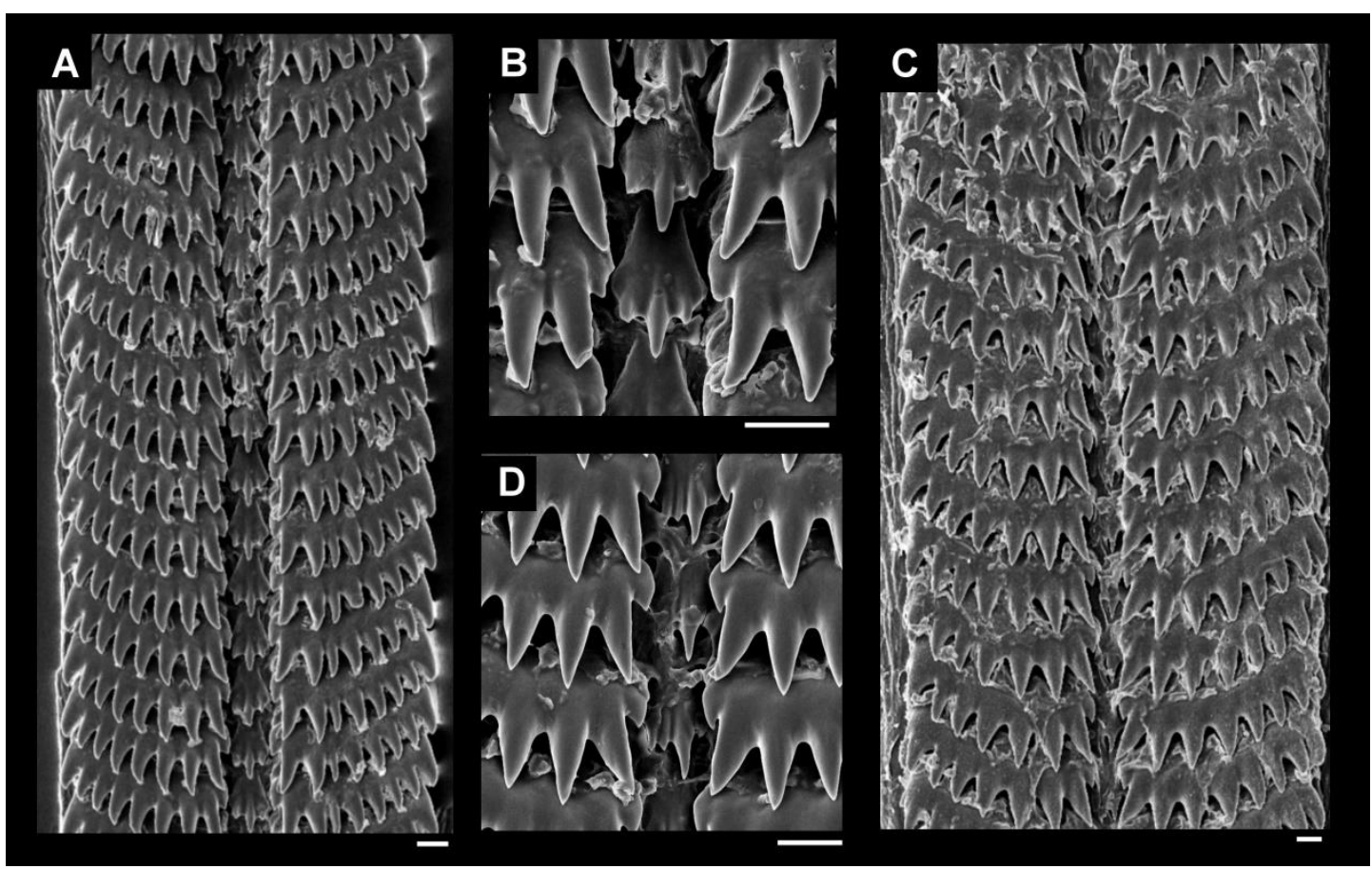

Figure 38. Chryseofusus graciliformis, radula. A-B: MNHN IM-2013-19938. A: panoramic view. B: detail of rachidian tooth. C-D: MNHN IM-2013-19921. D: panoramic view. D: detail of 


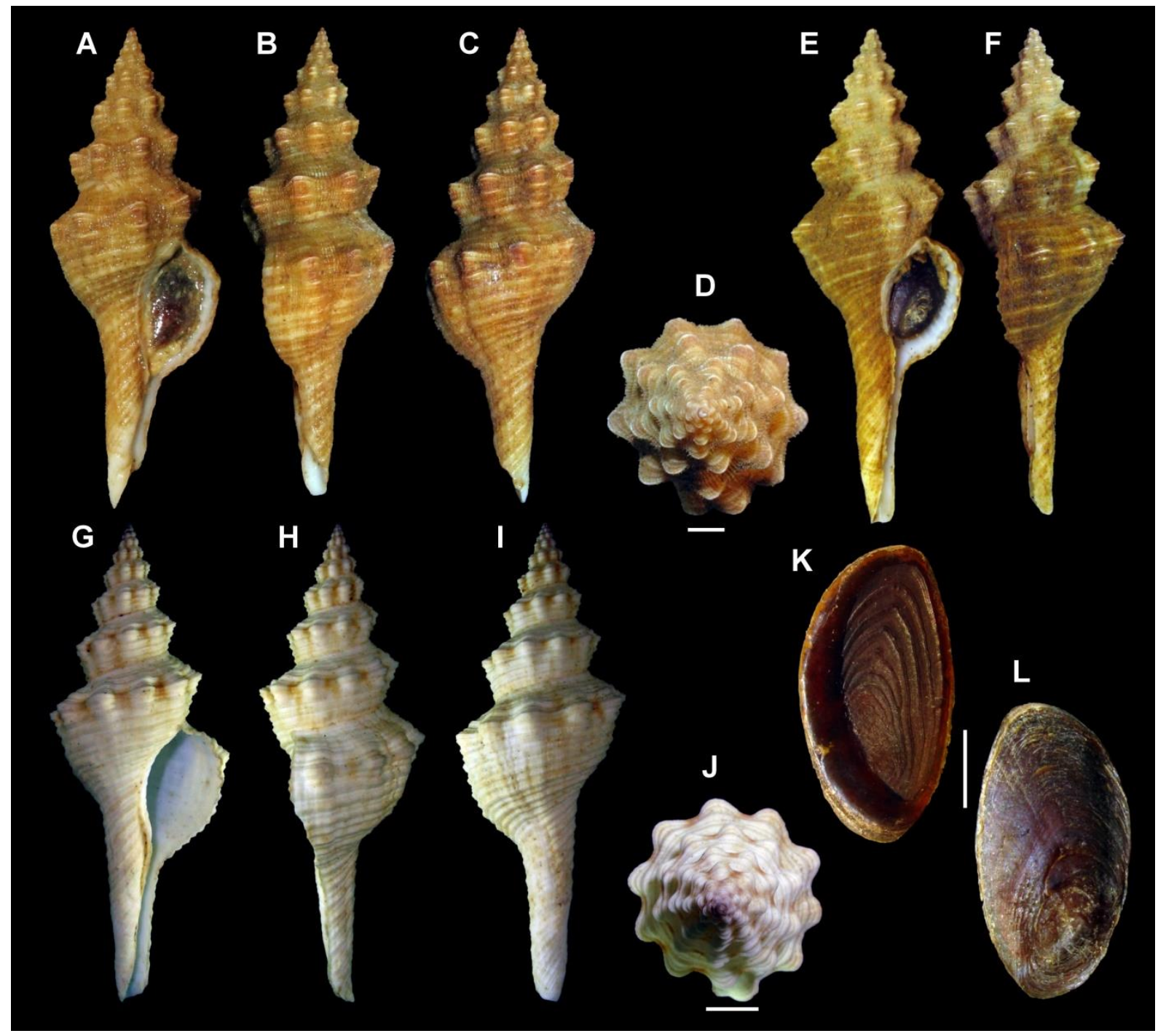

Figure 39. Fusinus brasiliensis, shell and operculum. A-D: MZSP 70512 (97.4mm). E-F: MNRJ 8660 (96.4mm). G-J: MNRJ 8960 (97.4mm). K: operculum, inner view. L. operculum, outer view. Scale bars = $5 \mathrm{~mm}$.

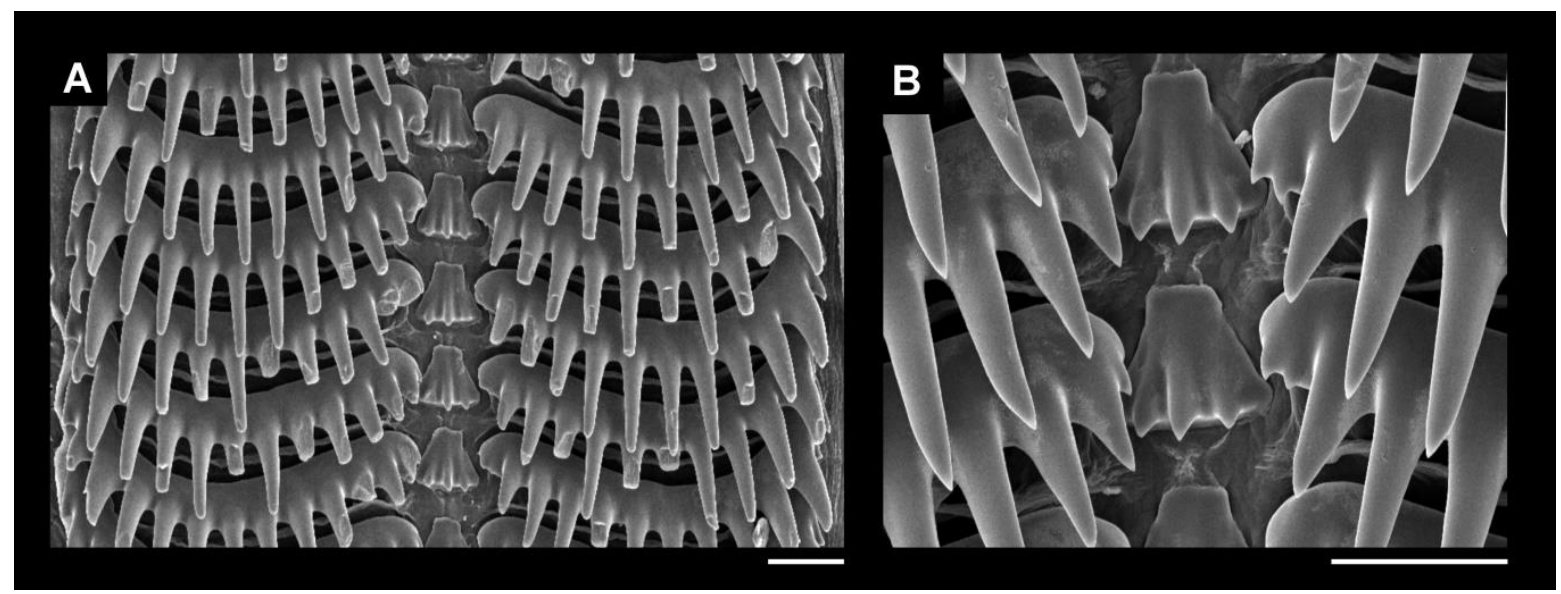

Figure 40. Fusinus brasiliensis, radula. A-B: MNRJ 8660. A: panoramic view. B: detail of rachidian tooth. Scale bars $=50 \mu \mathrm{m}$. 


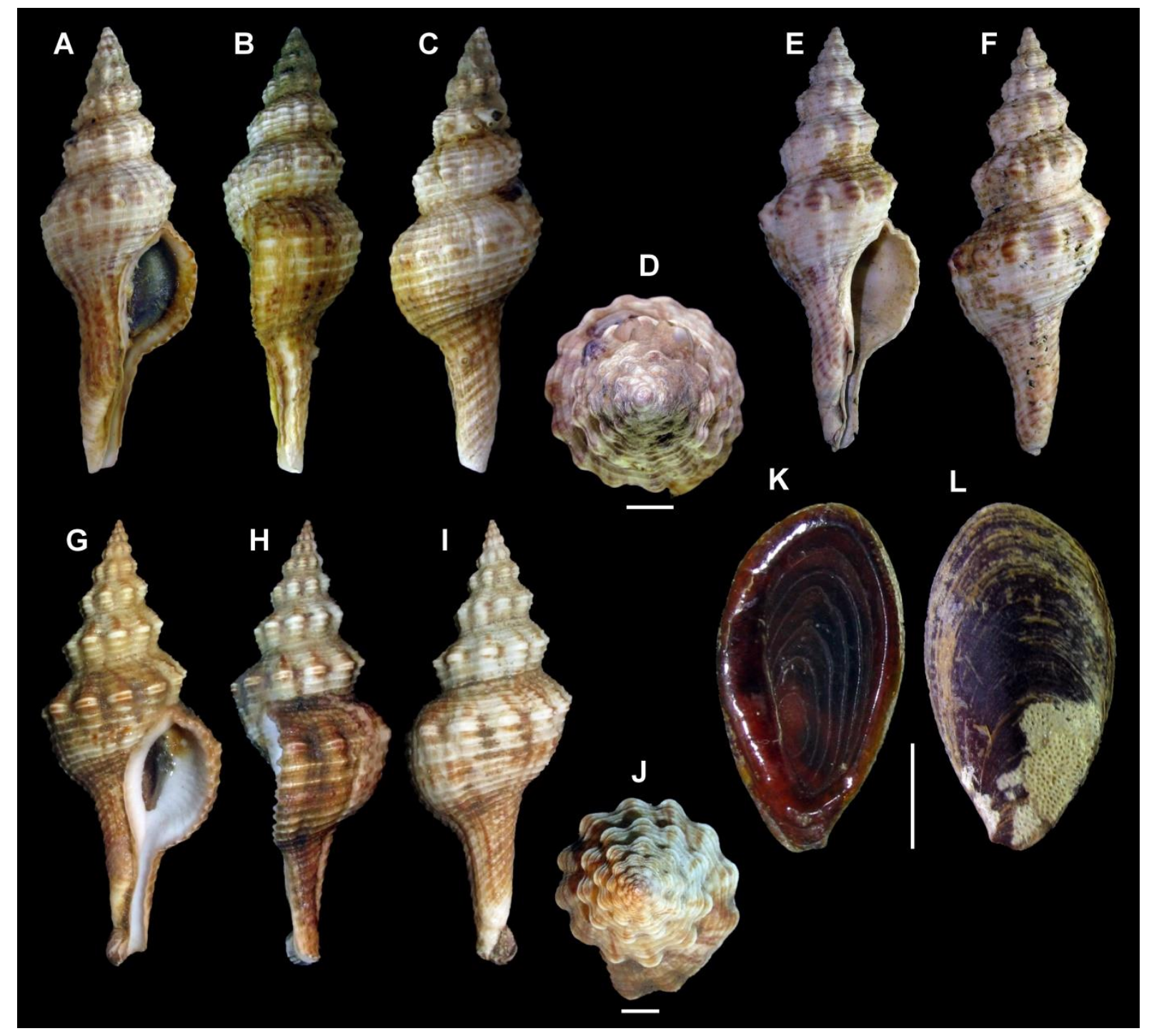

Figure 41. Fusinus marmoratus, shell and operculum. A-D: MNRJ 14489 (97.8mm). E-F: MNRJ 14588 $(89.1 \mathrm{~mm})$. G-J: MZSP 77515 (87.8mm). K: operculum, inner view. L. operculum, outer view. Scale bars = $5 \mathrm{~mm}$. 


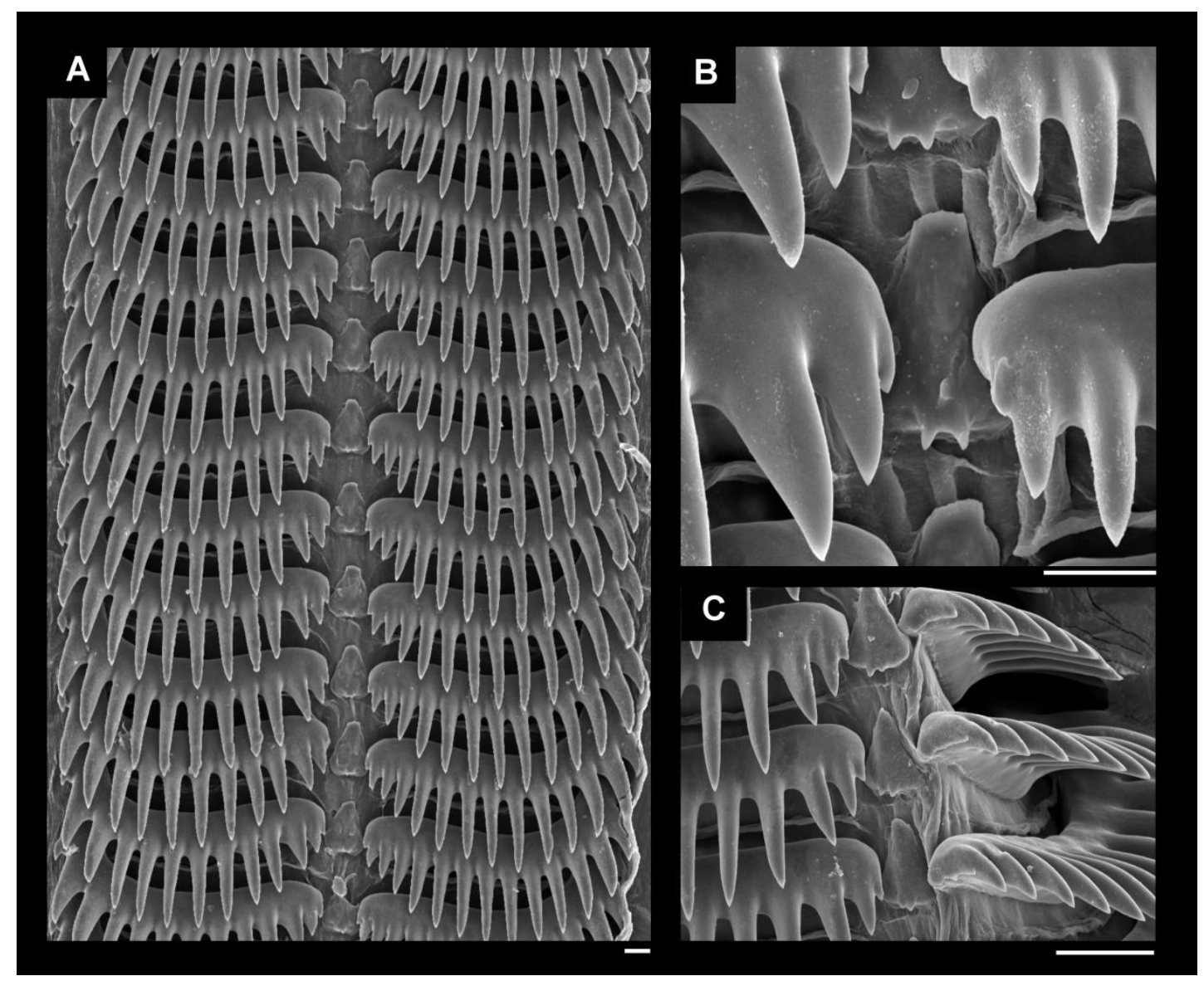

Figure 42. Fusinus marmoratus, radula. A-D: MNRJ 10715. A: panoramic view. B-C: detail of rachidian tooth. Scale bars $=20 \mu \mathrm{m}$.

\section{Clade $3 \mathrm{c}^{1 \mathrm{a}}$ Fusinus marmoratus + Fusinus sp.}

Head medium-sized, its width: head-foot mass width 1/4-1/2 (13: 1), bearing short cephalic tentacles, its length: head width 1/2-2/3 (14: 1).

\section{Fusinus marmoratus (Figs. 41-42)}

Examined material: MNRJ 14243, Manguinho, Búzios, Rio de Janeiro state, Brazil. R. Arlé, B. M. Tursh, A. Coelho, S. Buitone \& A. Rosas cols. iii/31/1962 [2 specimens]. MNRJ 14489, João Fernandes Beach, Búzios, Rio de Janeiro state, Brazil. R. Novelli \& O. S. I. Neto cols. vii/20/1982 [2 specimens]. MNRJ 14588,

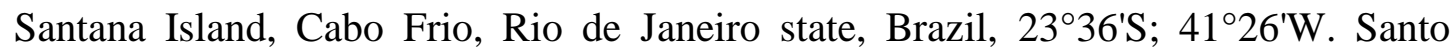
Antônio ship col. x/09-23/1964 [1 specimen]. MZSP 77515, Ubatuba, São Paulo state, 4m depth. L.R.L. Simone col. ix/29/1991 [3 specimens].

No known autapomorphies. 


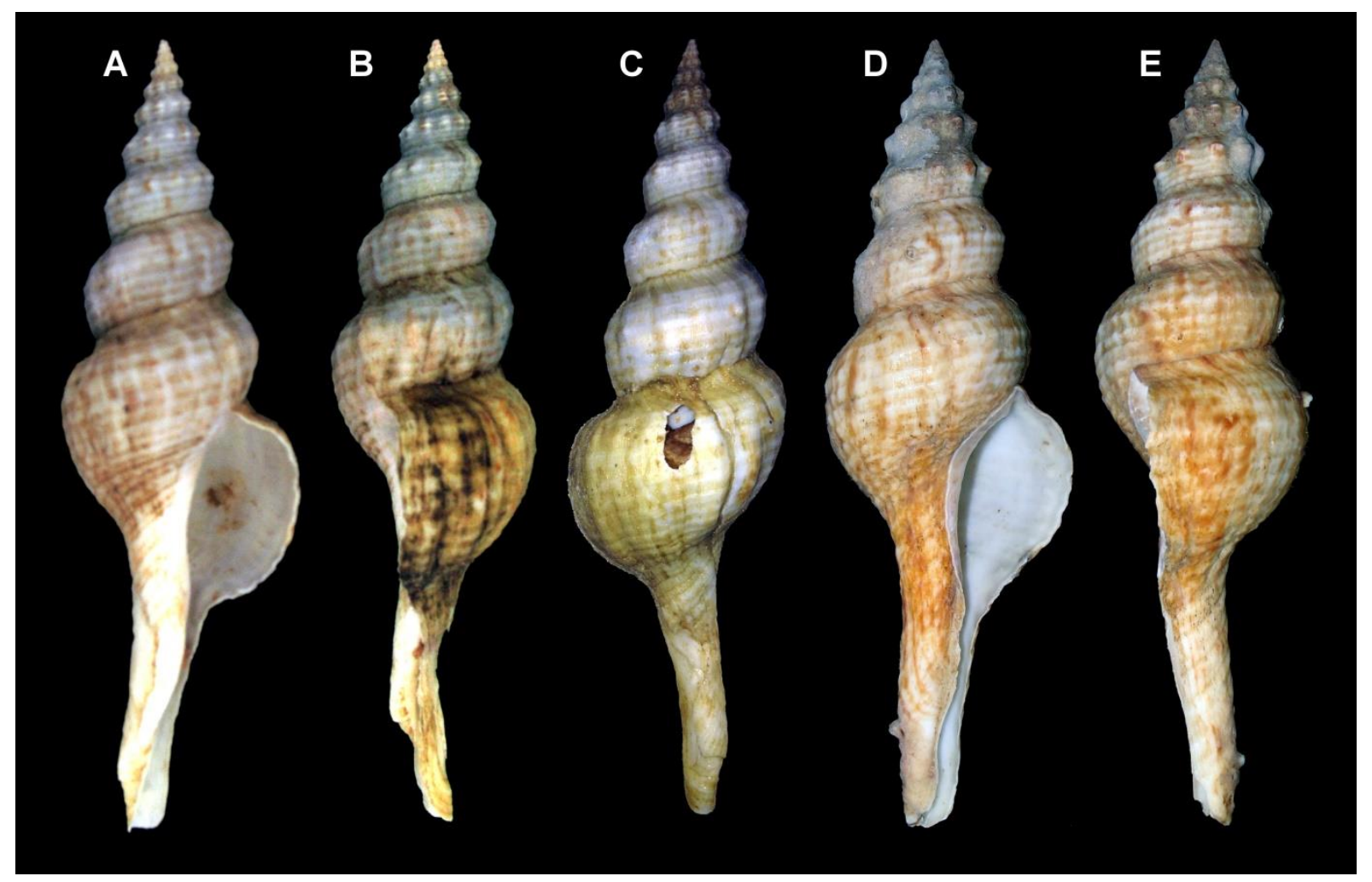

Figure 43. Fusinus sp., shell. A-C: MNRJ 6258 (183.5mm). D-E: MNRJ 6259 (203mm).

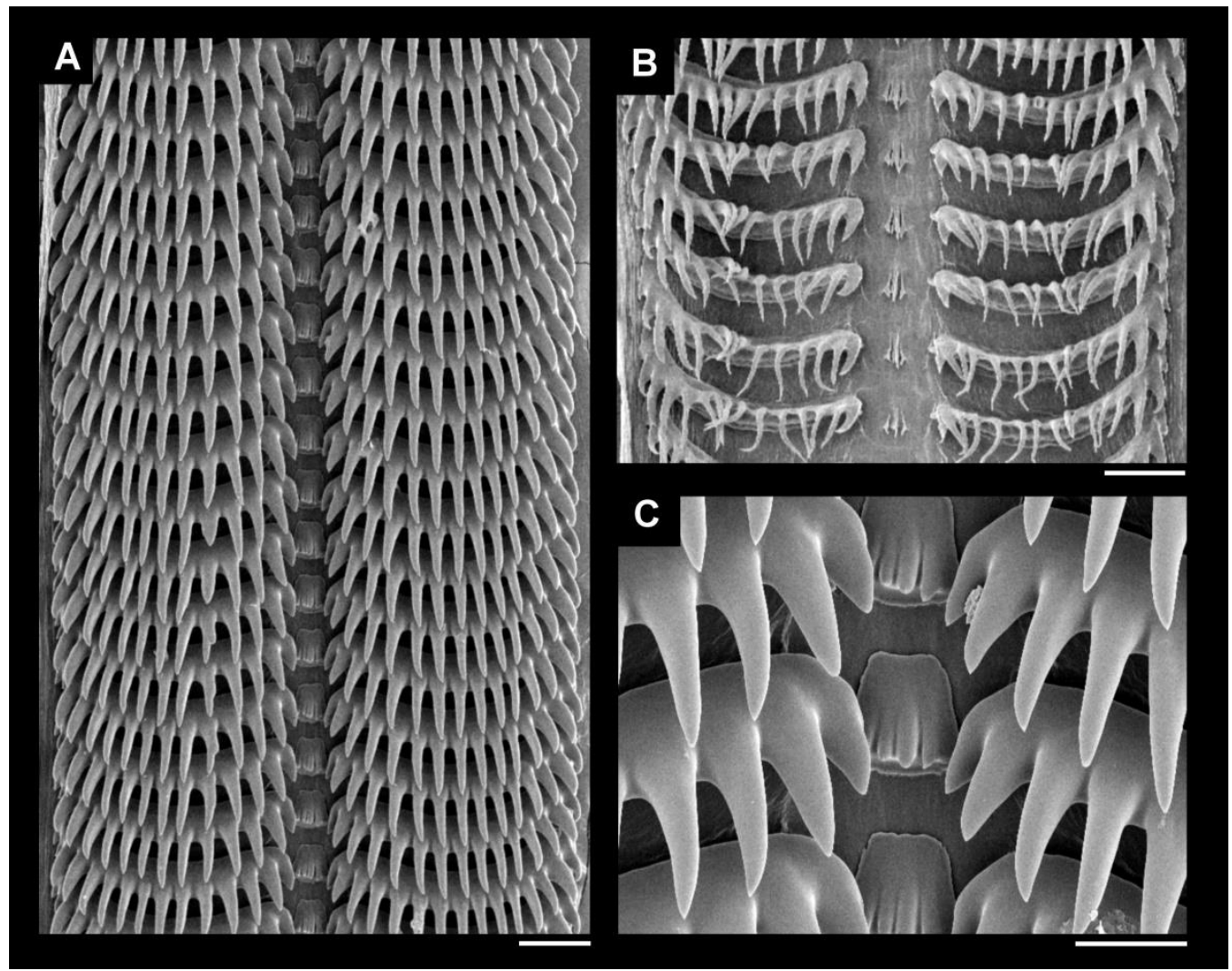

Figure 44. Fusinus sp., radula. A-C: MNRJ 6259. A: posterior region panoramic view. B: anterior region panoramic view. $\mathbf{C}$ : detail of rachidian tooth. Scale bars $=100 \mu \mathrm{m}$. 


\section{Fusinus sp. (Figs. 43-44)}

Examined material: MNRJ 6258, Paulista beach, Macaé, Rio de Janeiro state, Brazil, 70m depth, 22 ${ }^{\circ} 59^{\prime} \mathrm{S} ; 4^{\circ} 13^{\prime} \mathrm{W}$. v/10/1974 [1 specimen]. MNRJ 6259, Paulista

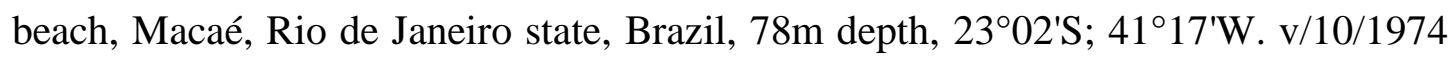
[1 specimen]

Rachidian tooth of radula trapezoidal-shaped, its base width: edge width 1/2-1 (50: 1).

\section{Clade 3d Fusinus "osphradium digitated"}

Osphradium bearing leaflets with digitated terminal shape (25: 1). Anus close to mantle border, its distance from mantle border: total pallial cavity length <1/3 (77: 0).

\section{Fusinus frenguelli (Figs. 45-46)}

Examined material: MNRJ 14414 (paratype), Rio de Janeiro state, Brazil. Santo M.S. Neves Antônio ship col. 1966 [3 specimens]. MNRJ 7829, Rio de Janeiro state, Brazil. xi/17/1995 [1 specimen]. MNRJ 14595, 35 miles off the coast of Guaratiba, Rio de Janeiro state, Brazil, 35-40m depth. M.S. Neves col. iv/1963 [5 specimens]. MNRJ 14487, Rio de Janeiro state, Brazil 236'S; 4317'W. 1976 [1 specimen]. MNRJ 14488, Laje dos Santos, Queimada Grande Island, São Paulo state, Brazil. M.S. Neves col. iv/1964 [2 specimens]. MNRJ 14709, Cape of Santa Marta, Santa Catarina state, Brazil, 85m depth, 29¹8'80"S; 4901'W. Almirante Saldanha oceanographic ship col. ix/25/1967 [1 specimen]. MZSP 77531, Alcatrazes Island, São Paulo state, Brazil, 32m depth. viii/1998 [17 specimens].

Rachidian tooth of radula trapezoidal-shaped, its base width: edge width 1/2-1 (50: 1), bearing minute, secondary cusps (52: 1). Cement gland opening centrally in foot sole (84: 0$)$. Duct of penis linear (87: 0). 


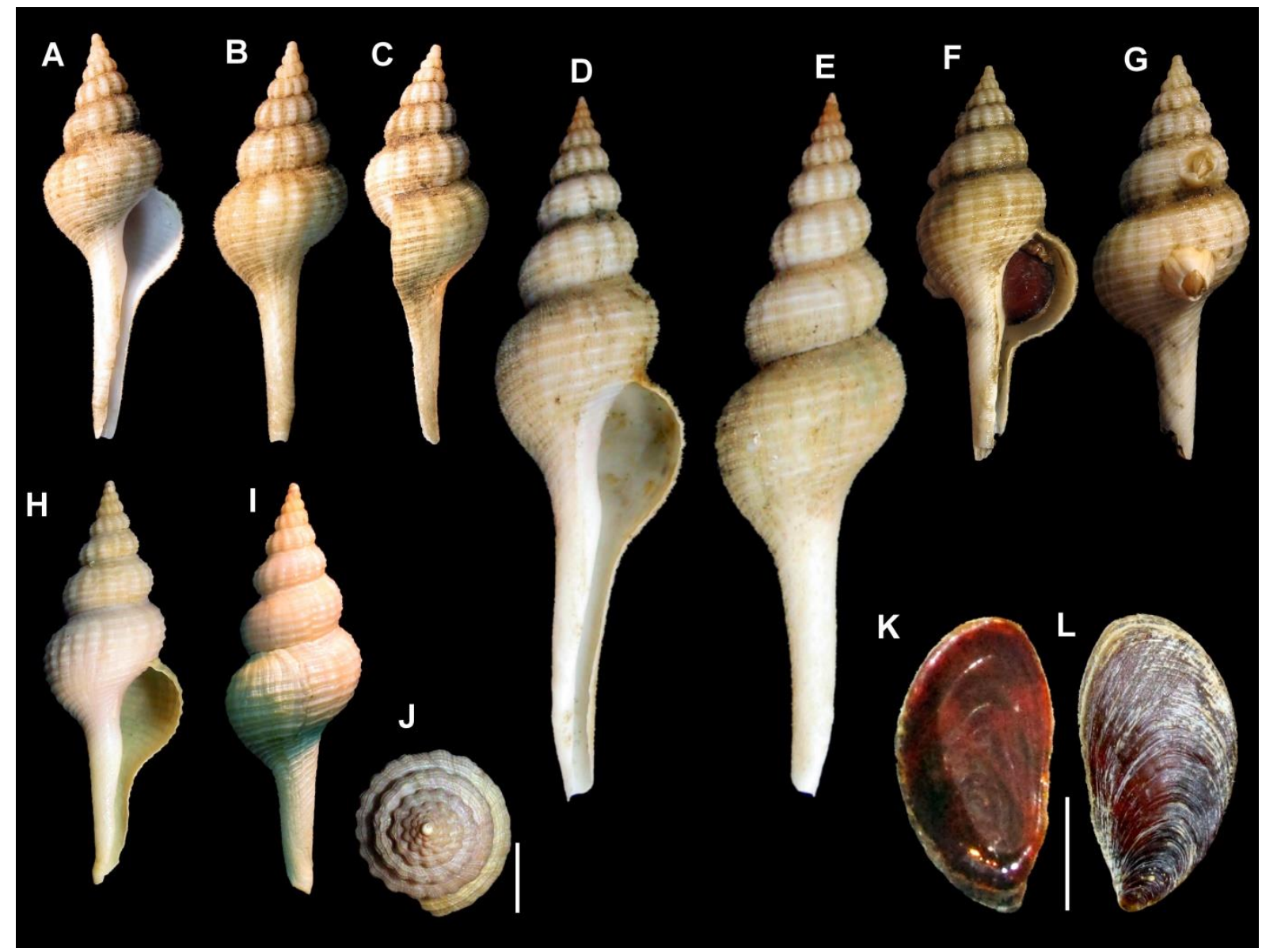

Figure 45. Fusinus frenguelli, shell. A-C: MNRJ 7829 (51.6mm). D-E: MZSP 77531 (89.2mm). F-G: MNRJ 14488 (56mm). H-J: MNRJ 14487 (50.4mm). K: operculum, inner view. L. operculum, outer view. Scale bars $=5 \mathrm{~mm}$.

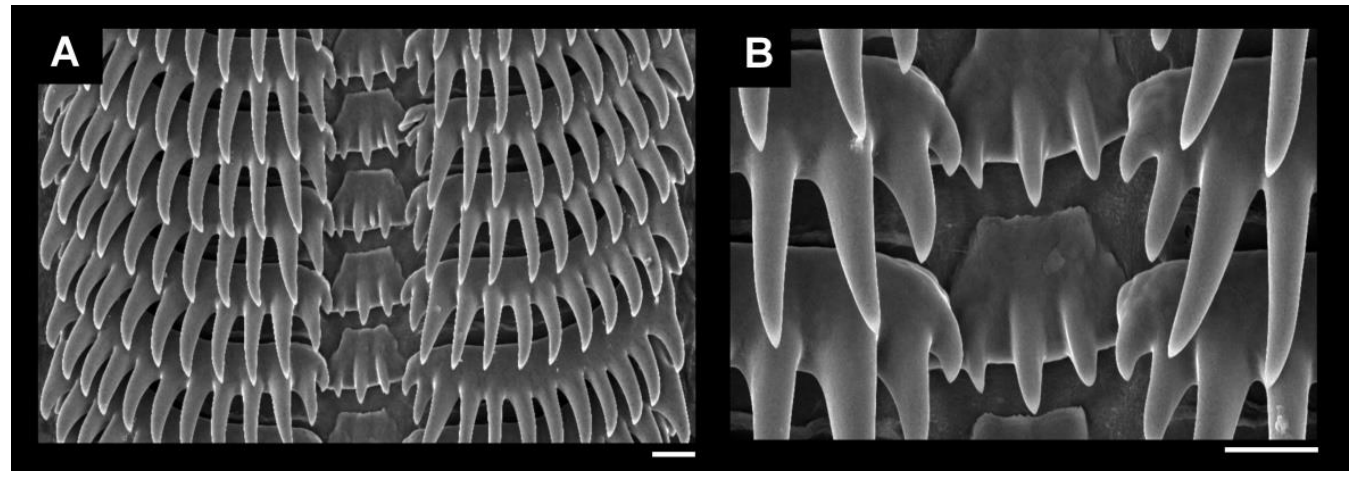

Figure 46. Fusinus frenguelli, radula. A-B: MZSP 47147. A: panoramic view. B: detail of rachidian tooth. Scale bars $=20 \mu \mathrm{m}$. 


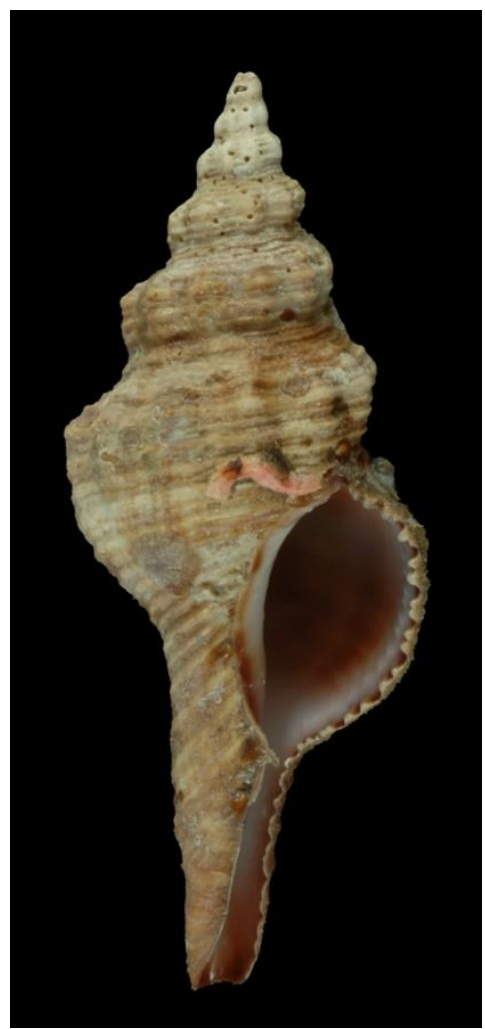

Figure 47. Fusinus australis. shell. MNHN IM-2013-42513 (57.1mm).

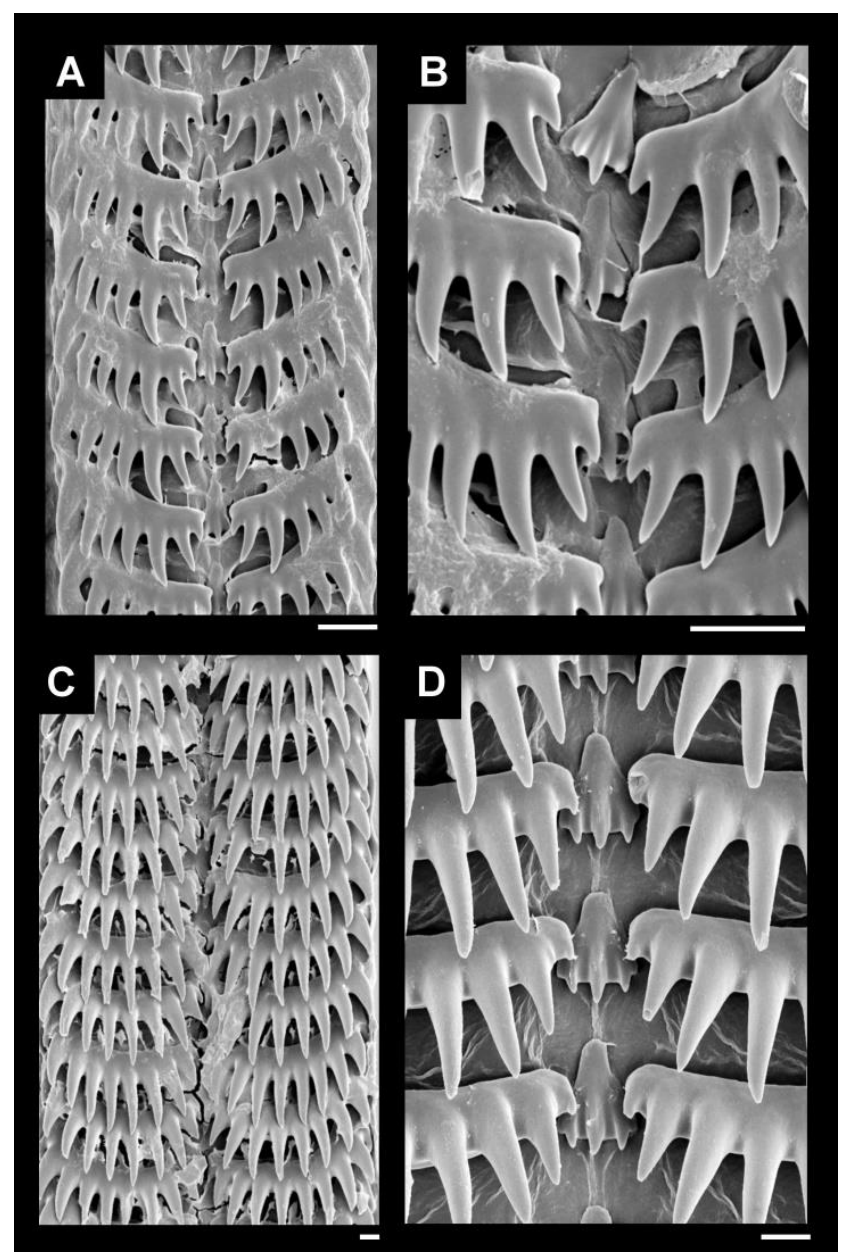

Figure 48. Fusinus australis, radula. A-D: MNHN IM2013-42513. A: panoramic view. B: detail of rachidian tooth. C: panoramic view. D: detail of rachidian tooth. Scale bars $=20 \mu \mathrm{m}$.

\section{Clade 3e Fusinus australis + Cyrtulus serotinus}

Outer lip of shell with continuous spiral cord sculpture (7: 1). Head medium-sized, its width: head-foot mass width 1/4-1/2 (13: 1), bearing short cephalic tentacles, its length: head width 1/22/3 (14: 1).

\section{Fusinus australis (Figs. 47-48)}

Examined material: MNHN IM-2013-42513, Albany, Mistaken Island, King George Sound, Australis. 5-12m depth, 35³'43.344"S; 11756'54.06"E. WESTERN AUSTRALIA 2011 expedition. xi/30/2011 [1 specimen]. MNHN IM-2013-42517. Albany, Cheyne Ledge, King George Sound, 350'30.672"S; 11757'6.84"E. WESTERN AUSTRALIA 2011 expedition. xi/27/2011 [1 specimen].

Proboscis retractor muscles inserting posteriorly (68: 0). 


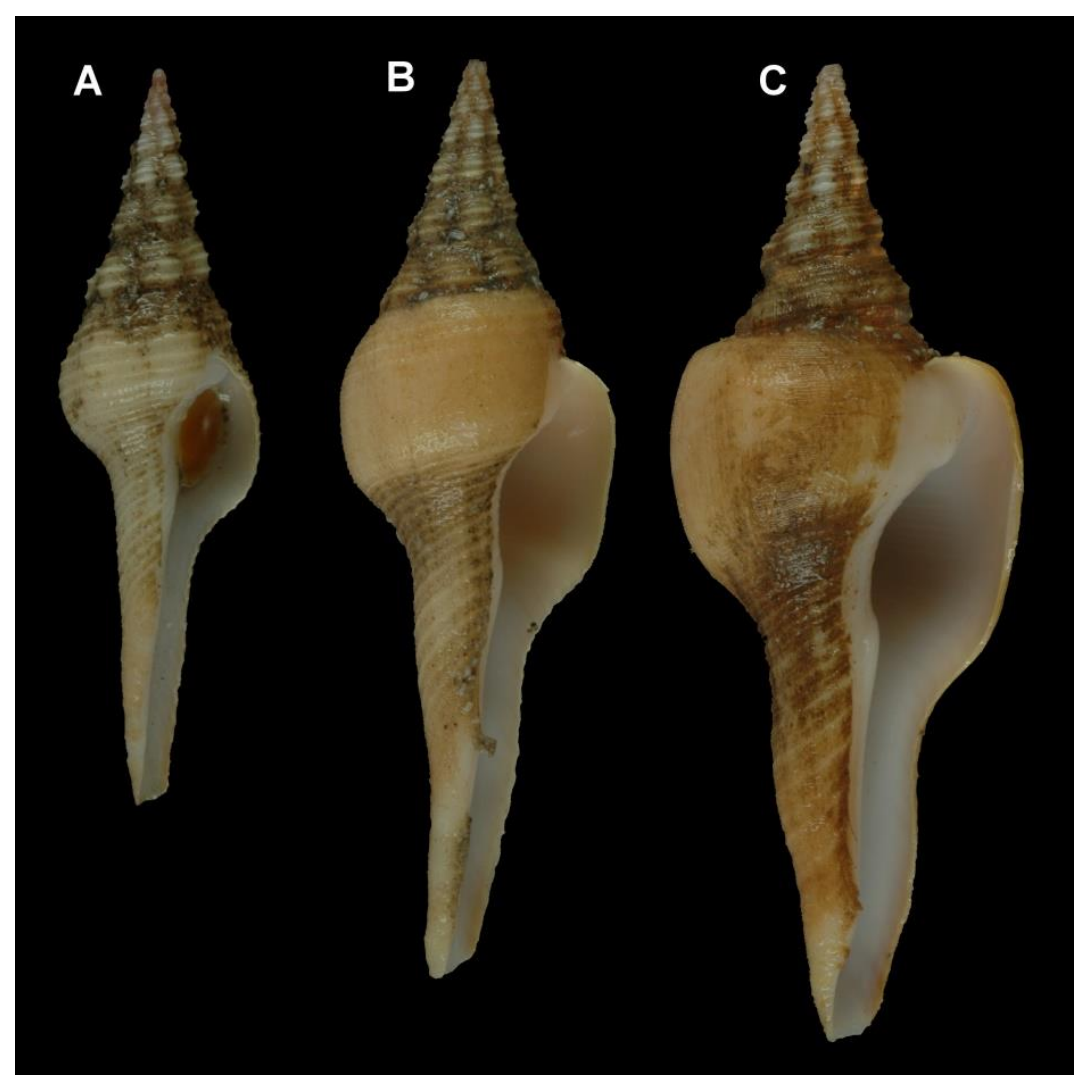

Figure 49. Cyrtulus serotinus, shell in growth series. A: MNHN IM2013-42530 (36.7mm). B: MNHN IM-2013-42531 (54.5mm). C: MNHN IM-2013-42532 (57.3mm).

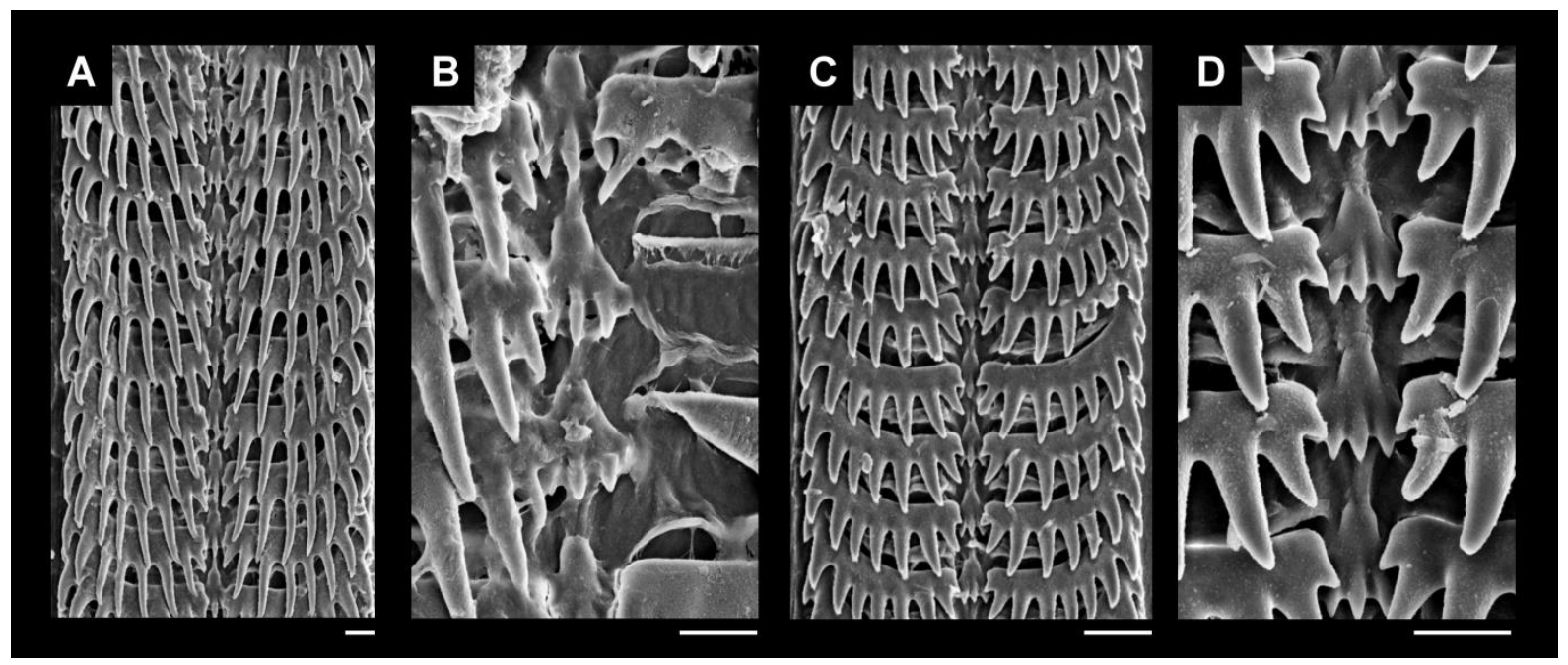

Figure 50. Cyrtulus serotinus, radula. A-B: MNHN IM-2013-42531. A: panoramic view. B: detail of rachidian tooth. C-D: MNHN IM-2013-42529. C: panoramic view. D: detail of rachidian tooth. Scale bars = $20 \mu \mathrm{m}$. 


\section{Cyrtulus serotinus (Figs. 49-50)}

Examined material: MNHN IM-2013-42529, Marquesas Archipelago, N bay of Vaituha, $7^{\circ} 58^{\prime} 46.4412^{\prime \prime S}$; $140^{\circ} 42^{\prime} 42.3 " \mathrm{~W}$. PAKAIHI I TE MOANA expedition. xi/24/2011 [1 specimen]. MNHN IM-2013-42530, Marquesas Archipelago, Tahuata, 958'49.9188"S; 1397'47.1"W. PAKAIHI I TE MOANA expedition. xii/05/2011 [1 specimen]. MNHN IM-2013-42531, Marquesas Archipelago, Tahuata, 9 58'49.9188"S; 1397'47.1"W. PAKAIHI I TE MOANA expedition. xii/05/2011 [1 specimen]. MNHN IM-2013-42532, Marquesas Archipelago, N bay of Vaituha, $7^{\circ} 58^{\prime} 46.4412 " \mathrm{~S} ; 140^{\circ} 42^{\prime} 42.3^{\prime \prime W}$. PAKAIHI I TE MOANA expedition. xi/24/2011 [1 specimen].

Outer lip of shell with apical growth (6: 0). Buccal ganglia commissure diminute, its length: buccal ganglia length $\leq 1 / 2$ (94: 0 ).

\section{Clade 4 Granulifusus + Peristerniinae + Fasciolariinae}

Ctenidium narrow, its width: osphradium width <1 (28: 0). Rhynchostome bearing lipped rim (40: 1).

\section{Clade 4a Granulifusus "round opercula, not filling entire aperture"}

Loss of inner sculpture of outer lip (7: 0). Head large, its width: head-foot mass width $\geq 1 / 2$ (13: 2), bearing long cephalic tentacles, its length: head width $\leq 2 / 3$ (14: 2). Operculum small, not filling entire shell aperture (16:2), its nucleus eccentric (17: 1) and lateral margin rounded (18: 0 ). Osphradium with right leaflets longer than left, heavily asymmetrical (23: 2). Loss of female cement gland (82: 0$)$. 


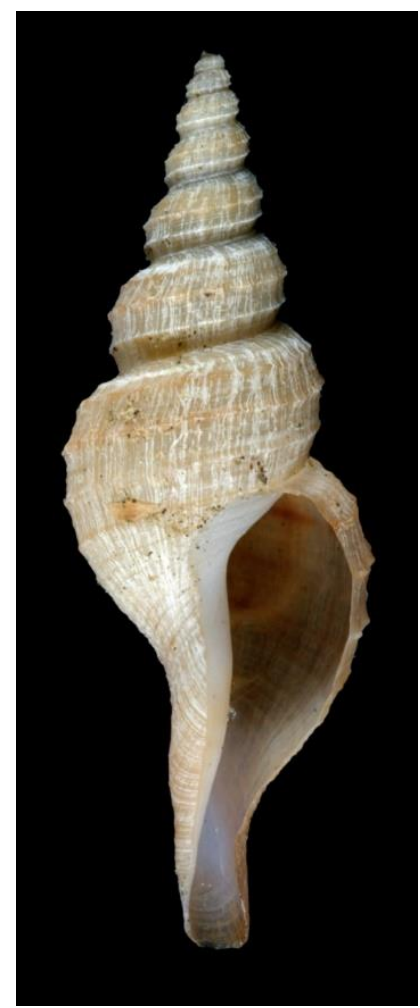

Figure 51. Granulifusus sp. shell. MNHN IM2013-19724 (56.2mm).

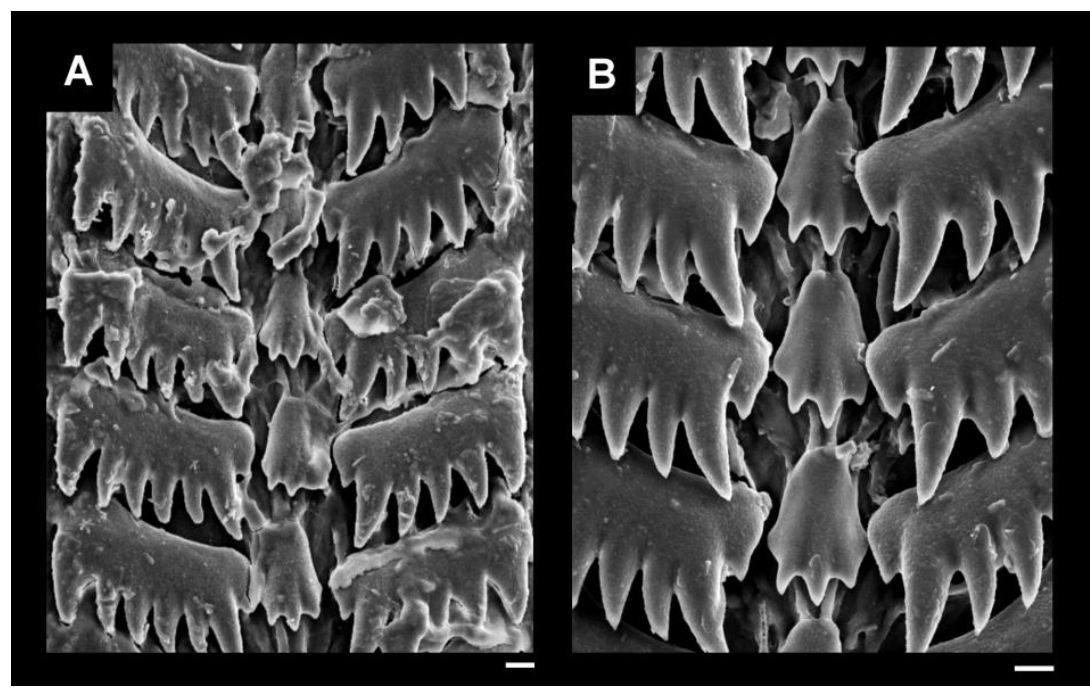

Figure 52. Granulifusus sp. radula. A-B: MNHN IM-2013-19724. A: panoramic view. $\mathbf{B}$ : detail of rachidian tooth. Scale bars $=10 \mu \mathrm{m}$.

\section{Granulifusus sp. (Figs. 51-52)}

Examined material: MNHN IM-2013-19724. N Long I. Bismarck Sea, 5¹0'51.4812"S; 147³'3.4164"E. PAPUA NIUGINI expedition, ship Alis col. xii/06/2012 [1 specimen].

Anus close to mantle border, its distance from mantle border: total pallial cavity length <1/3 (77: 0). Bursa copulatrix bearing anterior muscular bulb (81: 1) close to gonopore.

\section{Clade 4b}

Proboscis retractor muscles inserting posteriorly (68: 0). Seminal receptacle in pallial oviduct present (78:0). 

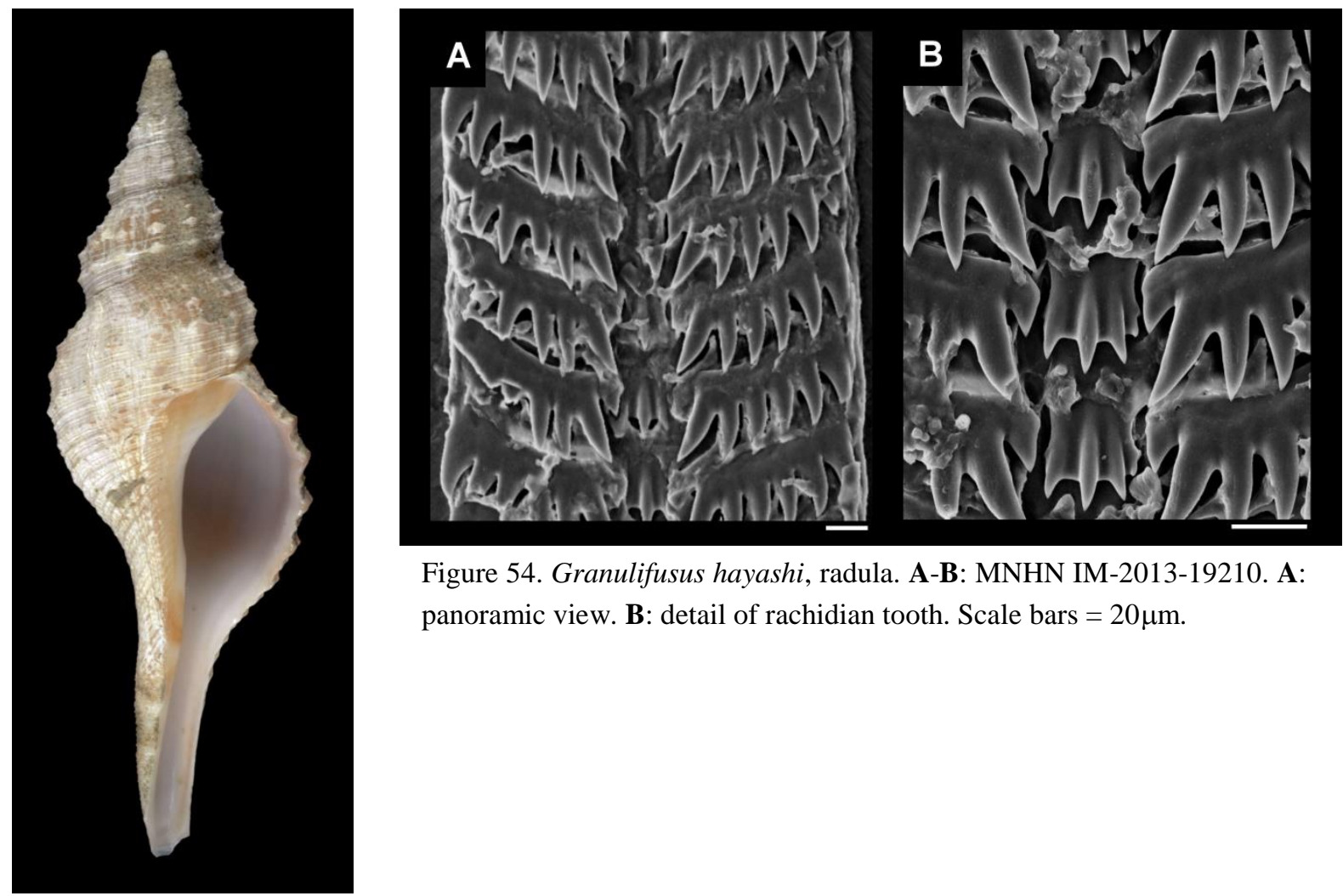

Figure 54. Granulifusus hayashi, radula. A-B: MNHN IM-2013-19210. A: panoramic view. B: detail of rachidian tooth. Scale bars $=20 \mu \mathrm{m}$.

Figure 53. Granulifusus hayashi, shell. MNHN IM2013-19210 (48.7mm).

\section{Granulifusus hayashi (Figs. 53-54)}

Examined material: MNHN IM-2013-19210, Dogreto Bay, Bismarck Sea, $3^{\circ} 17^{\prime} 41.7012 " S ; 143^{\circ} 2{ }^{\prime 22.3296 " E . ~ P A P U A ~ N I U G I N I ~ e x p e d i t i o n, ~ s h i p ~ A l i s ~ c o l . ~}$ xii/22/2012 [1 specimen].

Odontophore $\mathrm{m} 6$ muscle posterior free portion: odontophore length $\leq 1 / 6$ (45: 1). Rachidian tooth of radula square-shaped, its base width: edge width 1/2-1 (50: 0). Buccal ganglia commissure length: buccal ganglia length $\geq 1 / 2$ (94:1).

\section{Clade 4c Granulifusus kiranus + Pseudolatirus discrepans}

Margin of siphon bearing many longitudinal folds (30: 1). 


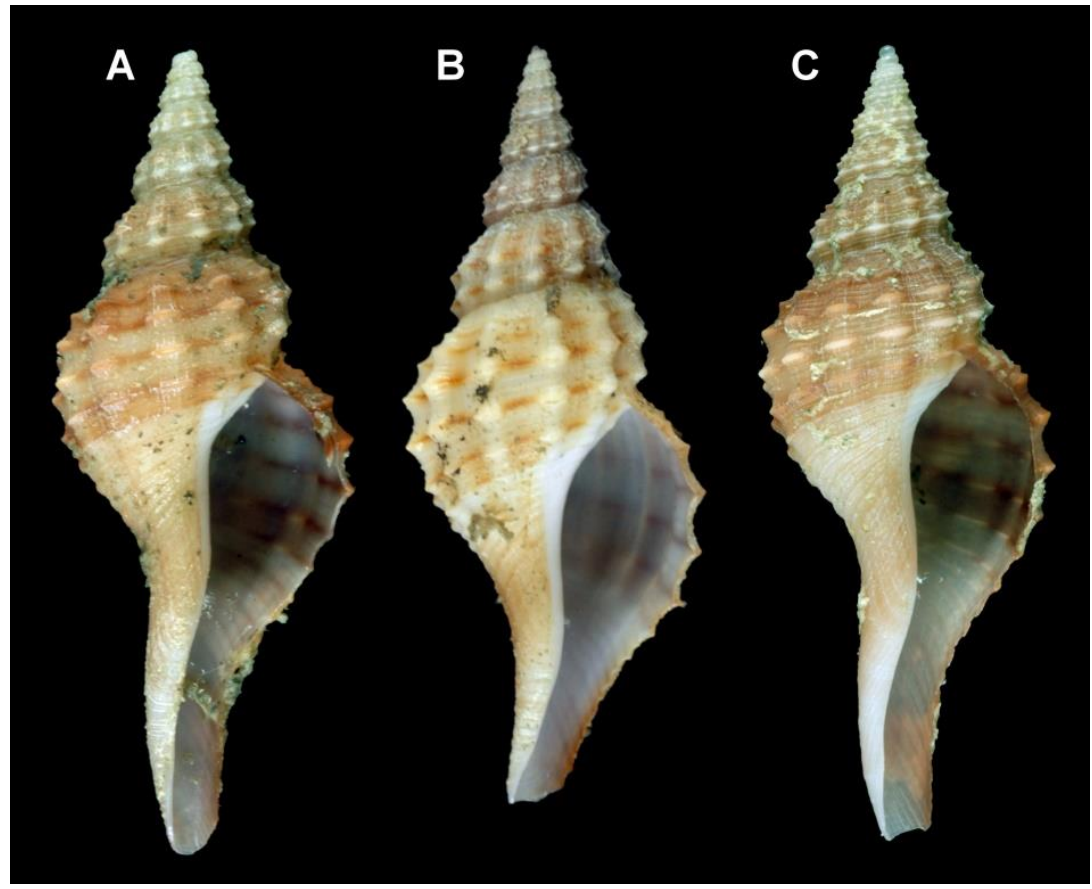

Figure 55. Granulifusus kiranus, shell. A: MNHN IM-2013-44502 (37.6mm). B: MNHN IM-2013-19037 (45.2mm). C: MNHN IM-2013$44449(33.9 \mathrm{~mm})$.

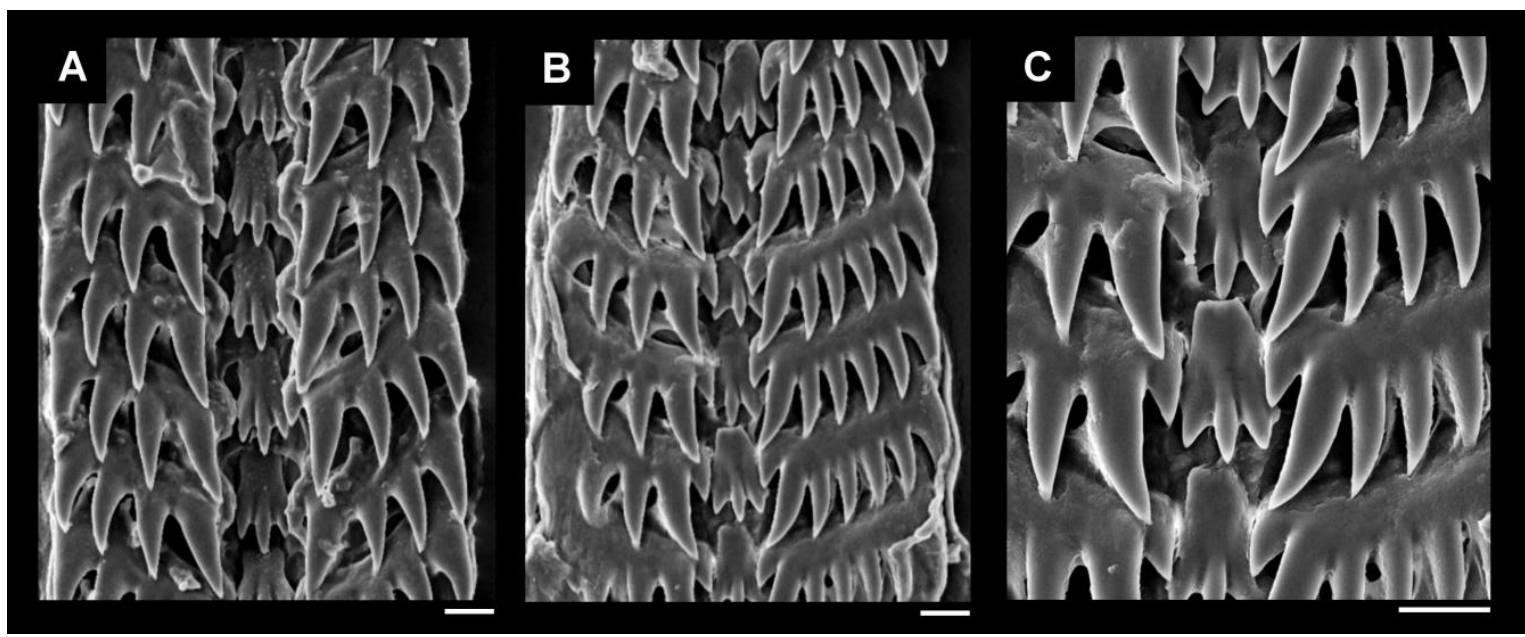

Figure 56. Granulifusus kiranus, radula. A: MNHN IM-2013-44502, panoramic view. B-C: MNHN IM2013-44449. B: panoramic view. C: detail of rachidian tooth. Scale bars $=20 \mu \mathrm{m}$. 


\section{Granulifusus kiranus (Figs. 55-56)}

Examined material:

MNHN IM-2013-44502, continental slope, China Sea, 333-421m depth, $20^{\circ} 11^{\prime} 52.3704 " \mathrm{~N} ; 14^{\circ} 9^{\prime} 21.3192^{\prime \prime E}$. NanHai 2014 expedition, Ocean Researcher 5 ship, Chen Wei-jen col. i/11/2014. [1 specimen]. MNHN IM-2013-19037, NE of Sissano, Bismarck Sea, 535-540m depth. 2०54'40.14"S; 142¹0'46.326"E. PAPUA NIUGINI expedition, ship Alis col. xii/20/2012 [1 specimen]. MNHN IM-201344449, Continental slop, China Sea, 262-298m depth, 20²'55.4532"N; $114^{\circ} 11^{\prime} 17.4984^{\prime \prime E}$. NanHai 2014 expedition, Ocean Researcher 5 ship, Chen Wei-jen col. i/03/2014 [1 specimen].

No known autapomorphies.

\section{Pseudolatirus discrepans (Figs. 57-58)}

Examined material: MNHN IM-2013-9777, Astrolabe Bay, Papua New Guinea, 340-385m depth, 5²1'54.36"S; 14547'48.9696"E. PAPUA NIUGINI expedition, ship Alis col. xii/14/2014 [1 specimen]. MNHN IM-2007-34604, Philippines, 342-358m depth, 160'52.2"N; 121 ${ }^{\circ} 51^{\prime} 11.9988^{\prime E}$. AURORA 2007 expedition, DA-BFAR ship col. v/20/2007 [1 specimen].

Shell with columellar folds presently in mid-aperture (8: 1). Head very small, its width: head-foot mass width <1/4 (13: 0), bearing very short cephalic tentacles, its length: head width <1/2 (14:0).

\section{Clade 5 Peristerniinae + Fasciolariinae}

Shell with columella bearing folds (8: 1) medially, pseudo-umbilicus (10:1) as shallow slit. Head-foot mass pigmentation dark-red (11: 3). Lateral margin of operculum hook-like (18: 2). Base of lateral tooth of radula slightly curved (59:1). 


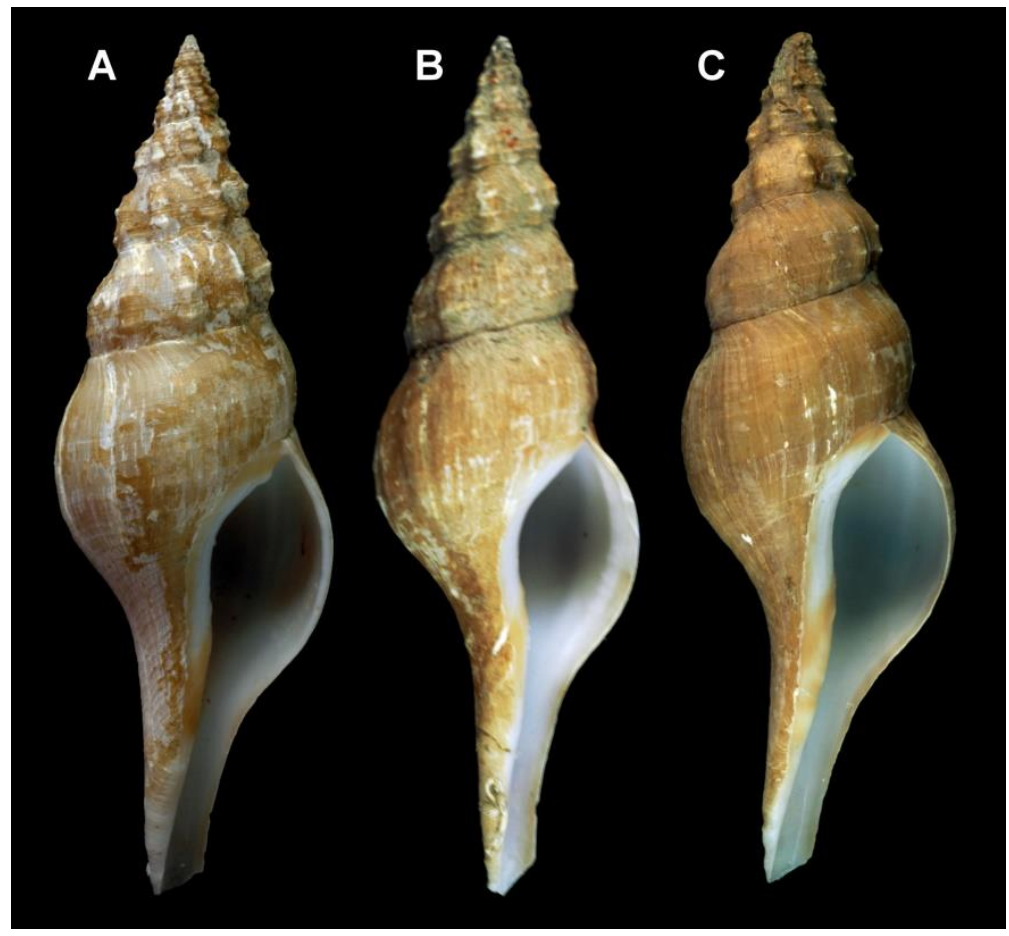

Figure 57. Pseudolatirus discrepans, shell. A: MNHN IM-200734604 (58.3mm). B: MNHN IM-2013-9777 (66mm). C: MNHN IM-2007-32791 (68.7mm).

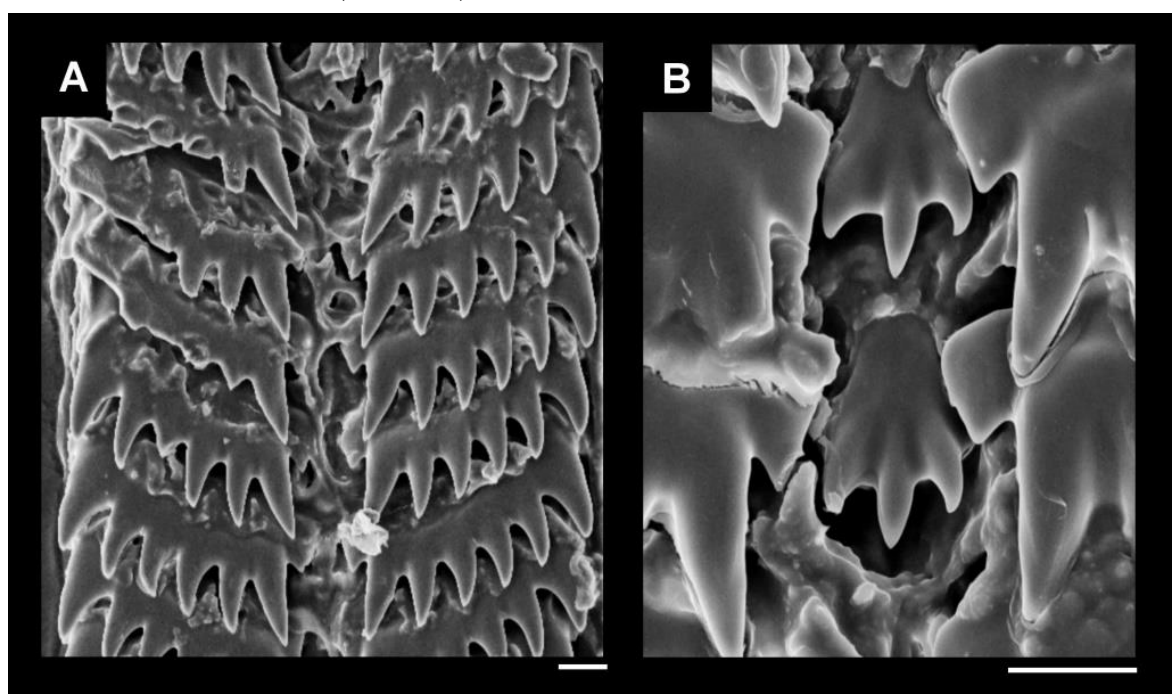

Figure 58. Pseudolatirus discrepans, radula. A-B: MNHN IM-2013-9777. A: panoramic view. B: detail of rachidian tooth. Scale bars $=20 \mathrm{um}$. 


\section{Clade 5a Peristerniinae}

Odontophore m6 muscle posterior free portion: odontophore length $\leq 1 / 6$ (45: 1). Cusps of lateral tooth of radula non-uniform in length and distribution (57:1), and bearing many secondary cusps (64: 1). Anus close to mantle border, its distance from mantle border: total pallial cavity length $<1 / 3$ (77: 0).

Fusolatirus bruijnii (Figs. 59-60)

Examined material: MNHN IM-2013-16671, inner slope, Papua New Guinea, 722m depth, 5²10'6.0024"S; 14550'14.9784"E. PAPUA NIUGINI expedition. xii/03/2012 [1 specimen]. MNHN IM-2013-18013, Papua New Guinea, 1-19m depth, 5¹0'18.0012"S; 14548'30.0024"E. PAPUA NIUGINI expedition. xii/07/2012 [1 specimen].

Loss of spiral sculpture of shell (3:0).

\section{Clade 5b Peristernia}

Siphonal canal of shell moderate-sized, its length: total shell length 1/6-1/4 (9: 1). Rachidian tooth of radula trapezoidal-shaped, its base width: edge width $\leq 1 / 2$ (50: 2); lateral tooth much wider than long, its length: width <1/3 (55: 4).

\section{Peristernia nassatula (Figs. 61-62)}

Examined material: MNHN IM-2007-32487, N of Malu Island, Vanuatu, 15³7'41.502"S; 167¹1'2.004"E. SANTO 2006 expedition, Aldric ship col. ix/16/2006. [1 specimen]. MNHN IM-2013-18061, Papua New Guinea, 1-8m depth. PAPUA NIUGINI expedition. xii/08/2012 [1 specimen]. MZSP 71241. Sovi Bay, Baravi, Southern Viti-Levu, Fiji. J coltro Femorale col. ix/10/2006 [2 specimens]. MNHN IM-2007-32541, Panglao Island, Napaling, Philippines, 9³7'12'N; 12346'23.9916"E. PANGLAO 2004 expedition. vi/15/2004 [1 specimen]. MNHN IM-2013-10796, Papua New Guinea, 5¹0'7.7412"S; 14550'32.4996"E. PAPUA NIUGINI expedition. xi/07/2012. [1 specimen].

Loss of lipped margin of rhynchostome (40: 0). Rachidian tooth of radula with 4 cusps (51: 3). 


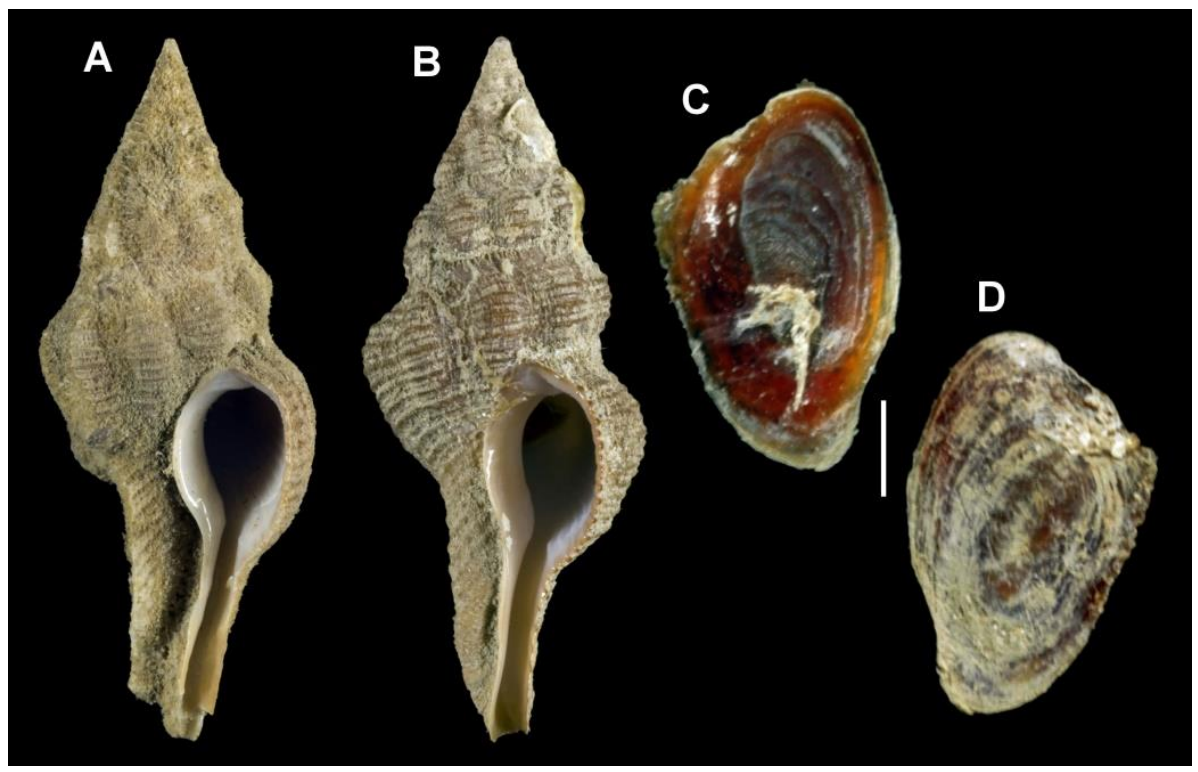

Figure 59. Fusolatirus bruijnii. shell and operculum. A: MNHN IM-2013-18013 (45.5mm). B: MNHN IM-2013-16671 (40mm). C: operculum, inner view. D: operculum. outer view. Scale bars $=1 \mathrm{~mm}$.

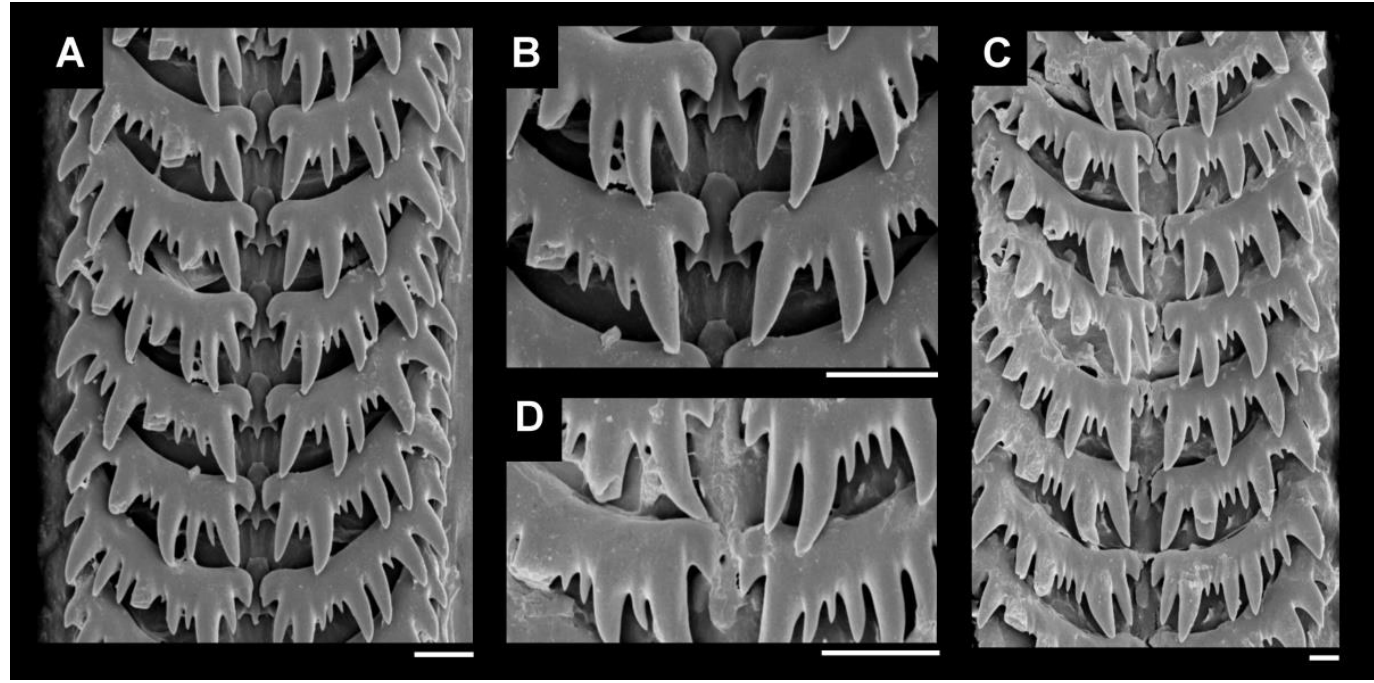

Figure 60. Fusolatirus bruijnii, radula. A-B: MNHN IM-2013-18013. A: panoramic view. B: detail of rachidian tooth. C-D: MNHN IM-2013-16671. C: panoramic view. D: detail of rachidian tooth. Scale bars $=20 \mu \mathrm{m}$. 


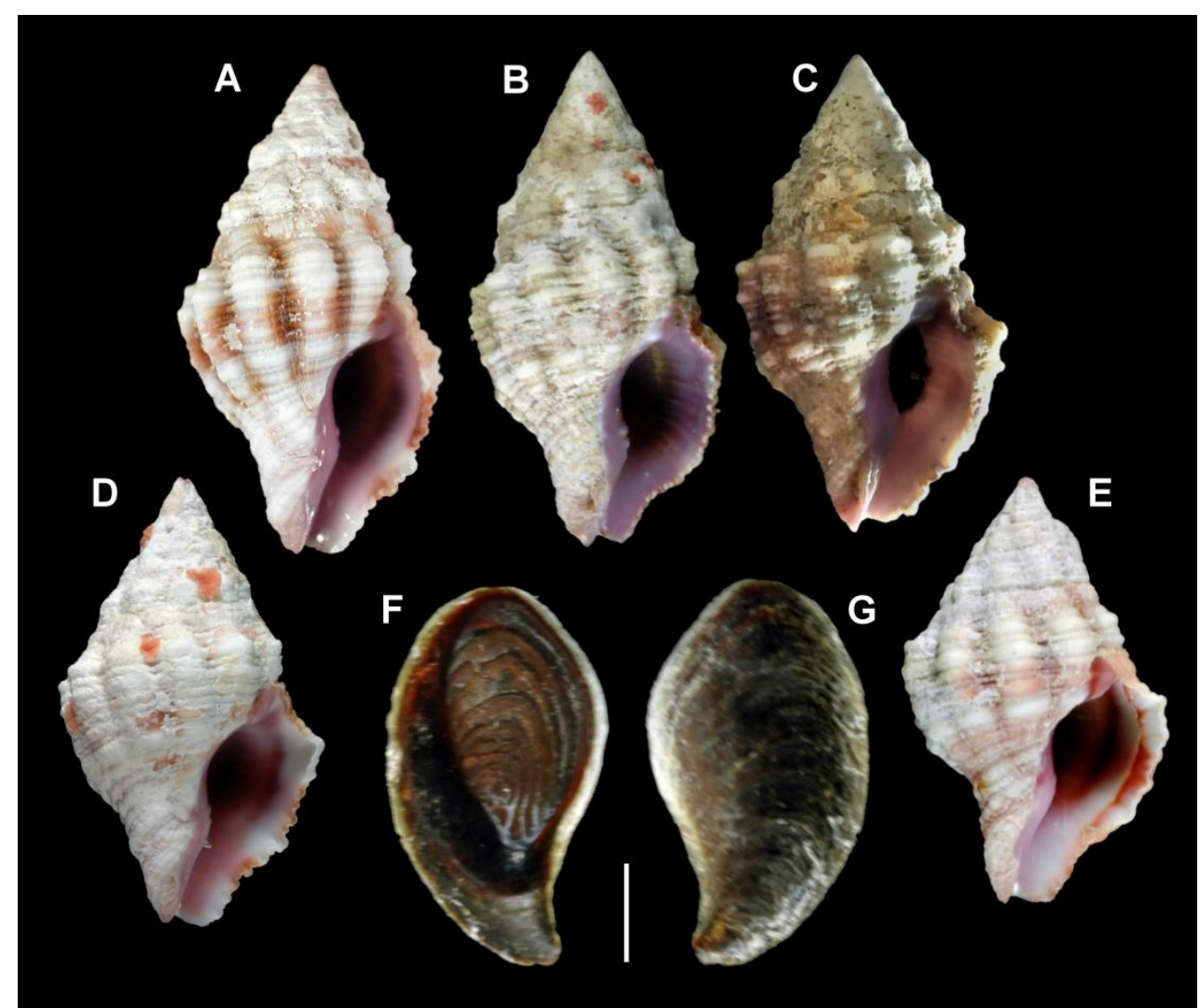

Figure 61. Peristernia nassatula, shell and operculum. A: MNHN IM-2007-32487 (28.6mm). B: MNHN IM-2013-18061 (35.5mm). C: MZSP 71241 (25mm). D: MNHN IM-2007-32541 (30.1mm). E: MNHN IM-2013-10796 (16.5mm). F: operculum, inner view. G: operculum, outer view. Scale bars $=2 \mathrm{~mm}$.

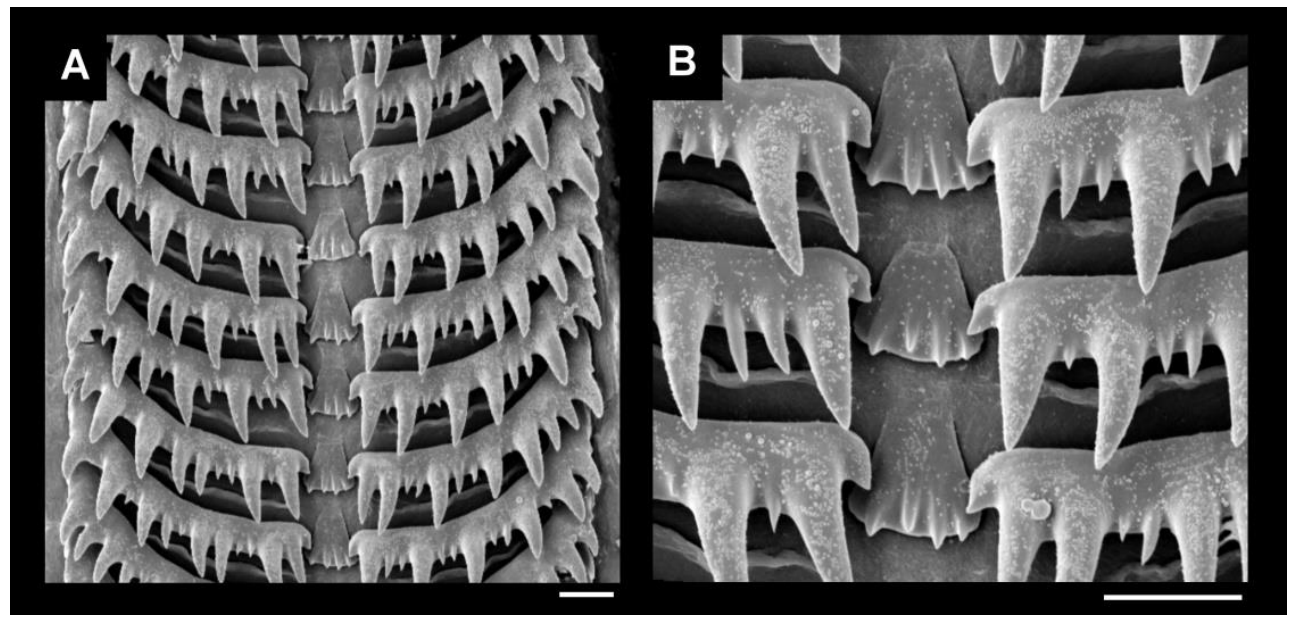

Figure 62. Peristernia nassatula, radula. A-B: MNHN IM-2013-18061. A: panoramic view. B: detail of rachidian tooth. Scale bars $=20 \mu \mathrm{m}$. 


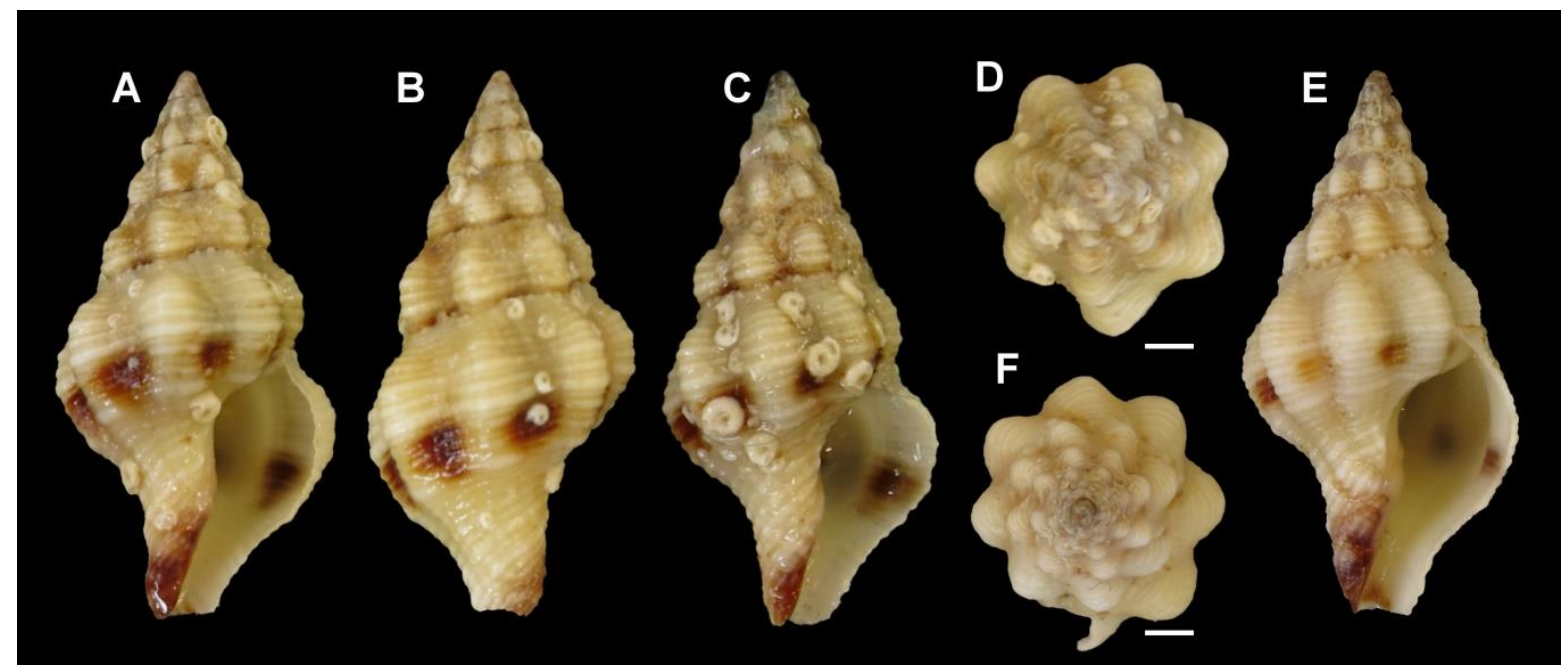

Figure 63. Peristernia marquesana, shell. A-D: MZSP 68507. A-B: (17.2mm). C: (18.3mm). E-F: MZSP 69249 (21.2mm). Scale bars $=2 \mathrm{~mm}$.

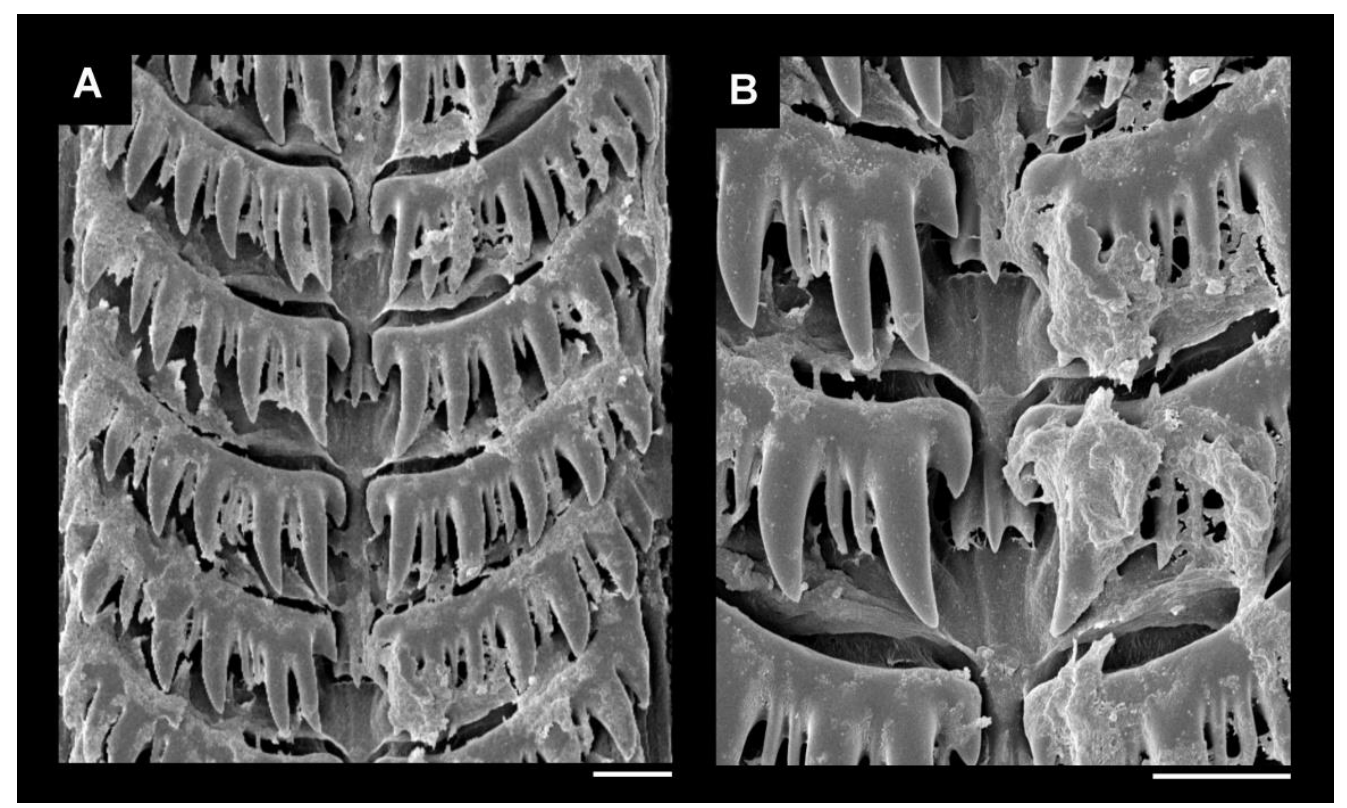

Figure 64. Peristernia marquesana, radula. A-B: MZSP 69249. A: panoramic view. B: detail of rachidian tooth. Scale bars $=20 \mu \mathrm{m}$.

\section{Peristernia marquesana (Figs. 63-64)}

Examined material: MZSP 68507, Okinawa city, Okinawa, Japan. J. Coltro Femorale col. v/2006 [2 specimens]. MZSP 69249, Malibu Beach, West Okinawa, Japan. . Coltro Femorale col. v/2006 [2 specimens].

Pallial cavity long, its extension $\geq 3 / 4$ whorls (19: 1). Rachidian tooth of radula triangle-shaped (48: 1), diminute, its width: lateral tooth width <1/4 (53: 3). Commissure of buccal ganglia inconspicuous (93:1). 


\section{Clade 6 Fasciolariinae}

Head medium-sized, its width: head-foot mass width 1/4-1/2 (13: 1), with short cephalic tentacles, its length: head width 1/2-2/3 (14: 1). Rachidian tooth of radula square-shaped, its base width: edge width 1/2-1 (50: 0). Salivary glands as free amorphous masses (69: 1).

\section{Clade 6a}

Lateral tooth of radula much wider than long, its length: width <1/3 (55: 4), bearing $\geq 16$ cusps (58: 3). Cement gland opening in foot sole centrally (84: 0). Commissure of buccal ganglia long, its length: buccal ganglia length $\geq 1 / 2(94: 1)$.

\section{Nodolatirus nodatus (Figs. 65-66)}

Examined material: MNHN IM-2013-42533, Tubuai, French Polynesia, Austral Archipelago, 23¹9'41.4012"S; 149²9'17.9772"W. Tuhaa Pae 2013 expedition, Alis ship col. iii/24/2013 [1 specimen]. NHN IM-2013-42533, Tubuai, French Polynesia, Austral Archipelago, 2325'7.7988"S; 149²7'0.3744"W. Tuhaa Pae 2013 expedition, Alis ship col. iii/23/2013 [1 specimen].

No known autapomorphies.

\section{Clade 6b}

Rhynchostome transverse (38: 0). Rachidian tooth of radula diminute, its width: lateral tooth width <1/4 (53:3); cusp 1 of lateral tooth absent (60:2).

\section{Latirus vischii (Figs. 67-68)}

Examined material: MNHN IM-2009-15038, Choumare Islet, S Madagascar,

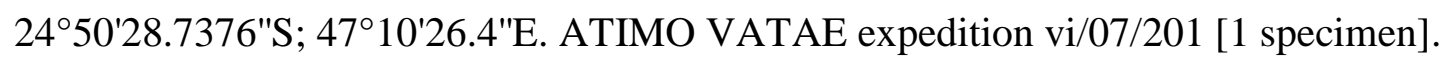

Loss of lipped margin of rhynchostome (40: 0). 


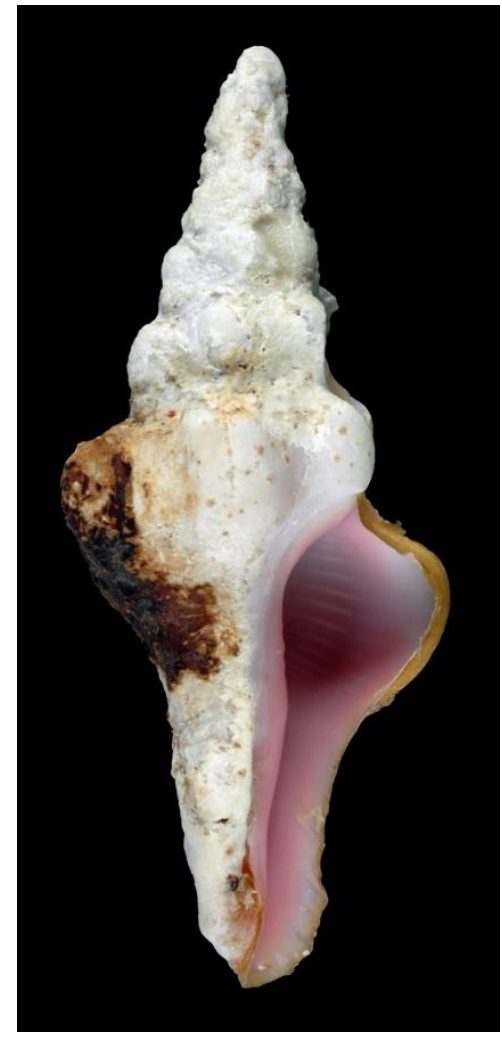

Figure 65. Nodolatirus nodatus, shell. MNHN IM-2013-42534 (76.5mm).

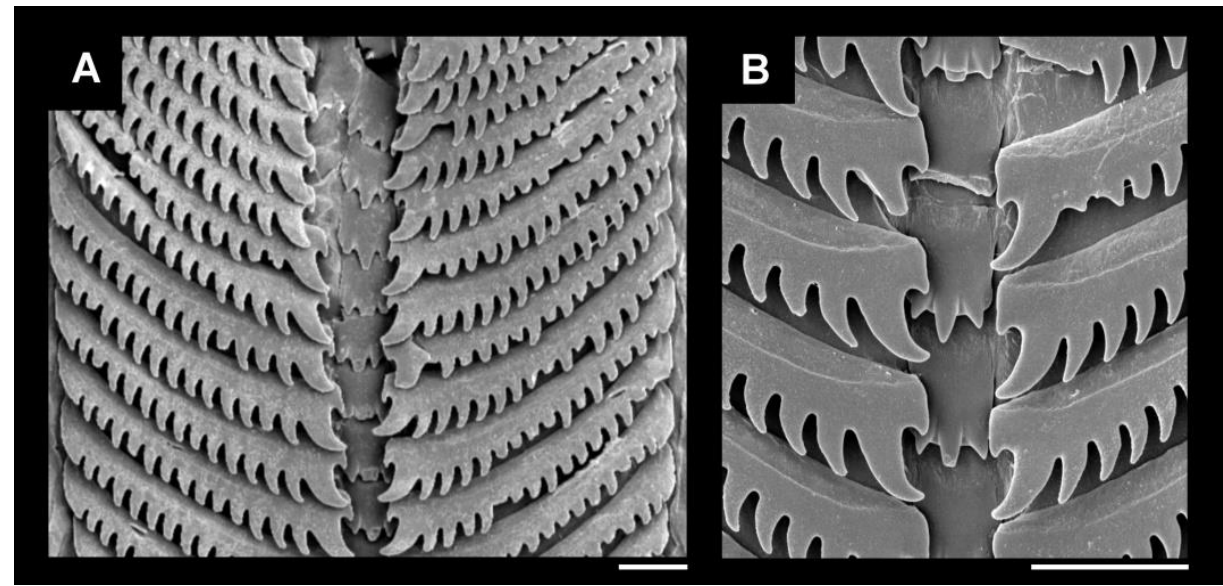

Figure 66. Nodolatirus nodatus, radula. A-B: MNHN IM-2013-42534. A: panoramic view. B: detail of rachidian tooth. Scale bars $=40 \mu \mathrm{m}$.

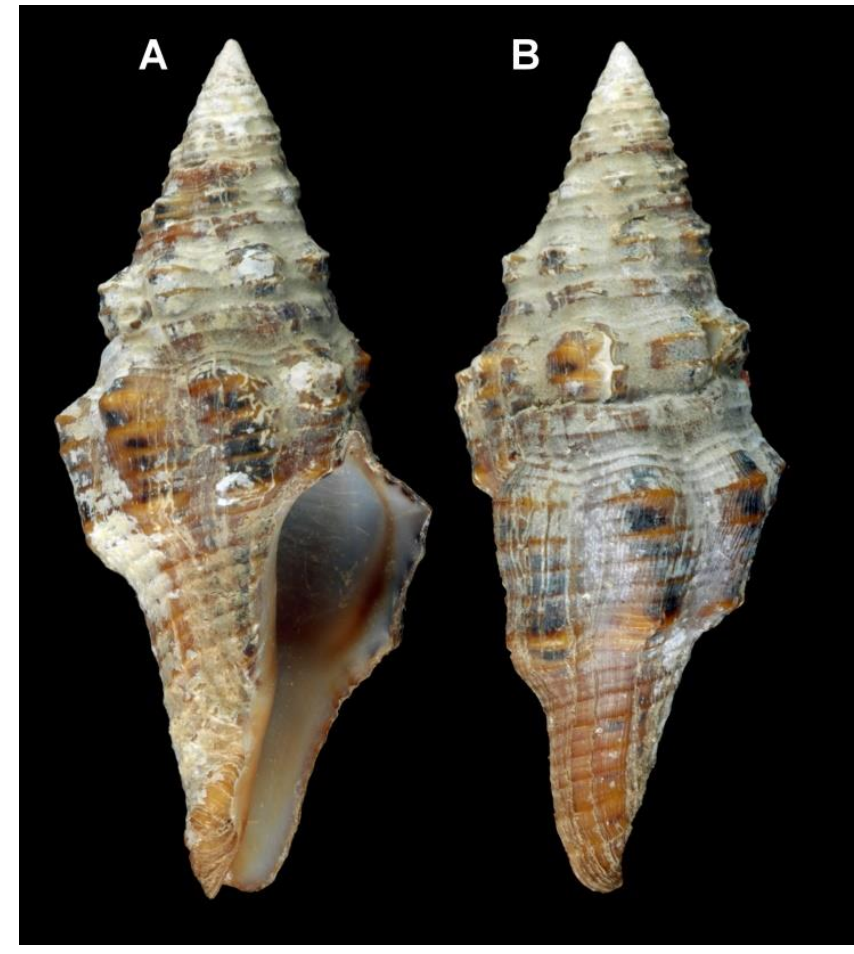

Figure 67. Latirus vischii, shell. A-B: MNHN IM-2009$15038(66.6 \mathrm{~mm})$.

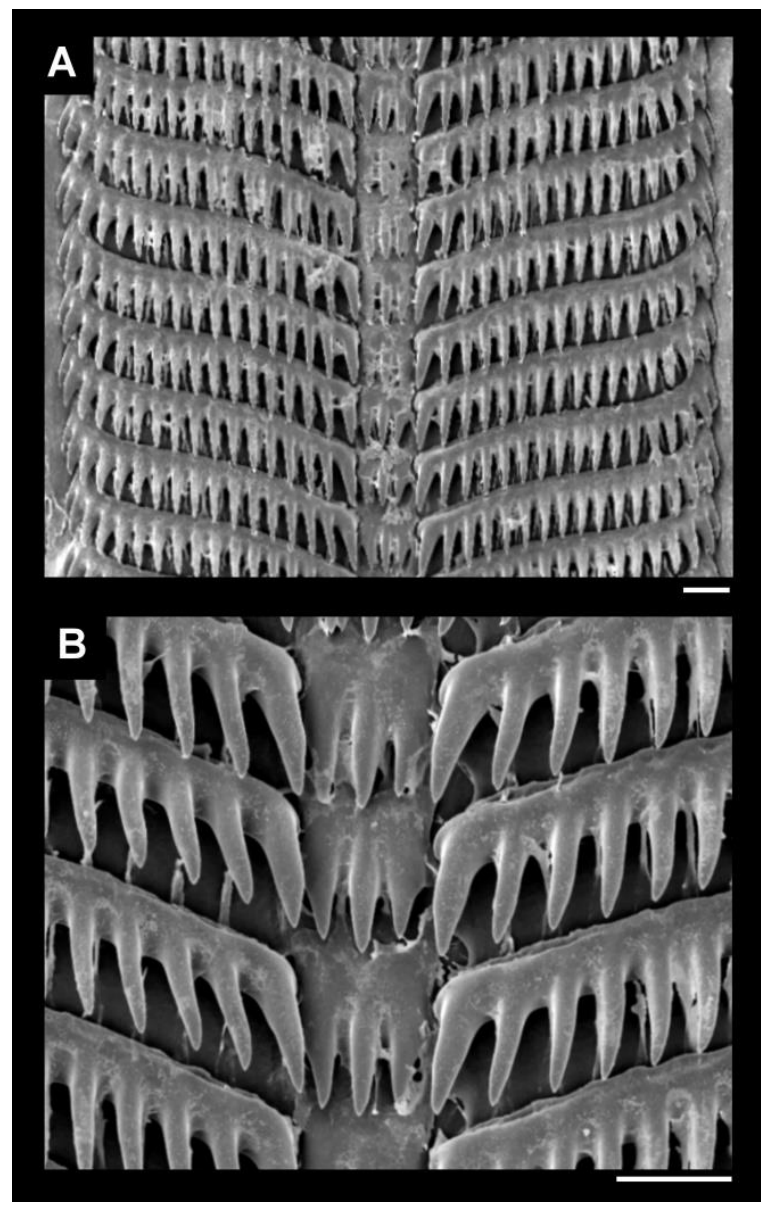

Figure 68. Latirus vischii, radula. A-B: MNHN IM-2009-15038. A: panoramic view. B: detail of rachidian tooth. Scale bars $=50 \mu \mathrm{m}$. 


\section{Clade 6c Fasciolariinae sensu stricto}

Shell coloration as blotchy spots, irregularly spaced (2: 0); siphonal canal moderate-sized, its length: total shell length 1/6-1/4 (9:1); loss of pseudo-umbilicus (10: 0). Renal aperture situated close to pericardium (36: 1). Odontophore long, its length: proboscis length 1 (42: 0). Retractor muscle of proboscis inserting posteriorly (68: 0). Posterior esophagus bearing sudden broadening in visceral region (74: 1), anterior to stomach.

\section{Fasciolaria tulipa (Figs. 69-70)}

Examined material: MZSP 69277, Roatan Island, Honduras, 80-100m depth. Femorale col. iii/2006 [1 specimen]. MZSP 35530, Marguerita Island, Venezuela, 3m depth. L.R. Simone col. [2 specimens]. MZSP 56870, Marguerita Island, El Yaque, Venezuela, 2m depth. L.R. Simone col. i/28/1998 [2 specimens].

Loss of spiral shell sculpture (3: 0). Odontophore m6 muscle posterior free portion: odontophore length $\leq 1 / 6$ (45: 1). Rachidian tooth of radula trapezoidal-shaped, its base width: edge width $1 / 2$ 1 (50: 1). 


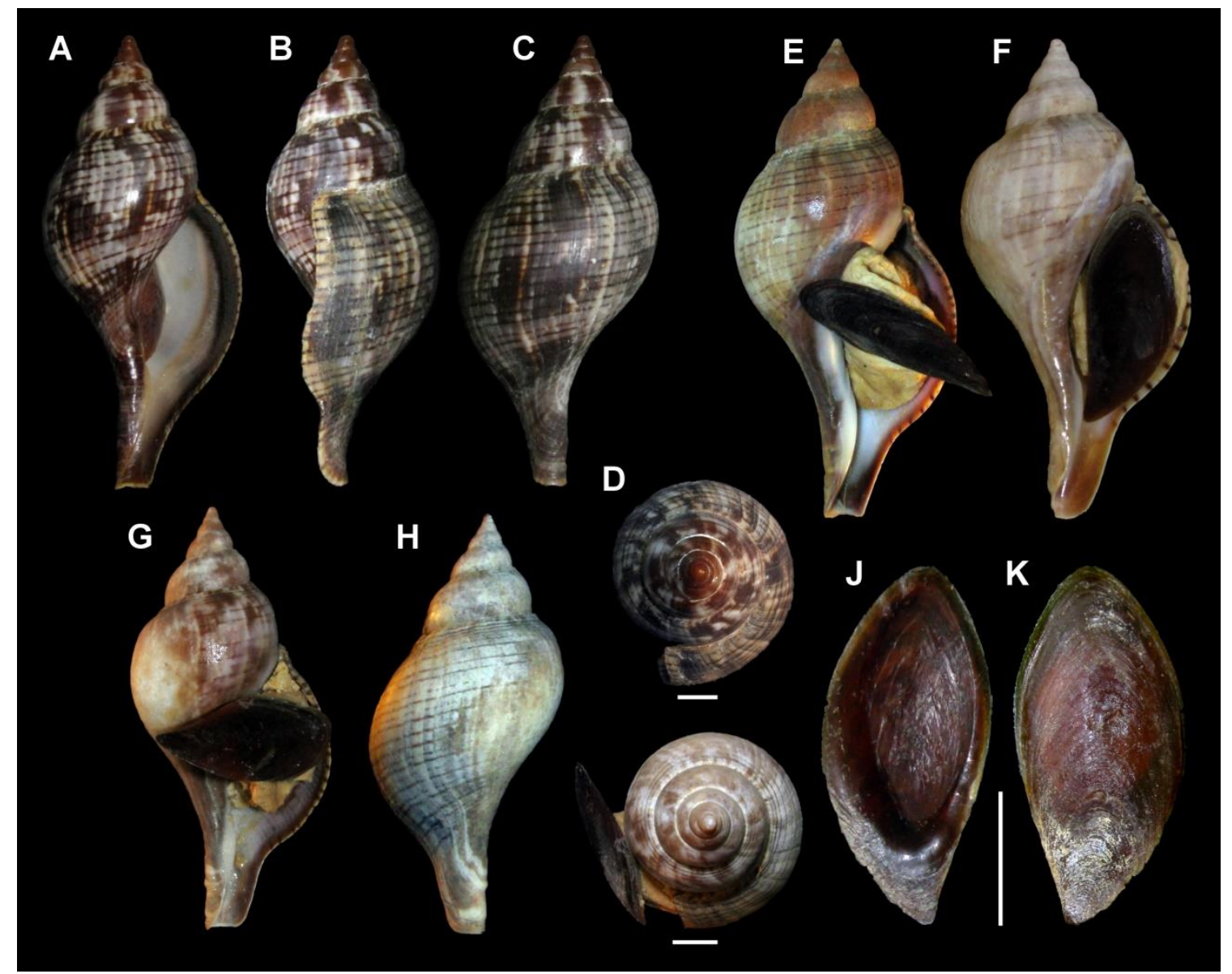

Figure 69. Fasciolaria tulipa, shell and operculum. A-D: MZSP 69277 (69.5mm). E-F: MZSP 35530. E: $(77,5 \mathrm{~mm})$. F: (107,9mm). G-I: MZSP 56870 (92,3mm). J: operculum, inner view. K: operculum, outer view. Scale bars $=10 \mathrm{~mm}$.

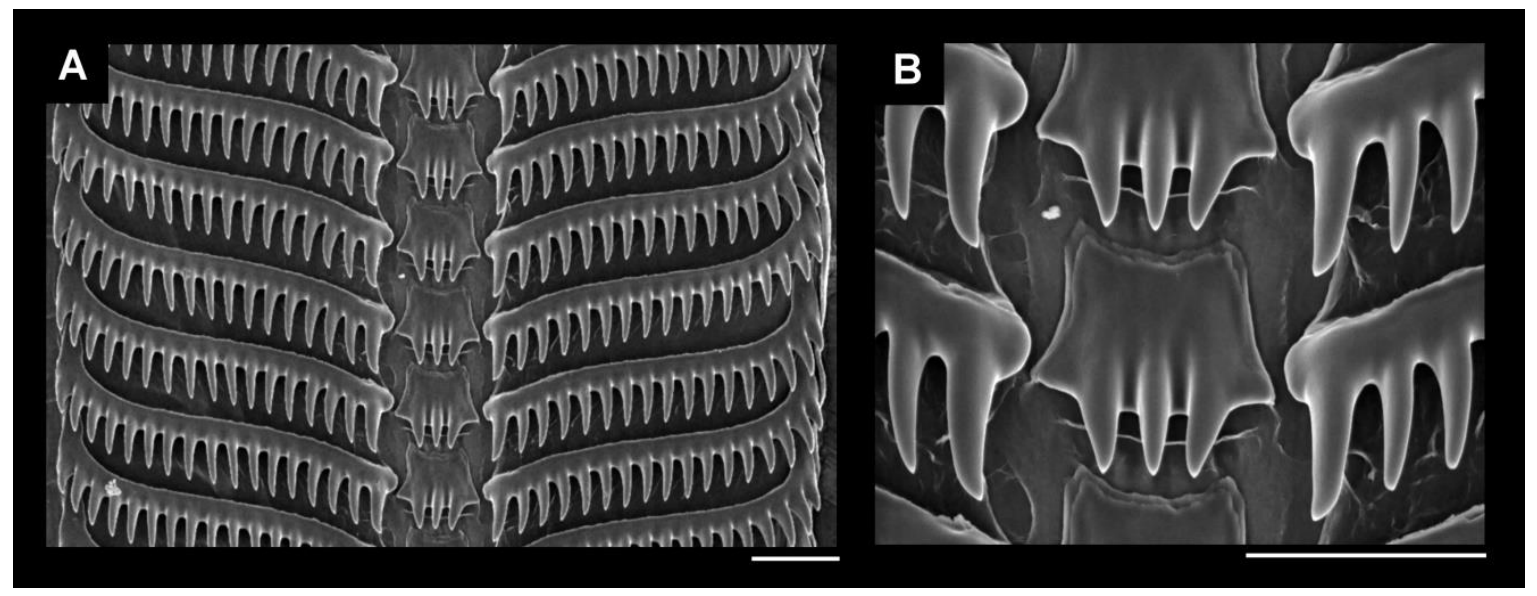

Figure 70. Fasciolaria tulipa, radula. A-B: MZSP 35530. A: panoramic view. B: detail of rachidian tooth. Scale bars $=100 \mu \mathrm{m}$. 


\section{Aurantilaria aurantiaca (Figs. 71-72)}

Examined material: CMPHRM 2765, Redonda Beach, Icapuí, Ceará state, Brazil. H. Matthews-Cascon col. ix-18-2009 [2 specimens]. MNRJ 8372, Retiro grande Beach, Aracati, Ceará state, Brazil. A.L. Castro col. i/1964 [1 specimen]. MNRJ 993, Itapagipe, Salvador, Bahia state, Brazil. , H. Souza Lopes col. [2 specimens]. MNRJ 8304, Nova Viçosa Reef, Nova Viçosa Bay, Bahia state, Brazil. P.S. Young \& C.B. Castro col. vii/18/1993 [1 specimen]. MNRJ 15161, Conceição, Itaparica Island, Bahia state, Brazil. D.R. Couto col. i/4/2010 [2 specimens]. MNRJ 14346, Santa Cruz, Espírito Santo state, Brazil. P. Jurberg col. i/18/1973 [2 specimens]. MNRJ 8369, Piloto Beach, Santa Cruz, Espírito Santo state, Brazil. D. Campos \& D. Campos col. viii/1973 [1 specimen]. MNRJ 6678, Rio de Janeiro state, Brazil. H.S. Lopes col. [1 specimen]. MZSP 33005, Cabo Branco Beach, João Pessoa, Paraíba state, Brazil. R. Leonel col. v/25/1998 [1 specimen]. MZSP 77496, Francês Beach, Marechal Deodoro, Alagoas state, Brazil, 5m depth. L.R.S. Simone col. vii/17/1989 [2 specimens]. MZSP 35976, Alcaçoba, Bahia state, Brazil. Coltro col. ix/2002 [3 specimens].

Body pigmentation orange to light red with reticulated lighter pattern (11: 2). Pallial cavity long, its extension $\geq 3 / 4$ whorls (19: 1). Osphradium leaflets non uniform (24: 1). Rachidian tooth of radula trapezoidal-shaped, its base width: edge width $1 / 2-1$ (50: 1), bearing minute, secondary cusps (52: 1). Female cement gland opening anteriorly (84:1) in foot sole. penis duct linear (87: $0)$.

\section{Clade 6d}

Head very small, its width: head-foot mass width <1/4 (13: 0), bearing very short cephalic tentacles, its length: head width <1/2 (14: 0). Cement gland immersed in foot as several saccular vesicles, branching from single opening (83:1). 


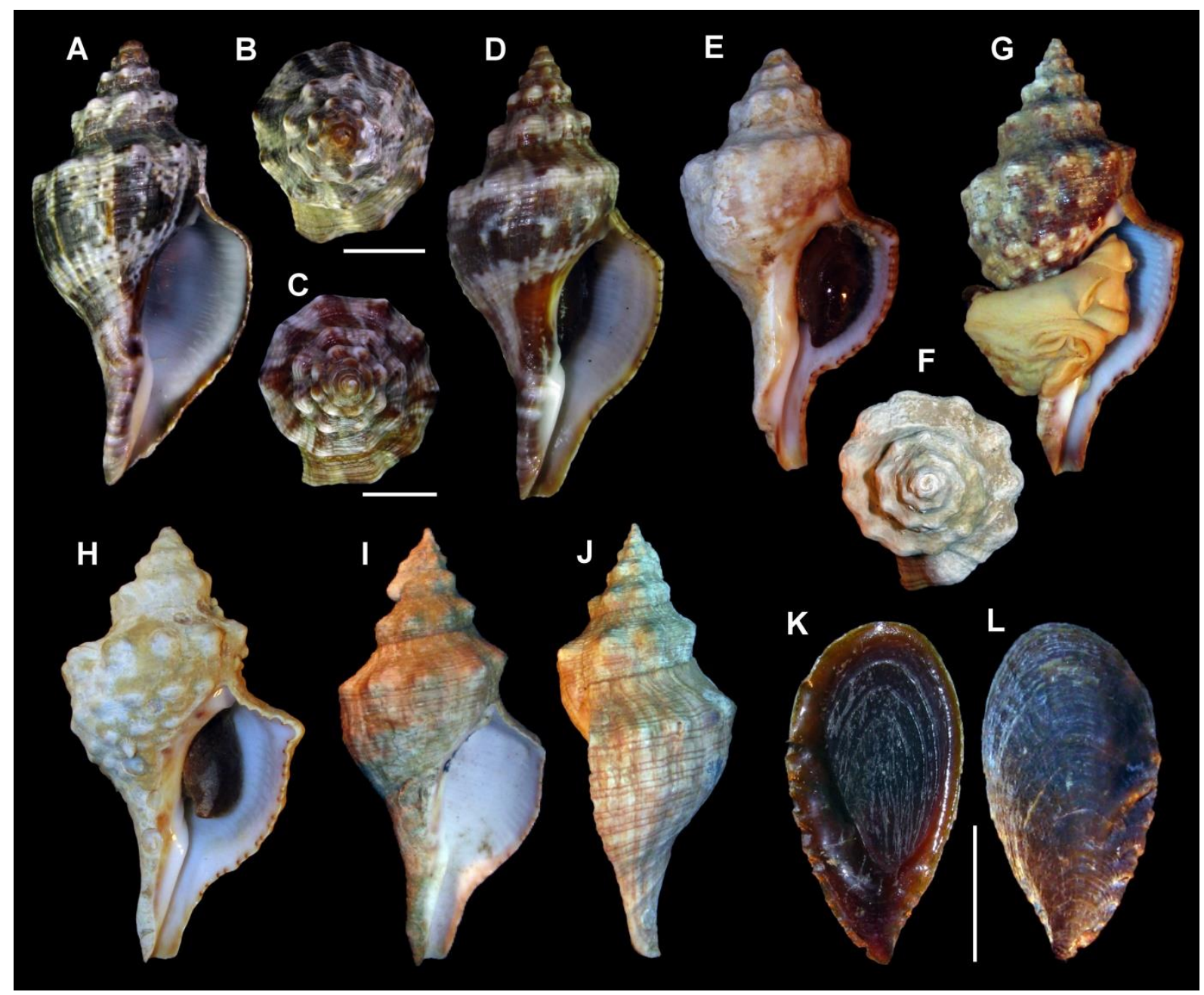

Figure 71. Aurantilaria aurantiaca, shell and operculum. A-D: CMPHRM 2765. A-B: $(48.3 \mathrm{~mm})$. C-D: (48.7mm). E-F: MZSP 77496 (75.8mm). G: MZSP 33005 (75.6mm). H: MNRJ 8304 (100.4mm). I-J: MNRJ 993 (75.9mm). K: operculum, inner view. L: operculum, outer view. Scale bars $=10 \mathrm{~mm}$. 


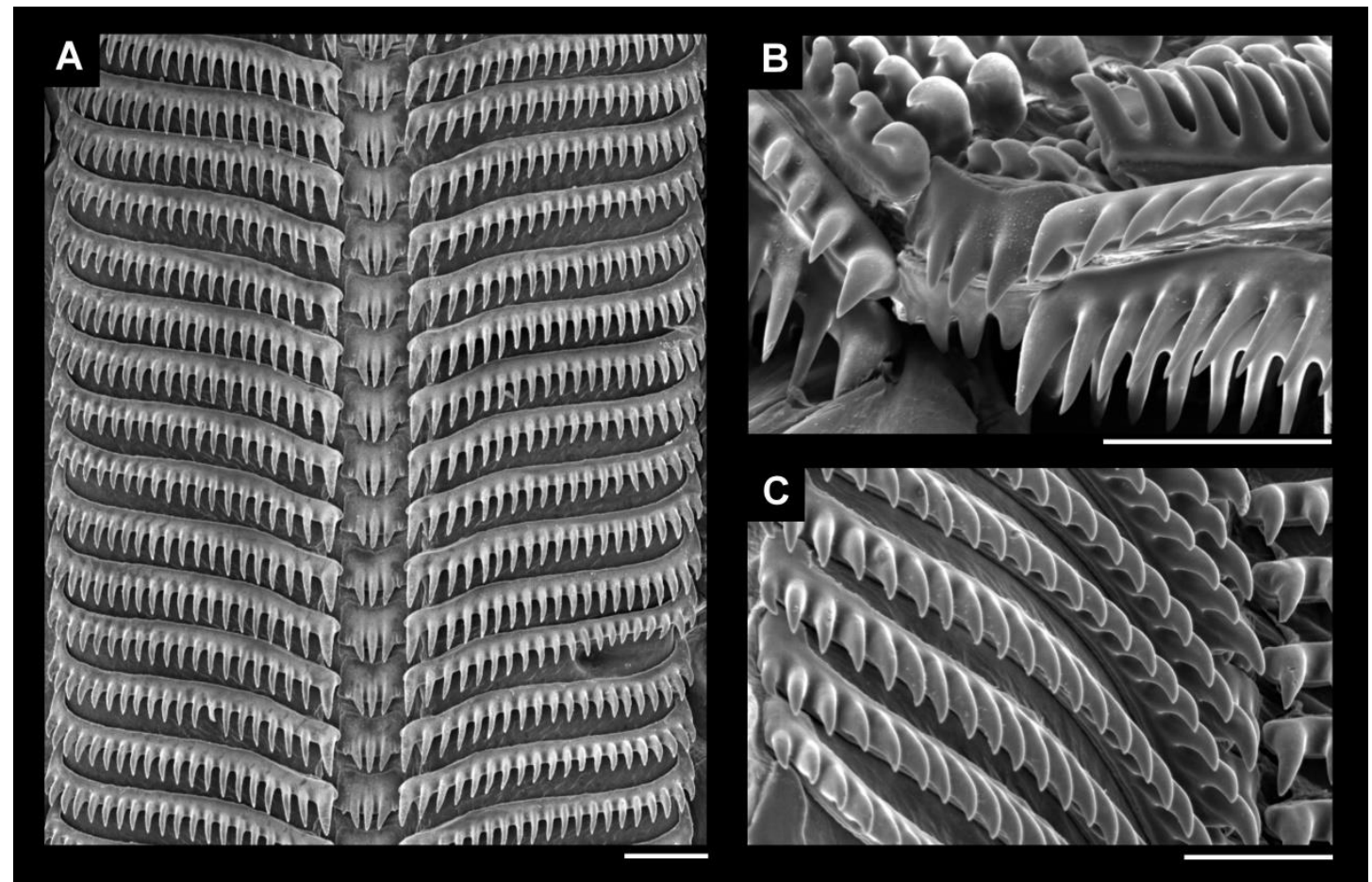

Figure 72. Aurantilaria aurantiaca, radula. A-B: MNRJ 15161. A: panoramic view. B: detail of rachidian tooth. C: MNRJ 14346 detail of lateral tooth. Scale bars $=100 \mu \mathrm{m}$.

\section{Filifusus filamentosus (Figs. 73-74)}

Examined material: MNHN IM-2013-13107, Papua New Guinea, 54'43.968"S; 14548'53.1108"E. PAPUA NIUGINI expedition. xi/14/2012 [1 specimen]. MNHN IM-2007-32592, Palikulo Bay, N Cape Undine, Vanuatu, 9-30m depth, 15²5'50.9412"S; 167²1'59.688"E. SANTO 2006 expedition, Aldric ship col. ix/26/2006 [1 specimen].

Loss of spiral sculpture of shell (3: 0). Pallial cavity long, its extension $\geq 3 / 4$ whorls (19: 1). Ctenidium ample, its width: osphradium width $\geq 1.5$ (28: 2). Radula rachidian bearing minute, secondary cusps (52: 1). 


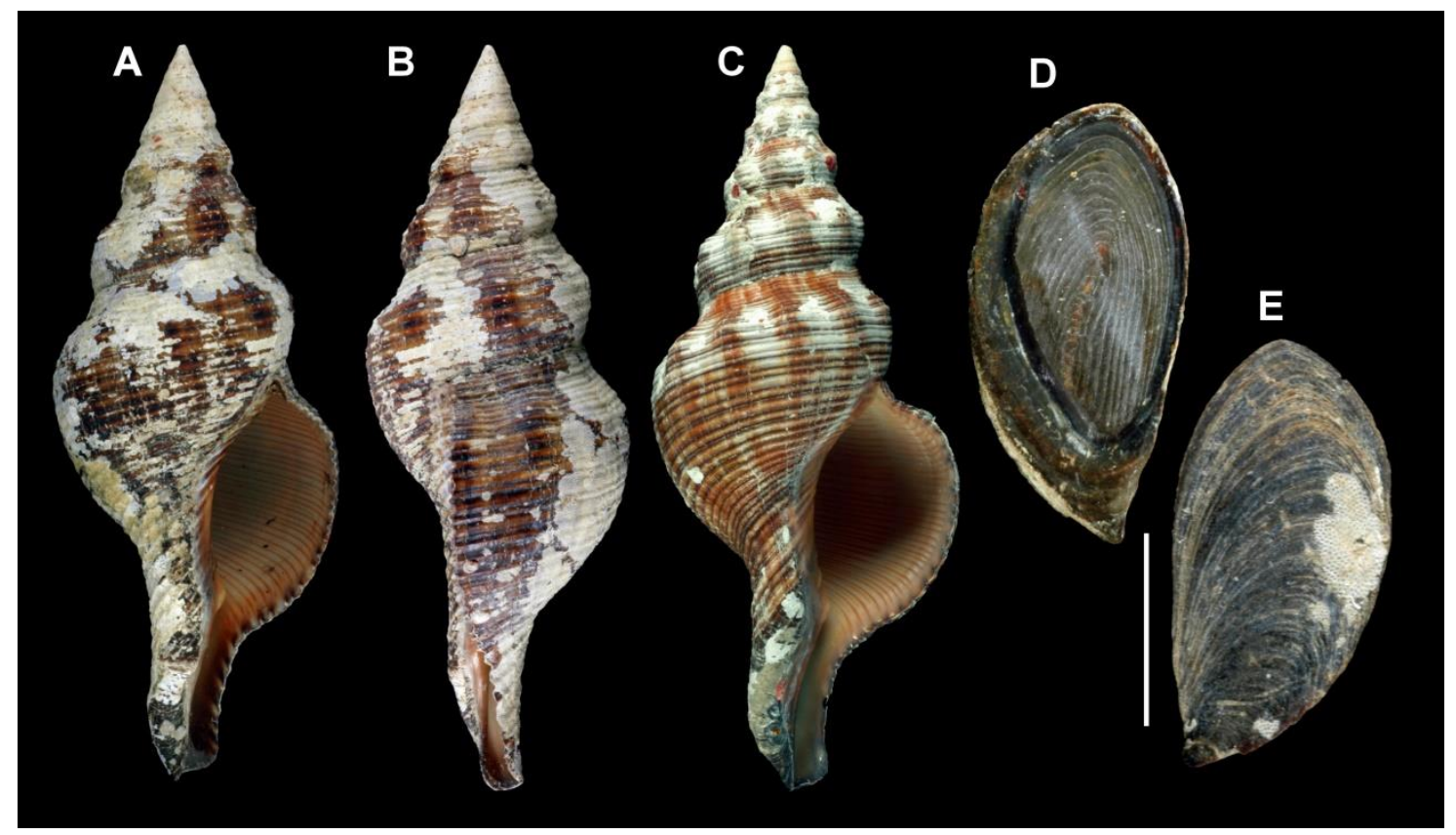

Figure 73. Filifusus filamentosus. shell and operculum. A-B: MNHN IM-2013-13107 (102.5mm). C: MNHN IM-2007-32592 (130mm). D: operculum, inner view. E: operculum, outer view. Scale bars = $10 \mathrm{~mm}$.

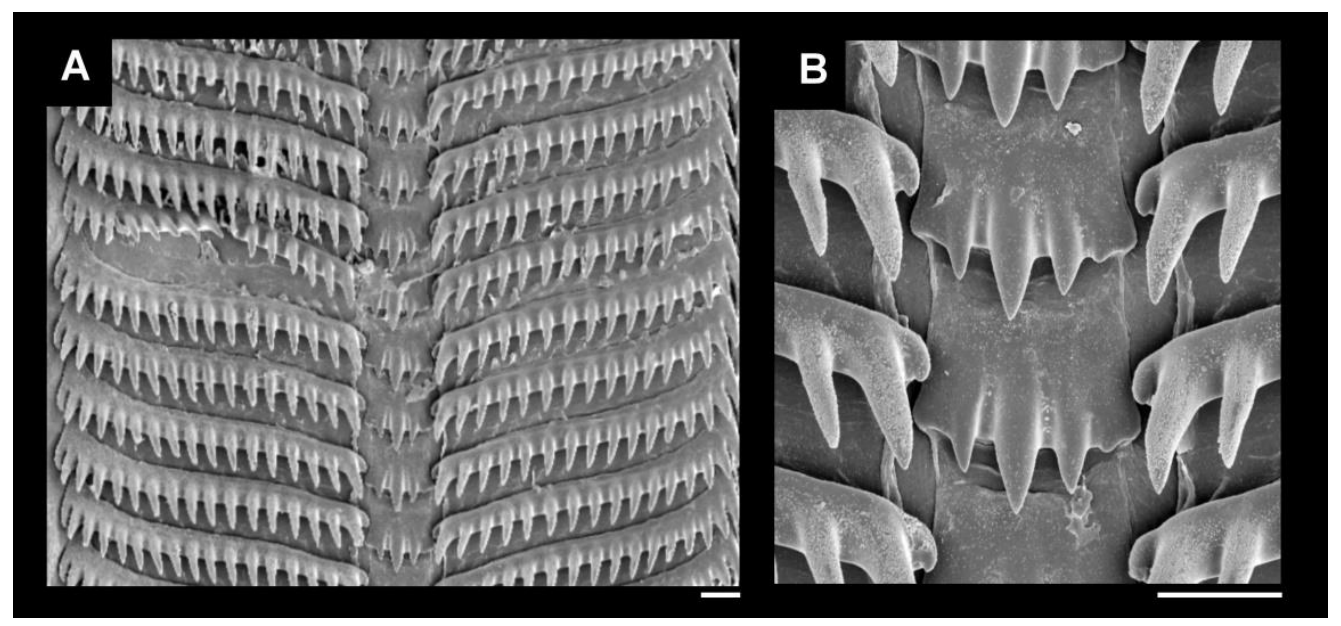

Figure 74. Filifusus filamentosus, radula. A-B: MNHN IM-2013-13107. A: panoramic view. B: detail of rachidian tooth. Scale bars $=50 \mu \mathrm{m}$. 


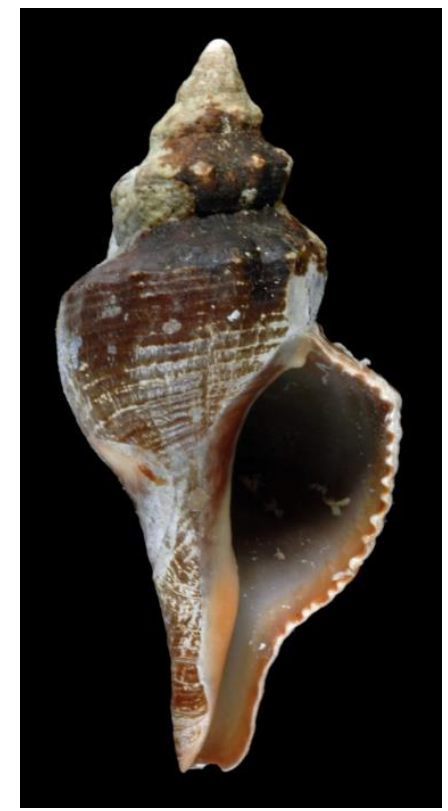

Figure 75. Australaria australasia, shell. MNHN IM-2013-42514 (61.2mm).

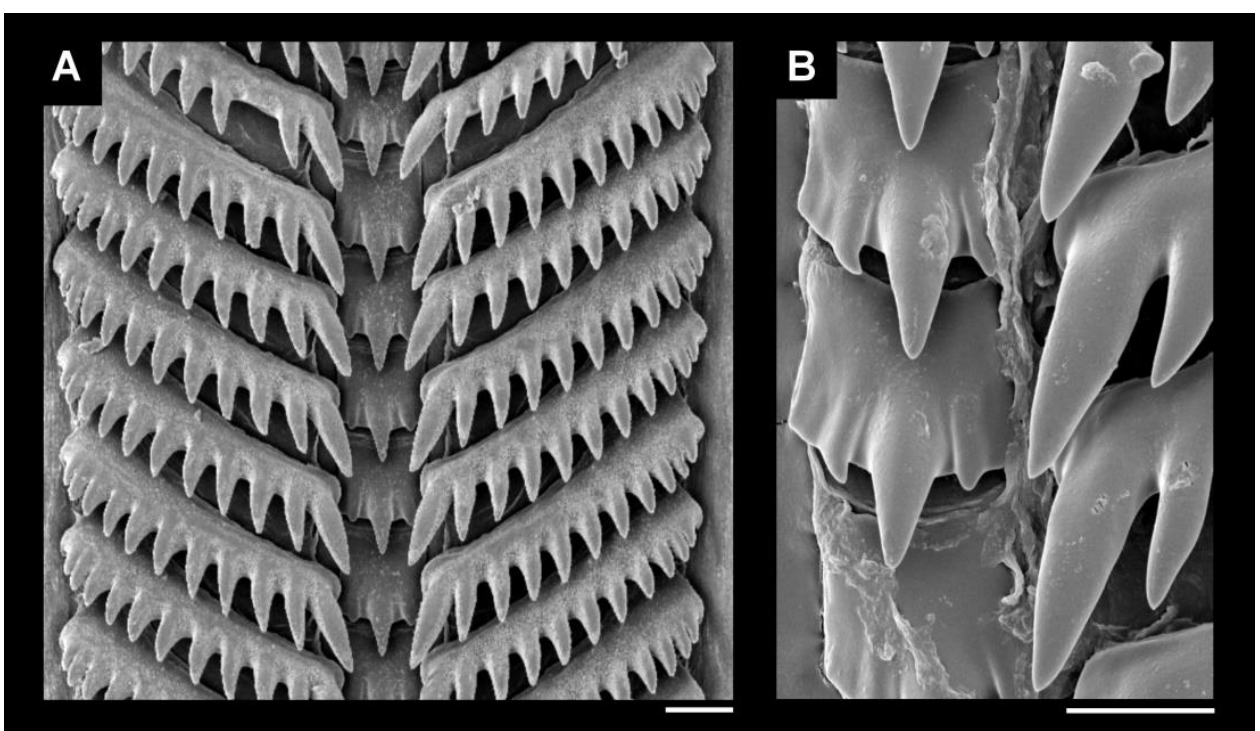

Figure 76. Australaria australasia, radula. A-B: MNHN IM-2013-42514. A: panoramic view. B: detail of rachidian tooth. Scale bars $=40 \mu \mathrm{m}$.

\section{Australaria australasia (Figs. 75-76)}

Examined material: MNHN IM-2013-42514, Island off Cape Le Grande, Esperance, Australia, 34¹'15.672"S; 1228'29.328"E. WESTERN AUSTRALIA 2011 expedition. xi/20/2011 [1 specimen]. MNHN IM-2013-42516, Island off Cape Le Grande, south side, Esperance, Australia, 34¹'15.672"S; 122²'29.328"E. WESTERN AUSTRALIA 2011 expedition. xi/20/2011. [1 specimen].

Osphradium leaflets non uniform in profile (24: 1). Lateral tooth of radula bearing 7-15 cusps (58: 2).

\section{Pleuroploca trapezium (Figs. 77-78)}

Examined material: MNHN IM-2009-15358, Ambatobe, Madagascar, 0-1m depth, 2527'23.6988"S; 4457'23.4036"E. ATIMO VATAE expedition v/24/2010 [1 specimen]. MNHN IM-2007-32591, Vanuatu. SANTO 2006 expedition, Alis ship col. [1 specimen].

No known autapomorphies. 


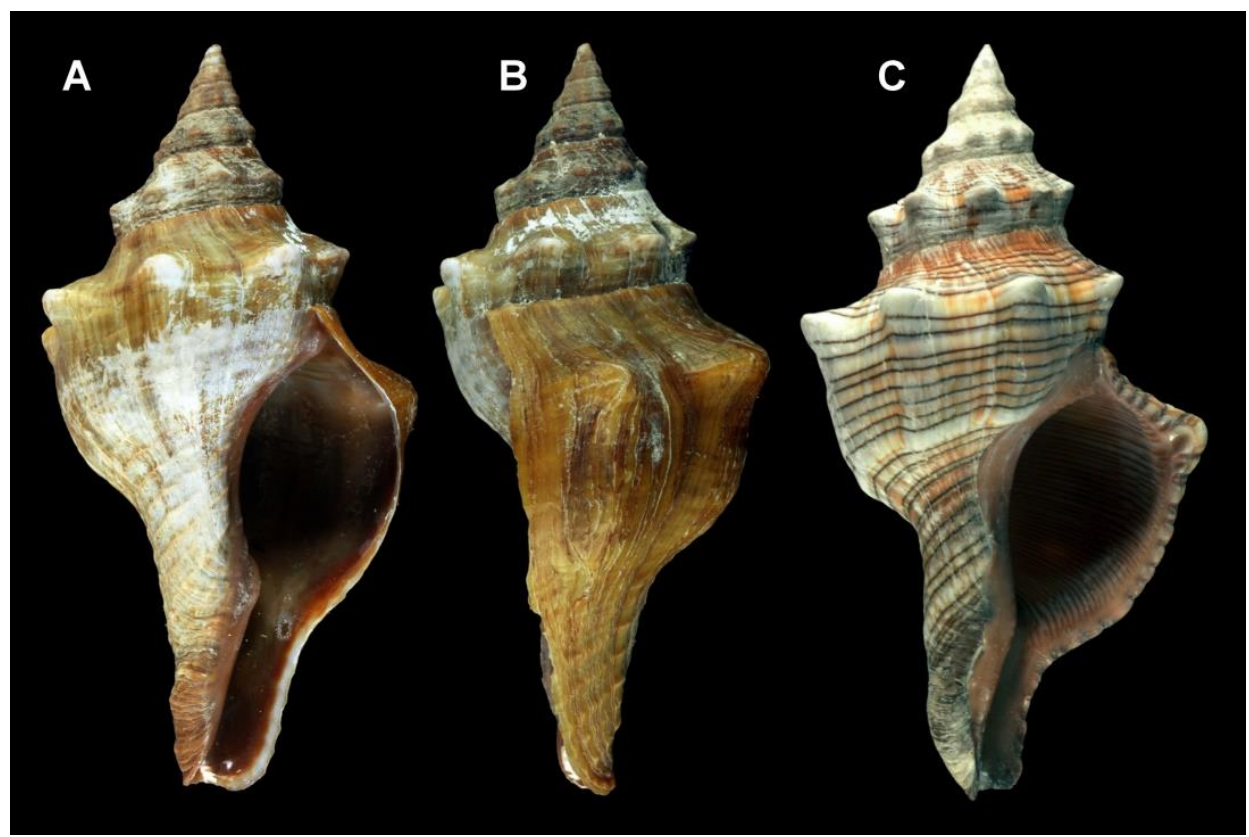

Figure 77. Pleuroploca trapezium, shell. A-B: MNHN IM-2009-15358 (66.5mm). C: MNHN IM-2007-32591 (185.5mm).

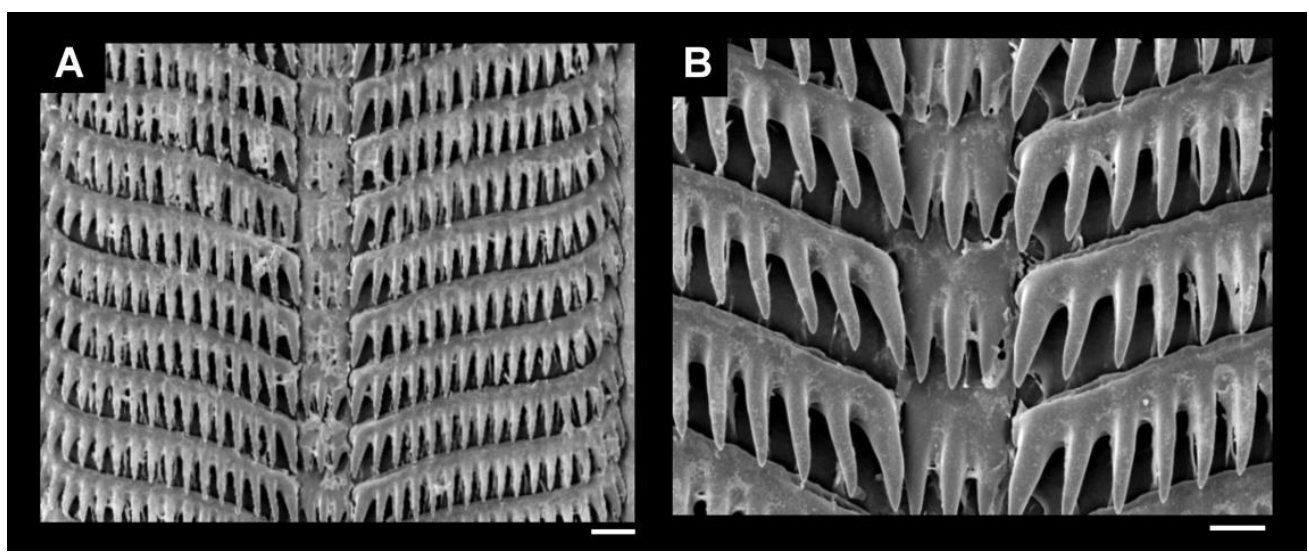

Figure 78. Pleuroploca trapezium, radula. A-B: MNHN IM-2009-15358. A: panoramic view. B: detail of rachidian tooth. Scale bars $=50 \mu \mathrm{m}$. 


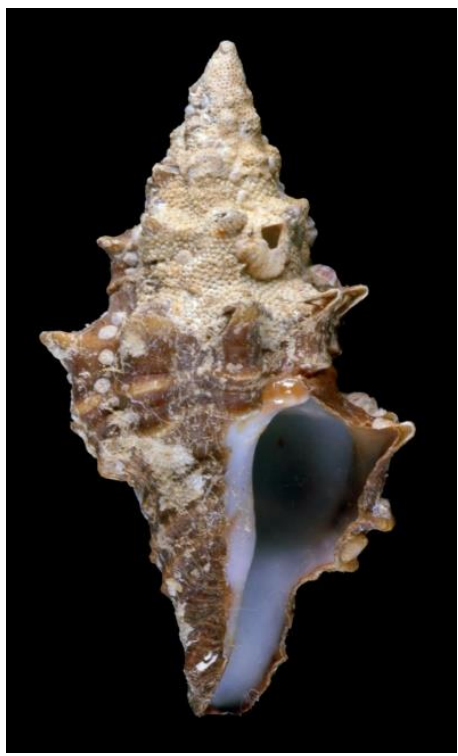

Figure 79. Hemipolygona armata, shell. MNHN IM2013-42509 (46.7mm).

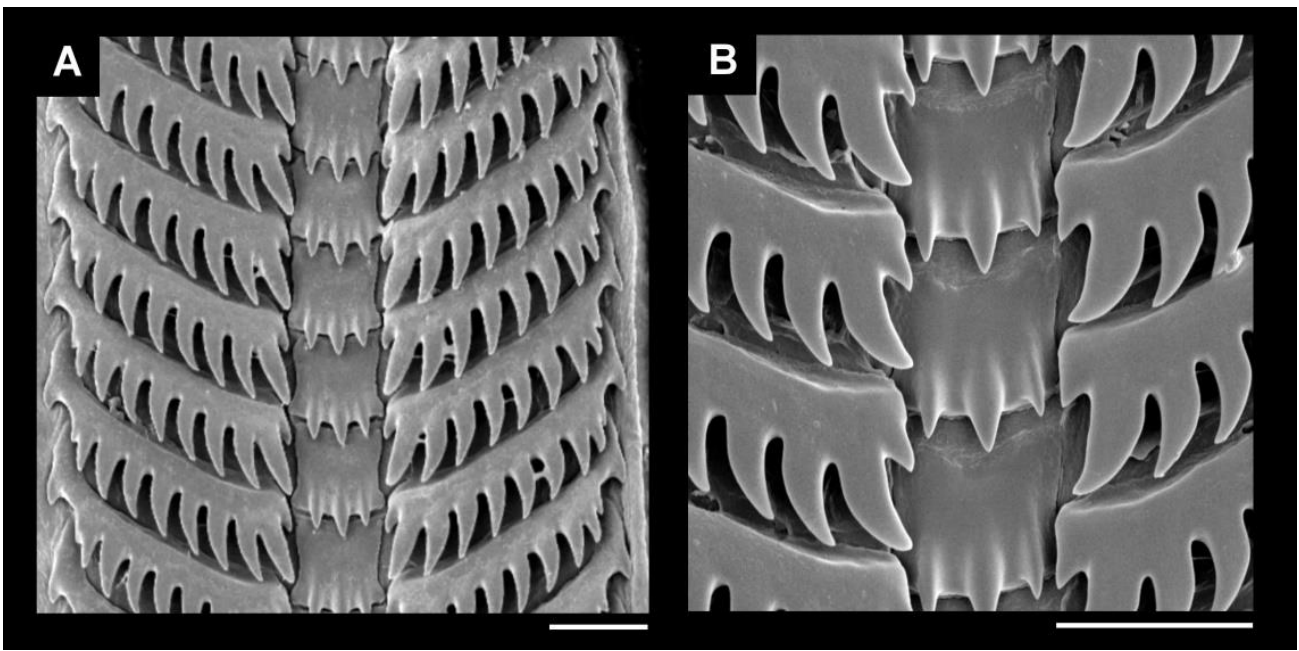

Figure 80. Hemipolygona armata, radula. A-B: MNHN IM-2013-42509. A: panoramic view. B: detail of rachidian tooth. Scale bars $=40 \mu \mathrm{m}$.

\section{Clade 7}

Inner sculpture of outer lip of shell bearing discontinuous spiral cords (7:2) or lirae; siphonal canal moderate-sized, its length: total shell length 1/6-1/4 (9: 1). Rhynchostome transverse slit (38: 0). Commissure of buccal ganglia inconspicuous (93:1).

\section{Hemipolygona armata (Figs 79-80)}

Examined material: MNHN IM-2013-42511, Gorée Island, Senegal, 1440'12"N; 17²3'48.0012"W. Dakar'09 expedition [1 specimen]. MNHN IM-2013-42509, Gorée Island, Senegal, 1440'12"N; 17²3'48.0012"W. Dakar'09 expedition [1 specimen].

Proboscis retractor muscle inserting posteriorly (68: 0).

\section{Clade 8}

Rhynchostome lipped margin lost (40: 0). Odontophore cartilages fused anteriorly $\geq 15 \%$ of total odontophore length (44: 2). 


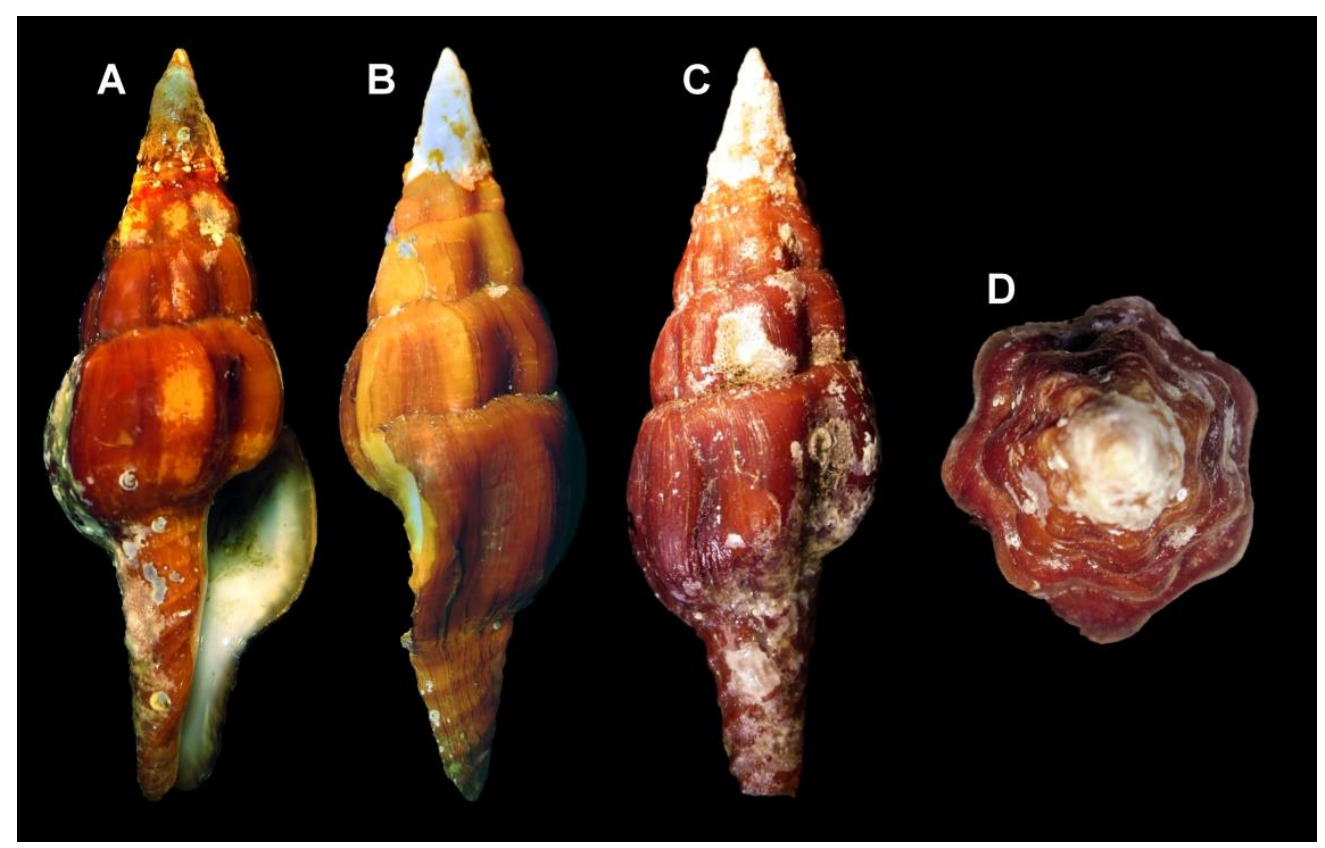

Figure 81. Pustulatirus mediamericanus, shell. A-D: MZSP 69500 (57.5mm).

\section{Clade 8a Pustulatirus}

Pallial cavity long, its extension $\geq 3 / 4$ whorls (19: 1 ). Rachidian tooth of radula bearing 4 cusps (51: 3); lateral tooth much wider than long, its length: width <1/3 (55: 4). Paired proboscis retractor muscles (67: 0), inserting posteriorly in proboscis (68: 0). Female cement gland opening centrally in foot (84: 0$)$.

\section{Pustulatirus mediamericanus (Fig. 81)}

Examined material: MZSP 69500, La Plata Island, Manabi, Ecuador. J. Coltro col. x/2002 [2 specimens]. MZSP 95273, Ecuador. Simone col. 2009 [15 specimens]. MZSP 67752, La Plata Island, Manabi, Ecuador. J. Coltro col. vi/2006 [1 specimen].

No known autapomorphies. 


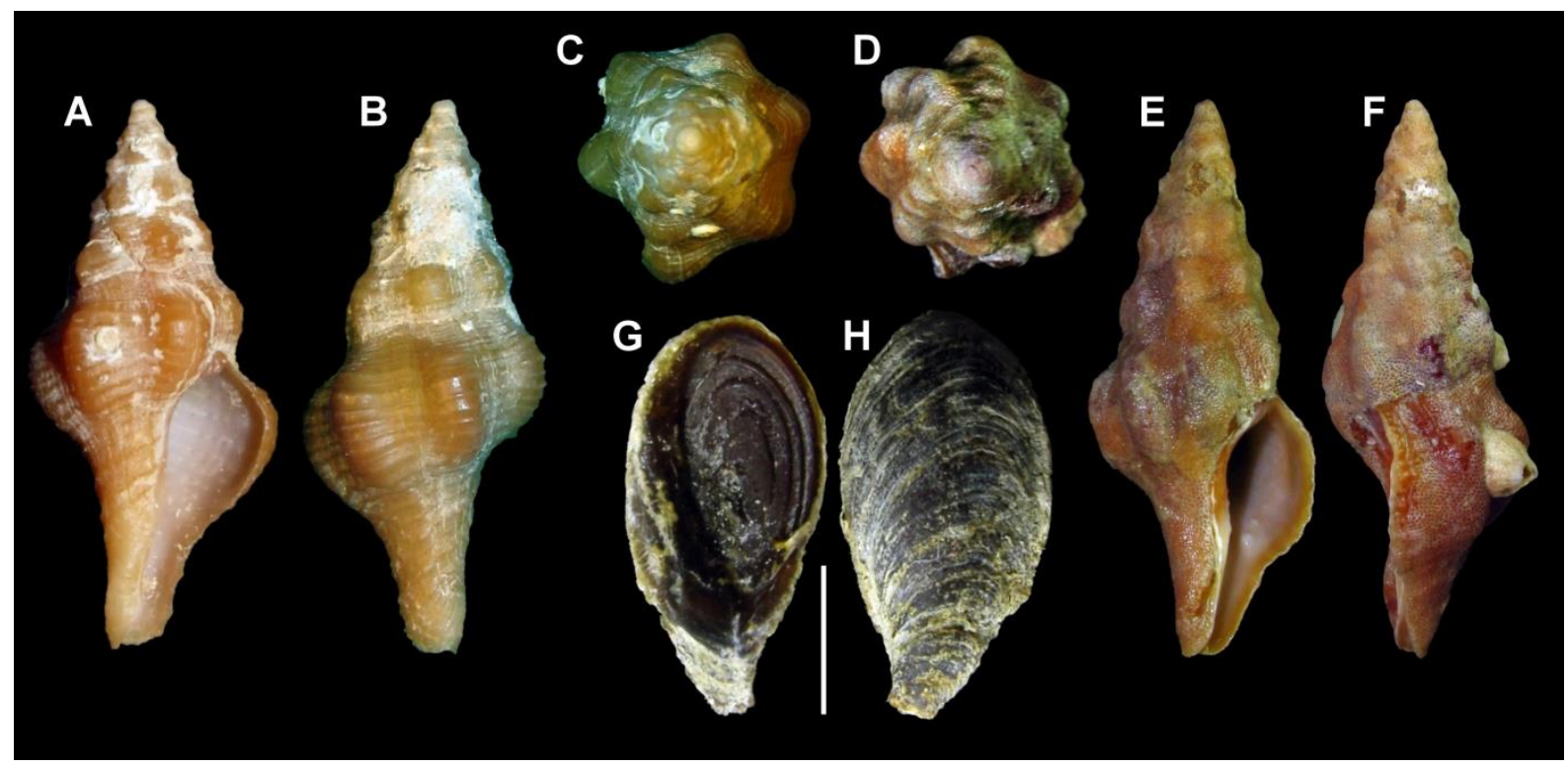

Figure 82. Pustulatirus ogum, shell and operculum. A-C: MZSP 68475 (22.2mm). D-F: MZSP 69301 (39.2mm). G: operculum, inner view. H: operculum, outer view. Scale bars $=3 \mathrm{~mm}$.

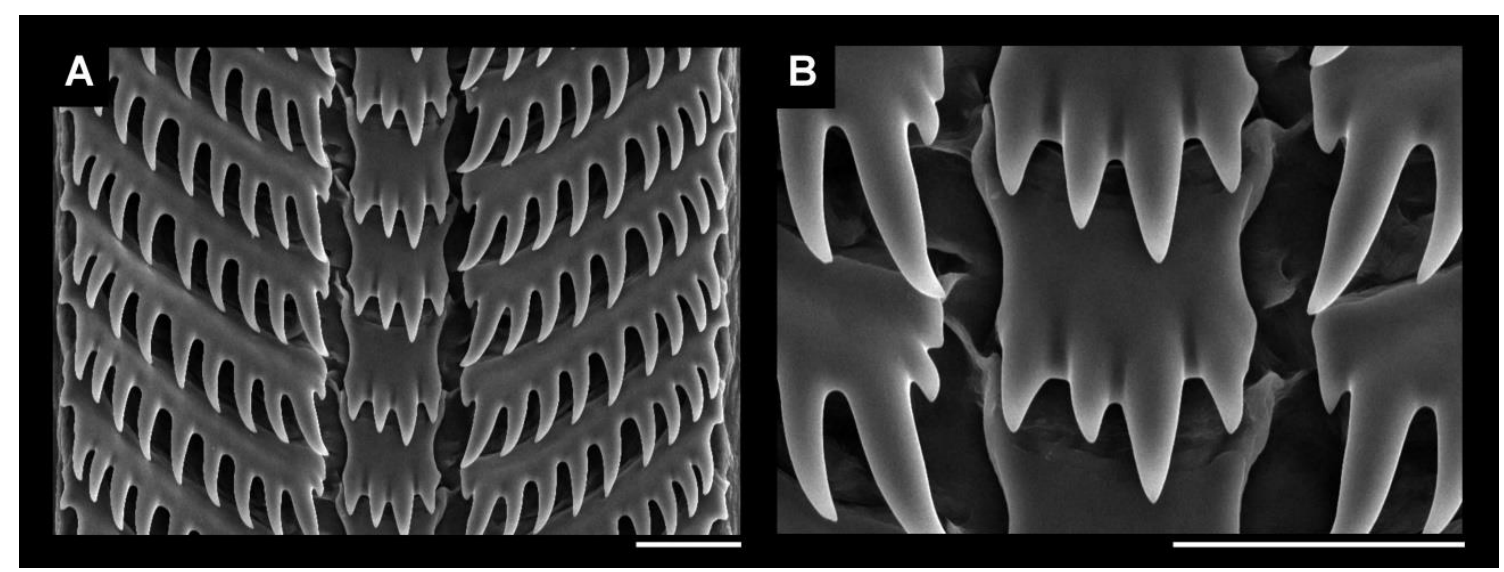

Figure 83. Pustulatirus ogum, radula. A-B: MZSP 69301. A: panoramic view. B: detail of rachidian tooth. Scale bars $=30 \mu \mathrm{m}$.

\section{Pustulatirus ogum (Figs. 82-83)}

Examined material: MZSP 68475, Alcaçoba, Bahia state, Brazil, 20-30m depth Femorale col. vi/2006 [16 specimens]. MZSP 69477, Guarapari, Espírito Santo state, Brazil, 20-30m depth. A. Bodart Femorale col. i/2006 [6 specimens]. MZSP 69301, Arraial do Cabo, Rio de Janeiro State, 30-35m depth. P. Conçalves Femorale col. $\mathrm{i} / 2005$ [2 specimens].

Rhynchostome longitudinal slit (38: 1). Anus situated close to mantle border, its distance from mantle border: total pallial cavity length <1/3 (77: 0). Duct of penis linear shape (87: 0). 


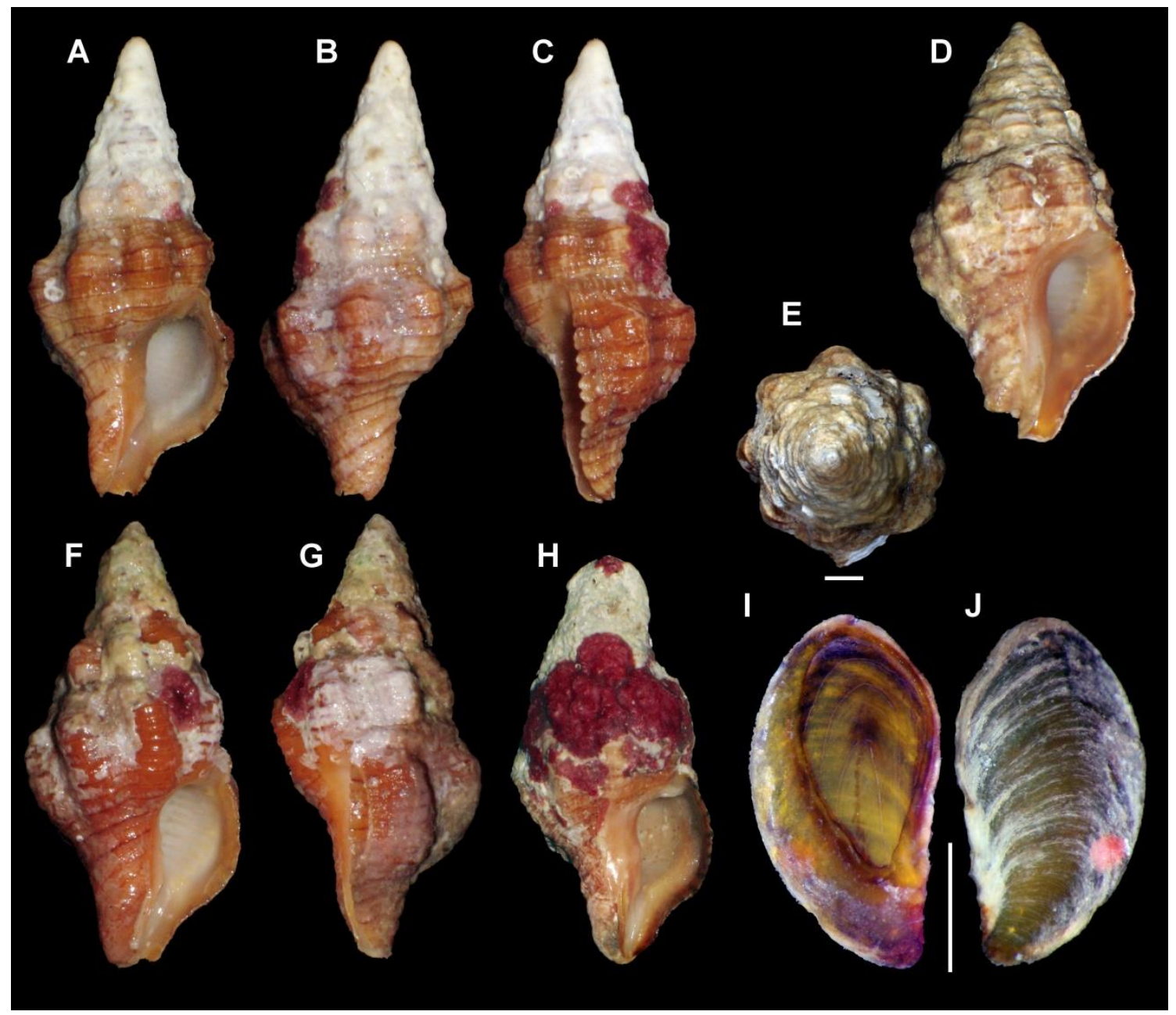

Figure 84. Polygona angulata, shell and operculum. A-C: MZSP 90047 (23.3mm). D-E: MZSP 31125 (18.7mm). F-G: MZSP 90774 (24.5mm). H: MZSP 112907 (29mm). I: operculum, inner view. J: operculum, outer view. Scale bars $=2 \mathrm{~mm}$. 


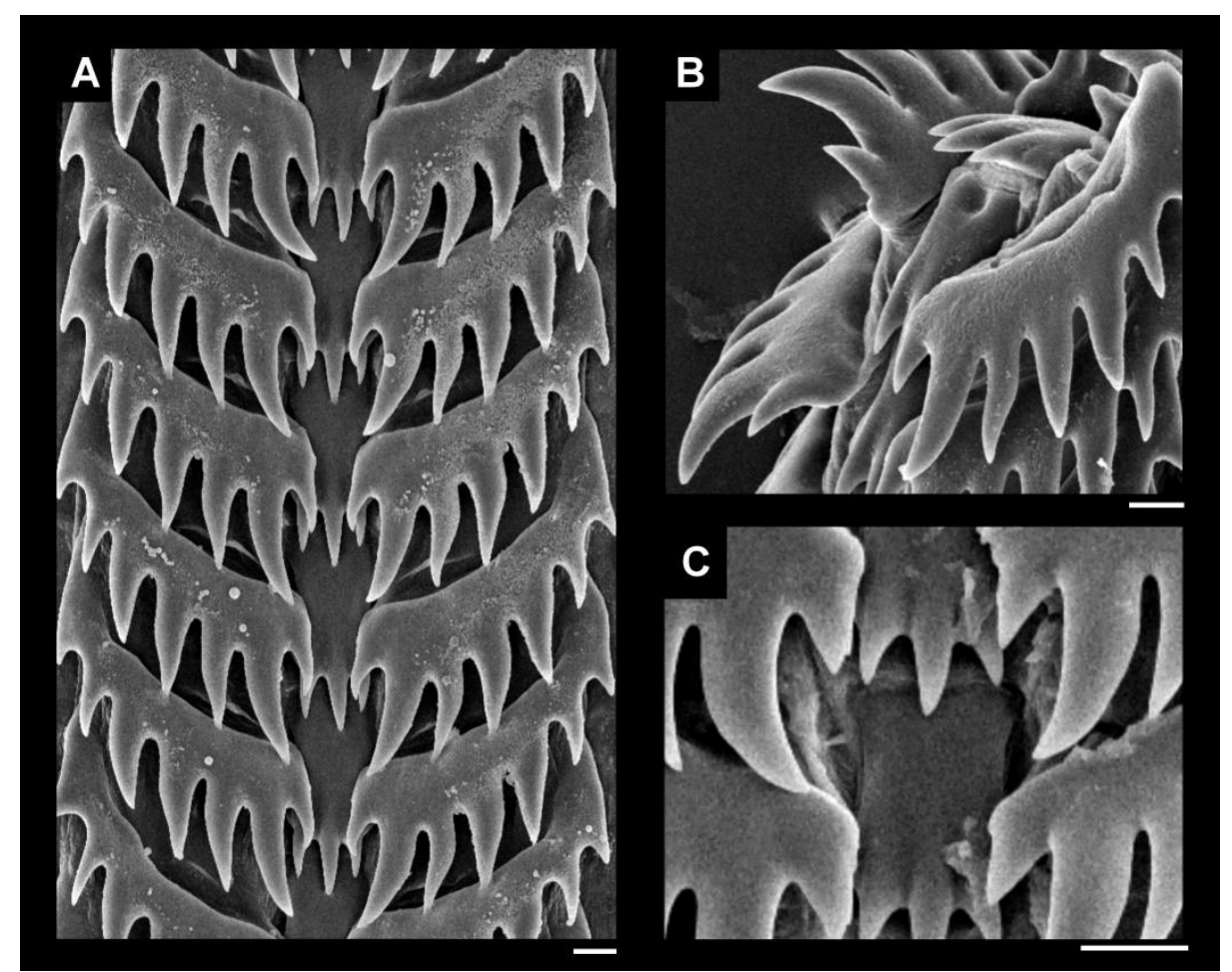

Figure 85. Polygona angulata, radula. A-B: MZSP 112907. A: panoramic view. B: detail of lateral tooth. C: MZSP 90774, detail of rachidian tooth. Scale bars $=10 \mu \mathrm{m}$.

\section{Clade 9}

Loss of lipped margin of renal aperture (34: 0).

\section{Polygona angulata (Figs 84-85)}

Examined material: MZSP 31125, Fernando de Noronha Archipelago, Pernambuco state, Brazil. L.R.L. Simone \& Souza col. vii/19/1999 [4 specimens]. MZSP 112907, Fernando de Noronha Archipelago, Pernambuco state, Brazil, 0349'44"S; 32²3'52"W. L.R.L. Simone cols. v/04/2013 [1 specimen]. MZSP 90774, Fernando de Noronha Archipelago, Pernambuco state, Brazil, 0349'48"S; 3223'57,3"W. L.R.L. Simone \& Cunha col. iii/11/2009 [2 specimens]; MZSP 112826, Fernando de Noronha Archipelago, Pernambuco state, Brazil, 5-10m depth, 0348'42"S; 32²3'45,18"W. L.R.L. Simone col. v/03/2013 [6 specimens]. MZSP 90047, Fernando de Noronha Archipelago, Pernambuco state, Brazil. L.R.L. Simone col. iii/10/2009 [2 specimens].

Anus located close to mantle border, its distance from mantle border: total pallial cavity length $<1 / 3$ (77: 0). Bursa copulatrix bearing anterior muscular bulb, close to gonopore (81: 1). 


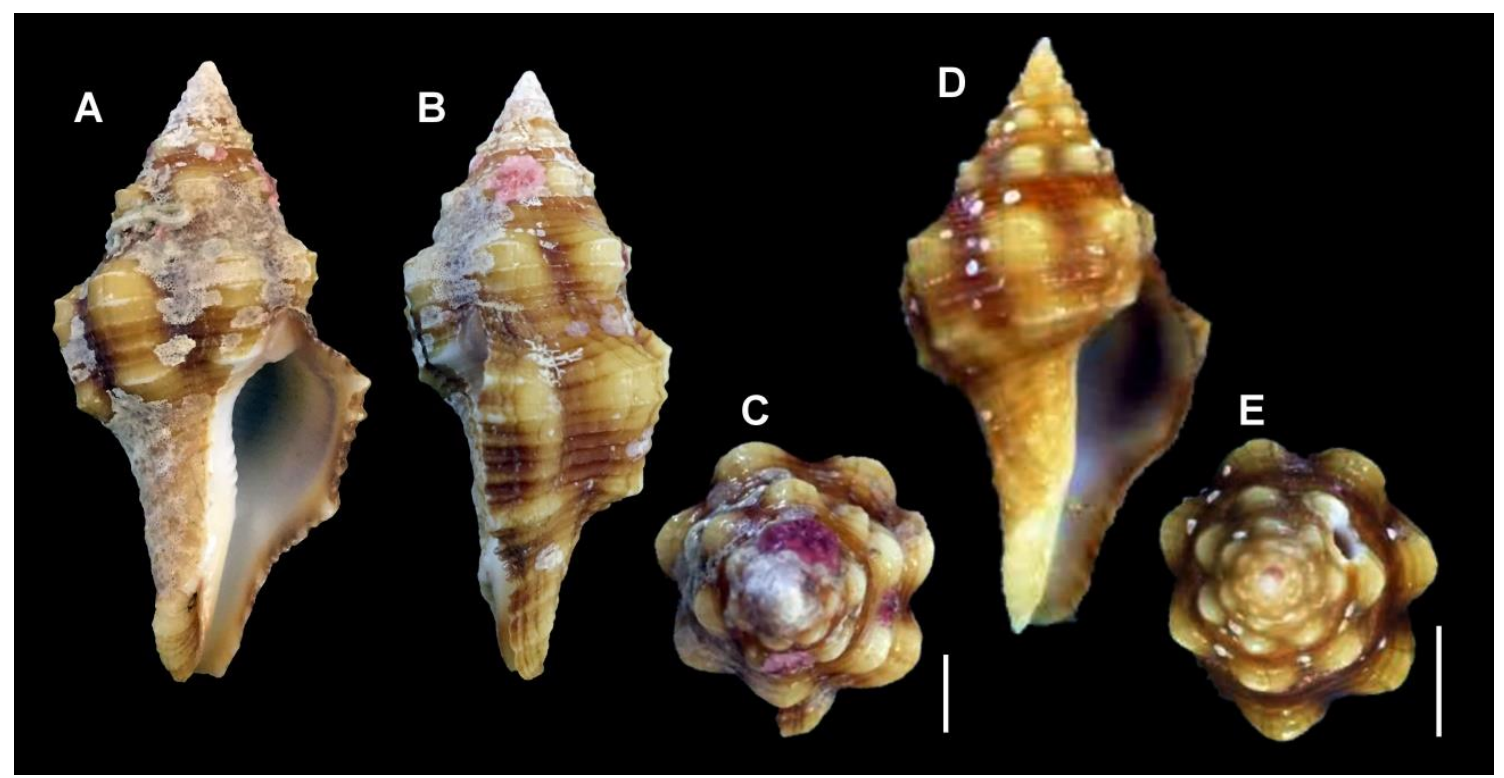

Figure 86. Latirus polygonus, shell. A-C: MZSP 71428 (65mm). D-E: MZSP 71869 (37.9mm). Scale bars $=1 \mathrm{~mm}$.

\section{Clade 10}

Kidney nephridial gland present in membrane between renal cavity and pericardium (35: 1).

\section{Latirus polygonus (Fig. 86)}

Examined material: MZSP 71428, Natandola Bay, west Sigatoka, Viti-Levu, Fiji. Coltro col. ix/06/2006 [1 specimen]. MZSP 71869, Viti-Levu, Fiji. C Henckes col. ix/10/2006 [1 specimen].

Odontophore fused anteriorly $\leq 15 \%$ of total odontophore length (44: 1). Rachidian tooth of radula diminute, its width: lateral tooth width $<1 / 4$ (53: 3); lateral tooth much wider than long, its length: width $<1 / 3(55: 4)$.

\section{Clade 11}

Head diminute, its width: head-foot mass width <1/4 (13: 0), bearing very short cephalic tentacles, its length: head width $<1 / 2(14: 0)$. 


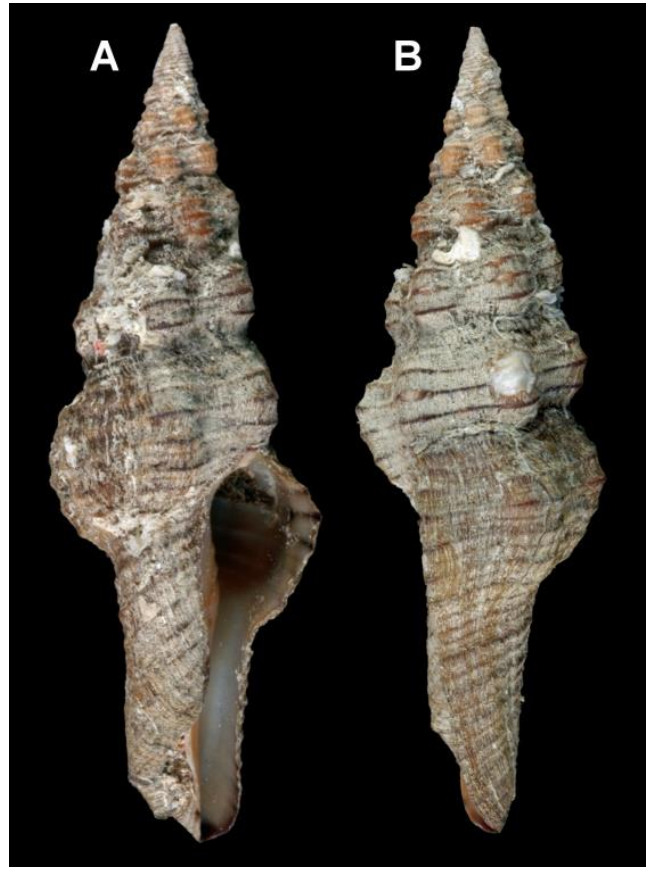

Figure 87. Polygona infundibulum, shell. A-B: MNHN IM-2013-19591 (66.5mm).

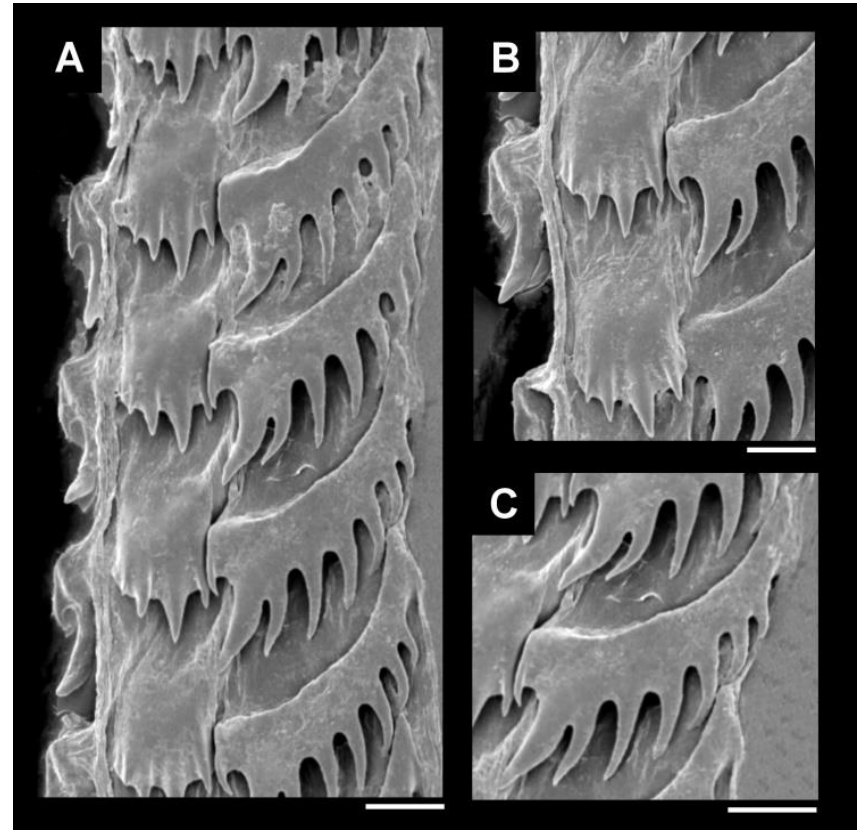

Figure 88. Polygona infundibulum, radula. A-C: MNHN IM-2013-19591. A: panoramic view. B: detail of rachidian tooth. $\mathbf{C}$ : detail of lateral tooth. Scale bars $=$ $20 \mu \mathrm{m}$.

\section{Polygona infundibulum (Figs. 87-88)}

Examined material: MNHN IM-2013-19591, Guadeloupe, 16²2'47.8812"N; 61³3'26.5212"W. KURUBENTHOS expedition. v/18/2012 [1 specimen].

Rhynchostome located longitudinally (38: 1). Rachidian teeth of radula bearing minute, secondary cusps (52:1).

\section{Clade 12}

Proboscis retractor muscle inserting posteriorly (68: 0). Commissure of buccal ganglia conspicuous (93: 0). 


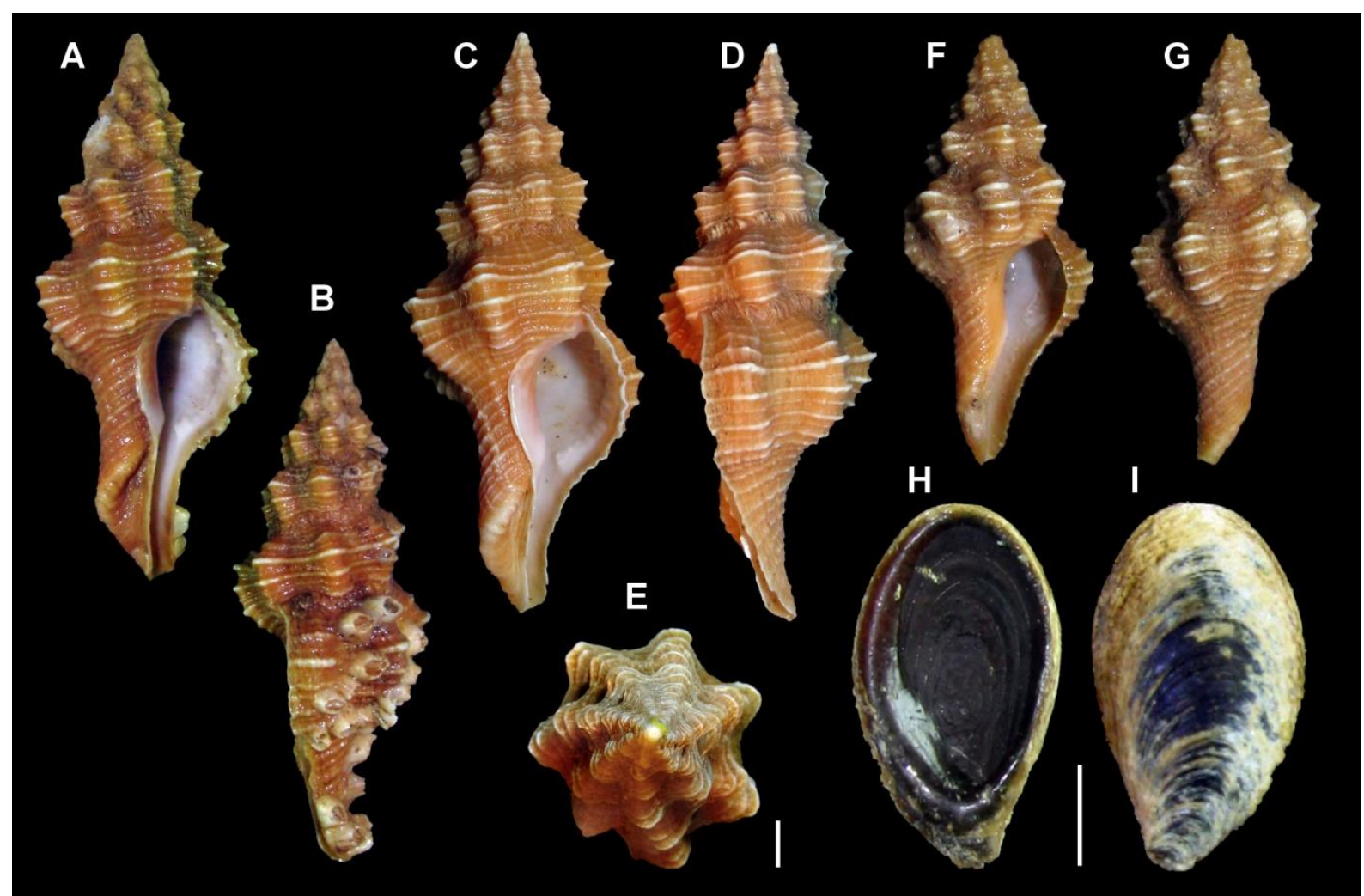

Figure 89. Hemipolygona beckyae, shell and operculum. A-B: MZSP 69764 (55.4mm). C-E: MZSP 57053 (52.4mm). F-G: MZSP 69482 (32.8mm). H: operculum, inner view. I: operculum, outer view. Scale bars = $3 \mathrm{~mm}$.

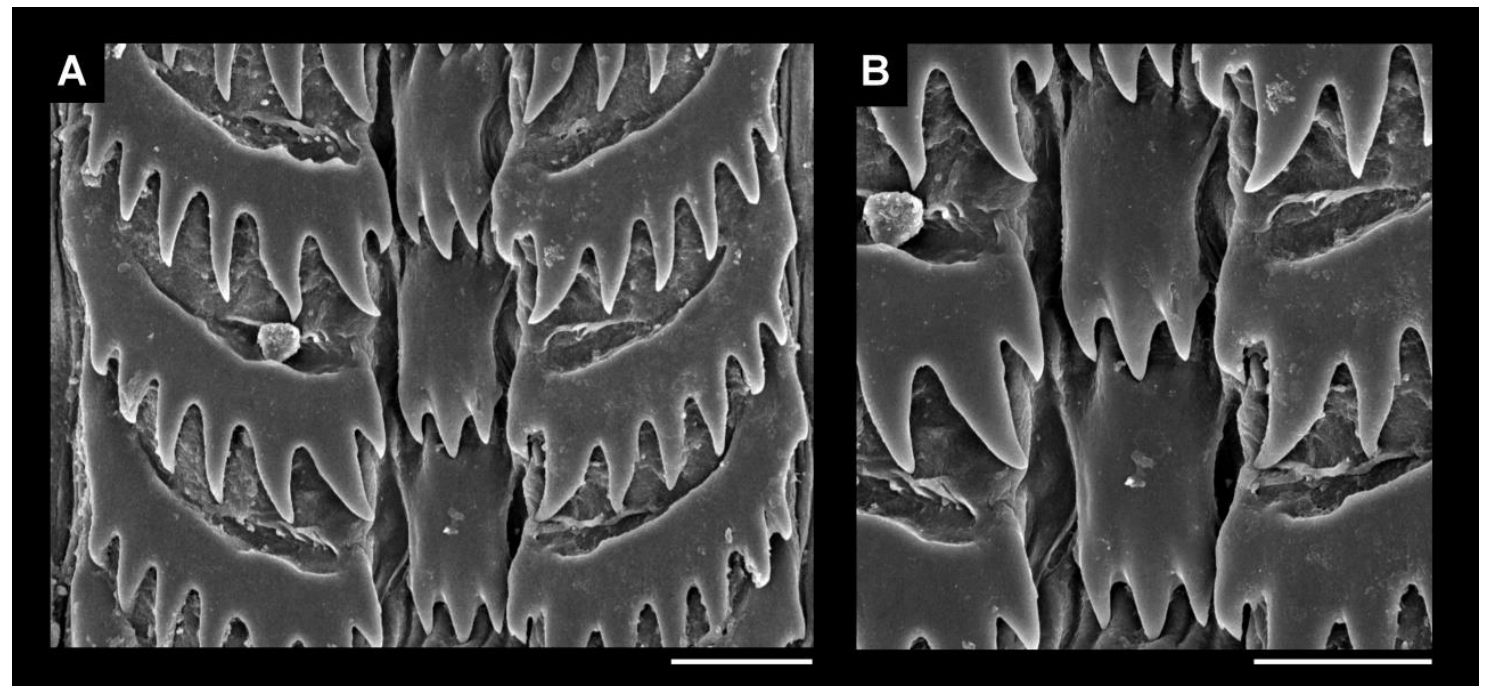

Figure 90. Hemipolygona beckyae, radula. A-B: MZSP 57053. A: panoramic view. B: detail of rachidian tooth. Scale bars $=30 \mu \mathrm{m}$. 


\section{Hemipolygona beckyae (figs. 89-90)}

Examined material: MNRJ 7696, Vitória, Espírito Santo state, Brazil, 30-50m depth. v/1994 [1 specimen, holotype]. MZSP 69482, Vitória, Espírito Santo state, Brazil, 30-35m depth. Femorale col. viii/2003 [3 specimens]. MZSP 57053, Guarapari, Espírito Santo state, Brazil. Coltro col. 2005 [1 specimen]. MZSP 69764, Espírito Santo state, Brazil, 30-35m depth. Femorale col. viii/2000 [1 specimen].

Rhynchostome positioned obliquely between cephalic tentacles (38:2).

\section{Clade 13}

Anus sited close to mantle, distance to mantle border: total pallial cavity length $<1 / 3$ (77: 0).

\section{Latirus pictus (Figs. 91-92)}

Examined material: MNHN IM-2013-10540, Kranket Island, Papua New Guinea,

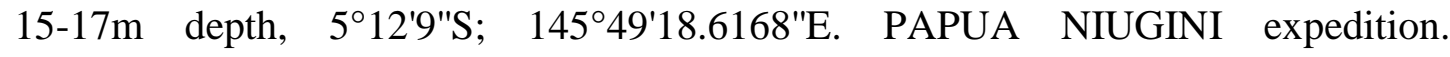
xi/06/2012 [1 specimen].

Margin of renal aperture emarginated by lipped rim (34: 1). Rachidian tooth of radula diminute, its width: lateral tooth width $<1 / 4$ (53: 3$)$.

\section{Clade 14 Leucozonia and Opeatostoma}

Ctenidium ample, its width: osphradium width $\geq 1.5$ (28: 2). Loss of longitudinal folds in margin of rhynchostome (39: 0). Odontophore long, its length: proboscis length 1 (42: 0). Cusp 1 of lateral tooth of radula absent (60: 2), cusp $2 \sim$ twice as other cusps (61: 1).

\section{Clade 14a Leucozonia ocellata, L. cerata and Opeatostoma pseudodon}

Margin of siphon bearing many longitudinal folds (30: 1). Rhynchostome distanced longitudinally from cephalic tentacles, not adjacent to them (37: 1), non-lipped (40: 1). Odontophore $\mathrm{m} 6$ muscle posterior free portion: odontophore length $\leq 1 / 6$ (45: 1). Female cement gland opening centrally in foot sole (84: 0). Duct of penis linear (87: 0). 

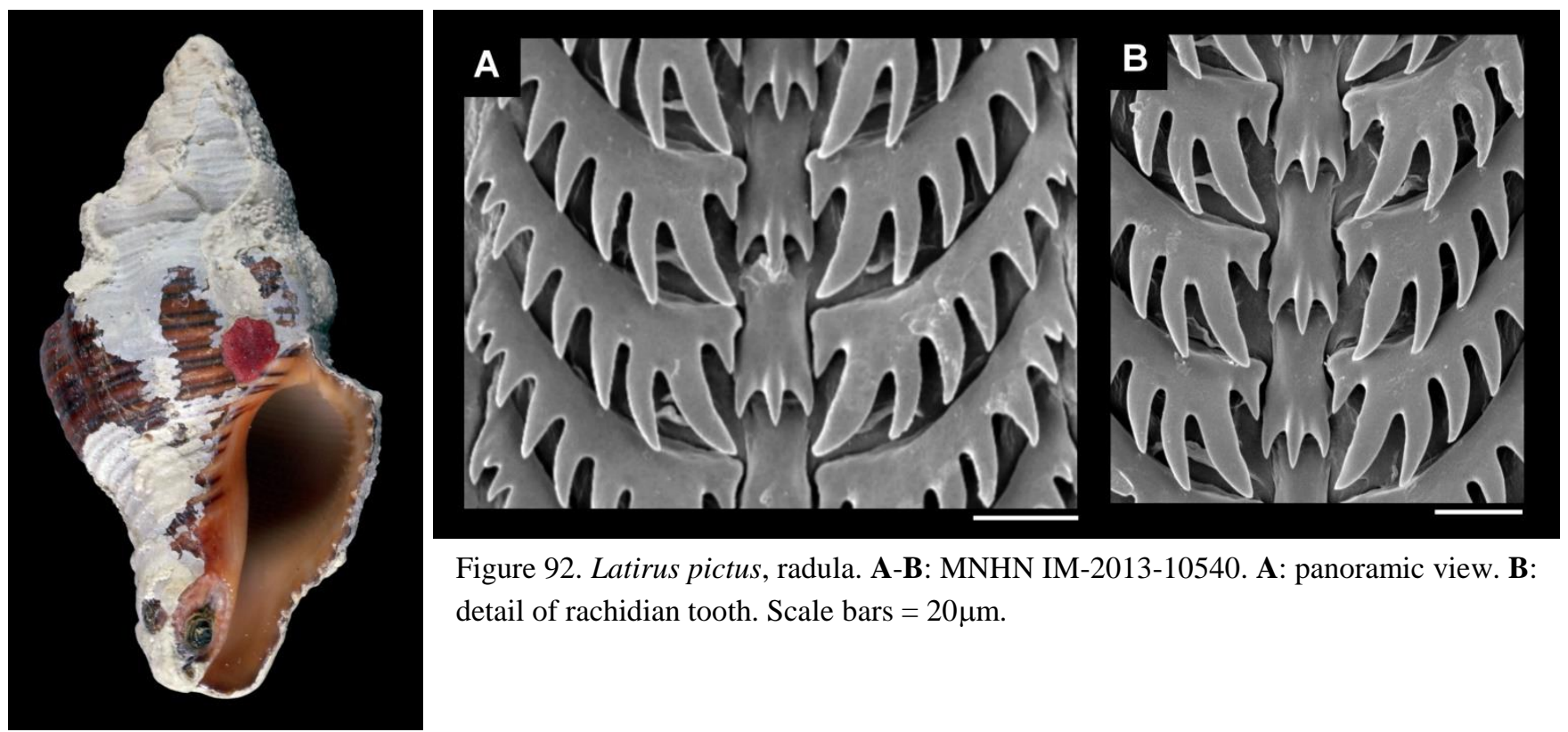

Figure 92. Latirus pictus, radula. A-B: MNHN IM-2013-10540. A: panoramic view. B: detail of rachidian tooth. Scale bars $=20 \mu \mathrm{m}$.

Figure 91. Latirus pictus, shell. MNHN IM-2013-10540 (66mm).

\section{Leucozonia ocellata (Figs. 93-94)}

Examined material: MNRJ 11174, Rasa Island, Fernando de Noronha Archipelago, Pernambuco state, Brazil. P.M.S. Costa col. vii/10/1999 [1 specimen]. MNRJ 11200, Fernando de Noronha Archipelago, Pernambuco state, Brazil. P.M.S. Costa col. vii/09/1999 [1 specimen]. MNRJ 4276, Atol das Rocas, Pernambuco state, Brazil. J.H.Leal, G.W.Nunam, C.B. Castro, D.F. Moraes. col. ii-iii/1982 [10 specimens]. MNRJ 5357, Itapoã Beach, Salvador state, Brazil. P. Jurberg col. vii/11/1980 [4 specimens]. MNRJ 12963, Santa Bárbara Island, Abrolhos Archipelago, Bahia state, Brazil. A.L. Castro, J. Becker, P. Jurberg \& A. Coelho col. ix/1968 [35 specimens]. MNRJ 10735, Santa Bárbara Island, Abrolhos Archipelago, Bahia state, Brazil. A.L. Castro, J. Becker, P. Jurberg \& A. Coelho col. ix/1969 [11 specimens]. MNRJ 14223, Rio de Janeiro state, Brazil. L.R. Tostes col. iii/1975 [1 specimen]. MNRJ 10736, Prainha Beach, Arraial do Cabo, Rio de Janeiro state, Brazil. A.L. Castro, J. Becker, P. Jurberg \& E.A. Coelho col. ix/1969 [1 specimen].

Osphradium heavily asymmetrical (23: 2). Rachidian tooth of radula bearing 5-6 cusps (58: 1); cusp 2 bearing secondary inner cusp (62: 1). Loss of seminal receptacle in pallial oviduct (78: 0). (84: 1). Female cement gland opening anteriorly in foot (84: 1). Commissure of buccal ganglia inconspicuous (93:1). 


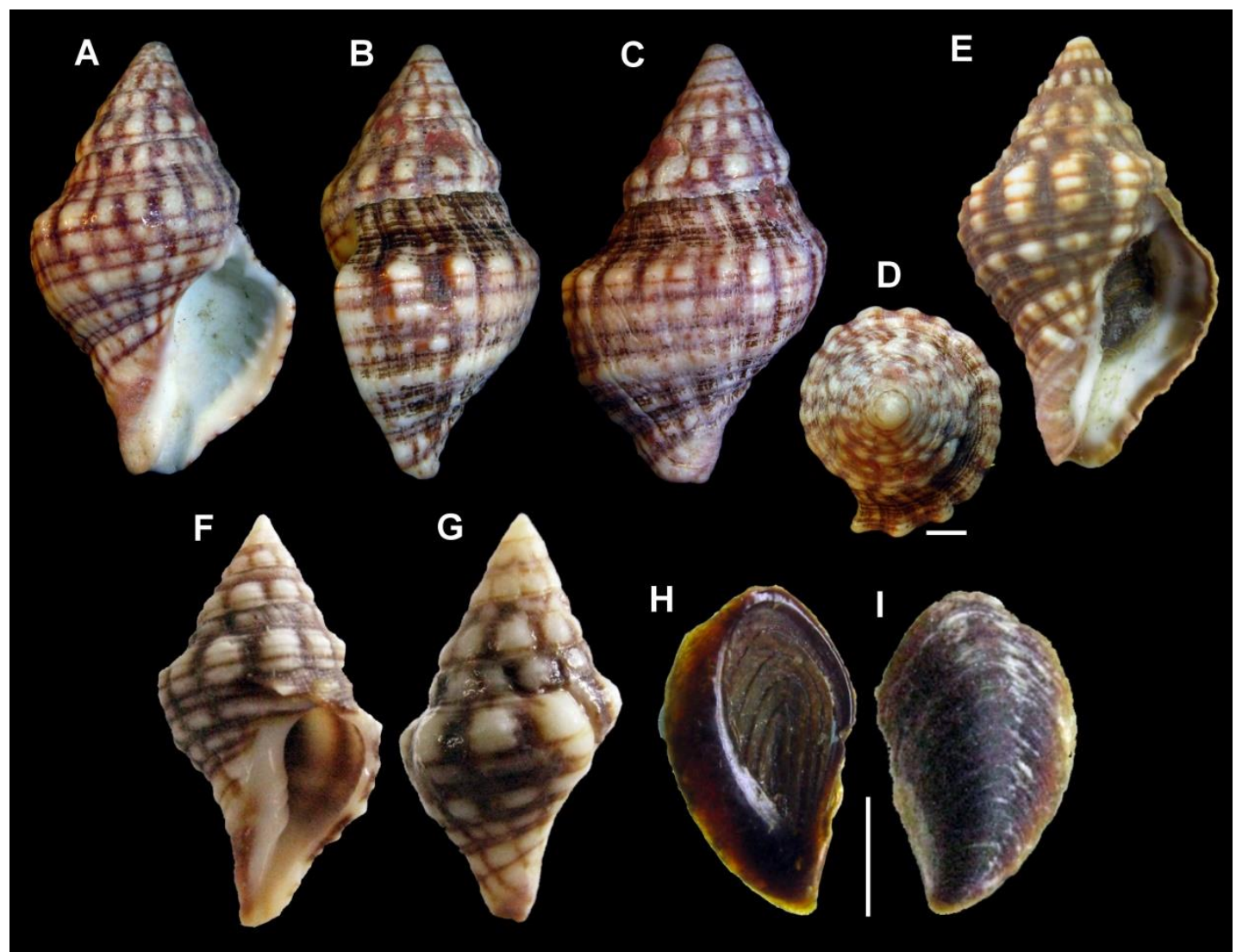

Figure 93. Leucozonia ocellata, shell and operculum. A-D: MNRJ 5357 (35.9mm). E: MNRJ 14223 (22.1mm). F-G: MNRJ 10735 (17mm). H: operculum, inner view. I: operculum, outer view. Scale bars $=3 \mathrm{~mm}$.

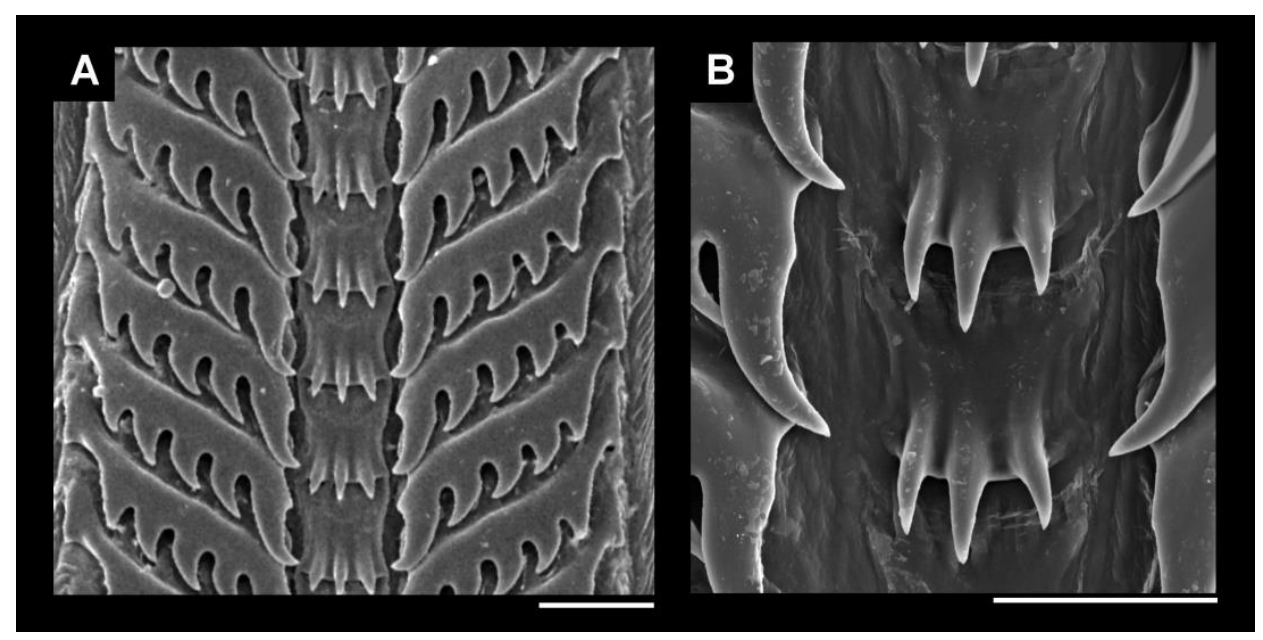

Figure 94. Leucozonia ocellata, radula. A-B: MNRJ 10735. A: panoramic view. B: detail of rachidian tooth. Scale bars $=50 \mu \mathrm{m}$. 


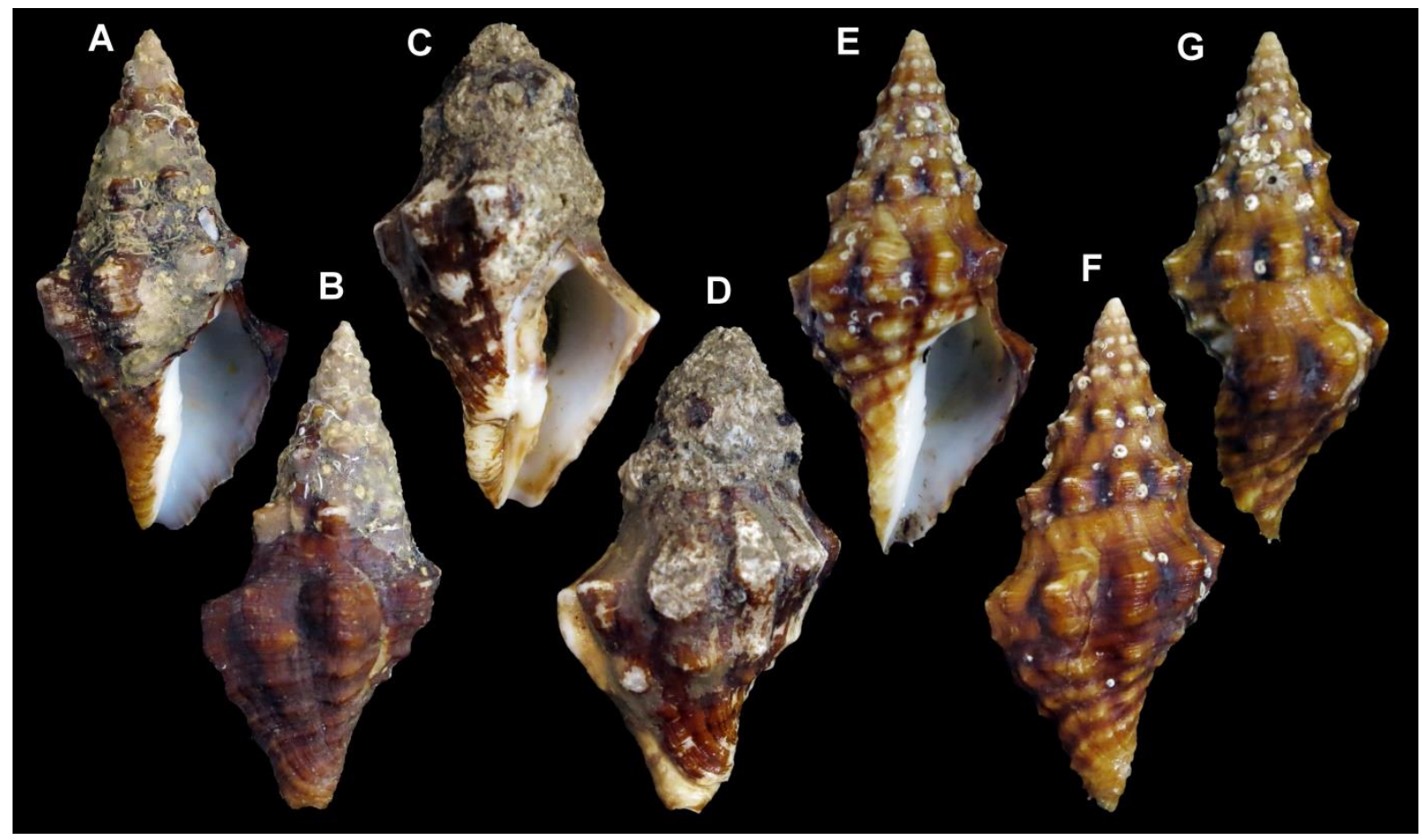

Figure 95. Leucozonia cerata, shell. A-B: MZSP 64252 (57.5mm). C-D: MZSP 64210 (62.1mm). E-G: MZSP 95287 (49.mm).

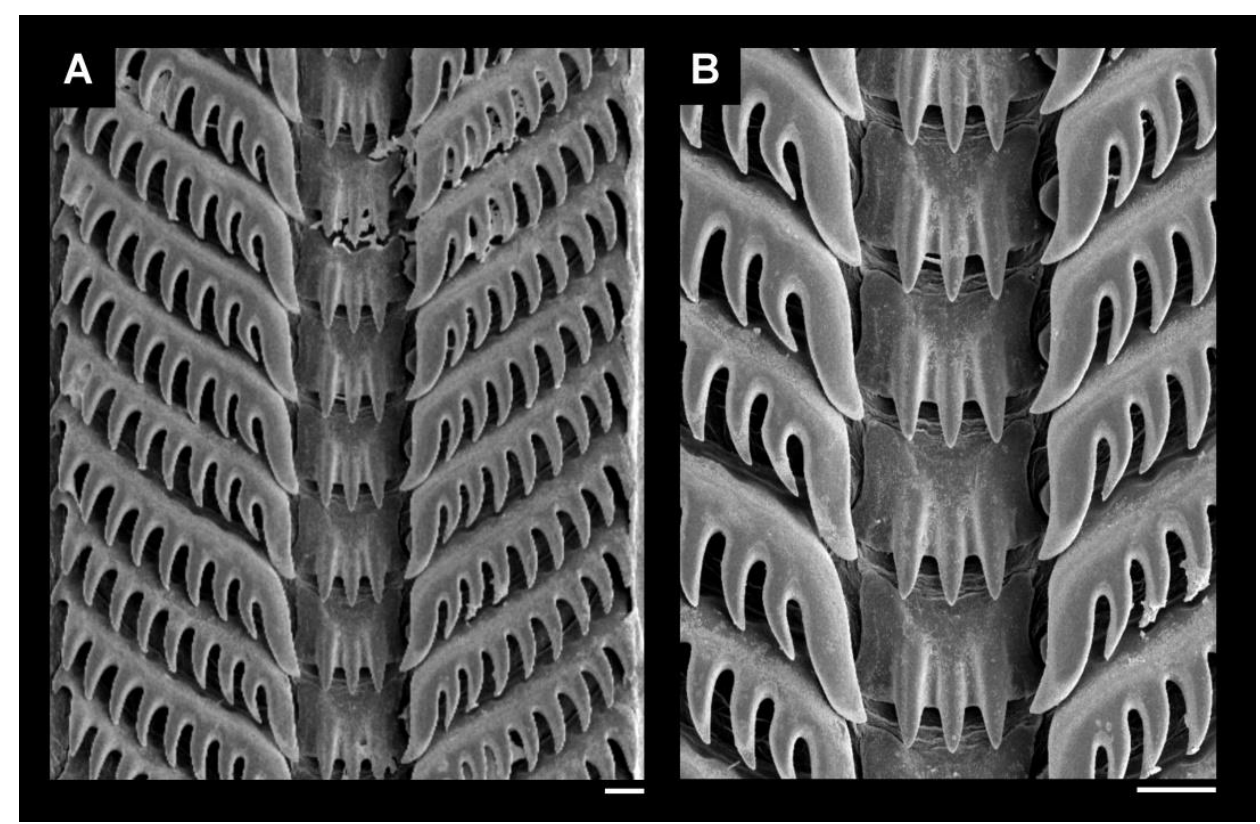

Figure 96. Leucozonia cerata, radula. A-B: MZSP 64252. A: panoramic view. B: detail of rachidian tooth. Scale bars $=30 \mu \mathrm{m}$. 


\section{Leucozonia cerata (Figs. 95-96)}

Examined material: MZSP 64252, Venedo Island, Panama. L.R.L. Simone col. i/30/2006 [2 specimens]. MZSP 64210, Venedo Island, Panama. L.R.L. Simone col. i/30/2006 [2 specimens]. MZSP 95287, Ecuador. J. Coltro col. 2009 [8 specimens].

Nephridial gland present in membrane between renal cavity and pericardium (35: 1). Odontophore fused anteriorly $\leq 15 \%$ of total odontophore length (44: 1). Buccal ganglia commissure long, its length: buccal ganglia length $\geq 1 / 2$ (94: 1).

\section{Opeatostoma pseudodon (Figs. 97-98)}

Examined material: MZSP 64204, Venedo Island, Panama. L.R.L. Simone col. i/30/2006 [6 specimens]. MZSP 67764, la de la Plata, Manabi, Ecuador. J. Coltro col. vi/2006 [3 specimens]. MZSP 68483, Isla Salango, Manabi, Ecuador. J. Coltro col. vii/2006 [3 specimens].

Loss of spiral sculpture of shell (3: 0). Labral tooth present in outer lip covered by mantle (5: 1) as a sharp ventrally pointed tooth. Osphradium leaflets low, its height: height of ctenidium $<1 / 2$ (26: 0). Loss of longitudinal folds in margin of siphon (30: 0). Margin of renal aperture emarginated by lipped rim (34: 1). Loss of nephridial gland in membrane between renal cavity and pericardium (35: 0). Renal aperture situated close to pericardium (36: 1). Rhynchostome longitudinally adjacent to cephalic tentacles (37: 0). Odontophore medium-sized, its length: proboscis length 1-1/2 (42: 1). Rachidian tooth of radula may bear $\geq 5$ cusps (51: 4). Posterior esophagus bearing sudden broadening in visceral region (74: 1), anterior to stomach. Penis ejaculatory duct as long convoluted tube immersed in haemocoel (89: 1).

\section{Clade 14b "Leucozonia nassa complex"}

Labral tooth may be present in outer lip, not covered by mantle as a blunt, short, ventral tooth. (5: 2). Head medium-sized, its width: head-foot mass width 1/4-1/2 (13: 1), bearing short cephalic tentacles, its length: head width 1/2-2/3 (14: 1). Pallial cavity long, its extension $\geq 3 / 4$ whorls (19: 1). Cusp of 2 lateral tooth of radula bearing secondary inner cusp (62: 1). Seminal receptacle in pallial oviduct present (78: 0). Bursa copulatrix short, its length: oviduct length <1/4 (80: 0). 


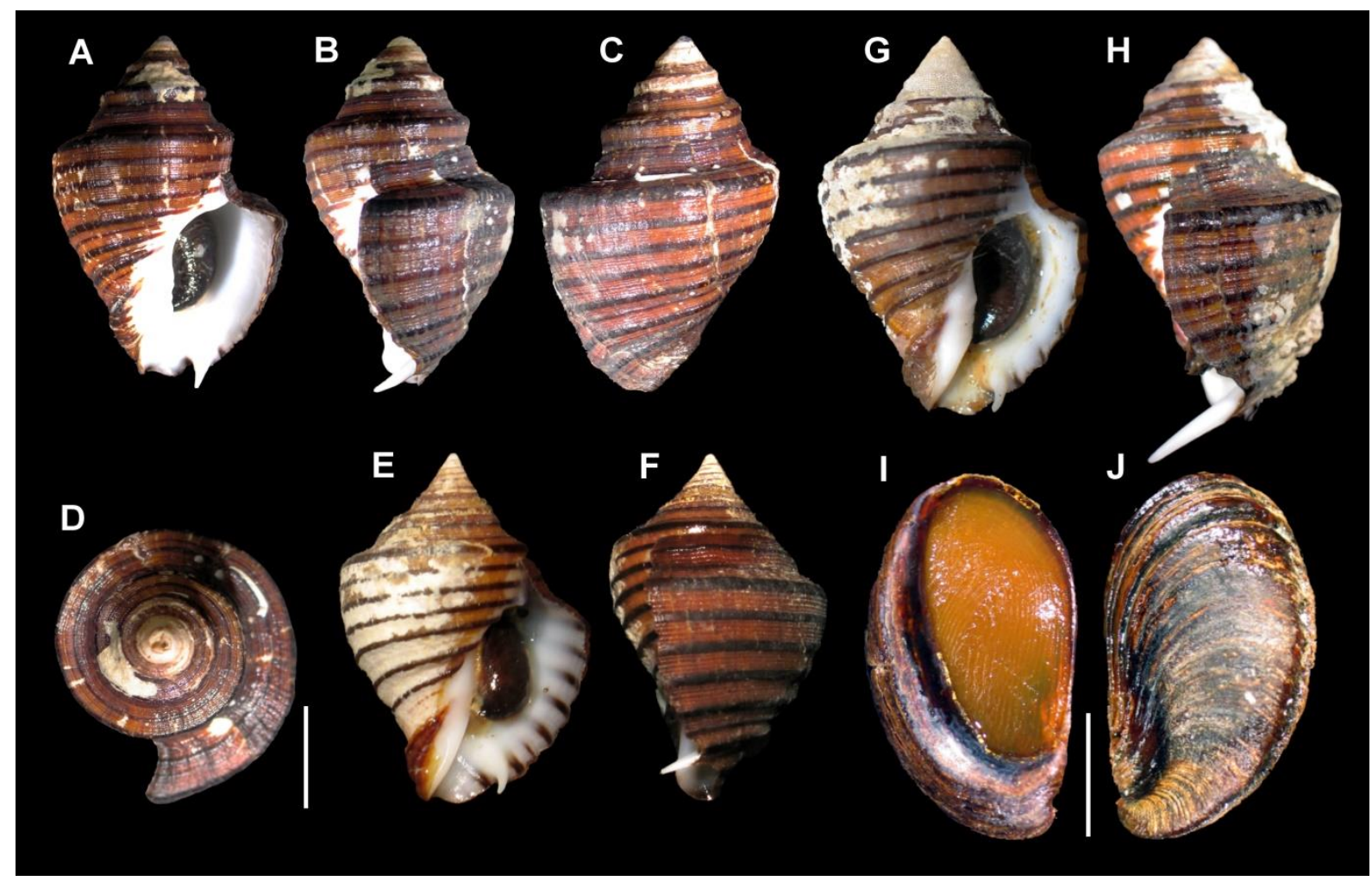

Figure 97. Opeatostoma pseudodon, shell and operculum. A-D: MZSP 64204 (54.3mm). E-F: MZSP 67764 (28.3mm). G-H: MZSP 68483 (65.7mm). I: operculum, inner view. J: operculum, outer view. Scale bars $=10 \mathrm{~mm}$.

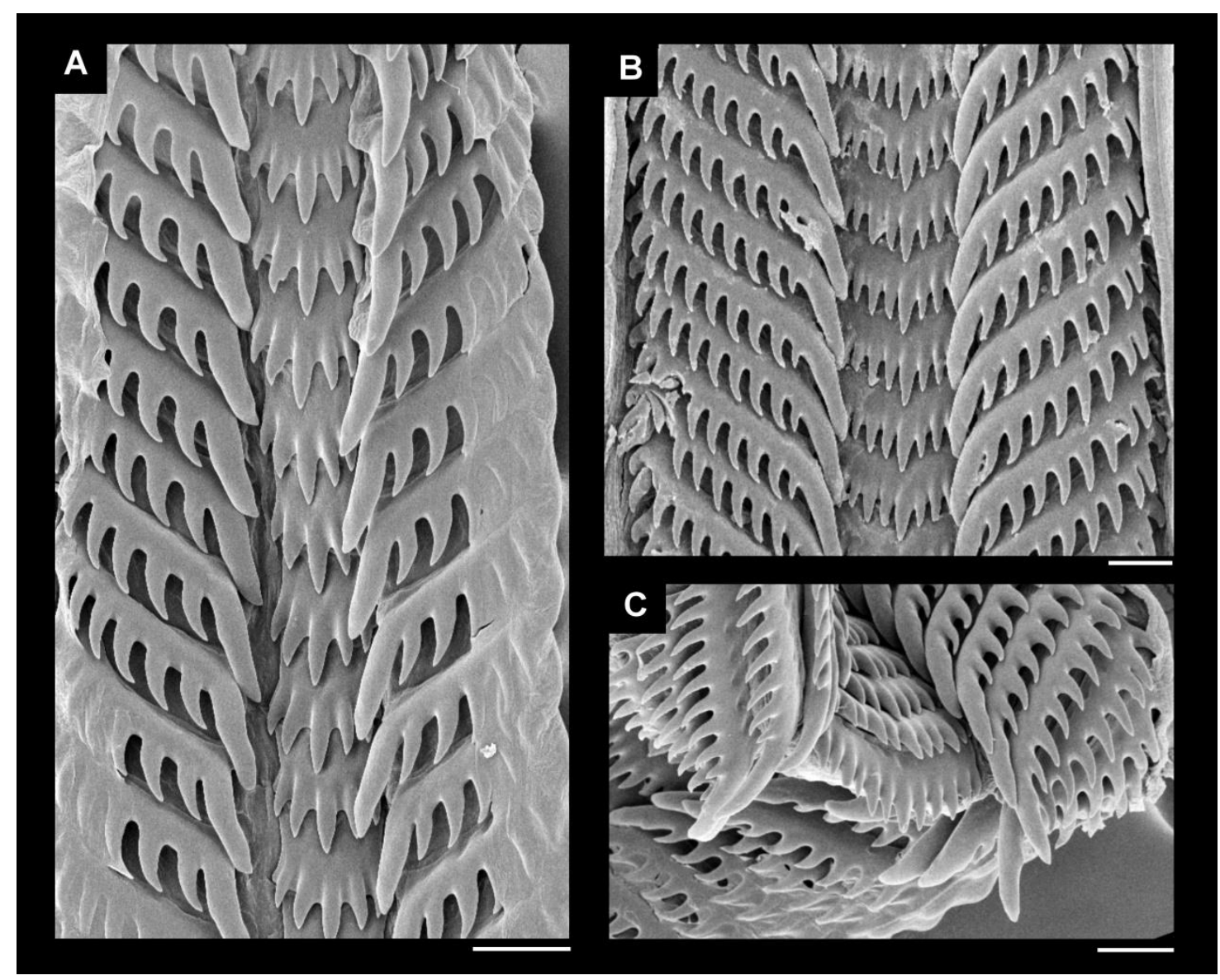

Figure 98. Opeatostoma pseudodon, radula. A-C: MZSP 68483. A: panoramic view, male. B: panoramic view, female. $\mathbf{C}$ : detail of rachidian tooth, female. Scale bars $=50 \mu \mathrm{m}$. 


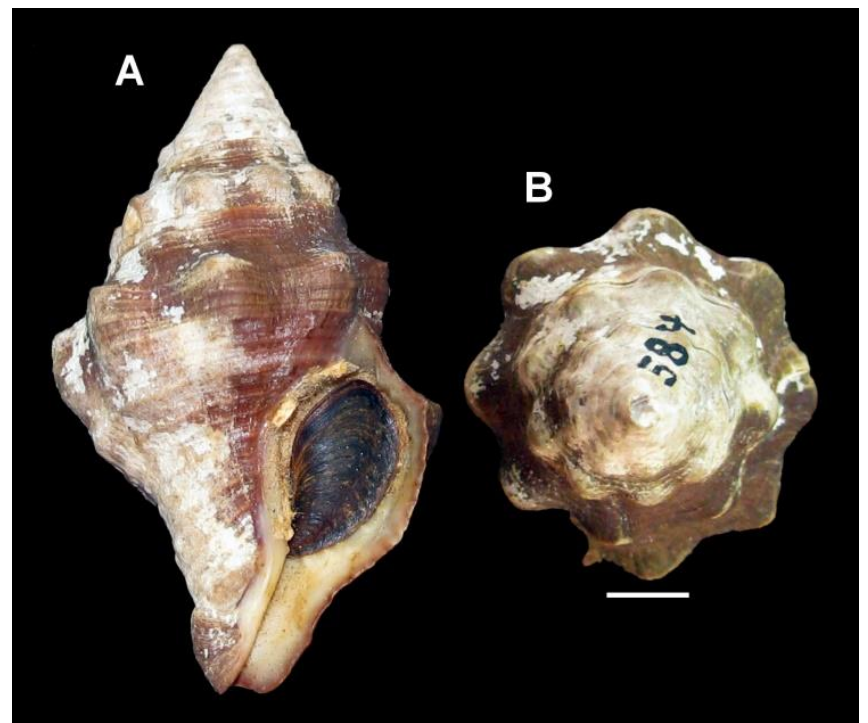

Figure 99. Leucozonia nassa nassa, shell. A-B: MNRJ $584(36 \mathrm{~mm})$. Scale bars $=5 \mathrm{~mm}$.

\section{Leucozonia nassa nassa (Figs. 99)}

Examined material: MNRJ 584, Marathon Key, Florida, USA. Mata col. iii/1951 [2 specimens]

No known autapomorphies.

\section{Leuczonia nassa cingulifera (Fig. 100)}

Examined material: MNRJ 14848, Itapuã, Salvador, Bahia state, Brazil. D. Mendonça col. xi/1964 [2 specimens]. MNRJ 10710, Tamandaré Bay, Pernambuco state, Brazil. S. Ypiranga col. xii/1962 [7 specimens]. MNRJ 11065, Fernando de Noronha Archipelago, Pernambuco state, Brazil. P.M.S. Costa col. vi/17/2000 [1 specimen]. MNRJ 14485, Trindade Island, Espírito Santo state, Brazil. F. Moraes col. xi/18/2003 [1 specimen].

No known autapomorphies. 


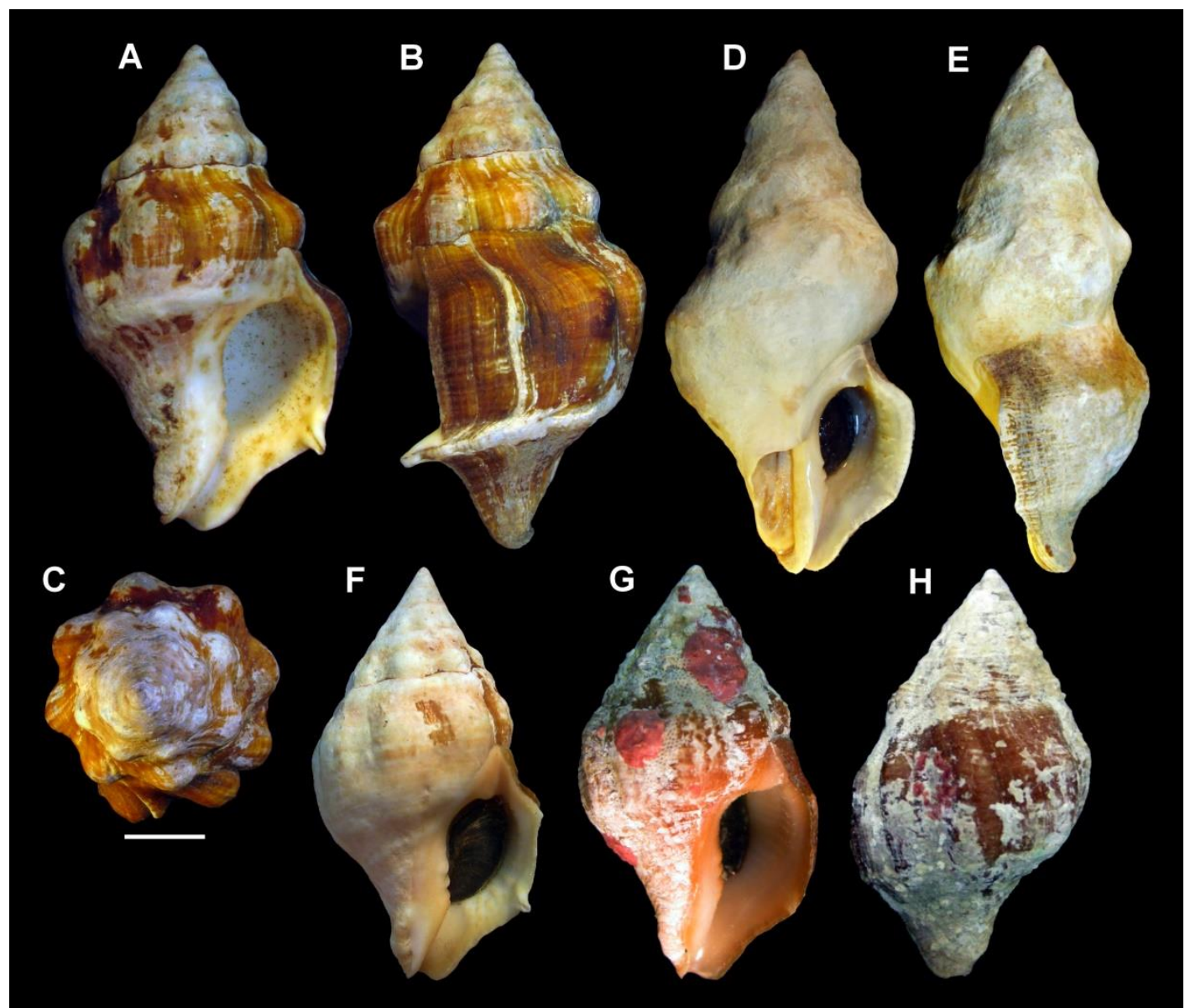

Figure 100. Leucozonia nassa cingulifera, shell. A-C: MNRJ 14848 (57.9mm). D-E: MNRJ 10710 (69.9mm). F: MNRJ 11065 (48.8mm). G-H: MNRJ 14485 (27.4mm). Scale bars $=$ $10 \mathrm{~mm}$.

Leucozonia nassa brasiliana (Figs. 101-102)

Examined material: MNRJ 10993, Japonês Beach, Cabo Frio, Rio de Janeiro state, Brazil. A.D. Pimenta, M.S. Costa, J.B. Alvim \& D.R. Couto col. i/18/2007 [66 specimens]. MZSP 69496, Scalvada Island, Guarapari, Espírito Santo state, Brazil, 12-20m depth. A. Bodart Femorale col. i/2005 [2 specimans]. MZSP 41814, Guarapari, Espírito Santo state, Brazil. Coltro col. 2003 [14 specimens].

No known autapomorphies. 


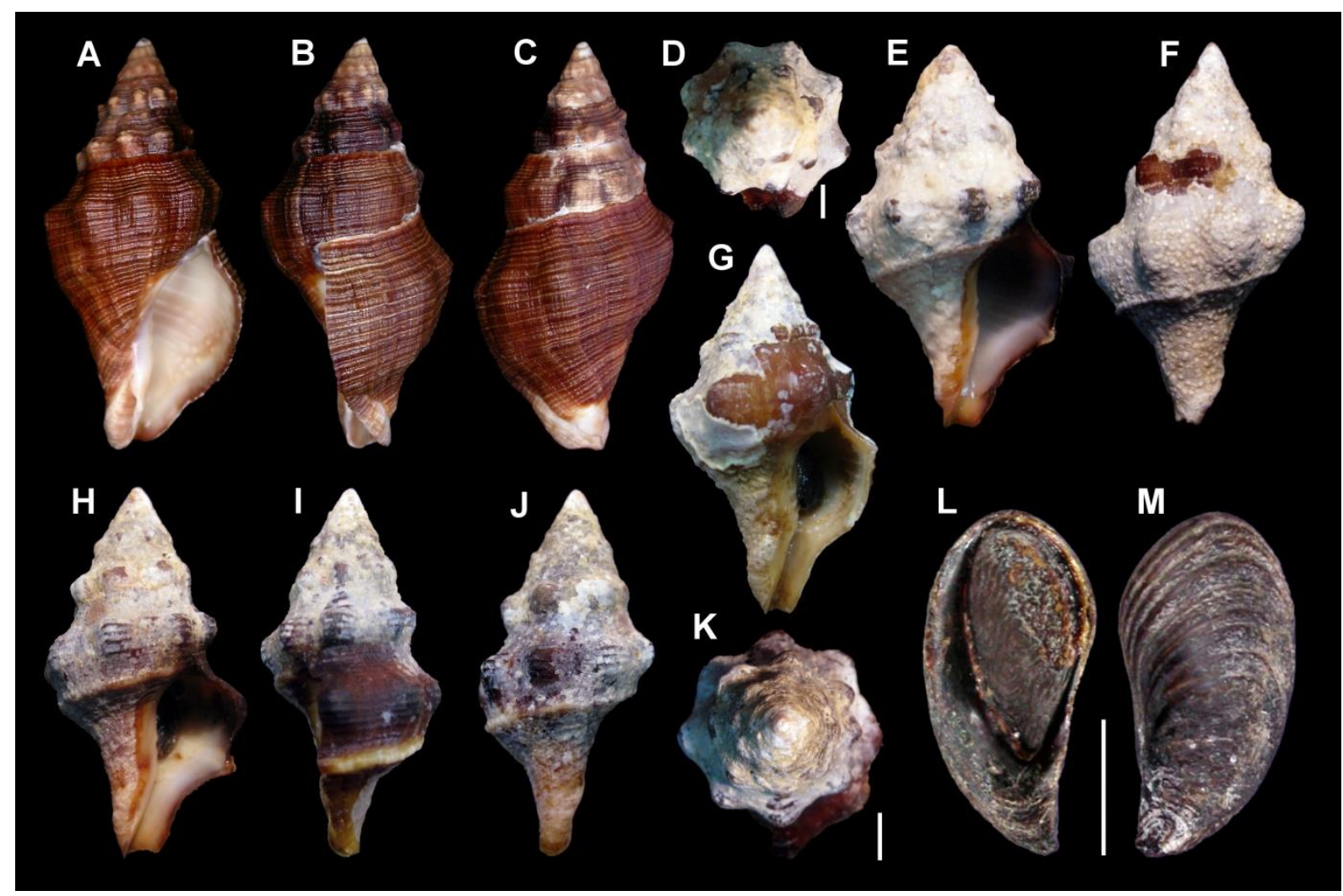

Figure 101. Leucozonia nassa brasiliana, shell. A-C: MNRJ 10993 (55.5mm). D-F: MZSP 69496 (28.1mm). G: MZSP 41814 (29.3mm). H-K: MZSP 69496 (34.5mm). L: operculum, inner view. M: operculum, outer view. Scale bars $=3 \mathrm{~mm}$.

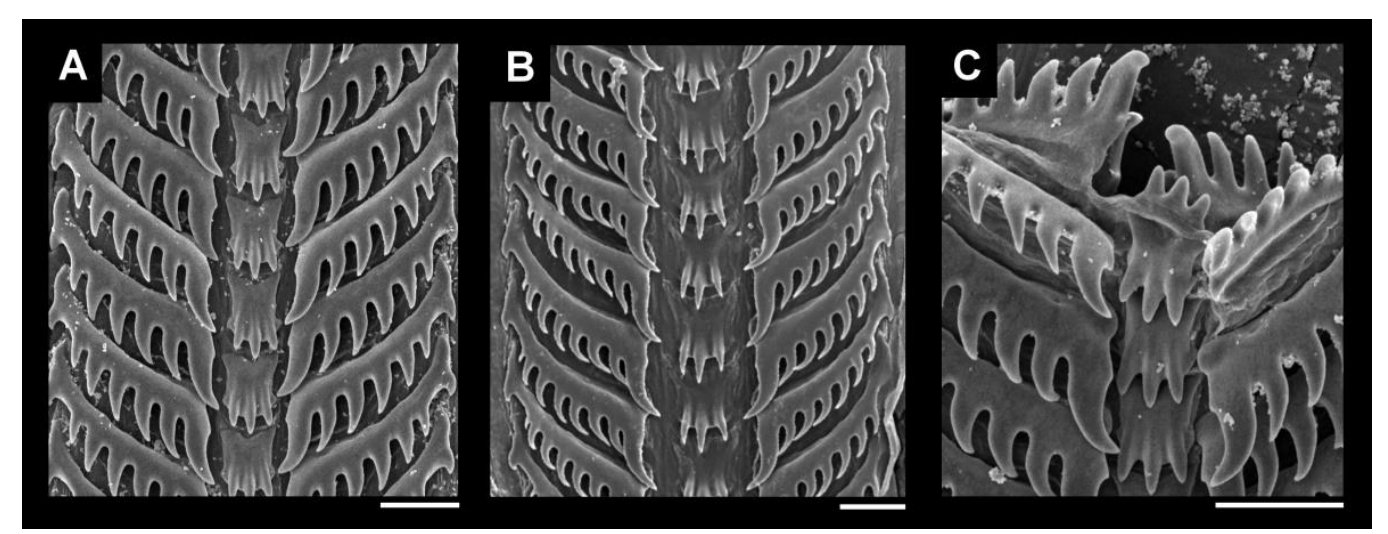

Figure 102. Leucozonia nassa brasiliana, radula. A-C: MNRJ 10993. A-B: panoramic view. C: detail of rachidian tooth. Scale bars $=50 \mu \mathrm{m}$. 


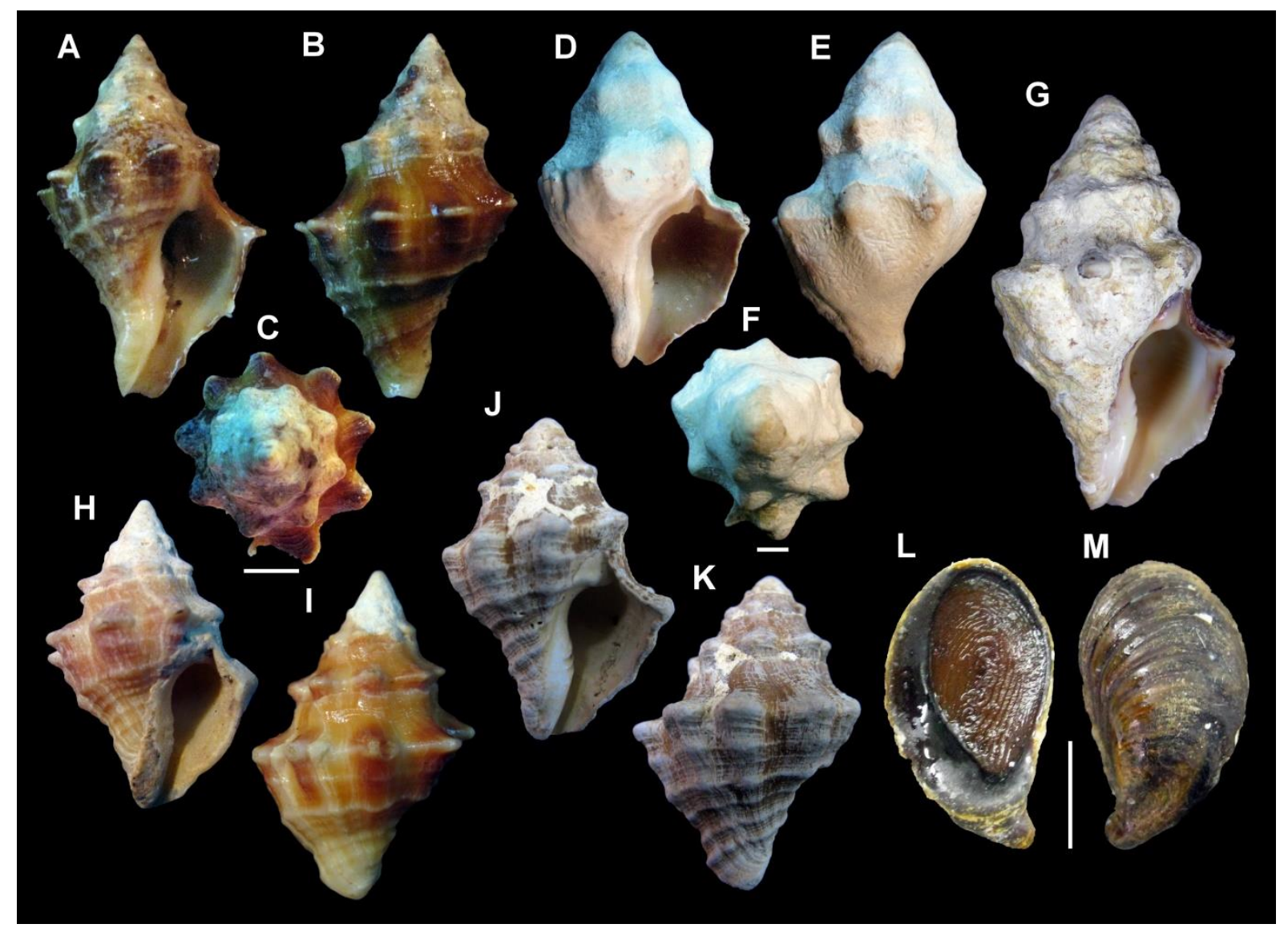

Figure 103. Leucozonia ponderosa, shell and operculum. A-C: MNRJ 14607 (28.6mm). D-F: MNRJ 5220 (44.2mm). G: holotype, MORG 39599 (47.3mm). H-I: MNRJ 5138 (31.4mm). J-K: MNRJ 5137 (37.3mm). L operculum, inner view. M: operculum, outer view. Scale bars $=5 \mathrm{~mm}$.

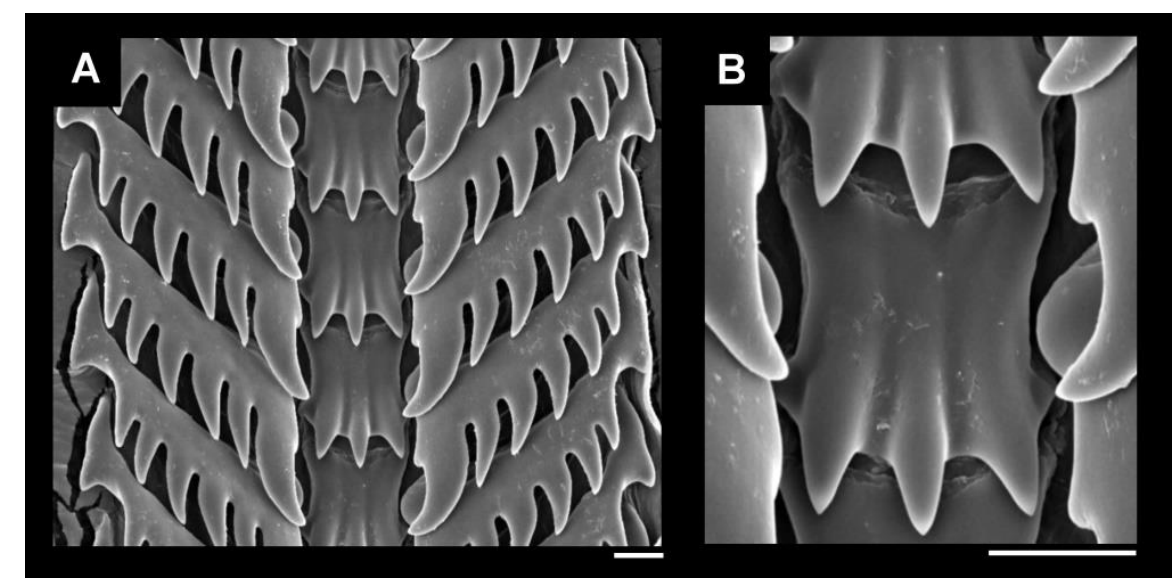

Figure 104. Leucozonia ponderosa, radula. A-B: MNRJ 5220. A: panoramic view. B: detail of rachidian tooth. Scale bars $=20 \mu \mathrm{m}$. 


\section{Leucozonia ponderosa (Figs. 103-104)}

Examined material: MORG 39299, Portuguese cove, Trindade Island, Espírito Santo state, Brazil, $10 \mathrm{~m}$ depth on rocky bottom, $20^{\circ} 30^{\prime} \mathrm{S} ; 29^{\circ} 20^{\prime} \mathrm{W}$. J.H. Leal \& P. Bouchet col. v/22/1987 [1 specimen, holotype]. MNRJ 14607, Fernando de Noronha Archipelago, Pernambuco state, Brazil, 12-18m depth. P.M.S. Costa col. viii/2009 [1 specimen]. MNRJ 5220, Cachoeira Beach, Trindade Island, Espírito Santo state, Brazil. J. Becker col. i/1959 [2 specimens]. MNRJ 5138, Galheta Beach, Trindade Island, Espírito Santo state, Brazil. B Prazeres col. xii/1975 [6 specimens]. MNRJ 5137, Cabritos Beach, Trindade Island, Espírito Santo state, Brazil. B Prazeres col. xii/1975 [3 specimens].

Pedal ganglia short, its length: nerve ring length <1/2 (90: 0). 


\section{Phylogenetic discussion}

The following discussion corresponds to the unweighted phylogenetic analysis, as specified in the Material and Methods section. Clades are numbered 1 through 15 in the main branch (for Fasciolariidae, outgroup taxa are numbered in decreasing order), while subsequent inner branches are labelled 1a, 1b, etc. as seen in Figure 6.

Important morphology morphology-based phylogenetic analyses were endeavored by Ponder \& Lindberg (1997), Strong (2003) and Simone (2011). Despite being more inclusive (Gastropoda and Neogastropoda), these important works are of great value to this discussion, and most taxonomical, phylogenetical and morphological considerations will be discussed subsequently in the next section. Figures 105-107 illustrates these phylogenetic hypotheses. 


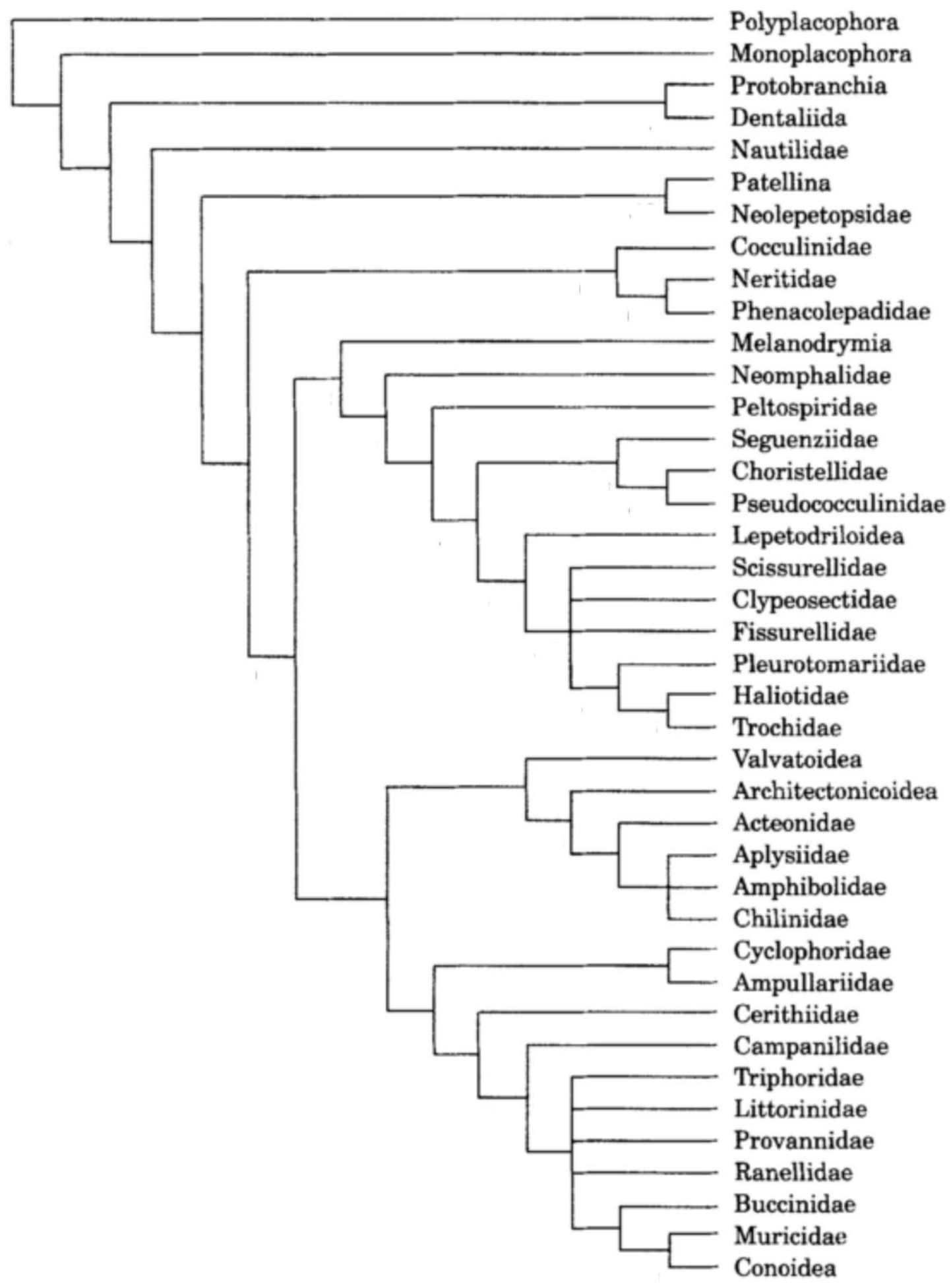

Figure 105. Strict consensus of the obtained trees from Ponder \& Lindberg (1997), based on morphological data (modified from Ponder \& Lindberg, 1997: Fig. 2) 


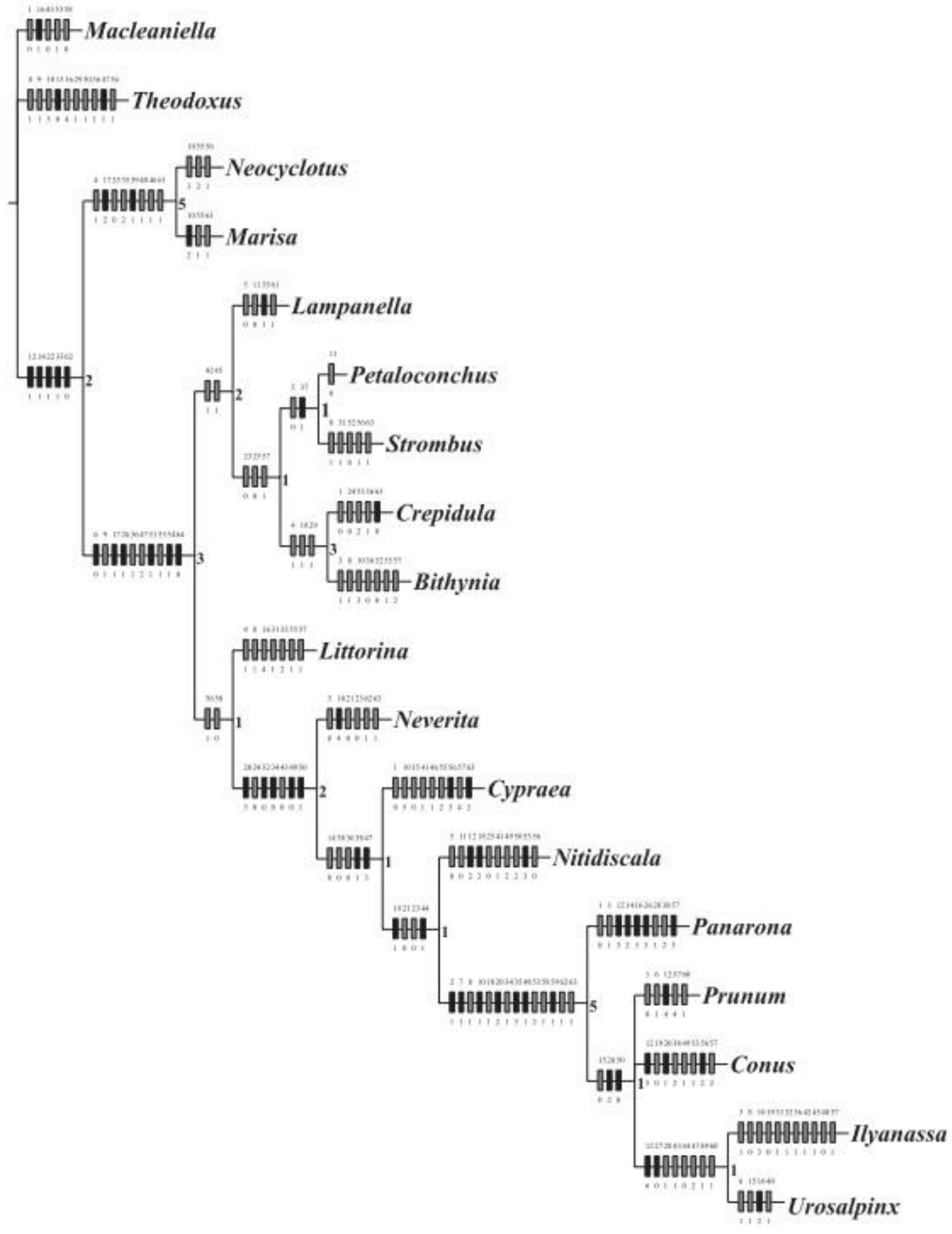

Figure 106. Strict consensus tree of the analysis of Caenogastropoda based on morphological characters of Strong (2003). Tree shows character optimizations, numbers at the nodes indicate Bremer support (modified from Strong, 2003: Fig. 26). 


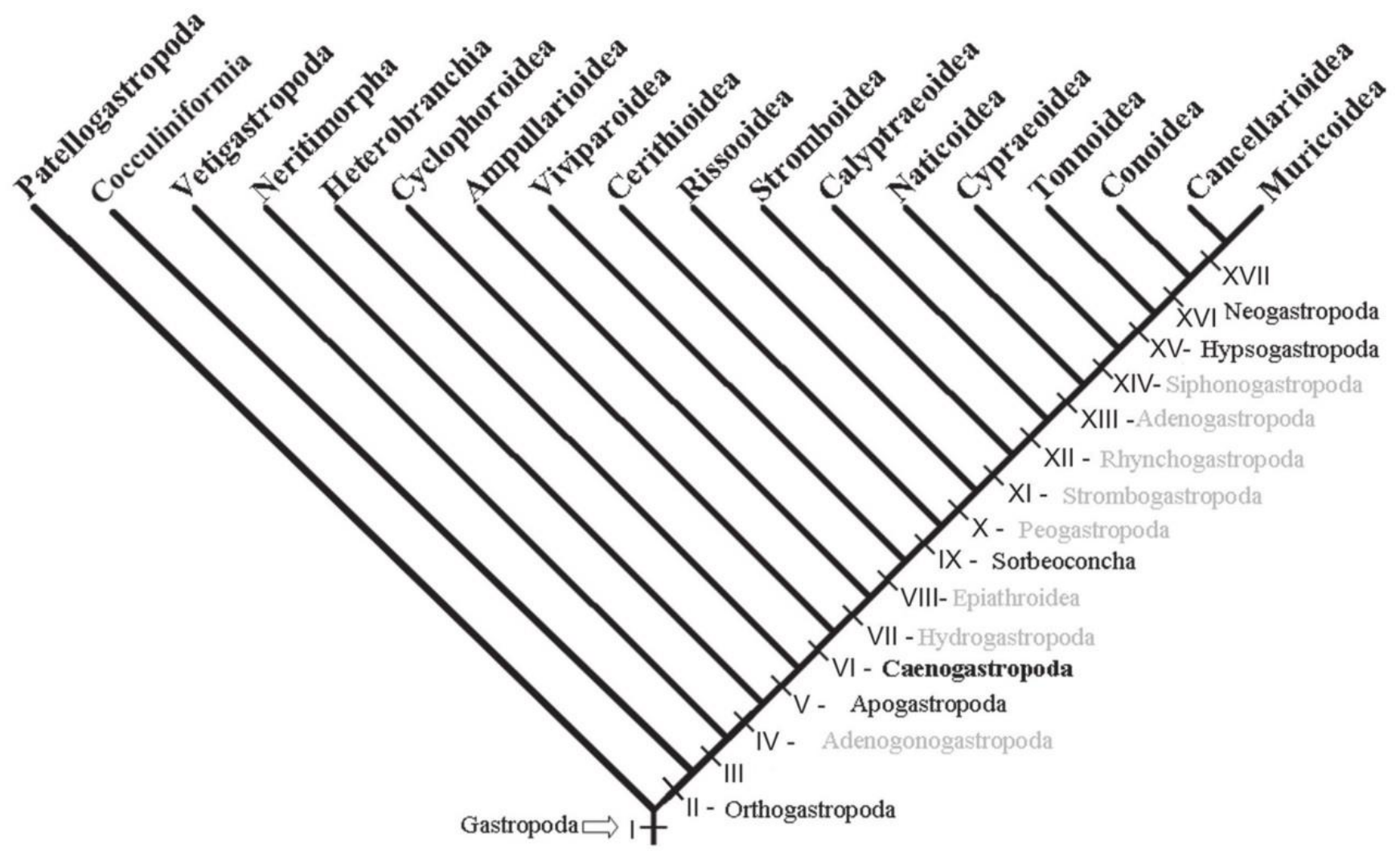

Figure 107. Strict consensus tree of the Caenogastropoda analysis of Simone (2011), based on morphological characters (modified from Simone, 2011: Fig. 21). 


\section{Clade -3 Neogastropoda}

Neogastropoda is the most diverse caenogastropod mollusk clade and are traditionally well defined morphologically, and several are its synapomorphies, including: presence of a pair of accessory salivary glands, a valve of Leiblein, and an anal or rectal gland (Kantor \& Fedosov, 2009); the work of Simone (2011) added: the loss of the jaws, the pair of retractor muscles of buccal mass passing through the nerve ring, the ducts of the salivary glands free from the nerve ring, the ventral esophageal gland individualized by a duct (known as the gland of Leiblein and the venom gland), and a highly concentration of the nerve ring. A brief discussion of the synapomorphies relevant to this work is ensued; however, a more thorough discussion of each character utilized for this analysis is found in the character discussion section.

Strong (2003) agreed that the pycnonephridial kidney is a synapomorphy of the neogastropods, and this is confirmed here. Although this traditional classification of kidney lamellae has been contested by several authors (e.g., Ponder, 1973), it is undoubted that on the current context, neogastropods have them differentiated: the kidney's interdigitating lamellae that occur in all neogastropod taxa are supplied by a two main branches: the dorsal and the ventral afferent renal vessel; the dorsal branch supplies the lobes while the ventral remains in the kidney floor (Strong, 2003). This is the type of pycnonephridians; in contrast, meronephridians have lamellae that are not interdigitated. Such renal vessel detail was not visualized in the present study. This was interpreted as a secondary reversion to the plesiomorphic state within noncancellariids neogastropods by Simone (2011).

The neogastropod odontophore cartilages are highly differentiated from other Caenogastropoda. Simone (2011) pointed to the loss of accessory pair of protractor muscles of odontophore (m14) in Neogastropoda; in the present analysis it was observed that the origin of the m11 muscles occur posteriorly in the odontophore cartilages, as opposed to inserted in the haemocoelic wall. This odontophore type occurs in all neogastropods present in the literature (e.g., Simone, 1996; Simone et al., 2009; Simone \& Pastorino, 2014; Couto et al., 2015a; 2015b). The m11 muscles are a pair of ventral tensor muscles of the radula, which enables the sliding movement of the radular ribbon (Ponder et al., 2008). In taxa which these muscles are diminute (as in the case of Caenogastropoda sensu Simone, 2011) this function is somewhat hampered and there is no sliding movement between the cartilages and the radula (Simone, 2011). Regardless of their true function, which is hard to access by itself, the muscles in the cypraeid Monetaria 
annulus (Linnaeus, 1758) are inserted in the haemocoelic wall, differing from Neogastropods which insert posteriorly in the odontophore.

Radula in Neogastropoda is characterized as being of the rachiglossate type, i.e., one rachidian flanked by one lateral in each side and lacking marginal teeth, adding to three teeth per row. The rachiglossate and toxoglossate (a posteriori modification of the rachiglossate type) radulae characterizing neogastropods are assumed to have arisen from a taenioglossate ancestral type (Ponder \& Lindberg, 1997). In contrast, non-neogastropod caenogastropods have a taenioglossate type, with a rachidian flanked by a pair of laterals and two pairs of marginals, completing seven teeth per row. Simone (2011) argued that the radula in Conoidea evolved from a taenioglossate type, at least twice in the group, and that the evolution of this character did not pass through a rachiglossate radula.

Another radular modification suffered by the Neogastropods in this analysis is the position of the lateral teeth in relation to the rachidian: in Monetaria annulus the teeth are directly adjacent to one another while in non-fasciolariid ("basal") neogastropods the teeth are somewhat apart. All Caenogastropoda radulae figured in the work by Bandel (1984) have this same configuration (e.g., Cypraea Linnaeus, 1758: Fig 126; Murex Linnaeus, 1758: Fig. 168; Engina Gray, 1839: Fig. 201).

One of the more traditional of neogastropod characteristics is the presence of a gland of Leiblein; being utilized as a synapomorphy in several morphological phylogenetic analysis (e.g., Ponder \& Lindberg, 1997; Strong, 2003; Simone, 2011). This structure is derived from the esophageal gland of other caenogastropods, and is thought to be homologous to the septated sac in Cypraeidae (Simone, 2011), despite some groups within Neogastropoda lacking this structure and others modified it to a venom gland (for a thorough review of the anatomy and function of the gland o Leiblein see Andrews \& Thorogood, 2005). The absence of this structure, along with other factors, has led to the supposition that the neogastropods are not monophyletic (more on this is discussed under Clade -2 Buccinoidea) by Kantor \& Fedosov (2009).

Thais speciosa (Valenciennes, 1832) (Fig. 7) is regarded as a non-neogastropod because of the absence of typical neogastropod synapomorphies and the radula typical for the genus (Fig. 8) (Bandel, 1984). Despite this species possessing some characteristics of buccinoideans such a pseudoumbilicus, a stomach bearing a posterior bulge and the presence of a penis ejaculatory duct as long convoluted tube, these are considered convergences. 


\section{Clade -2 Buccinoidea}

The superfamily Buccinoidea includes the families Buccinidae, Belomitridae, Busyconidae, Colubrariidae, Columbellidae, Nassariidae, Melongenidae and Fasciolariidae (Bouchet \& Rocroi, 2005; WoRMS, 2016). They are considered highly derived in the Neogastropoda scheme due to the probable loss of the accessory salivary glands and the anal or rectal glands (Fedosov \& Kantor, 2012).

Kantor \& Fedosov (2009) argued that the valve of Leiblein, an important Neogastropoda synapomorphy, is indeed homoplastic, and emerged at least twice in the evolution of this group. If this proves true, Neogastropoda becomes non-monophyletic because Buccinoidea will lack all of its synapomorphies (until now regarded as secondary losses, e.g., Melongenidae here represented by Pugilina tupiniquim Abbate \& Simone, 2015, Figs. 9-10).

In their complete mitochondrial genome and three nuclear-gene phylogeny, Osca et al. (2015) failed to recover Neogastropoda, and proposed the inclusion of Tonnoidea, or the exclusion of Cancellarioidea and possibly Volutidae from Neogastropoda. In the first case, tonnoideans would have secondarily lost the traditional neogastropod synapomorphies, while in the latter these synapomorphies would be considered homoplastic, in this sense agreeing with Kantor \& Fedosov (2009).

\section{Clade -2a Clade Buccinidae + Nassariidae}

This clade excludes the genus Engoniophos Woodring, 1928 (here represented by E. unicinctus [Say, 1826], Figs. 11-12), which has traditionally been recognized as a buccinid, although more recently has been revisited and is thought to belong to Nassariidae in both morphology (Abbate, 2016) and molecular-based (Galindo et al., 2016) analyses. It includes the nassariid species Nassarius reticulatus (Linnaeus, 1758) (Figs. 13-14) and Bullia laevissima (Gmelin, 1791) (Figs.15-16). In the present work, the probable cause for the exclusion of this taxon is the absence of a dorsal metapodial tentacle in this genus. A more thoroughly sampling will likely obtain similar results to those of Abbate (2016) and Galindo et al. (2016), since making any taxonomical decisions for the outgroup species in the present study (due to the lack of sampling) is tentative at best.

The rachidian tooth of species contained in this clade possess five or more sharp principal cusps (Figs. 14.16), which is unique for the Buccinoidea radula; Nassarius albus (Say, 1826) may 
have up to 18 cusps (Bandel, 1984), Engoniophos has a large increase in cusp number of the rachidian, and Bandel (1984) already indicated that they belong in the same family; although, presently, it was interpreted as a convergence. Morphology of the lateral teeth the Nassariidae is similar to most Buccinidae, only the characteristic central tooth of the nassariids differentiates their radula from that of other buccinids (e.g., Bandel, 1984). Buccinum undatum Linnaeus, 1758 (Fig. 18) has five cusps on the rachidian, but that is considered few in number for a nassariid, despite currently classified in Buccinidae.

\section{Clade -1 Clade Pisaniinae + Fasciolariidae}

The main feature that distinguishes species in this clade is the salivary ducts which merge in the anterior esophagus wall. This was observed for Fasciolariidae and was already reported as a diagnostic feature for the family by Fraussen et al. (2007). In Buccinidae, the ducts, after leaving the glands, follow freely along the anterior esophagus towards the anterior part of the proboscis where they enter the walls of the esophagus close to their entrance into the buccal cavity. In Fasciolariidae, on the other hand, the ducts, after leaving the glands, merge with the anterior esophagus walls close to the valve of Leiblein. They then follow to their openings into the buccal cavity under the lateral folds of the esophagus.

Although Pisania pusio (Linnaeus, 1758) (Fig. 19-20) is classified under Buccinidae, this group is surely a heterogeneous assemblage that deserves a scope of its own and likely forms several, independent, polyphyletic lineages.

The statocysts present in the nerve ring of all species of Pisania pusio occurs asymmetrically, i.e., one anterior, associated to the pedal ganglia, and another more posteriorly, associated to the cerebral ganglia; this situation is reversed in Teralatirus roboreus. Although there is some variation in the position of both statocysts (more anterior or posteriorly, e.g., Strong, 2003; Simone, 2011), an asymmetry has never been reported.

\section{Clade 1 Family Fasciolariidae}

With 541 extant species in 51 genera worldwide (WoRMS, 2016), fasciolariids comprise of three subfamilies: Peristerniinae Tryon, 1880: which includes, among other genera, Peristernia and Latirus; Fusininae: the spindle shells; and Fasciolariinae: with the conspicuous and wellknown tulips and horse-conchs. More recently, however, the group has undergone extensive 
taxonomical revision (e.g., Vermeij \& Snyder, 2002; 2006; Snyder et al., 2012; Lyons \& Snyder, 2013), that elevated several subgenera to genus rank as well as establishing new genera.

The sub-familiar categories for Fasciolariidae have been retained more-or-less stable; Couto et al. (2016) on its five-gene molecular phylogeny recovered all three of these subfamilies; although with an extensively revised inclusion of species and genera. This is so far the only extensive phylogenetic study of the family, since past works which included some fasciolariid taxa did not have the internal resolution to solve most internal clades. These authors were able to recognize the fusinines, with the inclusion of the genus Pseudolatirus; the peristerniines, which include the genera Peristernia and Fusolatirus; and the fasciolariines that include the bulk of Peristerniinae sensu lato and the Fasciolariinae (the only traditional clade that maintained its monophyly). The traditional peristerniines have representatives in all three clades, while the genera Teralatirus and Dolicholatirus were a separate group from the remaining fasciolariids, although its position remains uncertain, as the statistic tests made were not able to correctly access its position.

Knowledge of the anatomy of the Fasciolariidae is somewhat sparse. Marcus \& Marcus (1962) presented a fine anatomical study of Leucozonia nassa from Brazil. Although these authors provided a thorough characterization of the species from the state of São Paulo coast in southeastern Brazil, including histological sections, they did not illustrate several features such as the head-foot mass, pallial cavity, and male reproductive and digestive systems. More recently, several anatomical studies of Brazilian species of Fasciolariidae have been undertaken following a through anatomical endeavor (e.g., Couto \& Pimenta, 2012: on Leucozonia Gray, 1847 from Brazil; Couto et al., 2015a: on Pustulatirus and Hemipolygona species; Couto et al., 2015b: on Fasciolaria tulipa).

The current morphological analysis confirms several synapomorphies for Fasciolariidae, five of which are non-homoplastic. Those worth mentioning are: 1) the head with cephalic tentacles positioned with its bases side by side (non-homoplastic) (character 12, Fig. L); 2) the rhynchostome as longitudinal slit (character 38, Fig. AB); 3) the lateral tooth of the radula directly adjacent to rachidian (character 54, Fig. AN); 4) single or paired proboscis retractor muscles originating in the columellar muscle (non-homoplastic) (character 67, Fig. AW); 5) a stomach bearing a posterior bulge without a sorting area (character 75, Fig. BD); 6) a long bursa copulatrix (non-homoplastic) (character 80, Fig. BF); 7) buccal ganglia immersed in the nerve 
ring with its connectives not visible (non-homoplastic) (character 91, Fig. BN); and 8) buccal ganglia which is positioned dorsal to cerebro-pleural ganglia (non-homoplastic) (character 92, Fig. BN). For a description of all synapomorphies, in Fasciolariidae as well as all other clades, see section 'Phylogenetic Description' and refer to Fig. 6.

Kosyan et al. (2009) studied the comparative anatomy of seven fasciolariid species: Pustulatirus mediamericanus, Peristernia nassatula, P. ustulata, Opeatostoma pseudodon, Tarantinae lignaria, Latirus polygonus, and Turrilatirus turritus. Typically, according to Kosyan et al. (2009), fasciolariids lack a caecum (posterior sorting area) in the stomach and an ingesting gland in the pallial oviduct; additionally, as in buccinids, melongenids, and nassariids, they lack accessory salivary glands and an anal gland (Harasewych, 1998). Species of the family generally have light orange to red head-foot mass; however this characteristic does not take into consideration the clade consisting of the genus Dolicholatirus and Teralatirus that lack this coloration and is sister group of the remaining fasciolariids; more on this distinct clade will be discussed later.

A novel characteristic for the clade Fasciolariidae is the position of the cephalic tentacles in relation to each other. In the buccinoidean species, the bases are somewhat apart, while in fasciolariids they are adjacent to each other. This characteristic has never been reported as diagnostic at this level; all fasciolariid species illustrated in the literature have this conformation as well (e.g., Marcus \& Marcus, 1962; Kosyan et al., 2009; Fedosov \& Kantor, 2012).

Troschel \& Thiele (1865-1893) were the first to characterize the radula of Fasciolariidae, and according to these authors, the radula is characterized as having very wide laterals with many cusps; the rachidians are quadrangular and less wide than the laterals. Although not all fasciolariids have this conformation (clade of Dolicholatirus, discussed later), a single characteristic that can distinguish the fasciolariids at this level is the position of the rachidian that is adjacent to the lateral; in the buccinoideans the lateral is distanced in a way that you can see the radular ribbon between the teeth. Bandel (1984) illustrated and characterized the radulae of five Caribbean fasciolariids: Leucozonia nassa, L. ocellata, Polygona infundibulum (Gmelin, 1791), P. angulata (Röding, 1798) and Fasciolaria tulipa, and this feature conforms to all illustrations.

Fraussen et al. (2007) reported that a combination of anatomical characters is diagnostic for the Fasciolariidae, including the multicuspidate lateral teeth and a small rachidian, salivary ducts embedded in the esophagus wall (a feature shared with Pisania pusio), but also: a single or paired 
proboscis retractor muscle, and the characteristic stomach morphology. Kosyan et al. (2009) confirmed the proboscis retractor muscles as characteristic for the fasciolariids. The proboscis retractor muscles of fasciolariids consists of aggregated fibers that have its origin in the back of the diaphragmatic septum, attached to the columellar muscle. It is hypothesized that this corresponds to the same configuration as that pointed by Fraussen et al. (2007) and Kosyan et al. (2009). This differs from other Neogastropoda studied because they have the origin of the muscles in the floor of the haemocoel, as well as constituting several tuft of fibers. Troschelia berniciensis (King, 1846), a buccinid analyzed by Kosyan et al. (2009) has the proboscis attached to the bottom of the body haemocoel by several proboscis retractors emerging from its base, consisting of approximately six muscle tufts.

Kantor (2003) distinguished the Fasciolariidae by their distinct stomach morphology with low folds on the inner wall, transverse striations on the longitudinal fold and absence of a posterior mixing area, and stated that the superfamily Buccinoidea can be differentiated based on stomach characters. In the context of the superfamily, the typical fasciolariid stomach is one that lacks a posterior mixing area, (sometimes called as caecum), low relief of the folds on the inner stomach wall, presence of transverse striations on the low longitudinal fold, and the absence of clear differentiation of the gastric chamber into dorsal and ventral parts. Buccinoidean species, non-fasciolariids, on the other hand, have a posterior elongation of the stomach wall, and a division into ventral and dorsal chambers connected by a lateral sulcus (Kantor, 2003).

It is worth noting that only the combination of several of these above-mentioned characteristics has been reported as diagnostic for the family. However, other species belonging to other families may possess these characteristics individually. For example, Troschelia berniciensis has fasciolariid-like lateral radular teeth with five to ten cusps, but typical buccinidlike proboscis retractor muscles and stomach (Bouchet \& Warén, 1985; Kosyan et al., 2009); this species is currently attributed to Buccinidae (WoRMS, 2016). Thalassoplanes circumreta Lus, 1973 possesses a clearly fasciolariid-like radula, but the stomach has a very long posterior mixing area and salivary ducts which pass freely along the anterior oesophagus (Fraussen et al., 2007); it is currently a Buccinidae although originally in Fasciolariidae. The use of a rigorous phylogenetic analysis allows for the distinction between true synapomorphies and mere diagnostic characteristics, e.g., homoplasies, plesiomorphies or convergences. 
There is a general tendency in Caenogastropoda for the buccal mass to be located far from the nerve ring. However, muricoideans (sensu Simone, 2011: which includes Buccinoidea) have reverted to the plesiomorphic condition, possessing buccal ganglia closer to, or even incorporated into the nerve ring (Simone, 2011). In the context of the superfamily Buccinoidea, it is observed that fasciolariids have the ganglia incorporated into the nerve ring in a way that the connectives are not visible; being even closer to it, located dorsal to the cerebral ganglia. In non-fasciolariid buccinoideans the buccal commissures are visible and the ganglia are more anterior, less associated to the nerve-ring.

\section{Clade 1a Dolicholatirus + Teralatirus}

Dolicholatirus and Teralatirus (Figs. 21-26) are small buccinoid genera with distinctive shell characters whose taxonomic position in Fasciolariidae is ambiguous, although currently generally accepted (e.g., Snyder, 2003; WoRMS, 2016). Originally established (Bellardi, 1884) as a section of Latirus for two fossil species, the genus Dolicholatirus was attributed to Fasciolariidae without any arguments or analyses, on the basis of its fusiform shell superficially resembling many fasciolariids, although the presence of paired weak columellar plaits (uncommon in Fasciolariidae) was mentioned. Cossmann (1901) raised Dolicholatirus to full genus, designated the type species (Turbinella bronni Michelotti, 1847) and classified it in the family Fusidae (which Cossmann used in place of Fasciolariidae), subfamily Fusinae, also without providing supporting arguments. Subsequently, almost half of the genera included in Cossmann's Fusinae have since been transferred to other families of Neogastropoda (Columbarium Martens, 1881, now Columbariinae, Turbinellidae; Exilia Conrad, 1860, now Ptychatractidae; Thersitea Savornin, 1915, now Thersiteidae; Euthriofusus Defrance, 1820, now Buccinidae). Thiele (1929) reverted to Dolicholatirus as a section of Latirus, still included in the family Fasciolariidae, a position followed by Wenz (1943) and finally by Snyder (2003; but see Vermeij \& Snyder, 2006). Thus the current inclusion of Dolicholatirus in the Fasciolariidae goes back to Bellardi (1884) and is uncritically based on shell characters, which generally proves to be an unreliable diagnosis at best.

Couto et al. (2016) demonstrated the monophyly of the clade containing Dolicholatirus and Teralatirus through maximum likelihood (ML) and Bayesian inference (BI) analyses, and Dolicholatirus lancea (Gmelin, 1791), D. cayohuesonicus (Sowerby, 1878), D. spiceri (Tenison- 
Woods, 1876), Teralatirus noumeensis (Crosse, 1870) and T. roboreus were sampled. Its position as the sister group of the remaining fasciolariids remained uncertain, as the tests performed to calculate the probabilities according to the approximately unbiased test (Shimodaira, 2002), the Kishino-Hasegawa test (Kishino \& Hasegawa, 1989), and the Shimodaira-Hasegawa test (Shimodaira \& Hasegawa, 1999) could not statistically discriminate between the constrained (all fasciolariids and Dolicholatirus/Teralatirus) and unconstrained topologies. Regardless of their position within or out of Fasciolariidae, the deeper nodes between the ML and BI analyses of Couto et al. (2016) differed; in this way the clade of Dolicholatirus was a sister group of the Conoidea and Thais Röding, 1798 clade, but other sister-group inferences diverged between both.

Simone et al. (2013) pointed out the similarities between Dolicholatirus and Teralatirus, and suggested that most likely these should be better placed together, a hypothesis confirmed here and by Couto et al. (2016) as Teralatirus nested within Dolicholatirus in both the morphological and molecular analyses, respectively. Simone et al. (2013), nevertheless, followed a conservative approach with regard to their classification and no changes were made. Based on this analysis and in Couto et al. (2016), Teralatirus should be relocated to the genus Dolicholatirus.

The main difference that distinguishes this clade from all other fasciolariids is present in the radulae. Based on the differences in radula (also on shell morphology and on the shape of the egg capsules), Vermeij \& Snyder (2006) argued that Dolicholatirus likely belongs to Turbinellidae, a view followed by Beu (2011). Turbinellid radulae possess lateral teeth which are small, with a single cusp and a rachidian that is thin, with a single central cusp and curved outward (e.g., Turbinella angulata (Lightfoot, 1786) in Bandel, 1984: pl. 17, Fig. 4). This radula type is very similar to the Dolicholatirus (Fig. 22, 26) and Teralatirus presently studied (Fig. 24). This notable radular morphology difference is the sole reason that made previous authors disagree on the position of these taxa within Fasciolariidae, attributing the similarities to Turbinellidae as synapomorphic. Dolicholatirus and Teralatirus have a very minute body size (the largest, Dolicholatirus lancea, reaches length of up to $60 \mathrm{~mm}$, despite being very slender), it may be the case that this clade has suffered a miniaturization process, and that is evidenced also in shell features. Miniaturization events in nature are common, widespread phenomena in animals that result in extremely small adult body size whose phenotype is a complex combination of ancestral and derived traits, including reduction and structural simplification and increased variability 
(Hanken \& Wake, 1993). This hypothesis may explain why some typical fasciolariid features are not present in this clade, such as the body pigmentation coloration and the 'typical fasciolariidlike' radula.

This clade is characterized by the loss (reversion of Neogastropoda) of the spiral sculpture forming nodes in the shell; that is maintained in all species of this clade, despite some possessing the axial sculpture.

\section{Clade 1b}

This clade groups Teralatirus roboreus (Fig. 23) and Dolicholatirus aff. cayohuesonicus (Fig. 25); the most notable characteristics that unite both of these taxa are in the radula and the penis. In the radula, what distinguishes this clade from the remaining Dolicholatirus sp. is a much smaller rachidian in relation to the lateral (character: 50, Fig. AJ); in the penis, the clade has a pre-copulatory chamber bearing short terminal papilla contained within (character 88, Fig. BK), absent in Dolicholatirus sp.

The genus Dolicholatirus is distinguished from Teralatirus by the presence of strong spiral ribs and a long siphonal canal (e.g., Bullock, 1974), although it has been previously stated that Dolicholatirus contains the genus Teralatirus, as proved by the present work and by Couto et al. (2016). Dolicholatirus cayohuesonicus resembles the Indo-Pacific D. lancea, type of the genus, by the presence of strong axial ribs; however, it has a broader profile and shorter siphonal canal. Among the Caribbean species, D. cayohuesonicus resembles Teralatirus roboreus by the short siphonal canal. All the above cited species have strong spiral ridges along the spire and the base of the shell, and strong lirae on the inner side of the outer lip. Simone et al. (2013) argued that a feature that distinguishes Teralatirus roboreus from other Dolicholatirus species is the absence of strong axial ribs. Although specimens of T. festivus (Haas, 1941) may bear strong axial ribs (Simone et al., 2013: Figs. 19-27), the sculpture pattern is much more delicate.

The shell of Dolicholatirus cayohuesonicus was figured by Faber (2010: Figs. 4-5 [the type Latirus cayohuesonicus after Sowerby, 1878, is illustrated in Fig. 5]). While the figured individuals possess a rather long siphonal canal (approximately half of the total aperture length) and broad axial ribs, the specimens studied here lack such long siphonal canal. Teralatirus roboreus figured by Simone et al. (2013: Figs. 1-16) resembles somewhat the shell of $D$. cayohuesonicus, especially if one takes into consideration a degree of variation of Teralatirus; 
e.g., T. festivus (Simone et al., 2013: Figs. 17-27). This species is only conchologically recognizable through its spiral bands, which in all figured specimens have the same color pattern; however, there is considerable variation in the position, number and spacing of the axial ribs some even lacking the axial ribs altogether. The length of the siphonal canal, as well as its proportion to the aperture, and its shape also varies considerably.

The short siphonal canal of Dolicholatirus cayohuesonicus favor its inclusion in Teralatirus; while the presence of axial ribs favors more adequately its inclusion in Dolicholatirus. Because of this variation in form, the species is more adequately designated as Dolicholatirus aff. cayohuesonicus, in the hopes that future taxonomical works, including a much broader sampling, and molecular analyses will resolve this issue.

If this degree of variability occurred for D. cayohuesonicus, perhaps it is the case of a species complex of with $T$. roboreus and D. cayohuesonicus, with overlapping geographic variation. Both specimens of D. cayohuesonicus in Faber (2010: Figs. 4-5) are from localities in the western Caribbean (Belize and Key West, Florida, USA, respectively), while in this study there are only representatives of eastern Caribbean Puerto Rico. A taxonomical revision with sampling of multiple localities is desirable but beyond the means and scope of this work.

Anatomically, Dolicholatirus aff. cayohuesonicus is strikingly similar to Teralatirus roboreus (Simone et al., 2013). All of them lack a posterior sorting area in the stomach and the proboscis retractor muscles with a columellar muscle origin; however, the huge esophageal gland present in $T$. roboreus differs from D. cayohuesonicus, because in the latter a gland of Leiblein occurs. It was not possible to evaluate the ducts of the salivary glands of both species. All the above characteristics, with the exception of the esophageal gland in $T$. roboreus, favor the inclusion in Fasciolariidae.

A notable difference present in Dolicholatirus and Teralatirus is the radula, extremely slender, with narrow rachidian and bicuspidate laterals, with the internal cusp hook-like. Abbott (1958) was the first to examine the radula of D. cayohuesonicus and found it to be "the most highly modified of the Fasciolariidae radulae, and somewhat resembling those of Vasidae [currently Turbinellidae]."

The radulae of Dolicholatirus spiceri and another undescribed related species in Couto et al. (2015) (the Dolicholatirus sp. in this analysis: Fig. 22) are virtually identical to that of $D$. cayohuesonicus (Fig. 26) and T. roboreus (Fig. 24. see also Simone et al., 2013: Figs. 31-34). 
According to Couto et al. (2016) this is the characteristic radula type that likely occurs within all species in the group (a radula of Dolicholatirus was supposedly figured by Bandel (1984), however Couto et al., [2016] suspected this to be a misidentification, as this radula does not match their observations, and likely Bandel's specimen is instead a buccinid). The similarity of the radula of Crassicantharus norfolkensis Ponder, 1972 illustrated by Ponder (1972) suggests that Crassicantharus Ponder, 1972 may belong in the same clade, but Couto et al. (2016) did not include any species of this genus in their analysis.

In conclusion, although the molecular results obtained by Couto et al. (2016) do not reliably establish the position of Dolicholatirus and Teralatirus as belonging to, or outside of, fasciolariids, Dolicholatirus and Teralatirus formed a monophyletic group. In the morphological results obtained herein, this group also obtained its monophyletic status, but resulted as a sister clade to the remaining fasciolariids. Despite the radula being a strong morphological evidence that suggests a non-fasciolariid position (implying a possible miniaturization phenomenon), the 'fasciolariid-like' radula does not only include the previously typical morphotype, but rather, this morphotype appeared later in Fasciolariidae history. Perhaps future studies will be able to recover this part of the Neogastropoda tree with high support.

\section{Clade 2 Fasciolariidae non Dolicholatirus and Teralatirus}

This clade comprises the traditional Fasciolariidae, i.e., non-Dolicholatirus and Teralatirus fasciolariids. This clade has several non-autapomorphic synapomorphies, five in total: 1) body pigmentation orange to light-red (character 11, Fig. K), 2) osphradium slightly asymmetrical character 23, Fig. S), 3) radula rachidian tooth thin (character 50, Fig. AJ), 4) lateral tooth wide and (character 55, Fig. AN) 5) cusp one of the lateral with a reduced size (character 60, Fig. AS). The latter three synapomorphies correspond to radular characters, and all of these will be discussed subsequently.

Body pigmentation has been traditionally used to diagnose species of Fasciolariidae (Harasewych, 1998; Poppe, 2008). Traditionally, members of the fasciolariid subfamilies Fasciolariinae and Peristerniinae are notable due to the intensive red coloration of their head-foot that makes them easily recognizable at a glance; on the contrary, members of the subfamily Fusininae have bodies of a less intense, light-orange to cream pigmentation. Fedosov \& Kantor (2012), upon describing the new monospecific genus Angulofusus Fedosov \& Kantor, 2012, 
utilized the pigmentation of the live specimen to place it in the fasciolariid subfamily Fusininae. Despite difficulties of obtaining fresh material, necessary to analyze the body pigmentation (thus it was impossible to know if the clade of Dolicholatirus and Teralatirus possessed any), an intense red pigmentation of 'Peristerniinae' is a derived state of the 'Fusininae' light-orange one.

The asymmetry between the left and right filaments of the sensory organ in the pallial cavity is a synapomorphy of this clade, shared by all species; although this asymmetry is accentuated in certain groups. This has been described for species of the genus Amiantofusus and also observed for the eight fasciolariid species studied by Kosyan et al. (2009). The osphradium in other buccinoids is usually symmetrical (e.g., Germonea rachelae Harasewych \& Kantor 2004: Buccinidae; Pararetifusus tenuis [Okutani, 1966], Kosyan, 2006: Buccinidae; Dorsanum miran [Bruguière, 1789], Simone \& Pastorino, 2014: Nassariidae). However, an asymmetrical osphradium is not exclusive to fasciolariids, as there are reports of other non-fasciolariid buccinoids that possess it (e.g., Pararetifusus kantori Kosyan, 2006: Buccinidae). The asymmetry of the osphradium filaments has been connected to the miniaturization (Simone, 2011), as most of the species that have asymmetrical, or even monopectinated osphradia, are of small size. However, this is not the case of the present branch, which mostly includes large-sized animals.

The most remarkable characteristic of this fasciolariid clade is the highly modified radula, being what most previous authors have referred to as the 'typical fasciolariid radula'. Troschel \& Thiele (1865-1893) characterized the radula of the Fasciolariidae: the lateral teeth very wide, with many cusps; the central teeth are quadrangular and less wide than the lateral teeth. Bandel (1984), on his Caribbean caenogastropod radula survey (studying five fasciolariid species), observed the same pattern, however corrected that not all rachidian tooth can be called narrow, since in some species the central teeth are wider than long; all radular characterizations of the family have followed a more-or-less similar trend (wide laterals, thin rachidians, e.g., Taylor \& Lewis, 1995; Hadorn, 1999); Fraussen et al. (2007) included in their diagnosis this radula morphology to identify Fasciolariidae. All of the above cited authors did not take into consideration Dolicholatirus or Teralatirus in their diagnosis, and therefore this radula cannot be used to distinguish fasciolariids, but a more inclusive clade.

In this work, the synapomorphies related to the radula are: the increase in width of the lateral in relation to its length, a decrease of the width of the rachidian in relation to the width of the lateral and the reduction of cusp one of the lateral (characters 53, 55, 58; Figs AM, AN, AQ, 
respectively). The former two correspond to the 'fasciolariid-like' radula aforementioned, while the latter is a novel observation. The lateral innermost cusp is always reduced in length, when present (a few clades have lost cusp one, in that way the innermost cusp is the same length as the others; this will be discussed subsequently when relevant). All Fasciolariidae radulae figured in the literature possess this reduction in size of cusp one, except when it is absent (clades $6 b$ and 14).

The proboscis retractor muscles suffered a reduction in number, from a pair to one. In all non-fasciolariid neogastropods, a pair was observed; in this fasciolariid clade, only one occurs, likely due to the loss of the left one. A clade of Pustulatirus possess a pair, and Kosyan et al. (2009) also accounts to the existence of a pair in some Fasciolariidae species (e.g., Latirus polygonus and Fusinus tenerifensis). It may be the case that these latter cases are incorrectly assigned: a fasciolariid proboscis retractor has its origin in the columellar muscle, not the haemocoelic wall; some secondary muscles that attach to the haemocoel may be more conspicuous then the rest, in this way resembling the main retractors and so a pair may be perceived. This was not true for species of Pustulatirus, which will be discussed later.

\section{Clade 2a Angulofusus + Amiantofusus + Pseudolatirus kuroseanus}

Clades $2 \mathrm{a}, 3 \mathrm{a}$ and $4 \mathrm{a}$ correspond to representatives of the traditionally characterized subfamily Fusininae, plus the genus Pseudolatirus. This paraphyletic subfamily corresponds to the monophyletic clade of fusinines in Couto et al. (2016), which includes the genus Pseudolatirus as well. In their analysis, there were some topological differences between the ML and the BI results for this clade, which will be conveyed at the appropriate time in this discussion.

WoRMS (2016) reports ten extant genera for the subfamily Fusininae: Fusinus, Amiantofusus, Angulofusus, Chryseofusus, Granulifusus, Cyrtulus, Harasewychia Petuch, 1987, Marmarofusus Snyder \& Lyons, 2014, Trophonofusus Kuroda \& Habe, 1971, and Viridifusus Snyder et al., 2012. In this work are present representatives of the six former genera.

Fedosov \& Kantor (2012), upon describing the monotypic genus Angulofusus, noted a striking anatomical resemblance of A. nedae to Amiantofusus, both in digestive system anatomy (mainly radula and stomach) and mantle complex. However, upon examination of its Cytochrome $c$ oxidase subunit I (COI) sequence through BLAST scores in the NCBI database (http://www.ncbi.nlm.nih.gov/), a closer relationship to Granulifusus was proposed. A superficial 
conchological resemblance to some Conoidea was noted by its authors (Fedosov \& Kantor, 2012), notably the distinctive anal sinus (Fedosov \& Kantor, 2012: Fig 1H), evidencing once more the problems arising on conchologically based taxonomy.

The clade that contained Angulofusus nedae in Couto et al. (2016) nested within Amiantofusus, Granulifusus and Pseudolatirus kuroseanus in the ML, and as a sister group of all the remaining fusinines in the BI analysis. The former is a sister taxon to Granulifusus and Pseudolatirus kuroseanus, while Amiantofusus is sister to these. A topology similar to the one presented here, in which A. nedae is sister of Amiantofusus and Pseudolatirus kuroseanus is not observed, although a closer relation to Amiantofusus occurs in the ML analysis of Couto et al. (2016).

All species present in this clade have a characteristic rachidian tooth of the radula, i.e., very minute, nearly needle shaped and tri-cuspidate The cusps are sub-terminal; hence they do not originate in the terminal edge of the tooth and project forward, rather the cusps originate somewhat in the lateral edge of the tooth in a way that the edge is not visible (characters 48, 49; Fig. AI). This is typical for this clade, occurring solely on species within (Figs. 28-34).

\section{Clade 2b Amiantofusus + Pseudolatirus kuroseanus}

The genus Amiantofusus was described to accommodate deep-water species that possess shells that are strikingly similar to Buccinidae, short siphonal canal, but with unique protoconch morphology (multispiral protoconch) and fasciolariid-like radula and soft-part morphology (Fraussen et al., 2007). Conchologically, Pseudolatirus kuroseanus (Fig. 27) differs from Amiantofusus due to its long siphonal canal. In this context, P. kuroseanus most closely resembles Amiantofusus pacificus Fraussen et al., 2007, a species with much geographical variation, resembling “form B” sensu Fraussen et al. (2007: Figs. 36-37).

In Couto et al. (2016) Pseudolatirus kuroseanus maintained its sister group position to Granulifusus in both ML and BI analysis; this was not the case in this work, as the species is the sister taxon to Amiantofusus. Truly, P. kuroseanus shell is more Granulifusus-like than

Amiantofusus-like; however, this only accentuates the troublesome conchologically-based taxonomical issues. Regardless, due to the position of this species, and the non-monophyletic state of the genus Pseudolatirus, P. kuroseanus is better placed in Amiantofusus, despite molecular evidence proving a Granulifusus relation. 
Morphologically, two synapomorphies support this group: a loss of inner sculpture of outer lip (character 7, Fig. G), and a heavily asymmetrical osphradium (character 23, Fig. S). Both characters are convergent; the latter one occurred also in fusinine genera Granulifusus and Chryseofusus.

\section{Clade 2c Amiantofusus}

Both Amiantofusus species comprise this clade, with one of its synapomorphies, among others, is the insertion of the proboscis retractor muscle posteriorly in the proboscis, as opposed to medially (character 68, Fig. AX). This is a reversion of to the previous state.

The genus Amiantofusus was strongly supported in both analyses of Couto et al. (2016), but the relationship with other fusinines proved controversial. In the BI analysis, Amiantofusus is sister group of Fusinus and this clade in turn is the sister group of Chryseofusus and Pseudolatirus; the clade of Amiantofusus, Fusinus, Chryseofusus and Pseudolatirus is the sister group of Granulifusus and Pseudolatirus; and Angulofusus is a basal group of all the remaining fusinines. In the ML analysis, Amiantofusus is the sister genus to Granulifusus, Pseudolatirus and Angulofusus, while this group is sister to the remaining fusinines.

Amiantofusus pacificus (Figs. 29-30) was characterized by Fraussen et al. (2007) as having a strong degree of, mostly, geographic variability; its multispiral protoconch indicates a planktotrophic development and wide distribution, despite its bathymetric range being rather narrow (420-795m). Fraussen et al. (2007) pointed that the populations are separated by deeper water, causing a certain geographic isolation which is well reflected by the differences in shell morphology, however several intermediate forms are found between most of the forms, hence these authors considered these populations as not fully separated entities, nor subspecies, but merely variations.

Only one specimen of A. pacificus was available for anatomical dissections. The smooth form, from New Caledonia, corresponds to the form figured by Fraussen et al. (2007: Figs. 4243) which occurs in the same locality from circa (650-700m deep). The other, more robust form

of A. pacificus was studied in the molecular analysis of Couto et al. (2016); and both species appeared as sister taxa, which in turn are sister of A. sebalis Fraussen et al., 2007 and A. candoris Fraussen et al., 2007), the latter (Figs. 31-32) was also available for the morphological analysis herein. 


\section{Clade 3}

The presence of a long siphonal canal, which is generally characteristic of fusinines (but also occurring in some Pseudolatirus and Nodolatirus); and will be reverted in a peristerniine clade (e.g., Clade 8a).

Shells of the fusinine generalized morphology extend back to the early Cretaceous and, based on the fossil record, according to (Harasewych, 1990; Riedel, 2000), it is hypothesized that it is the plesiomorphic shell type of Neogastropoda. In the context of Fasciolariidae, the acquisition of a longer siphonal canal, which most notoriously represents the fusinine-like shell, is plesiomorphic to the peristerniine-like shell (shorter siphonal canal), only because Amiantofusus lacks a fossil record.

The continuing trend in the family of increasing the width of the lateral tooth of the radula, with a subsequent increase in the number of cusps, is once again observed in this node. The taxa included have at least five cusps in the lateral; this is not observed in any other buccinoid.

\section{Clade 3a}

The fusinine genera Fusinus, Cyrtulus, Chryseofusus and the previously peristerniine Pseudolatirus pallidus encompass this clade. This group is the second split from the paraphyletic Fusininae.

In the ML analysis of Couto et al. (2016) this group appeared (although unsupported) with almost the exact topology: Fusinus as the crown genus, sister to group of Chryseofusus and Pseudolatirus pallidus. The difference with the current morphological topology is that Fusinus and Chryseofusus form a group that is sister of Pseudolatirus pallidus. In the BI analysis, Fusinus was supported, being the sister genus of Amiantofusus, and that grouping with Chryseofusus and Pseudolatirus pallidus, much like in the ML analysis. In the present study, Pseudolatirus pallidus is the first split, followed by the genus Chryseofusus and Fusinus (including Cyrtulus).

The main synapomorphies of the group are the presence of a very long proboscis, in which the buccal mass is located anteriorly occupying only circa a quarter of the total proboscis length (character 42, Fig. AE). This proboscis is also coiled within its sheath (character 65, Fig. AV).

The same proboscis has been reported for other buccinoids in the literature (e.g., Troschelia berniciensis: Kosyan et al., 2009; Aulacofusus Dall, 1918: Kosyan \& Kantor, 2013), all in the family Buccinidae. None of the outgroup species of buccinid studied here (Pisania pusio or 
Buccinum undatum) have such proboscis type, albeit none belong to the same subfamily (as currently accepted: WoRMS, 2016).

Kosyan et al. (2009) analyzed the anatomy of Fusinus tenerifensis and noted that the proboscis is neither coiled nor long, but straight, and the buccal mass has the same length of the proboscis. These same authors stated that the fasciolariid proboscis is straight and never coiled within the rhynchodeum (proboscis sheath); but the only fusinine analyzed by them was Fusinus tenerifensis. These results contradict this clade's results, although no illustration of shell or radula was provided by Kosyan et al. (2009) in order to confirm the taxonomy of Fusinus tenerifensis.

Pseudolatirus pallidus (Fig. 33-34) is a Japanese species that appeared as sister species to Chryseofusus both here and in Couto et al. (2016). According to Callomon \& Snyder (2009), this species "may well prove too closely related to Fusinus to exclude from that genus", indicating that the placement in the peristerniine genus Pseudolatirus was merely provisional.

Several specimens of Pseudolatirus pallidus were analyzed, three of which were sampled in the analysis of Couto et al. (2016). Callomon \& Snyder (2009) pointed that many shells of this species differ somewhat among them (e.g., having finer and more broadly spaced axial sculpture and a slimmer profile), suggesting that this species, as well as others in the genus, require additional attention. Shell sculpture of Pseudolatirus pallidus varies enormously, usually with different placement of the axial sculpture, as noted by Callomon \& Snyder (2009) and by Couto et al. (2016). According to these last authors, who sampled three specimens, the lineage of Pseudolatirus sister of Chryseofusus comprises a species complex of Pseudolatirus pallidus (Pseudolatirus pallidus, P. aff. pallidus and Pseudolatirus sp. [sensu Couto et al., 2016]).

Since grouping with Chryseofusus seems an unlikely choice based on conchological characters alone, one must assume that the Pseudolatirus shell morphology is plesiomorphic, which is corroborated by the fact that this form is present in three independent clades: 1) sister of the group of Amiantofusus, 2) in Chryseofusus and 3) nested in Granulifusus. In Couto et al. (2016), the genus Pseudolatirus appeared in two distinct lineages.

\section{Clade 3b Chryseofusus + Fusinus}

This clade groups traditionally associated genera: Chryseofusus and Fusinus. The first was first described as a subgenus of the latter by Hadorn \& Fraussen (2003) and later elevated to genus category by Callomon \& Snyder (2009). 
Species herein are distinguished from others of this clade of fusinines (clade 3a) by the absence of the inner sculpture of the outer lip (character 7, Fig. G). The subfamily Fusininae is known to lack these sculptures, being ordinarily present in peristerniines and fasciolariines; with the discovery of new species and the re-examination of old taxonomy, this diagnosis can no longer be used precisely.

In Couto et al. (2016), who sampled four Chryseofusus species, the genera was recovered in both the ML and the BI analyses. The strict relationship with Fusinus, as implied in the literature (e.g., Hadorn \& Fraussen, 2003; Hadorn et al., 2008; Callomon \& Snyder, 2009) was only confirmed, however, in the ML analysis, in which the clade Chryseofusus and Pseudolatirus pallidus formed a sister group with Fusinus (albeit weakly supported). The present analysis corroborates this hypothesis, and Fusinus and Chryseofusus are grouped together

\section{Clade $3 b^{1}$ Chryseofusus}

The deep-sea genus Chryseofusus, groups a number of Indo-Pacific deep-water species occurring between 100 and 1900m that share conchological features different from typical Fusinus, mainly the reduced spiral and axial sculpture on the body whorl and a shorter spire and siphonal canal (Hadorn \& Fraussen, 2003). Upon their original description of the subgenera, Hadorn \& Fraussen (2003) distinguished Chryseofusus from other subgenera by its slightly convex whorls, axial ribs present only on the upper whorls, weak and close set spiral sculpture and an outer lip that is simple, lacking internal structures; the latter is also shared with Fusinus which difficult its diagnosis.

In the current analysis, the genus is characterized by many synapomorphies, including the loss of spiral sculpture of the shell (as originally described) (character 3, Fig. C); a heavily asymmetrical osphradium (character 23, Fig. S) and the female cement gland opening centrally in the sole of the foot (character 84. Fig. BH). Chryseofusus archerusius (Hadorn \& Fraussen, 2003) (Figs. 35-36) is distinguished from C. graciliformis (Sowerby, 1880) (Figs. 37-38) mainly by the more prominent axial nodes on the shoulder angulation and by a shorter, broader siphonal canal.

\section{Clade 3c Fusinus + Cyrtulus}

The name 'Fusus' has been used arbitrarily for numerous fossil and recent spindle-shaped shells (Snyder, 2003), and species in several distinct families received this designation. 
Historically, the genus Fusinus grouped species with an overall fusinine-like generalized morphology: a large size, tall elongated spire, long siphonal canal, usually with broad axial ribs and spiral cords, absence of columellar folds and operculum that corresponds to the size of the aperture (Hadorn \& Fraussen, 2003). Harasewych (1990) discussed that it likely represents the plesiomorphic shell type of Neogastropoda; Vermeij \& Snyder (2002), on the other hand, suggested that fusinines are a stem-group of fasciolariids distinguished from the other subfamilies by the absence of columellar folds. Some species of Fusinus bear resemblance to the genus Pseudolatirus (e.g., F. annae Snyder, 1986); however, the former genus lacks the one or two plicae that are characteristic of the latter (despite the fact that the genus Pseudolatirus is not monophyletic). More recently, Fusinus has undergone intensive taxonomical revisions, including descriptions of new species (Callomon \& Snyder, 2004; 2006; 2007; 2009), however, these focus mainly in the Pacific, mainly Japan and China Seas.

Of the nine extant genera o Fusininae (WoRMS, 2016), five have species previously attributed to the genus Fusus as the type species: 1) Amiantofusus (type: Fusus amiantus Dall, 1889); 2) Chryseofusus (type: Fusus chrysodomoides Schepman, 1911); 3) Granulifusus (type: Fusus niponicus Smith, 1879); 4) Viridifusus (type: Fusus buxeus Reeve, 1847); and finally, 5) the genus Fusinus (type: Murex colus Linnaeus, 1758)

Hadorn \& Rogers (2000) reviewed the taxonomy of extant Fusinus from the tropical western Atlantic; but out of the 37 species analyzed by these authors, only F. ansatus (Gmelin, 1791) has its occurrence assuredly reported for Brazil. Rosenberg (2009), on the other hand, reports seven species in the Brazilian coast, occurring in relatively shallow water (e.g., F. agatha [Simone \& Abbate, 2005] in 60m depth), this number is likely a sub-representation because of a lack of reported deep-water species.

Here, the genera Fusinus and Cyrtulus (Figs. 39-50) are grouped together, being corroborated by six synapomorphies, two of which are non-homoplastic and will be discussed here. The typical Fusinus radula, including that of Cyrtulus serotinus Hinds, 1843, has the lateral tooth with a progressive increase in the innermost cusps length (cusps one to three closest to rachidian) (character 63, Fig. AT); hence cusp one is smallest, followed by cusp two and sometimes cusp three (Figs. 40, 42, 44, 46, 48, 50). All radula figured in the literature (e.g., Hadorn \& Fraussen, 2006; Couto et al., [in prep]) have this conformation. 
The mid-esophagus of Fusinus and Cyrtulus has in its posterior side a ventral glandular region, posterior to the valve of Leiblein and anterior to the nerve ring. This structure was not observed for any other fasciolariid. It is worth mentioning that this is not the framboisse gland, which will be discussed later.

In the molecular analysis of Couto et al. (2016), the authors presented conflicting topological results with the present morphological analysis. In both their analyses (ML and BI), a first split within Fusinus separates F. australis (Quoy \& Gaimard, 1833), which is sister to the remaining Fusinus; a second split separates F. brasiliensis (Grabau, 1904) and Cyrtulus serotinus. On the other hand, in the present topology, two groups of Fusinus occur: a coastal Brazilian clade with F. marmoratus (Philippi, 1846), F. brasiliensis and Fusinus sp. and another clade with F. frenguelli (Carcelles, 1953), F. australis, and Cyrtulus serotinus. The biogeographical implications to these conflicting results are unclear, however.

\section{Clade $3 \mathrm{c}^{1}$ "Fusinus marmoratus complex"}

The southwestern Atlantic "Fusinus marmoratus complex" (sensu Hadorn \& Rogers, 2000) comprising of $F$. brasiliensis and F. marmoratus, are not related to other species in the northwestern Atlantic (Hadorn \& Rogers, 2000). This "complex" is extremely confusing and requires extensive taxonomical study (Hadorn \& Rogers, 2000) as it encompasses some similarshelled shallow water forms, with doubtful species-status and overlapping shell distinctions that superficially resemble $F$. marmoratus.

In this analysis, the clade $3 \mathrm{c}^{1}$ corresponds to the Fusinus marmoratus complex (F. marmoratus, F. brasiliensis and a Fusinus sp.); there are two reversions supporting it. First, the loss of the lipped margin of the renal aperture and second, the shorter pedal ganglia (characters 34, 90, Figs. Z, BM, respectively).

Currently in the database WoRMS (2016), Fusinus marmoratus is synonymized with $F$. verrucosus (Gmelin, 1791). There was no type locality of Fusinus marmoratus given by Philippi (1846), hence historically a lot of confusion over this species occur. Zenetos et al. (2005) reported $F$. verrucosus as an invasive Red Sea species in the eastern Mediterranean Sea via the Suez Canal; these authors synonymized $F$. verrucosus with $F$. marmoratus, but gave no basis for this action. WoRMS (2016), citing the Check List of European Marine Mollusca (CLEMAM), concurred with this taxonomic action, as have other authors (e.g., Buzzurro \& Russo, 2007); 
while many others maintain F. marmoratus as valid (e.g., Watson, 1886; Hadorn \& Rogers, 2000; Rios, 2009). Because no new designation for the Brazilian F. marmoratus was given by Zenetos et al. (2005), and because there are sufficient morphological differences that separate it from F. brasiliensis (Couto et al., in prep), Fusinus marmoratus is considered a valid species in the Brazilian coast.

Fusinus brasiliensis (Figs. 39-40) and F. marmoratus (Figs. 41-42) have very similar shells, mainly due to its size, the brownish coloration and the convex outline of its whorls. Both species are sympatric in the Southeastern coastal region in Brazil; however, F. marmoratus occurs more southward into the state of São Paulo (Rosenberg, 2009). They are distinguished from one another by the number of axial ribs: eight to ten in F. brasiliensis and 12 to 15 in $F$. marmoratus; and the sub-sutural ramp: slightly convex in $F$. brasiliensis and straight in $F$. marmoratus; the overall profile of the shell of $F$. marmoratus is somewhat broader and smoother than F. brasiliensis (Couto et al., in prep). Fusinus sp. (Figs. 43-44) is more closely related to Fusinus marmoratus based on head and cephalic tentacle characters.

\section{Clade 3d Fusinus}

The offshore Brazilian species Fusinus frenguelli and two pacific species, F. australis and Cyrtulus serotinus are grouped into this clade. The former species correspond to the first split of this clade, and the latter two are sister taxa. A notable, non-homoplastic synapomorphy of this clade is the presence of a unique osphradium: the leaflets of the right side, and sometimes both sides, possess a terminally digitated shape (character 25, Fig. U).

Fusinus frenguelli (Figs. 45-46) is distinguished from the other Brazilian Fusinus (F. marmoratus and F. brasiliensis, which are very similar to each other) based on the osphradium and female system traits (Couto et al., in prep). Fusinus frenguelli resembles somewhat $F$. lightbourni Snyder, 1984 from Bermuda however the latter is smaller and bears brownish spiral bands (see Hadorn \& Rogers, 2000). This species is the sister species of F. australis (Figs. 47-48) and Cyrtulus serotinus (Figs. 49-50), which have in common the spiral cords in the outer lip and similar head width and cephalic tentacle length.

The central Pacific species Cyrtulus serotinus is endemic to the Marquesas Archipelago in French Polynesia, and is the only species of the genus. The shape of its shell is unique within fusinines, with a last whorl embracing the earlier whorls, accompanied by a loss of ornamentation 
(see also Couto et al., 2016). Grabau (1907), in his essay on ontogenetic variation, stated that "no one can distinguish the young of Cyrtulus serotinus from that of any member of the Fusus series (...). Nevertheless, it remains true that Cyrtulus serotinus is a derivation of modern Fusus."

It is clear that this species is a Fusinus (Fusus, sensu Grabau [1907]) if one takes a look at a growth series (Couto et al., 2016: Figs. 6A-C). In light of the analysis of Couto et al. (2016), in which the species appeared nested within Fusinus and sister to the Philippine Fusinus longissimus (Gmelin, 1791) (on both ML and BI), the species is now considered as belonging to Fusinus (WoRMS, 2016). Presently, based on the topology presented here (agreeing with Couto et al., 2016 and WoRMS, 2016), this species is confirmed as a Fusinus, albeit highly derived.

\section{Clade 4 Granulifusus + Peristerniinae + Fasciolariinae}

This clade encompasses the fusinine genera Granulifusus, a bulk of the peristerniines and all fasciolariines. There is no non-homoplastic synapomorphy for the clade, but two homoplasies occur: a narrow osphradium (character 28, Fig. W) and a rhynchostome emarginated by a lipped rim (character 40, Fig. AC). Despite being grouped with Peristerniinae, Granulifusus was never suggested to belong with this subfamily; in Couto et al. (2016) the genus nested within other fusinines, differing from the topology herein.

\section{Clade 4a Granulifusus}

The genus Granulifusus, along with a species of the polyphyletic genus Pseudolatirus, comprehend this clade, being supported by numerous synapomorphies, including the loss of the inner sculpture of the outer lip (character 7, Fig. G), loss of the female cement gland (character 82, Fig. BH), a heavily asymmetrical osphradium (character 23, Fig. S) and features in the operculum (characters 16, 17, Figs. O, P, respectively). Operculum characters represent important non-homoplastic characters supporting this clade.

Granulifusus (type: Fusus niponicus Smith, 1879) was first described and characterized by Kuroda \& Habe (1952), based on Fusinus-like individuals with a granulated shell surface, radula with a small number of cusps on the lateral tooth and a small round operculum that does not fit entirely the aperture. The operculum also has a central nucleus, differing from other fasciolariids which have a terminal nucleus. All species of Granulifusus (including Pseudolatirus discrepans) 
figured in the literature have this operculum type (e.g., Hadorn \& Fraussen, 2005; Preetha et al., 2014). The genus currently accommodates 28 valid species worldwide (WoRMS, 2016).

Granulifusus is an Indo-Pacific genus and one of the Indo-Pacific elements occurring in Japanese warm waters (Shuto, 1958), being relatively common there. The genus was revised by Hadorn \& Fraussen (2005), who described several new species (e.g., G. bacciballus Hadorn \& Fraussen, 2005; G. benjamini Hadorn \& Fraussen, 2005) and transferred several others to it. The genus is monophyletic if Pseudolatirus discrepans is included (more on this species will be discussed later). In Couto et al. (2016) the genus is also monophyletic in both ML and BI analyses, with $P$. discrepans representing a first split in the clade.

An undescribed Granulifusus species (Fig. 51-52) with a deeply canaliculated suture and reduced granulated surface is the first split in the clade, while the group formed by G. Hayashi Habe, 1961, G. kiranus Shuto, 1958 and Pseudolatirus discrepans are sister to it. This Granulifusus sp. is the same specimen sequenced in Couto et al. (2016: Fig. 6L) and on their analysis this species is sister to G. kiranus, and this fact differs from the present work.

\section{Clade 4b}

In Couto et al. (2016), the whole of Granulifusus, Pseudolatirus discrepans, P. kuroseanus and P. kurodai Okutani \& Sakurai, 1964 form a monophyletic clade. In their topology, a first split separates $P$. kuroseanus and $P$. kurodai from the remaining; and while these species share

some similarities, there are very few resemblances between these shells and the typical Granulifusus-like shell (Couto et al., 2016: Fig. 6J). Because of this, a more conservative approach was taken and no taxonomical changes were made. Pseudolatirus discrepans corresponds to the sister taxa to all Granulifusus species in Couto et al. (2016), while here it is nested within the genus.

Pseudolatirus discrepans has been considered as a Granulifusus by several authors (e.g., Poppe, 2008), and based on the tree topology and on the sculpture of the initial whorls (which closely resembles that of many Granulifusus), the placement of Pseudolatirus discrepans in Granulifusus is likely correct. This is also corroborated by the results in Couto et al. (2016).

Clade $4 \mathrm{~b}$ is supported by two reversions: the proboscis retractor muscles inserting posteriorly and the presence of a seminal receptacle in the pallial oviduct. The Japanese species Granulifusus hayashi (Figs. 53-54) is the sister taxon to a group formed by G. kiranus (Figs. 55- 
56) and P. discrepans (Figs. 57-58). The latter two are sister species with a unique lamellated siphon. The speciation events, roughly visualized by the short branch lengths in Couto et al. (2016: Figs. 1-2) likely point to a rapid speciation, which may hinder taxonomical differentiation, especially conchological.

\section{Clade 5 Peristerniinae + Fasciolariinae}

This is an important clade of mostly peristerniines but also includes the monophyletic Fasciolariinae. Most synapomorphies supporting this clade are traditional diagnostic characteristics for the subfamily Peristerniinae: a shell with columellar folds medially in the aperture (character 8, Fig. H), a pseudoumbilicus (character 10, Fig. J) as a shallow slit, a headfoot mass pigmentation as dark-red (character 11, Fig. K) and a lateral margin of the operculum possessing a hook-like extension (character 18, Fig. Q).

The head-foot mass pigmentation is a non-homoplastic synapomorphy and mentioned by several authors when referring to species within this clade (e.g., Marcus \& Marcus, 1962: Leucozonia nassa; Poppe, 2008: Peristernia nassatula; Okutani, 2000: Fusolatirus pachyus Snyder \& Bouchet, 2006; Bouchet \& Snyder, 2013: Nodolatirus rapanus Bouchet \& Snyder, 2013). Harasewych (1998) reported as a distinguishing feature for Peristerniinae, and Fedosov \& Kantor (2012) used the coloration of the head-foot mass in live Angulofusus nedae to place it in the subfamily Fusininae.

Another head-foot mass character that is a non-homoplastic synapomorphy for this clade is a hook-like extension in the lateral margin of the operculum. Unlike previous opercula with a terminal nucleus, the nucleus of this type of operculum is located in lateral, hook-like extension (but see character discussion for more on this). Snyder \& Callomon (2005) stated the presence of a slightly hooked terminal nucleus for three Fusolatirus species, Couto \& Pimenta (2012) and Couto et al. (2015a; 2015b) for several peristerniine and fasciolariine species from Brazil.

This clade is corroborated by both ML and BI molecular analyses of Couto et al. (2016) which obtained a highly supported Peristerniinae and Fasciolariinae clade. In spite of the fact that the scope was not Fasciolariidae, Kosyan et al. (2009) obtained the peristerniine species (Turrilatirus turritus and Tarantinea lignaria) as the sister group of the fusinine species (Granulifusus niponicus and Fusinus akitai Kuroda \& Habe, 1961) based on their 16S rRNA analysis. Other works lack the species sampling to make any inference. 


\section{Clade 5a Peristerniinae}

The genus Fusolatirus was originally established by Kuroda et al. (1971), with the Japanese description a more detailed one than the English translation. Kuroda \& Habe (1971) noted that "the radula is the same as that of Peristernia, but [the new genus] is taller and more slender and differs particularly in its long siphonal process. [Members of] Pseudolatirus Bellardi, 1884 also have tall, slender shells, but they are larger and their siphonal processes" (Snyder \& Callomon, 2005). Snyder \& Callomon (2005) adds that a further Fusolatirus character not mentioned in the original description is a subsutural band found on all teleoconch whorls, which varies in prominence; additionally, there is a constriction of the aperture at the top of the siphonal canal that is caused by a deflection of the parietal wall. F. bruijnii (Tapparone-Canefri, 1876) fits this description, being very similar to Peristernia except for the long siphonal canal.

The type species of the subfamily Peristerniinae is Peristernia nassatula, a species sampled by Couto et al. (2016); because of this, on their analyses, the clade that contained this species corresponds to the subfamily Peristerniinae (a highly supported clade both in ML and BI analyses). This clade contained the genera Peristernia and Fusolatirus in Couto et al. (2016) and also in the morphology-based produced here, confirming the subfamily placement, and the relation between both genera, in this sense agreeing with Snyder \& Callomon (2005) and Snyder \& Bouchet (2006).

This clade is represented by Fusolatirus bruijnii (Figs. 59-60), Peristernia nassatula (Figs. 61-62) and P. marquesana (Adams, 1855) (Figs. 63-64). The radula (character 57, Fig. AP) is the main distinguishing feature for this clade, with the lateral teeth alternating smaller and larger cusps (Figs. 54, 56, 58); in other fasciolariids, however, the lateral teeth have regular cusp sizes. In fact all radulae of Peristernia and Fusolatirus figured in the literature (e.g., Bandel, 1984; Taylor \& Lewis, 1995; Kosyan et al., 2009 [Peristernia]; Snyder \& Bouchet, 2006 [Fusolatirus]) have 'Peristernia-like' radula. This dentition is variable to such a degree, that within one radula almost no lateral tooth is exactly like the other (Bandel, 1984). Other synapomorphies for this clade include reversions in the odontophore and anus (characters 45, 77, Figs. AG, BE, respectively).

Snyder \& Bouchet (2006) considered Fusolatirus a valid genus of peristerniine fasciolariids with long siphonal canal, imbricated subsutural spiral ridge and Peristernia-like radula. Despite these distinctions, the genus appeared diphyletic in the analyses of Couto et al. (2016) because 
Fusolatirus rikae (Fraussen, 2003) is the sister taxon of Peristernia and all other Fusolatirus species, and a clade nested within Peristernia comprises Fusolatirus pearsoni (Snyder, 2002), F . pachyus and F. bruijnii.

\section{Clade 5b Peristernia}

This clade groups Peristernia has been demonstrated to be non-monophyletic in the analysis of Couto et al. (2016), but because few taxa were used for the morphological analysis, this inference is not presently possible. This clade is supported by a reduction of the length of the siphonal canal (character 9, Fig. I), a radula with a more trapezoidal-shaped rachidian tooth and a wider lateral tooth (character 50, 55, Figs. AJ, AN).

The topology of the molecular analysis of Couto et al. (2016) shows a non-monophyletic genus: the clade including Peristernia marquesana and its closest relatives is supported in ML and BI analyses and it likely includes species related to P. ustulata and P. lyrata (Reeve, 1847) (see Poppe [2008: 108-109] for the illustration of several forms); the clade containing several species of Peristernia, including $P$. nassatula is the sister clade to several Fusolatirus and $P$. marquesana. These results contradict the present work, as Fusolatirus bruijnii is the sister taxon to the monophyletic Peristernia clade of $P$. nassatula and $P$. marquesana.

As these authors pointed out, the genus Peristernia and its allies have not been the subject of taxonomical revisions, and several species (Couto et al., 2016: Figs. 5E-F) are most likely new to science.

\section{Clade 6 Fasciolariinae}

Vermeij \& Snyder (2006) considered Fasciolariinae as derived from early peristerniines and the two groups are part of a single clade Fasciolariinae; Snyder et al. (2012) noted that both subfamilies are morphologically similar. Most taxa traditionally classified in Peristerniinae must in fact be relocated to Fasciolariinae, according to this analysis and those of Couto et al. (2016). This is due to the topology of their results, as traditional fasciolariines formed a clade derived from a group of Peristerniinae with high support, and in which the type species of Fasciolariinae, Fasciolaria tulipa, occurs in this clade containing the bulk of peristerniines non-Peristernia (this genus is included in Peristerniinae, as previously discussed). 
Morphologically, synapomorphies of this clade, none of which are non-homoplastic, include: head width and cephalic tentacle length (characters 13, 14, Fig. M), a reversion to a square-shaped rachidian tooth of radula (character 50, Fig. AJ) and salivary glands as two amorphous masses that are free from the nerve-ring (character 69, Fig. AY). This last character was only reported, among the seven species studied by Kosyan et al. (2009), for Fusinus tenerifensis and Tarantinae lignaria; however, these glands are usually made of a coarse and saccular structure that may be modified during preservation, interfering with the correct visualization.

Clade 6 comprises two distinct groups: clade 6a, with the previously assigned fasciolariines, Nodolatirus nodatus and Latirus vischii; and clade 7, with Hemipolygona, Pustulatirus, Polygona, Leucozonia, Opeatostoma, Latirus polygonus and L. pictus (Reeve, 1847). Couto et al. (2016) obtained three distinct groups for their corresponding clade, in which the topologies are more-or-less congruent between the ML and BI analyses; however, the relationship amongst them could not be discerned due to the low support for the deeper nodes (possibly indicating a fast speciation event). The differences between the morphological analysis undertaken here and the molecular analyses of Couto et al. (2016) are discussed in the following pages.

\section{Clade 6a}

The overall tendency for fasciolariids to increase the number of cusps in the lateral tooth of the radula attains its utmost extreme in this clade (with laterals bearing more than 16 cusps). Bandel (1984) illustrated many fasciolariid radulae, with three species of Fasciolaria, including F. tulipa; all radulae described agree with this pattern, despite some evidence that some fasciolariids increase the number of cusps in the lateral as the snail mature (e.g., Abbot, 1958 for Leucozonia nassa). All the cusps of the laterals of this clade possess more-or-less equal length, and the number of these is generally larger than in other fasciolariids (see Bandel, 1984: Figs. 257-268, for other examples of other fasciolariid radulae). The lateral teeth of the radula of Fasciolaria (Tarantinea) lignaria (Küster \& Kobelt, 1876; Kosyan et al., 2009) resemble that of many Latirus-like species, in having fewer, shorter and more strongly curved cusps. Snyder et al. (2012) placed this species in the genus Tarantinae Monterosato (1917) (see also WoRMS, 2016), previously a subgenus of Fasciolaria, due to the presence of an adapical sinus on the outer lip. 
Moreover, this species was considered a member of Peristerniinae "pending molecular confirmation" by these same authors.

Bouchet \& Snyder (2013) distinguished the newly-appointed genus Nodolatirus from other peristerniines by the presence of nodes and the heavy cords on the shell and by the "massive lateral tooth". The radula differs from Benimakia Habe, 1958 because this genus bears much thinner laterals, carrying five to six cusps (Bouchet \& Snyder, 2013: Figs 3A-F); it is this difference that prompted the consideration of a new genus.

Nodolatirus nodatus (Figs. 65-66) appeared on a clade with species of Latirus, Hemipolygona, Benimakia and Latirolagena Harris, 1897 in Couto et al. (2016), although with conflicting topologies between the ML and BI analyses and low support for some deeper nodes. The placement with Benimakia agrees with Bouchet \& Snyder (2013), but the radula, which is the main distinguishing feature between them, renders this species more related to clade $6 \mathrm{a}$, and that is confirmed here.

\section{Clade 6b}

This clade is characterized, among other features, by the absence of the innermost cusp of the radula's lateral tooth (cusp one) (character 60, Fig. AS). This is seen in the radula of most fasciolariines and in Latirus vischii. This species (Fig. 67) has a radula (Fig. 68) with a 'rounded' base of the tooth, (i.e., lacking the first cusp) as described by Couto et al. (2015b) for Fasciolaria tulipa. This feature according to Bullock (1974) distinguishes Latirus and related species (sic) from Leucozonia; he utilized the term denticle, which corresponds to cusp number one in this analysis. This 'denticle' was observed by Couto \& Pimenta (2012) and Couto et al. (2015a) for some Leucozonia species. The present work hypothesizes the loss of cusp one for two independent clades: clade $6 \mathrm{~b}$ and 14 , although in the latter, cusp two has a greatly increased length; all of these features are discussed more thoroughly in the character discussion section.

In Couto et al. (2016), Latirus vischii appeared as the sister taxon to Latirus polygonus and that is corroborated by shell morphology. Both species have very strong nodes on the shoulder angulation which are crossed by two whitish spiral cords, but the radula distinguishes both species: while in L. vischii it is a characteristic for this clade, in L. polygonus (Kosyan et al., 2009: Fig. 31), it is as most 'Latirus-like', with cusp one present and in reduced length. 


\section{Clade 6c}

Historically, most members of this clade have been assigned to the genera Fasciolaria or Pleuroploca. However, Snyder et al. (2012), after a thorough re-examination of their taxonomy, proposed several additional genera, e.g., Australaria, Aurantilaria, Viridifusus, etc. This clade contains species with broad axial ribs and nodose spiral sculpture (Aurantilaria aurantiaca [Lamarck, 1816], Filifusus filamentosus [Röding, 1798], Australaria australasia [Perry, 1811], Triplofusus giganteus [Kiener, 1840] and Pleuroploca trapezium [Linnaeus, 1758] - all traditionally in the genus Pleuroploca); while Fasciolaria and Cinctura Hollister, 1957 represent a Caribbean lineage with obsolete axial sculpture and weakly convex spiral whorls. Most other species of this group have some degree of nodose shells, but Snyder et al. (2012) noted that some species have both nodose and non-nodose forms, which may represent ecophenotypic, local or regional geographic variation.

In the analyses of Couto et al. (2016) the Caribbean species Fasciolaria tulipa, F. bullisi Lyons, 1972 and the related species Cinctura hunteria (Perry, 1811) appeared as a crown group, sister to the Indo-Pacific Pleuroploca trapezium. This group is sister to the remaining Aurantilaria, Filifusus, Triplofusus Olsson \& Harbison, 1953 and Australaria species, without support for their internal relationship and with conflicting ML and BI topologies. In this scenario, Caribbean lineages are present in the two main clades, representing at least two dispersal or vicariance scenarios. On the other hand, in the morphology-based topology presented here, the Caribbean species Aurantilaria aurantiaca and Fasciolaria tulipa form a polytomy with the remaining Indo-Pacific species Australaria australasia, Pleuroploca trapezium and Filifusus filamentosus. In the latter case only one biogeographic event occurs, a more parsimonious scenario than the one from Couto et al. (2016).

This clade seems highly derived, being characterized by several synapomorphies, none of which are non-homoplastic. Among them, noteworthy are the coloration of the shell that form blotchy spots (character 2, Fig. B), as opposed to regularly spaced; the loss of the pseudoumbilicus (character 10, Fig. J); the renal aperture situated close to pericardium (character 36, Fig. AA), as opposed to centrally in the membrane; the retractor muscle of the proboscis inserting posteriorly (character 68, Fig. AX); and an abrupt broadening of the posterior esophagus in the visceral region anterior to the stomach (character 74, Fig. BC). The anatomy of Fasciolaria 
tulipa was studied by Couto et al. (2015b) and these authors confirmed all of these characteristics. No other reports in the literature occur for these features, however.

Snyder et al. (2012) noted that the two species of Fasciolariinae that occur in Brazilian waters, Fasciolaria tulipa (Fig. 69-70) and Aurantilaria aurantiaca (Fig. 71-72), overlap in northern Brazil, and some geographic differentiation may occur. The former species has smooth axial sculpture while the latter has broad nodes on its shoulder angulation; a body pigmentation that is orange to light red with reticulated lighter pattern and the opening of the female cement gland is anterior.

Distinction of the Fasciolaria species from the West Atlantic is problematic (Lyons, 1972): while Rosenberg (2009) argued to the occurrence of at least seven distinct species occurring in sympatry in the Caribbean Sea: Fasciolaria tulipa; F. bullisi; F. hollisteri Weisbord, 1962; F. tephrina de Souza, 2002; F. branhamae Rehder \& Abbott, 1951; F. hunteria and F. lilium Fischer, 1807; Snyder et al. (2012) only recognized the first four as belonging to the genus. A more extensive sampling than one undergone here and in Couto et al. (2016) is necessary to resolve these taxonomic issues, likely due to recent dispersal events.

\section{Clade 6d}

This exclusively Indo-Pacific clade differs from the previous fasciolariines by its small head and cephalic tentacles (characters 13, 14, Fig. M) and by the cement gland (character 83, Fig. BH). This latter structure occurs immersed in the foot as several saccular vesicles branching from a single opening, and not as a single sac. Species here possess very broad and ample shells, with nodose sculpture present in the shoulder angulation, except for Filifusus filamentosus (Figs. 73-74), which has a more rounded profile. Australaria australasia (Figs. 75-76) and Pleuroploca trapezium (Figs. 77-78) have very similar shells, and the radula of the first has a reduction in the number of cusps of the lateral (Fig. 76), resembling somewhat other peristerniines in clade 7.

\section{Clade 7}

Clade 7 is the other main clade of Fasciolariinae, that includes the bulk of peristerniine-like species, such as Hemipolygona, Pustulatirus, Polygona, Leucozonia and certain Latirus. The most important synapomorphy of this group is the presence of discontinuous spiral cords, also called lirae, on the inner side of the outer lip (character 7, Fig. G). This feature was used by 
Vermeij \& Snyder (2006) to characterize the subfamily Peristerniinae; however, Vermeij \& Snyder (2002) pointed out that the beaded lirae likely evolved more than once in the Fasciolariidae. In the present analysis, this character is non-homoplastic, not supporting the hypothesis of Vermeij \& Snyder (2002).

The first split of this group is Hemipolygona armata (Adams, 1855) (Fig. 79-80) that is characterized by a reversion to a proboscis retractor muscle inserting posteriorly (character 68 , Fig. AX).

\section{Clade 8}

This clade is characterized by two reversions: the loss of the rhynchostome lipped margin (character 40, Fig. AC), and the reduction of the anterior fusion of the odontophore cartilages (character 44, Fig. AF). This clade groups species of peristerniine-like fasciolariines with the exception of Hemipolygona armata. The genus Hemipolygona is present in this analysis with two species: $H$. armata and $H$. beckyae. As with the analysis of Couto et al. (2016), the genus appeared non-monophyletic, with H. mcgintyi (Pilsbry, 1939) representing the first split of the Fasciolariinae clade, and H. armata sister to the genus Pustulatirus. Here, H. armata is the sister taxon to clade 8, and Pustulatirus the next split in the topology.

The genus Hemipolygona appeared as a non-monophyletic assemblage in Couto et al. (2016), although with a different taxon sampling then presently. In their ML analysis, H. mcgintyi is the basal most species of the clade (although unsupported), and H. armata is the sister to Pustulatirus species; in the BI analysis, H. mcgintyi attained the same position while H. armata is sister to Nodolatirus nodatus.

\section{Clade 8a Pustulatirus}

Species of Pustulatirus were previously classified in the genus Latirus (that was known until recently to be a polyphyletic taxon). The genus Latirus was restricted to the Indo-Pacific after the taxonomical review by Vermeij \& Snyder (2006); several other important taxonomical works on Latirus-like fasciolariids split the genus even more (e.g., Vermeij \& Snyder 2002; 2006) and the analyses of Couto et al. (2016) confirmed the placement of the Latirus complex as polyphyletic. Pustulatirus is an extant genus confined within the new world Atlantic and Pacific coasts, with a few fossil Neogene species (Lyons \& Snyder, 2013). The genus is recognized by 
six species in tropical western Atlantic and four in the Indo-Pacific (Lyons \& Snyder, 2013; WoRMS, 2016), being one of the few fasciolariid shallow-water genus with more representation in the new world.

Vermeij \& Snyder (2003) transferred numerous species to Benimakia, including B. ogum, originally described in the genus Latirus. These same authors characterized Benimakia as highspired fasciolariids with prominent axial ribs and a labral tooth at the end of the central cord of the outer lip. Couto et al. (2015a) noted that B. ogum (as Pustulatirus ogum) differs from other species of Benimakia in having a discontinuous beaded lirae on the inner side of the outer lip, in this respect resembling many Latirus (Vermeij \& Snyder 2003) and Pustulatirus (Vermeij \& Snyder, 2006). Species included in Benimakia by Habe (1958) and Vermeij \& Snyder (2003) occur in the west Indo-Pacific, with the exception of B. ogum, which putatively differs from other members of Peristerniinae related to Latirus in having a small labral tooth at the end of the basal cord (sic Vermeij \& Snyder, 2003). The presence of this tooth is questionable at best, as a labral tooth is not mentioned in the original description by Petuch (1979), nor was it found in Couto et al. (2015a). A pseudoumbilicus is also present, differentiating it from Benimakia, although it does occur in Pustulatirus. Based on these arguments, B. ogum clearly belongs to the genus Pustulatirus; this was evidenced by the topology in this study, sister species to $P$. mediamericanus and in the molecular analyses of Couto et al. (2016), sister to P. praestantior (Melvill, 1891) (in this sense also agreeing with Landau \& Vermeij, 2012; Lyons \& Snyder, 2013 and Couto et al., 2015a).

This study demonstrates the monophyly of the genus Pustulatirus, being supported by many reversions and non-homoplastic synapomorphies, most notable of which are the rachidian tooth bearing four principal cusps (character 55, Fig. AK) (also reported by Kosyan et al., 2009: Fig. 35), the paired proboscis retractor muscles inserting posteriorly (characters 67, 68, Figs. AW, AX, respectively) and the female cement gland opening centrally in the foot (character 84, Fig. $\mathrm{BH})$. It is the first split of the clade 8; in the ML analysis of Couto et al. (2016) the genus also appeared monophyletic and is sister Hemipolygona armata in the clade that includes Latirus polygonus, L. vischii and Latirolagena smaragdulus (Linnaeus, 1758), among others peristerniine-like, all previously assigned to the genus Latirus.

Pustulatirus mediamericanus (Fig. 81), the type species of the genus was not present in the analysis of Couto et al. (2016), although based on the topology presented here one may assume to 
belong in the same clade as $P$. ogum and $P$. praestantior. Pustulatirus mediamericanus resembles P. ogum (Figs. 82-83), and these are the largest congeners in the Pacific and Atlantic America, respectively. As with the shells of $P$. mediamericanus, the broad axial ribs of $P$. ogum assume a relatively lower profile as specimens approach maturity (Lyons \& Snyder, 2013); the smooth surfaces of intermediate spire whorls and the initial portion of the body whorl are supplanted by spiral cords that become prominent near the terminal edge of the shell in each species. Anatomically, P. ogum has a longitudinal rhynchostome and the duct of the penis is linear, differing from P. mediamericanus; both species share the four cusped rachidian tooth (Fig. 83).

\section{Clades 9 to 13}

The following clades form a grade (Figs. 84-92) that encompasses species of previously assigned Latirus; a genus in which the taxonomy has been confusing because it was used indiscriminately to include several species, some of them doubtfully related. Latirus was initially conceived as distributed worldwide; however, Vermeij \& Snyder (2006) constrained the known geographic range of the genus to be restricted to the western Indo-Pacific, and consequently raised several taxa previously considered as subgenera to genus rank (e.g., Polygona, Hemipolygona) and proposed new genera (e.g., Pustulatirus, Turrilatirus Vermeij \& Snyder, 2006).

The genus Polygona is the first split in the clade 9 and 11, evidencing its polyphyletic state. The genus is monophyletic in the analysis by Couto et al. (2016), highly supported and always grouped together with genus Turrilatirus. Vermeij \& Snyder (2006) considered Polygona and Turrilatirus similar in having broad axial ribs lacking nodes, and abapical denticles on the outer lip; however, Turrilatirus differs from Polygona in having a high spire, a short siphonal protuberance, and usually lacking a pseudoumbilicus.

Several authors have recognized informal groups within Polygona (Lyons, 1991; Vermeij \& Snyder, 2006); Vermeij \& Snyder (2006) also grouped species of Polygona into two groups but opted against giving them formal status in view of the "absence of more definitive molecular evidence". The first group contains P. angulata (Figs. 84-85), and possesses shells that are more stepped and nodose; the second group contains $P$. infundibulum (Figs. 87-88) with shells bearing a low shoulder angulation and axial ribs extending onto the long siphonal canal. In Couto et al. (2016), Polygona infundibulum grouped with P. bernadensis (Bullock, 1974), while this clade is 
the sister group of $P$. angulata; although a more thorough sampling of Polygona species is desirable, these groups concur with those recognized by Vermeij \& Snyder (2006) and may indeed justify formal separation, possibly as subgenera. These results do not agree with the present morphological analysis, since Polygona does not form a monophyletic group. The rachidian tooth of the radula of $P$. infundibulum bears secondary cusps in this sense differing from P. angulata (Figs. 85, 88).

Latirus polygonus (Fig. 86) and L. pictus (Figs. 91-92) are another case of the nonmonophyletic state of the genus. Both species were used in the analysis of Couto et al. (2016) and their results placed them in different positions: the first as the sister taxon to L. vischii and the second as sister to the clade of Turrilatirus and Polygona. Latirus vischii has the lateral tooth of the radula (Fig. 68) with the first innermost cusp lacking, and that is a synapomorphy of clade 6a; L. polygonus and L. pictus, on the other hand, have a typical "Latirus-like" (Fig. 92, but see Kosyan et al., 2009: Fig. 31) radula in having the first innermost cusp present, albeit reduced.

Hemipolygona beckyae (Figs. 89-90) is a Brazilian species with a prominent shoulder angulation as is characteristic for the genus lacking and a small number (four or five) of high, sharp spiral cords on the central sector of the last whorl and a more-or-less planar outer lip. Typical Hemipolygona have a more nodose shell, much like H. armata (Fig. 80). Morphologically, $H$. beckyae possess the rhynchostome positioned obliquely between the cephalic tentacles as an autapomorphy.

Fasciolariinae and Peristerniinae have a long history of divergence from the Cretaceous (approximately 140 Mya) but diversifying extensively during the Neogene (circa 24 Mya to the present) (Vermeij \& Snyder, 2006; Couto et al., 2016). In the analyses of Couto et al. (2016) many deep relationships within this clade received little or no support and are incongruent between the ML and BI analyses. However, all genera, with the exception of Hemipolygona, are monophyletic and show high support in both their analyses.

The fact of the short branch lengths and incongruent results of Couto et al. (2016) is likely the result of a very rapid speciation, which did not leave an imprint in genetic difference, at least in the analyzed genes. If speciation events are closely spaced in time, the amount of phylogenetic signal is often small, leading to short internal tree branches that are difficult to resolve (Philippe et al., 2011) This hypothesis agrees with the morphological one presented here, as each of the 
nodes in clades 9 to 13 is supported by very few synapomorphies (no more than two), none of which are non-homoplastic. This also indicates a rapid speciation event.

\section{Clade 14 Leucozonia and Opeatostoma}

The genus Leucozonia comprises shallow water coastal species that are usually very common in low rocky intertidal and sublittoral communities. The genus is exclusive to the new world coast, with nine extant species (WoRMS, 2016); however, it is poorly represented in the fossil record in Neogene fossils from the same locality (Vermeij, 1997).

Morphologically, clade 14 is well supported by many synapomorphies, including the loss of the longitudinal folds in the margin of the rhynchostome (character 39, Fig. AC), a long odontophore (character 42, Fig. AE) and the typical radula: the lateral tooth lacks cusp one, much like the fasciolariine clade $6 \mathrm{~b}$, however, unlike species in that clade, cusp two is longer, approximately twice in length as the other cusps (characters 60, 61, Fig. AS). In this sense, the functional innermost cusp is longer, and that is diagnostic for all species of this clade. This characterization of the radula as diagnostic for Leucozonia and Opeatostoma species seems to be true for all radulae figured in the literature (e.g., Leucozonia ocellata and L. nassa by Bandel, 1984: Figs. 261, 263; Leucozonia nassa by Matthews-Cascon et al., 1989: Fig. 3; Opeatostoma pseudodon by Kosyan et al., 2009: Fig. 37; L. nassa, L. ocellata and L. ponderosa by Couto \& Pimenta, 2012: Figs. 1P, 5F, 9N)

The radula of Latirus (sic) smaragdulus (Latirolagena smaragdula) figured by Bandel (1984: Fig. 264) seems to fit this patter, with a longer innermost cusp (due to the loss of cusp one). This author considered this to be a transitional form between the radulae of Latirus and Leucozonia species from the Caribbean and those of Fasciolaria species, with the many narrow cusps. The radula of this species is confirmed in Taylor \& Lewis (1995: Fig. 8), and indeed this radula type seems to belong to this clade. In the analyses of Couto et al. (2016) the position of $L$. smaragdula disagrees with this assumption because this species did not appear closely related to Leucozonia; the meaning of this is beyond the means of the present study.

In Couto et al. (2016), the genus Leucozonia was evidenced as non-monophyletic, with $L$. ocellata and L. cerata (Wood, 1828) as a natural group, and the remaining species of the genus and Opeatostoma pseudodon in a different clade. There were conflicting topologies between the ML and the BI analyses. 


\section{Clade 14a Leucozonia ocellata, L. cerata and Opeatostoma pseudodon}

Two Pacific species, Opeatostoma pseudodon and Leucozonia cerata, and the Atlantic $L$. ocellata, form this clade. The internal relations between these taxa are still dubious, due to the polytomy in the final strict consensus tree.

The present morphology-based topology shows a strong support with many synapomorphies for clade 14a, among the most important ones: the position and margin of the rhynchostome (character 37, Fig. AB), the female cement gland opening (character 84, Fig. BH) and the linear duct of the penis (character 87, Fig. BJ). When analyzed through molecular means, Couto et al. (2016) obtained a different result: in both ML and BI analyses, Leucozonia nassa, L. ponderosa and Opeatostoma pseudodon formed a highly supported clade, while L. ocellata and L. cerata appear as the sister clade to the clade of Turrilatirus and Polygona.

Couto \& Pimenta (2012) analyzed shell morphology and internal anatomy of the Leucozonia species from Brazil (L. nassa, L. ponderosa and L. ocellata). Despite L. nassa and L. ponderosa possessing a very similar internal anatomy, L. ocellata was shown to possess more differences; that corroborates with the present results ( $L$. nassa more closely related to $L$. ponderosa than to L. ocellata). Leucozonia ocellata (Figs. 93-94) is usually a smaller Leucozonia species characterized by the distinct shoulder axial sculpture bearing a white blotchy coloration and the absence of a labral tooth. Although L. ocellata shows considerable variation in shell form and sculpture, it is hard to identify geographical patterns in this species (Vermeij \& Snyder, 2002). The heavily asymmetrical osphradium and the rachidian tooth of the radula with fewer cusps (Fig. 98) are autapomorphies of this species.

The closest relative to L. ocellata, L. cerata (Figs. 95-96) is the sister species in the analysis of Couto et al. (2016), and both have many similarities in shell structure, including the absence of a labral tooth. Leucozonia cerata differs from the western Atlantic L. ocellata by attaining a much larger adult size, and usually having a higher spire, much weaker lirae, and stronger principal spiral cords. The autapomorphies of L. cerata, which distinguish it from its closely related L. ocellata, occur in the renal cavity, odontophore and nerve ring.

Opeatostoma pseudodon (Figs. 97-98) is a unique species characterized by a long and curved labral tooth that is completely enveloped by the mantle when the animal is active, which is evidenced by its very sharp edge (Vermeij, 2001). It is formed differently than that of Leucozonia because, in the former, it is formed as an extension of the spiral groove; while in the 
latter it is formed as an extension of a cord between the base and the central sector of the outer lip (Vermeij \& Snyder, 2002). In the phylogeny of Couto et al. (2016), O. pseudodon is the sister species to the western Atlantic Leucozonia nassa complex clade (clade 15), with high support; in the current morphology-based scenario, this species if grouped with Leucozonia ocellata and $L$. cerata, within a polytomy.

Opeatostoma pseudodon is highly modified, with many autapomorphies, most notable of which are: a lacking the spiral sculpture; a distinct labral tooth is present in the outer lip; the loss of the longitudinal folds in the margin of the siphon; the renal aperture is emarginated by a lipped rim; the rachidian tooth of the radula that may bear more than five cusps (Figs. 98B-C); the posterior esophagus has a broadening in the visceral region; and the presence of a penis ejaculatory duct as a long convoluted tube (characters 3, 5, 30, 34, 51, 74, 89, Figs. C, E, X, Z, AK, BC, BL, respectively).

This species was analyzed by Kosyan et al. (2009) and these authors confirmed its position within the fasciolariids based on anatomical features, notably the absence of a posterior sorting area (caecum) in the stomach and the typical radula. The rachidian tooth of the radula was reported possessing five cusps by Kosyan et al. (2009); here, up to 12 cusps occur and sexual dimorphism was discarded as all specimens analyzed were female. Bandel (1984) reported that the number of cusps in the lateral tooth grows as the snail matures, and that may be the case here, although a larger number of specimens must be studied in other to confirm this hypothesis.

\section{Clade 15 "Leucozonia nassa complex"}

The Leucozonia nassa complex is here represented as two closely related binomial species, L. nassa and L. ponderosa, and three subspecies of L. nassa. This clade contains a polytomy and it is not possible to more closely infer the relationships between these species.

Unlike the preciously discussed Opeatostoma pseudodon, a ventral labral tooth may be present in the outer lip in some of these taxa; however, it is not covered by the mantle, being blunt and short (character 5, Fig. E). Other synapomorphies include the medium-sized head and cephalic tentacles (characters 13, 14, Fig. M), a secondary inner cusp present in cusp two of the lateral tooth of the radula (character 62, Fig. AS), a seminal vesicle present in the oviduct and a short bursa copulatrix (characters 78, 80, Fig. BF). 
Leucozonia ponderosa is endemic of Trindade Island; an oceanic island off the coast of the state of Espírito Santo in southeastern Brazil. Leucozonia nassa sensu stricto has a wider geographical range on the continental shelf from the northeastern to the southern coast of Brazil, as well as the oceanic islands of Trindade and Fernando de Noronha (Leal, 1991; Rios, 2009). Both species undergo intracapsular or lecithotrophic development (Leal, 1991), as do other fasciolariids. The most common of these, Leucozonia nassa, has a marked geographical differentiation, leading to the occurrence of several synonyms, and at least three distinct morphs based solely on shell characters, which were considered by Vermeij (1997) as three different species, L. nassa, L. cingulifera (Lamarck, 1816), and L. brasiliana (d'Orbigny, 1841). In contrast, Vermeij \& Snyder (2002) argued that these characters alone may be insufficient to allow separation of species. Due to overlapping geographic ranges and the presence of intermediate forms, L. nassa is recognized as a single species (Rosenberg, 2009; WoRMS, 2015). The endemic species from Trindade Island, L. ponderosa was considered by Rios (2009) as a synonym of L. nassa.

Couto et al. (2016) sampled representatives of all three geographical subspecies of Leucozonia nassa, and they grouped as a single well supported clade. Based on their tree topology and the fact that Leucozonia nassa has a non-planktotrophic development (Leal, 1991), the forms that are geographical isolates may indeed constitute different species. Leucozonia ponderosa appeared as sister to L. nassa cingulifera from the Fernando de Noronha Archipelago, northeastern Brazil. These insular subspecies grouped with the coastal southeastern Brazilian $L$. nassa brasiliana, a clade that is sister group of the three Caribbean specimens corresponding to $L$. nassa nassa. The Caribbean clade was highly supported in both ML and BI analysis, albeit the other nodes within this group received weak support and conflicting topologies among analyses. The specimens utilized by Couto et al. (2016) correspond to the forms used in the present morphological analysis; hence the subspecies category was used in conformance with these authors.

The typical Leucozonia nassa nassa (Fig. 99) has a moderately broad shell and defined spiral and axial sculpture. The basal cord, in which the labral tooth emerges, is enlarged; in addition, spiral threads cover the entire shell surface. The siphonal canal is relatively long in relation to the other forms. Leucozonia nassa cingulifera (Fig. 100), is a large, extremely thickshelled form with a peach-colored aperture. Spiral sculpture in this form is usually in the 
presence of very weak cords or may be obsolete. Axial sculpture is also weakly developed, which may be accentuated by the presence of calcareous algae incrusted in the shell. Labral tooth is present and also very thick. Leucozonia nassa brasiliana (d'Orbigny, 1841) (Fig. 101-102), has a less nodose shell, with fewer and lower shoulder axial nodes on the shoulder angulations, also the spiral cords are weak and not enlarged as they are in the typical form of L. nassa nassa. The aperture is typically peach-colored, and the siphonal canal is short.

Couto \& Pimenta (2012) found no anatomical differentiation between these three forms, and they concluded that these forms are merely geographical variants, despite the fact that they do not possess planktotrophic dispersal. In fact, in the level of anatomical dissections presented here, no differences may be observed between these forms, and that is evidenced by the lack of autapomorphies and by the polytomy they occur in. Through molecular means, however, these forms seem to be in speciation, as proven by the topology in Couto et al. (2016).

Leucozonia ponderosa (Figs. 102-103) has a single autapomorphy (pedal ganglia length) and has been distinguished in shell characters by Couto \& Pimenta (2012). These authors distinguished this species as distinct from L. nassa on the basis of a more prominent spiral sculpture and a somewhat heavier nodulose shell. According to Vermeij \& Snyder (1998) and Couto \& Pimenta (2012), in the typical form of L. nassa, the two upper main cords lie very close together, whereas in L. ponderosa the second cord lies approximately midway between the shoulder cord and the central cord. Anatomically, the only minor difference is in the radula, which has a well-marked denticle on the inner margin of the lateral teeth, according to Couto \& Pimenta (2012); this denticle occurs much more pronouncedly in L. ponderosa than in other Leucozonia species (Fig. 104). 


\section{Character discussion}

The following pages list each of the 96 characters used in this analysis, and they are thoroughly discussed in a morphological point of view, as opposed to a phylogenetic point of view as seen in the Phylogenetic Discussion section. As before, discussion is based on the phylogenetic analysis using prior weighting only.

Each character is illustrated by a figure (numbered A, B, AA, AB, etc.) When a figure illustrates more than one character, following each figure caption is the character number (e.g., char. 31), followed by the state in which it is found (e.g., char. 31: 1). Readers are referred to the cladogram (Fig. 6) for the numbering of the clades present in this discussion.

\section{Shell, spire (fig. A)}

$$
\begin{gathered}
(\mathrm{L}=1 ; \mathrm{Ci}=100 ; \mathrm{Ri}=100) \\
\text { 0. Involute } \\
\text { 1. Visible }
\end{gathered}
$$

An involute spire occurs in the families included in Cypraeoidea (families Cypraeidae, Eratoidae, Lamellariidae, Ovulidae, Pediculariidae, Triviidae, and Velutinidae) sensu Simone (2011). While there are several degrees of involute shells caused by the apical growth of the outer lip, in most of

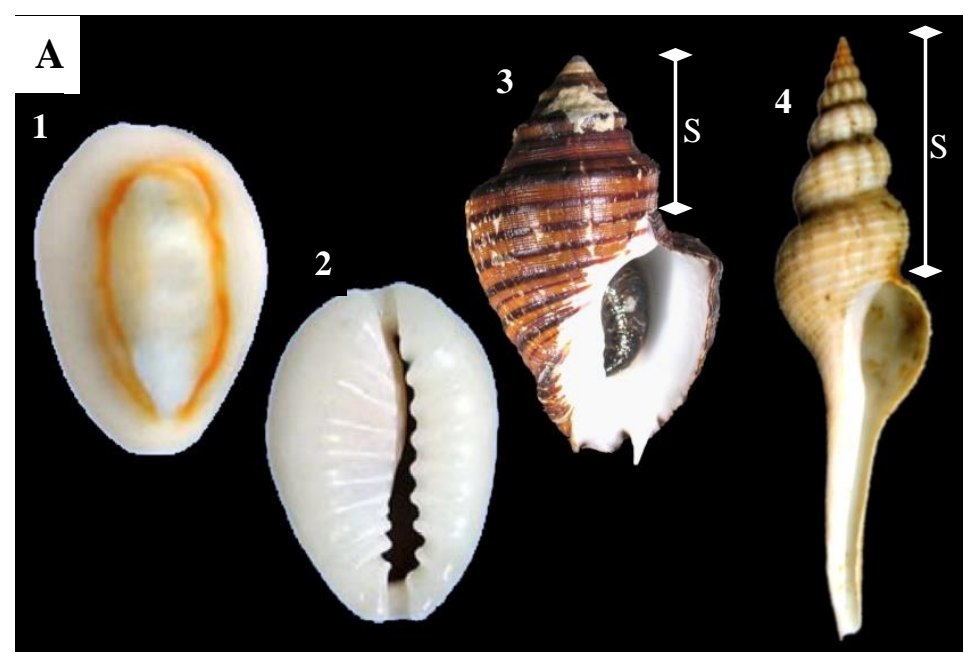

A. Shell in apertural and abapertural view. A1-2. Monetaria annulus (modified from Simone, 2004) involute spire (0); A3. Opeatostoma pseudodon and 4A. Fusinus frenguelli, visible spire (1). S: spire.

these the apex is completely covered as is the case herein for the outgroup species Monetaria annulus (0). A visible spire (1) on the other hand is present in most Neogastropoda (Simone, 2011), and all the remaining species. Because of the outgroup choice, this character is plesiomorphic in this analysis, however in the context of Caenogastropoda, it is actually apomorphic, as pointed out by Simone (2011). 


\section{Shell, pigmentation (fig. B)}

\section{$(\mathrm{L}=3 ; \mathrm{Ci}=33 ; \mathrm{Ri}=66)$ \\ 0 . Blotchy \\ 1. Absent or regular}

Fasciolariids, when possessing coloration in the shell, usually have a regular color pattern, with nodes or spiral bands evenly spaced throughout the entire shell (1). A blotchy color pattern (0) occurs when the coloration is not evenly arranged spirally or axially.

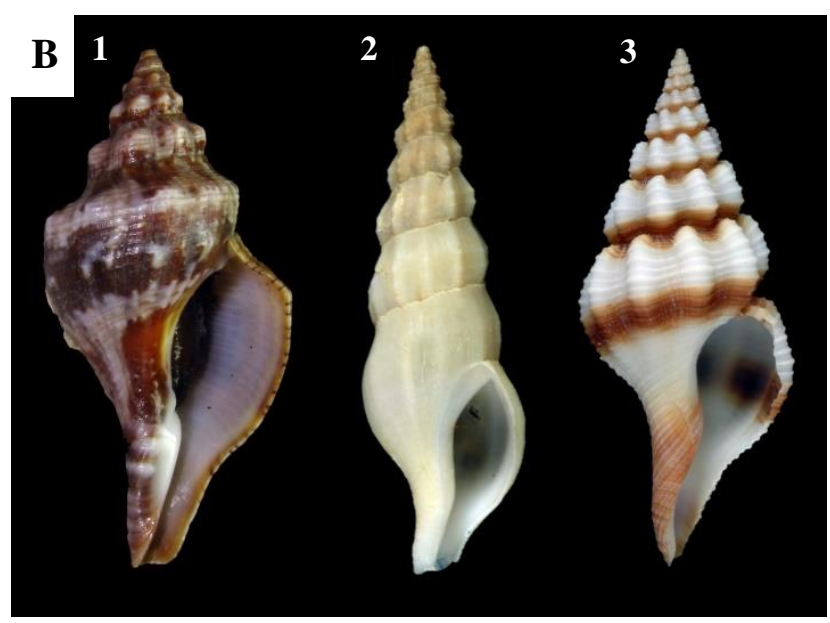

B. Shell in apertural view. B1. Aurantilaria aurantiaca, coloration of shell in blotchy pattern (0); $\mathbf{B 2}$. Amiantofusus candoris, coloration of shell absent (1); B3. Pseudolatirus sp. regular coloration pattern (1).

Fasciolariids have a coloration pattern that is

either regular or absent, except for clade $6 c$ of fasciolariines.

\section{Shell, spiral sculpture forming elevated nodes (fig. C)}

$$
(\mathrm{L}=9 ; \mathrm{Ci}=11 ; \mathrm{Ri}=27)
$$
0 . Absent
1. Present

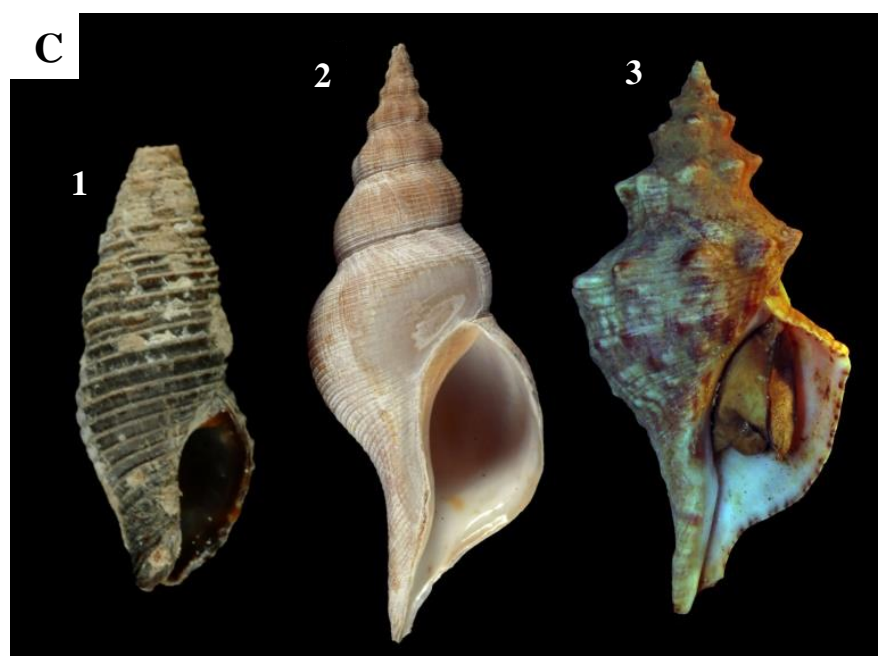

C. Shell in apertural view. C1. Dolicholatirus sp. and C2. Chryseofusus graciliformis spiral nodes absent (1); C3. Aurantilaria aurantiaca, spiral nodes present (0).
The presence of spiral sculpture forming elevated nodes is usually the case for most neogastropods, and it is evidenced here (1). In several cases within Fasciolariidae there has been a reversion of the spirally nodulose shell (0), as is the case for the Dolicholatirus and Teralatirus clade, for Chryseofusus, as well as four more times independently as autapomorphies. A DELTRAN optimization was chosen as to force independent reversions in the outgroup species Nassarius reticulatus and 
Bullia laevissima. The presence of strong spiral cords must not be mistaken for the presence of nodes, as most fasciolariids possess some spiral sculpture.

Some species (e.g., Leucozonia nassa, Aurantilaria aurantiaca, Pugilina tupiniquim), that normally have elevated nodes, may occur in individuals that lack any sculpture, although the ability to produce such nodes was indicated by the state (1), despite occurring in the (0) state. It is notable ability of shells to be molded by the environment; experimental and accidental transplantations of individuals from one environment to another are typically accompanied by dramatic changes in shell shape, sculpture, and color (Vermeij, 2002). This fact relates to most, if not all, shell characters herein. Fasciolariidae have a spiral sculpture forming nodes as a basal state, however clades 1a, $3 b^{1}$, Fusolatirus bruijnii, Fasciolaria tulipa, Filifusus filamentosus and Opeatostoma pseudodon have lost this characteristic.

\section{Shell, outer lip, anal notch (fig. D)}

$$
\begin{aligned}
& (\mathrm{L}=3 ; \mathrm{Ci}=66 ; \mathrm{Ri}=0) \\
& \text { 0. Absent } \\
& \text { 1. Present ventral in aperture } \\
& \text { 2. Present lateral in aperture }
\end{aligned}
$$

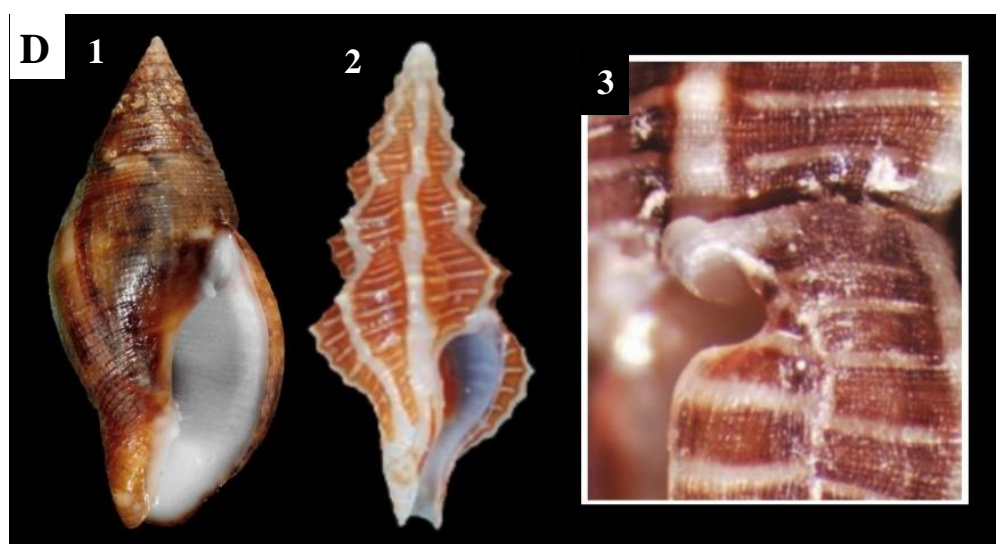

D. Shell in apertural view and detail of aperture. D1. Pisania pusio, anal notch present ventral to aperture (1); D2-3. Angulofusus nedae (modified from Fedosov \& Kantor, 2012), anal notch present lateral to aperture (2).
In the original description of Angulofusus nedae Fedosov \& Kantor, 2012, the only representative of the genus, a superficial conchological resemblance to some Conoidea was noted by its authors notably the distinctive anal notch. Upon closer examination, it was noted the similarity of a sinus in the apical apertural region of Pisania pusio (1), however the sinus in A. nedae is more lateral (2), suggesting a dorsal migration of the sinus and forming a notch in the mantle. 


\section{Shell, outer lip, labral tooth (fig. E)}

$$
\begin{aligned}
& (\mathrm{L}=3 ; \mathrm{Ci}=66 ; \mathrm{Ri}=85) \\
& \text { 0. Absent } \\
& \text { 1. Present, covered by mantle } \\
& \text { 2. Present, not covered by mantle }
\end{aligned}
$$

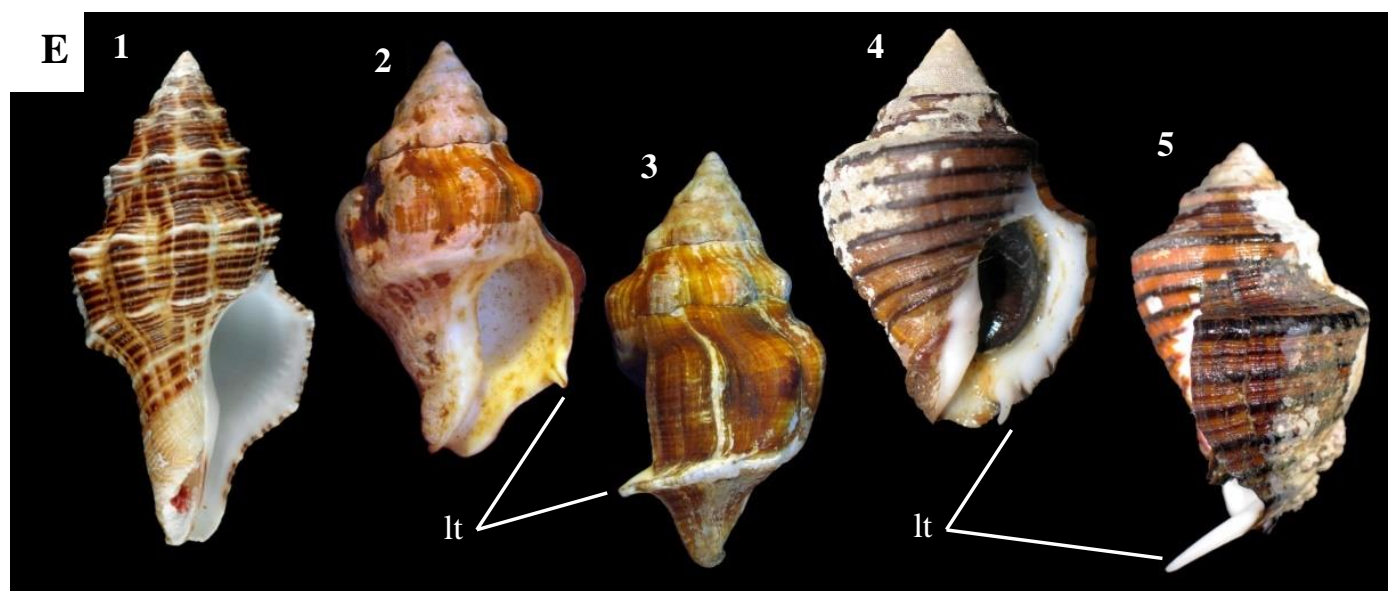

E. Shell in apertural and lateral view. E1. Latirus vischii, no labral tooth (1); E2-3. Leucozonia nassa cingulifera, labral tooth not covered by mantle (2); E4-5. Opeatostoma pseudodon, labral tooth covered by mantle (1). lt: labral tooth.

A labral tooth is a downwardly projecting tooth or spine formed at the edge of the outer lip of the shell. The labral tooth plays a more or less active part in predation on relatively large prey animals, such as helping to part bivalve mollusks or even anchorage in the substrate while predation takes place (Vermeij, 2002).

The highly unusual eastern Pacific species Opeatostoma pseudodon has the longest known labral tooth of any gastropod, being unusual for at least three reasons other than its length, as pointed out by Vermeij (2001): First, the tip of tooth is always sharp and never worn; second, it is entirely smooth, indicating that it is covered by an extension of the mantle in life; and third, it is separated from the adapical sector of the outer lip by a deep sinus, which exaggerates the tooth's length. This (1) is an autapomorphic state for Opeatostoma pseudodon. Leucozonia nassa nassa and L. ponderosa (clade 15) on the other hand, possesses a labral tooth that is ventrally directed and developed on outer lip at end of central spiral cord (2) and is not enveloped by mantle, as it is blunt and coarse. As pointed out by Simone \& Ramos (1986) for the Brazilian Leucozonia nassa 
complex, some populations lack the labral tooth altogether, not occurring in Leucozonia nassa brasiliana.

\section{Shell, outer lip, apical growth of last whorl (fig. F)}

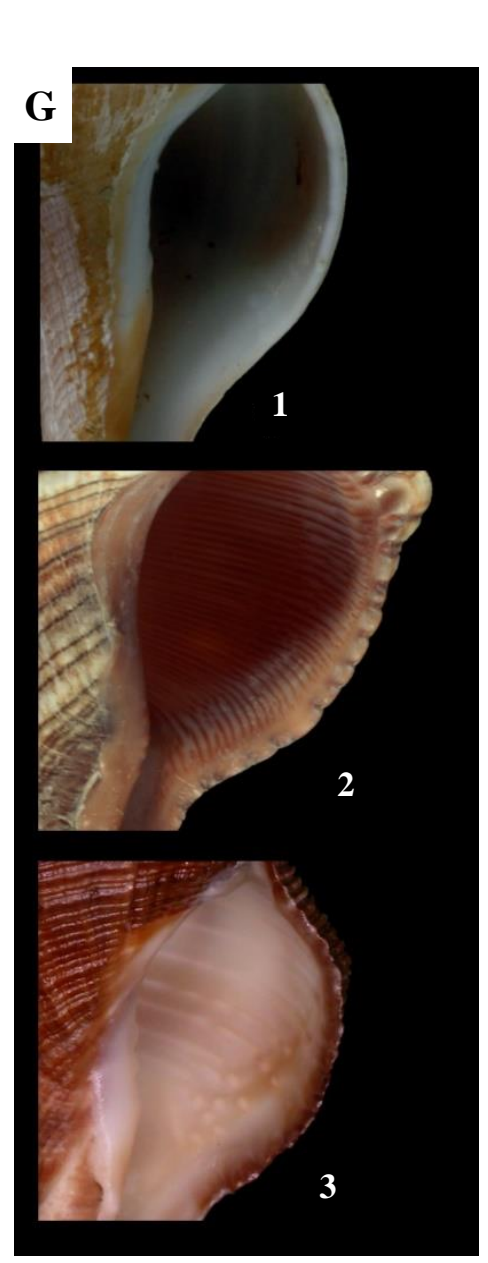

$$
(\mathrm{L}=5 ; \mathrm{Ci}=20 ; \mathrm{Ri}=20)
$$

0. Present

\section{Absent}

During the last stages of growth, the last whorl may grow towards the apex of the shell, or even

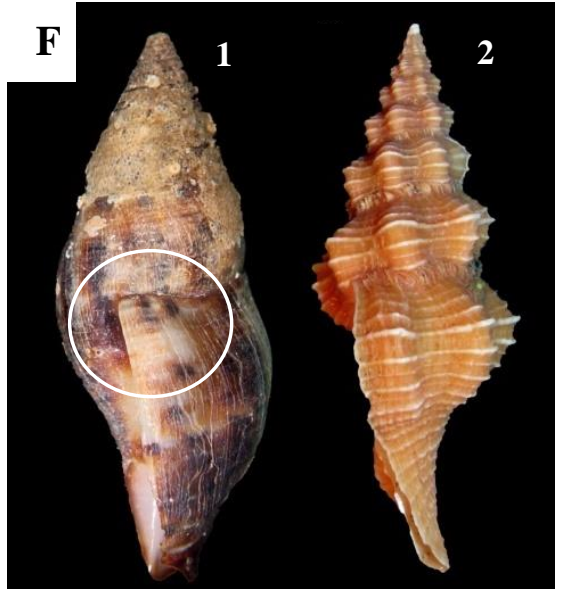

F. Shell, lateral view. F1. Pisania pusio, lateral view evidencing the apical growth of the last whorl (1); F2. Hemipolygona beckyae, no apical growth (1). encircle earlier whorls, such as in the case of Monetaria annulus. Usually, this apical growth (1) occurs to a certain degree in the outgroup species but never in Fasciolariidae, with the exception of Cyrtulus serotinus, which has a very aberrant shell in general.

\section{Shell, outer lip, inner sculpture (fig. G)}

$$
(\mathrm{L}=7 ; \mathrm{Ci}=28 ; \mathrm{Ri}=84)
$$

0 . Absent

1. Continuous spiral cords

2. Discontinuous spiral cords

G. Apertural view of shell. G1. Pseudolatirus discrepans, no inner sculpture on the outer lip (0); G2. Pleuroploca trapezium, inner sculpture of continuos spiral cords (1); G3. Leucozonia nassa, inner sculpture of discontinuous spiral cords (2).

The sculpture present on the inner side of the outer lip in the form of spiral ridges are lirae. In most gastropods with lirae they are continuous spiral cords (1) extending from near the edge of the outer lip to a variable distance within the aperture. Smooth lirae of this kind characterize the vast majority of fasciolariids; on the other hand, discontinuous lirae which appear granular or beaded (2), are rare among gastropods (Vermeij \& Snyder, 2002). The latter occur among neogastropods only in some species in the families Fasciolariidae, Costellariidae, and Buccinidae (Vermeij \& Rosenberg, 2003). 
Beaded lirae have been used to diagnose several fasciolariid groups (e.g., Latirus [Vermeij \& Snyder, 2006], Leucozonia [Vermeij \& Snyder, 2002], Pustulatirus [Lyons \& Snyder, 2013]), which appear distinct from the smooth continuous spiral cords. The presence of such sculpture has not been explicitly discussed in the literature, and nothing is known of their function. Vermeij \& Snyder (2002) hypothesized that it likely evolved more than once in the Fasciolariidae, a hypothesis not confirmed here, since it appeared only once: in the group composed of the genera Leucozonia, Hemipolygona, Polygona, Pustulatirus and Latirus polygonus and L. pictus (clade 7).

Continuous cords (1) are present basally in the family, and the absence of any sculpture (0) reversed in several groups within fasciolariids, including clades 2 b (Pseudolatirus kuroseanus and Amiantofusus), 3c (having reappeared in 3e) and 4a (Granulifusus and Pseudolatirus discrepans) Although such sculpture is present in mature shells, however, it may be poorly developed or absent on immature specimens (Lyons \& Snyder, 2013). Because discontinuous spiral lirae are likely derived from the continuous ones, an additive parsimony model was chosen $(0-1-2)$.

8. Shell, columellar folds (fig. $\mathrm{H}$ )

$(\mathrm{L}=4 ; \mathrm{Ci}=25 ; \mathrm{Ri}=86)$

0 . Absent

1. Present

A Columella fold is any ridge on the inner lip of the aperture that extends along the columella for a number of

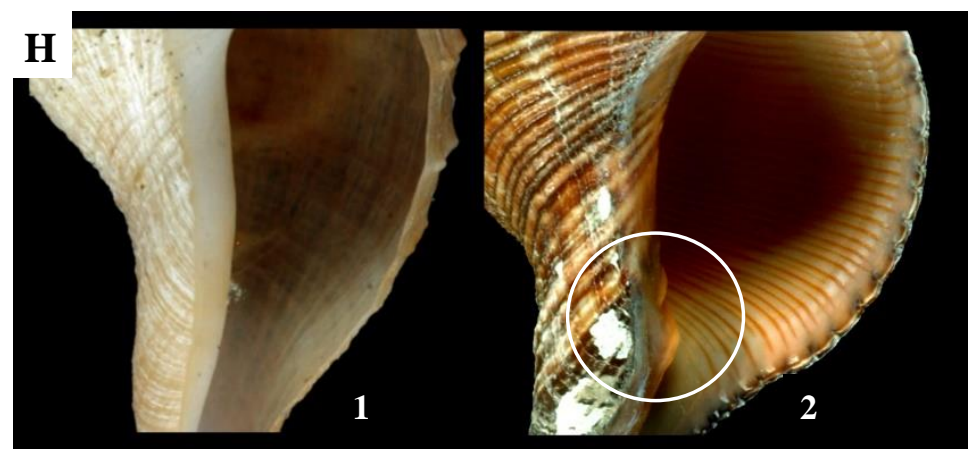

H. Apertural view of shell. H1. Granulifusus sp. columella lacking columellar folds (0); H2. Filifusus filamentosus, evidencing the columellar folds (1). whorls, but usually all the way to the apex (1). Folds in fasciolariids are the folds located at the bottom of the inner lip of the aperture, near the entrance to the siphonal canal (1), and in some it may be absent (0). Not unlike the beaded lirae discussed earlier, internal ornamentation such as folds are gradually deposited in the wrinkles that would form when the large mantle retracted into the shell (Dall, 1894). Researchers (e.g., Kier \& Smith, 1985) often assumed that columellar folds are a type of internal ornamentation that enhances the performance of the columellar muscle, however, Price (2003), through several measurement parameters and biomechanical observations, 


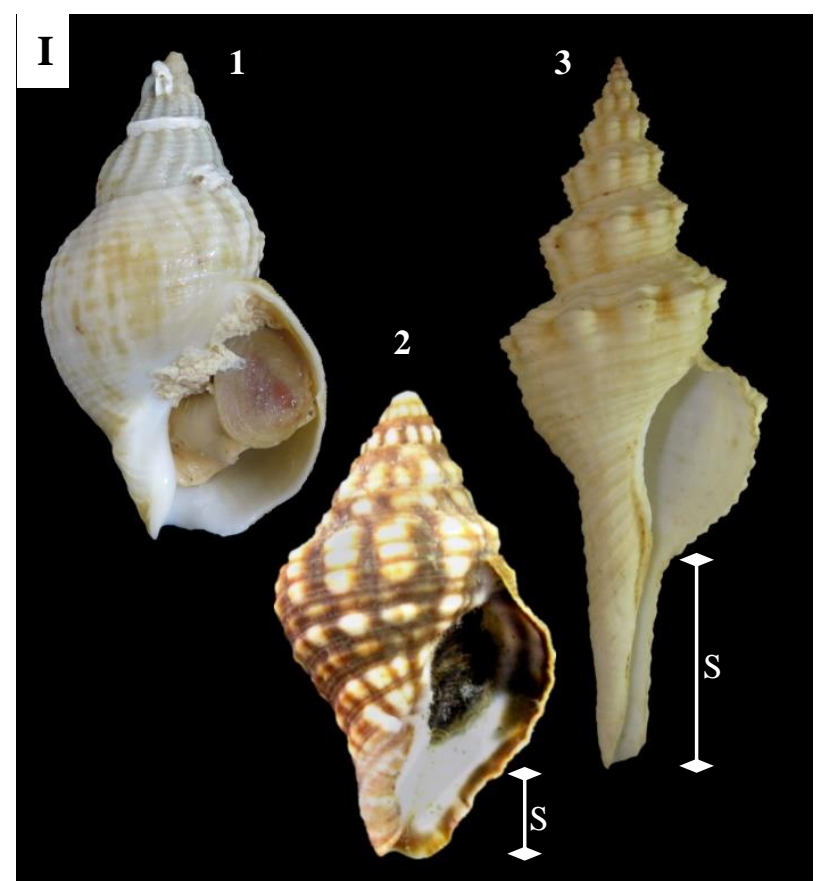

I. Shell in apertural view. I1. Buccinum undatum, siphonal canal, length: total shell length ratio of $1 / 6$ or less (0); I2. Leucozonia ocellata, ratio is between $1 / 6$ and 1/4 (1); I3. Fusinus brasiliensis, ratio is more than $1 / 4$ (2). S: siphonal canal. concluded that the folds neither increase nor decrease the animal's ability to maneuver its shell nor facilitate deeper withdrawal.

For fasciolariids, columellar folds are traditionally characteristic for the subfamilies Peristerniinae and Fasciolariinae, while Fusininae are known for their absence (Harasewych, 1998). Although it is true that most peristerniines sensu lato have such folds, it appeared in several clades independently, in clades 1b, 5, Angulofusus nedae and Pseudolatirus discrepans. Price (2003) augmented that the folds are an easily evolvable solution to many functional problems (none of which are fully understood), and that observable in this analysis.

\section{Shell, siphonal canal, length: total shell length (fig. I)}

$$
\begin{aligned}
& (\mathrm{L}=7 ; \mathrm{Ci}=28 ; \mathrm{Ri}=76) \\
& 0.1 / 6 \text { or less } \\
& \text { 1. Between 1/6 and 1/4 } \\
& \text { 2. More than } 1 / 4
\end{aligned}
$$

Simone (2011) described Siphonogastropoda, in which the main characteristic is the development of a pallial siphon; caenogastropod taxa included are Cypraeoidea, Tonnoidea and Neogastropoda (a siphon in the shell is also convergent in Cerithioidea and Stromboidea, but in those cases it is not followed by a pallial siphon).

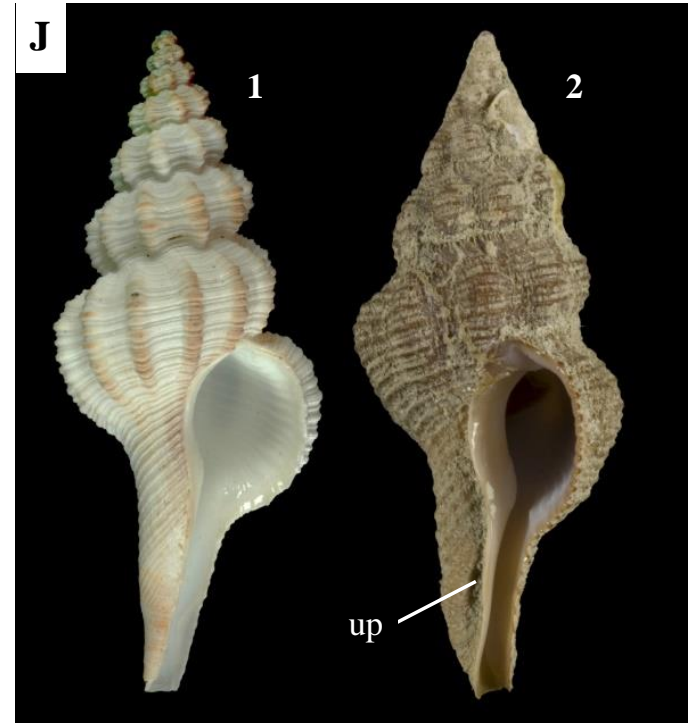

J. Shell in apertural view 1J. Pseudolatirus pallidus, no pseudo-umbilicus (0); 2J. Fusolatirus bruijnii, pseudo-umbilicus is present (1). up: pseudo-umbilicus.

Fasciolariidae (clade 1) has the basal state of a ratio between 1/6 and 1/4 (1), and that is maintained for clade 1a (with a reversion in Dolicholatirus sp.) and clade 2a (Amiantofusus and Pseudolatirus discrepans). Clade 3, the remaining fasciolariids, have elongated the siphonal 
canal in relation to the total shell length, to a ratio of more than $1 / 4$ (2), as seen for most of the traditional fusinines. However, most peristerniines and fasciolariines have reversed to a shorter siphonal canal in relation to the aperture (1), as seem for clades $5 b, 6 c$ and 7 . Due to the quantitative nature of this character, an additive parsimony model was chosen (0-1-2).

\section{Shell, pseudo-umbilicus (fig. J)}

$$
\begin{gathered}
(\mathrm{L}=5 ; \mathrm{Ci}=20 ; \mathrm{Ri}=83) \\
\text { 0. Absent } \\
\text { 1. Present }
\end{gathered}
$$

A pseudo-umbilicus is a cavity formed close to the siphonal canal, at base of the shell. It is not a true umbilicus because it is not formed by the complete coiling of the shell. A pseudo-umbilicus can be shallow or deeply-recessed, but in most fasciolariids it is merely a shallow longitudinal slit. In fasciolariids, this structure (1) is found in Dolicholatirus and Teralatirus (clade 1a) and in the major group of peristerniines (clade 5), however it is lost (0) in the fasciolariines (clade 6c).

\section{1. head-foot, body pigmentation (fig. K)}

$$
\begin{aligned}
& (\mathrm{L}=4 ; \mathrm{Ci}=75 ; \mathrm{Ri}=95) \\
& \text { 0. Absent } \\
& \text { 1. Orange to light red } \\
& \text { 2. Orange to light red with a reticulated pattern } \\
& \text { 3. Dark red }
\end{aligned}
$$

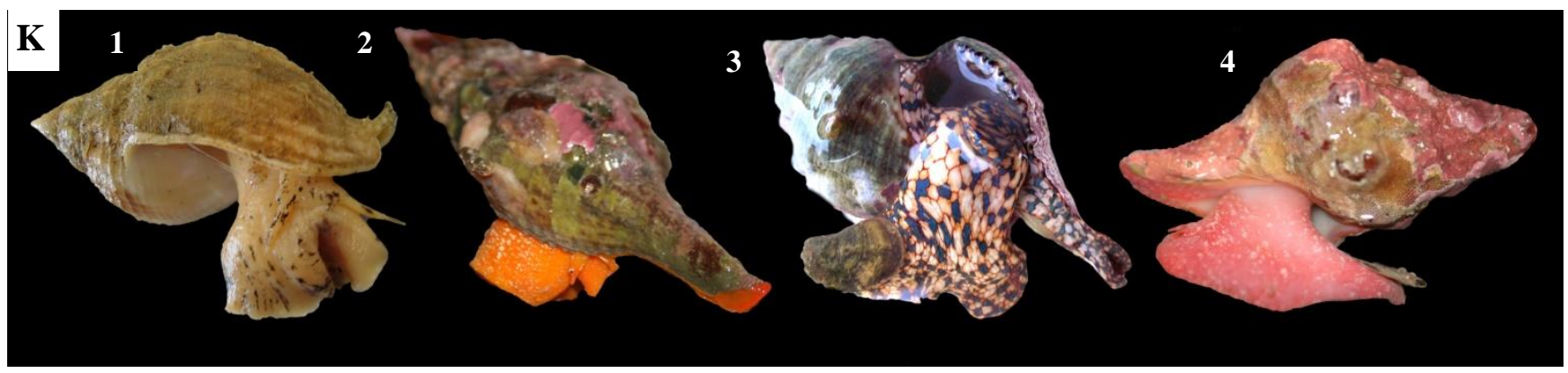

K. Live specimens with body extended. K1. Buccinum undatum, (https://en.wikipedia.org/wiki/Buccinum undatum) no body pigmentation (0); K2. Fusinus brasiliensis, coloration orange to light red (1); K3. Aurantiaca aurantiaca, coloration orange to light red with a reticulated pattern (2); K4.Leucozonia nassa brasiliana, coloration dark red (3). 

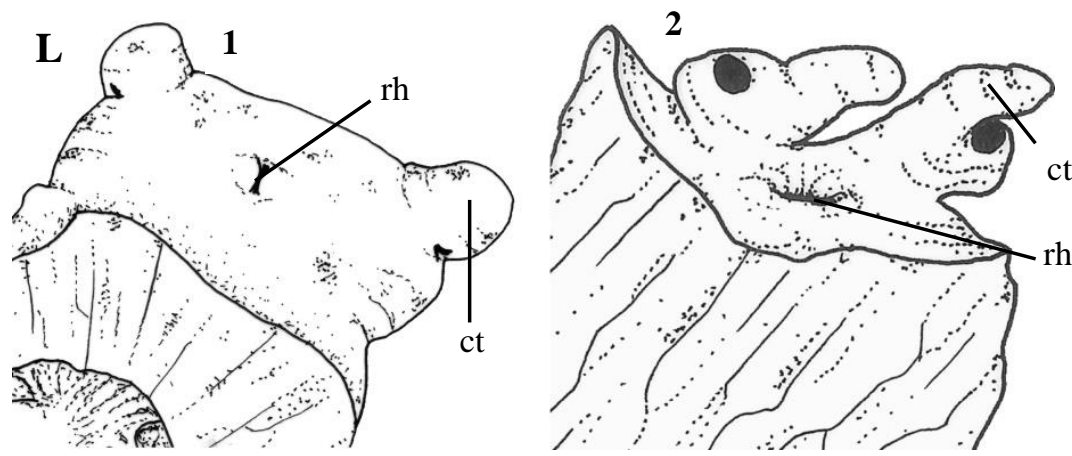

L. Head in ventral view. L1. Buccinum undatum, cephalic tentacles with bases apart (0); L2. Polygona angulata, bases side by side (1). ct: cephalic tentacle; rh: rhynchostome.
Members of Fasciolariidae are known to possess a red-orange color in the head-foot, terminally in the proboscis and edges of the mantle border and siphon. The coloration is a very notable character being used to diagnose members of the family (Harasewych, 1998). Fedosov \&

Kantor (2012) diagnosed the new species Angulofusus nedae as a Fusininae partly due to the softorange coloration of the head-foot, as most fusinines are known for. Because color fades over time when in contact with a fixative, this character is not accessible to researchers most of the time. All fasciolariids have some color in the head-foot, although in Dolicholatirus and Teralatirus roboreus it is not possible to infer, traditional fusinines have an orange to light red coloration (1), beginning on clade 2 , the traditional peristerniines a darker red (3), clade 5, while Aurantilaria aurantiaca a lighter orange with a reticulated pattern (2) .

\section{Head, cephalic tentacles, position (fig. L)}

$$
\begin{gathered}
(\mathrm{L}=1 ; \mathrm{Ci}=100 ; \mathrm{Ri}=100) \\
\text { 0. Bases apart } \\
\text { 1. Bases side by side }
\end{gathered}
$$

The presence of a pair of cephalic tentacles is a synapomorphy of the Gastropoda (Simone, 2011). The position of the tentacles in relation to each other is an important character; the ancestral state corresponds to a pair not adjacent to each other (0), in all Fasciolariidae, however, their bases are next to each other (1).
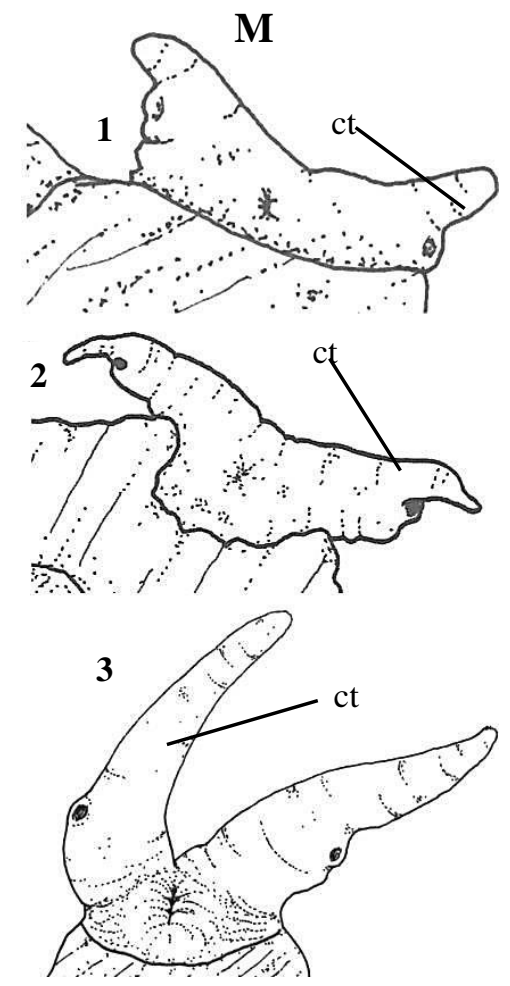

M. Head in ventral view. M1. Pseudolatirus pallidus, width of head in relation to adjacent head-foot (char. 13: 0) and length of cephalic tentacles in relation to width of head (char. 14: 0); M2. Fusinus brasiliensis (char. 13 \& 14: 1); M3. Granulifusus sp. (char. 13 \& 14: 2). ct: cephalic tentacles. 


\section{Head, width: head-foot width (fig. M)}

$(\mathrm{L}=19 ; \mathrm{Ci}=10 ; \mathrm{Ri}=41)$

$0.1 / 4$ or less

1. More than $1 / 4$ and less than $1 / 2$

2. $1 / 2$ or more

The width of the head is the transversal distance between both cephalic tentacles, and here it is correlated to the width of the adjacent head-foot. The ancestral state for fasciolariids is a small head relative to the head-foot (0), with groups having a ampler head (1) and culminating in a very broad head (2) in groups such as Granulifusus, Chryseofusus graciliformis and Pseudolatirus discrepans. This is a very homoplastic character, dotted by many reversions, and a DELTRAN optimization was chosen.

Members of fasciolariids have the basal state of $1 / 4$ or less of the ratio between head width by head-foot width (0), although several changes occurred: an increase in the ratio to more than $1 / 4$ to less than $1 / 2$ (1) in clades $1 \mathrm{~b}, 3 \mathrm{e}, 3 \mathrm{c}^{1 \mathrm{a}}$ and 6 . For this latter clade, clades $6 \mathrm{~d}$ and 11 reverted to the previous state 0 (clade 15 reverted yet again to state 1). Pseudolatirus kuroseanus, Chryseofusus graciliformis and clade 4a (with a posterior reversion in Pseudolatirus discrepans) have increased this ratio to $1 / 2$ or more (2).

\section{Head, cephalic tentacles, length: head width (fig M)}

$$
\begin{gathered}
(\mathrm{L}=18 ; \mathrm{Ci}=11 ; \mathrm{Ri}=42) \\
\text { 0. } 2 / 3 \text { to } 2 \\
\text { 1. Less than } 2 / 3 \\
\text { 2. More than } 2 / 3
\end{gathered}
$$

This character is directly correlated to the previous one, as the size of the cephalic tentacles increases as the width of the head, hence longer cephalic tentacles rest on broader heads (the exceptions to this case are Buccinum undatum and Nassarius reticulatus). As previously, DELTRAN was chosen, and optimization the of character states mimics the previous character. 
15. Foot, metapodial tentacles (fig. N)

$$
\begin{gathered}
(\mathrm{L}=2 ; \mathrm{Ci}=50 ; \mathrm{Ri}=0) \\
\text { 0. Absent } \\
\text { 1. Present }
\end{gathered}
$$

Metapodial tentacles are (1) dorsal projections of the foot, and are a synapomorphy of Nassariidae. Galindo et al. (2016) showed that the ancestor of the Nassariidae probably had a single tentacle and the apparition of the second happened after the divergence of Dorsaninae, while the loss of one or two tentacles happened independently during evolution. Engoniophos unicinctus, which closely resembles a nassariid, lack any metapodial tentacles (0), as do all other fasciolariids and outgroups studied (Abbate \& Simone, 2016).

\section{Operculum (fig. O)}

$(\mathrm{L}=2 ; \mathrm{Ci}=100 ; \mathrm{Ri}=100)$
0 . Absent
1. Filling entire aperture
2. Not filling entire aperture

The presence of an operculum, which seals the shell aperture, is one of the synapomorphies of Gastropoda; all gastropods possess it in the embryonic stage, but may be reduced or lost

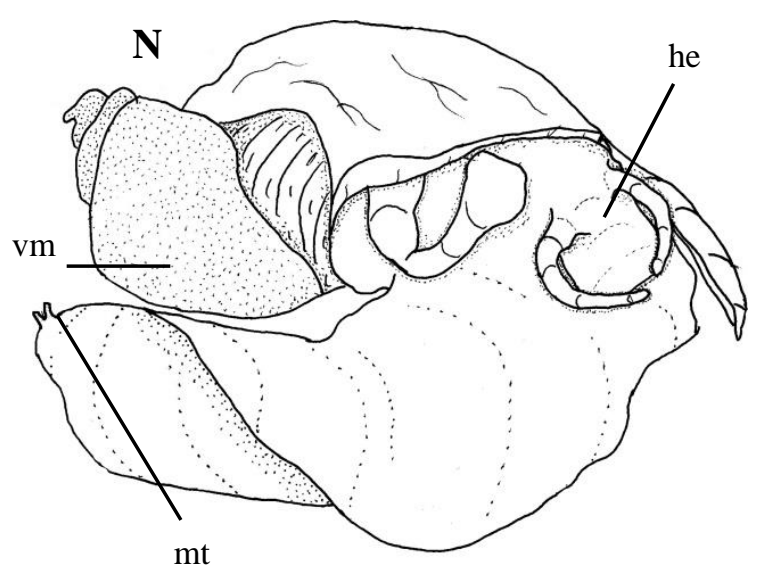

N. Bullia laevissima (modified from Abbate \& Simone, 2016), head-foot and visceral mass in dorsal view. he: head; mt: metapodial tentacle; vm: visceral mass.

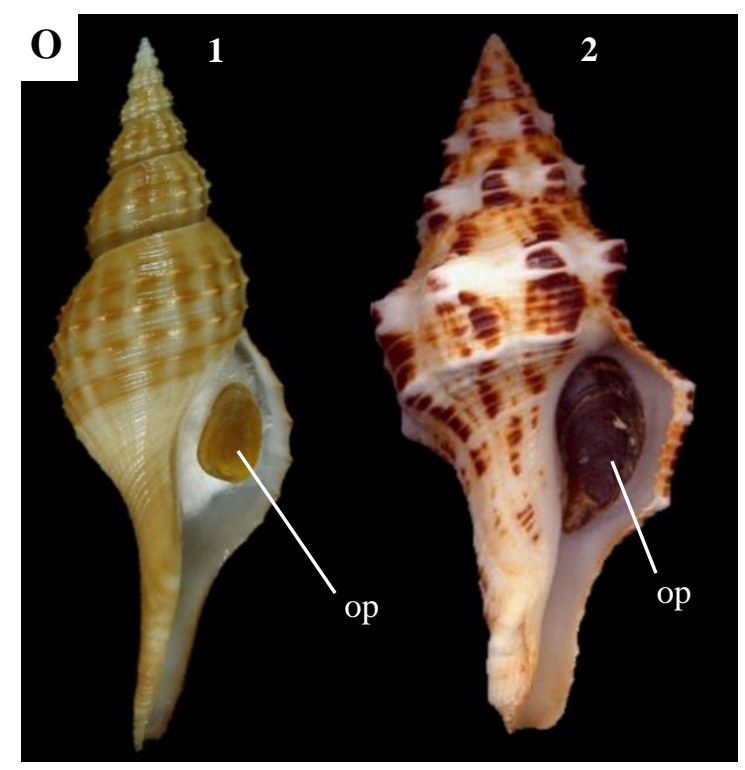

O. Shell in apertural view. O1. Granulifusus kiranus, shell with operculum that does not fill the entire aperture (2); O2. Latirus polygonus, operculum fills entire aperture (1); both taken from Femorale (http://www.femorale.com/shellphotos accessed vi/09/2016). op: operculum.

(0) in the adult in several groups such as in Monetaria annulus (Ponder \& Lindberg, 1997; Simone, 2011). Operculum of Granulifusus (clade 4) are highly differentiated; first, it does not fill the entire aperture (2), unlike all other taxa examined (1) and; secondly, has a circular 
eccentric nucleus, not terminal like all other fasciolariid (more of this will be discussed in the next section). Because of the outgroup choice, the absence (0) is plesiomorphic, but in the context of Gastropoda, this is an apomorphic state.

\section{Operculum, nucleus (fig. P)}

$$
\begin{gathered}
(\mathrm{L}=1 ; \mathrm{Ci}=100 ; \mathrm{Ri}=100) \\
\text { 0. Terminal } \\
\text { 1. Eccentric }
\end{gathered}
$$

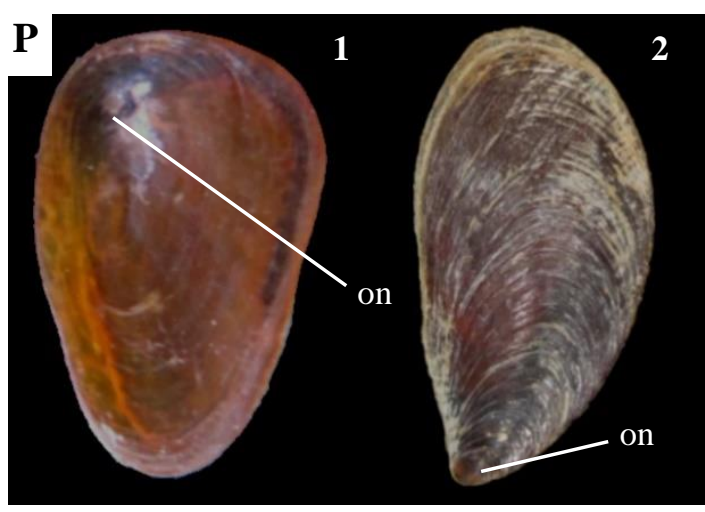

P. Operculum in dorsal view. P1. Granulifusus poppei (modified from Preetha et al., 2014) operculum with an eccentric nucleus (1); P2. Fusinus frenguelli, operculum with a terminal nucleus (0). on: operculum nucleus.

In the more basal gastropod taxa, the operculum is generally circular, and larval or very young individuals also have spiral opercula, suggesting that this is the plesiomorphic type (Simone, 2011). The genus Granulifusus (clade 4) has a modified operculum in which it does not fill the entire aperture (discussed earlier) and an eccentric nucleus (1), which differs from all other studied opercula with a terminal nucleus (0). Hadorn \& Fraussen (2005) described several Granulifusus species, and all specimens analyzed have an operculum of this type, being likely that Pseudolatirus discrepans (which has belonged to Granulifusus [e.g., Poppe, 2008]) also does.

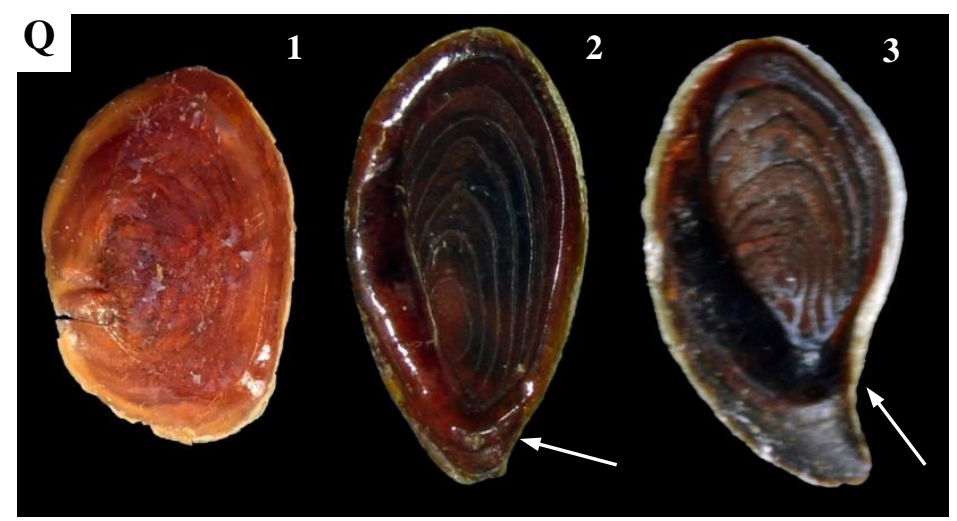

Q. Operculum in ventral view. Q1. Buccinum undatum, round operculum (0); Q2. Fusinus marmoratus, arrow indicates the slightly curved posterior margin (1); Q3. Peristernia nassatula, arrow indicates the hook-like posterior margin (2).
18. Operculum, lateral margin (fig. Q)

$(\mathrm{L}=3 ; \mathrm{Ci}=66 ; \mathrm{Ri}=96)$

0 . Round

1. Terminally slightly curved

2. Terminally hook-like

The posterior margin of the operculum of peristerniines of clade 5 possesses a hook-like extension (2) such that the muscles scar occupies circa $2 / 3$ of the total operculum area. Fasciolariids have 
a basal state in which the opercula has the lateral margin slightly curved (1), but does not form such hook-like profile; the muscle scar in this operculum type occupies a much larger area in relation to the rest of the operculum. The genera Granulifusus (clade 4a) with its much modified operculum that does not fit the aperture and eccentric nucleus, has a round margin $(0)$, as do other non-fasciolariids such as Buccinum undatum.

\section{Pallial cavity, extension in whorls (fig. R)}

$(\mathrm{L}=10 ; \mathrm{Ci}=10 ; \mathrm{Ri}=30)$

0 . Up to $3 / 4$

1. longer than $3 / 4$

Ponder \& Lindberg

observed that the range of the length of the pallial cavities were very similar among some of their studied taxa, and did not utilize this character in their study. Nevertheless, this character (the measurement of the length of the pallial cavity, from the mantle edge to the renal membrane and kidney)

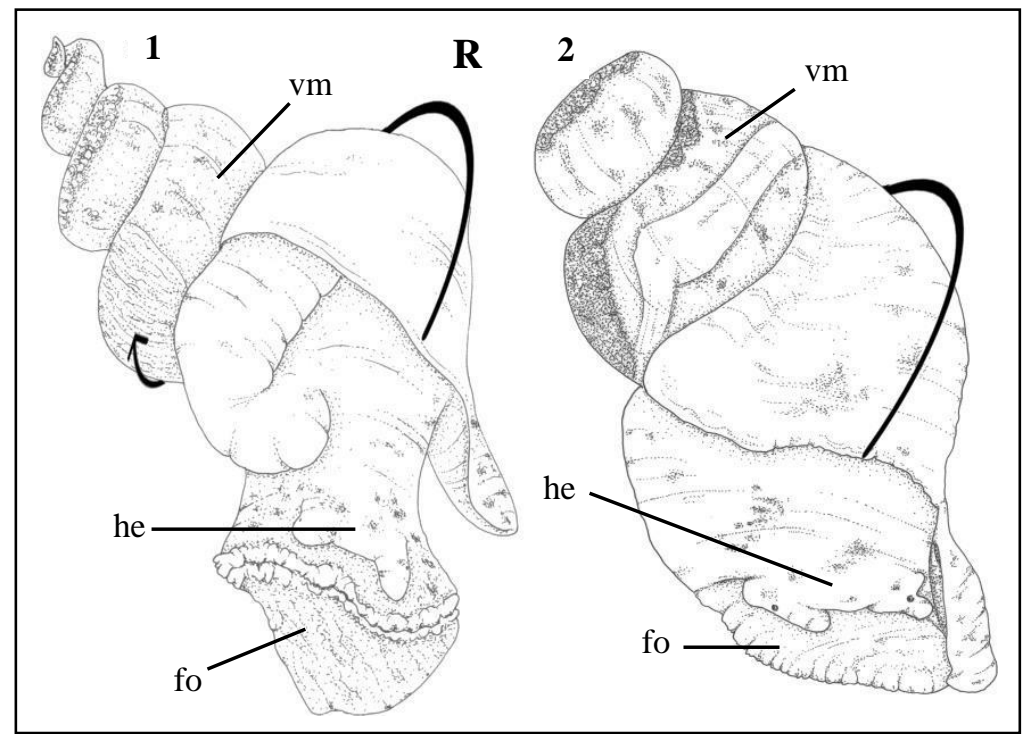

R. head-foot and visceral mass. R1.. Buccinum undatum (1); R2. Pisania pusio (0). Arrows indicate the length of the pallial cavity, counted in number of spiral whorls. fo: foot; he: head; vm: visceral mass.

showed highly homoplastic. Fasciolariidae have basally a pallial cavity of up to $3 / 4$ whorls (0), with several modifications to a greater extent (1): on clades 1a (Dolicholatirus and Teralatirus roboreus) 8a (Pustulatirus), 15, Angulofusus nedae, Peristernia marquesana, Aurantilaria aurantiaca and Filifusus filamentosus. An ACCTRAN optimization was used.

\section{Mantle border, lobes}

$(\mathrm{L}=1 ; \mathrm{Ci}=100 ; \mathrm{Ri}=100)$

0. Two

1. One 
The following characters (20, 21 and 22) are synapomorphies of the Cypraeoideans, and no Neogastropoda possess them.

Cypraeoideans have two mantle lobes (left and right) covering most of outer surface of shell. This is a synapomorphy of the superfamily, being a derived character among Caenogastropods (Simone, 2004, 2011). The tendency to internalize the shell reaches its peak in the cypraeoideans, where the mantle extends to the dorsal surface of the shell, being functionally external and the shell is functionally internal, exposed only when the animal is disturbed. In a branch of the cypraeoideans, the Lamellariidae, the shell is permanently internal (Simone, 2004).

\section{Mantle border, papillae}

$(\mathrm{L}=1 ; \mathrm{Ci}=100 ; \mathrm{Ri}=100)$

0. Present

1. Absent

Another synapomorphy of exclusive of the Cypraeoideans is the presence of papillae on the outer surface of the exposed part of mantle and siphon (Simone, 2004).

\section{Osphradium, branches}

$(\mathrm{L}=1 ; \mathrm{Ci}=100 ; \mathrm{Ri}=100)$

0 . Three

\section{Two}
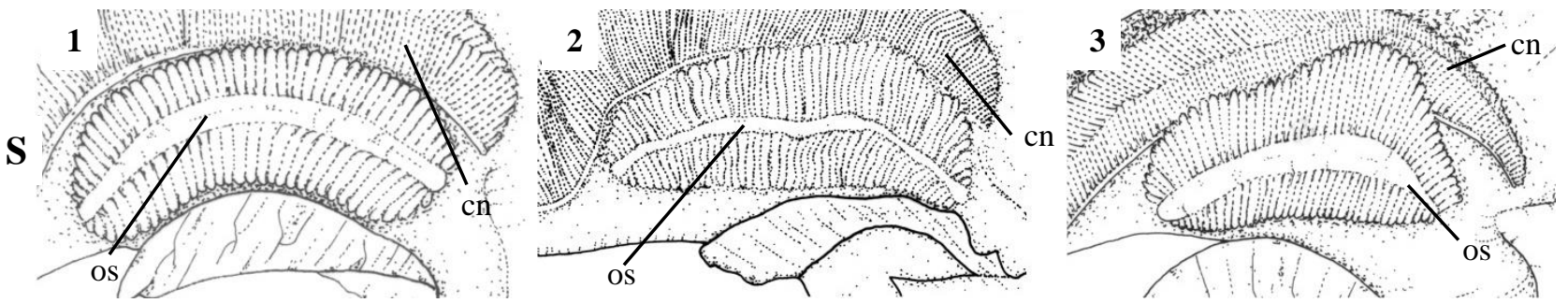

S. Ventral view of the roof of the pallial cavity evidencing the osphradium. 1S. Dolicholatirus cayohuesonicus, symmetrical osphradium (0); 2S. Fusinus frenguelli, slightly asymmetrical osphradium (1); 3S. Amiantofusus candoris, heavily asymmetrical osphradium (2). cn: ctenidium; os: osphradium. 
An osphradium bearing two branches is a feature of the "higher" caenogastropods, being an adaptation to increasing the surface of this sensory organ (Simone, 2004, 2011). In the case of the cypraeids, this organ has 3 branches running equidistant from each other; one branch is turned towards the anterior end, another towards the posterior end and another towards the right branch (the right branch is a new acquisition) (Simone, 2004).

\section{Osphradium, longitudinal shape (fig. S)}

$(\mathrm{L}=6 ; \mathrm{Ci}=33 ; \mathrm{Ri}=77)$

\section{0 . Symmetrical}

\section{Slightly asymmetrical}

2. Heavily asymmetrical

Most fasciolariids have some form of asymmetry in the osphradium (the left leaflets smaller than the right ones) with the exception of Dolicholatirus and Teralatirus roboreus. This character corresponds to the length of the osphradium leaflet, although some variation in form between them occurs.

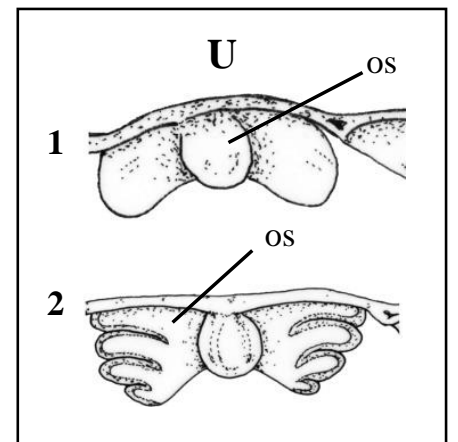

U. Transversal section of the roof of the pallial cavity in the osphradium region. U1. Dolicholatirus cayohuesonicus, osphradium profile rounded (0); U2. Fusinus australis, osphradium profile digitated (1). os: osphradium.
The basal state for the family is a symmetrical osphradium (0) and that is maintained for clade 1a. In most fasciolariids beginning in clade 2 , there is a slight asymmetry (1). A heavily asymmetrical osphradium (2) occurred independently on clades $2 b, 3 b^{1}, 4 a$, Pseudolatirus pallidus and Leucozonia ocellata.
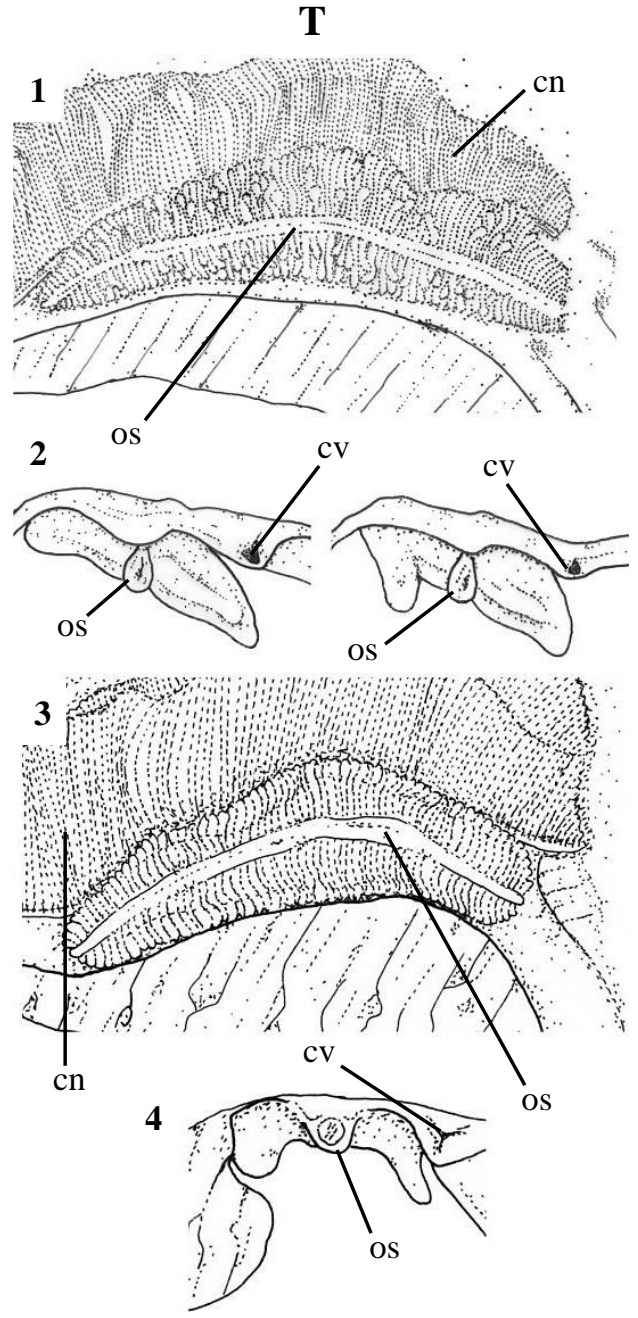

T. Ventral view of osphradium and transversal section of the roof of the pallial cavity, evidencing the osphradium. T1-2. Aurantilaria aurantiaca, osphradium ventral view and profile, evidencing the nonuniform disposition of the leaflets (1); T3-4. Opeatostoma pseudodon, uniform osphradium leaflets (0). cn: ctenidium cv, ctenidium vein; os: osphradium. 


\section{Osphradium, leaflets, form (fig. T)}

\section{$(\mathrm{L}=2 ; \mathrm{Ci}=50 ; \mathrm{Ri}=0)$ \\ 0. Uniform \\ 1. Non-uniform}

The shape of the bi-pectinated osphradium leaflets may be the same shape, i.e., in a uniform fashion (0), or they may have an asymmetry in their shape (1). Only two taxa presented this character as a homoplasy: Aurantilaria aurantiaca and Australaria australasia.

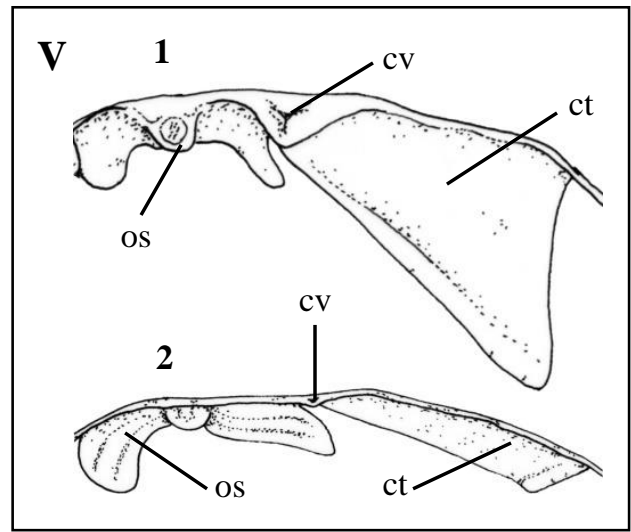

V. Transversal section of the roof of the pallial cavity in the osphradium and ctenidium region. V1. Opeatostoma pseudodon, osphradium height: height of ctenidium less than $1 / 2 \quad(0) ; \quad \mathbf{V} 2$. Granulifusus sp. $1 / 2$ or more (1). cn: ctenidium cv, ctenidium vein; os: osphradium

\section{Osphradium, leaflets, terminal shape (fig. U)}

$(\mathrm{L}=1 ; \mathrm{Ci}=100 ; \mathrm{Ri}=100)$

0 . Rounded or truncated

1. Digitated

In a few taxa, the osphradium leaflets may possess terminally a profile that is digitated, bearing three rounded lobes. This character (1) is a synapomorphy of a Fusinus frenguelli, Fusinus australis and Cyrtulus serotinus, clade $3 \mathrm{~d}$, while in all other studied taxa the leaflet is round or truncated (0).

\section{Osphradium, leaflets, height: height of ctenidium (fig. V)}

$(\mathrm{L}=3 ; \mathrm{Ci}=33 ; \mathrm{Ri}=66)$

0 . Less than $1 / 2$

1. $1 / 2$ or more

This character corresponds to the proportion between the height of the osphradium by the height of the ctenidium, i.e., osphradia that are taller have the state (1), while those that are low receive a (0). There is an observable tendency that the osphradia become taller in fasciolariids, including Pisania pusio, its sister group, and there is a reversion to the previous state for Opeatostoma pseudodon. 


\section{Ctenidium, position}

\section{$(\mathrm{L}=1 ; \mathrm{Ci}=100 ; \mathrm{Ri}=100)$ \\ 0 . Not adjacent to osphradium \\ 1. Adjacent to osphradium}

The position of the ctenidium is always adjacent to the osphradium (1) in all taxa except for Monetaria annulus, in which the ctenidium is somewhat distanced laterally from the osphradium (0). This state of character is reported in all cypraeoidean species except lamellariids (Simone, 2004), being linked to the lateralization of the shell. This morphological phenomenon results in an encroachment of the visceral mass at the right region of the pallial cavity, including pericardium and heart, which is dislocated from the posterior part of the gill to its dorsum, and produces some changes in the inner anatomy (e.g., position of the pericardium, genital system, kidney and gill and osphradium position in the pallial cavity) (Simone, 2004).
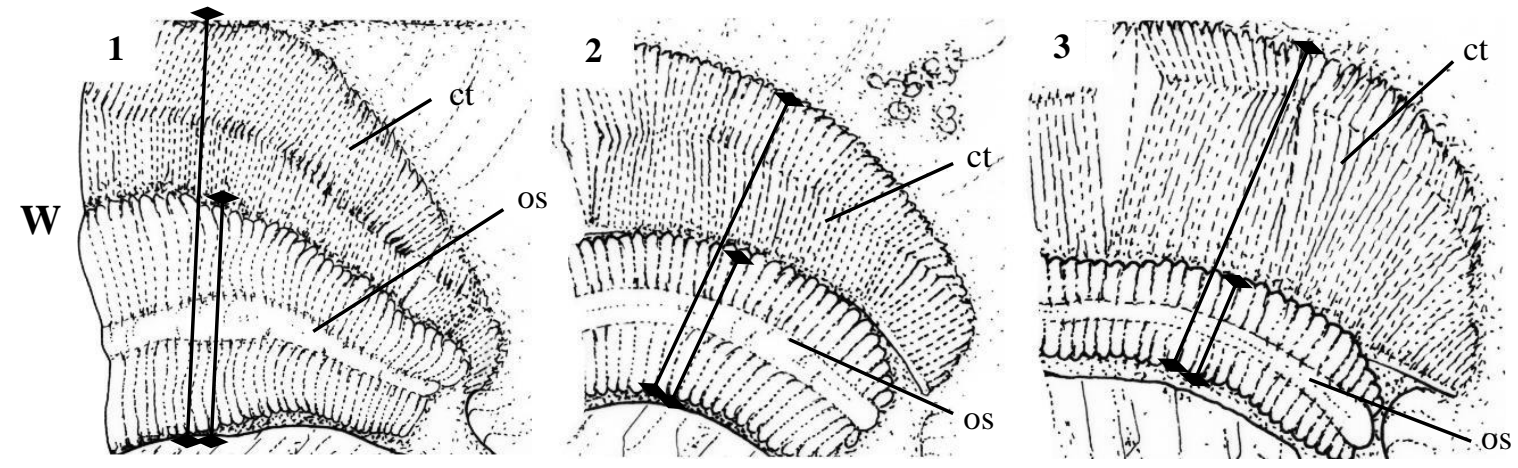

W. Roof of the pallial cavity in the osphradium and ctenidium region. W1. Peristernia nassatula, ctenidium by osphradium width ratio is less than $1(0)$; W2. Dolicholatirus sp. ctenidium by osphradium width ratio is 1 to less than 1.5 (1); W3. Buccinum undatum, ctenidium by osphradium width ratio is 1.5 or greater (2). Lines indicate the ratio of the width, evidencing the gradual increase in Ctenidium width by osphradium width ratio. ct: ctenidium; os: osphradium.

\section{Ctenidium, width: width of osphradium (fig. W)}

$(\mathrm{L}=10 ; \mathrm{Ci}=20 ; \mathrm{Ri}=72)$

0 . Less than 1 .

1. 1 to less than 1.5

2. 1.5 or greater 
This character is an increase in the ratio of the width of the ctenidium by the width of the osphradium. This highly homoplastic character received an ACCTRAN optimization, as it is likely that Dolicholatirus sp. will receive the same state as the others of the same group.

Fasciolariids have a width of 1 to less than 1.5 of this ratio (1), but this state is only maintained for clade $3 b^{1}$ (Chryseofusus), Pseudolatirus pallidus, Angulofusus nedae and clade 2c. A ratio of less than 1 (0) is present in clade 1a, 3c, 4 and on Pseudolatirus kuroseanus. A proportion of 1.5 or greater (2) occurs on clade 14 and on Filifusus filamentosus.

\section{Ctenidium, posterior tip position}

$(\mathrm{L}=1 ; \mathrm{Ci}=100 ; \mathrm{Ri}=100)$

0 . Away from pericardium

1. Adjacent to pericardium

This is yet another character that is a result of the lateralization of the shell aperture that occurs in cypraeoideans. This results in

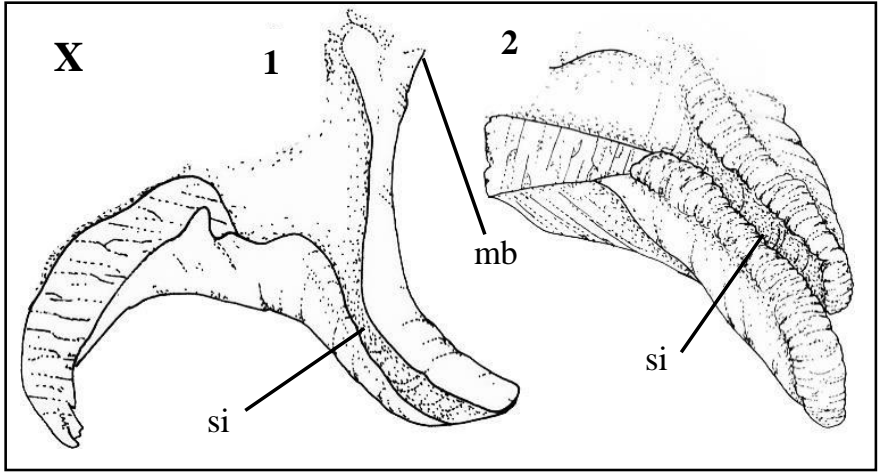

X. Siphon X1. Granulifusus sp. margin of the siphon smooth (0); X2. Leucozonia cerata, margin bearing longitudinal folds (1). mb: mantle border; si: siphon. the transposition of the visceral mass to the right region of the pallial cavity, including pericardium and heart, which leads to a longer ctenidium vein running without gill filaments.

\section{Siphon, margin (fig. X)}

$(\mathrm{L}=3 ; \mathrm{Ci}=33 ; \mathrm{Ri}=33)$

\section{Smooth}

1. Bearing longitudinal folds

The presence of longitudinal folds in the margin of the siphon occurs in four taxa: as a synapomorphy of Pseudolatirus discrepans and
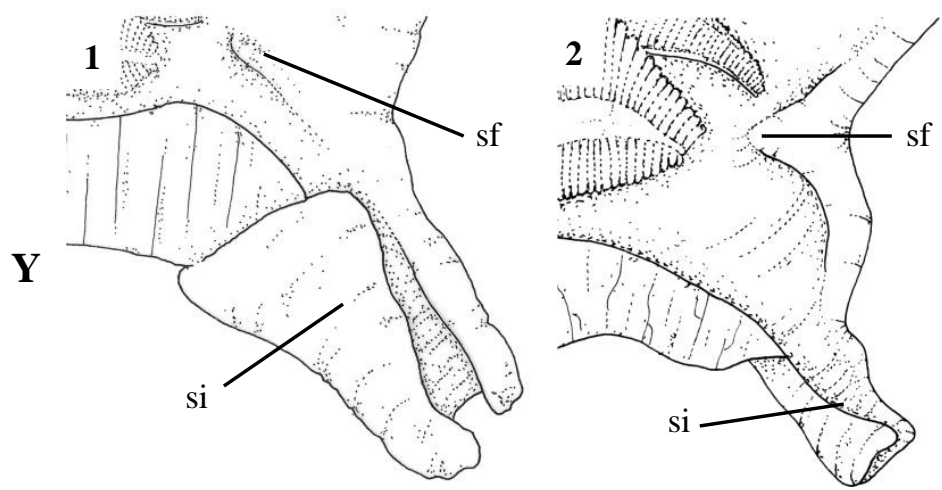

Y. Siphon. Y1. Amiantofusus candoris, siphon flap with a narrow base (0); Y2. Fusinus marmoratus, wide base (1). sf: siphon ventral fold; si: siphon.

Granulifusus kiranus (clade 4c), Leucozonia ocellata and L. cerata (clade 14a) and, choosing an ACCTRAN optimization, reversing in Opeatostoma pseudodon. 
31. Siphon, ventral fold, shape (fig. Y)

$(\mathrm{L}=2 ; \mathrm{Ci}=50 ; \mathrm{Ri}=60)$

0 . Flap, narrow base

1. Flap, wide base

The entrance to the siphon in the pallial cavity occurs near the osphradium and ctenidium, and it bears a muscular flap that project downward. In most fasciolariids this flap has a narrow base (0), but in two groups this flap is strong and muscular with a very broad base (1): in Chryseofusus, clade $3 b^{1}$ and in Amiantofusus, clade $2 \mathrm{c}$ as a homoplasy.

\section{Anal siphon}

$(\mathrm{L}=1 ; \mathrm{Ci}=100 ; \mathrm{Ri}=100)$

0 . Present

1. Absent

Cypraeoideans present an anal siphon in the shell, and in cypraeids and ovulids this appears as a fold differentiated from the mantle border, the anal siphon, which apparently evolved similarly, but in the opposite side, to the incurrent siphon (Simone, 2004). This character occurs only in Monetaria annulus.

\section{Kidney}

$(\mathrm{L}=1 ; \mathrm{Ci}=100 ; \mathrm{Ri}=100)$

0 . Meronephridial

1. Pycnonephridial

Most caenogastropods possess a kidney comprised of excretory tissue with a uniform and characteristic vacuolated appearance. However, a number of taxa possess two distinct lobes of excretory tissue (pycnonephridial sensu Perrier [1889] and Ponder [1973]) that are microscopically and macroscopically distinct, including all neogastropods. The traditional bipartite classification of differentiated kidney types (meronephridial vs. pycnonephridial) has been used to distinguished the interdigitating lamellae of the kidney (1) for pycnonephridians to 
the simple lamellae (0) for meronephridians (Strong, 2003). This character occurs only in Monetaria annulus.

\section{Renal aperture, lipped margin (fig. Z)}

$(\mathrm{L}=5 ; \mathrm{Ci}=20 ; \mathrm{Ri}=75)$

\section{Absent}

1. Present

The renal aperture, or nephrostome, is situated in the posterior region of the pallial cavity, as an access from the kidney. In Fasciolariidae it occurs as a mere slit (0) or as a slit emarginated by a lipped rim. A DELTRAN optimization was chosen, because there was no data on this character for the clade of Angulofusus nedae, Pseudolatirus kuroseanus and Amiantofusus. In Fasciolariidae, the basal state 0 is maintained for clade $1 \mathrm{a}$ and $2 \mathrm{a}$, while it attained state 1 beginning on clade 3 . Clade $3 c^{1}$ and 9 reverted to state 0 (with another reversion in Latirus pictus and Opeatostoma pseudodon).

\section{Nephridial gland}

$$
\begin{gathered}
(\mathrm{L}=4 ; \mathrm{Ci}=25 ; \mathrm{Ri}=57) \\
\text { 0. Absent } \\
\text { 1. Present }
\end{gathered}
$$

The nephridial gland is a mass of glandular tissue immersed between the kidney and pericardium, lined with ciliated cells and penetrated by haemocoelic spaces (Fretter \& Graham, 1962). Saccular invaginations of the gland surface bring hemolymph and urine into close contact; hemolymph flows into the haemocoelic spaces of the gland from the renal lamellae, is collected into the efferent nephridial vein, and subsequently flows to the auricle of the heart (Fretter \& Graham, 1962; Strong, 2003). 
Nephridial gland histology is remarkably uniform across the caenogastropods (Strong, 2003), and is one of the synapomorphies of the predominantly marine taxa except for Cerithioideae and Eulimidae; although it disappeared in some taxa (e.g., xenophorids) (Simone, 2011). In fasciolariids, the gland is absent in clade 10 of Latirus polygonus, L. pictus and Leucozonia (subsequently reverted in Leucozonia cerata and Opeatostoma pseudodon), although in order to truly confirm the presence or absence of this structure, a histological study is required.

A DELTRAN optimization was chosen

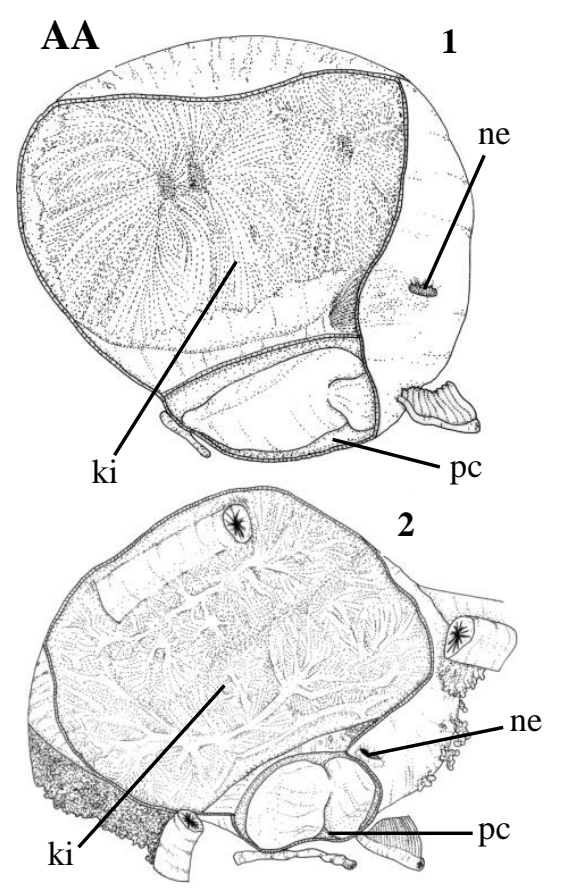

AA. Kidney and pericardium. 1AA. Pustulatirus ogum, renal aperture situated centrally in the membrane (0); AA2. Aurantilaria aurantiaca. renal aperture situated close to pericardium (1). ki: kidney; ne: nephrostome; pc: pericardium.

\section{Renal aperture, position in membrane (fig. AA)}

$(\mathrm{L}=2 ; \mathrm{Ci}=50 ; \mathrm{Ri}=75)$

0 . Centrally

1. Close to pericardium

The renal aperture may occur centrally in the membrane separating pericardium and kidney (0) or dislocated closer to pericardium (1). This is a synapomorphy of Fasciolariinae (clade 6c), and a homoplastic autapomorphy for Opeatostoma pseudodon. DELTRAN was chosen because of the missing data of Latirus vischii.

37. Rhynchostome, distance from cephalic tentacles (fig. $\mathrm{AB})$

$(\mathrm{L}=2 ; \mathrm{Ci}=50 ; \mathrm{Ri}=0)$

0 . Close to base

1. Distanced from base

The rhynchostome is the outer opening of the introverted proboscis, being only visible when the proboscis is in a contracted state. In fasciolariids this structure is located ventrally close to the cephalic tentacles (0), except for Leucozonia ocellata and L. cerata (clade 14a), which is located distant from the cephalic tentacle (1). ACCTRAN was chosen as an optimization, meaning in Opeatostoma pseudodon there was a reversion. 


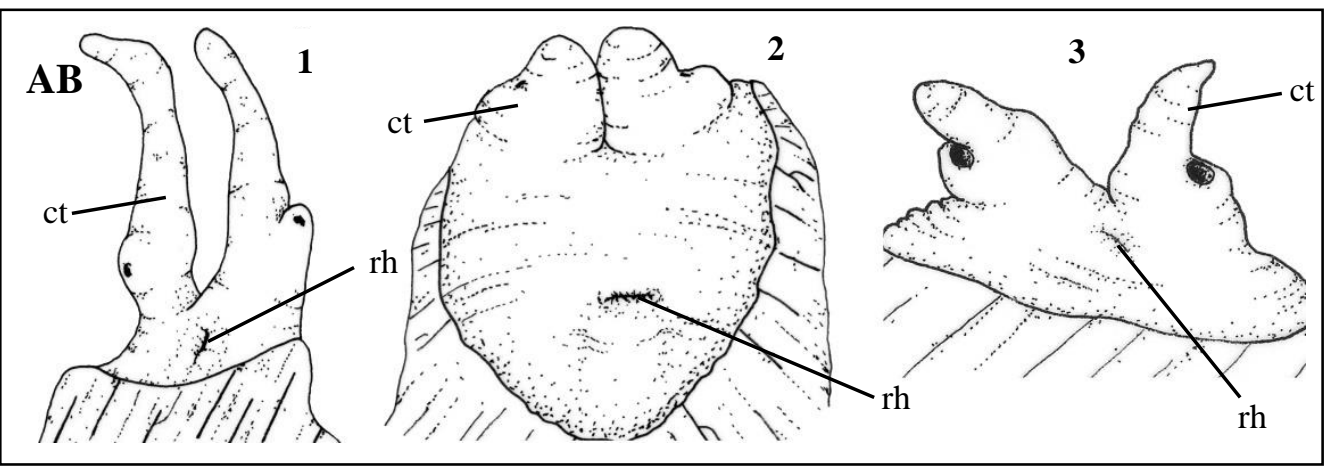

AB. Head in ventral view. AB1. Granulifusus kiranus, rhynchostome located close to the base of cephalic tentacles (char. 38: 0) as a longitudinal slit (char. 39: 1); AB2. Leucozonia cerata, located distanced from the base of cephalic tentacles (char. 38: 1) as a transverse slit (char. 39: 0); AB3. Hemipolygona beckyae, located close to the base of cephalic tentacles (char. 38: 0) as an oblique slit (char. 39: 2). ct: cephalic tentacle; rh: rhynchostome.

\section{Rhynchostome, position (fig. AB)}

$(\mathrm{L}=9 ; \mathrm{Ci}=22 ; \mathrm{Ri}=66)$

0 . Transverse

1. Longitudinal

2. Oblique

The position of the rhynchostome is an

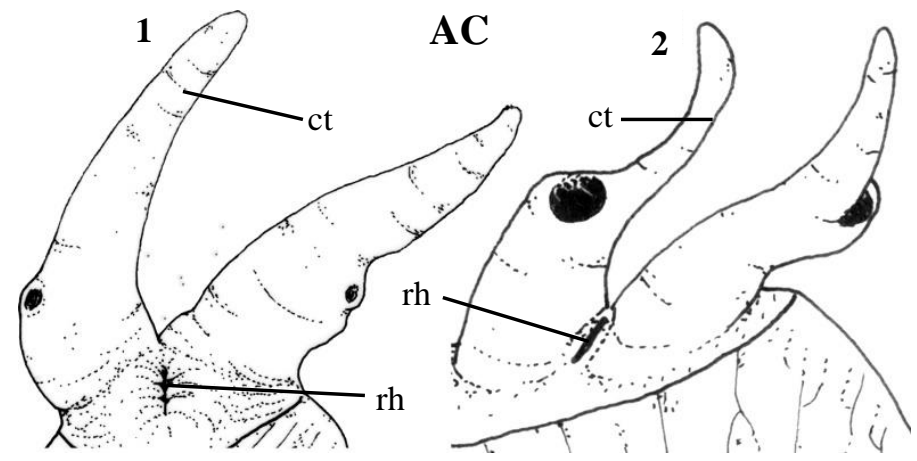
important character; it may be a slit transverse to the body axis (0),

AC. Head in ventral view. 1AC. Granulifusus sp. rhynchostome bearing longitudinal folds (char. 40: 1) and a longitudinal (1) or oblique (2). For fasciolariids, the basal state is a lipped rim (char.41: 1); 2AC. Dolicholatirus cayohuesonicus, rhynchostome without longitudinal folds (char. 40: 0) and a simple margin (char. 41:0). ct: cephalic tentacle; rh: rhynchostome.

longitudinal slit which occurs in most fusinines, Dolicholatirus and Teralatirus roboreus, and in Nodolatirus nodatus. In most peristerniines (clade 7) and fasciolariines (clade 6b), the slit is transverse, with reversions occurring independently in Pustulatirus ogum and Polygona infundibulum. In Hemipolygona beckyae the slit is oblique (2), it is an autapomorphy. The optimization chosen was DELTRAN.

\section{Rhynchostome, longitudinal folds in margin (fig. AC)}

$$
(\mathrm{L}=6 ; \mathrm{Ci}=16 ; \mathrm{Ri}=70)
$$

\section{0 . Absent}

1. Present 
The rhynchostome in fasciolariids sometimes bear, internally and protruding externally, longitudinal folds or ridges. Basally, fasciolariids lack these folds (0), but it appeared (1) in Amiantofusus pacificus and clade 3 and reverted to the absence of the folds (0) in Chryseofusus archerusius and in clade 14 of Leucozonia and Opeatostoma pseudodon. An ACCTRAN optimization was chosen.

\section{Rhynchostome, lipped rim (fig. AC)}

$(\mathrm{L}=7 ; \mathrm{Ci}=14 ; \mathrm{Ri}=72)$

\section{Absent \\ 1. Present}

The presence of a lipped rim is independent of the presence/absence of longitudinal folds (character 39), and is highly homoplastic. The absence of a lip (0) is the plesiomorphic state, while the presence (1) occurred several times independently: In Fusinus and Cyrtulus serotinus (clade 3c), clade 4 and 14; it reverted back to the plesiomorphic state in Peristernia nassatula, Latirus vischii and in clade 8 .

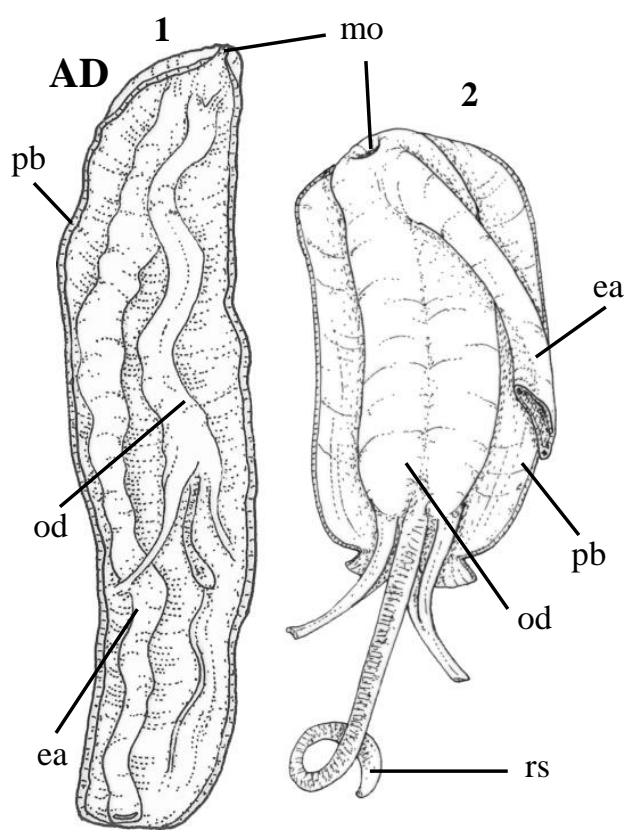

AD. Proboscis opened laterally. AD1. Polygona angulata. radular sac contained within proboscis (1); AD2. Thais speciosa, radular sac extending beyond proboscis $(0)$. ea: anterior esophagus; mo: mouth opening; od: odontophore tube; pb: proboscis; rs: radular sac.

\section{Odontophore, radular sac (fig. AD)}

$(\mathrm{L}=1 ; \mathrm{Ci}=100 ; \mathrm{Ri}=100)$

0 . Extending beyond proboscis

1. Contained within proboscis

The foregut anatomy is rather uniform in all buccinoideans, and is characterized by a long proboscis, large paired or fused salivary glands, usually a well-developed valve and gland of Leiblein, and by the absence of accessory salivary glands (Fraussen et al., 2007). This occurs for all Neogastropoda with the exception of Conoidea (Simone, 2011). The features of the anterior digestive system will be discussed throughout the following characters (characters 41 to 71 ). 
The odontophore is the organ that produces and moves the radula, and is thought to be homologous among gastropods (the possibility of non-homology between the cartilages of the heterobranchs and other gastropods has been raised by several authors, e.g., Golding et al., [2009]) (Simone, 2011). The odontophore characters show great importance of the structure in comparative studies, being utilized up to species-level (Simone, 2004; 2007; Simone et al., 2011; Couto \& Pimenta, 2012; Couto et al., 2015; 2016). Although detailed studies on the odontophore are surprisingly scarce in the literature, it shows surprising variation for phylogenetic analysis, and characters related to this structure will be discussed in the next five characters.

The radular sac in which the radular nucleus is located (where the teeth of the radula is formed), is situated posteriorly, storing the teeth that may migrate to the buccal cavity while the teeth have been spent or lost. The radular portion inside the radular sac is coiled and its teeth are

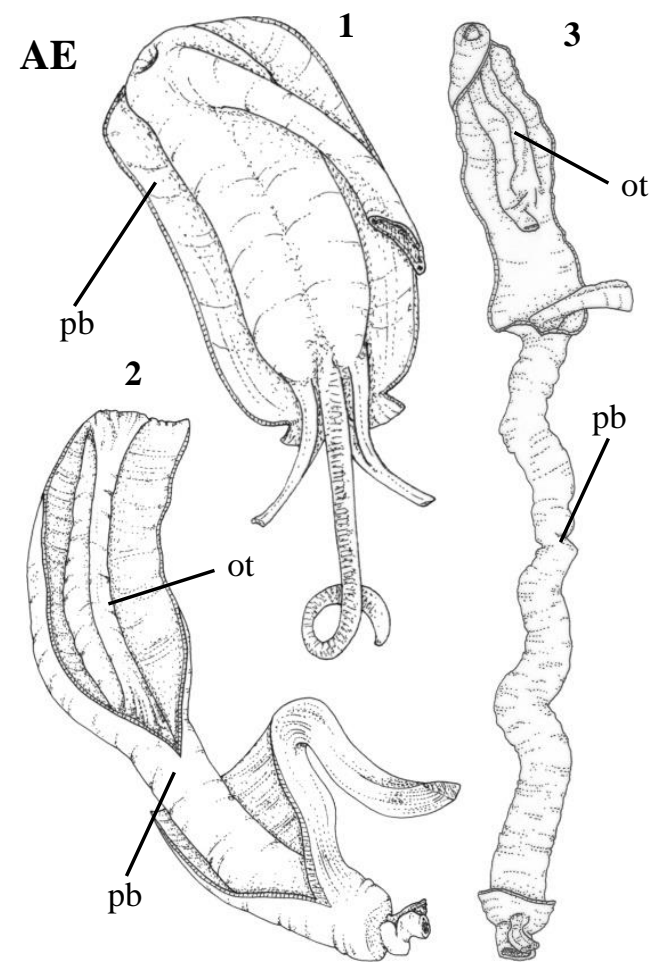

AE. Proboscis opened laterally AE1. Thais speciosa, odontophore by proboscis lengths is one (0); AE2. Granulifusus sp., ratio is between one to $1 / 2$ (1); AE3. Fusinus brasiliensis, ratios is less than $1 / 2$ (2). ot: oral tube; $\mathbf{p b}$, proboscis. positioned inwards (Simone, 2011). The length of the radular sac may be correlated to feeding patterns although Ponder \& Lindberg (1997) could not find any correlations in their studied taxa; these same authors utilized the coiling of the radular sac as a synapomorphy for Sorbeoconcha. In buccinoids including fasciolariids, the radular sac is confined within the proboscis, i.e., it does not extend to the haemocoel (1); however, the outgroup taxa Monetaria annulus (Cypraeoidea) and Thais speciosa (Muricoidea) the radular sac projects posteriorly into the haemocoel (0).

\section{Odontophore, length: proboscis length (fig. AE)}
$(\mathrm{L}=9 ; \mathrm{Ci}=22 ; \mathrm{Ri}=72)$
0 . One
1. Between 1 and $1 / 2$
2. $1 / 2$ or less 
This character corresponds to the relation between the lengths of the odontophore by the proboscis. Fasciolariids have this ratio between one and 1/2 of the length (0), and that is the synapomorphic state for the family, although a few modifications in this ratio occurred.

On clades 2c of Amiantofusus, 6c of the traditional fasciolariines and 14 of Leucozonia (although it returned to the previous state in Opeatostoma pseudodon), the odontophore shortened in relation to the proboscis obtaining a ratio of 1 (0), as some species in the outgroup (e.g., Pisania pusio, Bullia laevissima). The opposite happened on clade 3a, whose related taxa Fusinus, Chryseofusus, Cyrtulus serotinus and Pseudolatirus pallidus all possess an extremely long proboscis in relation to the odontophore (2). This relates to character 66 , the coiling of the proboscis within its sheath; however, this will be discussed later. Because of the hypothesized quantitative nature of this character, an additive parsimony model was chosen (0-1-2), with a DELTRAN optimization.

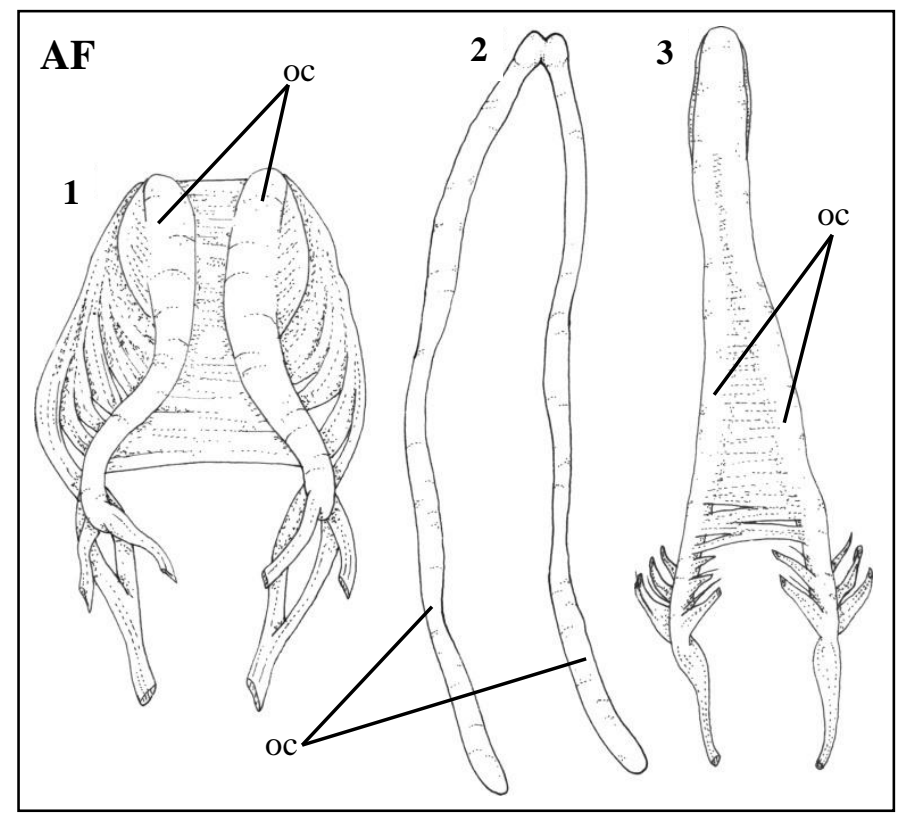

AF. Ventral view of odontophore cartilages and associated muscles AF1. Thais speciosa, cylindrical odontophore cartilages (char. 44: 0) not fused (char. 45: 0); AF2. Chryseofusus archerusius, concave odontophore cartilages (char. 44: 1), muscles removed, and fused less than $15 \%$ (char. 45: 1); AF3. Fusinus brasiliensis, cylindrical cartilages (char. 44: 0) and fused more than 15\% (char. 45: 2). oc: odontophore cartilage.
43. Odontophore cartilages shape (fig. AF)

$(\mathrm{L}=1 ; \mathrm{Ci}=100 ; \mathrm{Ri}=100)$

0. Cylindrical

1. Concave

Only the outgroup species Monetaria annulus and Thais speciosa possess cylindrical odontophore cartilages (0). Concave cartilages (1) correspond to buccinoideans in the analysis, and all species of the superfamily have a similar odontophore (e.g., Simone. 2011; Couto \& Pimenta, 2012; Couto et al., 2015; Simone et al., 2013; Abbate \& Simone, 2015). 


\title{
44. Odontophore cartilages, anterior fusion (fig. AF)
}

\author{
$(\mathrm{L}=8 ; \mathrm{Ci}=25 ; \mathrm{Ri}=71)$ \\ 0 . Not fused \\ 1. Fused $15 \%$ or less \\ 2. Fused greater than $15 \%$
}

Another notable modification in the odontophore is the fusion of the cartilages in the anterior region of some Buccinoidea (e.g., Buccinidae, Nassaridae, Columbellidae) (e.g., Simone Couto et al., 2012; 2015; Simone et al., 2013; Abbate \& Simone, 2015). Strong (2003) observed that caenogastropods may possess several degrees of fusion in the odontophore. Members of Fasciolariidae exhibit odontophore cartilages that are fused, like most buccinoideans and unlike the cypraeoidean (Monetaria annulus) and muricoidean (Thais speciosa) which have two separate cartilages, unfused (0). Teralatirus roboreus, and likely the genus Dolicholatirus, (clade 1a) have odontophore cartilages fused in more than $15 \%$ (2), much like most buccinoideans analyzed. Species in clade 2 possess a fusion of less than $15 \%$ (1), except for those clades that

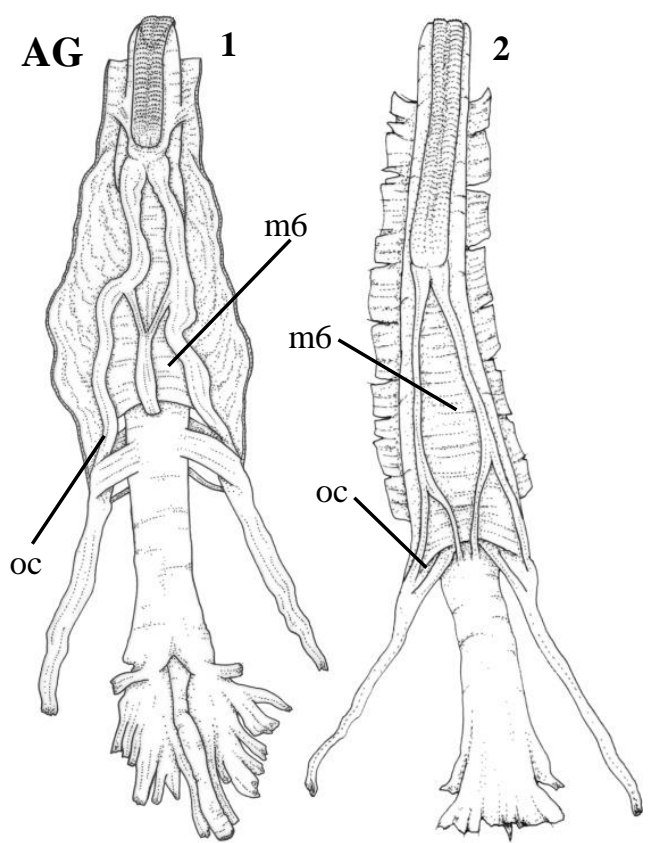

AG. Odontophore in ventral view AG1. Pustulatirus ogum, free portion of $\mathrm{m} 6$ more than $1 / 6$ of cartilage length (0); AG2. Fusinus sp. 1/6 or less (1); m6: horizontal muscle; oc: odontophore cartilage.

reverted to the previous state, i.e., clade $3 \mathrm{c}$ and 8 (Latirus polygonus and Leucozonia cerata acquired independently a greater percentage of fusion). Due to the quantitative nature of this character, an additive parsimony model was chosen (0-1-2).

\section{Odontophore, m6, posterior free portion: odontophore length (fig. AG)}

$(\mathrm{L}=8 ; \mathrm{Ci}=12 ; \mathrm{Ri}=65)$

0 . More than $1 / 6$

1. $1 / 6$ or less 
The horizontal muscle (m6) is the easiest to compare among the taxa because of its peculiar situation (Simone, 2011), as it is single muscle bearing transverse fibers connecting the left and right odontophore cartilages. Neogastropods have this muscle very thin, as also observed by Simone (2011), being inserted anteriorly on the opposite cartilage; posteriorly, the cartilages have a portion that is not connected by m6. The length of this portion is more than of the ratio between the odontophore length $(0)$ in fasciolariids, with several independent reversions to the previous state (1/6 or less) (1) in clades 3b, 5a, 14a, Granulifusus hayashi and Fasciolaria tulipa.

\section{Odontophore cartilages, $\mathrm{m} 11$}

$(\mathrm{L}=1 ; \mathrm{Ci}=100 ; \mathrm{Ri}=100)$

0 . Origin in haemocoel

1. Origin odontophore cartilage

Traditionally, the pair of ventral tensor muscles (m11) insert internally in the subradular membrane; runs posteriorly along the subradular membrane connected to it, and progress out to the haemocoelic cavity, one on each side of the radular sac (Simone, 2011). According to Simone (2011), this muscle is somewhat modified in the Neogastropoda (excluding Conoidea), that apparently reverted to the sliding movement, which is also corroborated by the loss of the thickness of the subradular cartilages in this taxon (Golding et al., 2009).

The haemocoelic origin of m11 (0) is only present in the cypraeoidean Monetaria annulus, while all other taxa its origin is ventrally and posteriorly in the odontophore cartilages (1).

\section{Radula, marginal tooth (fig. $\mathrm{AH})$}

$(\mathrm{L}=1 ; \mathrm{Ci}=100 ; \mathrm{Ri}=100)$

0 . Present

1. Absent

Next to the shell, the radula is the most accessible character complex in gastropods, being used

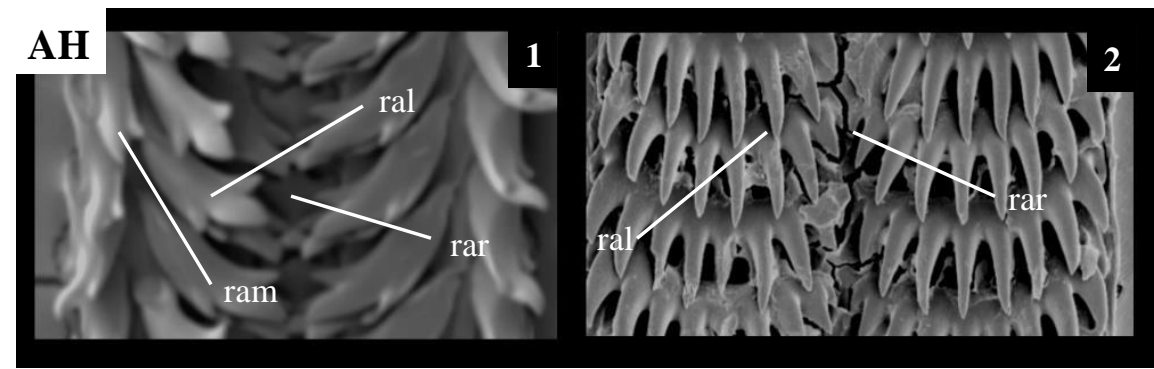

AH. Radula. HA1. Monetaria annulus (modified from Simone, 2004), marginal teeth present (0); AH2. Fusinus australis, no marginal teeth (1). ral: radula lateral; ram: radula marginal; rar: radula rachidian. 


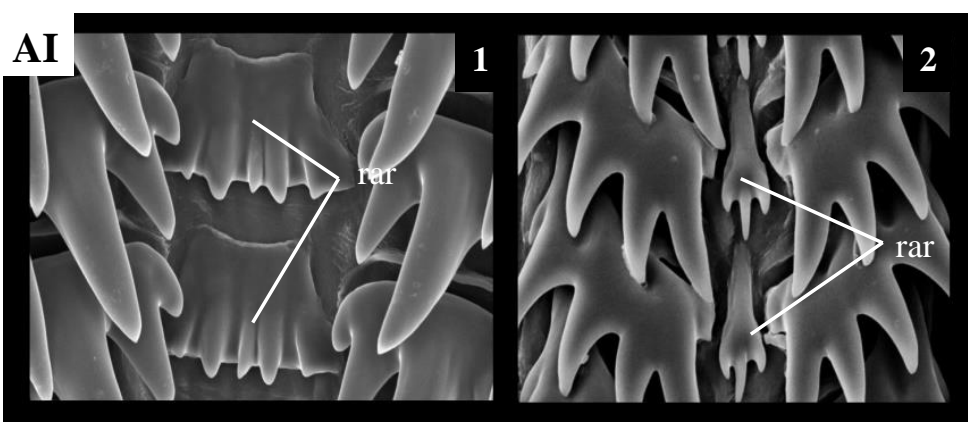

AI. Radula, detail of rachidian. AI1. Fusinus frenguelli, rachidian square to trapezoidal (char 49: 0) with terminal cusps (char: 50: 0); AI2. Pseudolatirus kuroseanus, rachidian triangular (char. 49: 1) bearing sub-terminal cusps (char. 50: 1). rar: radula rachidian.

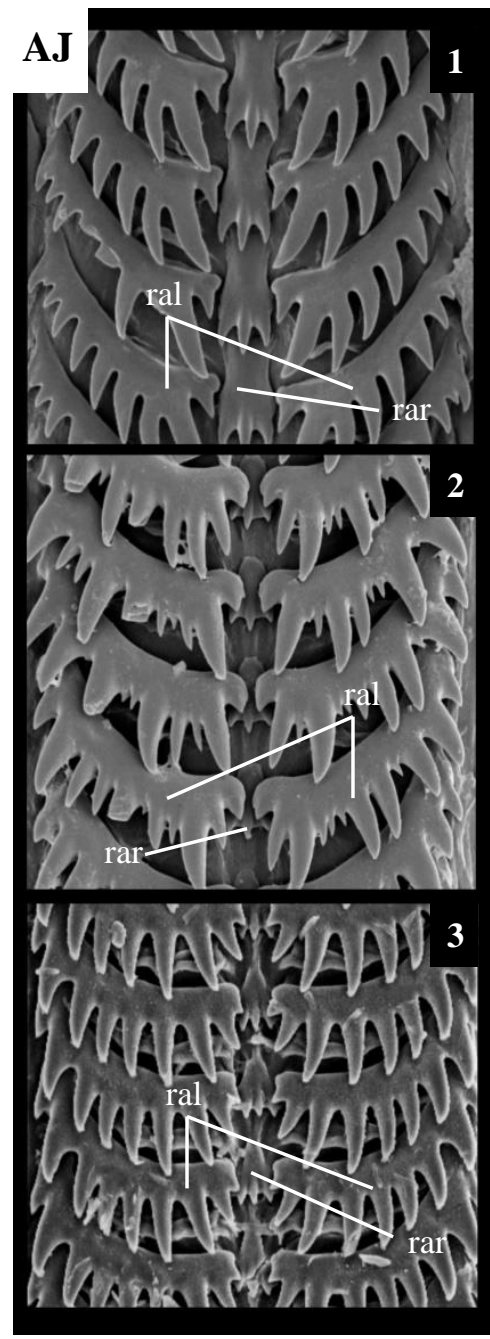

AJ. Radula. AJ1. Latirus pictus, ratio of the width of the base by the width of the edge of rachidian is one (0); $\mathbf{A J 2}$. Fusolatirus bruijnii, ratio is less than 1 and more than $1 / 2$ (1); AJ3. Cyrtulus serotinus, ratio is $1 / 2$ or less (2). ral: radula lateral; rar: radula rachidian. lack them (1).

$(\mathrm{L}=2 ; \mathrm{Ci}=50 ; \mathrm{Ri}=75)$

1. Triangular diversely for taxonomical and cladistic studies; in fact, classical studies (e.g., Gray, 1854; Thiele, 1929) has produced many classification such as Rachiglossa, Toxoglossa, Taeniglossa, etc. that are based on radulae. This structure has shown to be a reliable source of phylogenetic information, and the next 17 characters are all radular characters. Although homology problems arise when comparing distantly related species, it is usually not the case for closely related taxa (Ponder \& Lindberg, 1997; Strong, 2003), such in the case of fasciolariids presented here.

Neogastropods presumably have a radula of the rachiglossate type, which is assumed to have arisen from a taenioglossate ancestral type (Ponder \& Lindberg, 1997). The rachiglossate radula has three teeth per row (a central or rachidian, flanked by laterals), and a lack of marginal teeth. Monetaria annulus is the only species in which marginal teeth are present (0), while other taxa, all neogastropods,

\section{Radula, rachidian, shape (fig. AI)}

0. Square to trapezoidal

The rachidian in fasciolariids is square or trapezoidal shaped (0), being the plesiomorphic state present in all outgroup species. Certain groups modified this basic scheme to a very thin and triangular shaped rachidian (1): in clade 2a (Amiantofusus, Pseudolatirus kuroseanus, Angulofusus nedae) and Peristernia marquesana. This has a direct correlation to character 49 , discussed next. 


\title{
49. Radula, rachidian, lateral edge (fig. AI)
}

\author{
$(\mathrm{L}=1 ; \mathrm{Ci}=100 ; \mathrm{Ri}=100)$ \\ 0 . Terminal \\ 1. Subterminal
}

Cusps in the rachidian are present terminally, i.e., they originate in the terminal edge of the tooth and project forward (0), and this is the plesiomorphic state. For clade 2a, the lateral cusps originate somewhat in the lateral edge of the tooth (1), in a way that the lateral base is not visible.

\section{Radula, rachidian, base width: edge width (fig. AJ)}

$(\mathrm{L}=9 ; \mathrm{Ci}=22 ; \mathrm{Ri}=75)$

0 . One

1. Less than 1 and more than $1 / 2$

2. $1 / 2$ or less

This character measures the ratio of the width of the base by the width of the cusped edge, i.e., square or rectangular-like rachidians have a ratio of one $(0)$. This is the case for most outgroups and for clade 1a of Dolicholatirus and Teralatirus roboreus; in clade 2 , however, the rachidian became more or less trapezoidal in shape, with

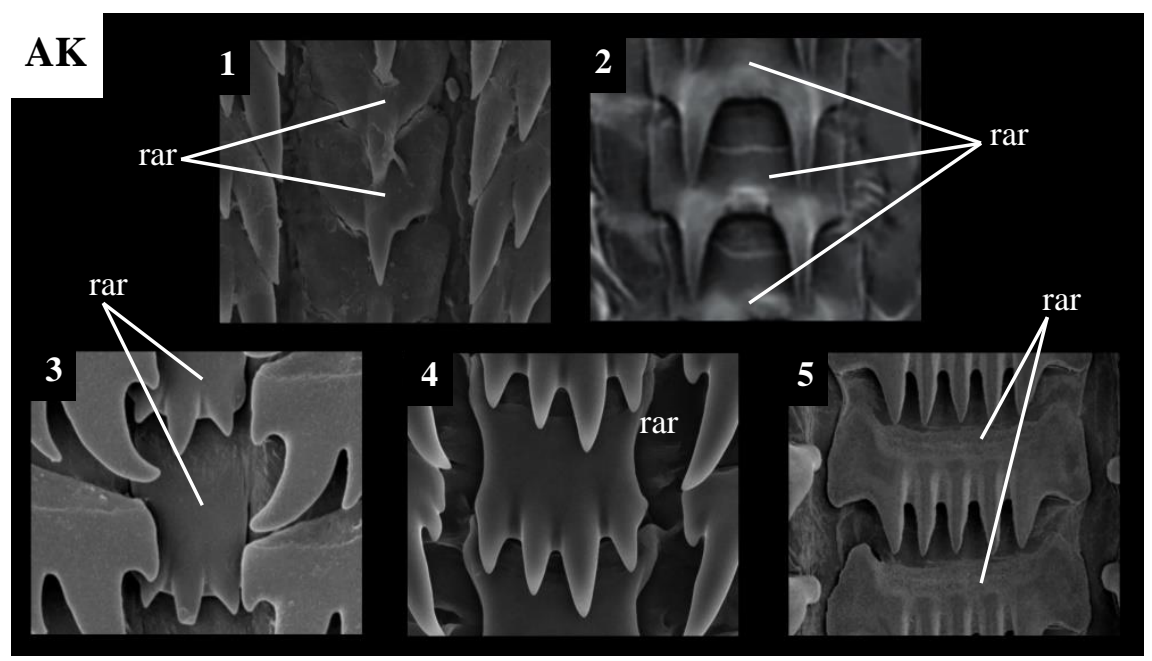

AK1. Radula detail of rachidian. AK1. Latirus sp. rachidian tooth, one cusp (0); AK2. Pugilina tupiniquim, (modified from Abbate \& Simone, 2015) two cusps (1); AK3. Nodolatirus nodatus, three cusps (2); AK4. Pustulatirus ogum, four cusps (3); AK5. Buccinum undatum, five or more cusps (4). rar: radula rachidian.

a ratio of less than one and

more than $1 / 2$ (1). Clade $5 \mathrm{~b}$ and $3 \mathrm{a}$ saw the occurrence of a ratio of $1 / 2$ or less (i.e., very thin rachidian base), with a posterior reversion in Fusinus sp. and Fusinus frenguelli. 
Beyond the peristerniine clade 6 there was a reversion to state 0 , which also occurred in Granulifusus hayashi; The fasciolariines Aurantilaria aurantiaca and Fasciolaria tulipa reverted to a lesser ratio (state 1) independently. Opeatostoma pseudodon has a very variable rachidian; hence the states in this taxon were coded 1,2 and 3.

Due to the quantitative nature of this character, an additive parsimony model was used ( 0 1-2), and a DELTRAN optimization.

\section{Radula, rachidian, number of principal cusps (fig. AK)}

$$
\begin{aligned}
& (\mathrm{L}=11 ; \mathrm{Ci}=36 ; \mathrm{Ri}=50) \\
& \text { 0. One } \\
& \text { 1. Two } \\
& \text { 2. Three } \\
& \text { 3. Four } \\
& \text { 4. Five or more }
\end{aligned}
$$

Typically, the rachidian tooth bears three primary cusps, and some taxa may have secondary ones. This pattern or three cusps (2) is the plesiomorphic state, and it remains more or less constant within fasciolariids, with a few modifications. Dolicholatirus and Teralatirus roboreus (clade 1a) have reduced this number to only one principal cusp (0). Only the outgroup species Pugilina tupiniquim has 2 cusps (1), while other outgroup species corresponding to nassariids and buccinids (e.g., Nassarius reticulatus, Buccinum undatum) have increased the cusp number to five or more (4). In one specimen of Opeatostoma pseudodon, there are over ten cusps, while in another it bears five; this may be the case of an anomaly, but in either way, it is coded for state 4 . An increase to four cusps (3) occurs in clade 8a (genus Pustulatirus) and in Peristernia nassatula. An additive parsimony model was used in this case (0-1-2-3-4), with each increase or decrease in cusp number counting as one step.

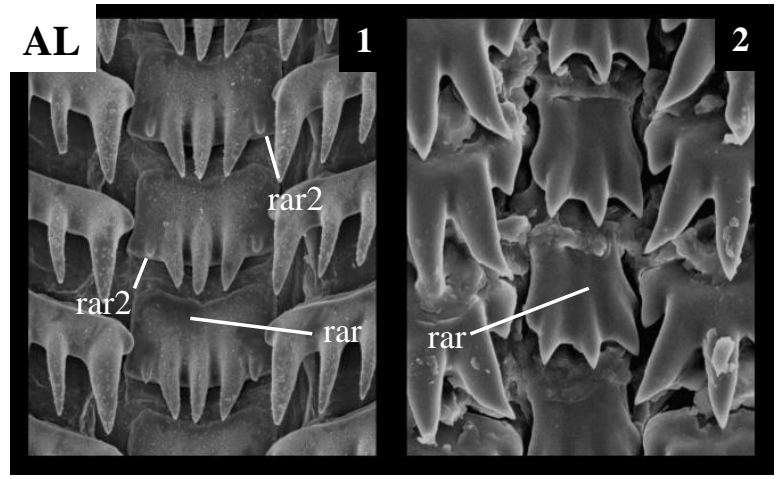

AL. Radula, detail of rachidian. AL1. Aurantilaria aurantiaca, rachidian tooth, secondary cusps present (1); AL2. Pustulatirus pallidus, no secondary cusps (1). rar: radula rachidian; rar2, radula rachidian secondary cusp. 


\section{Radula, rachidian, secondary cusps (fig. AL)}

$$
\begin{gathered}
(\mathrm{L}=7 ; \mathrm{Ci}=14 ; \mathrm{Ri}=14) \\
\text { 0. Absent } \\
\text { 1. Present }
\end{gathered}
$$

This highly homoplastic character explains the minute cusps some fasciolariids and other outgroup species possess. The absence (0) is plesiomorphic in the family, while the occurrence (1) originated independently as autapomorphies in four species: Fusinus frenguelli, Aurantilaria aurantiaca, Filifusus filamentosus and Polygona infundibulum. Because of the highly independent origins of the secondary cusps, a DELTRAN optimization was chosen, as independent origins for Pisania pusio and clade 1a

\section{Radula, rachidian, width: lateral width (fig. AM)}

$$
(\mathrm{L}=9 ; \mathrm{Ci}=33 ; \mathrm{Ri}=78)
$$

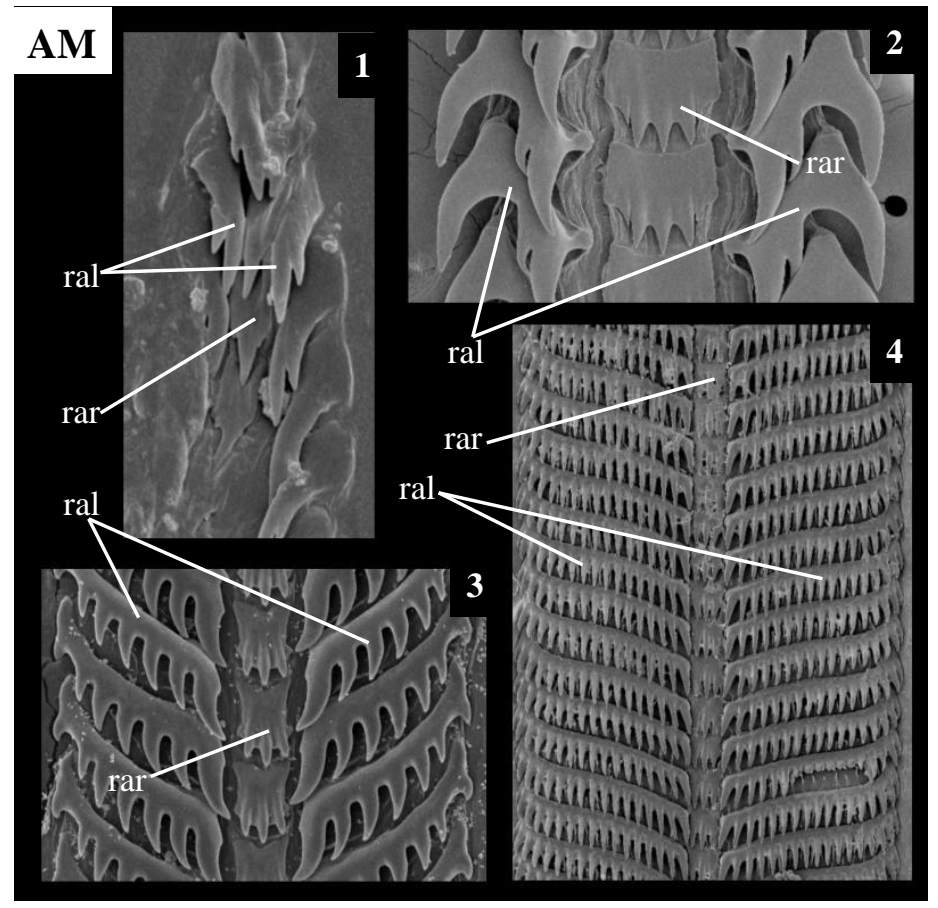

AM. Radula. AM1. Dolicholatirus cayohuesonicus, ratio of the width of the rachidian by the lateral tooth is one or more (0); AM2. Pisania pusio, ratio is $1 / 2$ to less than 1 (1); AM3. Leucozonia nassa, ratio is $1 / 4$ to less than $1 / 2$ (2); AM4. Latirus vischii, ratio is less than $1 / 4$ (3). ral: radula lateral; rar: radula rachidian.
0. One or more

1. $1 / 2$ to less than 1

2. $1 / 4$ to less than $1 / 2$

3. Less than $1 / 4$

The ratio of the width of the rachidian by the lateral is expressed in this character. The plesiomorphic state for, which is retained for Dolicholatirus and for Teralatirus roboreus (clade 1a), is the rachidian tooth as wide, or wider, than the laterals, with a ratio of rachidian by lateral width equal to one or more (0). This is the overall plesiomorphic radular type for neogastropods; however, beyond clade 2, (i.e., all fasciolariids except clade 1a), there was significant increase in lateral 
width, also expressed by the number of lateral cusps, leading to a smaller ratio of $1 / 4$ to less than $1 / 2(2)$.

Bandel (1984) also noted the smaller rachidian by lateral proportion, and argued that Dolicholatirus should not belong in Fasciolariidae, but should be placed in Buccinidae instead. Fraussen et al. (2007) characterized the radula of fasciolariids in the context of Buccinoidea, as having wider than longer laterals and a very small rachidian, also excluding Dolicholatirus from this diagnosis.

There is a general tendency for the ratio of the rachidian by lateral width to decrease even more. A ratio of less than 1/4 (3) occurs several times in fasciolariids: clade 2a, 6b, Peristernia marquesana, Latirus polygonus and L. pictus. Although this proportion is more or less the same in these clades, the cause for this is likely not; species of clade 2a, and Peristernia marquesana, have a very minute rachidian, leading to a much smaller ratio. On the other hand, other taxa which have this proportion have increased the number of cusps in the lateral and consequently its width; that is especially true for fasciolariines.

Opeatostoma pseudodon received an ambiguous state due to the variation in rachidian shape, as already mentioned, and it received state 1 (ratio of $1 / 2$ to less than one) and 2 (ratio of $1 / 4$ to less than $1 / 2$; this state was only received for outgroup taxa Pugilina tupiniquim and Pisania pusio). The optimization was DELTRAN, utilizing an additive parsimony model.

\section{Radula, lateral, position (fig. AN)}

$(\mathrm{L}=2 ; \mathrm{Ci}=50 ; \mathrm{Ri}=83)$

0 . Close to rachidian

1. Distanced from rachidian

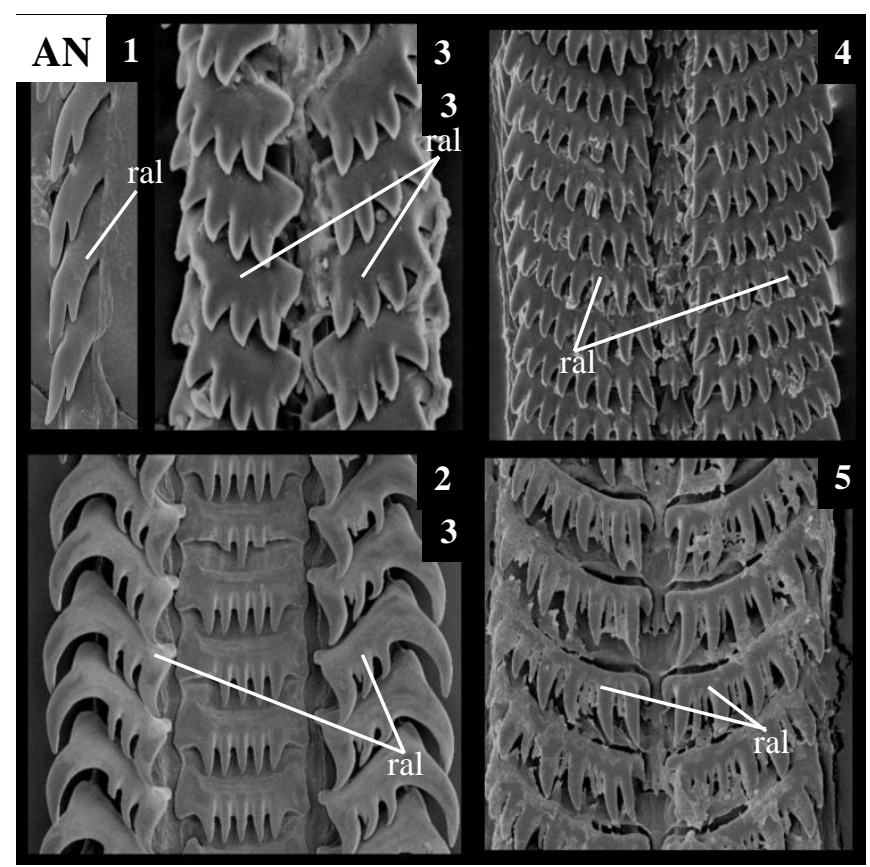

AN. Radula. AN1. Dolicholatirus cayohuesonicus, lateral teeth close to rachidian (char. 55: 0), ratio of the lateral length by it width is more than 1 (char. 56: 0); AN2. Buccinum undatum, laterals distanced from rachidian (char. 55: 1), ratio is one (char. 56: 1); AN3. Amiantofusus candoris, lateral close to rachidian (char. 55: 0), ratio is less than 1 to more than 1/2 (char. 56: 2); AN4. Chryseofusus graciliformis, lateral close to rachidian (char. 55: 0), ratio is 1/2 to 1/3 (char. 56: 3); AN5. Peristernia marquesana, lateral close to rachidian (char. 55: 0), ratio is less than 1/3 (char. 56: 4). ral: radula lateral. 
In the non-fasciolariid buccinoideans, the lateral teeth are somewhat distanced from the rachidian (1), while fasciolariids have them closely set (0).

\title{
55. Radula, lateral, length: width (fig. AN)
}

\author{
$(\mathrm{L}=8 ; \mathrm{Ci}=50 ; \mathrm{Ri}=89)$ \\ 0 . More than 1 \\ 1. One \\ 2. Less than 1 to more than $1 / 2$ \\ 3. $1 / 2$ to $1 / 3$ \\ 4. Less than $1 / 3$
}

The proportion of the lateral length by its width corresponds to this character, and hypothesized with an additive parsimony model. As with the previous character 54, there is a tendency for this ratio to decrease in fasciolariids, however, the present character does not take into consideration the rachidian width (and this may have contributed to same character states in very distinct groups for character 54).

Fasciolariidae (clade 1) have a ratio of lateral length by width of one (1), but this is only retained for Dolicholatirus sp.; clade $1 \mathrm{~b}$ reversed to a ratio of more than one (0) (i.e., laterals longer than wider). Clade 2's lateral length by width ratio dropped to less than 1 to more than 1/2 (2) and this was preserved for clade $2 \mathrm{a}$; an even greater decrease to $1 / 2$ to $1 / 3$ in the lateral length by width proportion (3) occurred on clade 3 . Finally the decrease in the length by width ratio of the lateral tooth to less than $1 / 3$ (4) occurred four times independently: clades 5b (Peristernia), 6a, 8a (Pustulatirus) and in Latirus polygonus.

56. Radula, lateral, cusps (fig. AO)

$$
\begin{gathered}
(\mathrm{L}=1 ; \mathrm{Ci}=100 ; \mathrm{Ri}=100) \\
\text { 0. Curved inward } \\
\text { 1. Curved outward }
\end{gathered}
$$

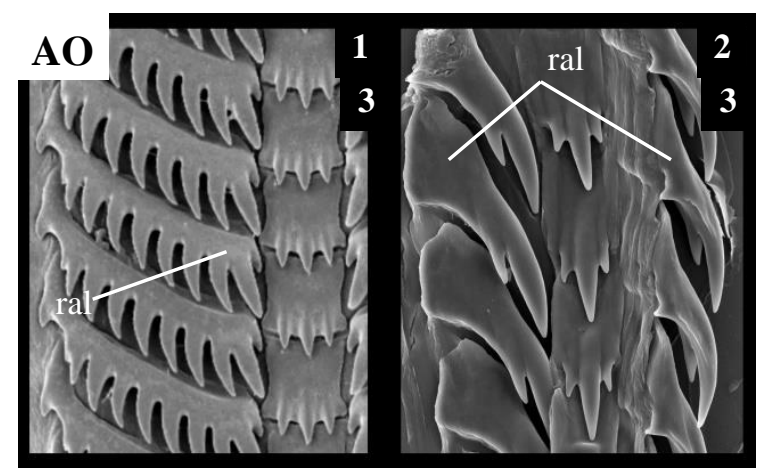

AO. Radula. A01. Hemipolygona armata, lateral cusps curved inward (0); AO2. Dolicholatirus cayohuesonicus, cusps curved outward (1). ral: radula lateral. 
The cusps in the lateral tooth may be curved inward, facing the rachidian tooth $(0)$ or outward (1), facing the lateral extremities. This is a synapomorphy to clade 1a of Dolicholatirus and Teralatirus roboreus.

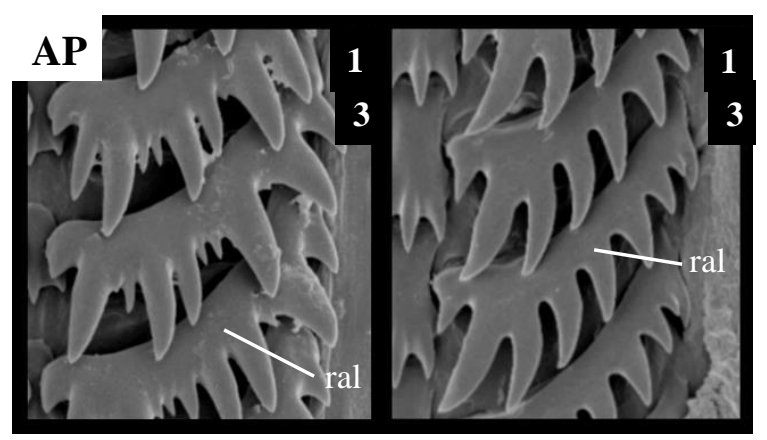

AP. Radula, detail of lateral. AP1. Fusolatirus bruijnii, non-uniform lateral cusps (1); AP2. Latirus pictus, uniform (0). ral: radula lateral.

57. Radula, lateral, cusps, variability (fig. AP)

$$
\begin{gathered}
(\mathrm{L}=1 ; \mathrm{Ci}=100 ; \mathrm{Ri}=100) \\
\text { 0. Uniform } \\
\text { 1. Not uniform }
\end{gathered}
$$

The lateral cusps of the lateral teeth usually occur in a uniform pattern, i.e., the cusps are of approximately equal size or there is a gradual decrease in length centrally or outwardly (0). In clade 5a of Peristernia and Fusolatirus bruijnii, the lateral cusps are not uniform in this sense, with an irregular pattern (1), bearing secondary cusps that are unevenly distributed across teeth of the same row or not. These secondary cusps will be discussed in character 65 .

This has been observed by Bandel (1984) and by Taylor \& Lewis (1995), stating that all fasciolariids have a radula with comb-like, multicuspidate, lateral teeth; while those of Peristernia have both large and small cusps with great variability in cusp pattern between teeth in sequential row. The genus Fusolatirus was established on the grounds that the type species "has the shell of Latirus-form and the radula of Peristernia-formula" (Kuroda \& Habe, 1971). Later works on Fusolatirus radulae have showed the same pattern (e.g., Snyder \& Bouchet, 2006); while this genus and Peristernia were shown to be polyphyletic in respect to each other in the phylogenetic study of Couto et al. (2016).

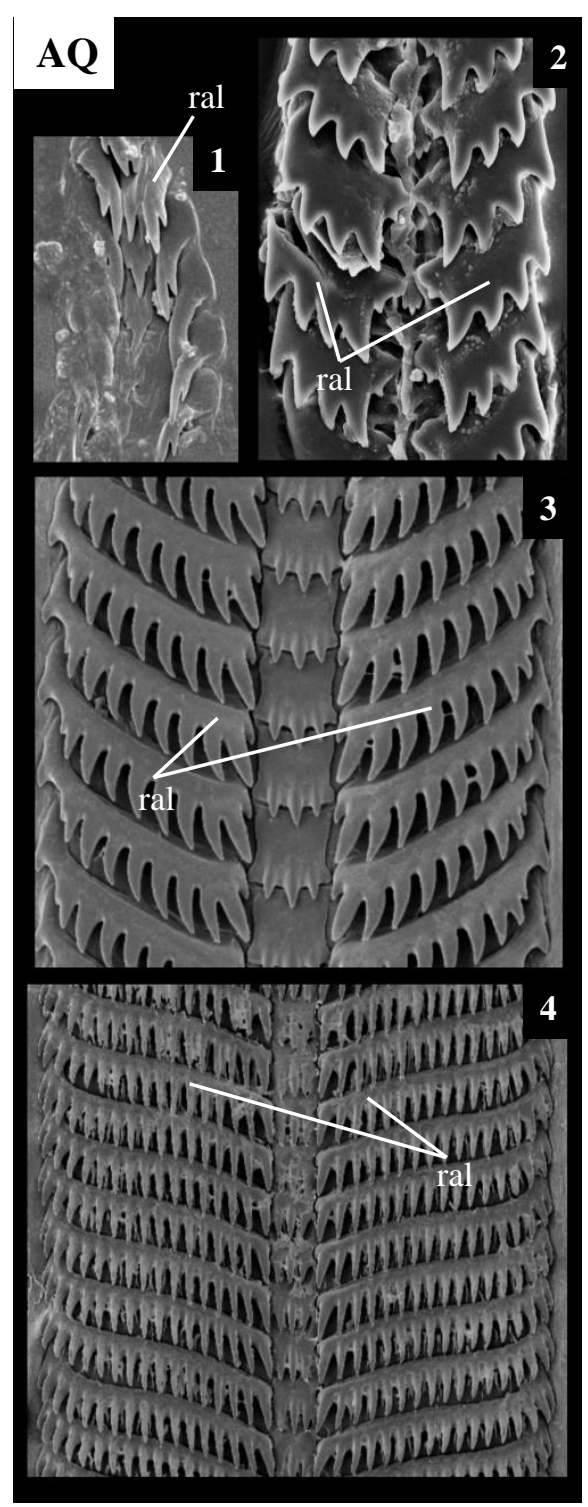

AQ. Radula. AQ1. Dolicholatirus cayohuesonicus, radula, lateral with up to four cusps (0); AQ2. Amiantofusus pacificus, five to six cusps (1); AQ3. Hemipolygona armata, seven to 15 cusps (2); AQ4. Pleuroploca trapezium, 7 to 15 cusps (3). ral: radula lateral. 


\section{Radula, lateral, cusps, number (fig. AQ)}

$$
\begin{gathered}
(\mathrm{L}=5 ; \mathrm{Ci}=60 ; \mathrm{Ri}=93) \\
\text { 0. Up to } 4 \\
\text { 1. } 5 \text { to } 6 \\
\text { 2. } 7 \text { to } 15 . \\
\text { 3. } 16 \text { or more }
\end{gathered}
$$

Character 59 is another evidence of an increase in the length and cusp number of the laterals, as already discussed previously in character 53 and 55. With the exception of Dolicholatirus and Teralatirus roboreus (clade 1a), that only have up to four cusps (0), all fasciolariids have increased the number of cusps in the lateral, being a diagnostic characteristic for fasciolariids in the buccinoidean context.

Clade 2 saw an increase in the number of cusps in the laterals to five to six (1), but that was retained only for clade $2 \mathrm{a}$; clade 3 increased to seven to 15 cusps (2), and this was maintained for most fasciolariids. Leucozonia ocellata reverted to the previous state of five to six cusps; however, a group that corresponds mostly to fasciolariines but also Nodolatirus nodatus and Latirus vischii greatly increased the number cusps to more than 16 (3), although Australaria australasia reverted back to the previous state of seven to 15 cusps. The evident transitional transformation of increased cusp number denotes an additive parsimony model is desirable (0-12-3).

59. Radula, lateral, base (fig. AR)

$$
\begin{gathered}
(\mathrm{L}=6 ; \mathrm{Ci}=16 ; \mathrm{Ri}=64) \\
\text { 0. Straight } \\
\text { 1. Curved }
\end{gathered}
$$

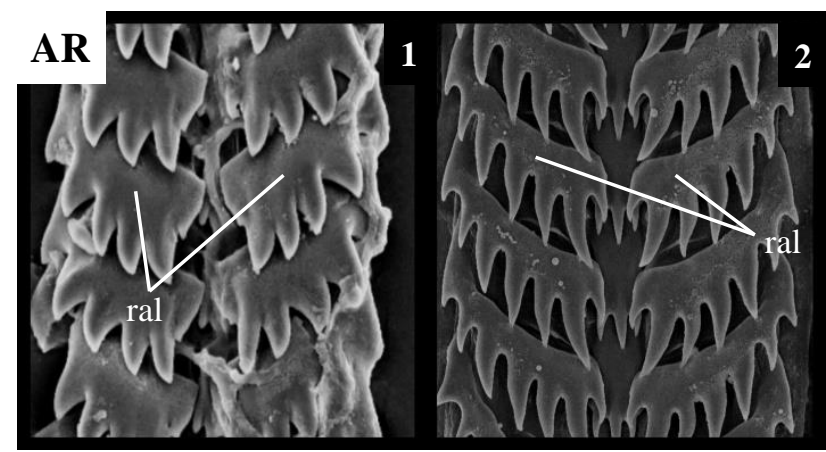

The lateral tooth's base exists in two ways: a

AR. Radula. AR1. Amiantofusus candoris, radula, lateral base straight (0); AR2. Polygona angulata, lateral base straight (0) or curved (1). The former occurs curved (1). ral: radula lateral.

as the basal state for fasciolariids, while the latter appeared three times independently, in Angulofusus nedae, clade 3b (Chryseofusus, Fusinus and Cyrtulus serotinus) and 5 (most of the peristerniines). 


\section{Radula, lateral, cusp 1 (fig. AS)}

$$
\begin{aligned}
& (\mathrm{L}=3 ; \mathrm{Ci}=66 ; \mathrm{Ri}=95) \\
& \text { 0. Present, same or greater size } \\
& \text { 1. Present, reduced size } \\
& \text { 2. Absent }
\end{aligned}
$$

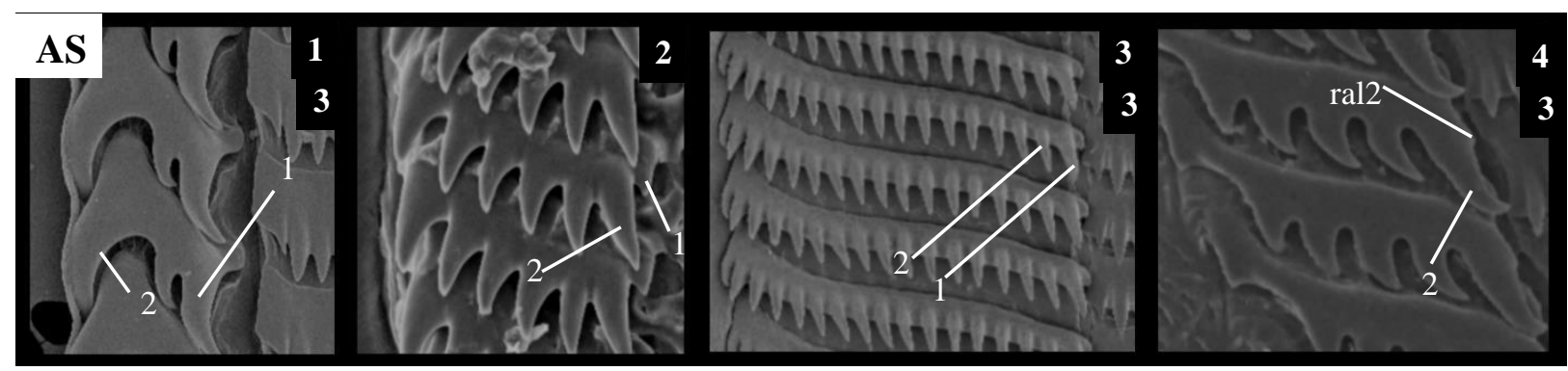

AS. Radula, detail of lateral. AS1. Pisania pusio, radula lateral teeth, cusp 1 same or greater size (char. 61: 0), cusp 2 twice as other cusps (char. 62: 1), secondary cusp in cusp 2 absent (char. 63: 0); AS2. Pseudolatirus discrepans, cusp 1 reduced size (char. 61: 1), cusp 2 same length other cusps (char. 62: 0), secondary cusp in cusp 2 absent (char. 63: 0); AS3. Filifusus filamentosus, cusp 1 absent (char. 61: 2), cusp 2 same length other cusps (char. 62: 0), secondary cusp in cusp 2 absent (char. 63: 0); AS4. Leucozonia ocellata, cusp 1 absent (char. 61: 2), cusp 2 twice as other cusps (char. 62: 1), secondary cusp in cusp 2 present (char. 63: 1). Numbers indicate cusp number as indicated by text. ral: radula lateral; ral2: radula lateral secondary cusp.

The first cusp of the lateral tooth of the radula is hereinafter referred to as the innermost cusp (cusp 1). Bandel (1984) argued that the radula of fasciolariids is much like that of other buccinids, but while in the latter the outermost cusp is the largest, in the former the innermost cusp is largest. This can be confirmed here, as the innermost cusp is bigger or at least the same size as the other cusps in the non-fasciolariid buccinoidean studied; in fasciolariids however (except clade 1a), it is exactly the opposite.

In Dolicholatirus and Teralatirus roboreus (clade 1a) radular modifications did not take place (as discussed in characters 54, 56, 59: increase in width and cusp number of the lateral tooth), remaining much like other buccinoideans: cusp 1 the same length as other cusps (0). A synapomorphy of the remaining fasciolariids is the reduction of this cusp (1), whereas the complete absence (2) occurred twice independently, on clades $6 \mathrm{~b}$ (fasciolariines and Latirus vischii) and 14 (Leucozonia and Opeatostoma pseudodon).

Differences in fasciolariid radulae were observed previously in the literature, more specifically those among peristerniines. Bullock (1974) noted that the feature that distinguishes 
Latirus and related species (sic) from Leucozonia is: the absence in Leucozonia of a 'denticle' in the form of a small projection at the base of the lateral, next to the rachidian tooth, whereas is present in Latirus. Couto \& Pimenta (2012) and Couto et al. (2015) observed that the 'denticle' that is present in some Leucozonia species, corresponds to the same structure as the cusp 1 of other fasciolariids; this view is rejected here based on observed anatomical differences: the cusp 1 of fasciolariines emerges from the base of the tooth whereas in Leucozonia this denticle emerges laterally from the innermost cusp (i.e., cusp 2). More on this 'denticle' will be discussed on character 63 .

\section{Radula, lateral, cusp 2, length (fig. AS)}

$$
\begin{gathered}
(\mathrm{L}=3 ; \mathrm{Ci}=33 ; \mathrm{Ri}=86) \\
\text { 0. Same or smaller than other cusps } \\
\text { 1. Twice as other cusps }
\end{gathered}
$$

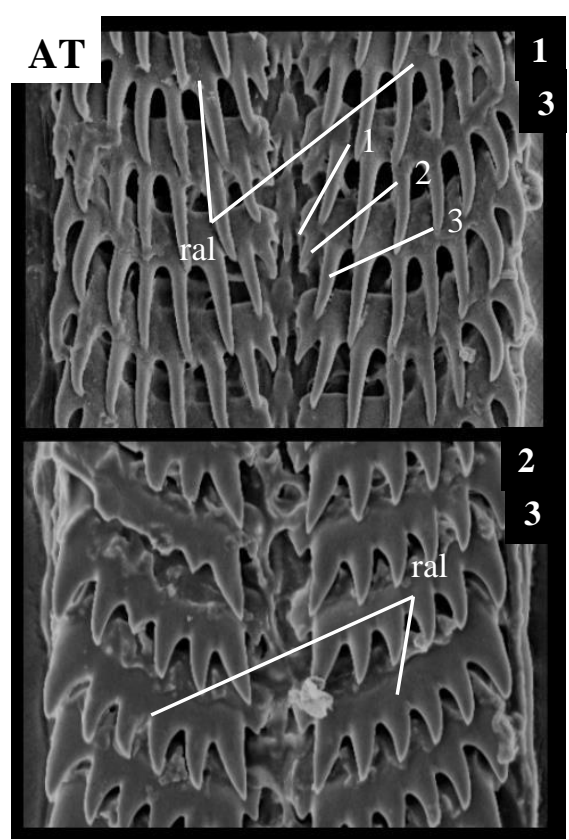

AT. Radula. AT1. Cyrtulus serotinus, innermost cusps with a gradual increase in length (1); AT2. Pseudolatirus discrepans, no gradual lengthening (0). Numbers indicate cusp number as indicated by text. ral: radula lateral.
The size of cusp 2 (i.e., the second innermost principal cusp of the lateral tooth) is generally longer than the other cusps in non-fasciolariid buccinoideans (e.g., Abbate \& Simone, 2015: Melongenidae; Bandel, 1984: Columbellidae, Buccinidae, Nassariidae). Clade 1a lacks any cusps other than cusp 1; in clade 2, as well as the reduction of the first cusp (discussed more thoroughly in the character 61 ), cusp 2 became the same size or smaller than the other cusps (0).

As previously discussed (character 60), clade 14 has completely lost cusp 1; and here it has also observed an increase in the length of cusp 2 to twice the size of the other cusps (1) even though cusp 2 is functionally the innermost cusp. The optimization that best suits the hypothesis that the non-Dolicholatirus fasciolariids have reduced the length of cusp 2 is DELTRAN, so it is used here. 


\section{Radula, lateral, cusp 2, secondary inner cusp (fig. AS)}

$$
\begin{gathered}
(\mathrm{L}=2 ; \mathrm{Ci}=50 ; \mathrm{Ri}=75) \\
\text { 0. Absent } \\
\text { 1. Present }
\end{gathered}
$$

The presence of a secondary cusp occurring in the lateral innermost cusp of the lateral tooth (1) is expressed as this character; because this secondary cusp only occurs in taxa in which cusp 1 is absent, the innermost cusp is cusp 2. As previously discussed in character 60, this secondary cusp is not the 'denticle' sensu Bullock (1984), Couto \& Pimenta (2012) and Couto et al. (2015). This character is absent (0) in all fasciolariids except in clade 15 and in Leucozonia ocellata.

\section{Radula, lateral, innermost cusps (1 to 3) (fig. AT)}

$$
\begin{aligned}
& (\mathrm{L}=1 ; \mathrm{Ci}=100 ; \mathrm{Ri}=100) \\
& \text { 0. Same length } \\
& \text { 1. Progressive increase in length }
\end{aligned}
$$

It is here defined as a progressive increase in the length of the innermost cusps (1) as a gradual lengthening of the cusps outwards from the cusp of the lateral closest to the rachidian; hence cusp 1 is smallest, followed by cusp 2 and sometimes cusp 3. This occurs for clade 3c only (Fusinus and Cyrtulus serotinus), while in all other fasciolariids this increase does not occur (0).

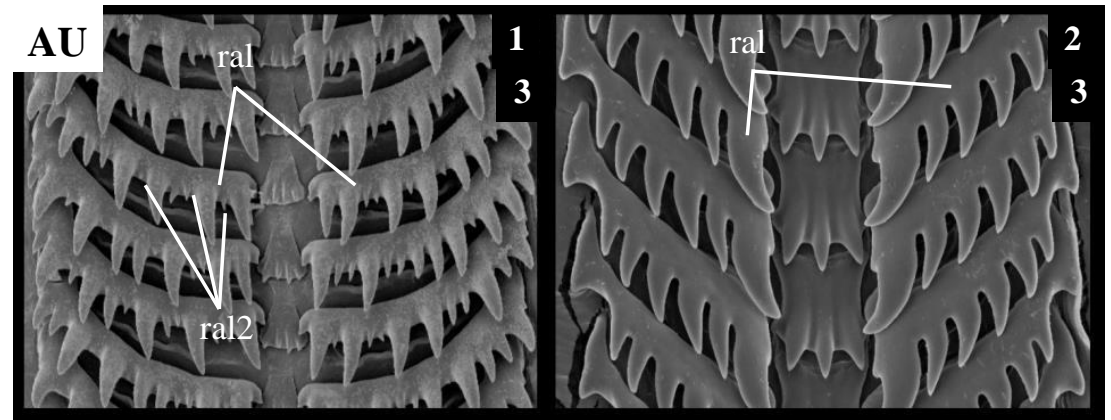

AU. Radula. AU1. Peristernia nassatula, laterals bearing secondary cusps (1); AU2. Leucozonia ponderosa, laterals without secondary cusps (0). ral: radula lateral; ral2: radula lateral secondary cusp.
64. Radula, lateral, secondary cusps (fig. AU) $(\mathrm{L}=1 ; \mathrm{Ci}=100 ; \mathrm{Ri}=100)$

0 . Absent

1. Present

Secondary cusps in the teeth may occur in the rachidian

(character 55, fig. AL) but in the laterals as well. In fasciolariids, secondary cusps in the lateral tooth (1) occur in clade 5a of Fusolatirus bruijnii and Peristernia, whose non-uniform cusp 
distribution (as mentioned in character 58, fig AP), with its alternating principal and secondary cusps are characteristic for this group. Species in clade 1a (Dolicholatirus and Teralatirus roboreus) also bear a minute secondary cusp in the lateral tooth; while it may occur in outgroup species of nassariids and some buccinids. All the remaining fasciolariids this feature does not occur (0). A DELTRAN optimization was chosen to account for the multiple independent origins of secondary cusps in the groups anteceding Fasciolariidae.

\section{Proboscis, shape (fig. AV)}

\section{$(\mathrm{L}=1 ; \mathrm{Ci}=100 ; \mathrm{Ri}=100)$ \\ 0. Straight \\ 1. Coiled}

A proboscis is formed from the invagination of the snout and is found in most caenogastropods, and two main types are recognized: an acrembolic type with the retractor muscles at the tip, and

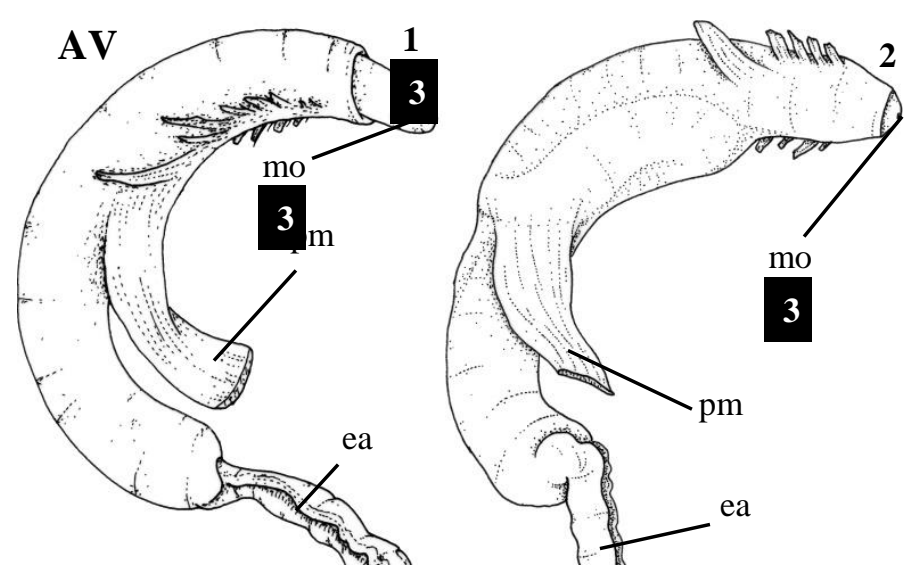

AV. Proboscis. AV1. Granulifusus sp. proboscis retracted straight into the sheath (0); AV2. Fusinus frenguelli, proboscis coiled within its sheath (1). ea: anterior esophagus; mo: mouth; pm: proboscis retractor muscle. the pleurembolic type, with retractors inserted in the middle of the proboscis; although several other subtypes have been described (Ponder \& Lindberg, 1997). A separation between snout and proboscis is not clear, except the fact that a snout lacks any retractor muscles (Simone, 2011).

In Fasciolariidae, there is but a single proboscis type, pleurembolic; for most members, the proboscis is retracted within the rhynchodeum (also called proboscis sheath) in a straight fashion

(0), however in a group that consists of Chryseofusus, Fusinus, Cyrtulus serotinus and Pseudolatirus pallidus (clade 3a), it is retracted in a coiled manner (1). In this latter group the proboscis is very long, and as discussed in character 43 , the small buccal mass occurs at the very tip of the proboscis. 
Kosyan et al. (2009) examined the anatomy of several fasciolariids, including one Fusinus species (F.tenerifensis); these authors characterized the proboscis of all species as straight and never coiled within the rhynchodeum like in the buccinid Troschelia berniciensis (proboscis extremely long, narrow compactly folded within rhynchodeum). Because these authors reported paired proboscis retractor muscles (instead of one) and did not characterize the radula for $F$. tenerifensis, the suspicion is that this species analyzed by Kosyan et al. (2009) does not belong in the genus Fusinus; although no image of the shell was provided in order to confirm the taxonomy.

This characteristic coiling of the proboscis occurs in other buccinids (Troschelia Mörch, 1876: Kosyan et al., 2009; Aulacofusus: Kosyan \& Kantor, 2013; Calagrassor Kantor et al., 2013: Kantor et al., 2013). Although Buccinidae is evidently a polyphyletic group, as demonstrated by many molecular studies (e.g., Kosyan et al., 2009; Zou et al., 2011; Couto et al., 2016) this characteristic proboscis probably emerged in parallel, as the possession of a particular proboscis type does not necessarily indicate homology (Ponder \& Lindberg, 1997). Kantor (1990) has shown, on the basis of differences in musculature, that a pleurembolic proboscis has evolved independently in the Tonnoidea and Neogastropoda, and advocates an independent evolution of the proboscis of all major groups of marine predatory gastropods, a hypothesis refuted by Simone (2011), which demonstrated all higher caenogastropod proboscis are of a same, homologous type, raising the name Rhynchogastropoda (proboscis-bearing) to that branch.

\section{Proboscis, retractor muscles, origin (fig. AW)}

\section{$(\mathrm{L}=1 ; \mathrm{Ci}=100 ; \mathrm{Ri}=100)$ \\ 0. Haemocoel \\ 1. Columellar muscle}

Studies of comparative morphological investigation suggest that the muscles in the proboscis and snout anatomy are not yet fully understood. Caenogastropods show that there is undescribed diversity in both snout/proboscis wall composition and introversion/retraction musculature with morphological evidence that suggests that a proboscis evolved separately in at least four separate caenogastropod groups, each characterized by the presence of novel retractor muscles and different modifications of plesiomorphic "aortic muscles" (Golding et al., 2009). 
These muscles are important for higher but also for family-level studies; being one of the diagnostic characteristic for the family Fasciolariidae, sensu Fraussen et al. (2007): in Buccinidae the retractors are usually numerous and are attached in bundles laterally to the proboscis sheath (or rhynchodeum); in Fasciolariidae there is either the single pair of the retractors, or a single powerful retractor. In either of these cases (a pair or single), the retractors originate in the columellar muscle (1), posteriorly, close to the diaphragmatic septum and run anteriorly, inserting posterior or anterior to the rhynchodeum. Non-fasciolariids, which have bundles of fibers instead of a pair or a single muscle, on the other hand, have these originating through several insertion points at the base of the haemocoel (0).

\section{Proboscis, retractor muscles, bundles of muscles (fig. AW)}

\section{$(\mathrm{L}=3 ; \mathrm{Ci}=33 ; \mathrm{Ri}=80)$}

0 . Two bundles

1. One bundle

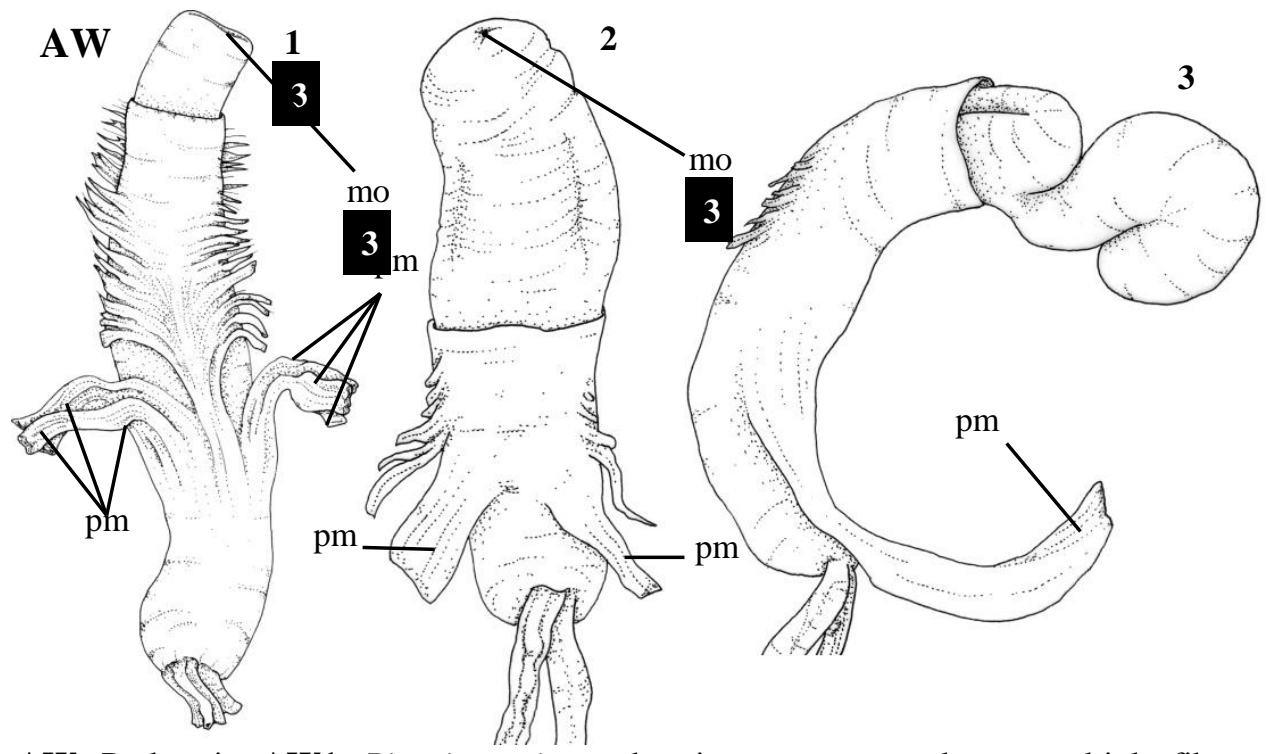

AW. Proboscis. AW1. Pisania pusio, proboscis retractor muscles as multiple fibers, inserted in haemocoel wall (char. 68: 0), arranged in two bundles (char. 68: 0); AW2. Pustulatirus ogum, retractor muscles originating in columellar muscles (char. 67: 1) and arranged in two bundles (char 68: 0); AW3. Fusinus marmoratus, retractor muscles originating in columellar muscles (char. 67: 1) and arranged as a single powerful muscle (1). mo: mouth opening; pm: proboscis retractor muscle. 
Neogastropods have the proboscis muscles arranged in two lateral bundles, one in each side, of the proboscis (e.g., Enigmaticolus Fraussen, 2008: Kantor et al., 2013; Aulacofusus: Kosyan \& Kantor, 2013). Non-fasciolariids have the several muscle fibers with haemocoelic origins; fasciolariids on the other hand have one or two strong muscles with the origin in the columellar muscle (as previously discussed).

The scenario hypothesized here suggests that Fasciolariidae arranged each of these bundles into a single muscle (creating, thus, two bundles one in each side of the proboscis) with columellar muscle origin; posteriorly the left muscle tuft was lost and, for most of the fasciolariids remained so. This is congruent with a DELTRAN optimization, in which there were two independent losses of the right muscle tuft (1): one for Dolicholatirus cayohuesonicus and another for clade 2 (containing most members of the family). Species of Pustulatirus (clade 8a) reverted to the previous state, and have two bundles of muscles.

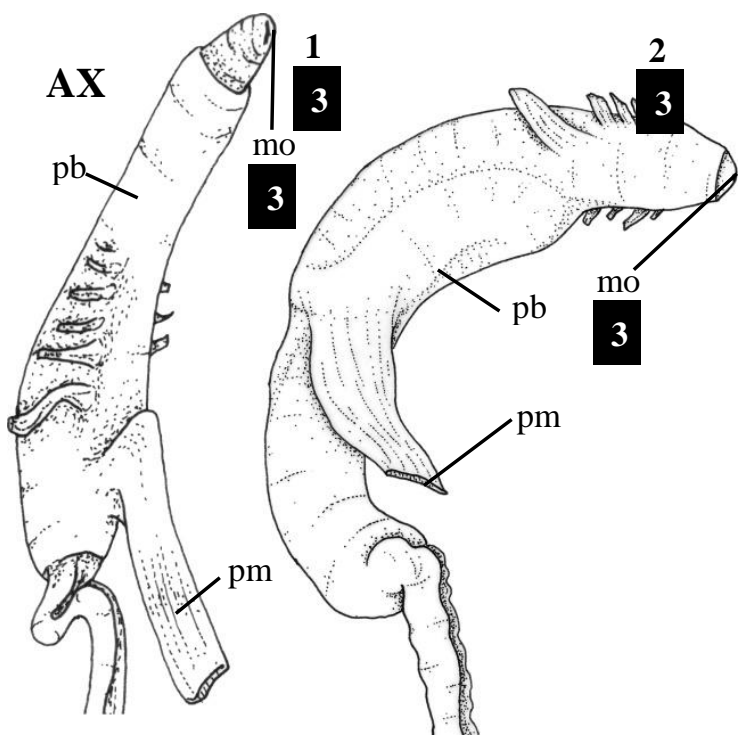

AX. Proboscis. AX1. Dolicholatirus cayohuesonicus, proboscis retractor muscle inserted posteriorly in rhynchodeum (0); AX2. Fusinus frenguelli, proboscis retractor inserted medially (1). mo: mouth opening; pb: proboscis; pm: proboscis retractor muscle.

\section{Proboscis, retractor muscles, position in} proboscis (fig. AX)

$$
\begin{gathered}
(\mathrm{L}=13 ; \mathrm{Ci}=7 ; \mathrm{Ri}=45) \\
\text { 0. Posterior } \\
\text { 1. Median }
\end{gathered}
$$

This highly homoplastic character denotes the insertion of the proboscis retractor muscles in the rhynchodeum wall. In most fasciolariids species, being the plesiomorphic state, the muscles are inserted in the posterior region of the proboscis (0), while an insertion medially (1) in the rhynchodeum occurs in several clades or species independently: in Dolicholatirus cayohuesonicus, clade 2c (Amiantofusus), Pseudolatirus pallidus, Fusinus australis, clade 4b, 6c, Hemipolygona armata, clade 8a (Pustulatirus) and 12. The optimization chosen was DELTRAN. 
69. Salivary glands, position (fig. AY)
$(\mathrm{L}=3 ; \mathrm{Ci}=33 ; \mathrm{Ri}=91)$
0. Close to nerve ring
1. Free

Kosyan et al. (2009) found that some fasciolariids have 'separate' salivary glands while others have 'free' salivary glands, this former probably refers to the state 0 (close to nerve ring). There same authors listed

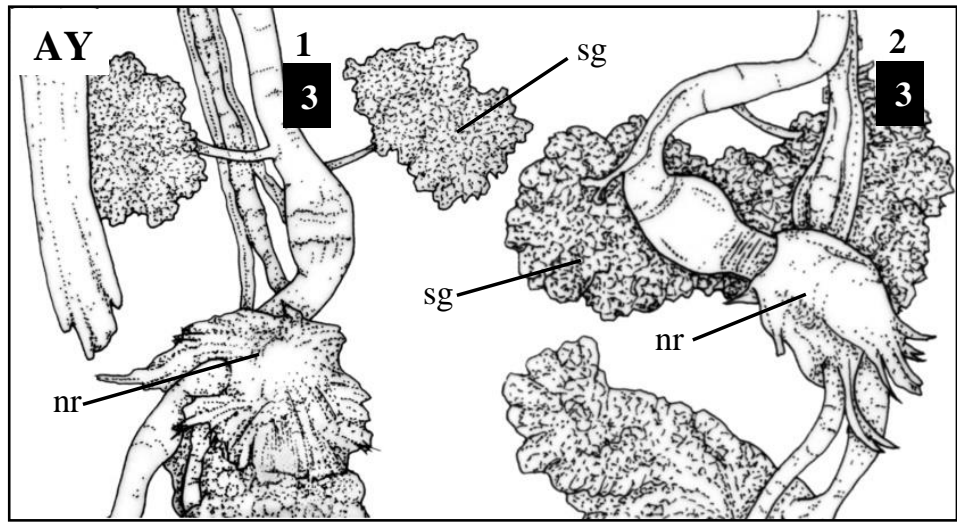

AY. Mid-esophagus. AY1. Fasciolaria tulipa, salivary glands as paired and free amorph masses (1); AY2. Fusinus sp. salivary glands close to nerve ring (0). nr: nerve ring; sg: salivary glands.

Fusinus tenerifensis has having the salivary glands 'separate' and Opeatostoma pseudodon and Pustulatirus mediamericanus as 'fused'; this is the opposite state found in the present study for Fusinus and for the two latter species. The meaning for this is doubtful, but perhaps preservation quality plays a crucial role for this character in particular

Fraussen et al. (2007) reported that the genus Amiantofusus has salivary glands that are

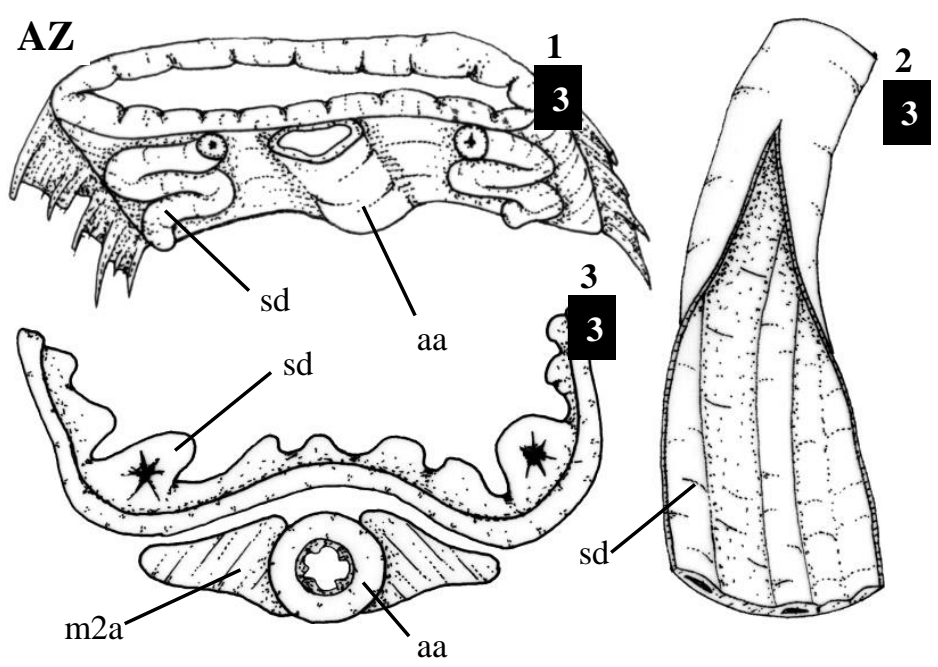

AZ. Section of the anterior esophagus immediately after valve of Leiblein. AZ1. Buccinum undatum, salivary ducts immersed in anterior esophagus wall (0); AZ2. Polygona infundibulum, salivary ducts immersed in esophagus wall (1); AZ3. Fusinus australis, salivary ducts immersed in esophagus wall (1). aa: anterior aorta; $\mathbf{m 2 a}$ : accessory odontophore retractor muscles; sd: salivary gland duct. situated on both sides of the anterior part of the rhynchodeum and the nerve ring, suggesting that they have correspond to state 'close to nerve ring' (0), much like most fasciolariids. Contrarily, clade 6 has salivary glands that are separate from each other (1), and this occurs on the outgroup species Buccinum undatum and Pisania pusio.

70. Salivary ducts (fig. AZ)

$(\mathrm{L}=1 ; \mathrm{Ci}=100 ; \mathrm{Ri}=100)$

0 . Free

1. Immersed in esophagus wall 
The salivary gland ducts which bypass the nerve ring is an important character for distinguishing the Neogastropoda from other mesogastropods (Ponder \& Lindberg, 1997; Strong, 2003; Simone, 2011). In the scope of the superfamily Buccinoidea, however, there are some differences that are worth noting. In the family Buccinidae, the ducts, after leaving the salivary glands, follow freely along the anterior esophagus towards the anterior part of the proboscis, where they enter the walls of the esophagus close to their entrance into the buccal cavity (Fraussen et al., 2007); in Fasciolariidae (e.g., Leucozonia nassa: Couto \& Pimenta, 2012; Pustulatirus ogum and Hemipolygona beckyae: Couto et al., 2015; Latirus polygonus: Kosyan et al., 2009), the ducts, shortly after leaving the glands, enter the anterior esophagus walls in front of the valve of

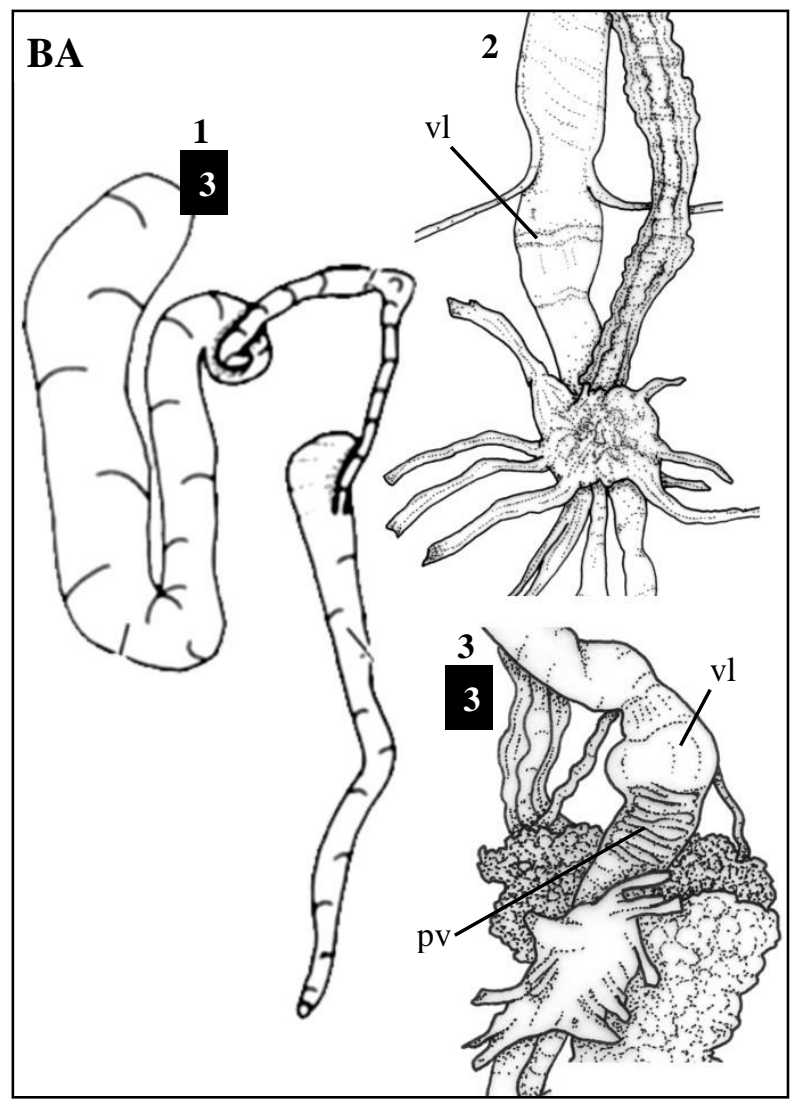

BA. Anterior and middle esophagus. BA1. Pugilina tupiniquim (modified from Abbate \& Simone, 2015), valve of Leiblein absent (char. 72: 0) and ventral glandular region absent (char. 73: 0); BA2. Aurantilaria aurantiaca, valve of Leiblein present (char. 72: 1) and ventral glandular region absent (char. 73: 0); BA3. Fusinus frenguelli, valve of Leiblein present (char. 72: 1) and ventral glandular region present (char. 73: 1). pv: ventral glandular region of mid esophagus; vl, valve of leiblein.
Leiblein.

Kosyan et al. (2009) observed mixed results for this feature in fasciolariids: while in Latirus polygonus the salivary ducts are embedded in the esophagus wall, in Pustulatirus mediamericanus, Turrilatirus turritus, Peristernia nassatula, P. ustulata and Opeatostoma pseudodon the ducts are reported as free. This contradicts the diagnosis for the family of Fraussen et al. (2007); Couto et al. (2015) has pointed that this fact deserves further investigation. I have dissected four out of the six species that Kosyan et al. (2009) reported as having the salivary ducts free from the anterior esophagus and found this not to be true. Likely, these authors mistakenly identified the accessory odontophore retractor muscles $(\mathrm{m} 2 \mathrm{a})$ that follow the aorta anteriorly from the nerve ring, ventral to the anterior esophagus as the ducts, while these run immersed in the gut wall.

Fasciolariids have, with the outgroup species Pisania pusio the ducts immersed in the 
anterior esophagus wall immediately posterior to the valve of Leiblein (1). The ducts follow their openings into the buccal cavity under the lateral folds of the esophagus. This condition is also true for other neogastropods (Simone, 2011), although they become immersed only near the buccal mass, much more anterior (0).

\section{Valve of Leiblein (fig. BA)}

$(\mathrm{L}=3 ; \mathrm{Ci}=33 ; \mathrm{Ri}=0)$

0 . Absent

1. Present

The valve of Leiblein, a pyriform bulbous or pear-shaped organ lying at the transition of the anterior and mid-esophagus, is restricted to the non-conoideans neogastropods (Ponder, 1973; Ponder \& Lindberg, 1997; Strong, 2003; Simone, 2011). It is composed of a cone-shaped bulge that is enclosed in a chamber formed by the expanded walls of the anterior portion of the midesophagus (Kantor \& Fedosov, 2009) and is fringed with extremely long cilia (Fretter \& Graham, 1962). The main function of the valve is to prevent the reflow of food from the posterior esophagus during proboscis elongation, acting partially mechanically, partially chemically (exposure to secretions of the digestive gland or stomach contents causes the valve to close (Kantor \& Fedosov, 2009). The supposition was done earlier in the studies of the valve, since there is a correlation between presence or absence of the valve and size or placement of the gland of Leiblein; taxa lacking a gland or have duct of the gland of Leiblein that bypasses the esophagus, lack a valve of Leiblein (Ponder, 1994; Strong, 2003).

Fedosov \& Kantor (2009) have demonstrated significant differences in the morphology and embryogenesis of the valve of Leiblein in different neogastropods, (Muricidae and Buccinidae at least). This suggests that the homology of the valve of Leiblein within Neogastropoda is questionable despite the superficial similarity.

According to these authors, Neogastropoda have three key autapomorphies: the accessory salivary glands, the rectal (or anal) gland and the valve of Leiblein. Because buccinoideans lack the two former neogastropod autapomorphies, if these authors' assumption is correct, then buccinoideans do not share any of the previously hypothesized autapomorphies with the rest of neogastropods. This raises the prospect of a paraphyletic Neogastropoda with two stems, one 
including of Buccinoidea, and another with the remaining neogastropod families. This scenario is in conformation with some molecular studies that challenge the neogastropod concept (e.g., Winnepenninckx et al., 1998; Colgan et al., 2007; Cunha et al., 2009). Another likely scenario is the secondary loss of these structures independently by some buccinoids.

This global discussion on valve of Leiblein morphology and homology is beyond the present study, since undoubtedly fasciolariid valves have the same origin (1), and only a few outgroup species such as Pugilina tupiniquim lack this structure (0).

\section{Mid-esophagus, posterior ventral glandular region (fig. BA)}

$(\mathrm{L}=3 ; \mathrm{Ci}=100 ; \mathrm{Ri}=100)$

0. Absent

1. Present

In some fasciolariids, namely Fusinus and Cyrtulus serotinus (clade 3c), there is a series of transverse rings, generally orange to brown color, posterior to the valve of Leiblein (1). This structure is not visible (0) in other fasciolariids.

These circular structures are likely the remnants of the 'glande framboisée' (framboisse gland) sensu Amaudrut (1898). Andrews \& Thorogood (2005) and Simone (2011) described this part of the mid-esophagus, anterior to the nerve ring, as a section rich in mucous glands on the hypertrophied dorsal folds (the pre-torsional left larger than the right); being an autapomorphy of some Muricidae (Simone 2011: including, e.g., Phyllonotus Swainson, 1833, Siratus Jousseaume, 1880, Chicoreus Montfort, 1810; but not including genus Thais). The assumption of homology is based on the position and arrangement of the mid-esophagus; however, no further investigation has been undertaken, neither histological nor embryological. What is clear is that the (re?)appearance of this feature is unique in the clade of Fusinus and Cyrtulus serotinus, with all other fasciolariids lacking. 


\section{Esophageal gland, form (fig. BB)}

\section{$(\mathrm{L}=3 ; \mathrm{Ci}=66 ; \mathrm{Ri}=0)$ \\ 0 . Ventral septated sac \\ 1. Gland of Leiblein \\ 2. Absent}

The esophagus in gastropods is not merely a passage between mouth and stomach, and food content generally undergoes several digestive processes as a result of intense glandular activity found in it (Fretter \& Graham, 1962; Salvini-Plawén, 1988; Ponder \& Lindberg,

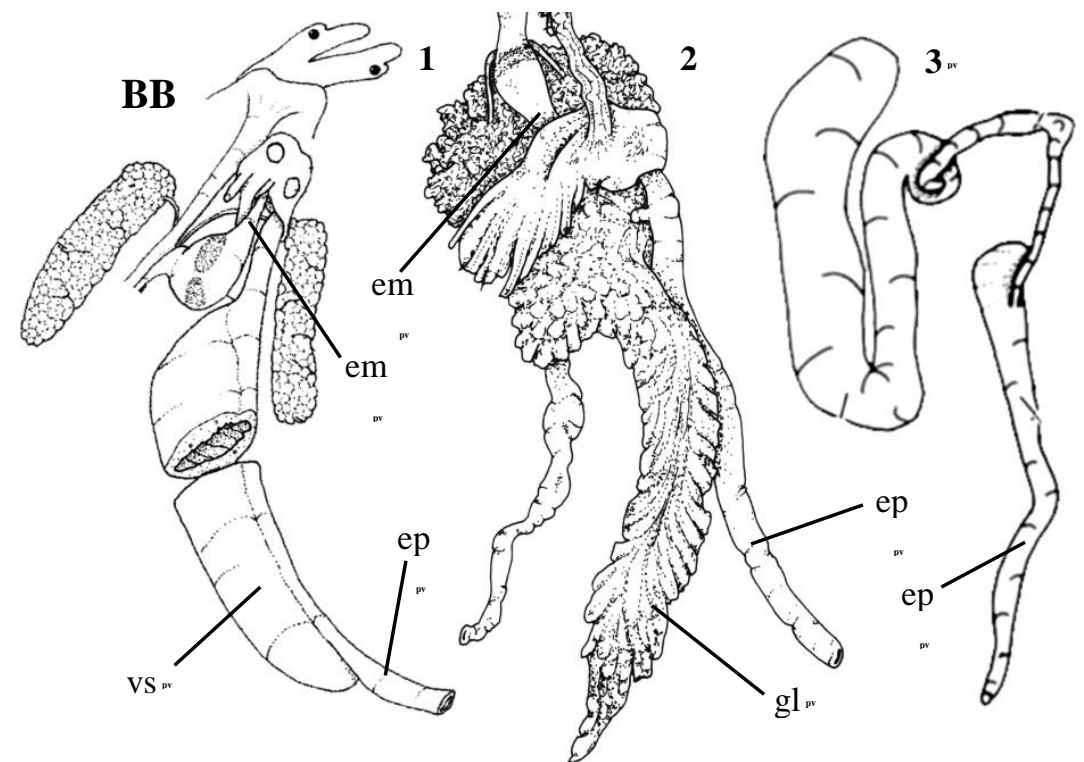

BB. Anterior digestive system. BB1. Teralatirus roboreus (modified from Simone et al., 2013), esophageal gland as a ventral septated sac (0); BB2. Granulifusus sp. esophageal gland as the gland of Leiblein (1); BB3. Pugilina tupiniquim (modified from Abbate \& Simone, 2015), esophageal gland absent (2). em: mid-esophagus; ep. posterior esophagus; gl: gland of Leiblein; vs: ventral septated sac.

1997; Strong, 2003; Simone,

2011). In some archeogastropods the esophagus bears a pair of esophageal pouches laterally, but this does not have the same origin as the dorsal esophageal gland and the gland of Leiblein (Strong, 2003; Simone, 2011) of interest in this study.

The esophageal gland is located in the mid-posterior esophagus, and is present in most caenogastropods; while it is derived from a dorsal glandular strip, torsion shifted its position to ventral (Simone, 2011). In some taxa such as Naticoidea and Cypraeoidea the middle region of the esophagus possesses a large ventral diverticulum being nodose or transversely (Simone, 2011).

In neogastropods, the esophageal gland lacks septa, and has a uniform tissue; it is connected to the ventral surface of the esophagus by means of a duct. In some Cancellarioidea, Muricoidea (sensu Simone, 2011: muricoideans, buccinoideans, olivoideans and pseudolivoideans) and Conoidea, a gland of Leiblein occurs; conoideans have a modified variation, the venom gland (Strong, 2033; Simone, 2011). The gland of Leiblein is absorptive as well as secretory, acting as a reservoir for solute-rich liquid entering it from the esophagus in both directions (Andrews \& Thorogood, 2005). Preliminary ultrastructural examination indicates 
that the gland absorbs cadmium not only from the blood but also directly from its lumen and that it may have the capacity to sequester a wide range of toxins, that contributed to a modified secretory function of some gastropods (e.g., Conidae: venom gland) (Andrews \& Thorogood, 2005).

Some buccinoideans have secondarily lost the gland of Leiblein, according to most morphological analysis (Ponder \& Lindberg, 1997; Strong, 2003; Simone, 2011). The possibility that Neogastropoda is not monophyletic, as was discussed earlier on character 73 , raises the hypothesis that these taxa did not secondarily loose this structure, instead never acquired it. This is not, however, the scope of this study. Melongenids (Pugilina tupiniquim) lack a valve or a gland of Leiblein (2), nor any gland in the mid-esophagus.

All Fasciolariids have a gland of Leiblein (1), except Teralatirus roboreus, which has an esophagus that resembles those of non-neogastropods, bearing a ventral expansion (0); it greatly resembles the esophagus corresponding to non-neogastropod taxa, such as cypraeoideans, illustrated by Simone (2011: fig. 16C). Some cancellariids have a glandular strip within the midesophagus that is homologous to the gland of Leiblein (Strong, 2003) and that seems to be the case in Teralatirus roboreus as well; it is certain however, that the reversal to a state without a gland of Leiblein occurred on several occasions within caenogastropods.

\section{Posterior esophagus, diameter (fig. BC)}

$(\mathrm{L}=6 ; \mathrm{Ci}=33 ; \mathrm{Ri}=50)$

0. Constant

1. Broadening in visceral region

2. Broadening in haemocoel
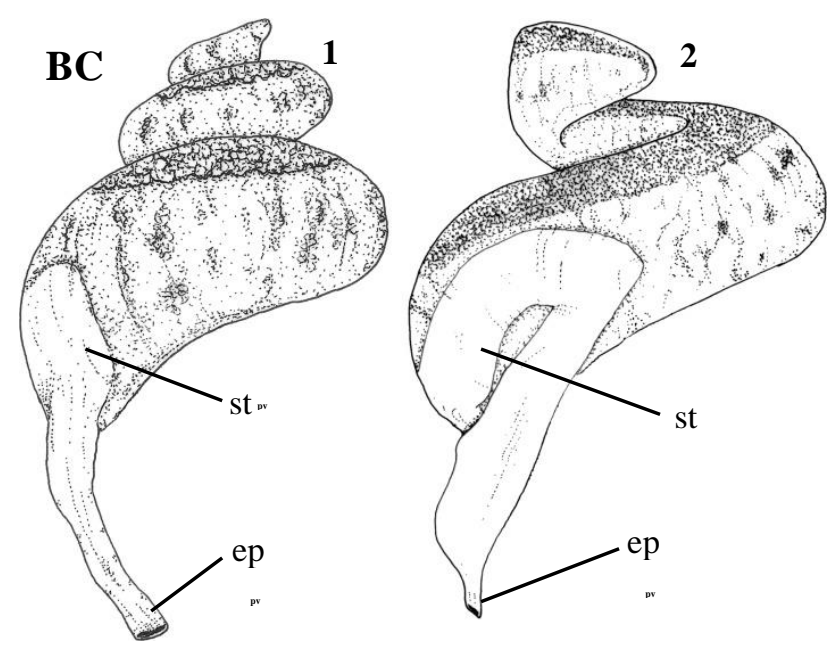

BC. Visceral mass. BC1. Polygona angulata, posterior esophagus constant in diameter (0); BC2. Aurantilaria aurantiaca; posterior esophagus with a broadening anterior to the stomach (1). ep: posterior esophagus; st: stomach. 
The posterior esophagus penetrates the diaphragmatic septum posteriorly and follows into the stomach, in the visceral region. In most fasciolariids, the transition between the septum is smooth, the diameter of the esophagus in this region is constant (0). In the clade of fasciolariines

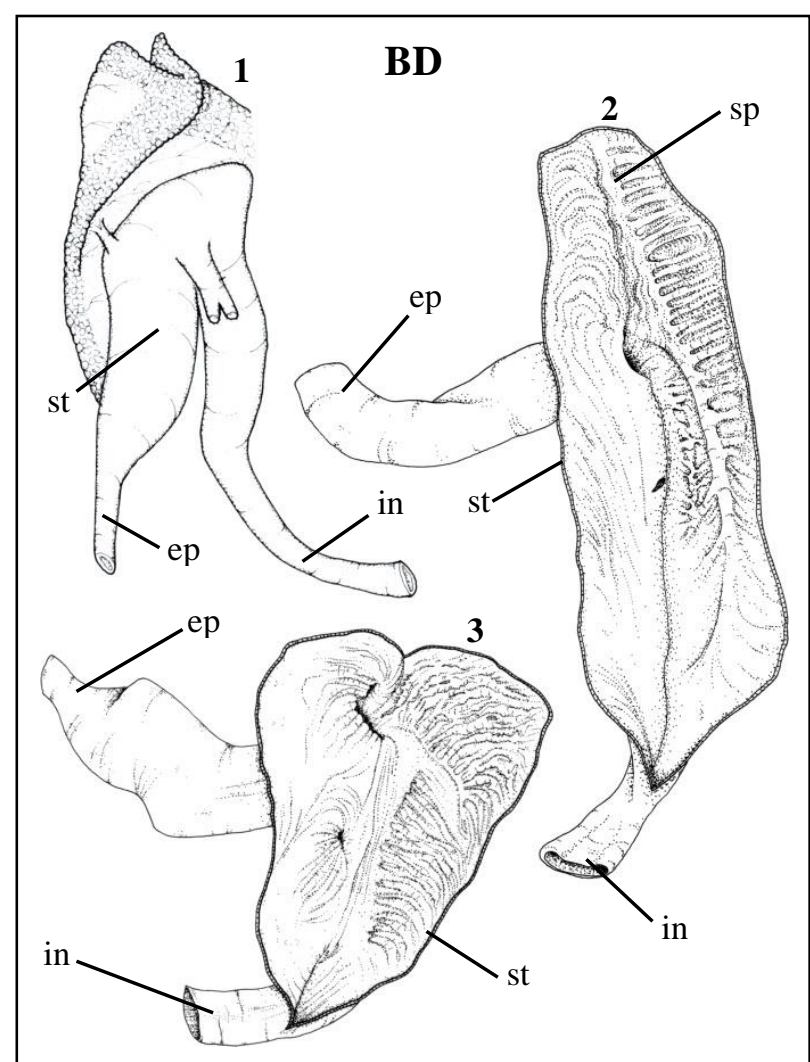

BD. Stomach in dorsal view and lumen. BD1. Monetaria annulus (modified from Simone, 2011), stomach as a simple passage from esophagus to intestine (0); BD2. Pisania pusio, stomach bearing a dorsal posterior bulge with sorting area (1); BD3. Fasciolaria tulipa, stomach with dorsal posterior bulge, no sorting area (2). ep: posterior esophagus; in: intestine; sp: stomach posterior sorting area; st: stomach. (clade 6c) and in Opeatostoma pseudodon, there is a sudden broadening in the diameter (1), right before entering the stomach. A broadening in the haemocoel (2) occurs in the nassariids Engoniophos unicinctus and Bullia laevissima.

75. Stomach, posterior bulge (fig. BD)

$(\mathrm{L}=3 ; \mathrm{Ci}=65 ; \mathrm{Ri}=75)$

\section{0 . Absent}

1. Present, with sorting area

2. Present, without sorting area

The stomach is one of the most complex organ of the digestive (Kantor, 2003) and remains as a poorly studied structure, that is intensified by the fact that it is usually too poorly fixed for examination. Observations on the circulatory patterns of the ciliary currents in the stomachs in live specimens suggest that food absorption occurs through

the stomach walls, rather than in the tubules of the digestive gland (Kantor, 2003).

The stomach in caenogastropods is divided into two chambers: the proximal (or gastric) chamber and a distal chamber (or style sac) (Strong, 2003). Strong (2003) revised several stomach (sic midgut) characters and revealed that the evolution of midgut structure is highly mosaic, reflected on patterns of feeding, diet and foregut complexity. One such simplification occurred in predatory carnivores, with an emphasis on extracellular digestion, and the gastric shield, crystalline sac and/or gastric caecum may, but not always will be, lost independently 
(Strong, 2003). Despite this correlation of alimentary habits/stomach types, there is evidence that similarities in stomach anatomy more likely reflect phylogenetic relationships, rather than similarities in diet (Kantor, 2003; Strong, 2003).

Basal clades of Caenogastropoda are herbivorous or microphages, while the terminal branches are predatory carnivores; a contrast to this is the cypraeoideans that have a very simplified stomach but are herbivores, supposedly grazing feeders (Simone, 2011). Stomach of this type is a mere passage from the posterior esophagus to the intestine (0), and only the outgroup taxa Monetaria annulus possess this type.

In Neogastropods, the gastric (or proximal) chamber may have a more or less long, blind, posterior extension called caecum or posterior sorting area (not to be mistaken with the caecum of vetigastropod stomach) (Kantor, 2003). All buccinoideans in the present analysis have a stomach with a posterior mixing area (1), except all studied fasciolariids. Kantor (2003) distinguished species of Fasciolariidae from other buccinoideans by the low relief of the folds on the inner stomach wall; presence of transverse striations on the low longitudinal fold; absence of clear differentiation of the gastric chamber into dorsal and ventral parts; a shallow lateral sulcus; and absence of a posterior mixing area. The absence of a posterior mixing area was also appointed by Fraussen et al. (2007) as diagnostic for the family; and this was the same result for the fasciolariids in this study (2).

\section{Rectum}

$(\mathrm{L}=1 ; \mathrm{Ci}=100 ; \mathrm{Ri}=100)$

0 . Free from pallial gonoduct

1. Enveloped by the pallial gonoduct

The rectum runs laterally in the left side of the pallial cavity, being completely free from the pallial gonoduct (0) in the Cypraeoideans (Monetaria annulus); in the neogastropods examined, including all fasciolariids, the rectum is enveloped with the pallial gonoduct (prostate or oviduct) by a thin longitudinal membrane (1). 


\section{Anus, position in pallial cavity: total pallial cavity length (fig. BE)}

$(\mathrm{L}=9 ; \mathrm{Ci}=11 ; \mathrm{Ri}=61)$

0 . Less than $1 / 3$

1. $1 / 3$ or more

The rectum terminates in the anus on the left

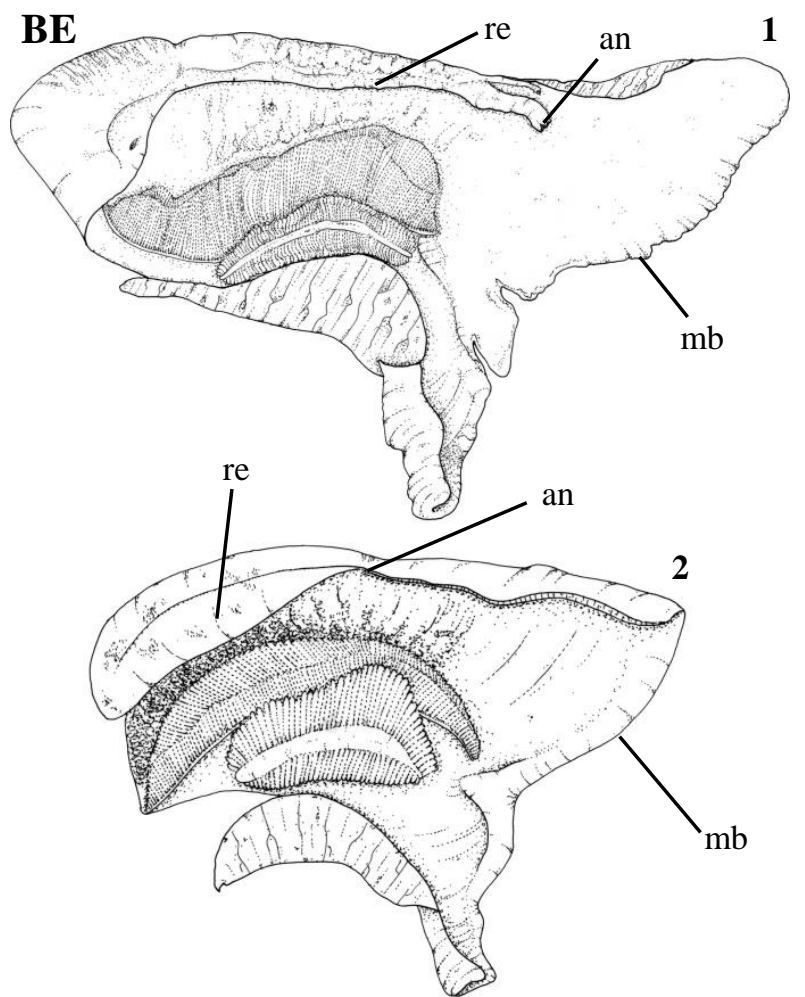

BE. Roof of the pallial cavity in ventral view. BE1. Opeatostoma pseudodon, anus position from mantle edge is less than $1 / 3$ the total length of the pallial cavity (0); BE2. Amiantofusus candoris, anus position from the mantle edge is $1 / 3$ or more of the total length of the pallial cavity (1). an: anus; mb: mantle border; re: rectum. side of the animal; the depth of which the anus occurs in the pallial cavity is measured by the distance from the pallial border by the total pallial cavity length. Fasciolariids have a basal state of more than $1 / 3$ of this ratio (1), while in five groups this ratio reverted to less than $1 / 3$ (0): clades 3d, 5a, 13, Granulifusus sp., Pustulatirus ogum and Polygona angulata. This character was optimized under an ACCTRAN optimization.

78. Oviduct, seminal receptacle (fig. $\mathrm{BF}$ )

$$
\begin{gathered}
(\mathrm{L}=6 ; \mathrm{Ci}=16 ; \mathrm{Ri}=50) \\
\text { 0. Present }
\end{gathered}
$$

1. Absent

The following 12 characters correspond to female and male reproductive systems. It is worth noting that due to the maturation of certain specimens and the availability of either male or female, these characters (characters 78 to 90) contain the largest amount of missing data, nonetheless they remain very informative.

The presence of a seminal receptacle $(0)$ as observed in a few fasciolariids, while the basal state for the family is the absence (1). It is present in clades 4b, 15 and in Leucozonia ocellata. The optimization used was DELTRAN. 
79. Bursa copulatrix, position

$(\mathrm{L}=1 ; \mathrm{Ci}=100 ; \mathrm{Ri}=100)$

0 . Posterior

1. Anterior

Characters 79 and 80 (seminal receptacle and bursa copulatrix respectively) are structures derived from the pallial oviduct responsible for storing sperm; the former storing oriented (head attached to epithelium and tail aligned) and the latter storing unoriented sperm (Ponder \& Lindberg, 1997; Strong, 2003). In noncaenogastropods, the seminal receptacles are not homologous with those of caenogastropods, given their different position and structure (Ponder
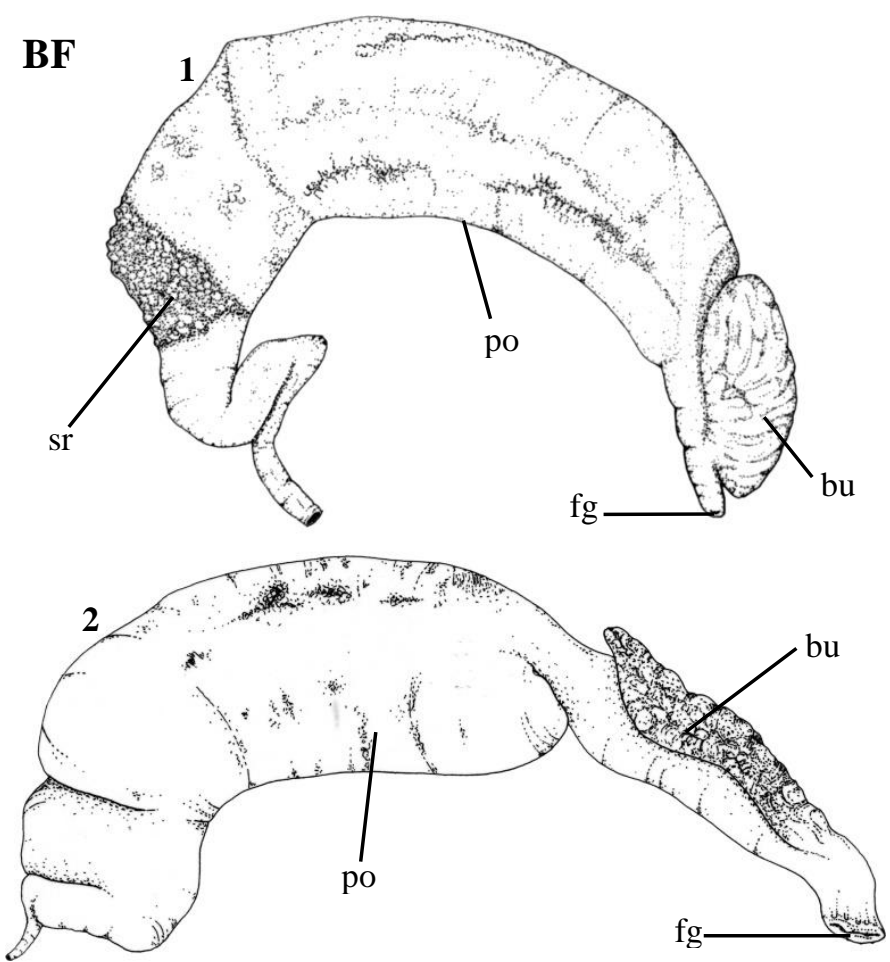

BF. Pallial oviduct. BF1. Leucozonia ocellata, seminal receptacle present (char.79: 0), ratio of the length of the bursa copulatrix by the length of oviduct is less than 1/4 (char. 81: 0); BF2. Opeatostoma pseudodon, seminal receptacle absent (char. 79: 1), ratio of the length of the bursa copulatrix by the length of oviduct is $1 / 4$ or more (char. 81: 1). bu: bursa copulatrix; fg: female gonopore; po: pallial oviduct; sr: seminal receptacle.

\& Lindberg, 1997). Normally in

animals that possess both of these organs the bursa copulatrix is the structure that receives the sperm, spermatophore, or equivalent, during copulation; afterwards the spermatozoa are transferred to the seminal receptacle via a ciliated furrow. The sperm responsible for fertilization is supplied from the seminal receptacle (Simone, 2011).

The bursa copulatrix in the outgroup taxa Monetaria annulus is posterior to the gonopore, laterally to the seminal receptacle (0). In all other taxa, including Fasciolariidae, the bursa occurs anteriorly, i.e., terminally in the pallial oviduct (1).

\section{Bursa copulatrix, length: length of oviduct (fig. BF)}

$(\mathrm{L}=3 ; \mathrm{Ci}=33 ; \mathrm{Ri}=71)$

0 . Less than $1 / 4$

1. $1 / 4$ or more 
The ratio between length of the bursa copulatrix by the total length of the oviduct is represented in this character. While this may vary according to sexual maturation, a synapomorphy of the family, fasciolariids have this proportion of less than 1/4 (1), with two independent reversions to a ratio of less than 1/4 (0), in a group of Leucozonia (clade 15) and in Chryseofusus archerusius.

An ACCTRAN optimization was used.

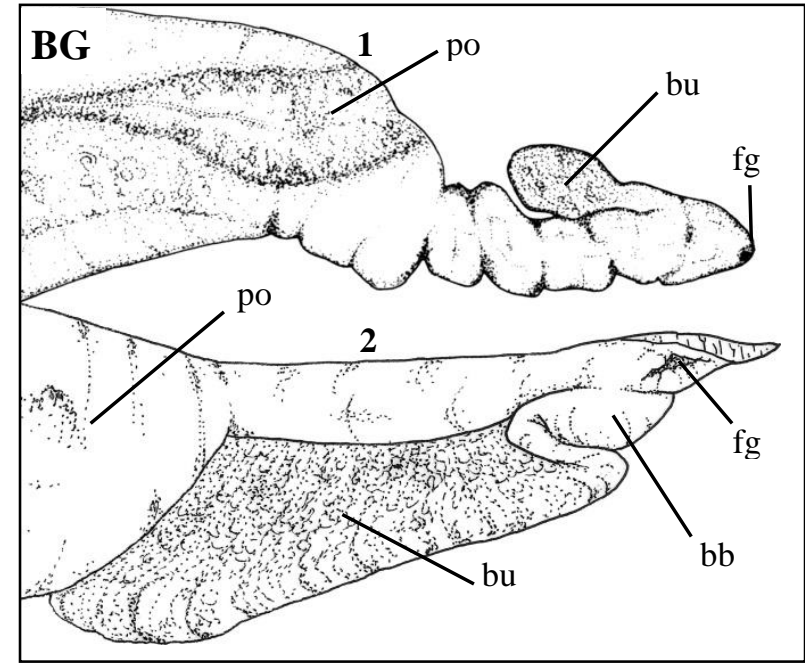

BG. Terminal portion of pallial oviduct. BG1. Granulifusus hayashi, bursa copulatrix with bulb absent (0); BG2. Polygona angulata, bursa copulatrix with an anterior bulb (1). bb: bursa copulatrix bulb; br: bursa copulatrix; fg: female gonopore; po: pallial oviduct.
81. Bursa copulatrix, anterior bulb (fig. BG)

$$
\begin{gathered}
(\mathrm{L}=3 ; \mathrm{Ci}=33 ; \mathrm{Ri}=0) \\
\text { 0. Absent } \\
\text { 1. Present }
\end{gathered}
$$

In most fasciolariids, the bursa copulatrix connects to the terminal portion of the pallial oviduct with a simple duct (0); in Granulifusus sp. and in Polygona angulata, however, the presence of an anterior bulb was observed. This bulb (1) occurs anteriorly to the bursa, close to the gonopore, being muscular than the bursa itself, suggesting a pumping function.

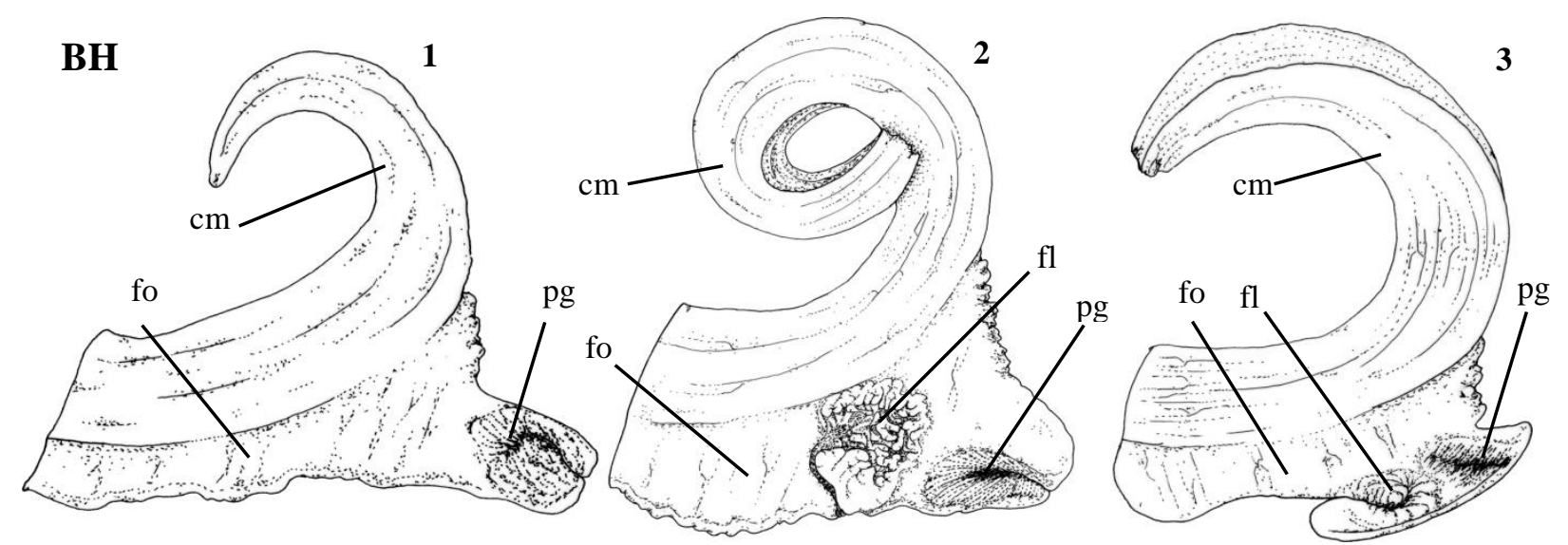

BH. Longitudinal section of foot and columellar muscle, haemocoel removed. BH1. Pseudolatirus discrepans, cement gland absent (char: 83: 0); BH2. Filifusus filamentosus, cement gland present (char. 83: 1), multi-branched (char. 84: 1) its opening centrally in the foot (char. 85: 0); BH3. Dolicholatirus cayohuesonicus, cement gland present (char. 83: 1) single branched (char. 84: 0) its opening anteriorly in the foot (char. 85: 1). cm: columellar muscle; fl: female cement gland; fo: foot; pg: pedal gland. 
82. Cement gland (fig. $\mathrm{BH}$ )

$$
\begin{gathered}
(\mathrm{L}=3 ; \mathrm{Ci}=33 ; \mathrm{Ri}=60) \\
\text { 0. Absent } \\
\text { 1. Present }
\end{gathered}
$$

The cement gland (ventral pedal gland sensu Strong, 2003) is an unpaired glandular structure that is situated in median line of the foot sole (Simone, 2011). This organ is different from the pedal gland of some caenogastropods that also play a role in reproduction (Strong, 2003). Both Strong (2003) and Simone (2011) agree that this structure has received little attention on homology assessment and requires additional studies. Additionally, it is possible that the gland has not been observed in some taxa because females were not sexually mature, as well as much less obviously developed in some e.g., those with lens-shaped capsules (Simone, 2011).

In Fasciolariidae, clade 4a (Granulifusus and Pseudolatirus discrepans) lacks this structure (0). All the remaining members of the family have a cement gland (1), which is the basal state for the family. An ACCTRAN optimization was chosen.

\section{Cement gland, form (fig. $\mathrm{BH}$ )}

$(\mathrm{L}=1 ; \mathrm{Ci}=100 ; \mathrm{Ri}=100)$

0 . One or two branches

1. Multi-branched

In a clade of fasciolariine species (6d), the cement gland occurs as several saccular vesicles ramifying from a main branch (1). This type of gland differs from the more common one or two branching patterns $(0)$ of most fasciolariids.

84. Cement gland, opening position in foot (fig. $\mathrm{BH}$ )

$(\mathrm{L}=9 ; \mathrm{Ci}=11 ; \mathrm{Ri}=11)$

0. Centrally

1. Anteriorly 
Simone (2011) described the position of the cement gland opening in the anterior third of the foot sole; this is true for most fasciolariids herein, with the opening anteriorly (1). The opening has migrated posteriorly on several occasions in Fasciolariidae, assuming a more or less central position in the foot sole (0). Based on an ACCTRAN optimization, clades $3 b^{1}$ (Chryseofusus), $6 \mathrm{a}$, 8a (Pustulatirus), 14a and Fusinus frenguelli assumed a central opening in the foot sole (and posteriorly Leucozonia ocellata reverted to an anterior opening).

85. Prostate, shape (fig. BI)

$(\mathrm{L}=2 ; \mathrm{Ci}=40==50 ; \mathrm{Ri}=0)$

0. Simple

1. Coiled

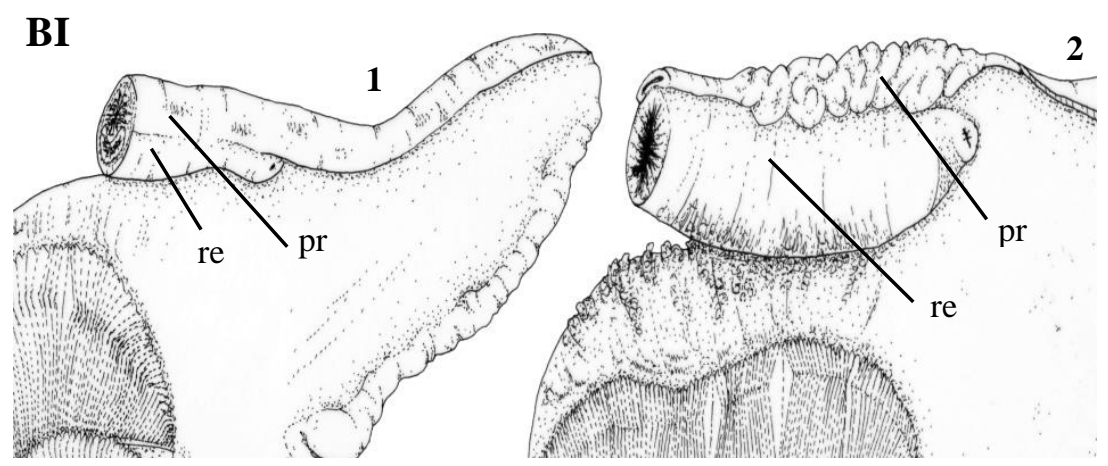

BI. Right side of roof of pallial cavity, male. BI1. Latirus vischii, prostate as a simple, linear tube (0); BI2. Buccinum undatum, proboscis coiled (1). pr: Characters 86 to 90 are features prostate; re: rectum.

of the male reproductive system.

The prostate is, like the seminal vesicle, a modification of the vas deferens that runs on the right side of the roof of the pallial cavity, adjacent to the rectum; it is normally a glandular thickening of the epithelium (Simone, 2011).

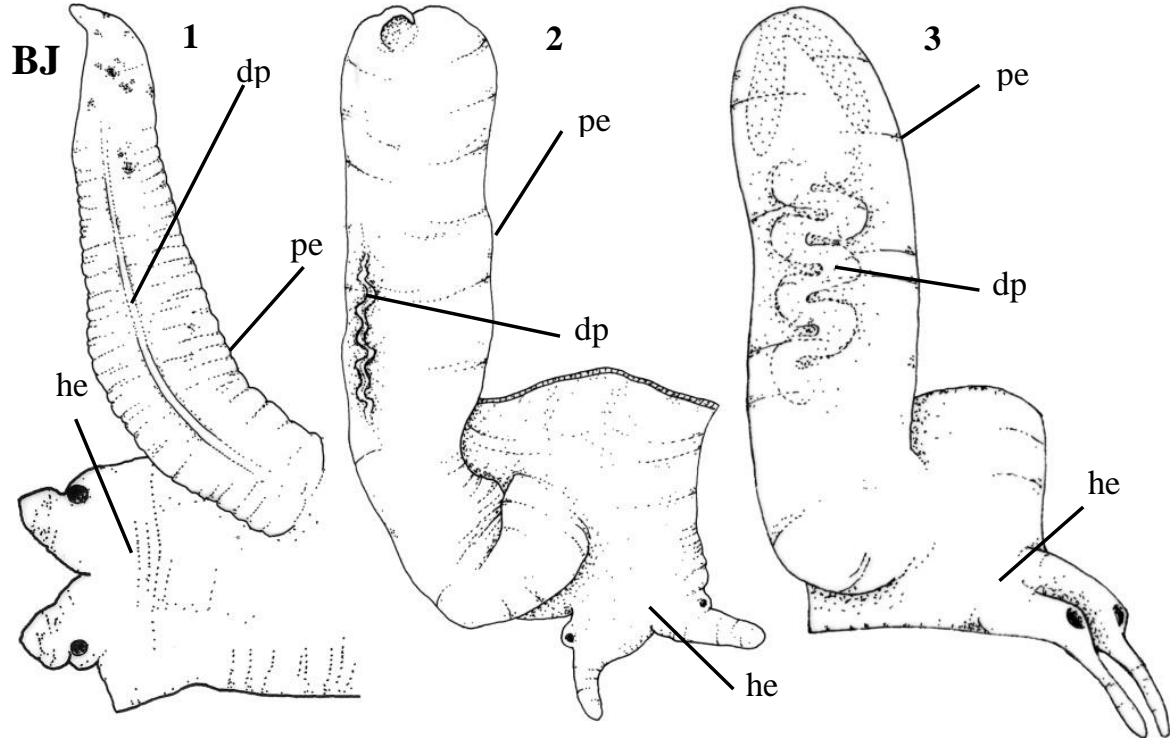

BJ. Penis and adjacent head-foot in dorsal view. BJ1. Pustulatirus ogum, duct of penis linear (0); BJ2. Pseudolatirus pallidus, duct of penis sinuous (1); BJ3. Dolicholatirus cayohuesonicus, duct of penis convolute (2). dp: duct of penis; he: head; pe: penis.
The prostate in fasciolariids is always a simple tube (0), and a prostate gland is almost inconspicuous in certain species, regardless of sexual maturation. In some outgroup species however, the prostate is visible as a convolution of the vas deferens, somewhat muscular (1). The optimization utilized was ACCTRAN. 


\section{Penis, duct}

$$
\begin{gathered}
(\mathrm{L}=1 ; \mathrm{Ci}=100 ; \mathrm{Ri}=100) \\
\text { 0. Open } \\
\text { 1. Closed }
\end{gathered}
$$

Strong (2003) appointed as a synapomorphy of Neogastropoda the prostate that communicates with the mantle cavity via a small duct, i.e., the vas deferens is completely closed without communication with the pallial cavity. In the analysis of Simone (2011) the condition of a closed vas deferens, much like that of the penis, occurred several times independently.

A fully closed system is the plesiomorphic condition here for fasciolariids, and the penis duct is no exception, being closed (1). Only the outgroup species Monetaria annulus has this open (0).

\section{Penis, duct, shape (fig. BJ)}

$$
\begin{gathered}
(\mathrm{L}=10 ; \mathrm{Ci}=20 ; \mathrm{Ri}=27) \\
\text { 0. Linear } \\
\text { 1. Sinuous } \\
\text { 2. Convolute }
\end{gathered}
$$

The penis is an exophalic copulatory structure used in the transference of the sperm and/or spermatophore, characteristically positioned at the head-foot, close and posterior to the male right cephalic tentacle and innervated by the pedal ganglia (Ponder \& Lindberg, 1997; Simone, 2011). The history of a copulatory organ in the evolution of caenogastropods is a convergent one, with several novelties and losses independently in distinct groups (Strong, 2003; Simone, 2011). The caenogastropod penis differs from those found in heterobranchs because in the former it is permanently exteriorized (exophalic) while in the latter it is retractile (Simone, 2001).

Because of a fully closed male reproductive system, the duct of the penis extends from base to tip, and may occur in several fashions: linear (0), sinuous (1) or convolute i.e., when the curves are tangent to one another (2). This character has been idealized as additive because of the hypothesized increase in the curvature of the duct. 
The penis duct is sinuous for most fasciolariids, being this the basal state for the family. In clade $1 b$ the duct is convolute (although because of missing data for Dolicholatirus sp. it is impossible to know if this is a synapomorphy for clade 1a). On the other hand, the duct reverted to linear in Fusinus frenguelli, Aurantilaria aurantiaca, Pustulatirus ogum and in clade 14a. The optimization used was DELTRAN.
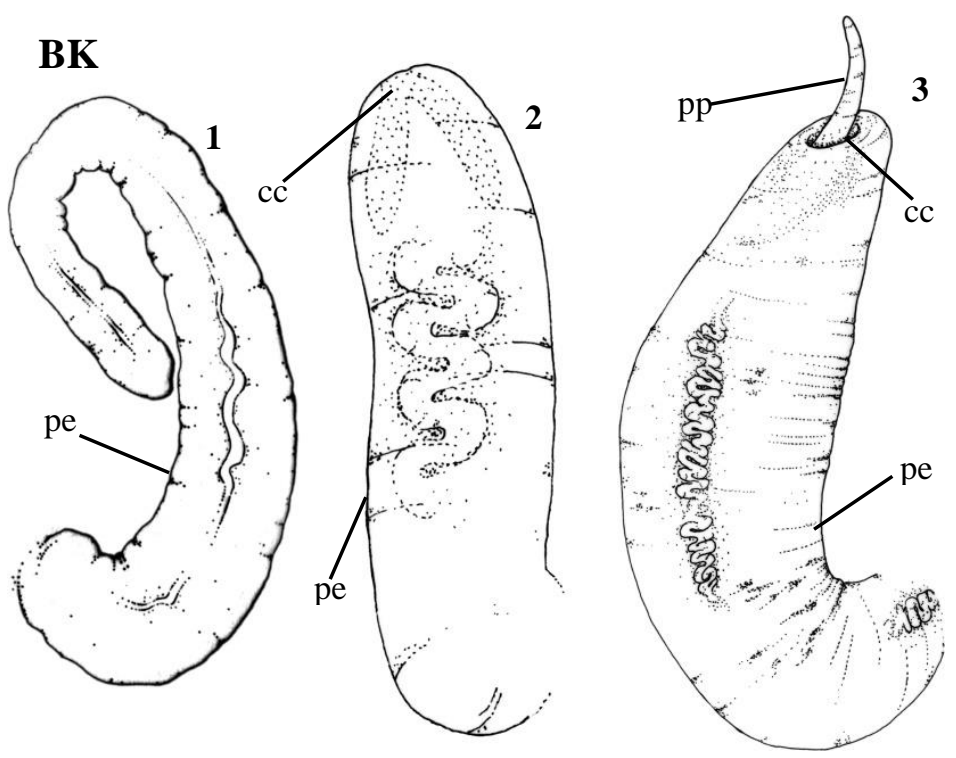

BK. Penis. BK1. Leucozonia ocellata, penis without a precopulatory chamber (0); BK2. Dolicholatirus cayohuesonicus, penis with copulatory chamber bearing short papilla (1); BK3. Pisania pusio, penis with copulatory chamber bearing long papilla (2). cc: pre-copulatory chamber; pe: penis; pp: penis papilla.

\section{Penis, pre-copulatory chamber (fig. BK)}
$(\mathrm{L}=3 ; \mathrm{Ci}=66 ; \mathrm{Ri}=50)$
0 . Absent
1. Present bearing short papilla
2. Present bearing long papilla

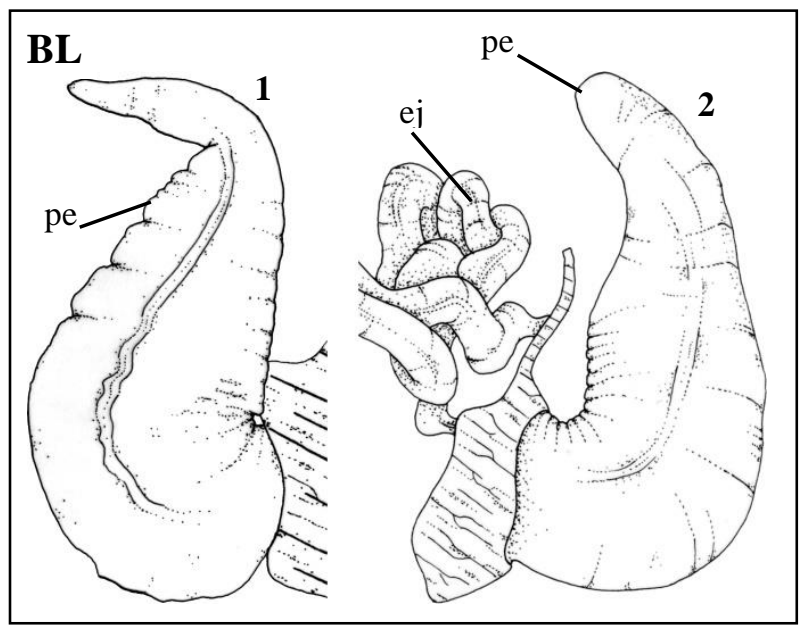

BL. Penis and section of tegument. BL1. Fusinus frenguelli, haemocoelic ejaculatory duct absent (0); BL2. Opeatostoma pseudodon, haemocoelic ejaculatory duct present (1). ej: ejaculatory haemocoelic duct; pe: penis.
The pre-copulatory chamber is a cavity present at the tip of the penis of certain species and is the preputial-like protection sensu Simone (2011). The cavity may house a short papilla (1) or along one (2), in a way that it extends out of the chamber; in most fasciolariids, though, it is absent (0).

Conoideans have a preputial-like protection and a short papilla (Simone, 2011); in the present study the only group in which this occurs is clade $1 \mathrm{~b}$ with a short papilla (and possibly 1a, if not for the uncertainty in 
Dolicholatirus sp.); and the outgroup species Pisania pusio with a long papilla. As with the previous character, the optimization utilized was DELTRAN.

\section{Ejaculatory haemocoel duct (fig. BL)}

$$
\begin{gathered}
(\mathrm{L}=3 ; \mathrm{Ci}=33 ; \mathrm{Ri}=0) \\
\text { 0. Absent } \\
\text { 1. Present }
\end{gathered}
$$

The Ejaculatory tube is a long, convoluted muscular portion of the pallial vas deferens immersed in the haemocoelic spaces, on the right side, and protruding into pallial floor. This has been

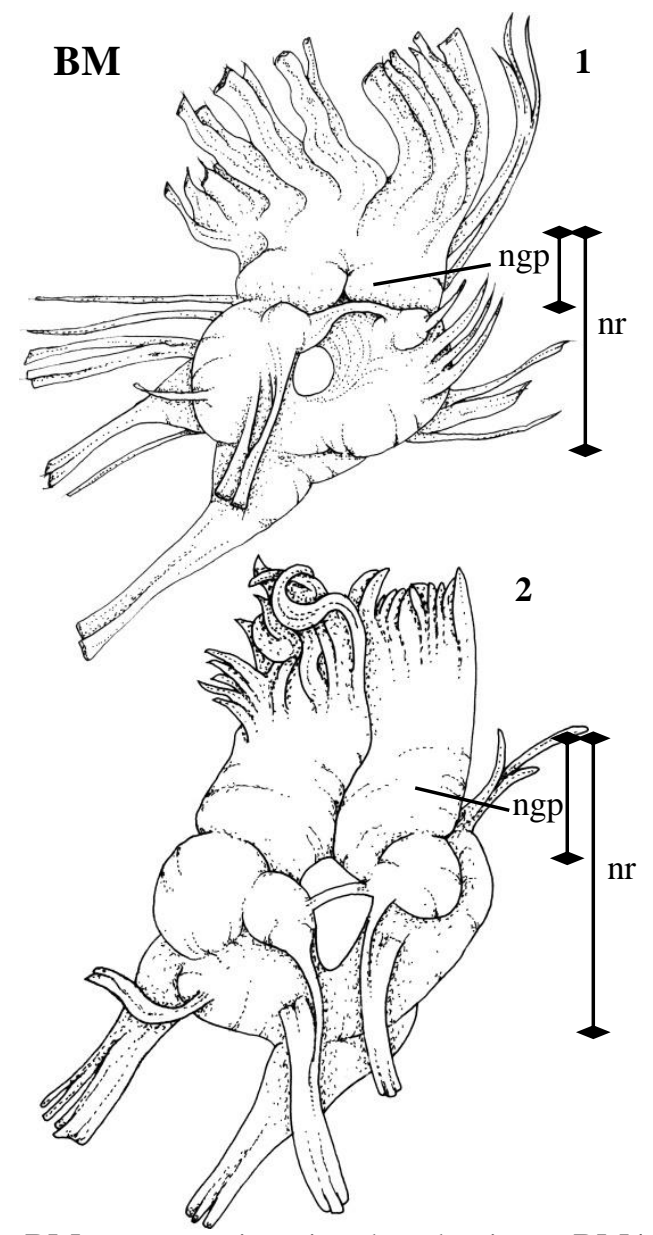

BM. Nerve ring in dorsal view. BM1. Fusinus sp. pedal ganglia length is less than $1 / 2$ of total nerve ring length (0); BM2. Filifusus filamentosus, pedal ganglia length is $1 / 2$ or greater than total nerve ring length (1). ngp: pedal ganglion; $\mathbf{n r}$ : nerve ring. observed as a synapomorphy of the Conoidea by Simone (2011). This highly homoplastic character (1) occurs in two fasciolariids independently, in Pseudolatirus pallidus and Opeatostoma pseudodon; all other fasciolariids lack this structure (0).

90. Pedal ganglia, length: length of nerve ring (fig. $\mathrm{BM})$

$$
\begin{gathered}
(\mathrm{L}=2 ; \mathrm{Ci}=20 ; \mathrm{Ri}=50) \\
\text { 0. Less than } 1 / 2 \\
\text { 1. } 1 / 2 \text { or greater }
\end{gathered}
$$

Much emphasis has been given in the configuration of the nervous system of higher gastropod classification, as reflected in names e.g., Streptoneura, Euthyneura, (Taylor \& Sohl, 1962), Triganglionata and Pentaganglionata (Salvini-Plawén \& Haszprunar, 1987); much like the gill and radulae (Ponder \& Lindberg, 1997).

The central nervous system is located posteriorly of the buccal mass in caenogastropods, and it 
corresponds to the nerve ring in the examined taxa. This circumesophageal (i.e., surrounds the esophagus) nerve ring in caenogastropods is in an epiathroid condition in which the pair of pleural ganglia is located closer to the cerebral and far from the pedals, a condition that is convergent with heterobranchs, although much more concentrated in the former group (Strong, 2003; Simone, 2011). It appears that nervous system characters, while useful, should be used with caution in defining major taxonomic divisions (Ponder \& Lindberg, 1997; Strong, 2003; Simone, 2011).

Caenogastropods have a nervous system that is concentrated with well-defined cerebral and pedal ganglia (Ponder et al., 2008). Despite the trend, in Gastropoda in general, for the concentration of ganglia in the nerve ring, the pedal ganglia are one of the few that are undoubtedly distinguishable. Fasciolariids have as a synapomorphy the ratio between the length of the pedal ganglia by the total length of the nerve ring equal to $1 / 2$ or greater (1). For some taxa however, there was a reversion to the previous state of a proportion of less than $1 / 2(0)$ : In clades $3 c^{1}$ and in Leucozonia ponderosa. An ACCTRAN optimization was used here.

\section{Buccal ganglia, position (fig. $\mathrm{BN}$ )}

$(\mathrm{L}=2 ; \mathrm{Ci}=100 ; \mathrm{Ri}=100)$

0. Close to buccal mass

1. On nerve ring

2. Immersed in nerve ring

The presence of short buccal connectives is the plesiomorphic condition for Caenogastropoda (Simone, 2011), but most groups have long connectives (probably due to the tendency for the buccal ganglia to be situated far from the nerve ring). The

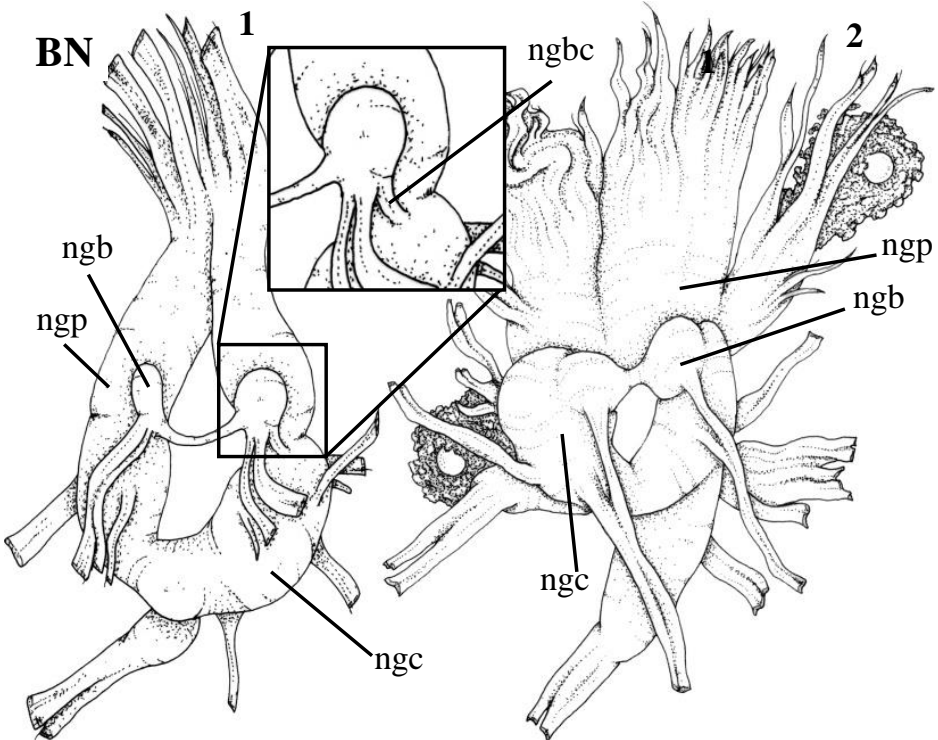

BN. Nerve ring in dorsal view. BN1. Buccinum undatum, buccal connective observed (char. 92: 1), buccal ganglia dorsal do pedal ganglia (char. 93: 0); BN2. Hemipolygona beckyae, buccal connective not observed (char. 92: 2), buccal ganglia dorsal to cerebral ganglia (char. 93: 1). ngb: buccal ganglion; ngbc: buccal ganglion commissure; ngc: cerebral ganglion; ngp: pedal ganglion. muricoideans (i.e., also included here the buccinoideans sensu Simone, 2011) have reverted to the plesiomorphic condition, possessing buccal ganglia closer to, or even incorporated into the nerve 
ring (Simone, 2011). This is the scenario observed here, with very short connectives that are strongly associated with the adjacent ganglia

This is the scenario observed for all studied taxa, including the buccinoideans (but not the cypraeoidean species Monetaria annulus, in which the buccal ganglia is not incorporated in the nerve ring [0]). The buccal ganglia are visible as a bulge in the nerve ring, and several degrees of fusion with the adjacent pedal/cerebro ganglia are observed: The buccal ganglia may rest dorsally in the nerve ring but its connectives are still observable (1); or the buccal ganglia are firmly attached, dorsally to the nerve ring and its connectives are not visible (2). The latter state was observed solely and for all fasciolariids, and it is a synapomorphy.

\section{Buccal ganglia, position in nerve ring (fig. $\mathrm{BN}$ )}

$(\mathrm{L}=1 ; \mathrm{Ci}=100 ; \mathrm{Ri}=100)$

0 . Dorsal to pedal ganglia

1. Dorsal to cerebral ganglia

The topological optimization of this character is strictly associated with the previous character (character 91), due to the fact that when the buccal ganglia is immersed in the nerve ring (in the sense that the connectives aren't visible), its position is always dorsal to the cerebral (1) ganglia; as opposed to dorsal to the pedal ganglia (0). The former state is a synapomorphy to the fasciolariids.

\section{Buccal ganglia, commissure (fig. $\mathrm{BO}$ )}

$$
\begin{gathered}
(\mathrm{L}=7 ; \mathrm{Ci}=14 ; \mathrm{Ri}=33) \\
\text { 0. Conspicuous } \\
\text { 1. Inconspicuous }
\end{gathered}
$$

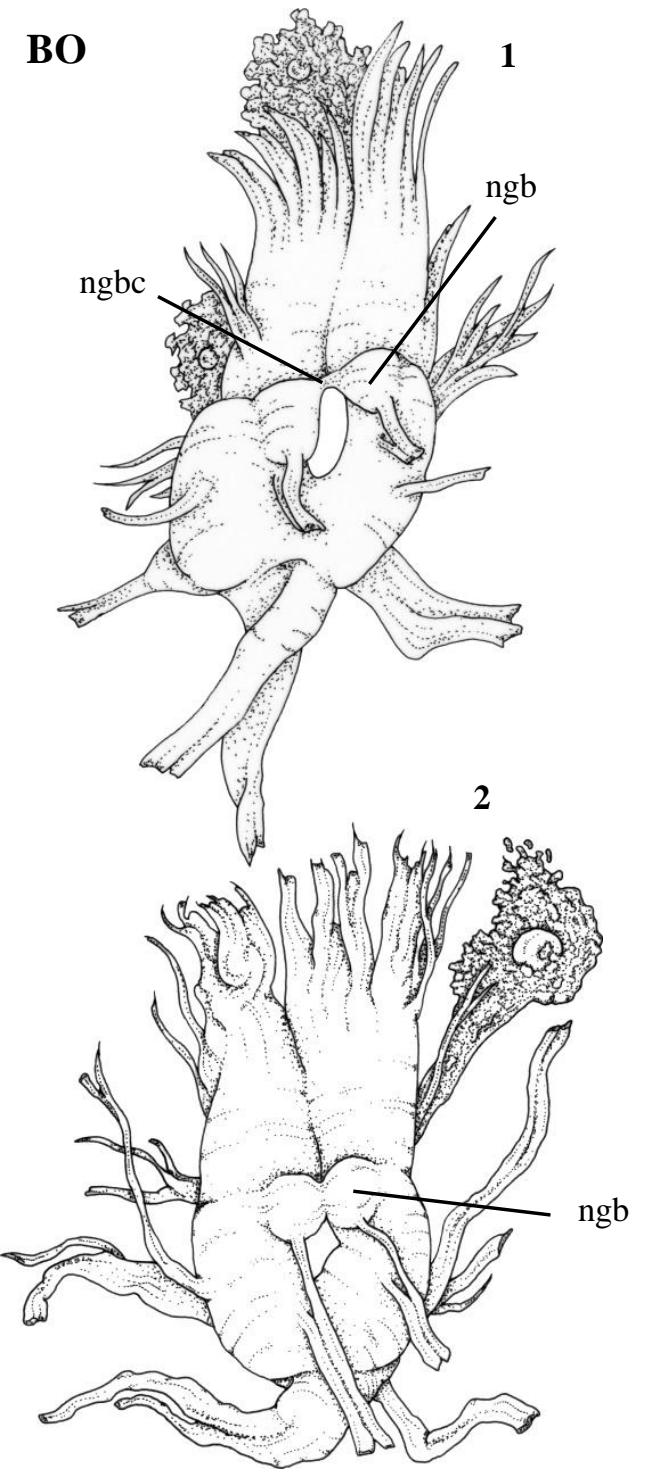

BO. Nerve ring in dorsal view. BO1. Leucozonia ponderosa buccal ganglia commissure conspicuous (0); BO2. Pustulatirus ogum, buccal commissure inconspicuous (1). ngb: buccal ganglion; ngbc: buccal ganglia commissure. 
The buccal ganglia commissure is the only visible commissure in the highly concentrated nerve ring of fasciolariids (and the buccinoideans studied). The fact that the degree of concentration of ganglia in the nerve ring is associated with the degree of dilatation of the esophagus (which passes through it) (Simone, 2011) suggests that this character is associated with the alimentary habits of the animal. This means that predatory carnivorous that ingest the prey whole have a longer commissure, or that the animal had just ingested on the moment it was killed. It is not certain if this holds true for this level of phylogenetic analysis, but in greater groups this has been observed (e.g., Calyptraeoidea: Simone, 2011).

In Fasciolariidae, the buccal commissure is conspicuous (0), with several groups having reduced the distance between the buccal ganglia and the commissure was internalized (1). The latter scenario occurred for clades 1a, 2c (Amiantofusus), 8a (Pustulatirus), Peristernia marquesana, Hemipolygona armata, Polygona angulata, P. infundibulum and Leucozonia ocellata. This highly homoplastic character was optimized under an ACCTRAN optimization.

\section{Buccal ganglia, commissure, length: buccal ganglia length (fig. BP)}

$(\mathrm{L}=8 ; \mathrm{Ci}=12 ; \mathrm{Ri}=46)$

0 . Less than $1 / 2$

1. $1 / 2$ or greater

On the fasciolariid taxa in which a buccal commissure occurs, this character measures their length by the total length of the buccal ganglia. This is the ratio of the commissure by the length of the buccal ganglion. As discussed in the previous character (character 93), this may be related to the alimentary habits of the animal Fasciolariids have this proportion of less than $1 / 2(0)$, and several increases in the

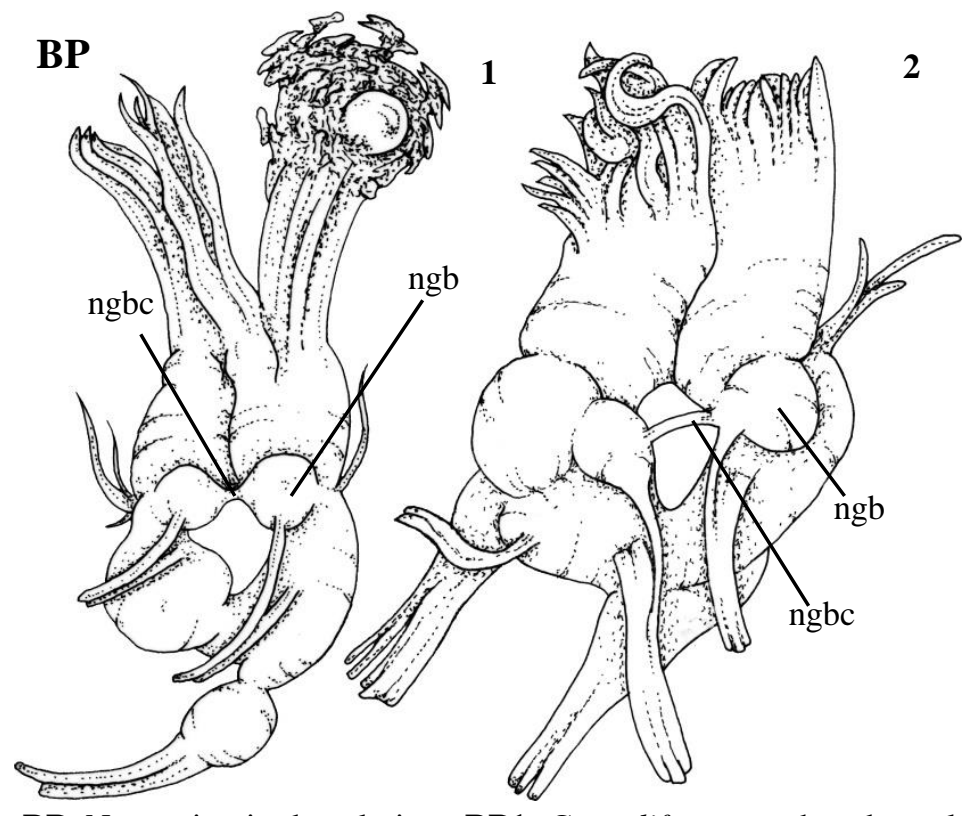

BP. Nerve ring in dorsal view. BP1. Granulifusus sp. short buccal commissure, less than $1 / 2$ the total length of the buccal ganglia (0); BP2. Filifusus filamentosus, long buccal commissure, $1 / 2$ or greater than the total length of the buccal ganglia (1). ngb: buccal ganglion; ngbc: buccal ganglia commissure. length to 1/2 or greater (1) occurred: on clades 3c of Fusinus (Cyrtulus serotinus reverting to the 
previous state), 6a, of the fasciolariines and Nodolatirus nodatus and in Leucozonia cerata. An ACCTRAN was used for optimization.

\section{Statocysts (fig. BQ)}

$(\mathrm{L}=2 ; \mathrm{Ci}=50 ; \mathrm{Ri}=80)$

0 . Both anterior

1. Anterior and posterior

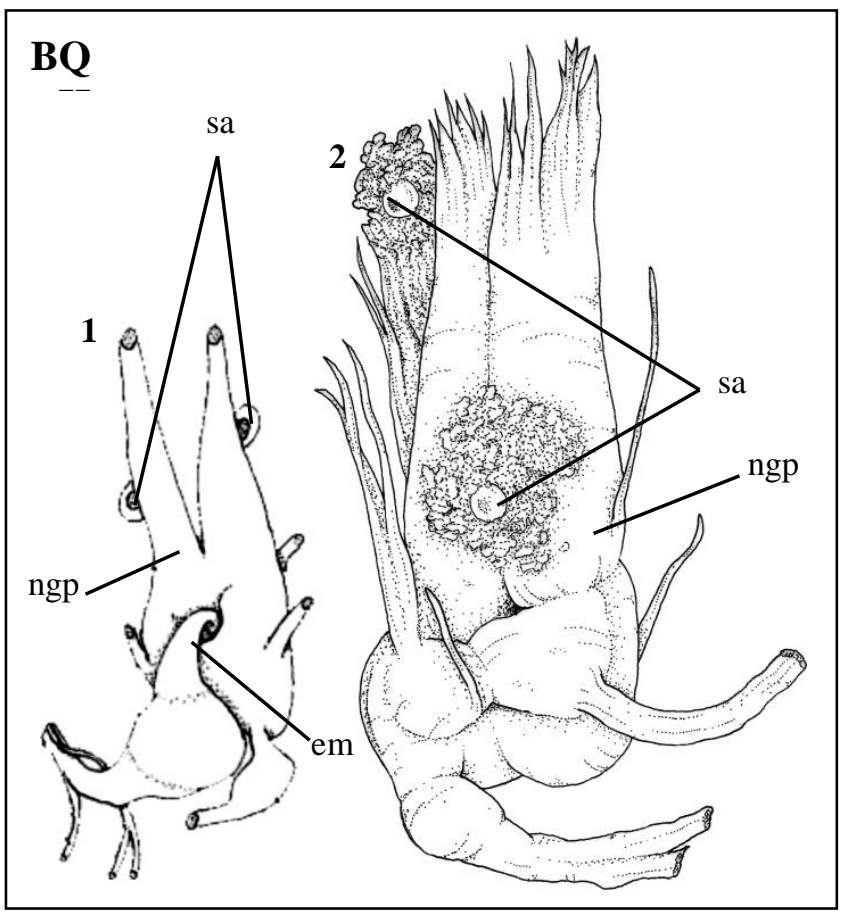

BQ. Nerve ring. BQ1. Teralatirus roboreus (modified from Simone et al., 2013), dorsal view showing both statocysts located anteriorly (0); BQ2. Polygona angulata, ventral view showing statocysts positioned asymmetrically (1). em: mid-esophagus; ngp: pedal ganglion; sa: statocyst.
Statocysts are structures responsible for the balance and positioning of gastropods. It consists of hollow vesicles covered internally by sensitive cells, which have one statolith or several staconia within; due to gravity, these objects tend to stay at the bottom of the vesicle, which is then detected for equilibrium purposes (Simone, 2011). Haszprunar (1988) assumed it to be a synapomorphy of conchiferan mollusks based on their positioning and formation.

The statocyst is innervated by the cerebral ganglia but associated with the pedal ganglia (Ponder \& Lindberg, 1997; Simone, 2011); it is immersed in the musculature of the foot and connected with the nerve ring by narrow nerves (Simone, 2011). Statocysts in

the Hypsogastropoda (sensu Ponder \& Lindberg, 1997: "higher caenogastropods") bear a single statolith, as opposed to many staconia as opposed to many staconia in archeogastropods and heterobranchs (Simone, 2011)

The Neogastropod statocysts are ventral in position (Strong, 2003) associated with the pedal gland, however, in some cases there may be some slight asymmetry between the right and left sides (Strong, 2003). Most fasciolariids have an asymmetry in the positioning of the 
statocysts in the nerve ring: the left is positioned more posteriorly in the nerve ring, more closely related to the cerebral ganglia (1). However, for all outgroup taxa except Pisania pusio, and for the fasciolariid Teralatirus roboreus, the statocysts are symmetrical, and anteriorly positioned (0). 


\subsection{Character matrix}

\begin{tabular}{|c|c|c|c|c|c|c|c|c|c|c|c|c|c|c|c|c|c|c|c|}
\hline CHARACTER & & & & & & & & & & & & & & & & & & & \\
\hline TAXON & 1 & 2 & 3 & 4 & 5 & 6 & 7 & 8 & 9 & 0 & 1 & 2 & 3 & 4 & 5 & 6 & 7 & 8 & 9 \\
\hline Monetaria annulus & 0 & 0 & 0 & 0 & 0 & 0 & 0 & 0 & 0 & 0 & 0 & 0 & 0 & 0 & 0 & 0 & - & - & 0 \\
\hline Thais speciosa & 1 & 1 & 1 & 0 & 0 & 1 & 0 & 0 & 0 & 1 & $?$ & 0 & 0 & 0 & 0 & 1 & 0 & 1 & 0 \\
\hline Pugilina tupiniquim & 1 & 1 & 1 & 0 & 0 & 1 & 1 & 0 & 1 & 1 & 0 & 0 & 0 & 0 & 0 & 1 & 0 & 1 & 1 \\
\hline Nassarius reticulatus & 1 & 1 & 0 & 0 & 0 & 0 & 0 & 0 & 0 & 0 & $?$ & 0 & 2 & 0 & 1 & 1 & 0 & 0 & 1 \\
\hline Bullia laevissima & 1 & 1 & 0 & 0 & 0 & 0 & 0 & 0 & 0 & 0 & 0 & 0 & 1 & 1 & 1 & 1 & 0 & 0 & 0 \\
\hline Pisania pusio & 1 & 0 & 1 & 1 & 0 & 0 & 1 & 0 & 1 & 0 & 0 & 0 & 1 & 1 & 0 & 1 & 0 & 1 & 0 \\
\hline Engoniophos unicinctus & 1 & 1 & 1 & 0 & 0 & 0 & 0 & 0 & 0 & 0 & 0 & 0 & 0 & 0 & 0 & 1 & 0 & 1 & 0 \\
\hline Buccinum undatum & 1 & 1 & 1 & 0 & 0 & 1 & 0 & 0 & 0 & 0 & 0 & 0 & 2 & 1 & 0 & 1 & 0 & 0 & 1 \\
\hline Teralatirus roboreus & 1 & 1 & 0 & 0 & 0 & 1 & 1 & 1 & 1 & 1 & $?$ & 1 & 1 & 1 & 0 & 1 & 0 & 1 & 1 \\
\hline Dolicholatirus aff. cayohuesonicus & 1 & 1 & 0 & 0 & 0 & 1 & 1 & 1 & 1 & 1 & $?$ & 1 & 1 & 1 & 0 & 1 & 0 & 1 & 1 \\
\hline Dolicholatirus sp. & 1 & 1 & 0 & 0 & 0 & 1 & 1 & 0 & 0 & 1 & $?$ & $?$ & $?$ & $?$ & $?$ & $?$ & $?$ & $?$ & $?$ \\
\hline Angulofusus nedae & 1 & 1 & 1 & 2 & 0 & 1 & 1 & 1 & 1 & 0 & 1 & 1 & 0 & 0 & 0 & 1 & 0 & 1 & 1 \\
\hline Amiantofusus pacificus & 1 & 1 & 1 & 0 & 0 & 1 & 0 & 0 & 1 & 0 & $?$ & 1 & 0 & 0 & 0 & 1 & 0 & 1 & 0 \\
\hline Amiantofusus candoris & 1 & 1 & 1 & 0 & 0 & 1 & 0 & 0 & 1 & 0 & $?$ & 1 & 0 & 0 & 0 & 1 & 0 & 1 & 0 \\
\hline Pseudolatirus kuroseanus & 1 & 1 & 1 & 0 & 0 & 1 & 0 & 0 & 1 & 0 & $?$ & 1 & 2 & 2 & 0 & $?$ & $?$ & $?$ & 0 \\
\hline Pseudolatirus discrepans & 1 & 1 & 1 & 0 & 0 & 1 & 0 & 1 & 2 & 0 & $?$ & 1 & 0 & 0 & 0 & $?$ & $?$ & $?$ & 0 \\
\hline Granulifusus aff. kiranus & 1 & 1 & 1 & 0 & 0 & 1 & 0 & 0 & 2 & 0 & $?$ & 1 & 2 & 2 & 0 & 2 & 1 & 0 & 0 \\
\hline Granulifusus hayashi & 1 & 1 & 1 & 0 & 0 & 1 & 0 & 0 & 2 & 0 & $?$ & 1 & 2 & 2 & 0 & 2 & 1 & 0 & 0 \\
\hline Granulifusus sp. & 1 & 1 & 1 & 0 & 0 & 1 & 0 & 0 & 2 & 0 & $?$ & 1 & 2 & 2 & 0 & 2 & 1 & 0 & 0 \\
\hline Pseudolatirus pallidus & 1 & 1 & 1 & 0 & 0 & 1 & 1 & 0 & 2 & 0 & $?$ & 1 & 0 & 0 & 0 & $?$ & $?$ & ? & 0 \\
\hline Chryseofusus acherusius & 1 & 1 & 0 & 0 & 0 & 1 & 0 & 0 & 2 & 0 & $?$ & 1 & 0 & 0 & 0 & 1 & 0 & 1 & 0 \\
\hline Chryseofusus graciliform is & 1 & 1 & 0 & 0 & 0 & 1 & 0 & 0 & 2 & 0 & $?$ & 1 & 2 & 2 & 0 & 1 & 0 & 1 & 0 \\
\hline Fusinus australis & 1 & 1 & 1 & 0 & 0 & 1 & 1 & 0 & 2 & 0 & 1 & 1 & 1 & 1 & 0 & 1 & 0 & 1 & 0 \\
\hline Cyrtulus serotinus & 1 & 1 & 1 & 0 & 0 & 0 & 1 & 0 & 2 & 0 & $?$ & 1 & 1 & 1 & 0 & $?$ & $?$ & ? & 0 \\
\hline Fusinus frenguelli & 1 & 1 & 1 & 0 & 0 & 1 & 0 & 0 & 2 & 0 & $?$ & 1 & 0 & 0 & 0 & 1 & 0 & 1 & 0 \\
\hline Fusinus brasiliensis & 1 & 1 & 1 & 0 & 0 & 1 & 0 & 0 & 2 & 0 & 1 & 1 & 0 & 0 & 0 & 1 & 0 & 1 & 0 \\
\hline Fusinus marmoratus & 1 & 1 & 1 & 0 & 0 & 1 & 0 & 0 & 2 & 0 & 1 & 1 & 1 & 1 & 0 & 1 & 0 & 1 & 0 \\
\hline Fusinus sp. & 1 & 1 & 1 & 0 & 0 & 1 & 0 & 0 & 2 & 0 & $?$ & 1 & 1 & 1 & 0 & 1 & 0 & 1 & 0 \\
\hline Fusolatirus bruijnii & 1 & 1 & 0 & 0 & 0 & 1 & 1 & 1 & 2 & 1 & 3 & 1 & 0 & 0 & 0 & 1 & 0 & 2 & 0 \\
\hline Peristernia marquesana & 1 & 1 & 1 & 0 & 0 & 1 & 1 & 1 & 1 & 1 & $?$ & 1 & 0 & 0 & 0 & 1 & 0 & 2 & 1 \\
\hline Peristernia nassatula & 1 & 1 & 1 & 0 & 0 & 1 & 1 & 1 & 1 & 1 & 3 & 1 & 0 & 0 & 0 & 1 & 0 & 2 & 0 \\
\hline Pustulatirus mediamericanus & 1 & 1 & 1 & 0 & 0 & 1 & 2 & 1 & 1 & 1 & $?$ & 1 & 1 & 1 & 0 & 1 & 0 & 2 & $?$ \\
\hline Pustulatirus ogum & 1 & 1 & 1 & 0 & 0 & 1 & 2 & 1 & 1 & 1 & $?$ & 1 & 1 & 1 & 0 & 1 & 0 & 2 & 1 \\
\hline Latirus polygonus & 1 & 1 & 1 & 0 & 0 & 1 & 2 & 1 & 1 & 1 & 3 & 1 & 1 & 1 & 0 & 1 & 0 & 2 & 0 \\
\hline Nodolatirus nodatus & 1 & 1 & 1 & 0 & 0 & 1 & 1 & 1 & 2 & 1 & 3 & 1 & 1 & 1 & 0 & 1 & 0 & 2 & 0 \\
\hline Hemipolygona beckyae & 1 & 1 & 1 & 0 & 0 & 1 & 2 & 1 & 1 & 1 & $?$ & 1 & 0 & 0 & 0 & 1 & 0 & 2 & 0 \\
\hline Hemipolygona armata & 1 & 1 & 1 & 0 & 0 & 1 & 2 & 1 & 1 & 1 & $?$ & 1 & 1 & 1 & 0 & 1 & 0 & 2 & 0 \\
\hline Latirus vischii & 1 & 1 & 1 & 0 & 0 & 1 & 1 & 1 & 2 & 1 & $?$ & 1 & 1 & 1 & 0 & $?$ & $?$ & $?$ & ? \\
\hline Australaria australasia & 1 & 0 & 1 & 0 & 0 & 1 & 1 & 1 & 1 & 0 & 3 & 1 & 0 & 0 & 0 & 1 & 0 & 2 & 0 \\
\hline Pleuroploca trapezium & 1 & 0 & 1 & 0 & 0 & 1 & 1 & 1 & 1 & 0 & 3 & 1 & 0 & 0 & 0 & 1 & 0 & 2 & 0 \\
\hline Filifusus filam entosus & 1 & 0 & 0 & 0 & 0 & 1 & 1 & 1 & 1 & 0 & 3 & 1 & 0 & 0 & 0 & 1 & 0 & 2 & 1 \\
\hline Aurantilaria aurantiaca & 1 & 0 & 1 & 0 & 0 & 1 & 1 & 1 & 1 & 0 & 2 & 1 & 1 & 1 & 0 & 1 & 0 & 2 & 1 \\
\hline Fasciolaria tulipa & 1 & 0 & 0 & 0 & 0 & 1 & 1 & 1 & 1 & 0 & 3 & 1 & 1 & 1 & 0 & 1 & 0 & 2 & 0 \\
\hline Polygona infundibulum & 1 & 1 & 1 & 0 & 0 & 1 & 2 & 1 & 1 & 1 & $?$ & 1 & 0 & 0 & 0 & $?$ & $?$ & ? & $?$ \\
\hline Polygona angulata & 1 & 1 & 1 & 0 & 0 & 1 & 2 & 1 & 1 & 1 & $?$ & 1 & 1 & 1 & 0 & 1 & 0 & 2 & 0 \\
\hline Latirus pictus & 1 & 1 & 1 & 0 & 0 & 1 & 2 & 1 & 1 & 1 & 3 & 1 & 0 & 0 & 0 & $?$ & $?$ & $?$ & 0 \\
\hline Leucozonia ocellata & 1 & 1 & 1 & 0 & 0 & 1 & 2 & 1 & 1 & 1 & 3 & 1 & 0 & 0 & 0 & 1 & 0 & 2 & 0 \\
\hline Leucozonia cerata & 1 & 1 & 1 & 0 & 0 & 1 & 2 & 1 & 1 & 1 & 3 & 1 & 0 & 0 & 0 & 1 & 0 & 2 & 0 \\
\hline Leucozonia nassa nassa & 1 & 1 & 1 & 0 & 2 & 1 & 2 & 1 & 1 & 1 & 3 & 1 & 1 & 1 & 0 & 1 & 0 & 2 & 1 \\
\hline Leucozonia nassa cingulifera & 1 & 1 & 1 & 0 & 2 & 1 & 2 & 1 & 1 & 1 & 3 & 1 & 1 & 1 & 0 & 1 & 0 & 2 & 1 \\
\hline Leucozonia nassa brasiliana & 1 & 1 & 1 & 0 & 2 & 1 & 2 & 1 & 1 & 1 & 3 & 1 & 1 & 1 & 0 & 1 & 0 & 2 & 1 \\
\hline Leucozonia ponderosa & 1 & 1 & 1 & 0 & 2 & 1 & 2 & 1 & 1 & 1 & 3 & 1 & 1 & 1 & 0 & 1 & 0 & 2 & 1 \\
\hline Opeatostoma pseudodon & 1 & 1 & 0 & 0 & 1 & 1 & 2 & 1 & 1 & 1 & 3 & 1 & 0 & 0 & 0 & 1 & 0 & 2 & 0 \\
\hline
\end{tabular}




\begin{tabular}{|c|c|c|c|c|c|c|c|c|c|c|c|c|c|c|c|c|c|c|c|}
\hline CHARACTER & & & & 2 & 2 & & 2 & 2 & 2 & $\begin{array}{l}2 \\
0\end{array}$ & & & & & & & & & \\
\hline TAXON & 0 & & & & 4 & & 6 & 7 & 8 & 9 & 0 & & & 3 & & 5 & & & \\
\hline Monetaria annulus & 0 & 0 & 0 & 0 & 0 & 0 & 0 & 0 & 0 & 0 & 0 & 0 & 0 & 0 & 0 & 0 & 0 & 0 & 0 \\
\hline Thais speciosa & 1 & 1 & 1 & 0 & 0 & 0 & 0 & 1 & 1 & 1 & 0 & 0 & 1 & 1 & 0 & 0 & 0 & 0 & 0 \\
\hline Pugilina tupiniquim & 1 & 1 & 1 & 0 & 0 & 0 & 1 & 1 & 1 & 1 & 0 & 0 & 1 & 1 & 0 & 0 & 0 & 0 & 1 \\
\hline Nassarius reticulatus & 1 & 1 & 1 & 0 & 0 & 0 & 0 & 1 & 2 & 1 & 0 & 0 & 1 & 1 & 0 & 0 & 0 & 0 & 1 \\
\hline Bullia laevissima & 1 & 1 & 1 & 0 & 0 & 0 & 0 & 1 & 2 & 1 & 0 & 0 & 1 & 1 & 0 & 0 & 0 & 0 & 1 \\
\hline Pisania pusio & 1 & 1 & 1 & 0 & 0 & 0 & 1 & 1 & 1 & 1 & 0 & 0 & 1 & 1 & 0 & 0 & 0 & 0 & 0 \\
\hline Engoniophos unicinctus & 1 & 1 & 1 & 0 & 0 & 0 & 0 & 1 & 1 & 1 & 0 & 0 & 1 & 1 & 0 & 0 & 0 & 0 & 0 \\
\hline Buccinum undatum & 1 & 1 & 1 & 0 & 0 & 0 & 0 & 1 & 2 & 1 & 0 & 0 & 1 & 1 & 0 & 1 & 0 & 0 & 1 \\
\hline Teralatirus roboreus & 1 & 1 & 1 & 0 & 0 & ? & $?$ & 1 & 0 & 1 & 0 & 0 & 1 & 1 & ? & ? & ? & 0 & 1 \\
\hline Dolicholatirus aff. cayohuesonicus & 1 & 1 & 1 & 0 & 0 & 0 & 1 & 1 & 0 & 1 & 0 & 0 & 1 & 1 & 0 & 0 & 0 & 0 & 1 \\
\hline Dolicholatirus sp. & ? & ? & $?$ & ? & $?$ & ? & $?$ & ? & $?$ & $?$ & ? & ? & ? & ? & ? & ? & ? & ? & ? \\
\hline Angulofusus nedae & 1 & 1 & 1 & 1 & 0 & ? & 1 & 1 & 1 & 1 & 0 & ? & 1 & ? & ? & ? & ? & 0 & ? \\
\hline Amiantofusus pacificus & 1 & 1 & 1 & ? & $?$ & ? & $?$ & ? & $?$ & $?$ & 0 & 1 & 1 & 1 & ? & ? & ? & 0 & 1 \\
\hline Amiantofusus candoris & 1 & 1 & 1 & 2 & 0 & 0 & 1 & 1 & 1 & 1 & 0 & 1 & 1 & 1 & ? & ? & ? & 0 & 1 \\
\hline Pseudolatirus kuroseanus & 1 & 1 & 1 & 2 & 0 & 0 & 1 & 1 & 0 & $?$ & 0 & 0 & 1 & 1 & ? & ? & ? & 0 & 1 \\
\hline Pseudolatirus discrepans & 1 & 1 & 1 & 2 & 0 & 0 & 1 & 1 & 0 & 1 & 1 & 0 & 1 & 1 & 1 & 0 & 0 & 0 & 1 \\
\hline Granulifusus aff. kiranus & 1 & 1 & 1 & 2 & 0 & 0 & 1 & 1 & 0 & 1 & 1 & 0 & 1 & 1 & 1 & 0 & 0 & 0 & 1 \\
\hline Granulifusus hayashi & 1 & 1 & 1 & 2 & 0 & 0 & 1 & 1 & 0 & 1 & 0 & 0 & 1 & 1 & 1 & 0 & 0 & 0 & 1 \\
\hline Granulifusus sp. & 1 & 1 & 1 & 2 & 0 & 0 & 1 & 1 & 0 & 1 & 0 & 0 & 1 & 1 & 1 & ? & 0 & 0 & 1 \\
\hline Pseudolatirus pallidus & 1 & 1 & 1 & 2 & 0 & 0 & 1 & 1 & 1 & 1 & 0 & 0 & 1 & 1 & ? & ? & ? & 0 & 1 \\
\hline Chryseofusus acherusius & 1 & 1 & 1 & 2 & 0 & 0 & 1 & 1 & 1 & 1 & 0 & 1 & 1 & 1 & ? & ? & ? & 0 & 1 \\
\hline Chryseofusus graciliform is & 1 & 1 & 1 & 2 & 0 & 0 & 1 & 1 & 1 & 1 & 0 & 1 & 1 & 1 & 1 & ? & ? & 0 & 1 \\
\hline Fusinus australis & 1 & 1 & 1 & 1 & 0 & 1 & 1 & 1 & 0 & 1 & 0 & 0 & 1 & 1 & 1 & 0 & 0 & 0 & 1 \\
\hline Cyrtulus serotinus & 1 & 1 & 1 & 1 & 0 & 1 & 1 & 1 & 0 & 1 & 0 & 0 & 1 & 1 & 1 & 0 & 0 & 0 & 1 \\
\hline Fusinus frenguelli & 1 & 1 & 1 & 1 & 0 & 1 & 1 & 1 & 0 & 1 & 0 & 0 & 1 & 1 & 1 & 0 & 0 & 0 & 1 \\
\hline Fusinus brasiliensis & 1 & 1 & 1 & 1 & 0 & 0 & 1 & 1 & 0 & 1 & 0 & 0 & 1 & 1 & 0 & ? & 0 & 0 & 1 \\
\hline Fusinus marmoratus & 1 & 1 & 1 & 1 & 0 & 0 & 1 & 1 & 0 & 1 & 0 & 0 & 1 & 1 & 0 & ? & 0 & 0 & 1 \\
\hline Fusinus sp. & 1 & 1 & 1 & $?$ & $?$ & $?$ & $?$ & $?$ & $?$ & $?$ & 0 & 0 & 1 & $?$ & ? & ? & ? & 0 & 1 \\
\hline Fusolatirus bruijnii & 1 & 1 & 1 & 1 & 0 & 0 & 1 & 1 & 0 & 1 & 0 & 0 & 1 & ? & ? & ? & ? & 0 & 1 \\
\hline Peristernia marquesana & 1 & 1 & 1 & 1 & 0 & 0 & 1 & 1 & 0 & 1 & 0 & 0 & 1 & $?$ & ? & ? & ? & 0 & 1 \\
\hline Peristernia nassatula & 1 & 1 & 1 & 1 & 0 & 0 & 1 & 1 & 0 & 1 & 0 & 0 & 1 & ? & ? & ? & ? & 0 & 1 \\
\hline Pustulatirus mediamericanus & 1 & 1 & 1 & 1 & 0 & 0 & 1 & 1 & 0 & 1 & 0 & 0 & 1 & ? & ? & ? & ? & 0 & 0 \\
\hline Pustulatirus ogum & 1 & 1 & 1 & 1 & 0 & 0 & 1 & 1 & 0 & 1 & 0 & 0 & 1 & 1 & 1 & 0 & 0 & 0 & 1 \\
\hline Latirus polygonus & 1 & 1 & 1 & 1 & 0 & 0 & 1 & 1 & 0 & 1 & 0 & 0 & 1 & 1 & 0 & 1 & 0 & 0 & 0 \\
\hline Nodolatirus nodatus & 1 & 1 & 1 & 1 & 0 & 0 & 1 & 1 & 0 & 1 & 0 & 0 & 1 & 1 & 1 & 0 & 0 & 0 & 1 \\
\hline Hemipolygona beckyae & 1 & 1 & $?$ & $?$ & $?$ & ? & $?$ & ? & $?$ & $?$ & 0 & 0 & 1 & 1 & ? & ? & ? & 0 & 2 \\
\hline Hemipolygona armata & 1 & 1 & 1 & 1 & 0 & 0 & 1 & 1 & 0 & 1 & 0 & 0 & 1 & 1 & 1 & 0 & 0 & 0 & 0 \\
\hline Latirus vischii & 1 & 1 & 1 & 1 & 0 & 0 & 1 & 1 & 0 & 1 & 0 & 0 & 1 & $?$ & ? & ? & ? & 0 & 0 \\
\hline Australaria australasia & 1 & 1 & 1 & 1 & 1 & 0 & 1 & 1 & 0 & 1 & 0 & 0 & 1 & 1 & 1 & 0 & 1 & 0 & 0 \\
\hline Pleuroploca trapezium & 1 & 1 & 1 & 1 & 0 & 0 & 1 & 1 & 0 & 1 & 0 & 0 & 1 & 1 & 1 & 0 & 1 & 0 & 0 \\
\hline Filifusus filamentosus & 1 & 1 & 1 & 1 & 0 & 0 & 1 & 1 & 2 & 1 & 0 & 0 & 1 & ? & ? & $?$ & ? & 0 & 0 \\
\hline Aurantilaria aurantiaca & 1 & 1 & 1 & 1 & 1 & 0 & 1 & 1 & 0 & 1 & 0 & 0 & 1 & 1 & 1 & 0 & 1 & 0 & 0 \\
\hline Fasciolaria tulipa & 1 & 1 & 1 & 1 & 0 & 0 & 1 & 1 & 0 & 1 & 0 & 0 & 1 & 1 & 1 & 0 & 1 & 0 & 0 \\
\hline Polygona infundibulum & 1 & 1 & 1 & 1 & 0 & ? & $?$ & 1 & 0 & 1 & 0 & 0 & 1 & $?$ & $?$ & $?$ & ? & 0 & 1 \\
\hline Polygona angulata & 1 & 1 & 1 & 1 & 0 & 0 & 1 & 1 & 0 & 1 & 0 & 0 & 1 & 1 & 0 & 0 & 0 & 0 & 0 \\
\hline Latirus pictus & 1 & 1 & 1 & 1 & 0 & 0 & 1 & 1 & 0 & 1 & 0 & 0 & 1 & 1 & 1 & 1 & 0 & 0 & 0 \\
\hline Leucozonia ocellata & 1 & 1 & 1 & 2 & 0 & 0 & 1 & 1 & 2 & 1 & 1 & 0 & 1 & 1 & 0 & 1 & 0 & 1 & 0 \\
\hline Leucozonia cerata & 1 & 1 & 1 & 1 & 0 & 0 & 1 & 1 & 2 & 1 & 1 & 0 & 1 & $?$ & ? & 0 & ? & 1 & 0 \\
\hline Leucozonia nassa nassa & 1 & 1 & 1 & 1 & 0 & 0 & 1 & 1 & 2 & 1 & 0 & 0 & 1 & 1 & 0 & 1 & 0 & 0 & 0 \\
\hline Leucozonia nassa cingulifera & 1 & 1 & 1 & 1 & 0 & 0 & 1 & 1 & 2 & 1 & 0 & 0 & 1 & 1 & 0 & 1 & 0 & 0 & 0 \\
\hline Leucozonia nassa brasiliana & 1 & 1 & 1 & 1 & 0 & 0 & 1 & 1 & 2 & 1 & 0 & 0 & 1 & 1 & 0 & 1 & 0 & 0 & 0 \\
\hline Leucozonia ponderosa & 1 & 1 & 1 & 1 & 0 & 0 & 1 & 1 & 2 & 1 & 0 & 0 & 1 & 1 & 0 & 1 & 0 & 0 & 0 \\
\hline Opeatostom a pseudodon & 1 & 1 & 1 & 1 & 0 & 0 & 0 & 1 & 2 & 1 & 0 & 0 & 1 & 1 & 1 & 0 & 1 & 0 & 0 \\
\hline
\end{tabular}




\begin{tabular}{|c|c|c|c|c|c|c|c|c|c|c|c|c|c|c|c|c|c|c|c|c|}
\hline CHARACTER & 5 & 5 & 5 & 5 & & & & & & & 0 & 6 & & 6 & & & & & & \\
\hline TAXON & 0 & 1 & 2 & 3 & 4 & 5 & 6 & 7 & 8 & 9 & 0 & 1 & 2 & 3 & 4 & 5 & 6 & 7 & 8 & \\
\hline Monetaria annulus & 0 & 2 & 0 & 0 & 0 & 0 & 0 & 0 & $\overline{0}$ & 0 & 0 & $\overline{0}$ & 0 & $\overline{0}$ & $\overline{0}$ & 0 & 0 & $\overline{0}$ & $\overline{0}$ & \\
\hline Thais speciosa & 0 & 2 & 1 & 0 & 1 & 0 & 0 & 0 & 0 & 0 & 0 & - & - & - & 0 & 0 & 0 & 0 & 1 & \\
\hline Pugilina tupiniquim & 0 & 1 & 0 & 1 & 1 & 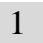 & 0 & 0 & 0 & 1 & 0 & 1 & 0 & 0 & 0 & 0 & 0 & 0 & 0 & \\
\hline Nassarius reticulatus & 0 & 4 & 0 & 0 & 1 & 1 & 0 & 0 & 0 & 1 & 0 & 1 & 0 & 0 & 1 & 0 & 0 & 0 & 0 & \\
\hline Bullia laevissima & 0 & 4 & 0 & 0 & 1 & 1 & 0 & 0 & 0 & 1 & 0 & 1 & 0 & 0 & 1 & 0 & 0 & 0 & 1 & \\
\hline Pisania pusio & 0 & 2 & 1 & 1 & 1 & 1 & 0 & 0 & 0 & 0 & 0 & 1 & 0 & 0 & 1 & 0 & 0 & 0 & 1 & 1 \\
\hline Engoniophos unicinctus & 0 & 4 & 0 & 0 & 1 & 1 & 0 & 0 & 0 & 1 & 0 & 1 & 0 & 0 & 0 & 0 & 0 & 0 & 0 & 0 \\
\hline Buccinum undatum & 0 & 4 & 0 & 0 & 1 & 1 & 0 & 0 & 0 & 0 & 0 & 1 & 0 & 0 & 1 & 0 & 0 & 0 & 1 & 1 \\
\hline Teralatirus roboreus & ? & ? & ? & ? & 0 & 0 & 1 & 0 & 0 & 0 & 0 & - & - & 0 & 1 & 0 & 1 & 0 & 1 & 0 \\
\hline Dolicholatirus aff. cayohuesonicus & 0 & 0 & 1 & 0 & 0 & 0 & 1 & 0 & 0 & 0 & 0 & - & - & 0 & 1 & 0 & 1 & 1 & 0 & 0 \\
\hline Dolicholatirus sp. & 0 & 0 & 1 & 0 & 0 & 1 & 1 & 0 & 0 & 0 & 0 & - & - & 0 & 1 & $?$ & $?$ & ? & ? & \\
\hline Angulofusus nedae & 1 & 2 & 0 & 3 & 0 & 2 & 0 & 0 & 1 & 1 & 1 & 0 & 0 & 0 & 0 & 0 & 1 & 1 & 1 & \\
\hline Amiantofusus pacificus & 1 & 2 & 0 & 3 & 0 & 2 & 0 & 0 & 1 & 0 & 1 & 0 & 0 & 0 & 0 & 0 & 1 & 1 & 0 & 0 \\
\hline Amiantofusus candoris & 1 & 2 & 0 & 3 & 0 & 2 & 0 & 0 & 1 & 0 & 1 & 0 & 0 & 0 & 0 & 0 & 1 & 1 & 0 & \\
\hline Pseudolatirus kuroseanus & 1 & 2 & 0 & 3 & 0 & 2 & 0 & 0 & 1 & 0 & 1 & 0 & 0 & 0 & 0 & 0 & 1 & 1 & 1 & \\
\hline Pseudolatirus discrepans & 1 & 2 & 0 & 2 & 0 & 3 & 0 & 0 & 2 & 0 & 1 & 0 & 0 & 0 & 0 & 0 & 1 & 1 & 0 & \\
\hline Granulifusus aff. kiranus & 1 & 2 & 0 & 2 & 0 & 3 & 0 & 0 & 2 & 0 & 1 & 0 & 0 & 0 & 0 & 0 & 1 & 1 & 0 & 0 \\
\hline Granulifusus hayashi & 0 & 2 & 0 & 2 & 0 & 3 & 0 & 0 & 2 & 0 & 1 & 0 & 0 & 0 & 0 & 0 & 1 & 1 & 0 & \\
\hline Granulifusus sp. & 1 & 2 & 0 & 2 & 0 & 3 & 0 & 0 & 2 & 0 & 1 & 0 & 0 & 0 & 0 & 0 & 1 & 1 & 1 & 0 \\
\hline Pseudolatirus pallidus & 2 & 2 & 0 & 2 & 0 & 3 & 0 & 0 & 2 & 0 & 1 & 0 & 0 & 0 & 0 & 1 & 1 & 1 & 0 & \\
\hline Chryseofusus acherusius & 2 & 2 & 0 & 2 & 0 & 3 & 0 & 0 & 2 & 1 & 1 & 0 & 0 & 0 & 0 & 1 & 1 & 1 & 1 & 0 \\
\hline Chryseofusus graciliform is & 2 & 2 & 0 & 2 & 0 & 3 & 0 & 0 & 2 & 1 & 1 & 0 & 0 & 0 & 0 & 1 & 1 & 1 & 1 & 0 \\
\hline Fusinus australis & 2 & 2 & 0 & 2 & 0 & 3 & 0 & 0 & 2 & 1 & 1 & 0 & 0 & 1 & 0 & 1 & 1 & 1 & 0 & 0 \\
\hline Cyrtulus & 2 & 2 & 0 & 2 & 0 & 3 & 0 & 0 & 2 & 1 & 1 & 0 & 0 & 1 & 0 & 1 & 1 & 1 & 1 & 0 \\
\hline Fusinus frenguelli & 1 & 2 & 1 & 2 & 0 & 3 & 0 & 0 & 2 & 1 & 1 & 0 & 0 & 1 & 0 & 1 & 1 & 1 & 1 & 0 \\
\hline Fusinus brasiliensis & 2 & 2 & 0 & 2 & 0 & 3 & 0 & 0 & 2 & 1 & 1 & 0 & 0 & 1 & 0 & 1 & 1 & 1 & 1 & 0 \\
\hline Fusinus marmoratus & 2 & 2 & 0 & 2 & 0 & 3 & 0 & 0 & 2 & 1 & 1 & 0 & 0 & 1 & 0 & 1 & 1 & 1 & 1 & U \\
\hline Fusinus sp. & 1 & 2 & 0 & 2 & 0 & 3 & 0 & 0 & 2 & 1 & 1 & 0 & 0 & 1 & 0 & 1 & 1 & 1 & 1 & 0 \\
\hline Fusolatirus bruijnii & 1 & 2 & 0 & 2 & 0 & 3 & 0 & 1 & 2 & 1 & 1 & 0 & 0 & 0 & 1 & 0 & 1 & 1 & 1 & 0 \\
\hline Peristernia marquesana & 2 & 2 & 0 & 3 & 0 & 4 & 0 & 1 & 2 & 1 & 1 & 0 & 0 & 0 & 1 & 0 & 1 & 1 & 1 & 0 \\
\hline Peristernia nassatula & 2 & 3 & 0 & 2 & 0 & 4 & 0 & 1 & 2 & 1 & 1 & 0 & 0 & 0 & 1 & 0 & 1 & 1 & 1 & 0 \\
\hline Pustulatirus mediame & 0 & 3 & 0 & 2 & 0 & 4 & 0 & 0 & 2 & 1 & 1 & 0 & 0 & 0 & 0 & 0 & 1 & 0 & 0 & 1 \\
\hline Pustulatirus & 0 & 3 & 0 & 2 & 0 & 4 & 0 & 0 & 2 & 1 & 1 & 0 & 0 & 0 & 0 & 0 & 1 & 0 & 0 & 1 \\
\hline Latirus polygonus & 0 & 2 & 0 & 3 & 0 & 4 & 0 & 0 & 2 & 1 & 1 & 0 & 0 & 0 & 0 & 0 & 1 & 1 & 1 & 1 \\
\hline Nodolatiru & 0 & 2 & 0 & 2 & 0 & 4 & 0 & 0 & 3 & 1 & 1 & 0 & 0 & 0 & 0 & 0 & 1 & 1 & 1 & 1 \\
\hline Hemipolygona beckyae & 0 & 2 & 0 & 2 & 0 & 3 & 0 & 0 & 2 & 1 & 1 & 0 & 0 & 0 & 0 & 0 & 1 & 1 & 0 & 1 \\
\hline Hemipolygona & 0 & 2 & 0 & 2 & 0 & 3 & 0 & 0 & 2 & 1 & 1 & 0 & 0 & 0 & 0 & 0 & 1 & 1 & 0 & 1 \\
\hline Latirus vischii & 0 & 2 & 0 & 3 & 0 & 4 & 0 & 0 & 3 & 1 & 2 & 0 & 0 & 0 & 0 & 0 & 1 & 1 & 1 & 1 \\
\hline Australaria australasia & 0 & 2 & 0 & 3 & 0 & 4 & 0 & 0 & 2 & 1 & 2 & 0 & 0 & 0 & 0 & 0 & 1 & 1 & 0 & 1 \\
\hline Pleuroploca trapezium & 0 & 2 & 0 & 3 & 0 & 4 & 0 & 0 & 3 & 1 & 2 & 0 & 0 & 0 & 0 & 0 & 1 & 1 & 0 & 1 \\
\hline Filifusus filamentosus & 0 & 2 & 1 & 3 & 0 & 4 & 0 & 0 & 3 & 1 & 2 & 0 & 0 & 0 & 0 & 0 & 1 & 1 & 0 & 1 \\
\hline Aurantilaria aurantiaca & 1 & 2 & 1 & 3 & 0 & 4 & 0 & 0 & 3 & 1 & 2 & 0 & 0 & 0 & 0 & 0 & 1 & 1 & 0 & 1 \\
\hline Fasciolaria tulipa & 1 & 2 & 0 & 3 & 0 & 4 & 0 & 0 & 3 & 1 & 2 & 0 & 0 & 0 & 0 & 0 & 1 & 1 & 0 & 1 \\
\hline Polygona infundibulum & 0 & 2 & 1 & 2 & 0 & 3 & 0 & 0 & 2 & 1 & 1 & 0 & 0 & 0 & 0 & 0 & 1 & 1 & 1 & 1 \\
\hline Polygona angulata & 0 & 2 & 0 & 2 & 0 & 3 & 0 & 0 & 2 & 1 & 1 & 0 & 0 & 0 & 0 & 0 & 1 & 1 & 1 & 1 \\
\hline Latirus pictus & 0 & 2 & 0 & 3 & 0 & 3 & 0 & 0 & 2 & 1 & 1 & 0 & 0 & 0 & 0 & 0 & 1 & 1 & 0 & 1 \\
\hline Leucozonia ocellata & 0 & 2 & 0 & 2 & 0 & 3 & 0 & 0 & 1 & 1 & 2 & 1 & 1 & 0 & 0 & 0 & 1 & 1 & 0 & 1 \\
\hline Leucozonia cerata & 0 & 2 & 0 & 2 & 0 & 3 & 0 & 0 & 2 & 1 & 2 & 1 & 0 & 0 & 0 & 0 & 1 & 1 & 0 & 1 \\
\hline Leucozonia nassa & 0 & 2 & 0 & 2 & 0 & 3 & 0 & 0 & 2 & 1 & 2 & 1 & 1 & 0 & 0 & 0 & 1 & 1 & 0 & 1 \\
\hline Leucozonia nassa cingulife & 0 & 2 & 0 & 2 & 0 & 3 & 0 & 0 & 2 & 1 & 2 & 1 & 1 & 0 & 0 & 0 & 1 & 1 & 0 & 1 \\
\hline Leucozonia nassa brasiliana & 0 & 2 & 0 & 2 & 0 & 3 & 0 & 0 & 2 & 1 & 2 & 1 & 1 & 0 & 0 & 0 & 1 & 1 & 0 & 1 \\
\hline & 0 & 2 & 0 & 2 & 0 & 3 & 0 & 0 & 2 & 1 & 2 & 1 & 1 & 0 & 0 & 0 & 1 & 1 & 0 & \\
\hline Opeatostoma pseudodon & $0-1-2$ & 4 & 0 & $1-2$ & 0 & 3 & 0 & 0 & 2 & $?$ & 2 & 1 & 0 & 0 & 0 & 0 & 1 & 1 & 0 & 1 \\
\hline
\end{tabular}




\begin{tabular}{|c|c|c|c|c|c|c|c|c|c|c|c|c|c|c|c|c|c|c|c|c|c|c|c|c|c|}
\hline CHARACTER & & & & & & & & 7 & 8 & & & & & & $\begin{array}{l}8 \\
4\end{array}$ & 5 & & & & & 0 & & 2 & & \\
\hline$\overline{\text { Monetaria annulus }}$ & 0 & & & $\overline{0}$ & $\overline{0}$ & & & & & 0 & 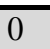 & $\overline{0}$ & $\overline{0}$ & - & $\overline{-}$ & & $\overline{0}$ & & & & & 0 & & & \\
\hline Thais speciosa & 0 & & 0 & 1 & 0 & & & & & ? & ? & ? & ? & ? & $?$ & 0 & 1 & 1 & & & U & 1 & & 0 & \\
\hline Pugilina tupiniquim & 0 & 0 & & 2 & 0 & & & & & & - & - & 1 & 0 & 0 & 0 & 1 & 1 & & & U & 1 & & 1 & \\
\hline Nassarius reticulatus & 0 & 1 & 0 & 1 & 0 & & & & & & - & - & 0 & - & - & $?$ & ? & ? & & & 1 & 1 & 0 & 0 & \\
\hline Bullia laevissima & 0 & 0 & & 1 & 2 & & & 0 & & & - & - & 1 & 0 & 1 & $?$ & 1 & 0 & 0 & 0 & 0 & 1 & 0 & ? & \\
\hline Pisania pusio & 1 & 1 & 0 & 1 & 0 & & 1 & 1 & 1 & 1 & 0 & 0 & 1 & 0 & 1 & 1 & 1 & 2 & & 0 & 0 & 1 & 0 & 0 & 1 \\
\hline Engoniophos unicinctus & 0 & & 0 & 1 & 2 & ? & 1 & 0 & 0 & & - & - & 1 & 0 & 1 & 0 & 1 & 0 & & 0 & 0 & 1 & 0 & 0 & \\
\hline Buccinum undatum & 0 & 1 & 0 & 1 & 0 & 1 & 1 & 1 & 1 & 1 & 0 & 1 & 1 & 0 & 0 & 1 & 1 & 2 & & 0 & 1 & 1 & 0 & 0 & \\
\hline Teralatirus roboreus & ? & 1 & $?$ & 0 & 0 & 2 & 1 & 1 & ? & 1 & ? & ? & ? & ? & 1 & 0 & 1 & 2 & & & & 2 & 1 & 1 & \\
\hline Dolicholatirus aff. cay & ? & 1 & 0 & 1 & 0 & 2 & 1 & 1 & $?$ & ? & ? & ? & 1 & 0 & 1 & 0 & 1 & 2 & & & & 2 & 1 & & \\
\hline Dolicholatirus sp. & ? & $?$ & $?$ & ? & ? & ? & ? & ? & $?$ & ? & ? & ? & ? & ? & $?$ & $?$ & ? & & & & & $?$ & ? & & \\
\hline Angulofusus nedae & 1 & & 0 & 1 & ? & 2 & 1 & 1 & $?$ & $?$ & ? & ? & ? & ? & $?$ & ? & ? & & & & & $?$ & ? & & \\
\hline Amiantofusus pacificus & 1 & & 0 & 1 & ? & 2 & 1 & 1 & $?$ & 1 & & ? & ? & ? & $?$ & 0 & 1 & & & & & ? & & & \\
\hline Amiantofusus candoris & 1 & & 0 & 1 & ? & ? & 1 & 1 & ? & 1 & ? & ? & ? & ? & ? & ? & ? & ? & & & & 2 & 1 & 1 & \\
\hline Pseudolatirus kuroseanus & 1 & & 0 & 1 & 0 & ? & 1 & 1 & ? & 1 & & ? & ? & ? & ? & 0 & 1 & 1 & & & & 2 & & & \\
\hline Pseudolatirus discrep & 1 & & 0 & 1 & 0 & ? & 1 & 1 & 0 & 1 & 1 & 0 & 0 & - & - & ? & ? & ? & & & & 2 & & & \\
\hline Gran & 1 & 1 & 0 & 1 & 0 & ? & 1 & 1 & ? & 1 & $?$ & ? & 0 & - & - & 0 & 1 & 1 & & & 1 & 2 & & & \\
\hline Granulifusus hayashi & 1 & 1 & 0 & 1 & 0 & $?$ & 1 & 1 & 0 & 1 & 1 & 0 & 0 & - & - & ? & ? & $?$ & & & & 2 & & 0 & \\
\hline ifusus & 1 & 1 & 0 & 1 & 0 & $?$ & 1 & 0 & 1 & 1 & 1 & 1 & 0 & - & - & $?$ & ? & $?$ & & & 1 & 2 & 1 & 0 & \\
\hline atirus pallidus & 1 & 1 & 0 & 1 & 0 & 2 & 1 & 1 & $?$ & 1 & $?$ & ? & $?$ & $?$ & $?$ & 0 & 1 & 1 & & & 1 & 2 & 1 & 0 & 0 \\
\hline herusius & 1 & 1 & 0 & 1 & 0 & 2 & 1 & 1 & 1 & 1 & 0 & 0 & 1 & 0 & 0 & 0 & 1 & 1 & & & & 2 & 1 & 0 & 0 \\
\hline Chr & 1 & 1 & 0 & 1 & 0 & 2 & 1 & 1 & $?$ & 1 & $?$ & ? & 1 & 0 & $?$ & 0 & 1 & 1 & & & 1 & 2 & & 0 & 0 \\
\hline Fus & 1 & 1 & 1 & 1 & 0 & $?$ & 1 & 0 & 1 & 1 & 1 & 0 & 1 & 0 & 1 & 0 & 1 & 1 & & & & 2 & 1 & 0 & 1 \\
\hline Cyr & 1 & 1 & 1 & 1 & 0 & $?$ & 1 & 0 & $?$ & 1 & ? & ? & $?$ & $?$ & $?$ & ? & ? & $?$ & & & 1 & 2 & 1 & & 0 \\
\hline Fusi & 1 & 1 & 1 & 1 & 0 & 2 & 1 & 0 & ? & 1 & $?$ & ? & 1 & 0 & 0 & 0 & 1 & 0 & & & & $?$ & ? & & $?$ \\
\hline Fusinus brasiliensis & 1 & 1 & 1 & 1 & 0 & 2 & 1 & 1 & $?$ & 1 & $?$ & $?$ & 1 & 0 & 1 & 0 & 1 & 1 & & 0 & 0 & 2 & 1 & 0 & \\
\hline Fusinus $m$ & 1 & 1 & 1 & 1 & 0 & 2 & 1 & 1 & ? & 1 & ? & ? & 1 & 0 & 1 & 0 & 1 & 1 & & 0 & ? & $?$ & ? & ? & \\
\hline Fusinu & \begin{tabular}{|lll} 
& 1
\end{tabular} & 1 & 1 & 1 & 0 & 2 & 1 & 1 & ? & 1 & ? & ? & 1 & 0 & 1 & $?$ & ? & ? & & 0 & & 2 & 1 & 0 & \\
\hline Fusolatirus bruijnii & 1 & 1 & 0 & 1 & 0 & ? & 1 & 0 & 1 & 1 & 1 & 0 & 1 & 0 & 1 & ? & ? & ? & ? & & 1 & 2 & 1 & 0 & $\begin{array}{ll}0 & 1\end{array}$ \\
\hline quesan & 1 & 1 & 0 & 1 & 0 & ? & 1 & 0 & ? & $?$ & ? & ? & ? & ? & $?$ & $?$ & ? & ? & ? & ? & 1 & 2 & 1 & 1 & \\
\hline tula & 1 & 1 & 0 & 1 & 0 & 2 & 1 & 0 & 1 & 1 & 1 & 0 & 1 & ? & $?$ & 0 & 1 & 1 & 0 & ? & 1 & 2 & 1 & 0 & $\begin{array}{ll}0 & 1\end{array}$ \\
\hline Pustulatiru & 1 & 1 & 0 & 1 & 0 & 2 & 1 & 1 & ? & 1 & ? & ? & 1 & 0 & 0 & ? & ? & ? & & ? & ? & $?$ & ? & $?$ & ? \\
\hline Pus & 1 & 1 & 0 & 1 & 0 & 2 & 1 & 0 & ? & 1 & $?$ & ? & ? & ? & $?$ & 0 & 1 & 0 & & 0 & 1 & 2 & 1 & 1 & \\
\hline$L a$ & 1 & 1 & 0 & 1 & 0 & 2 & 1 & 1 & 1 & 1 & 1 & 0 & 1 & 0 & 1 & $?$ & ? & ? & & ? & ? & $?$ & ? & ? & ? ? \\
\hline atus & 1 & 1 & 0 & 1 & 0 & ? & 1 & 1 & ? & ? & ? & ? & ? & ? & $?$ & 0 & 1 & 1 & & 0 & 1 & 2 & 1 & 0 & 1 \\
\hline Hem & 1 & 1 & 0 & 1 & 0 & 2 & 1 & 1 & ? & 1 & ? & 0 & 1 & 0 & 1 & 0 & 1 & 1 & & 0 & 1 & 2 & 1 & 0 & 0 \\
\hline Hem & 1 & 1 & 0 & 1 & 0 & 2 & 1 & 1 & ? & ? & ? & ? & 1 & 0 & 1 & 0 & 1 & 1 & & 0 & 1 & 2 & 1 & 1 & 1 \\
\hline Latir & 11 & 1 & 0 & 1 & 0 & ? & 1 & ? & ? & $?$ & ? & ? & ? & ? & $?$ & $?$ & ? & ? & ? & ? & 1 & 2 & 1 & 0 & 1 \\
\hline Australaria australasia & 1 & 1 & 0 & 1 & 1 & ? & 1 & 1 & 1 & 1 & 1 & 0 & 1 & 1 & 0 & ? & ? & ? & ? & ? & 1 & 2 & 1 & 0 & 1 \\
\hline Pleuroploca trapezium & 1 & 1 & 0 & 1 & 1 & ? & 1 & 1 & ? & ? & ? & ? & ? & ? & $?$ & ? & ? & ? & ? & ? & 1 & 2 & 1 & 0 & 1 \\
\hline Filifusus filamentosus & 1 & 1 & 0 & 1 & 1 & ? & 1 & 1 & ? & 1 & ? & 0 & 1 & 1 & 0 & ? & ? & ? & ? & $?$ & 1 & 2 & 1 & 0 & 1 \\
\hline Aurantilaria aurantiaca & 1 & 1 & 0 & 1 & 1 & 2 & 1 & 1 & 1 & 1 & 1 & 0 & 1 & 0 & 1 & 0 & 1 & 0 & 0 & 0 & ? & $?$ & ? & ? & $?$ \\
\hline Fasciolaria tulipa & 1 & 1 & 0 & 1 & 1 & 2 & 1 & 1 & 1 & 1 & 1 & 0 & 1 & 0 & 0 & 0 & 1 & 1 & 0 & 0 & ? & $?$ & ? & ? & \\
\hline Polygona infundibulum & 1 & 1 & 0 & 1 & 0 & ? & 1 & ? & ? & $?$ & ? & ? & ? & ? & $?$ & ? & ? & ? & ? & ? & 1 & 2 & 1 & 1 & \\
\hline Polygona angulata & 1 & 1 & 0 & 1 & 0 & 2 & 1 & 0 & 1 & 1 & 1 & 1 & 1 & 0 & 1 & 0 & 1 & 1 & 0 & 0 & 1 & 2 & 1 & 1 & \\
\hline Latirus pictus & 1 & 1 & 0 & 1 & 0 & 2 & 1 & 0 & $?$ & ? & $?$ & ? & ? & ? & $?$ & 0 & 1 & 1 & 0 & 0 & 1 & 2 & 1 & 0 & 0 \\
\hline Leucozonia ocellata & 1 & 1 & 0 & 1 & 0 & 2 & 1 & 0 & 0 & 1 & 1 & 0 & 1 & 0 & 1 & 0 & 1 & 0 & 0 & 0 & 1 & 2 & 1 & 1 & \\
\hline Leucozonia cerata & 1 & & 0 & 1 & 0 & 2 & 1 & 0 & $?$ & ? & ? & ? & 1 & 0 & 0 & 0 & 1 & 0 & & 0 & 1 & 2 & 1 & & \\
\hline Leucozonia nassa na & 1 & & 0 & 1 & 0 & 2 & & 0 & 0 & 1 & 0 & 0 & 1 & 0 & 1 & 0 & 1 & 1 & & 0 & & 2 & 1 & & \\
\hline Leucozonia nassa cingulif & 1 & & 0 & 1 & 0 & 2 & & 0 & 0 & 1 & 0 & 0 & 1 & 0 & 1 & 0 & 1 & & & & & 2 & 1 & & \\
\hline Leucozonia nassa brasiliana & 1 & & 0 & 1 & 0 & 2 & & 0 & 0 & 1 & 0 & 0 & 1 & 0 & 1 & 0 & 1 & 1 & & & & 2 & 1 & & 0 \\
\hline Leuc & 1 & & 0 & 1 & 0 & 2 & 1 & 0 & & 1 & 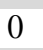 & 0 & 1 & 0 & 1 & 0 & 1 & 1 & & & & 2 & 1 & 0 & 0 \\
\hline Opeatostoma pseudodon & 1 & & 0 & & 1 & 2 & 1 & 0 & & & 1 & 0 & 1 & 0 & 0 & & 1 & 0 & & 1 & & 2 & 1 & 0 & \\
\hline
\end{tabular}




\section{References}

Abbate D. 2016. Estudo Filogenético da subfamília Nassariinae (Neogastropoda, Buccinoidea, Nassariidae). Tese (Doutorado em Ciências, área de Zoologia) - Instituto de Biociências, Universidade de São Paulo, São Paulo. 234p.

Abbate D. \& Simone L.R.L. 2015. Review of Pugilina from the Atlantic, with description of a new species from Brazil (Neogastropoda, Melongenidae). African Invertebrates, 56(3): $559-577$.

Abbate D. \& Simone L.R.L. 2016. Anatomy of Bullia laevissima from Cape Town, South Africa (Mollusca, Caenogastropoda, Nassariidae). Spixiana, 39(1): 1-10.

Abbott R.T. 1958. The marine mollusks of Grand Cayman Island, British West Indies. Monographs of the Academy of Natural Sciences of Philadelphia, 11: 1-138.

Absalão R.S., Caetano C.H.S. \& Fortes R.R. 2006. Filo Mollusca. In: Lavrado H.P. \& Ignacio B.L. (Eds). Biodiversidade bentônica da região central da Zona Econômica Exclusiva Brasileira. Rio de Janeiro, Museu Nacional. p. 211-260. (Série Livros 18)

Amaudrut A. 1898. La partie antérieure du tube digestif et la torsion chez les mollusques gastéropodes. Annales des Sciences Naturelles, Serie 8, 7:1-291, pls. 1-10.

Andrews E.B. \& Thorogood K.E. 2005. An ultrastructural study of the gland of Leiblein of muricid and nassariid neogastropods in relation to function, with a discussion on its homologies in other caenogastropods. Journal of Molluscan Studies, 71(3): 269-300. http://doi.org/10.1093/mollus/eyi036.

Bandel K. 1984. The radulae of Caribbean and other Mesogastropoda and Neogastropoda. Zoologische Verhandelingen. 214: 1-188.

Bandel K. 1993. Caenogastropoda during Mesozoic times. Scripta Geologica, (Special issue 2): 7-56. 
Bellardi L. 1884. I molluschi dei terreni terziarii del Piemonte e della Liguria. Parte IV. Fasciolariidae e Turbinellidae, Torino, Ermano Loescher. 62p.

Benton M.J. 1993. The Fossil Record. Chapman \& Hall, London, v. 2, 845p.

Beu A.G. 2011. Marine Mollusca of isotope stages of the last 2 million years in New Zealand. Part 4. Gastropoda (Ptenoglossa, Neogastropoda, Heterobranchia). Journal of the Royal Society of New Zealand, 41(1): 1-153.

Bieler R. \& Simone L.R.L. 2005. Anatomy and morphology of Stephopoma nucleogranosum Verco, 1904 (Caenogastropoda: Siliquariidae) from Esperance Bay, Western Australia. In: Wells F., Walker D.I. \& Kendrick G.A. (Eds.). The Marine Flora and Fauna of Esperance, Western Australia. Western Australian Museum, Perth. p. 159-175.

Bouchet P. \& Rocroi J.P. 2005. Classification and nomenclator of gastropod families. Malacologia, 47: 1-397.

Bouchet P. \& Snyder M.A. 2013. New and old species of Benimakia (Neogastropoda: Fasciolariidae) and a description of Nodolatirus, new genus. Journal of Conchology, 41(3): 331341.

Bouchet P. \& Waren A. 1985. Revision of the Northeast Atlantic bathyal and abyssal Neogastropoda excluding Turridae (Mollusca, Gastropoda). Bollettino Malacologico, (Suppl 1): 1- 296.

Bronwen J., Scott J. \& Kenny R. 1998. Morphology and Physiology of the Mollusca. In: Beesley P.L., Ross G.J.B. \& Wells A. Mollusca: The Southern Synthesis. Fauna of Australia. CSIRO Publishing, Melbourne. p. 11-23.

Bullock R.C. 1974. A contribution to the systematics of some West Indian Latirus (Gastropoda: Fasciolariidae). The Nautilus, 88: 69-79.

Buzzurro G. \& Russo P. 2007. Fusinus del Mediterraneo. published by the authors. 280p. 
Callomon P. \& Snyder M.A. 2004. On some Fusinus (Gastropoda: Fasciolariidae) from Japan, with type selections. Venus: Japanese Journal of Malacology, 63(1): 13-27.

Callomon P. \& Snyder M.A. 2007. On the Genus Fusinus in Japan III: Nine Further Species, with Type Selections. Venus: Japanese Journal of Malacology, 66(1): 19-47.

Callomon P. \& Snyder M.A. 2009. On the genus Fusinus in Japan V: further species, an unnamed form and discussion. Venus: Japanese Journal of Malacology, 67 (3-4): 1-14.

Callomon P. \& Snyder M.A. 2006. On the Genus Fusinus in Japan II: F. undatus, F. similis and Related Pacific Taxa, with the Description of $F$. mauiensis n. sp. (Gastropoda: Fasciolariidae). Venus: Japanese Journal of Malacology, 65(3): 177-191.

Colgan D.J., Ponder W.F., Beacham E. \& Macaranas J. M. 2003. Gastropod phylogeny based on six segments from four genes representing coding or non-coding and mitochondrial or nuclear DNA. Molluscan Research, 23: 123-148. http://doi.org/10.1071/MR03002

Colgan D.J., Ponder W.F., Beacham E. \& Macaranas, J. 2007. Molecular phylogenetics of Caenogastropoda (Gastropoda: Mollusca). Molecular Phylogenetics and Evolution, 42(3): 717737. http://doi.org/10.1016/j.ympev.2006.10.009.

Cossmann M. 1901. Essais de paléoconchologie comparée, 4. The author and Société d'Éditions Scientifiques. Paris. 293p.

Couto D.R. \& Pimenta A.D. 2012. Comparative morphology of Leucozonia from Brazil (Neogastropoda: Buccinoidea: Fasciolariidae). American Malacological Bulletin, 30: 103-116.

Couto D.R., Bouchet P., Kantor Y.I., Simone L.R.L. \& Giribet G. 2016. A multilocus molecular phylogeny of Fasciolariidae (Neogastropoda: Buccinoidea). Molecular phylogenetics and evolution, 99: 309-322.

Couto D.R., Simone L.R.L. \& Pimenta A.D. 2015a. Comparative anatomy of the fasciolariids Pustulatirus ogum and Hemipolygona beckyae from Brazil (Gastropoda: Buccinoidea: Peristerniinae). Scientia Marina, 79(1): 1-17. 
Couto D.R., Simone L.R.L. \& Pimenta A.D. 2015b. Morphology of Fasciolaria tulipa from Venezuela (Gastropoda: Buccinoidea: Fasciolariidae). Journal of Conchology, 42(2), 163173.

Cunha R.L., Grande C. \& Zardoya R. 2009. Neogastropod phylogenetic relationships based on entire mitochondrial genomes. BMC Evolutionary Biology, 9(210): 1-16. http://doi.org/10.1186/1471-2148-9-210.

Dall W.H. 1894. The mechanical cause of folds in the aperture of the shell of Gastropoda. American Naturalist, 28: 909-914.

Faber M.J. 2010. Marine gastropods from the ABC islands and other localities 34. The genus Teralatirus Coosmans, 1965 (Gastropoda: Fasciolariidae). Miscellania Malacologica, 4(1): 9-12.

Farris J.S. 1969. A Successive Approximations Approach to Character Weighting. Systematic Zoology 18 (4): 374-385. http://doi:10.2307/2412182.

Fedosov A. \& Kantor Y.I. 2012. A new species and genus of enigmatic turriform Fasciolariidae from the Central Indo-Pacific (Gastropoda: Neogastropoda). Archiv Für Molluskenkunde, 141(2): 137-144. http://doi.org/10.1127/arch.moll/1869-0963/141/137-144.

Fedosov A., Puillandre N., Kantor Y.I. \& Bouchet P. 2015. Phylogeny and systematics of mitriform gastropods (Mollusca: Gastropoda: Neogastropoda). Zoological Journal of the Linnaean Society: 1-24. http://doi.org/10.1111/zoj.12278.

Fitch W. 1971. Toward defining the course of evolution: minimal change for a specific tree topology. Systematic Zoology, 20: 406-416.

Fraussen K., Kantor Y.I. \& Hadorn R. 2007. Amiantofusus gen. nov. for Fusinus amiantus Dall, 1889 (Mollusca: Gastropoda: Fasciolariidae) with description of a new and extensive IndoWest Pacific radiation. Novapex, 8(3-4): 79-101. 
Fretter V. \& Graham A. 1962. British Prosobranch Molluscs. Their functional anatomy and ecology. Ray Society Publications, London. 755p.

Galindo L.A., Puillandre N., Strong E.E. \& Bouchet P. 2014. Using microwaves to prepare gastropods for DNA barcoding. Molecular Ecology Resources, 14:700-705. http://doi.org/10.1111/1755-0998.12231.

Galindo L.A., Puillandre N., Utge J., Lozouet P. \& Bouchet P. 2016. The phylogeny and systematics of the Nassariidae revisited (Gastropoda, Buccinoidea). Molecular Phylogenetics and Evolution, 99: 337-353. http://doi.org/10.1016/j.ympev.2016.03.019.

Giribet G. 2015. Morphology should not be forgotten in the era of genomics - a phylogenetic perspective. Zoologischer Anzeiger, 256: 96-103. http://doi.org/10.1016/j.jcz.2015.01.003.

Giribet G., Edgecombe G.D. \& Wheeler W.C. 2001. Arthropod Phylogeny Based on Eight Molecular Loci and Morphology. Nature, 413: 157-161.

Giribet G., Edgecombe G.D., Wheeler W.C. \& Babbitt C. 2002. Phylogeny and Systematic Position of Opiliones: A Combined Analysis of Chelicerate Relationships Using Morphological and Molecular data. Cladistics, 18: 5-70.

Golding R.E., Ponder W.F. \& Byrne M. 2009. Three-dimensional reconstruction of the odontophoral cartilages of caenogastropoda (mollusca: gastropoda) using micro-ct: Morphology and phylogenetic significance. Journal of Morphology, 270: 558-587. http://doi.org/10.1002/jmor.10699.

Goloboff P.A. 1993. Estimating character weights during tree search. Cladistics, 9: 83-91.

Goloboff P.A., Carpenter J.M., Arias J.S. \& Miranda-Esquivel D.R. 2008. Weighting against homoplasy improves phylogenetic analysis of morphological data sets. Cladistics, 24: 758-773. http://doi.org/10.1111/j.1096-0031.2008.00209.x. 
Grabau A.W. 1907. Studies of Gastropoda, III. On Orthogenetic variation in Gastropoda. The American Naturalist, 41(490): 607-651.

Gray J.E. 1854. On the division of ctenobranchous gasteropodous Mollusca into larger groups and families. Proceedings of the Zoological Society of London, 21: 32-44.

Habe T. 1958. On the radulae of Japanese marine gastropods. Venus - Japanese Journal of Malacology, 20: 43-60.

Hadorn R. 1999. Two new Fusinus (Gastropoda: Fasciolariidae) from South Mozambique and Natal: Fusinus rogersi sp. nov. and Fusinus kilburni sp. nov. Vita Marina, 46(3-4): 101-110.

Hadorn R. \& Fraussen K. 2003. The deep-water Indo-Pacific radiation of Fusinus (Chryseofusus subgen. nov.)(Gastropoda: Fasciolariidae). Iberus, 21: 207-240.

Hadorn R. \& Fraussen K. 2002. Four new Fusinus from East Africa (Gastropoda: Fasciolariidae). Iberus, 20(1), 63-72.

Hadorn R. \& Fraussen K. 2005. Revision of the genus Granulifusus Kuroda \& Habe 1954 with description of some new species (Gastropoda: Prosobranchia: Fasciolariidae). Archiv Für Molluskenkunde, 134(2): 129-171.

Hadorn R. \& Fraussen K. 2006. Five new species of Fusinus (Gastropoda: Fasciolariidae) from western Pacific and Arafura Sea. Novapex, 7(4): 91-102.

Hadorn R. \& Rogers B. 2000. Revision of recent Fusinus (Gastropoda: Fasciolariidae) from tropical western Atlantic, with description of six new species. Argonauta, 14(1): 5-57.

Hadorn R., Snyder M.A. \& Fraussen K. 2008. A new Chryseofusus (Gastropoda: Fasciolariidae: Fusinus) from South and Western Australia. Novapex, 9(2-3): 95-99.

Hanken J. \& Wake D.B. 1993. Miniaturization of body size: organismal consequences and evolutionary significance. Annual Review of Ecology and Systematics, 24: 501-519. 
Harasewych M.G. 1990. Studies on bathyal and abyssal Buccinidae (Gastropoda: Neogastropoda): 1. Metula fusiformis Clench and Aguayo, 1941. The Nautilus, 104: 120-130.

Harasewych M.G. 1998. Family Fasciolariidae. In: Beesley P.L., Ross G.J.B. \& Wells A. (Eds) Mollusca: The Southern Synthesis. Fauna of Australia. CSIRO Publishing, Melbourne, Australia. p. 832-833.

Harasewych M.G., Adamkewicz S.L., Blake J.A., Saudek D., Spriggs T. \& Bult C.J. 1997. Neogastropod phylogeny: a molecular perspective. Journal of Molluscan Studies, 63, 327-351. http://doi.org/10.1093/mollus/63.3.327.

Harasewych M.G. \& Kantor Y.I. 2004. The deep-sea Buccinoidea (Gastropoda: Neogastropoda) of the Scotia Sea and adjacent abyssal plains and trenches. The Nautilus, 118(1): 1-42.

Haszprunar G. 1988. On the origin and evolution of major gastropods group, with special reference to the Streptoneura. Journal of Molluscan Studies, 54: 367-441. http://doi.org/10.1093/mollus/54.4.367.

Hayashi S. 2005. Molecular phylogeny of the Buccinidae (Caenogastropoda: Neogastropoda) as inferred from the complete mitochondrial 16S rRNA gene sequences of selected. Molluscan Research, 25(2): 85-98.

Kantor Y.I. 1990. Anatomical basis for the origin and evolution of the toxoglossan mode of feeding. Malacologia, 32 (1): 3-18.

Kantor Y.I. 1996. Phylogeny and relationships of Neogastropoda In: Taylor, J.D. (Ed.). Origin and evolutionary radiation of the Mollusca. Oxford University Press, Oxford. p. 221230

Kantor Y.I. 2003. Comparative Anatomy of the Stomach of Buccinoidea (Neogastropoda). Journal of Molluscan Studies, 69: 203-220. http://doi.org/10.1093/mollus/69.3.203. 
.Kantor Y.I. \& Fedosov A. 2009. Morphology and development of the valve of Leiblein in Neogastropoda: possible evidence for paraphyly of the Neogastropoda. The Nautilus, 123(3): 73-82.

Kantor Y.I., Puillandre N., Fraussen K., Fedosov A. \& Bouchet P. 2013. Deep-water Buccinidae (Gastropoda: Neogastropoda) from sunken wood, vents and seeps: molecular phylogeny and taxonomy. Journal of the Marine Biological Association of the United Kingdom, 93(8): 2177-2195. http://doi.org/10.1017/S0025315413000672.

Kier W.M. \& Smith K.K. 1985. Tongues, tentacles and trunks: the biomechanics of movement in muscular-hydrostats. Zoological Journal of the Linnaean Society, 83: 307-324.

Kishino H. \& Hasegawa M. 1989. Evaluation of the maximum likelihood estimate of the evolutionary tree topologies from DNA sequence data, and the branching order in Hominoidea. Journal of Molecular evolution, 29: 170-179.

Kosyan A.R. 2006. Two new species of the genus Pararetifusus Kosuge, 1967 (Buccinidae: Colinae), with notes on the morphology of Pararetifusus tenuis (Okutani, 1966). Ruthenica, 16(1-2): 5-15.

Kosyan A.R. \& Kantor Y.I. 2009. Phylogenetic analysis of the subfamily Colinae (Neogastropoda: Buccinidae) based on morphological characters. The Nautilus, 123: 83-94.

Kosyan A.R. \& Kantor Y.I. 2013. Revision of the genus Aulacofusus Dall, 1918 (Gastropoda : Buccinidae). Ruthenica, 23(1): 1-33.

Kosyan A.R., Modica M.V. \& Oliverio M. 2009. The anatomy and relationships of Troschelia (Neogastropoda: Buccinidae): New evidence for a closer fasciolariid-buccinid relationship? The Nautilus, 123(3): 95-105.

Kuroda T. \& Habe T. 1952. Checklist and bibliography of the recent marine Mollusca of Japan. Tokyo, L.W. Stalch. p.59. 
Kuroda T. \& Habe T. 1971. Descriptions of genera and species. In: Kuroda T., Habe T. \& Oyama K. The Sea Shells of Sagami Bay collected by his majesty the emperor of Japan. Maruzen, Tokio.741p.

Kuroda T., Habe T. \& Oyama K. 1971. The Sea Shells of Sagami Bay collected by his majesty the emperor of Japan. Maruzen, Tokio.741p.

Küster H.C. \& Kobelt W. 1844-1876. Die geschwäntzen unbewehrten Purpurschnecken. Erste hälfte: Turbinella und Fasciolaria. In: Martini F.H.W. \& Chemnitz J.H. (Eds). Systematisches Conchylien-Cabinet. 2. ed. p.1-164, pls. 1-32, 9a, 9b, $13 \mathrm{~b}$.

Landau B. \& Vermeij G.J. 2012. The Peristerniinae (Mollusca: Gastropoda, Buccinoidea, Fasciolariidae) from the Neogene of Venezuela. Cainozoic Research, 9(1): 87-99.

Leal J.H. 1991. Marine Prosobranch Gastropods from Oceanic Islands off Brazil: Species Composition and Biogeography. Universal Book Services/W, Backhuys. 418p.

Lyons W.G. 1972. A New Fasciolaria from the Northeastern Gulf Of Mexico. The Nautilus, 85(3): 96-99.

Lyons W.G. 1991. Post-Miocene species of Latirus Montfort, 1810 (Mollusca: Fasciolariidae) of Southern Florida, with a review of regional marine biostratigraphy. Biological Sciences, 35(3): 131-208.

Lyons W.G. \& Snyder M.A. 2013. The genus Pustulatirus Vermeij and Snyder, 2006 (Gastropoda: Fasciolariidae: Peristerniinae) in the western Atlantic, with descriptions of three new species. Zootaxa, 3636: 35-58.

Maddison W.P. \& Maddison D.R. 2016. Mesquite: a modular system for evolutionary analysis. Version 3.10 http://mesquiteproject.org. Last access vi/2016.

Marcus E. \& Marcus E. 1962. On Leucozonia nassa. Boletim da Faculdade de Filosofia, Ciências e Letras da Universidade de São Paulo, Zoologia 24: 11-30. 
Matthews-Cascon H., Matthews H.R. \& Kotzian C.B. 1989. Os gêneros Fasciolaria Lamarck, 1799 e Leucozonia Gray, 1847 no nordeste brasilieiro (Mollusca: Gastropoda: Fasciolariidae). Memórias do Instituto Oswaldo Cruz, 84(Supplement IV): 357-364.

McCormack J.E., Hird S.M., Zellmer A.J., Carstens B.C. \& Brumfield R.T. 2013. Applications of next-generation sequencing to phylogeography and phylogenetics. Molecular Phylogenetics and Evolution, 66(2): 526-538.

Nixon K.C. \& Carpenter J.M. 1993. On Outgroups. Cladistics, 9: 413-426. http://doi:10.1111/j.1096-0031.1993.tb00234.x.

Nixon K.C. 1999-2002. WinClada ver. 1.0000 Published by the author, Ithaca, NY.

Okutani T. 2000. Marine Mollusks in Japan. Tokai University Press, Tokyo. 1173p.

Oliverio M. \& Modica M.V. 2010. Relationships of the hematophagous marine snail Colubraria (Rachiglossa: Colubrariidae), within the neogastropod phylogenetic framework. Zoological Journal of the Linnaean Society, 158(4): 779-800. http://doi.org/10.1111/j.1096$\underline{3642.2009 .00568 . x}$.

Osca D., Templado J. \& Zardoya R. 2015. Caenogastropod mitogenomics. Molecular Phylogenetics and Evolution, 93: 118-128. http://doi.org/10.1016/j.ympev.2015.07.011.

Perrier R. 1889. Recherches sur l'anatornie et l'histologie du rein des gastéropodes, Prosobranchiata. Annales des Sciences Naturelles. Zoologie et Biologie Animale, 8: 61-192.

Petuch E.J. 1979. New gastropods from the Abrolhos Archipelago and reef complex, Brazil. Proceedings of the Biological Society of Washington, 92(3): 510-526.

Philippe H., Brinkmann H., Lavrov D.V., Littlewood D.T.J., Manuel M., Wörheide G. \& Baurain D. 2011. Resolving difficult phylogenetic questions: Why more sequences are not enough. PLoS Biology, 9(3): 1-10. http://doi.org/10.1371/journal.pbio.1000602. 
Platnick N.I., Griswold C.E. \& Coddington J.A. 1991. On missing entries in cladistic analysis. Cladistics, 7: 337-343.

Ponder W.F. \& Lindberg D.R. 1997. Towards a phylogeny of gastropod molluscs: an analysis using morphological characters. Zoological Journal of the Linnaean Society, 119: 83265. http://doi.org/10.1006/zjls.1996.0066.

Ponder W.F. 1973. The origin and evolution of the Neogastropoda. Malacologia, 12: 295338.

Ponder W.F., Colgan D.J., Healy J.M., Nützel A., Simone L.R.L. \& Strong E.E. 2008. Caenogastropoda. In: Ponder W.F. \& Lindberg D.R. (Eds.). Phylogeny and Evolution of the Mollusca. University of California Press. p. 331-383.

Ponder W.F. 1972. Notes on some Australian Species and Genera of the Family Buccinidae (Neogastropoda). Journal of the Malacological Society of Australia, 2(3): 249-265. http://doi.org/10.1080/00852988.1972.10673857.

Poppe G.T. 2008. Philippine Marine Mollusks: Gastropoda. Hackenheim, ConchBooks. v.2, pt. 2,848 p.

Preetha K., Ravinesh R., Bijukumar A., Dhaneesh K.V. \& George S. 2014. First record of Granulifusus poppei (Mollusca: Fasciolariidae) from Indian coast. Marine Biodiversity Records, 7(e95): 1-3. http://doi.org/10.1017/S1755267214000992.

Price R.M. 2003. Columellar muscle of neogastropods: muscle attachment and the function of columellar folds. Biological Bulletin, 205: 351-366. http://doi.org/10.1086/277797.

Riedel F. 2000. Ursprung und evolution der "höheren" Caenogastropoda. Berliner Geowissenschaftliche Abhandlungen Reihe e Paläobiologie, 32: 1-240.

Rios E.C. 2009. Compendium of Brazilian Sea Shells. Rio Grande, RS, Evangraf. 676p.

Rosenberg G. 1992. The encyclopedia of Seashells. Robert Hale Ltda, London. 224p. 
Rosenberg G. 2009. Malacolog 4.1.1: A Database of Western Atlantic Marine Mollusca. [WWW database (version 4.1.1)] URL http://WwW.malacolog.org/.

Salvini-Plawen L.V. 1988. The structure and function of molluscan digestive systems. In: Trueman E.R. \& Clarke M.R. (Eds) The Mollusca: Form and function. Academic Press, London. p. 301-379.

Salvini-Plawen L.V. \& Haszprunar G. 1987. The Vetigastropoda and systematics of streptoneurous Gastropoda (Mollusca). Journal of Zoology, London, 211: 747-770.

Shendure J. \& Ji H. 2008. Next-generation DNA sequencing. Nature Biotechnology, 26(10): 1135-1145. http://doi.org/10.1038/nbt1486.

Shimodaira H. 2002. An approximately unbiased test of phylogenetic tree selection. Systematic Biology, 51: 492-508.

Shimodaira H. \& Hasegawa M. 1999. Multiple comparisons of log-likelihoods with applications to phylogenetic inference. Molecular Biology and Evolution, 16: 1114-1116.

Shuto T. 1958. Granulifusus from the Miyazaki group (Paleontological study of the Miyazaki group - V). Transactions and Proceedings of the Paleontological Society of Japan, 31: 253-264.

Simone L.R.L. 1996. Anatomy and systematics of Buccinanops gradatus (Deshayes, 1844) and Buccinanops moniliferus (Kiener, 1834) (Neogastropoda, Muricoidea) from the Southeastern coast of Brazil. Malacologia, 38(1-2): 87-102.

Simone L.R.L. 2001. Phylogenetic analyses of Cerithioidea (Mollusca, Caenogastropoda) based on comparative morphology. Arquivos de Zoologia, São Paulo, 36(2): 147-263.

Simone L.R.L. 2004. Morphology and phylogeny of the Cypraeoidea (Mollusca, Caenogastropoda). Papel Virtual. 185p. 
Simone L.R.L. 2005. Comparative morphological study of representatives of the three families of Stromboidea and the Xenophoroidea (Mollusca, Caenogastropoda), with an assessment of their phylogeny. Arquivos de Zoologia, São Paulo, 37(2): 141-267.

Simone L.R.L. 2011. Phylogeny of the Caenogastropoda (mollusca), based on comparative morphology. Arquivos de Zoologia, São Paulo, 42(4): 161-323.

Simone L.R.L., Cavallari D.C. \& Abbate D. 2013. Revision of the genus Teralatirus Coomans 1965 in the Western Atlantic, with an anatomical description of T. roboreus (Reeve 1845). Archiv Für Molluskenkunde, 142(2): 215-226. http://doi.org/10.1127/arch.moll/1869$\underline{0963 / 142 / 215-226 .}$

Simone L.R.L., Herbert G.S. \& Merle D. 2009. Unusual anatomy of the ectoparasitic muricid Vitularia salebrosa (King \& Broderip, 1832) (neogastropoda: muricidae) from the pacific coast of Panama. The Nautilus, 123(3): 137-147.

Simone L.R.L. \& Pastorino G. 2014. Comparative morphology of Dorsanum miran and Bullia granulosa from Morocco (Mollusca: Caenogastropoda: Nassariidae). African Invertebrates, 55(1): 125-142. http://doi.org/10.5733/afin.055.0107

Simone L.R.L. \& Ramos L.V. 1986. Variação constatada em Leucozonia nassa no litoral do Brasil (Buccinacea, Fasciolariidae, Peristeniinae). Informativo da Sociedade Brasileira de Malacologia, São Paulo, v. 58: 15-16.

Snyder M.A. 2003. Four new species of Latirus (Gastropoda: Fasciolariidae) from the Philippine Islands and the southern Caribbean. Iberus, 21(1), 1-9.

Snyder M.A. \& Bouchet P. 2006. New species and new records of deep-water Fusolatirus (neogastropoda: fasciolariidae) from the West Pacific. Journal of Conchology, 39(1): 1-12.

Snyder M.A. \& Callomon P. 2005. On some Fusolatirus from Japan and the Philippines, with description of a new species (Gastropoda: Fasciolariidae). Venus: Japanese Journal of Malacology, 63(3-4): 109-119. 
Snyder M.A., Vermeij G.J. \& Lyons W.G. 2012. The genera and biogeography of Fasciolariinae (Gastropoda, Neogastropoda, Fasciolariidae). Basteria, 76(1-3): 31-70.

Taylor D.W. \& Sohl N.F. 1962. An outline of gastropod classification. Malacologia, 1: 732.

Taylor J.D. \& Lewis A. 1995. Diet and radular morphology of Peristernia and Latirolagena (Gastropoda: Fasciolariidae) from Indo-Pacific coral reefs. Journal of Natural History, 29: 1143-1154. http://doi.org/10.1080/00222939500770481.

Thiele J. 1929-1935. Handbuch der Systematischen Weichtierkunde. Gustav Fischer, Jena. 1134 p.

Troschel F.H. \& Thiele J. 1865-1893. Das Gebiss du Schnechen, zur Begrundung einer naturlichen Classification. Berlin, Nicolaische Verlags-Buchhandlungen. 2 v.

Tryon G.W. 1880-1881. Manual of conchology, structural and systematic, with illustrations of the species. Volume 3. Tritonidae, Fusidae, Buccinidae. Philadelphia. p.1-64, pls 1-24 [1880]; p. 65-310, pls 25-87 [1881].

Turner H. \& Zandee R. 1995. The behaviour of Goloboff's tree fitness measure F. Cladistics, 11: 57-72.

Vermeij G.J. 1997. The genus Leucozonia (Gastropoda: Fasciolariidae) in the Neogene of tropical America. Tulane Studies in Geology and Paleontology, 29: 129-134.

Vermeij G.J. 2001. Innovation and evolution at the edge: origins and fates of gastropods with a labral tooth. Biological Journal of the Linnaean Society 72: 461-508.

Vermeij G.J. 2002. Characters in context: molluscan shells and the forces that mold them. Paleobiology, 28(1): 41-54. http://doi.org/10.1666/0094-8373(2002)028<0041:CICMSA>2.0. $\mathrm{CO} ; 2$. 
Vermeij G.J. \& Rosenberg G. 2003. Dentifusus, a new genus of fasciolariid gastropod from the Philippine with labral tooth. Proceedings of the Academy of Natural Sciences of Philadelphia, 153: 23-26. http://doi.org/10.1635/0097-3157(2003)153[0023:DANGOF]2.0.CO.

Vermeij G.J. \& Snyder M.A. 1998. Leucozonia ponderosa, a new fasciolariid gastropod from Brazil. The Nautilus, 112: 117-119.

Vermeij G.J. \& Snyder M.A. 2002. Leucozonia and related genera of fasciolariid gastropods: shell-based taxonomy and relationships. Proceedings of the Academy of Natural Sciences of Philadelphia 152: 23-44.

Vermeij G.J. \& Snyder M.A. 2003. The fasciolariid gastropod genus Benimakia: New species and a discussion of Indo-Pacific genera in Brazil. Proceedings of the Academy of Natural Sciences of Philadelphia, 153:15-22. http://doi.org/10.1635/00973157(2003)153[0015:TFGGBN] 2.0.CO;2.

Vermeij G.J. \& Snyder M.A. 2006. Shell characters and taxonomy of Latirus and related fasciolariid groups. Journal of Molluscan Studies, 72: 413-424. http://doi.org/10.1093/mollus/eyl020.

Wahlberg N., Braby M.F., Brower A.V.Z., de Jong R., Lee M., Nylin S., Pierce N.E., Sperling F.A.H., Vila R., Warren A.D. \& Zakharov E. 2005. Synergistic effects of combining morphological and molecular data in resolving the phylogeny of butterflies and skippers. Proceedings of the Royal Society B, Biological Science, 272: 1577-1586.

Watson R.B. 1886. Report on the Scaphopoda and Gasteropoda collected by HMS Challenger during the years 1873-1876. In: Reports of the scientific results of the voyage of H.M.S. "Challenger", Zoology. London, H.M. Stationary Off. v.15 (part 42): 1-756, pl. 1-50.

Wenz W. 1938-1944. Teil 1: Allgemeiner Teil und Prosobranchia. In: Schindewolf, O.H. (Ed.). Handbuch der Paläozoologie, Band 6, Gastropoda. Berlin, Borntraeger. 1639p. 
Winnepenninckx B., Steiner G., Backeljau T. \& Wachter R. 1998. Details of gastropod phylogeny inferred from 18S rRNA sequences. Molecular Phylogenetics and Evolution, 9(1): 55-63. http://doi.org/10.1006/mpev.1997.0439.

WoRMS 2016. World Register of Marine Species. http://www.marinespecies.org/ (accessed November 22, 2016).

Zenetos A., Çinar M.E., Pancucci-Papadopoulou M.A., Harmelin J.G. \& Furnari G. 2005. Annotated list of marine alien species in the Mediterranean with records of the worst invasive species. Mediterranean Marine Science, 6(2): 63-118.

Zou S., Li Q. \& Kong L. 2011. Additional gene data and increased sampling give new insights into the phylogenetic relationships of Neogastropoda, within the caenogastropod phylogenetic framework. Molecular Phylogenetics and Evolution. 61: 425-435. 
Molecular phylogeny of Fasciolariidae with a total evidence analysis in POY (Gastropoda: Buccinoidea) 


\section{Introduction}

In the age of phylogenomics, it is crucial that molecular data be integrated into phylogenetic frameworks. Common practice in phylogenetics today involves the use of molecular datasets, and is partly due to the unprecedented amount of information that DNA sequences provide researchers with, in the form of nucleotide bases or amino-acids numbers, as opposed to morphological characters. Likewise, a thorough use of morphology requires greater amounts of time to extract a character, since dissection and study of specimens is more time consuming than current procedures of DNA isolation, amplification and sequencing.

The use of a mixed dataset, comprising of both molecular and morphological data is known as a total evidence analysis, and it may be pursued through a statistical model, such as MrBayes (utilizing a Bayesian inference analysis) or a parsimonious model, such as in POY. The inclusion of morphological data in molecular studies helps to resolve many internal clades, (e.g., as encountered in other groups such as butterflies by Wahlberg et al., 2005; arthropods by Giribet et al. 2001; Opiliones by Giribet et al., 2002).

Couto et al. (2016) have endeavored in an extensive phylogenetic molecular study, and their results were discussed extensively in Chapter I of this dissertation, by comparing the clades obtained through morphology/molecular data. This work proves especially useful, as most terminals were scored for both the molecular and morphological datasets, providing a useful tool for comparison.

\section{Objectives}

1. To complement the molecular analysis of Couto et al. (2016) through the use of a parsimony criterion in the program POY;

2. To analyze the molecular data from Couto et al. (2016) with the morphological matrix from Chapter I in a total evidence analysis;

3. Upon the combined analysis, to provide a more realistic scenario of evolution in which the taxonomy may be more firmly rooted. 


\section{Material and Methods}

The ultimate goal of this study is to include morphological data in a combined analysis with the use of direct optimization, implemented in the program POY 5.1.1 (Varón et al., 2010). This method allows for DNA transformations to be assessed without the need for a previous multiple sequence alignment, in which indels appear as transformations linking ancestral and descendent sequences without the need of a fifth character state. The character and the character state are accessed at the same time (Wheeler, 1996) and the included morphological character transformations are weighted according to each parameter set. This averts the use of an ad hoc hypothesis of alignment.

Six analyses using only molecular data was used in order to determine the best parameter of weighting scheme (1110, 2110, 3221, 1210, 2210 and 3211). These will be explained subsequently. For full description of taxon sampling, DNA extraction, amplification, molecular markers and sequencing see Couto et al. (2016) (Appendix).

\subsection{Parsimony analyses - molecular data}

POY analyses were done in Inspiron 5537, Intel(R) Core(TM) i7 4500U CPU with 8.00GB personal computer. Processor number was set to four in POY 5.1.1; four independent timed searches of $6 \mathrm{~h}$ were performed in order to obtain a global optimum.

In order to better ascertain the homology of the nucleotides, each individual sequence of the non-protein encoding genes (18S rRNA, 28S rRNA and 16S rRNA) was partitioned (using the pound sign ' $\#$ '). In this way isolating homologous fragments, corresponding more-or-less to the stem regions of the DNA, which are more conserved. The loop regions that, contrarily, are more variable, were analyzed with greater certainty of base correspondence. For the protein encoding genes Cytochrome $c$ Oxidase subunit I (COI) e Histone H3 a single fragment was used because these lack any indels (Table 1)

Parameters used for this study follows other works that include parsimonious analysis using POY (e.g., Edgecombe \& Giribet, 2006; 2009; Aktipis et al., 2011; Giribet \& Edgecombe. 2013; Giribet et al., 2014). Each parameter corresponds to different weighting schemes for indel opening, transversions, transitions and indel extensions. Six parameters routinely used were chosen for this study: 
1. 1110 (indel opening cost $=1$; transversions $=$ transitions $=1$; indel extension $\operatorname{cost}=0$ );

2. 2110 (indel opening cost $=2$; transversions $=$ transitions $=1$; indel extension $\operatorname{cost}=0$ );

3. 3221 (indel opening cost $=3$; transversions $=$ transitions $=2$; indel extension $\operatorname{cost}=1$ );

4. 1210 (indel opening cost $=1$; transversions $=2$; transitions $=1$; indel extension $\operatorname{cost}=0$ );

5. 2210 (indel opening cost $=2$; transversions $=2$; transitions $=1$; indel extension $\operatorname{cost}=0$ );

6. 3211 (indel opening cost $=3$; transversions $=2$; transitions $=1$; indel extension $\operatorname{cost}=1$ ).

Nodal support for the optimal parameter set was estimated via jackknifing (50 replicates) with a $50 \%$ of characters removed per pseudo-replicate. Jackknife was estimated via the Cyber infrastructure for Phylogenetic Research (CIPRES) gateway (Miller et al., 2010) (https://www.phylo.org/) for the optimal parameter chosen.

POY Scripts for all analysis are found in the appendix section.

Table 1: Number of taxa and fragments analyzed for each coding or non-coding loci.

\begin{tabular}{l|l|l|l}
\hline 16S rRNA: & 104 taxa & 8 fragments & \multirow{2}{*}{ non-coding } \\
\cline { 1 - 3 } 18S rRNA: & 133 taxa & 9 fragments & \multirow{2}{*}{ 28S rRNA: } \\
\cline { 1 - 3 } Cytochrome $\boldsymbol{c}$ Oxidase COI: & 132 taxa & 17 fragments & \\
\cline { 1 - 3 } Histone H3: & 127 taxa & 1 fragment & \multirow{2}{*}{ coding } \\
\hline
\end{tabular}

\subsection{Parsimony analyses - Total evidence data}

Total evidence analysis, combining the molecular data aforementioned with the morphological data from Chapter I of this dissertation was done in the Cyber infrastructure for Phylogenetic Research (CIPRES) portal (Miller et al., 2010). For the morphological methodology, character descriptions, and morphological matrix, refer to chapter I. The weighting scheme parameter was the same as specified for the molecular analysis.

Out of the 140 taxa analyzed for both the molecular ad the morphological part, eight species were excluded, because they lacked any molecular data: Pugilina tupiniquim, Engoniophos unicinctus, Bullia laevissima, Pisania pusio, Fusinus marmoratus, Fusinus sp., Hemipolygona beckyae and Pustulatirus mediamericanus. This was opted because the results obtained with the inclusion of these species did not provide any information on their position, and sometimes with misleading topologies. Table 2 lists all taxa for the total evidence analysis. 
Table 2: Taxa used for morphological (chapter I) and molecular analyses. All taxa from the Molecular column were employed in the total evidence analysis. Shadings: light grey, same-genus species; dark grey, outgroup species.

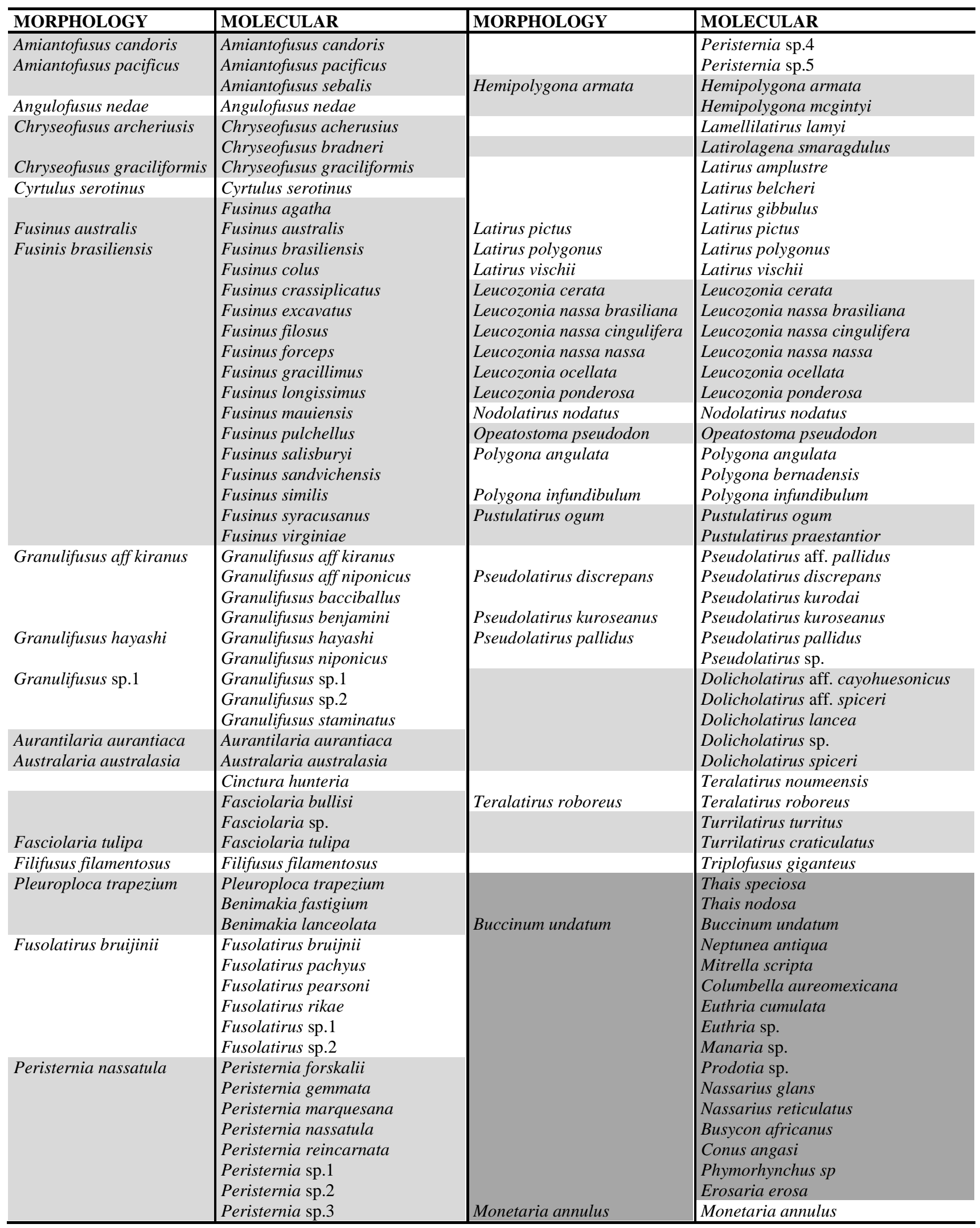




\section{Results}

The tree obtained through the molecular data of five loci is shown in Figure 1, using a parsimony criterion of direct optimization as implemented in POY 5.1.1. Jackknife support is indicated above each node; this tree was obtained through the optimal parameter set as discussed hereinafter.

One parameter set, 3221, follows the proposal of DeLaet (2005) in which gap openings are assigned a cost of 3 , nucleotide transformations (transversions $=$ transitions) are assigned a cost of 2 and gap extensions cost is 1 . This was the parameter chosen (and the resulting tree hypothesis), and was also the one used for fissurellid gastropods in Aktipis et al. (2011).

Usually in the case of multiple parameters, a sensitivity analysis (Wheeler, 1995) is done in order to determine the best tree. However this was not the case here as one can explore an infinite number of parameters given an infinite number of hypotheses and still the choice is an arbitrary one: sensitivity analysis is therefore independent of hypothesis selection (Giribet, 2003). The optimality criterion aims at choosing the optimal set of parameters (among the explored ones) for a given data set, i.e., the parameters that maximize precision among partitions (the agreement among data, using an ILD-derived index: Wheeler, 1995; DeLaet, 2005; 2014).

As mentioned above, sensitivity analyses do not conflict with the notion of choosing the best (most corroborated) phylogenetic hypothesis (i.e., the tree obtained under the most congruent parameter set or under the most likely model). Sometimes several trees are presented simultaneously, usually side by side with the strict consensus of all the analyzed parameters (Wheeler, 1995; Wheeler \& Hayashi, 1998; Edgecombe et al., 1999, 2002; Giribet \& Boyer, 2002; Giribet \& Wheeler, 2002). Figures 2-6 illustrate the chosen hypothesis tree plotted with Navajo rugs: a graphic representation in which the parameter space (including the ML and the BI analyses of Couto et al., 2016) is represented as a grid with each square corresponding to a different parameter (as evidenced in the bottom right). Filled squares indicate that the node is corroborated for the specified hypothesis.

The molecular results evidence three major well-supported deep clades of Fasciolariidae, but none of these correspond to the traditional contents of the recognized subfamilies, apart from the clade of Dolicholatirus and Teralatirus species. A first split (corroborated in all but parameter 3211) divides fasciolariids into a clade mostly corresponding to Fusininae, but also including the 
clearly non-monophyletic genus Pseudolatirus traditionally classified in the Peristerniinae. Because this clade includes Fusinus colus, the type species of Fusinus (type genus of Fusininae), it is henceforth referred to as the Fusinus colus clade. Fasciolariinae, which appears monophyletic and fully supported in all parameter sets, is nested within a subclade of Fasciolariinae and Peristerniinae; as it includes Fasciolaria tulipa, the type species of Fasciolaria (type genus of Fasciolariinae), we will refer to it as the Fasciolaria tulipa clade. Finally, its sister group is a fully supported clade containing various taxa of Peristerniinae; as it includes Peristernia nassatula the type species of Peristernia (type genus of Peristerniinae), we will refer to it as the Peristernia nassatula clade.

The clade containing Dolicholatirus and Teralatirus was highly supported, its monophyly confirmed in all parameters, despite not included in Fasciolariidae. Its position varied among parameter sets, however.

Total evidence analysis based on the parameter 3221 is shown in the Figure 7. This is the most complete analysis of the family Fasciolariidae: five molecular loci (totaling circa $5.3 \mathrm{kbp}$ ) and 95 morphological characters. The topology evidences the same major clades as the previous molecular analysis and those of Couto et al. (2016): A Fusinus colus clade, a Peristernia nassatula clade, a Fasciolaria tulipa clade and a Dolicholatirus and Teralatirus clade. The latter one was shown to be monophyletic, but not belonging to the family Fasciolariidae. 


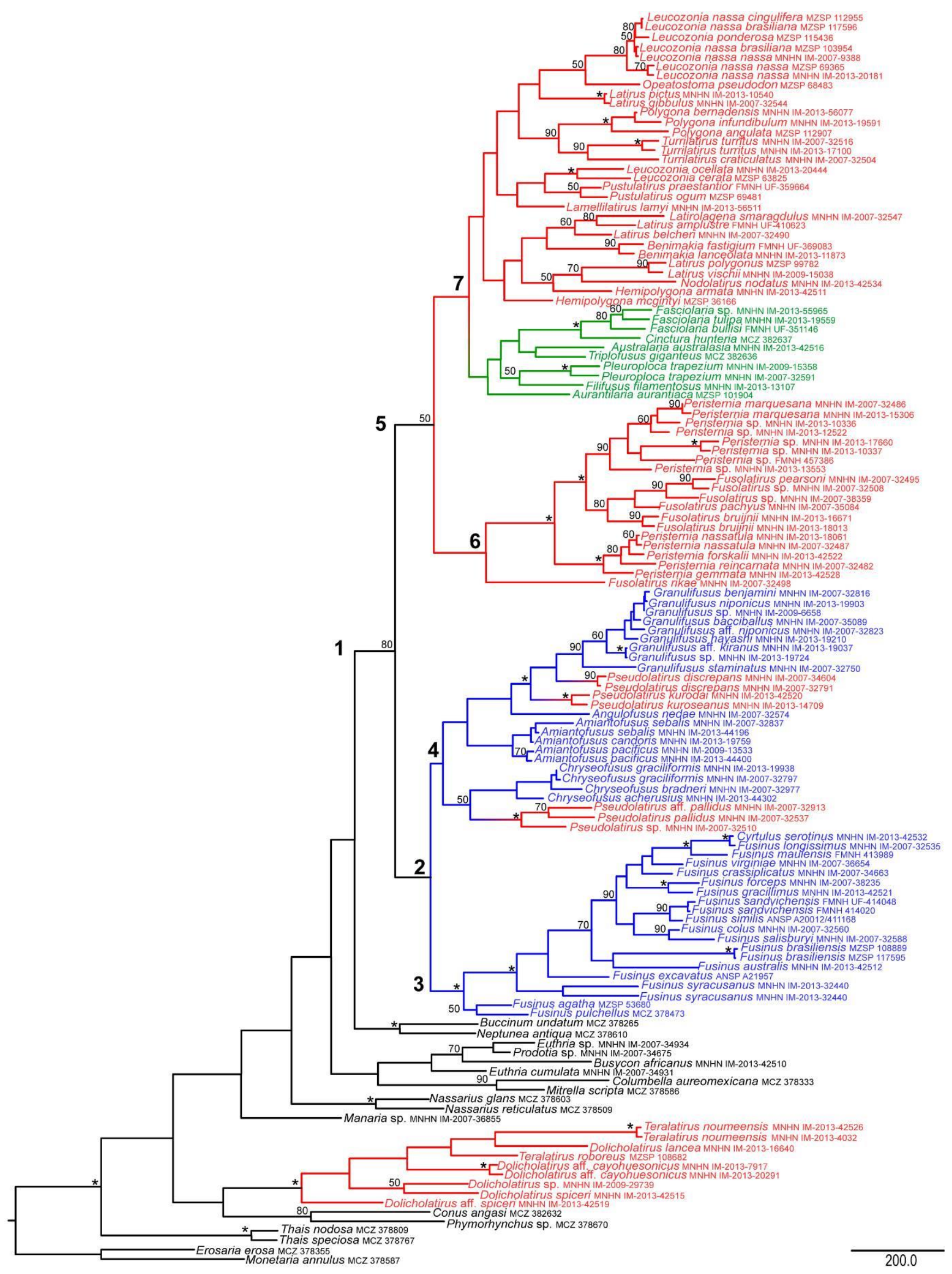

Figure 1. Phylogenetic relationships based on a parsimonious analysis done in POY under parameter 3221. Small numbers on nodes indicate jackknife support, only supports over 50 are shown, * indicate full support. Color scheme: Black: non-fasciolariids. Blue: fusinines. Red: peristerniines. Green: fasciolariines. 


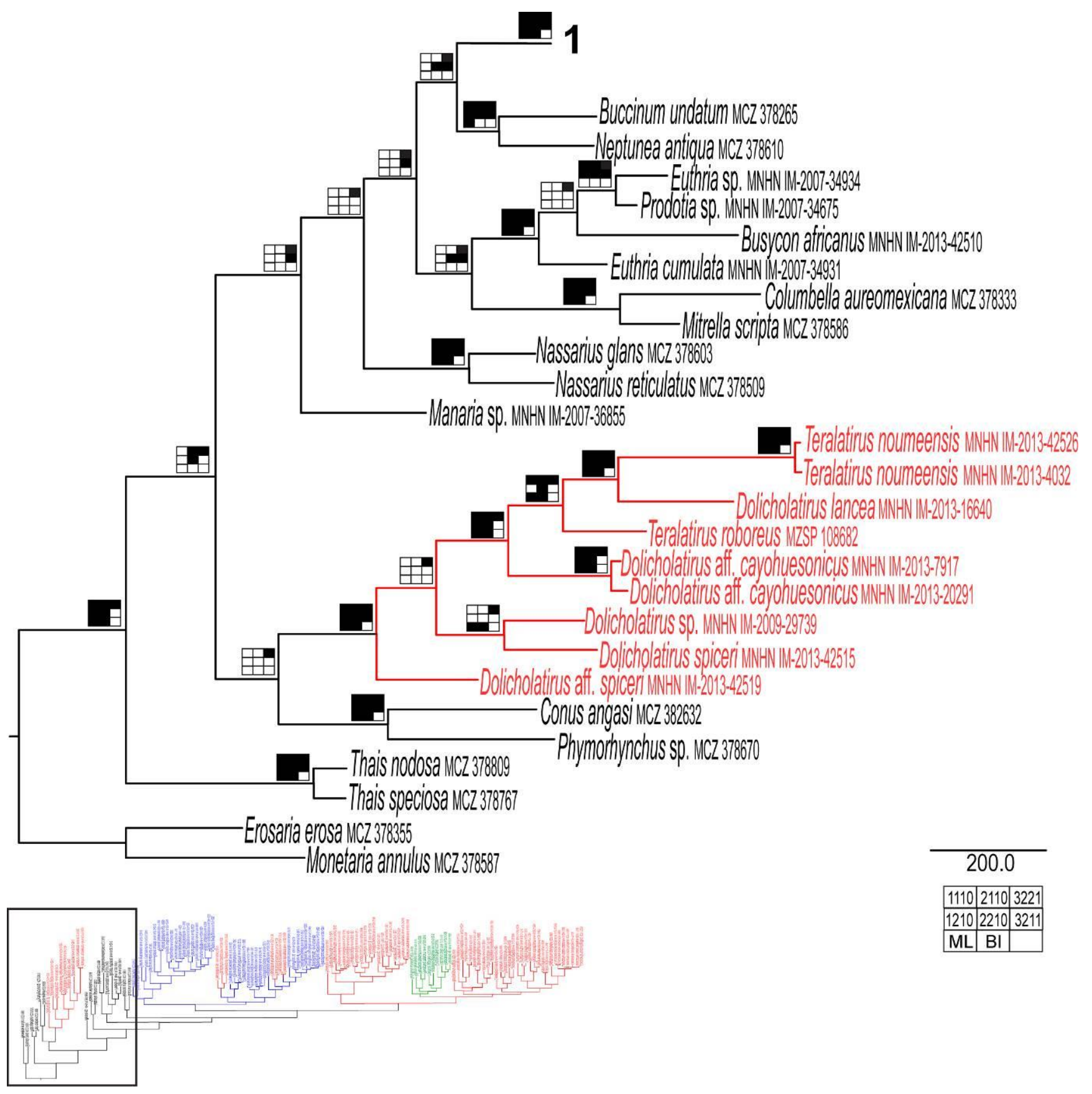

Figure 2. Phylogenetic relationships (part one) based on a parsimonious analysis done in POY under parameter 3221. Navajo rugs indicate support for the given parameter (bottom right). Node numbers are the same across all figures. Color scheme: Black: non-fasciolariids. Blue: fusinines. Red: peristerniines. Green: fasciolariines. 


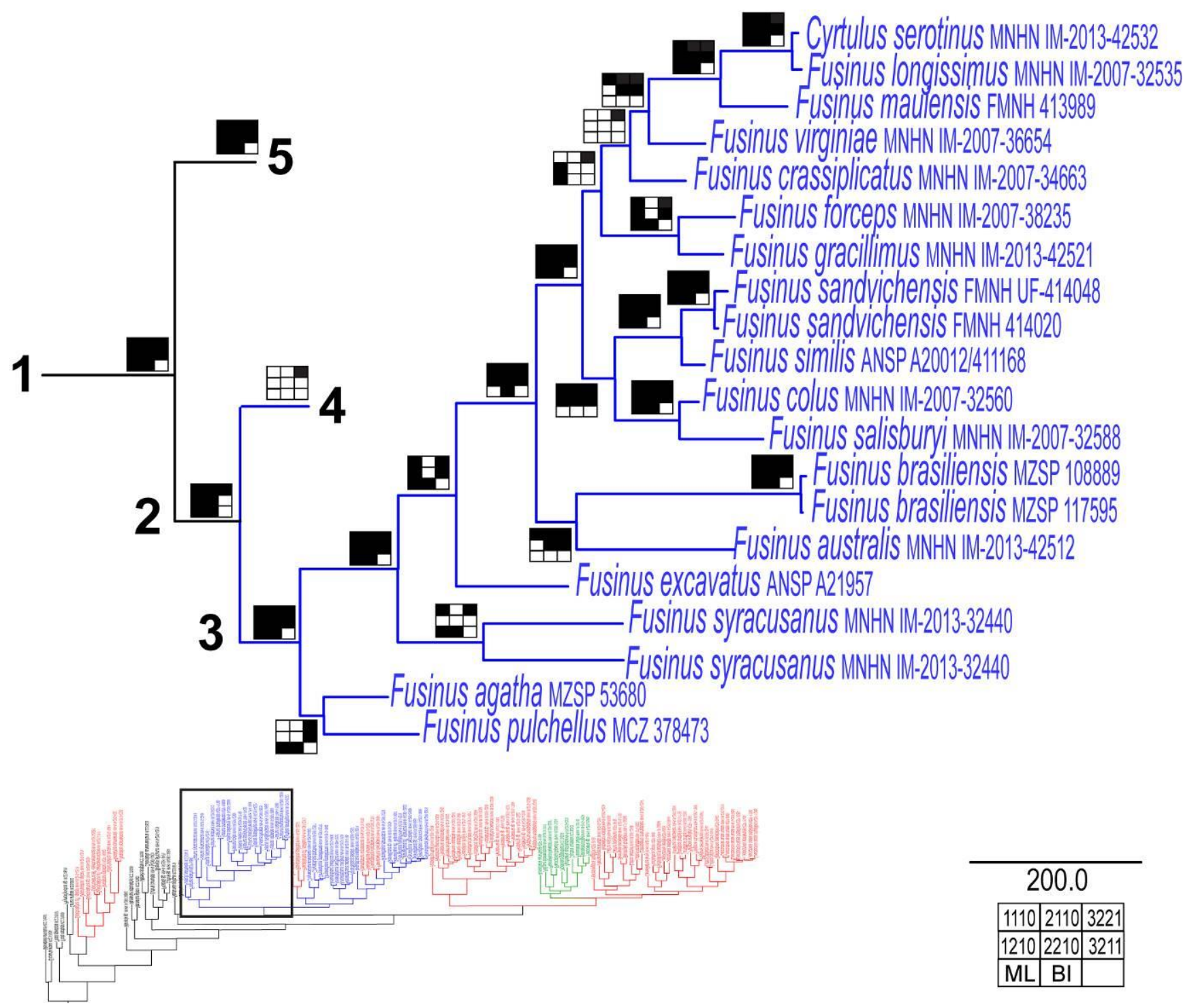

Figure 3. Phylogenetic relationships (part two) based on a parsimonious analysis done in POY under parameter 3221. Navajo rugs indicate support for the given parameter (bottom right). Node numbers are the same across all figures. Color scheme: Black: non-fasciolariids. Blue: fusinines. Red: peristerniines. Green: fasciolariines. 


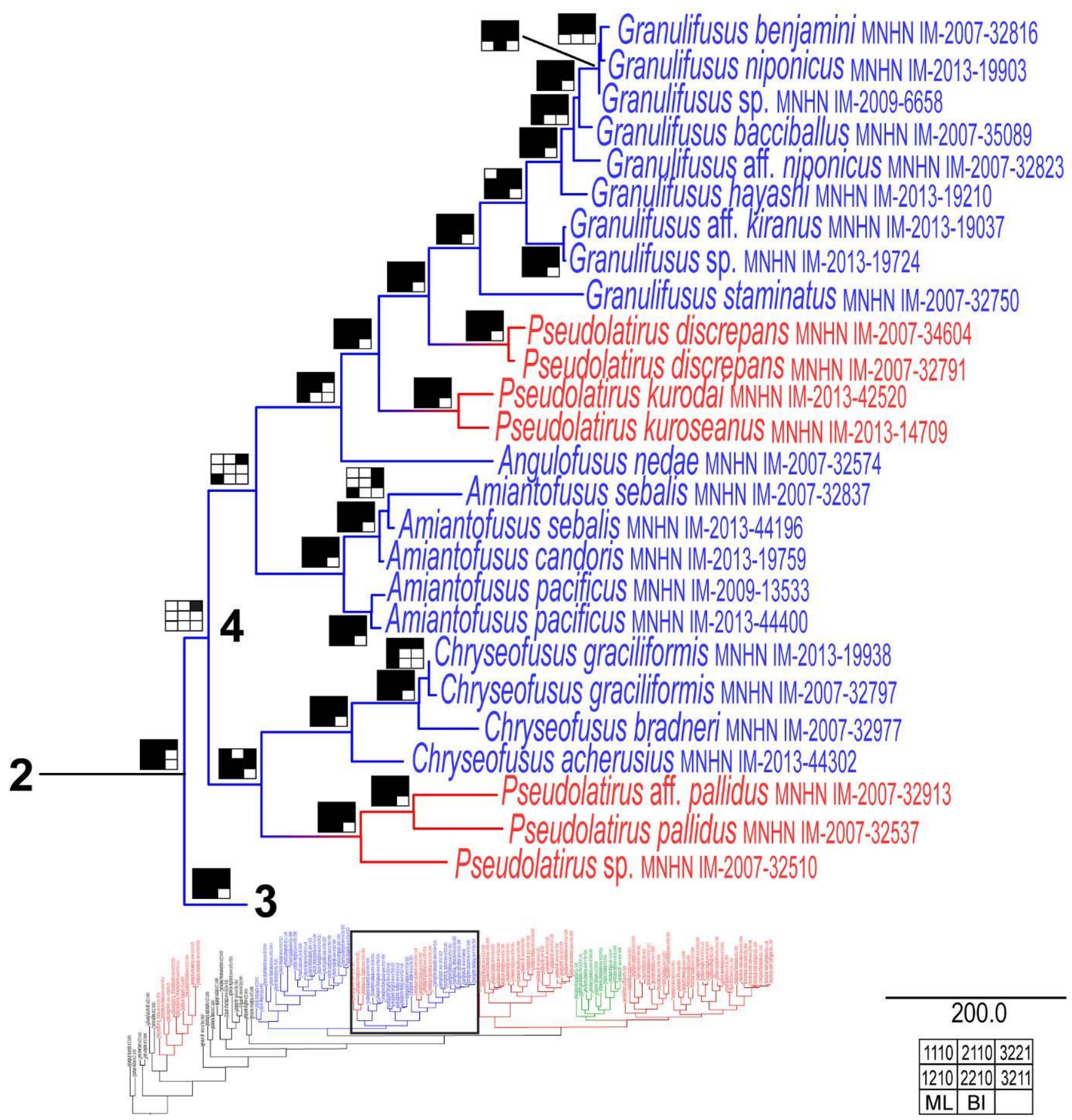

Figure 4. Phylogenetic relationships (part three) based on a parsimonious analysis done in POY under parameter 3221. Navajo rugs indicate support for the given parameter (bottom right). Node numbers are the same across all figures. Color scheme: Black: non-fasciolariids. Blue: fusinines. Red: peristerniines. Green: fasciolariines. 


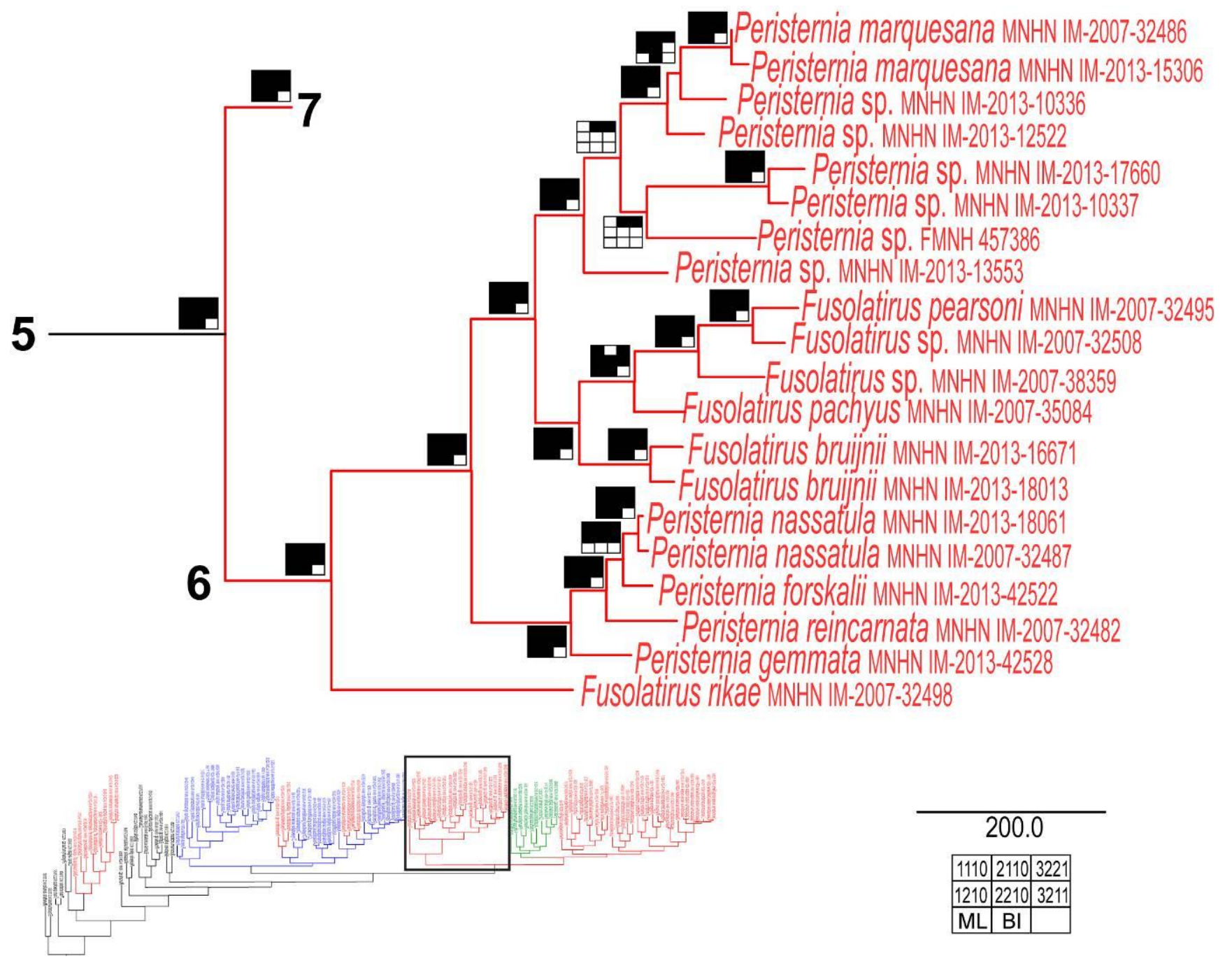

Figure 5. Phylogenetic relationships (part four) based on a parsimonious analysis done in POY under parameter 3221. Navajo rugs indicate support for the given parameter (bottom right). Node numbers are the same across all figures. Color scheme: Black: non-fasciolariids. Blue: fusinines. Red: peristerniines. Green: fasciolariines.

Figure 6 (following page). Phylogenetic relationships (part five) based on a parsimonious analysis done in POY under parameter 3221. Navajo rugs indicate support for the given parameter (bottom right) Node numbers are the same across all figures. Color scheme: Black: non-fasciolariids. Blue: fusinines. Red: peristerniines. Green: fasciolariines. 

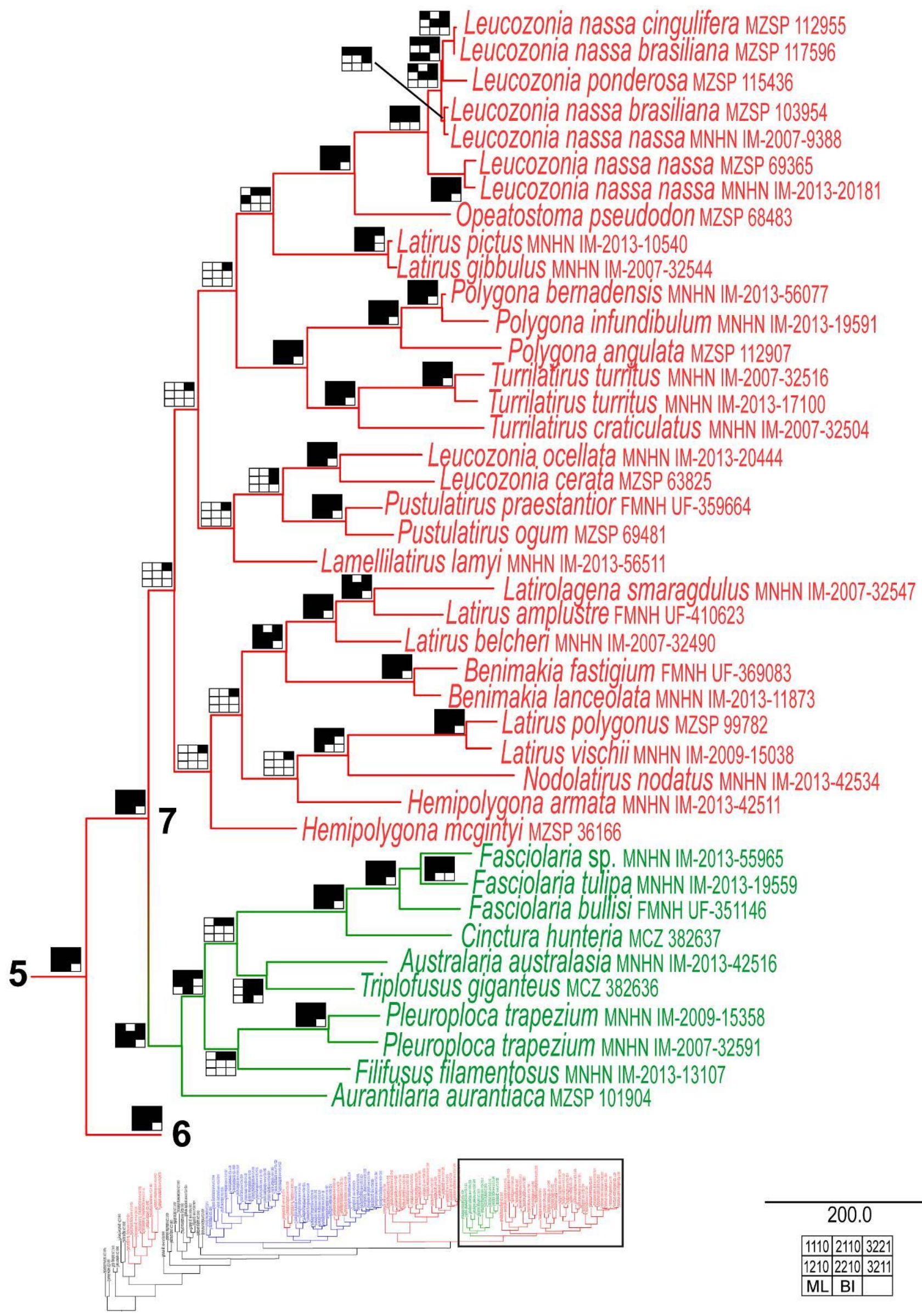

200.0

\begin{tabular}{|l|l|l|l|}
\hline 1110 & 2110 & 3221 \\
\hline
\end{tabular} \begin{tabular}{|l|l|l|}
\hline 1210 & 2210 & 3211 \\
\hline
\end{tabular} \begin{tabular}{|l|l|l|}
\hline $\mathrm{ML}$ & $\mathrm{BI}$ & \\
\hline
\end{tabular} 


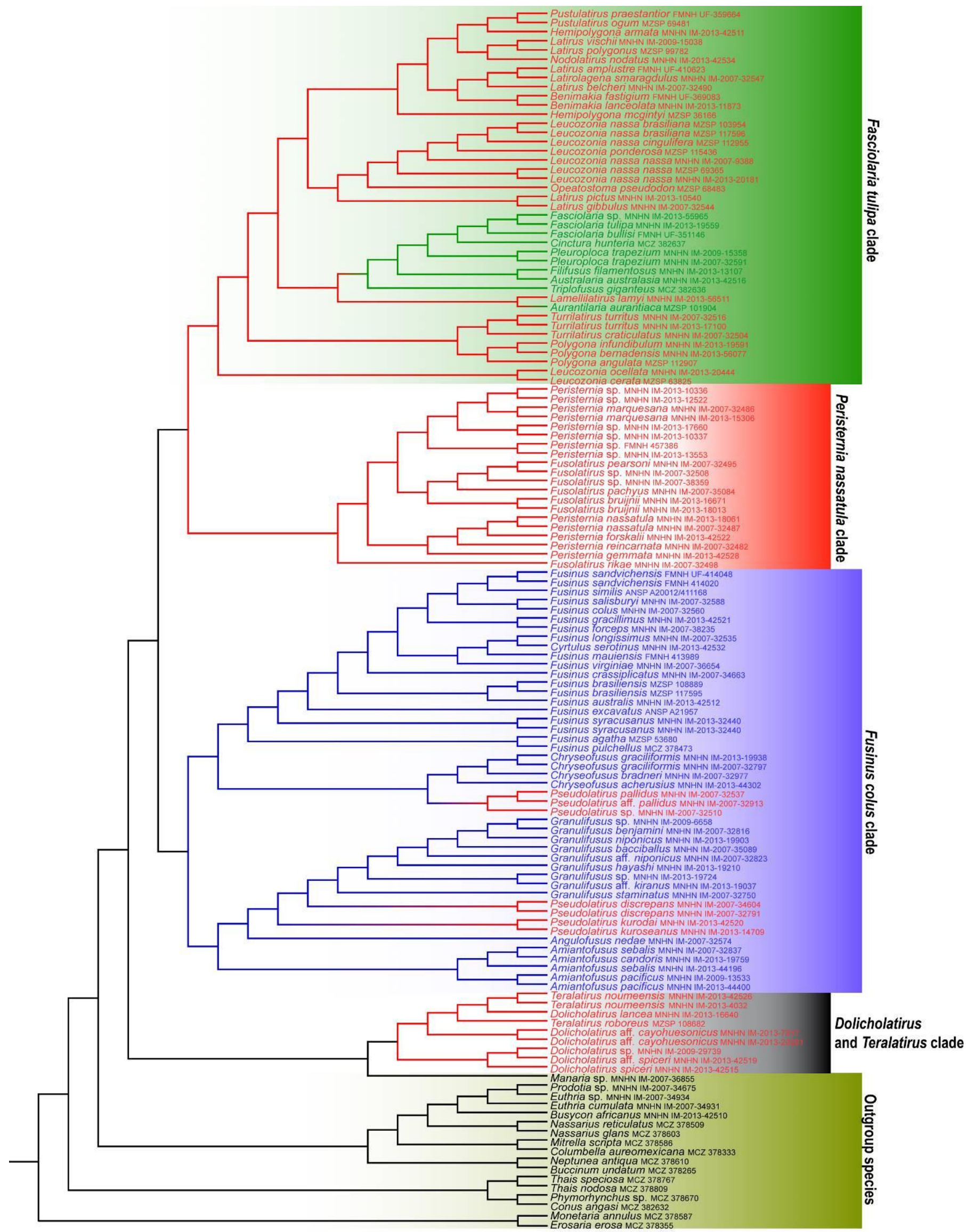

Figure 7. Phylogenetic relationships of Fasciolariidae for the total evidence analysis as implemented in POY under parameter 3221. Color scheme for text: Black: non-fasciolariids. Blue: fusinines. Red: peristerniines. Green: fasciolariines. Color shadings for each clade represent the supported clades. 


\section{Discussion}

This is the most extensive phylogenetic analysis of the family Fasciolariidae endeavored to date being the first to include morphological and molecular data in a combined analysis. Within this brief section will be discussed the main differences and similarities between the total evidence analysis done in POY (Fig. 7) with the morphological analysis from Chapter I of this dissertation; a more extensive taxonomical and morphological discussion is also undertaken at the Chapter I. It is for the sake of readability that the section will be divided into the four main clades plus the outgroup species.

\subsection{Outgroup species}

Muricoids (species of Thais, Muricidae) and Conoids (Conus angasi and Phymorhynchus sp.) form a monophyletic group, that is the sister group of the remaining buccinoids, including Buccinidae, Nassariidae, Columbellidae and Fasciolariidae families. This agrees with Strong (2003), in which Buccinoidea is the sister taxon of Conoidea and Muricoidea in a polytomy. However, this scenario does not concur with Ponder \& Lindberg (1997: Buccinoidea + Muricoidea sister to Cancellarioidea) or Simone (2011: Muricoidea + Cancellarioidea sister to Conoidea), but because very few taxa were sampled, it is not possible to make a concrete inference.

As with most analyses discussed so far, Buccinidae is not monophyletic, and in this case, assumes a polyphyletic state, with species of Nassariidae and Columbellidae intercalating buccinid species.

The inclusion of morphological data from outgroup species reveals the incongruence between the molecular data and morphology, as the achieved topology was not recovered in any of the analyzed weighting parameters or from Couto et al. (2016).

\subsection{Dolicholatirus and Teralatirus clade}

The clade containing species of the Fasciolariidae sensu lato Dolicholatirus and Teralatirus forms the sister group of a buccinid, Manaria sp. This genus possess species which superficially resemble fasciolariids, more specifically the genus Amiantofusus, but distinguish from it by the more reticulated shell pattern across the whole of the shell surface (Bouchet \& Warén, 1985). 
Manaria are related to deep-sea buccinids, e.g., Eosipho, Termosipho, etc. (Kantor et al., 2013) and are very conchologically similar to Amiantofusus.

In all analyses (morphological, molecular, total evidence) the clade of Dolicholatirus and Teralatirus appear as highly supported, with virtually the same topology; neither genera is monophyletic. No further insights into the group may be given that have not already been done in Chapter I of this dissertation.

\subsection{Fusinus colus clade}

The combined molecular and morphological dataset evidences two main groups: a first split separates the more fusiform shells of the genera Fusinus, Cyrtulus and Chryseofusus (corresponding to clade 3a from Chapter I), from the remaining genera Amiantofusus, Angulofusus and Granulifusus. The polyphyletic genus Pseudolatirus corresponds to two lineages, being related to Chryseofusus and the other to Granulifusus, much like discussed in Chapter I and in Couto et al. (2016).

\subsection{Peristernia nassatula clade}

This clade groups Peristernia and Fusolatirus species. Clade 5a from Chapter I, is highly supported in both analyses of Couto et al. (2016) and in the parsimony analysis done in POY. The topology within this node is virtually identical among all analyses, which shows the congruence between the analyzed genes and morphology.

\subsection{Fasciolaria tulipa clade}

This clade has suffered the most modifications from the inclusion of morphological data in the analysis. As with the previous cases, the deep nodes evidenced much incongruence among the topologies, with each parameter analyzed generating a different relationship scheme, and different hypotheses of relation between the ML and the BI analysis of Couto et al. (2016).

Because the bulk of the peristerniines (clade 7 of Chapter I) appeared as a grade in the morphological analysis, only a few clades matched those of the combined dataset analysis. Clade 14 containing the genera Leucozonia and Opeatostoma was well recovered in both topologies, while clade $6 \mathrm{~d}$ containing the precious fasciolariines, but here is included Lamellilatirus lamyi. Lyons \& Snyder (2007) described the genus Lamellilatirus (type Fusus ceramidus Dall, 1889) 
distinguishing it from Fusinus because of its peristerniine-like radula (ten cusps in the wide laterals, three cusps in the rachidian). The radula of Lamellilatirus ceramidus (Lyons \& Snyder, 2007: fig. 3a) indeed resembles a typical peristerniine, lacking the gradual increase in the lateral inner cusps like Fusinus and the reduced cusp one of the lateral (resembling somewhat Hemipolygona armata and Pustulatirus ogum (Figs. 80, 83, Chapter I). The species L. lamyi was not analyzed morphologically, but if the radula resembles L. ceramidus, as illustrated by Lyons \& Snyder (2007), than likely this species would be placed near clade 7 (Fig. 6, Chapter I). Another prospect is that this is the plesiomorphic radula type for this clade. The type species of Lamellilatirus lamyi (https://science.mnhn.fr/institution/mnhn/collection/im/item/2000-25714) resembles Hemipolygona armata.

Based on the total evidence analysis, the clade of Dolicholatirus and Teralatirus does not belong to Fasciolariidae, despite morphological evidence. The results obtained through the molecular dataset show a strong dissimilarity between Dolicholatirus/Teralatirus species from the remaining taxa, while exhibiting a strong affinity among themselves. This can be easily observed in the individual gene analyses of Couto et al. (2016: suppl. mat. 1-5): in all trees, Dolicholatirus and Teralatirus is well supported (in detriment to most of the other major groups).

The inclusion of morphological data has done little in altering the topology of the three major clades of Fasciolariidae. All three main clades suffered minor modifications internally but remained with the same inclusion of taxa as in the molecular analysis. However, with the inclusion of molecular data, the morphological tree suffered more drastically.

The main difference in Fasciolariidae that occurs for the analyzed molecular dataset (including the total evidence analysis) from the morphological dataset occurs within the clade of fusinines: in the first it is a crown-group, sister to the remaining fasciolariids, while in the latter it is a stem-group, comprising of three major clades (the clade of mainly Amiantofusus, Chryseofusus and Fusinus, and a clade of Granulifusus). The other major groups, Peristernia and Fusolatirus and Fasciolariinae remained more-or-less stable for morphological and most molecular analyses. 


\section{Conclusions}

1. The molecular data was more determinant for the final topology than the morphological data;

2. Dolicholatirus and Teralatirus form a monophyletic group, external to Fasciolariidae;

3. The remaining fasciolariids were recovered as a monophyletic clade that fall into three main clades that correspond to the three currently recognized subfamilies, but with their taxonomic extension considerably revised;

4. The Fusinus colus clade, containing all the Fusininae, consisting of five major lineages corresponding to the genera Amiantofusus, Angulofusus, Chryseofusus, Fusinus and Granulifusus, and also including the non-monophyletic Pseudolatirus;

5. Pseudolatirus, a polyphyletic fusinine genus, is present in two lineages: related to Chryseofusus and another to Granulifusus;

6. The Peristernia nassatula clade, consisting of the non-monophyletic genera Peristernia and Fusolatirus; the name Peristerniinae can be retained for this clade;

7. The Fasciolaria tulipa clade, consisting of a monophyletic Fasciolaria-Pleuroploca clade and many other genera currently classified as peristerniines; the taxonomic extension of the subfamily Fasciolariinae can be revised to encompass this third clade;

8. The Fasciolaria - Pleuroploca clade also groups Lamellilatirus lamyi;

9. The genus Leucozonia is non-monophyletic; L. cerata - L. ocellata forms a monophyletic group; the L. nassa complex forms a monophyletic clade that is sister of Opeatostoma pseudodon;

10. The genera Latirus and Hemipolygona are polyphyletic; 


\section{References}

Aktipis S.W., Boehm E. \& Giribet G. 2011. Another step towards understanding the slit-limpets (Fissurellidae, Fissurelloidea, Vetigastropoda, Gastropoda): A combined five-gene molecular phylogeny. Zoologica Scripta, 40(3): 238-259. http://doi.org/10.1111/j.14636409.2010.00468.x.

Bouchet P. \& Warén A. 1985. Revision of the Northeast Atlantic bathyal and abyssal Neogastropoda excluding Turridae (Mollusca, Gastropoda). Bollettino Malacologico (Suppl 1): 1-296.

Couto D.R., Bouchet P., Kantor Y.I., Simone L.R.L. \& Giribet G. 2016. A multilocus molecular phylogeny of Fasciolariidae (Neogastropoda: Buccinoidea). Molecular phylogenetics and evolution, 99: 309-322.

De Laet J. 2005. Parsimony and the problem of inapplicables in sequence data. In: Albert V.A. $(E d)$, Parsimony, phylogeny, and genomics. Oxford, Oxford University Press. p. 81-116.

De Laet J. 2014. Parsimony analysis of unaligned sequence data: Maximization of homology and minimization of homoplasy, not minimization of operationally defined total cost or minimization of equally weighted transformations. Cladistics, 31(5): 550-567, 2015. http://doi.org/10.1111/cla.12098.

Edgecombe G.D. \& Giribet G. 2006. A century later - A total evidence re-evaluation of the phylogeny of scutigeromorph centipedes (Myriapoda: Chilopoda). Invertebrate Systematics, 20(5): 503-525. http://doi.org/10.1071/IS05044.

Edgecombe G.D. \& Giribet G. 2009. Phylogenetics of scutigeromorph centipedes (Myriapoda: Chilopoda) with implications for species delimitation and historical biogeography of the Australian and New Caledonian faunas. Cladistics, 25(4): 406-427. http://doi.org/10.1111/j.1096-0031.2009.00253.x.

Edgecombe G.D., Giribet G. \& Wheeler W.C. 1999. Phylogeny of Chilopoda: Combining 18S and 28S rRNA sequences and mor- phology. In: Melic A., De Haro J.J., Mendes, M. \& 
Ribera I. (Eds). Evolución y Filogenia de Arthropoda, Boletín de la Sociedad Entomológica Aragonesa 26: 293-331.

Edgecombe G.D., Giribet G. \& Wheeler W.C. 2002. Phylogeny of Henicopidae (Chilopoda: Lithobiomorpha): A combined analysis of morphology and five molecular loci. Systematic Entomology 27: 31-64.

Giribet G. 2003. Stability in phylogenetic formulations and its relationship to nodal support. Systematic Biology, 52(4): 554-564.

Giribet G. \& Boyer S.L. 2002. A cladistic analysis of the cyphophthalmid genera (Opiliones, Cyphophthalmi). Journal of Arachnology, 30(1): 110-128.

Giribet G. \& Edgecombe G.D. 2013. Stable phylogenetic patterns in scutigeromorph centipedes (Myriapoda: Chilopoda: Scutigeromorpha): dating the diversification of an ancient lineage of terrestrial arthropods. Invertebrate Systematics, 27: 485-501.

Giribet G., Edgecombe G.D. \& Wheeler W.C. 2001. Arthropod Phylogeny Based on Eight Molecular Loci and Morphology. Nature, 413: 157-161.

Giribet G., Edgecombe G.D., Wheeler W.C. \& Babbitt C. 2002. Phylogeny and Systematic Position of Opiliones: A Combined Analysis of Chelicerate Relationships Using Morphological and Molecular data. Cladistics, 18: 5-70.

Giribet G., McIntyre E., Christian E., Espinasa L., Ferreira R.L., Francke O.F., Harvey M.S., Isaia M., Kováč L., McCutchen L., Souza M.F.V.R. \& Zagmajster M. 2014. The first phylogenetic analysis of Palpigradi (Arachnida) - The most enigmatic arthropod order. Invertebrate Systematics, 28: 350-360. http://doi.org/10.1071/IS13057.

Giribet G. \& Wheeler W.C. 2002. On bivalve phylogeny: a high-level analysis of the Bivalvia (Mollusca) based on combined morphology and DNA sequence data. Invertebrate Biology, 121(4): 271-324. http://doi.org/10.1111/j.1744-7410.2002.tb00132.x. 
Kantor Y.I., Puillandre N., Fraussen K., Fedosov A. \& Bouchet P. 2013. Deep-water Buccinidae (Gastropoda: Neogastropoda) from sunken wood, vents and seeps: molecular phylogeny and taxonomy. Journal of the Marine Biological Association of the United Kingdom, 93(8): 2177-2195. http://doi.org/10.1017/S0025315413000672.

Lyons W.G. \& Snyder M.A. 2007. New genera and species of Peristerniinae (Gastropoda: Fasciolariidae) from the Caribbean region, with comments on the fasciolariid fauna of Bermuda. The Veliger, 50(3): 225-240.

Miller M.A., Pfeiffer W. \& Schwartz T. 2010. Creating the CIPRES Science Gateway for inference of large phylogenetic trees. Gateway Computing Environments Workshop (GCE), 1-8.

Ponder W.F. \& Lindberg D.R. 1997. Towards a phylogeny of gastropod molluscs: an analysis using morphological characters. Zoological Journal of the Linnaean Society, 119: 83265. http://doi.org/10.1006/zjls.1996.0066.

Simone L.R.L. 2011. Phylogeny of the Caenogastropoda (mollusca), based on comparative morphology. Arquivos de Zoologia, São Paulo, 42(4): 161-323.

Varón A., Vinh L.S. \& Wheeler W.C. 2010. POY version 4: Phylogenetic analysis using dynamic homologies. Cladistics, 26:72-85. http://doi.org/10.1111/j.10960031.2009.00282.x.

Wahlberg N., Braby M.F., Brower A.V.Z., de Jong R., Lee M., Nylin S., Pierce N.E., Sperling F.A.H., Vila R., Warren A.D. \& Zakharov E. 2005. Synergistic Effects of Combining Morphological and Molecular Data in Resolving the Phylogeny of Butterflies and Skippers. Proceedings of the Royal Society of London, B, 272: 1577-1586.

Wheeler W.C. 1995. Sequence alignment, parameter sensitivity, and the phylogenetic analysis of molecular data. Systematic Biology, 44(3): 321-331. http://doi.org/10.1080/ 10635150290155881. 
Wheeler W.C. 1996. Optimization Alignment: the End of Multiple Sequence Alignment in Phylogenetics? Cladistics, 12: 1-9. http://doi.org/10.1006/clad.1996.0001.

Wheeler W.C. \& Hayashi C.Y. 1998. The phylogeny of the extant chelicerate orders. Cladistics, 14(2): 173-192. 
A complement to the phylogenetic analysis of the work of Simone (2011): "Phylogeny of the Caenogastropoda (Mollusca), based on comparative morphology" 


\section{Introduction}

The classification and phylogeny of Caenogastropoda were analyzed by Simone (2011) in his work entitled "Phylogeny of the Caenogastropoda (Mollusca), based on comparative Morphology". This taxon is considered the most diverse among Mollusca, representing more than half of the number of species of the phylum (Ponder et al., 2008, Simone, 2011). Its phylogenetical implications to the morphology and taxonomy in the fasciolariid framework have been extensively discussed in Chapter I of this dissertation.

In Simone`s (2011) work a total 305 species were examined, including representatives of most families of Caenogastropoda, totaling 270 ingroup and 35 outgroups species. The morphological data was compiled through using several anatomical characters, from shell to all soft-parts, including detailed structures of the odontophore and nerve-ring, as well as behavioral and ecological data. In total 676 morphological characters were coded. The polarization was based on non-caenogastropod representatives, comprising of 27 heterobranchs, neritimorphs, cocculiniforms, patellogastropods and vetigastropods; eight representatives of other classes were also included; Rooting was in done in a Polyplacophora. Phylogenetic analysis resulted in 48 most parsimonious trees and the Strict consensus $(L=3.036 ; \mathrm{CI}=51 ; \mathrm{RI}=94)$ was used to discuss groups and character evolution (See Chapter I, Fig. 107).

The Caenogastropoda monophyly is supported by 60 synapomorphies, and this clade is the sister group of Heterobranchia. The paraphyly of architaenoglossates was also corroborated. Among the most relevant results of this analysis is the monophyly of Neogastropoda, which include three superfamilies: Cancellarioidea, Conoidea and Muricoidea. The analysis did not recognize, nor had sufficient taxon sampling at this level, the Buccinoidea as a separate entity, although some representatives were recovered as a monophyletic clade within the superfamily Muricoidea.

The inclusion of more taxa in the analysis will increase the robustness of the analysis. It is likely that an increased pool of representatives, especially of buccinoideans, will corroborate more recent classifications which include Buccinoidea as a separate superfamily (e.g., Bouchet \& Rocroi, 2005; WoRMS, 2016). 


\section{Objectives}

1. To insert the analyzed taxa present in Chapter I of this dissertation in the data matrix of Simone (2011) in order to test the phylogenetic position of Fasciolariidae and consequently, Buccinoidea.

\section{Material and Methods}

The examined material is the same as analyzed in chapter I of this dissertation. These taxa were inserted in the morphological data matrix of Simone (2011).

For full reference of taxa, characters and character states present see Simone (2011); additionally, the following character states were added in order to implement the analysis:

1. Character 98 (Retractor muscles of snout): state 8 (one, inserted laterally).

2. Character 285 (Nephridial gland): state 2 (present, inconspicuous).

3. Character 450 (Salivary ducts): state 5 (free from nerve ring and immersed in esophagus wall).

For search strategies, algorithms and full phylogenetic methodology the reader is referred to the chapter I of this dissertation.

\section{Results}

The traditional search through a TBR algorithm, using prior weighting only (best hit scored 742 times out of 1000 , best TBR $=3207$ [overflow was achieved and trees were than subjected to another round of TBR with the trees stored in memory]), generated 1296 equally parsimonious trees of 5518 steps (L), a consistency index of $28(\mathrm{Ci})$ and a retention index of 92 (Ri). The resulting strict consensus generated a tree with $\mathrm{L}=5533, \mathrm{Ci}=28$ and $\mathrm{Ri}=92$ (Figs. 1, 2).

The topology of the tree (Fig. 1) revealed a monophyletic Buccinoidea and, more inclusively, Fasciolariidae. Thais speciosa (Muricoidea) and Monetaria annulus (Cypraeoidea) are not shown in this clade since they were recovered within cypraeids and muricids, respectively. 
Within Fasciolariidae, many polytomies are present, but few groups are recognizable: 1) The Fusininae clade with three major groups: 1.1) A clade grouping Fusinus, Chryseofusus, Cyrtulus serotinus and Pseudolatirus pallidus; 1.2) Amiantofusus and Pseudolatirus kuroseanus and; 1.3) Granulifusus and Pseudolatirus discrepans. 2) The genus Pustulatirus. 3) A group of mainly Leucozonia species and Opeatostoma pseudodon. 4) Dolicholatirus and Teralatirus and Leucozonia nassa brasiliana and L. ponderosa. 5) The traditional Fasciolariinae, Latirus vischii and Nodolatirus nodatus.

Color scheme used for all terminals and branches in the trees correspond to each of the assigned subfamilies: black: outgroup species, non-fasciolariids; blue: fusinines; red: peristerniines; green: fasciolariines. This does not correspond to the natural subfamilies but the one previously assigned (pre-analysis). 


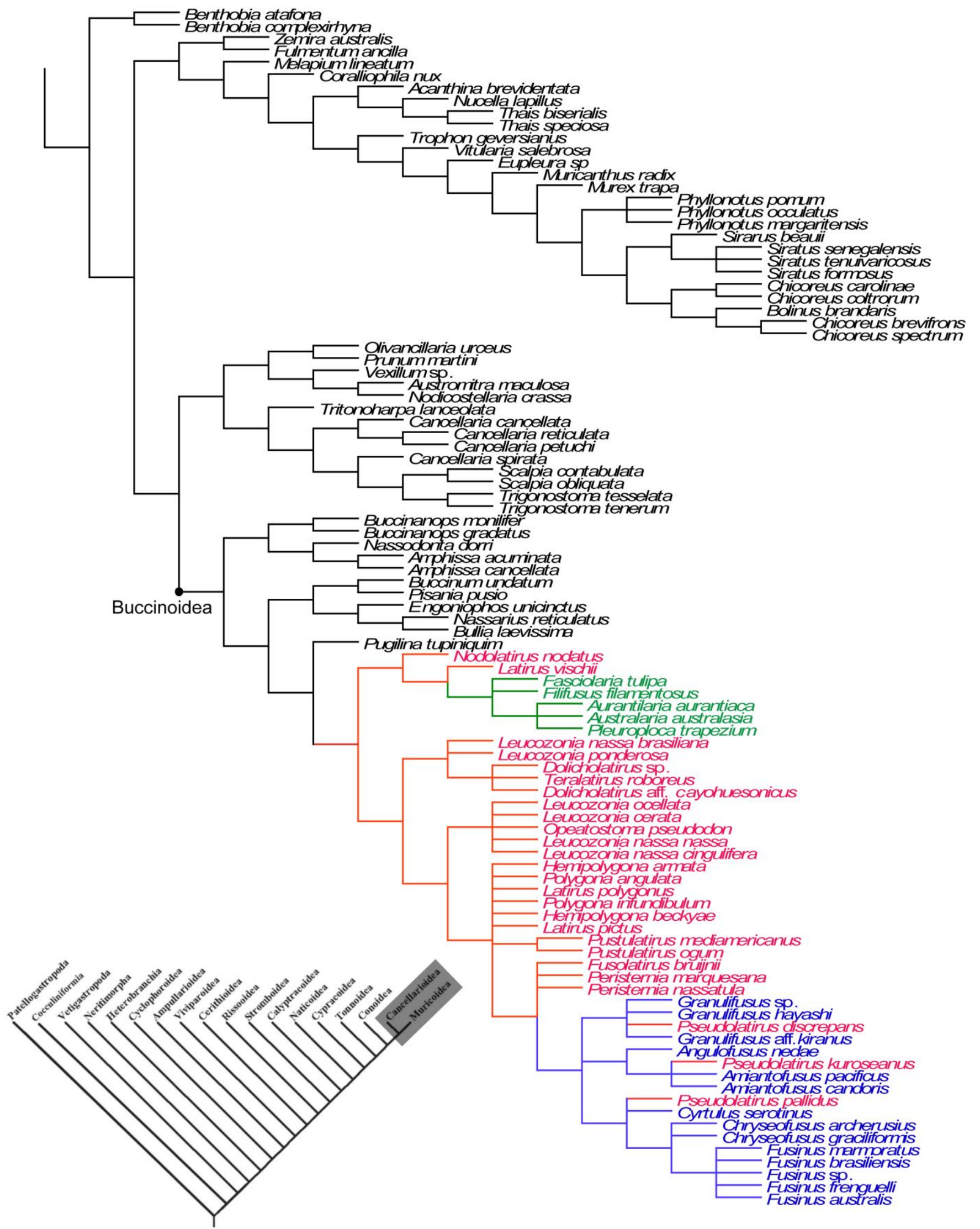

Figure 1: Phylogenetic tree obtained through parsimonious analysis in TnT using prior, unweighted characters; the Fasciolariidae taxa were included in the morphological dataset from Simone (2011). Figure shows clade of Muricoidea and Cancellarioidea (bottom left) in detail. Color reference, see text. 


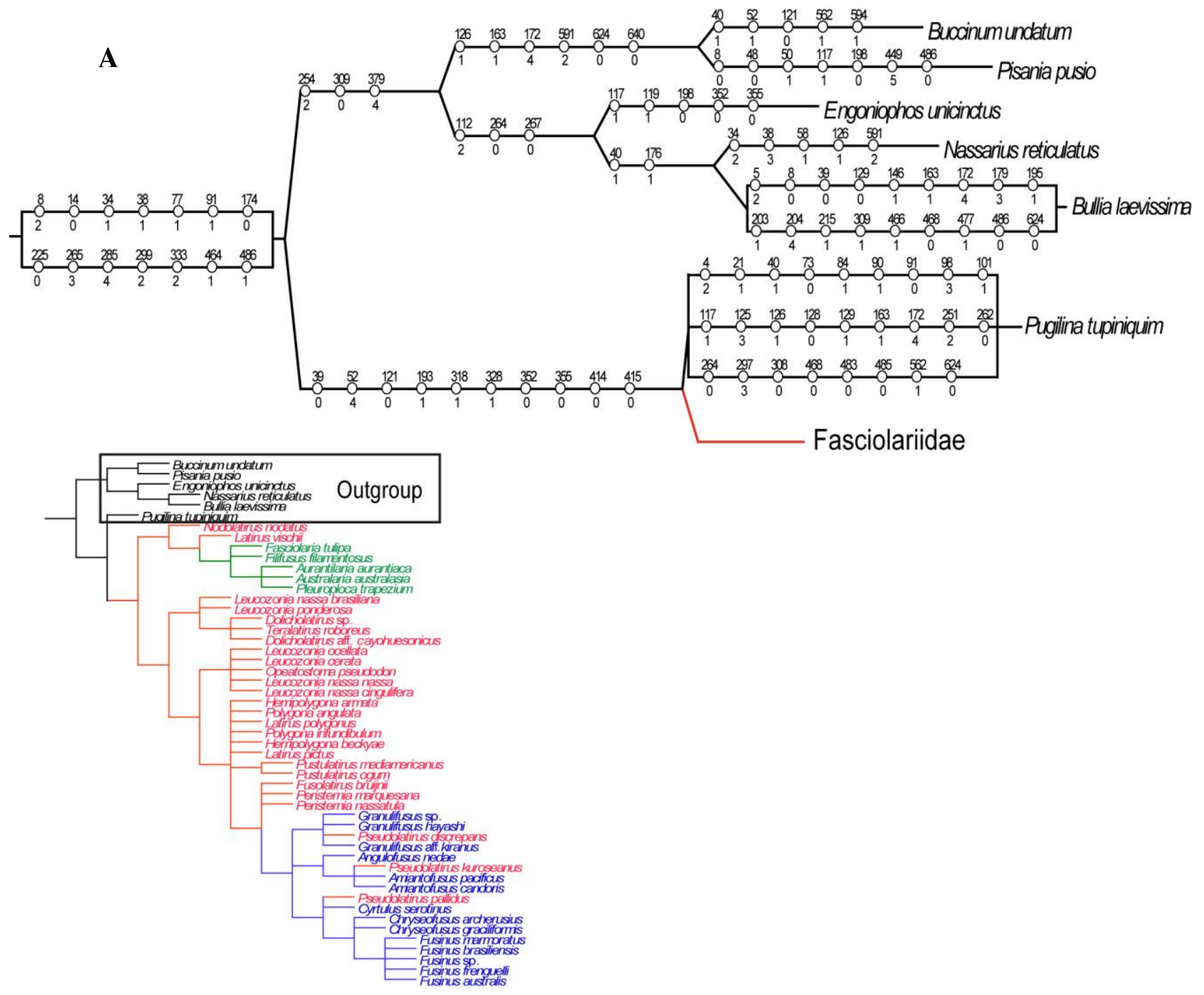

Figure 2A: Phylogenetic tree of the included taxa, with synapomorphies (dark circles) and homoplasies (empty circles). Number above each symbol represents the character, while the number below indicates the character state of according to Simone (2011). Color reference, see text. 


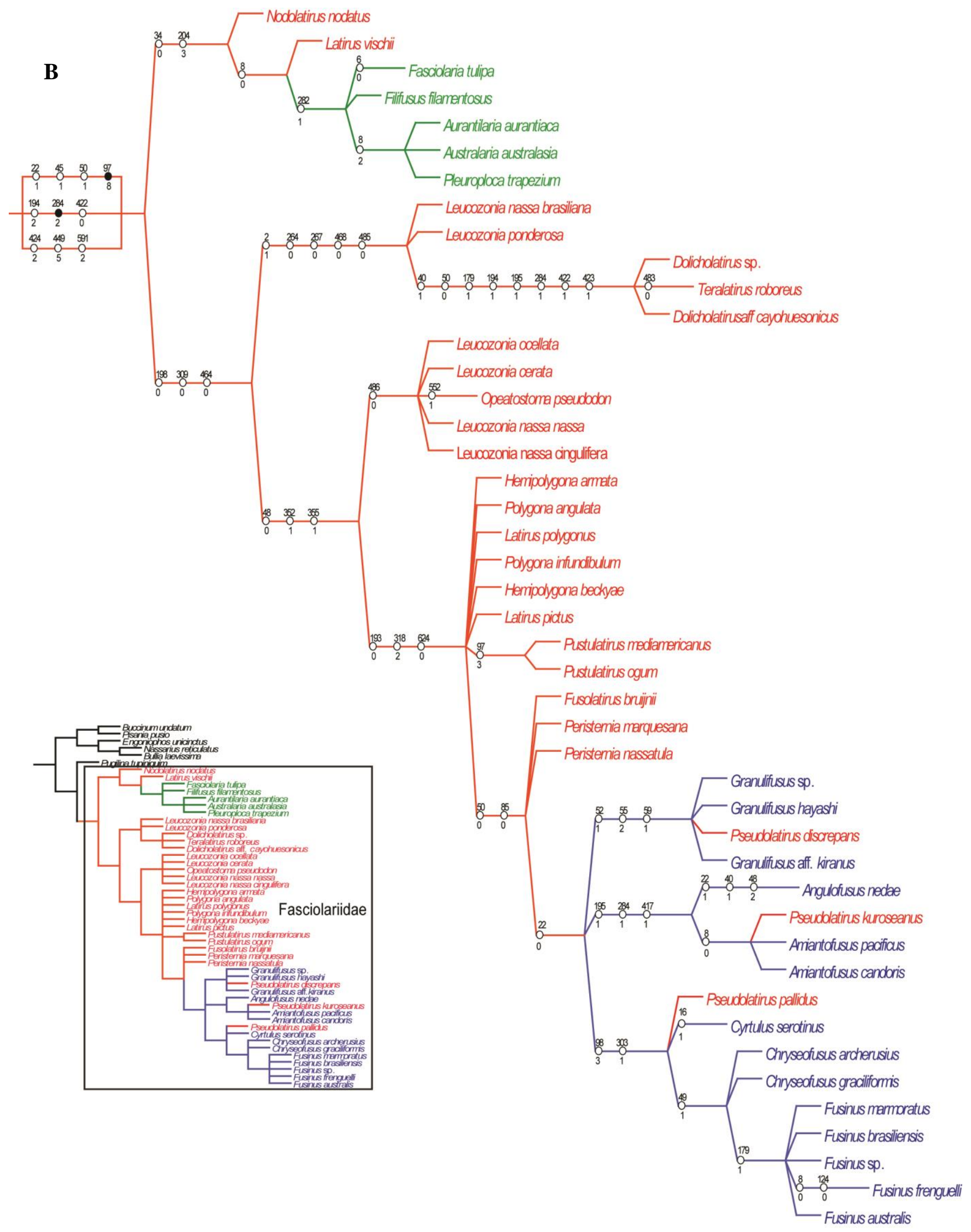

Figure 2B: Phylogenetic tree of the included taxa, with synapomorphies (dark circles) and homoplasies (empty circles). Number above each symbol represents the character, while the number below indicates the character state of according to Simone (2011). Color reference, see text. 


\section{Discussion}

The analysis of Simone (2011) recovered three main clades in Neogastropoda: The first split separates Conoidea from the remaining Cancellarioidea and Muricoidea, although with the taxonomy of ingroup species thoroughly revised (as that would require some taxa to be included in Cancellarioidea, e.g., Cancellaria).

Contrarily, in the present analysis Buccinoidea was recovered monophyletic, with all buccinoid species from Simone (2011) present in this clade: Buccinanops gradatus, B. monolifer, Amphissa acuminata, A. cancellata and Nassodonta dorri. In this context, Cancellarioidea sensu Simone (2011) is the sister group of Buccinoidea, and this is the sister group of Muricoidea (Fig. 1). This in turn would be the sister clade of Conoidea. This scenario of evolution is congruent with the idea that the superfamily Buccinoidea is considered highly derived in the Neogastropoda scheme (due to several losses of typical neogastropod synapomorphies: mainly the accessory salivary glands and the rectal gland [Kantor \& Fedosov, 2009]).

The superfamily was supported by many homoplasies, shown in Fig. 2. Worth noting is the head-foot groove (char 77: 1), the inconspicuous nephridial gland (char 285: 2) and Gland of Leiblein with a long duct (char 486: 1). The gland of Leiblein is highly variable in Neogastropoda; Kantor \& Fedosov (2009) argue in favor of independent origins of the Gland and valve of Leiblein. These authors hypothesized that the Neogastropoda is paraphyletic, mainly because the main synapomorphies that support Neogastropoda are lacking in Buccinoidea (anal gland, accessory salivary glands), since the Gland and Valve of Leiblein are not homologous among the different lineages.

The family Fasciolariidae contained many polytomies in the internal nodes; this is because the characters provided in the dataset from Simone (2011) lack the resolution to clarify the internal relationship among the many lineages. Despite this, there are some striking differences the present analysis has from the one presented in Chapter I. Notable, the clade of Dolicholatirus and Teralatirus is immersed within fasciolariid, not basally, as the analysis in Chapter I. The Fusinines also appeared as a crown group, as opposed to a paraphyletic, stem group. Finally, the Fasciolaria and Pleuroploca clade, despite appearing with the same topology as the previous analysis, represents the first split in the group of Fasciolariids. 
The purpose of this analysis, in verifying the position of the studied Fasciolariidae taxa in a broader context, within Neogastropoda and Buccinoidea, including the dataset from Simone (2011), proved successful. On the other hand, the characters used in this analysis are considered more conservative and, therefore, of limited utility for more inclusive groups, such as the case for fasciolariids.

It is good to remark that this analysis has made possible the resolution of the superfamily Buccinoidea, which was not recovered in the original analysis of Simone (2011). This proves that the inclusion of a variable pool of taxa is needed in order to clarify the relationship of more inclusive groups. The inclusion of more buccinoid taxa will most certainly clarify the relationship between the families contained in the superfamily, proving that an ample taxonomical sampling is vital. 


\subsection{Character matrix}

\begin{tabular}{|c|c|c|c|c|c|c|c|c|c|c|c|c|c|c|c|c|c|c|c|c|c|c|c|c|c|c|c|c|c|c|c|c|c|c|c|}
\hline TAXON & & & & & & 7 & & & & & & & & & & & & & & & & & & & & & & & & & & & & & \\
\hline Monetaria annulus & 4 & 4 & $\overline{0}$ & $\overline{2}$ & 32 & 7 & 0 & & 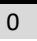 & 0 & - & - & -1 & 0 & 1 & 1 & & & & & & & & & & & & & $\overline{1}$ & & & & & & \\
\hline ais & 4 & 2 & 0 & 0 & 0 & $1 \& 2$ & 0 & & 0 & 0 & & - & -1 & 0 & 0 & 0 & & & & & & 1 & & & & & & & 1 & & & & & & \\
\hline Pugilina tupiniquim & 4 & & 0 & 0 & 2 & $1 \& 2$ & 0 & 2 & 0 & 0 & & . & -0 & 0 & 0 & 0 & & & & & & 0 & & 0 & 1 & & & & 1 & & & & & & \\
\hline ggoniophos unicinctus & 4 & & 0 & & 0 & $1 \& 2$ & 0 & & 0 & & - & - & -0 & & 0 & 0 & & & & & 0 & U & & 0 & 1 & & & & 1 & & & & & 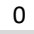 & \\
\hline assarius & 4 & & 0 & & 0 & $1 \& 2$ & 0 & & 0 & & - & & -0 & & 0 & 0 & & & & & U & 0 & & 0 & 1 & 1 & U & & 1 & 1 & & & & 0 & \\
\hline Bullia laevissima & 4 & & 0 & & 02 & $1 \& 2$ & 0 & & 0 & & - & & -0 & 0 & 0 & 0 & & U & & 0 & 0 & 0 & & 0 & 1 & 1 & 0 & 0 & 1 & & & $\mathrm{c}$ & 0 & 0 & \\
\hline Buccin & 4 & & 0 & & 01 & $1 \& 2$ & 0 & & 0 & & & - & -0 & 0 & 0 & 0 & - & U & & 0 & 0 & 0 & & 0 & 1 & 1 & 0 & 0 & 1 & & & c & & J & \\
\hline Pisani & 4 & & 0 & & 01 & $1 \& 2$ & 0 & & 0 & & & - & -0 & 0 & 0 & 0 & & 0 & & 0 & 0 & 0 & & 0 & 1 & $\perp$ & 0 & 0 & 1 & & & C & & 0 & \\
\hline us sp. & 4 & & & & 01 & $1 \& 2$ & 0 & 2 & 0 & & & - & -0 & 0 & 0 & $u$ & & U & & 0 & 1 & 0 & & 0 & 1 & & 0 & & 1 & & & C & & & \\
\hline Teralati & 4 & & & & 0 1 & $1 \& 2$ & 0 & 2 & 0 & & & & -0 & 0 & 0 & 0 & - & 0 & & 0 & 1 & 0 & & 0 & 1 & & 0 & 0 & & & & c & & & \\
\hline olich & 4 & & & & 01 & $1 \& 2$ & 0 & 2 & 0 & & & - & -0 & U & 0 & 0 & - & & & 0 & 1 & 0 & & 0 & 1 & & & 0 & & & & & ) & & \\
\hline & 4 & 1 & 0 & 0 & 01 & $1 \& 2$ & 0 & 2 & 0 & 0 & - & - & -0 & 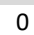 & 0 & 0 & & & & 0 & 1 & 0 & & 0 & 1 & & & 0 & 1 & & & & 0 & & \\
\hline Pset & 4 & 1 & 0 & 0 & D 1 & $1 \& 2$ & 0 & 0 & 0 & 0 & - & - & -0 & 0 & 0 & 0 & & 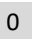 & & 0 & 0 & 0 & & 0 & 1 & 1 & & 0 & 1 & & & & ) & & \\
\hline Amia & 4 & 1 & 0 & 0 & D 1 & $1 \& 2$ & 0 & 0 & 0 & 0 & - & - & -0 & 0 & 0 & 0 & - & 0 & & 0 & 0 & 0 & & 0 & 1 & 1 & 0 & 0 & 1 & & & & 0 & & \\
\hline oris & 4 & 1 & 0 & 0 & 01 & $1 \& 2$ & 0 & 0 & 0 & 0 & - & - & -0 & 0 & 0 & 0 & - & 0 & & 0 & 0 & 0 & & 0 & 1 & 1 & 0 & 0 & 1 & & & & 0 & & \\
\hline lidus & 4 & & 0 & 0 & 01 & $1 \& 2$ & 0 & 2 & 0 & 0 & - & - & -0 & 0 & 0 & 0 & - & 0 & & 0 & 0 & 0 & & 0 & 1 & 1 & 0 & 0 & 1 & & & & 0 & & \\
\hline hry & 4 & & 0 & & $\begin{array}{ll}01 \\
0\end{array}$ & 2 & 0 & & 0 & & - & - & -0 & 0 & 0 & 0 & - & 0 & & 0 & 0 & 0 & & 0 & 1 & 1 & 0 & & & & & C & 0 & & 1 \\
\hline hrys & 4 & 1 & 0 & & $\begin{array}{ll}01 \\
0\end{array}$ & 2 & 0 & & 0 & 0 & - & - & -0 & 0 & 0 & 0 & - & 0 & & 0 & 0 & 0 & & 0 & 1 & 1 & 0 & 0 & 1 & & & c & & & ) 1 \\
\hline Fusin & 4 & & 0 & & $\begin{array}{ll}0 & 1\end{array}$ & $1 \& 2$ & 0 & 2 & 0 & & & - & -0 & 0 & 0 & 0 & - & 0 & & 0 & 0 & 0 & & 0 & 1 & 1 & 0 & & 1 & & & 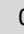 & & & \\
\hline Fusin & 4 & 1 & 0 & 0 & 0 1 & $1 \& 2$ & 0 & 2 & 0 & 0 & - & - & -0 & 0 & 0 & 0 & - & 0 & & 0 & 0 & 0 & & 0 & 1 & 1 & 0 & 0 & 1 & & & C & & & \\
\hline tsi & 4 & 1 & 0 & 0 & 01 & 2 & 0 & 2 & 0 & 0 & - & - & -0 & 0 & 0 & 0 & & & & 0 & 0 & 0 & & 0 & 1 & 1 & 0 & 0 & 1 & & & C & & & \\
\hline Fusi & 4 & & 0 & 0 & 01 & $1 \& 2$ & 0 & 0 & 0 & 0 & - & - & -0 & 0 & 0 & 0 & & 0 & & 0 & 0 & 0 & & 0 & & 1 & 0 & 0 & 1 & & & & & & \\
\hline $\boldsymbol{F}$ & 4 & & 0 & 0 & $\begin{array}{ll}0 & 1\end{array}$ & 2 & 0 & 2 & 0 & 0 & - & - & -0 & 0 & 0 & 0 & & 0 & & 0 & 0 & 0 & & 0 & & 1 & U & 0 & & & & & & & \\
\hline & 4 & & 0 & 0 & 01 & 2 & 0 & 2 & 0 & 0 & - & - & -0 & U & 1 & 0 & -1 & U & & 0 & 0 & 0 & & 0 & & 1 & U & & & & & & & & \\
\hline Gra! & 4 & 1 & 0 & 0 & $\begin{array}{ll}0 & 1\end{array}$ & $1 \& 2$ & 0 & 2 & 0 & 0 & - & - & -0 & 0 & 0 & 0 & & & & 0 & 0 & 0 & & 0 & 1 & 1 & 0 & 0 & 1 & & & & 0 & & \\
\hline Gra & 4 & 1 & 0 & 0 & 01 & $1 \& 2$ & 0 & 2 & 0 & 0 & - & - & -0 & 0 & 0 & 0 & 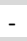 & 0 & & 0 & 0 & 0 & & 0 & & 1 & 0 & 0 & 1 & & & & 0 & & \\
\hline & 4 & 1 & 0 & 0 & 01 & $1 \& 2$ & 0 & 2 & 1 & 0 & - & - & -0 & 0 & 0 & 0 & - & 0 & & 0 & 0 & 0 & & 0 & 1 & 1 & 0 & 0 & 1 & & & & 0 & & \\
\hline & 4 & 1 & 0 & 0 & D 1 & $1 \& 2$ & 0 & 2 & 14 & 0 & - & - & -0 & 0 & 0 & 0 & - & 0 & & 0 & 0 & 0 & ) & 0 & 1 & 1 & 0 & 0 & 1 & 1 & 1 & c & 0 & 0 & 1 \\
\hline & 4 & 1 & 0 & 0 & 01 & $1 \& 2$ & 0 & 2 & 0 & 0 & - & - & -0 & 0 & 0 & 0 & & 0 & & 0 & 1 & 0 & ) & 0 & 1 & 1 & 0 & 0 & 1 & 1 & 1 & 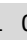 & 0 & & 1 \\
\hline $\boldsymbol{P}$ & 4 & 1 & 0 & 0 & 01 & $1 \& 2$ & 0 & 2 & 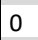 & 0 & - & - & -0 & 0 & 0 & 0 & - & 0 & & 0 & 1 & 0 & & 0 & 1 & 1 & 0 & 0 & & & & 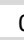 & & 0 & 1 \\
\hline wa & 4 & 1 & 0 & 0 & 01 & $1 \& 2$ & 0 & 2 & 0 & 0 & - & - & -0 & 0 & 0 & 0 & & & & 0 & 1 & 0 & & 0 & 1 & 1 & 0 & 0 & 1 & & & C & c & & 1 \\
\hline 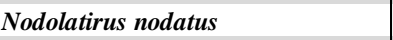 & 4 & 1 & 0 & 0 & 01 & $1 \& 2$ & 0 & 2 & C & 0 & - & - & -0 & 0 & 0 & 0 & & & & 0 & 1 & 0 & & 0 & 1 & 1 & 0 & 0 & 1 & 1 & & C & & & 1 \\
\hline hii & 4 & 1 & 0 & 0 & 01 & $1 \& 2$ & 0 & 0 & 0 & 0 & - & - & -0 & 0 & 0 & 0 & - & & & 0 & 1 & 0 & & 0 & 1 & 1 & 0 & 0 & 1 & & & & & & \\
\hline & 4 & 1 & 0 & 0 & 01 & $1 \& 2$ & 0 & 2 & 0 & 0 & - & - & -0 & 0 & 0 & 0 & & U & & 0 & 1 & 0 & & 0 & & 1 & 0 & 0 & 1 & & & c & 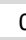 & & \\
\hline & 4 & 1 & 0 & & D 1 & 0 & 0 & 0 & 10 & 0 & - & - & -0 & 0 & 0 & 0 & & 0 & & 0 & 1 & 0 & & 0 & & 1 & 0 & 0 & 1 & 1 & & ( & 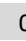 & & \\
\hline & 4 & & 0 & 0 & $\begin{array}{l}0 \\
0\end{array}$ & 2 & 0 & 2 & 14 & 0 & - & - & -0 & 0 & 0 & 0 & - & 0 & & 0 & 1 & 0 & & 0 & & 1 & 0 & 0 & 1 & & & & $c$ & & \\
\hline & 4 & 1 & 0 & 0 & $\begin{array}{ll}0 & 1\end{array}$ & $1 \& 2$ & 0 & 2 & 0 & 0 & - & - & -0 & 0 & 0 & 0 & - & 0 & & 0 & 1 & 0 & & 0 & 1 & 1 & & 0 & 1 & 1 & & & J & & \\
\hline & 4 & 1 & 0 & 0 & 01 & 1 & 0 & 0 & 0 & 0 & - & - & -0 & 0 & 0 & 0 & - & & & 0 & 1 & 0 & ) & 0 & 1 & 1 & 0 & 0 & 1 & & & 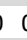 & 0 & & \\
\hline & 4 & 1 & 0 & 0 & 01 & $1 \& 2$ & 0 & 2 & 0 & 0 & - & - & -0 & 0 & 0 & 0 & - & 0 & & 0 & 1 & 0 & ) & 0 & 1 & 1 & 0 & 0 & 1 & 1 & L & c & ) & & \\
\hline & 4 & 1 & 0 & 0 & D 1 & $1 \& 2$ & 0 & 2 & 0 & 0 & - & - & -0 & 0 & 0 & 0 & & & & 0 & 1 & 0 & ) & 0 & 1 & 1 & 0 & 0 & 1 & 1 & L & c & 0 & 0 & b \\
\hline & 4 & 1 & 0 & 0 & 01 & $1 \& 2$ & 0 & 2 & 0 & 0 & - & - & -0 & 0 & 0 & 0 & & 0 & & 0 & 1 & 0 & & 0 & 1 & 1 & 0 & 0 & 1 & 1 & 1 & C & ) & & 1 \\
\hline & & 1 & 0 & 0 & 01 & $1 \& 2$ & 0 & 2 & 0 & 0 & - & - & -0 & 0 & 0 & 0 & & 0 & & 0 & 1 & 0 & & 0 & 1 & 1 & 0 & 0 & 1 & 1 & 1 & C & ) & 0 & b \\
\hline ius & 4 & 1 & 0 & & 0 1 & $1 \& 2$ & 0 & 2 & 10 & 0 & - & - & -0 & 0 & 0 & 0 & & 0 & & 0 & 1 & 0 & & 0 & 1 & 1 & 0 & 0 & 1 & 1 & 1 & 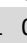 & ) & & 1 \\
\hline dib & 4 & 1 & 0 & & D 1 & $1 \& 2$ & 0 & 2 & 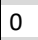 & 0 & - & - & -0 & 0 & 0 & 0 & & & & 0 & 1 & 0 & & 0 & & 1 & 0 & 0 & 1 & & & C & $c$ & & \\
\hline & 4 & 1 & 0 & & D 1 & $1 \& 2$ & 0 & 2 & 10 & 0 & & - & -0 & 0 & 0 & 0 & & & & 0 & 1 & 0 & & 0 & & 1 & 0 & & 1 & & & C & $c$ & & \\
\hline & 4 & & 0 & & $\begin{array}{l}0 \\
0\end{array}$ & 1 & 0 & 2 & 10 & 0 & - & - & -0 & 0 & 0 & 0 & & 0 & & 0 & 1 & 0 & & C & & 1 & 0 & & 1 & & & 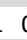 & $c$ & & \\
\hline & 4 & & 0 & 0 & ? 1 & $?$ & 0 & 2 & 14 & 0 & - & - & -0 & 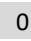 & 0 & 0 & & 0 & & 0 & 1 & 0 & & C & & 1 & 0 & & 1 & 1 & & c & $c$ & & \\
\hline & 4 & & 0 & & ? 1 & 1 & 0 & 2 & 0 & 0 & & - & -0 & & 0 & 0 & & & & 0 & 1 & 0 & & & & 1 & & & 1 & 1 & & c & 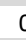 & & 1 \\
\hline & 4 & & 0 & & ? 1 & & 0 & 2 & 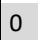 & 0 & - & - & -0 & & 0 & & & & & 0 & 1 & 0 & & & & 1 & & & 1 & & & & $c$ & 0 & 1 \\
\hline & 4 & & 0 & 0 & ? & $1 \& 2$ & 0 & 2 & 0 & 0 & - & - & -0 & & & & & & & 0 & 1 & 0 & & 0 & & 1 & & 0 & 1 & & & C & ) & & 1 \\
\hline & 4 & & 0 & 0 & ? & $1 \& 2$ & 0 & 2 & 0 & 0 & & 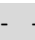 & -0 & & & & & & & 0 & 1 & 0 & & 0 & & & & 0 & 1 & & & $C$ & C & 0 & \\
\hline & 4 & & 1 & & 0 & $1 \& 2$ & ( & & 10 & & & & - & & & & & & & & & 0 & & & & & & & & & & & & & \\
\hline ucoz & 4 & & 1 & & $\begin{array}{ll}0 & 1\end{array}$ & $1 \& 2$ & 0 & & 0 & 0 & & & & & & & & & & & & U & & & & & & 0 & & 1 & & & & & \\
\hline
\end{tabular}




\begin{tabular}{|c|c|c|c|c|c|c|c|c|c|c|c|c|c|c|c|c|c|c|c|c|c|c|c|c|c|c|c|c|c|c|c|c|c|c|c|c|c|c|c|c|c|c|}
\hline CHARACTER & & $\begin{array}{l}4 \\
1 \\
\end{array}$ & & & 4 & 5 & 6 & 7 & & 9 & 0 & & 2 & 3 & 4 & & & & & & & $\begin{array}{l}0 \\
0\end{array}$ & 1 & 2 & & 4 & & & & & & & & & & 3 & & & & & & 9 \\
\hline Monetaria annulus & 2 & 1 & 2 & 1 & 1 & U & - & 0 & & 0 & 0 & 0 & 2 & ? & ? & & & & & & 0 & ? & $?$ & 0 & & 0 & & & & & & 0 & & & & 1 & & 0 & & & & 0 \\
\hline Thais speciosa & 2 & 1 & 0 & 0 & 0 & 1 & - & 0 & & 2 & 0 & 0 & - & 3 & 1 & & & & & & 0 & 0 & 0 & 0 & & 0 & & & & & & & & & & 1 & & & & & & 0 \\
\hline Pugilina tupiniquim & 0 & 1 & 0 & 0 & 0 & 0 & 0 & 0 & & 2 & 1 & 0 & - & 4 & 1 & & & & & U & 0 & 0 & 0 & 0 & & 0 & & & & & & & & & & 1 & & & & 0 & & 0 \\
\hline engoniophos unicinctus & 1 & 0 & 0 & 0 & 0 & 0 & 0 & 0 & & 2 & 0 & 0 & - & 3 & & & & & & 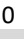 & 0 & 0 & 0 & 0 & & 0 & & & & & & & & & & 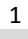 & & & D & 0 & 1 & 0 \\
\hline Nassarius reticulatus & 1 & 1 & 0 & 0 & 0 & 0 & 0 & 0 & & 2 & 0 & 0 & - & 3 & 1 & & & & & 0 & 1 & 0 & 0 & 0 & & 0 & 0 & & & & & & & & & 1 & & & J & 0 & 1 & 0 \\
\hline Bullia laevissima & 0 & 1 & 0 & 0 & 0 & 0 & 0 & 0 & & 2 & 0 & 0 & - & 3 & 1 & 2 & & & 3 & 0 & 0 & 0 & 0 & 0 & 1 & 0 & 0 & & ( & & & 0 & 0 & & - & 1 & & 0 & 0 & 0 & & 0 \\
\hline Buccinum undatum & 1 & 1 & 0 & 0 & 0 & 0 & 0 & 0 & - & 2 & 0 & 0 & - & 1 & 1 & 2 & & & 3 & 0 & 0 & 0 & 0 & 0 & 1 & 0 & 0 & & & & & 0 & 0 & ? & - & 1 & 1 & 0 & 0 & 0 & 1 & 0 \\
\hline Pisania pusio & 1 & 0 & 0 & 0 & 0 & 0 & 0 & 0 & 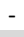 & 0 & 0 & 1 & - & 3 & 1 & 2 & & & 3 & 0 & 0 & 0 & 0 & 0 & 1 & 0 & 0 & & & & & 0 & 0 & ? & - & 1 & 1 & U & 0 & 0 & 1 & 0 \\
\hline Dolicholatirus sp. & 0 & 1 & 0 & 0 & 0 & 0 & 1 & 0 & & 2 & 0 & 0 & - & 4 & 1 & 2 & & & 3 & 0 & 0 & 0 & 0 & 0 & 1 & 0 & 0 & & 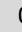 & & & U & 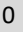 & & & 1 & & U & 0 & 0 & 1 & 0 \\
\hline Teralatirus roboreus & 0 & 1 & 0 & 0 & 0 & 0 & 1 & 0 & 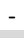 & 2 & 0 & 0 & - & 4 & $\perp$ & 2 & & & & 0 & 0 & 0 & 0 & 0 & 1 & 0 & U & & 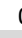 & & & 0 & 0 & & - & 1 & & & 0 & 0 & 1 & 0 \\
\hline Dolicholatirus aff. $c$ & 0 & 1 & 0 & 0 & 0 & 0 & 1 & 0 & & 2 & 0 & 0 & - & 4 & 1 & 2 & & & & 0 & 0 & 0 & 0 & 0 & 1 & 0 & 0 & & & & & 0 & & & - & 1 & & & 0 & 0 & & 0 \\
\hline Angulofusus & 0 & 1 & 0 & 0 & 0 & 0 & 1 & 0 & & 2 & 10 & 0 & - & 4 & 1 & 2 & & & 3 & 0 & 0 & 0 & 0 & 0 & 1 & 0 & 0 & & & & & 0 & 0 & & - & 1 & 1 & 0 & 0 & 0 & 1 & 0 \\
\hline Pseudolatirus kurosean & 0 & 0 & 0 & 0 & 0 & 0 & 1 & 0 & & 0 & 0 & 0 & - & 4 & 1 & 2 & & & 3 & 0 & 0 & 0 & 0 & 0 & 1 & 0 & 0 & C & & & & 0 & 0 & ? & - & 1 & 1 & & 0 & 0 & 1 & 0 \\
\hline Amiantofusus pacificus & 0 & 0 & 0 & 0 & 0 & 0 & 1 & 0 & & 0 & 0 & 0 & - & 4 & 1 & 2 & & & 3 & 0 & 0 & 0 & 0 & 0 & 1 & 0 & 0 & 0 & ( & & & 0 & 0 & ? & - & 1 & 1 & 0 & 0 & 0 & 1 & 0 \\
\hline Amiantofusus candoris & 0 & 0 & 0 & 0 & 0 & 0 & 1 & 0 & & 0 & 0 & 0 & - & 4 & 1 & 2 & & & 3 & 0 & 0 & 0 & 0 & 0 & 1 & 0 & 0 & & ( & & & 0 & & : & 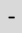 & 1 & & U & 0 & 0 & 1 & 0 \\
\hline Pseudolatirus pallidus & 0 & 0 & 0 & 0 & 0 & 0 & 1 & 0 & - & 0 & 0 & 0 & - & 4 & 1 & 2 & & & 3 & 0 & 0 & 0 & 0 & 0 & 1 & 0 & 0 & 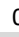 & 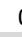 & & & 0 & & & - & 1 & & & 0 & 0 & 1 & 0 \\
\hline Chryseofusus archerusius & 0 & 0 & 0 & 0 & 0 & 0 & 1 & 0 & & 0 & 1 & 0 & - & 4 & 1 & 2 & & & ( & 0 & 0 & 0 & 0 & 0 & 1 & 0 & 0 & 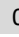 & & & & U & & & . & 1 & & & 0 & 0 & 1 & 0 \\
\hline Chryseofusus gracilifor & 0 & 0 & 0 & 0 & 0 & 0 & 1 & 0 & & 0 & 1 & 0 & - & 4 & 1 & 2 & & & 3 & 0 & 0 & 0 & 0 & 0 & 1 & 0 & 0 & 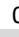 & & & & 0 & 0 & ? & - & 1 & 1 & & 0 & 0 & 1 & 0 \\
\hline Fusinus marmoratus & 0 & 0 & 0 & 0 & 0 & 0 & 1 & 0 & & 0 & 1 & 0 & - & 4 & 1 & 2 & & & 3 & 0 & 0 & 0 & 0 & 0 & 1 & 0 & 0 & C & & & & 0 & 0 & ? & & 1 & 1 & & 0 & 0 & & 0 \\
\hline Fusinus brasiliensis & 0 & 0 & 0 & 0 & 0 & 0 & 1 & 0 & & 0 & 1 & 0 & - & 4 & 1 & 2 & & & 3 & 0 & 0 & 0 & 0 & 0 & 1 & 0 & 0 & C & ( & & $\mathrm{J}$ & 0 & 0 & ? & - & 1 & 1 & 0 & 0 & 0 & 1 & 0 \\
\hline Fusinus sp. & 0 & 0 & 0 & 0 & 0 & 0 & 1 & 0 & - & 0 & 1 & 0 & - & 4 & 1 & 2 & & & 3 & 0 & 0 & 0 & 0 & 0 & 1 & 0 & 0 & $c$ & ( & & J & 0 & 0 & ? & - & 1 & 1 & 0 & 0 & 0 & 1 & 0 \\
\hline Fusinus frenguelli & 0 & 0 & 0 & 0 & 0 & 0 & 1 & 0 & - & 0 & 1 & 0 & - & 4 & 1 & 2 & & & 3 & U & 0 & 0 & 0 & 0 & 1 & 0 & 0 & 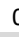 & & & & U & $v$ & ? & ${ }^{-}$ & 1 & $\perp$ & & 0 & 0 & 1 & 0 \\
\hline Fusinus australis & 0 & 0 & 0 & 0 & 0 & 0 & 1 & 0 & 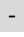 & 0 & 1 & 0 & - & 4 & 1 & 2 & & & 3 & 0 & 0 & 0 & 0 & 0 & 1 & 0 & 0 & & & & & 0 & & & 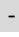 & 1 & & & 0 & 0 & 1 & 0 \\
\hline Cyrtulus serotinus & 0 & 0 & 0 & 0 & 0 & 0 & 1 & 0 & & 0 & 0 & 0 & - & 4 & 1 & 2 & & & 3 & 0 & 0 & 0 & 0 & 0 & 1 & 0 & 0 & & & & & & O & & 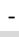 & 1 & & & b & 0 & 1 & 0 \\
\hline Granulifusus sp. & 0 & 0 & 0 & 0 & 0 & 0 & 1 & 0 & & 0 & 0 & 0 & - & 1 & 1 & 2 & & & 3 & 0 & 0 & 1 & 0 & 0 & 1 & 0 & 0 & 0 & ( & & & 0 & 0 & ? & - & 1 & 1 & 0 & 0 & 0 & 1 & 0 \\
\hline Granulifusus hayashi & 0 & 0 & 0 & 0 & 0 & 0 & 1 & 0 & - & 0 & 0 & 0 & - & 1 & 1 & 2 & & $?$ & 3 & 0 & 0 & 1 & 0 & 0 & 1 & 0 & U & C & & & J & 0 & U & ? & - & 1 & 1 & U & 0 & 0 & 1 & 0 \\
\hline Pseudolatirus discrepans & 0 & 0 & 0 & 0 & 0 & 0 & 1 & 0 & - & 0 & 0 & 0 & - & 1 & 1 & 2 & & $?$ & 3 & 0 & 0 & 1 & 0 & 0 & 1 & 0 & 0 & C & & & U & 0 & 0 & $?$ & - & 1 & 1 & 0 & 0 & 0 & 1 & 0 \\
\hline Granulifusus aff. kiranus & 0 & 0 & 0 & 0 & 0 & 0 & 1 & 0 & 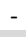 & 0 & 0 & 0 & - & 1 & 1 & & & 2 & 3 & U & 0 & 1 & 0 & 0 & 1 & 0 & U & & & & & 0 & 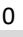 & ? & 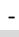 & 1 & + & 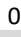 & U & U & 1 & 0 \\
\hline Fusolatirus bruijnii & 0 & 0 & 0 & 0 & 0 & 0 & 1 & 0 & . & 0 & 0 & 0 & - & 4 & 1 & 2 & & 7 & 3 & 0 & 0 & 0 & 0 & 0 & $\perp$ & 0 & 0 & & & & & 0 & & & - & 1 & - & & 0 & 0 & 1 & 0 \\
\hline Peristernia marquesc & 0 & 0 & 0 & 0 & 0 & 0 & 1 & 0 & & 0 & 0 & 0 & - & 4 & 1 & 2 & & & 3 & 0 & 0 & 0 & 0 & 0 & 1 & 0 & 0 & & & & & 0 & O & & 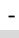 & 1 & & & 0 & 0 & 1 & 0 \\
\hline Peristernia nassatula & 0 & 0 & 0 & 0 & 0 & 0 & 1 & 0 & - & 0 & 0 & 0 & - & 4 & 1 & 2 & & & 3 & 0 & 0 & 0 & 0 & 0 & 1 & 0 & 0 & $C$ & & & & 0 & 0 & ? & - & 1 & 1 & 0 & 0 & 0 & 1 & 0 \\
\hline Nodolatirus nodatus & 0 & 0 & 0 & 0 & 0 & 0 & 1 & 0 & - & 2 & 1 & 1 & - & 4 & 1 & 2 & & 4 & 3 & 0 & 0 & 0 & 0 & 0 & 1 & 0 & 0 & 0 & & & & 0 & 0 & ? & - & 1 & 1 & 0 & 0 & 0 & 1 & 0 \\
\hline Latirus vischii & 0 & 0 & 0 & 0 & 0 & 0 & 1 & 0 & - & 2 & 1 & 1 & - & 4 & 1 & 2 & & & 3 & 0 & 0 & 0 & 0 & 0 & 1 & 0 & U & 0 & & & & 0 & 0 & ? & - & 1 & 1 & 0 & 0 & 0 & 1 & 0 \\
\hline Aurantilaria aurantiaca & 0 & 0 & 0 & 0 & 0 & 0 & 1 & 0 & 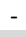 & 2 & 1 & 1 & - & 4 & 1 & & & 7 & כ & 0 & 0 & 0 & 0 & 0 & $\perp$ & 0 & U & 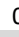 & & & & 0 & 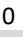 & 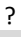 & - & 1 & $\perp$ & & 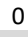 & 0 & 1 & 0 \\
\hline Fasciolaria tulipa & 0 & 0 & 0 & 0 & 0 & 0 & 1 & 0 & & 2 & 1 & 1 & - & 4 & 1 & & & & 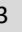 & & 0 & ) & 0 & 0 & & 0 & & & & & & 0 & & & . & 1 & & & 0 & 0 & 1 & 0 \\
\hline Australaria australasia & 0 & 0 & 0 & 0 & 0 & 0 & 1 & 0 & & 2 & 1 & 1 & - & 4 & 1 & 2 & & & 3 & 0 & 0 & 0 & 0 & 0 & & 0 & 0 & & & & & 0 & & & - & 1 & & & 0 & 0 & 1 & 0 \\
\hline Pleuroploca trapezium & 0 & 0 & 0 & 0 & 0 & 0 & 1 & 0 & - & 2 & 1 & 1 & - & 4 & 1 & 2 & & & 3 & 0 & 0 & 0 & 0 & 0 & 1 & 0 & 0 & 0 & & & & 0 & 0 & ? & - & 1 & 1 & 0 & 0 & 0 & 1 & 0 \\
\hline Filifusus filamentosus & 0 & 0 & 0 & 0 & 0 & 0 & 1 & 0 & - & 2 & 1 & 1 & - & 4 & 1 & 2 & & & 3 & 0 & 0 & 0 & 0 & 0 & 1 & 0 & 0 & 0 & & & & 0 & 0 & ? & - & 1 & 1 & 0 & 0 & 0 & 1 & 0 \\
\hline Hemipolygona armata & 0 & 0 & 0 & 0 & 0 & 0 & 1 & 0 & - & 0 & 0 & 1 & - & 4 & 1 & 2 & & 4 & 3 & 0 & 0 & 0 & 0 & 0 & 1 & 0 & 0 & 0 & & & & 0 & 0 & $?$ & - & 1 & 1 & 0 & 0 & 0 & 1 & 0 \\
\hline Pustulatirus mediameri & 0 & 0 & 0 & 0 & 0 & 0 & 1 & 0 & 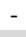 & 0 & 0 & 1 & - & 4 & 1 & 2 & & & כ & U & 0 & 0 & 0 & 0 & $\perp$ & 0 & U & 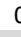 & & & & 0 & V & & - & 1 & $\perp$ & 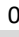 & 0 & 0 & 1 & 0 \\
\hline Pustulatirus ogum & 0 & 0 & 0 & 0 & 0 & 0 & 1 & 0 & & 0 & 0 & 1 & - & 4 & 1 & 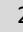 & & & 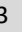 & 0 & 0 & 0 & 0 & 0 & \pm & 0 & 0 & & & & & 0 & & & - & 1 & & & U & 0 & 1 & 0 \\
\hline Polygona angulata & 0 & 0 & 0 & 0 & 0 & 0 & 1 & 0 & - & 0 & 0 & 1 & - & 4 & 1 & 2 & & & 3 & 0 & 0 & 0 & 0 & 0 & 1 & 0 & 0 & & & & & 0 & & ? & - & 1 & 1 & & 0 & 0 & 1 & 0 \\
\hline Latirus polygonus & 0 & 0 & 0 & 0 & 0 & 0 & 1 & 0 & - & 0 & 0 & 1 & - & 4 & 1 & 2 & & & 3 & 0 & 0 & 0 & 0 & 0 & 1 & 0 & 0 & $c$ & & & & 0 & 0 & ? & - & 1 & 1 & 0 & 0 & 0 & 1 & 0 \\
\hline Polygona infundibulum & 0 & 0 & 0 & 0 & 0 & 0 & 1 & 0 & - & 0 & 0 & 1 & - & 4 & 1 & 2 & & & 3 & 0 & 0 & 0 & 0 & 0 & 1 & 0 & 0 & C & & & 0 & 0 & 0 & ? & - & 1 & 1 & 0 & 0 & 0 & 1 & 0 \\
\hline Hemipolygona beckyae & 0 & 0 & 0 & 0 & 0 & 0 & 1 & 0 & 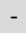 & 0 & 0 & 1 & - & 4 & 1 & 2 & & & 3 & 0 & 0 & 0 & 0 & 0 & 1 & 0 & 0 & 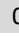 & & & & 0 & U & $?$ & - & 1 & 1 & U & 0 & 0 & 1 & 0 \\
\hline Latirus pictus & 0 & 0 & 0 & 0 & 0 & 0 & 1 & 0 & 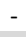 & 0 & 0 & 1 & - & 4 & 1 & 2 & & & 3 & U & 0 & 0 & 0 & 0 & $\perp$ & 0 & U & 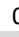 & 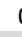 & & & 0 & U & 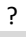 & - & 1 & $\perp$ & 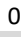 & 0 & 0 & 1 & 0 \\
\hline Leucozonia ocellata & 0 & 0 & 0 & 0 & 0 & 0 & 1 & 0 & 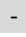 & 0 & 0 & 1 & - & 4 & $\perp$ & & & & 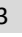 & 0 & 0 & 0 & 0 & 0 & 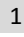 & 0 & 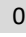 & & & & & 0 & & 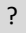 & - & 1 & & 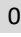 & 0 & 0 & 1 & 0 \\
\hline Leucozonia cerata & 0 & 0 & 0 & 0 & 0 & 0 & 1 & 0 & 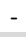 & 0 & 0 & 1 & - & 4 & & & & & 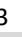 & 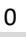 & 0 & 0 & 0 & 0 & & 0 & v & & & & & 0 & & ? & - & 1 & & & 0 & 0 & 1 & 0 \\
\hline Opeatostoma pseudodon & 0 & 0 & 0 & 0 & 0 & 0 & 1 & 0 & & 0 & 0 & 1 & - & 4 & 1 & & & & 3 & & 0 & 0 & 0 & 0 & & 0 & & & & & & 0 & 0 & ? & - & 1 & & & 0 & 0 & 1 & 0 \\
\hline Leucozonia nassa nassa & 0 & 0 & 0 & 0 & 0 & 0 & 1 & 0 & & 0 & 0 & 1 & - & 4 & 1 & 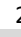 & & & 3 & 0 & 0 & 0 & 0 & 0 & 1 & 0 & 0 & C & & & & 0 & 0 & ? & - & 1 & 1 & U & 0 & 0 & 1 & 0 \\
\hline Leucozonia nassa cingulifera & 0 & 0 & 0 & 0 & 0 & 0 & 1 & 0 & & 0 & 0 & 1 & - & 4 & 1 & 2 & & & 3 & 0 & 0 & 0 & 0 & 0 & 1 & 0 & 0 & 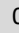 & & & & 0 & U & $?$ & - & 1 & & U & 0 & 0 & 1 & 0 \\
\hline Leucozonia nassa brasiliana & 0 & 0 & 0 & 0 & 0 & 0 & 1 & 0 & & 2 & 0 & 1 & - & 4 & $\perp$ & & & & (3) & 0 & $u$ & 0 & 0 & 0 & 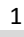 & 0 & 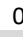 & & & & & 0 & 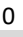 & : & 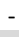 & 1 & + & 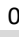 & 0 & 0 & 1 & 0 \\
\hline Leucozonia ponderosa & 0 & 0 & 0 & 0 & 0 & 0 & 1 & 0 & & 2 & 0 & 1 & - & 4 & \pm & & & & J & 0 & 0 & 0 & 0 & 0 & & 0 & & & & & 0 & 0 & 0 & & & 1 & & & 0 & 0 & & 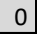 \\
\hline
\end{tabular}




\begin{tabular}{|c|c|c|c|c|c|c|c|c|c|c|c|c|c|c|c|c|c|c|c|c|c|c|c|c|c|c|c|c|c|c|c|c|c|c|c|}
\hline 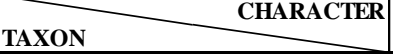 & & & & & & & & & & & & & & & & & & & & & & & & & & & & & & & & & & & \\
\hline Monetaria annulus & 0 & & 1 & 1 & & & & & & $\overline{0}$ & 1 & 5 & 5 & 0 & & $\overline{0}$ & & 1 & 10 & 0 & 0 & 0 & 0 & 0 & $\overline{0}$ & 0 & $\overline{1}$ & $\overline{0 c}$ & $\overline{00}$ & $\overline{0}$ & $\overline{0}$ & 0 & 0 & 2 & \\
\hline Thais speciosa & 0 & & 0 & ( & & & & & 1 & 0 & 8 & 5 & 5 & 0 & 0 & 0 & 3 & 2 & & 0 & 0 & 0 & 0 & 0 & 0 & 0 & & & 0 & 0 & & 0 & 0 & 2 & \\
\hline ugilina tupiniquim & 0 & & & 0 & & 0 & & & 1 & & & 5 & 5 & 0 & 0 & 0 & & & & & 0 & 0 & 0 & 0 & 0 & 0 & & & & & & 0 & 0 & 2 & \\
\hline goniophos unicinctus & 0 & & & D & 0 & 2 & & 1 & 1 & 0 & & 5 & 5 & 0 & 0 & 0 & 6 & & & & 0 & 0 & 0 & 0 & 0 & 01 & & & & 2 & & 0 & & 2 & \\
\hline assarius reticulatus & 0 & & 0 & 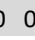 & & 2 & 1 & 1 & 1 & 0 & & 5 & 5 & 0 & 0 & 0 & 6 & & & 0 & 0 & 0 & 0 & 0 & 0 & 01 & & & & 2 & & 0 & 0 & 2 & \\
\hline ullia lae & 0 & & & 00 & 0 & 2 & 1 & 1 & 1 & 00 & & 5 & 5 & 0 & 0 & 0 & 6 & 2 & & & 0 & 0 & 0 & 0 & 0 & 01 & & & & 2 & & 0 & 0 & 2 & \\
\hline ucci & 0 & & 0 & 00 & 0 & 2 & 1 & 1 & 1 & 00 & & 5 & 5 & 0 & 0 & 0 & 6 & 1 & & 0 & 0 & 0 & 0 & 0 & 0 & 01 & & & & & & 0 & 0 & 2 & \\
\hline san & 0 & & 0 & 00 & & 0 & 1 & 1 & 1 & 00 & & 5 & 5 & 0 & 0 & 0 & 6 & 1 & 10 & & 0 & 0 & 0 & 0 & 0 & 0 & & & & & & 0 & 0 & & \\
\hline us sp. & 0 & & 0 & 00 & 0 & 1 & 1 & 1 & 1 & 00 & & 5 & 5 & 0 & 0 & 0 & 8 & 2 & 10 & & 0 & 0 & 0 & 0 & 0 & 0 & & & & & & 0 & 0 & 2 & \\
\hline reus & 0 & & 0 & 00 & 0 & 1 & 1 & 1 & 1 & 00 & & 5 & 5 & 0 & 0 & 0 & 8 & 2 & & & 0 & 0 & 0 & 0 & 0 & 01 & & & & & & 0 & 0 & & \\
\hline & 0 & & 0 & 00 & & 1 & 1 & 1 & 1 & & & 5 & 5 & 0 & 0 & 0 & 8 & 2 & & & 0 & 0 & 0 & 0 & 0 & 0 & & & & & & 0 & 0 & & \\
\hline$a e$ & 0 & & 0 & 00 & 0 & 0 & 1 & 1 & 1 & 00 & 01 & 15 & 5 & 0 & 0 & 0 & 8 & 2 & & 0 & 0 & 0 & 0 & 0 & 0 & 0 & & 0 & 00 & 00 & 0 & 0 & 0 & 24 & \\
\hline se & 0 & 0 & 0 & 00 & 0 & 0 & 1 & 1 & 1 & 00 & 01 & 15 & 5 & 0 & 0 & 0 & 8 & 2 & 10 & 0 & 0 & 0 & 0 & 0 & 0 & 0 & 1 & 0 & & 00 & 0 & 0 & 0 & 20 & \\
\hline us & 0 & 0 & 0 & 00 & 0 & 0 & 1 & 1 & 1 & 00 & 01 & 15 & 5 & 0 & 0 & 0 & 8 & 2 & 10 & 0 & 0 & 0 & 0 & 0 & 0 & 0 & 1 & 0 & 00 & $\begin{array}{ll}0 & 0\end{array}$ & & 0 & 0 & 2 & \\
\hline loris & 0 & 0 & 0 & 00 & & 0 & 1 & 1 & 1 & 00 & 01 & 15 & 5 & 0 & 0 & 0 & 8 & 2 & 10 & 0 & 0 & 0 & 0 & 0 & 0 & 0 & & 0 & & & & 0 & 0 & 2 & \\
\hline idus & 0 & & 0 & 00 & 0 & 0 & 1 & 1 & 1 & 00 & 01 & 15 & 5 & 0 & 0 & 0 & 8 & 3 & 10 & 0 & 0 & 0 & 0 & 0 & 0 & 0 & 1 & 0 & & $\begin{array}{ll}0 & 0\end{array}$ & & 0 & 0 & 2 & \\
\hline ierus & 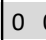 & & 0 & 00 & & 0 & 1 & 1 & 1 & 00 & 01 & & 5 & 0 & 0 & 0 & 8 & 3 & 10 & & 0 & 0 & 0 & 0 & 0 & 0 & & 0 & & 00 & & 0 & 0 & 2 & \\
\hline$h r$ & 0 & 0 & 0 & 00 & 0 & 0 & 1 & 1 & 1 & 00 & 01 & 15 & 5 & 0 & 0 & 0 & 8 & 3 & 10 & 0 & 0 & 0 & 0 & 0 & 0 & 0 & & 00 & & 00 & & 0 & & 2 & \\
\hline atus & 0 & 0 & 0 & 00 & 0 & 0 & 1 & 1 & 1 & 00 & 01 & 15 & 5 & 0 & 0 & 0 & 8 & 3 & 10 & 0 & 0 & 0 & 0 & 0 & 0 & 0 & & 0 & & 00 & & 0 & & 2 & \\
\hline is & 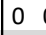 & 0 & 0 & 00 & 0 & 0 & 1 & 1 & 1 & 00 & 01 & 15 & 5 & 0 & 0 & 0 & 8 & 3 & 10 & 0 & 0 & 0 & 0 & 0 & 0 & 0 & 1 & 00 & & 00 & & 0 & & 2 & 0 \\
\hline$F$ & 0 & 0 & 0 & 00 & 0 & 0 & 1 & 1 & 1 & 00 & 01 & 15 & 5 & 0 & 0 & 0 & 8 & 3 & 10 & 0 & 0 & 0 & 0 & 0 & 0 & 0 & & 00 & & 00 & & 0 & & 2 & \\
\hline & 0 & 0 & 0 & 00 & 0 & 0 & 1 & 1 & 1 & 00 & 01 & 15 & 5 & 0 & 0 & 0 & 8 & 3 & 10 & 0 & 0 & 0 & 0 & 0 & 0 & 0 & & 00 & & 00 & & 0 & 0 & 2 & \\
\hline & 0 & 0 & 0 & 00 & 0 & 0 & 1 & 1 & 1 & 00 & 01 & 15 & 5 & 0 & 0 & 0 & 8 & 3 & 10 & 0 & 0 & 0 & 0 & 0 & 0 & 0 & & 0 & & 00 & & 0 & 0 & 2 & \\
\hline & 0 & 0 & 0 & 00 & 0 & 0 & 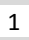 & 1 & 1 & 00 & 01 & 15 & 5 & 0 & 0 & 0 & 8 & 3 & 10 & 0 & 0 & 0 & 0 & 0 & 0 & 0 & & & & & & 0 & 0 & 2 & \\
\hline$G$ & 0 & 0 & 0 & 00 & 0 & 0 & 1 & 1 & 1 & 00 & 01 & 15 & 5 & 0 & 0 & 0 & 8 & 2 & 10 & 0 & 0 & 0 & 0 & 0 & 0 & 0 & & & & 00 & & 0 & 0 & 2 & \\
\hline & 0 & 0 & 0 & 00 & & 0 & 1 & 1 & 1 & 00 & 01 & 15 & 5 & 0 & 0 & 0 & 8 & 2 & 10 & 0 & 0 & 0 & 0 & 0 & 0 & 0 & & & & 00 & & 0 & 0 & 2 & \\
\hline & 0 & 0 & 0 & 0 & 0 & 0 & 1 & 1 & 1 & 00 & 01 & 15 & 5 & 0 & 0 & 0 & 8 & 2 & 10 & 0 & 0 & 0 & 0 & 0 & 0 & 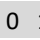 & 1 & 0 & & $\begin{array}{lll}0 & 0\end{array}$ & & 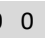 & 0 & 2 & \\
\hline & 0 & 0 & 0 & 0 & 0 & 0 & 1 & 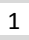 & 1 & 00 & 01 & 15 & 5 & 0 & 0 & 0 & 8 & 2 & 10 & 0 & 0 & 0 & 0 & 0 & 0 & 0 & 1 & 0 & & $\begin{array}{lll}0 & 0\end{array}$ & & 0 & 0 & 2 & \\
\hline & 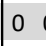 & 0 & 0 & 00 & 0 & 0 & 1 & 1 & 1 & 00 & 01 & 15 & 5 & 0 & 0 & 0 & 8 & 2 & 10 & 0 & 0 & 0 & 0 & 0 & 0 & 0 & 1 & 0 & 0 & 00 & 0 & 0 & 0 & 2 & \\
\hline & 0 & 0 & 0 & 0 & 0 & 0 & 1 & 1 & 1 & 00 & 01 & 15 & 5 & 0 & 0 & 0 & 8 & 2 & 10 & 0 & 0 & 0 & 0 & 0 & 0 & 0 & 1 & 00 & 0 & 00 & & 0 & 0 & 2 & 0 \\
\hline & . & 0 & 0 & 0 & 0 & 0 & 1 & 1 & 1 & 00 & 01 & 15 & 5 & 0 & 0 & 0 & 8 & 2 & 10 & 0 & 0 & 0 & 0 & 0 & 0 & 0 & 1 & 0 & 0 & $\begin{array}{ll}0 & 0\end{array}$ & & 0 & 0 & 2 & 0 \\
\hline & 0 & 0 & 0 & 0 & 0 & 1 & 1 & 1 & 1 & 00 & 01 & 15 & 5 & 0 & 0 & 0 & 8 & 2 & 10 & 0 & 0 & 0 & 0 & 0 & 0 & 0 & 1 & 0 & 0 & 00 & 0 & 0 & 0 & 2 & 0 \\
\hline & 0 & 0 & 0 & 0 & 0 & 1 & 1 & 1 & 1 & 0 & 01 & 15 & 5 & 0 & 0 & 0 & 8 & 2 & 10 & 0 & 0 & 0 & 0 & 0 & 0 & 0 & 1 & 0 & & 00 & & 0 & 0 & 2 & \\
\hline & 0 & 0 & 0 & 0 & 0 & 1 & 1 & 1 & 1 & 00 & 01 & 15 & 5 & 0 & 0 & 0 & 8 & 2 & 10 & 00 & 0 & 0 & 0 & 0 & 0 & 0 & 1 & 00 & 0 & 00 & & 0 & 0 & 2 & \\
\hline & 0 & 0 & 0 & 0 & 0 & 1 & 1 & 1 & 1 & 0 & 0 & 15 & 5 & 0 & 0 & 0 & 8 & 2 & 10 & 0 & 0 & 0 & 0 & 0 & 0 & 0 & & 0 & 0 & 00 & & 0 & 0 & 2 & $\begin{array}{lll}0 & 0\end{array}$ \\
\hline & . & 0 & 0 & 0 & & 1 & 1 & 1 & 1 | & 00 & 01 & 15 & 5 & 0 & 0 & 0 & 8 & 2 & 10 & 0 & 0 & 0 & 0 & 0 & 0 & 0 & 1 & 0 & 0 & $\begin{array}{ll}0 & 0\end{array}$ & & 0 & 0 & 2 & 00 \\
\hline & 0 & 0 & 0 & 0 & & 1 & 1 & 1 & 1 & 0 & 01 & 15 & 5 & 0 & 0 & 0 & 8 & 2 & 10 & 00 & 0 & 0 & 0 & 0 & 0 & 0 & & 00 & 0 & 00 & & 0 & 0 & 2 & \\
\hline & 0 & 0 & 0 & 0 & & 1 & 1 & 1 & 1 & 00 & 01 & 15 & 5 & 0 & 0 & 0 & 8 & 2 & 10 & 00 & 0 & 0 & 0 & 0 & 0 & 0 & & 00 & & 00 & & 0 & 0 & 2 & \\
\hline & 0 & 0 & 0 & 0 & & 1 & 1 & 1 & 1 & 00 & 01 & 15 & 5 & 0 & 0 & 0 & 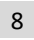 & 2 & 10 & 0 & 0 & 0 & 0 & 0 & 0 & 0 & & 0 & & $\begin{array}{lll}0 & 0\end{array}$ & & 0 & 0 & 2 & \\
\hline & 0 & 0 & 0 & 0 & 0 & 1 & 1 & 1 & 1 & 00 & 01 & 15 & 5 & 0 & 0 & 0 & 3 & 2 & 10 & 0 & 0 & 0 & 0 & 0 & 0 & 0 & 1 & 00 & & $\begin{array}{ll}0 & 0\end{array}$ & & 0 & 0 & 2 & $\begin{array}{lll}0 & 0\end{array}$ \\
\hline & 0 & 0 & 0 & 0 & 0 & 1 & 1 & & 1 & 00 & 01 & 1 & 5 & 0 & 0 & 0 & J & 2 & 10 & 0 & 0 & 0 & 0 & 0 & 0 & 0 & 1 & 0 & & 00 & & 0 & 0 & 2 & 00 \\
\hline & 0 & 0 & 0 & 0 & 0 & 1 & 1 & & 1 & 00 & 01 & 1 & 5 & 0 & 0 & 0 & 8 & 2 & 10 & 0 & 0 & 0 & 0 & 0 & 0 & 0 & 1 & 0 & & 00 & & 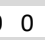 & 0 & 2 & 0 \\
\hline & 0 & 0 & 0 & 0 & & 1 & 1 & & 1 & 0 & 01 & 1 & 5 & 0 & 0 & 0 & 8 & 2 & 10 & 0 & 0 & 0 & 0 & 0 & 0 & 0 & 1 & c & & 00 & 0 & N & 0 & 2 & \\
\hline & 0 & 0 & 0 & 0 & & 1 & 1 & & 1 | & 0 & 01 & 1 & 5 & 0 & 0 & 0 & 8 & 2 & 10 & 0 & 0 & 0 & 0 & 0 & 0 & 0 & 1 & 00 & 0 & 00 & & 0 & 0 & 2 & \\
\hline & 0 & 0 & 0 & 0 & & & 1 & 1 & 1 & 00 & 01 & 1 & 5 & 0 & 0 & 0 & 8 & 2 & 10 & 0 & 0 & 0 & 0 & 0 & 0 & 0 & 1 & 00 & & 00 & & 0 & 0 & 2 & \\
\hline & 0 & 0 & 0 & 0 & & & & 1 & 1 & 00 & 01 & 1 & 5 & 0 & 0 & 0 & 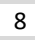 & 2 & 10 & 0 & 0 & 0 & 0 & 0 & 0 & 0 & 1 & 0 & 0 & 00 & & 0 & 0 & 2 & \\
\hline Leuc & 0 & 0 & 0 & 0 & & & 1 & 1 & 1 & 00 & 01 & 1 & 5 & 0 & 0 & 0 & 8 & 2 & 10 & 0 & 0 & 0 & 0 & 0 & 0 & 0 & 1 & 0 & & $\begin{array}{ll}0 & 0\end{array}$ & & 0 & 0 & 2 & \\
\hline & 0 & 0 & 0 & 0 & & & 1 & 1 & 1 & 0 & & 1 & 5 & 0 & 0 & 0 & 8 & 2 & 10 & 0 & 0 & 0 & 0 & 0 & 0 & 0 & 1 & 00 & & 00 & 0 & 0 & 0 & 2 & \\
\hline & 0 & 0 & 0 & 0 & & & 1 & & 1 & 0 & 01 & 1 & 5 & 0 & 0 & 0 & 8 & 2 & 10 & 0 & 0 & 0 & 0 & 0 & 0 & 0 & 1 & 0 & & 00 & 0 & 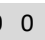 & 0 & 2 & \\
\hline & 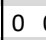 & 0 & 0 & 0 & & & 1 & & & 0 & 01 & 1 & 5 & 0 & 0 & 0 & 8 & 2 & 10 & 0 & 0 & 0 & 0 & 0 & 0 & 0 & 1 & 00 & & 00 & 0 & 0 & 0 & 2 & \\
\hline & 0 & 0 & 0 & 0 & & & & & & 0 & 0 & 1 & 5 & 0 & 0 & 0 & 8 & 2 & 10 & 0 & 0 & 0 & 0 & 0 & 0 & 0 & 1 & 0 & & 00 & & 0 & 0 & 2 & 00 \\
\hline & 0 & 0 & 0 & 0 & & & & & & 0 & 0 & & 5 & 0 & 0 & 0 & 8 & 2 & 10 & 0 & 0 & 0 & 0 & 0 & 0 & 0 & 1 & 0 & & 00 & & 0 & 0 & 2 & 0 \\
\hline & 0 & 0 & & $\begin{array}{lll}0 & 0\end{array}$ & & & & & & & & & & 0 & 0 & 0 & 0 & 2 & 10 & & 0 & 0 & 0 & 0 & 0 & 0 & & & & & & & 0 & & \\
\hline
\end{tabular}




\begin{tabular}{|c|c|c|c|c|c|c|c|c|c|c|c|c|c|c|c|c|c|c|c|c|c|c|c|c|c|c|c|c|c|c|c|c|c|c|c|c|}
\hline XON & & & & & & & & & & & & & & & & & & & & & & & & & & & & & & & & & & & & \\
\hline onetaria annulus & 0 & & 1 & 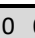 & 0 & 0 & 1 & & 1 & 2 & 1 & 1 & 1 & 2 & 8 & 0 & 0 & 0 & 2 & 2 & 1 & 1 & 0 & 0 & 4 & 01 & & 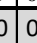 & & & 0 & 0 & 0 & & & \\
\hline Thais speciosa & 0 & & 1 & & 0 & 0 & 2 & 2 & & 2 & 4 & 1 & 1 & 2 & 1 & 2 & 2 & 0 & 0 & 1 & 0 & 1 & 0 & 0 & 00 & 0 & & & & & 0 & 0 & 0 & 0 & & \\
\hline Pugilina & 0 & & 0 & & 0 & & 1 & & 0 & 1 & ? & ? & & & & & & 00 & 0 & 1 & 0 & 1 & & 0 & & & & & & 0 & 0 & 0 & 0 & 0 & & \\
\hline ngoniophos unicinctus & 1 & & 1 & & 0 & 0 & 2 & 2 & & 2 & $?$ & ? & & & & 0 & 00 & 00 & 0 & 1 & 0 & 1 & 0 & 0 & 00 & & & & & 0 & 0 & 0 & 0 & 0 & & \\
\hline Nassarius reticulatus & 0 & & & & 0 & 10 & & 2 & & 2 & $?$ & ? & & 2 & & 0 & 00 & 00 & 0 & 1 & 0 & 1 & 0 & 0 & & 01 & & & & 0 & 0 & 0 & 0 & 0 & & \\
\hline Bullia laevissima & 0 & & 1 & & 0 & & 2 & & & 0 & $?$ & $?$ & & 2 & 1 & 0 & 00 & 0 & 0 & 1 & 0 & 1 & 0 & 0 & & & & & & 0 & 0 & 0 & 0 & 0 & & \\
\hline Buccinum undatum & 0 & & 0 & & 0 & 10 & 1 & 2 & & 2 & $?$ & $?$ & $?$ & 2 & 1 & 0 & 00 & 0 & 0 & 1 & 0 & 1 & 0 & 0 & 00 & & & & & 0 & 0 & 0 & 0 & 0 & & \\
\hline Pisal & 0 & & 1 & & 0 & 10 & 1 & 2 & & 2 & ? & ? & & 2 & & 00 & 00 & 00 & 0 & 1 & 0 & 1 & 0 & 0 & & & & & & 0 & 0 & 0 & 0 & 0 & & \\
\hline is $s$ & 0 & & 0 & & 0 & 10 & 2 & 2 & & 2 & ? & ? & & 2 & & & 00 & 0 & 0 & 1 & 0 & 1 & 0 & 0 & & & & & & 0 & 0 & & 0 & 0 & & \\
\hline Teralati & 0 & & 0 & & 01 & 10 & & 2 & & 2 & ? & ? & & 2 & & & 00 & 0 & 0 & 1 & 0 & 1 & 0 & 0 & & & & & & 0 & 0 & 0 & 0 & 0 & & \\
\hline ou & 0 & & 0 & 0 & 0 & 10 & & 2 & & 2 & $?$ & $?$ & & 2 & 1 & & & 0 & 0 & 1 & 0 & 1 & 0 & 0 & 00 & 02 & & & & 0 & 0 & 0 & 0 & 0 & & \\
\hline$a e$ & 0 & & 0 & 0 & 0 & 10 & 2 & 2 & & 2 & $?$ & $?$ & $? 2$ & 2 & 1 & 0 & 00 & 00 & 0 & 1 & 0 & 1 & 0 & 0 & 00 & 02 & & 00 & 1 & 0 & 0 & 0 & 0 & 0 & - & 1 \\
\hline Pseu & 0 & & 0 & 0 & 0 & 10 & 2 & 2 & & 2 & ? & ? & ? & 2 & 1 & 0 & 00 & 00 & 0 & 1 & 0 & 1 & 0 & 0 & 0 & 02 & & & & 0 & 0 & 0 & 0 & 0 & & 1 \\
\hline ificus & 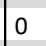 & & 0 & 0 & 0 & 10 & 2 & 2 & & 2 & $?$ & $?$ & ? & 2 & 1 & 0 & 00 & 00 & 0 & 1 & 0 & 1 & 0 & 0 & 0 & 02 & & & & 0 & 0 & 0 & 0 & 0 & & 1 \\
\hline doris & 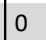 & & 0 & 0 & 0 & 10 & 2 & 2 & & 2 & $?$ & $?$ & $?$ & 2 & 1 & 0 & 00 & 0 & 0 & 1 & 0 & 1 & 0 & 0 & 0 & 02 & & & & 0 & 0 & 0 & 0 & 0 & & 1 \\
\hline seuc & 0 & & 0 & & 0 & 10 & 2 & 2 & & 2 & ? & ? & ? & 2 & 1 & 0 & 00 & 00 & 0 & 1 & 0 & 1 & 0 & 0 & 0 & 0 & & & & 0 & 0 & 0 & 0 & 0 & - & \\
\hline Chry & 0 & & 0 & 0 & 0 & 10 & & 2 & & 2 & $?$ & $?$ & $?$ & 2 & 1 & 0 & 00 & 0 & 0 & 1 & 0 & 1 & 0 & 0 & 0 & 0 & & & & 0 & 0 & 0 & 0 & 0 & & \\
\hline bry & 0 & & 0 & 0 & 0 & 10 & 2 & 2 & & 2 & $?$ & $?$ & $?$ & 2 & 1 & 0 & 00 & 0 & 0 & 1 & 0 & 1 & 0 & 0 & 0 & 02 & & 00 & & 0 & 0 & 0 & 0 & 0 & & \\
\hline tus & 0 & & 0 & 0 & 0 & 10 & 2 & 2 & & 2 & $?$ & $?$ & ? & 2 & 1 & 0 & 00 & 0 & 0 & 1 & 0 & 1 & 0 & 0 & 0 & 02 & & & & 0 & 0 & 0 & 0 & 0 & & \\
\hline$\therefore$ & 0 & & 0 & 0 & 0 & 10 & 2 & 2 & & 2 & $?$ & $?$ & ? & 2 & 1 & 0 & 00 & 00 & 0 & 1 & 0 & 1 & 0 & 0 & 0 & 02 & & 0 & & 0 & 0 & 0 & 0 & 0 & . & \\
\hline$F$ & 0 & & 0 & 0 & 0 & 10 & 2 & 2 & & 2 & $?$ & $?$ & $?$ & 2 & 1 & 0 & 00 & 0 & 0 & 1 & 0 & 1 & 0 & 0 & 0 & & & & & & 0 & 0 & 0 & 0 & & \\
\hline olli & 0 & & 0 & 0 & 0 & 00 & 2 & 2 & & 2 & $?$ & $?$ & $?$ & 2 & 1 & 0 & 00 & 00 & 0 & 1 & 0 & 1 & 0 & 0 & 0 & 02 & & 00 & & 0 & 0 & 0 & 0 & & . & \\
\hline Fusi & 0 & & 0 & 0 & 0 & 10 & 2 & 2 & & 2 & $?$ & ? & ? & 2 & 1 & 0 & 00 & 0 & 0 & 1 & 0 & 1 & 0 & 0 & 0 & 0 & & & & 0 & 0 & 0 & 0 & & - & \\
\hline & 0 & & 0 & & 0 & 10 & & 2 & & 2 & ? & ? & ? & 2 & 1 & & 00 & 0 & 0 & 1 & 0 & 1 & 0 & 0 & 0 & & & & & 0 & 0 & 0 & 0 & & - & \\
\hline & 0 & & 0 & 0 & 0 & 10 & 2 & 2 & & 2 & ? & ? & ? & 2 & 1 & 0 & 00 & 00 & 0 & 1 & 0 & 1 & 0 & 0 & 0 & 0 & & & & 0 & 0 & 0 & 0 & ( & & \\
\hline & 0 & & 0 & 0 & 0 & 10 & 2 & 2 & & 2 & ? & ? & ? & 2 & 1 & 0 & 00 & 00 & 0 & 1 & 0 & 1 & 0 & 0 & 0 & 0 & & 00 & & 0 & 0 & 0 & 0 & 0 & & 1 \\
\hline Pset & 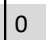 & & 0 & 0 & 0 & 10 & 2 & 2 & & 2 & $?$ & ? & ? & 2 & 1 & 0 & 00 & 0 & 0 & 1 & 0 & 1 & 0 & 0 & 0 & 0 & & 0 & J & 0 & 0 & 0 & 0 & & - & 1 \\
\hline Gra & 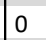 & & 0 & 0 & 0 & 10 & 2 & 2 & & 2 & $?$ & ? & ? & 2 & 1 & 0 & 00 & 00 & 0 & 1 & 0 & 1 & 0 & 0 & 0 & 02 & & 0 & 1 & 0 & 0 & 0 & 0 & 0 & - & 1 \\
\hline & 0 & & 0 & 0 & 0 & 10 & 2 & 2 & & 2 & ? & ? & ? & 2 & 1 & 0 & 00 & 0 & 0 & 1 & 0 & 1 & 0 & 0 & 0 & 02 & & 0 & 1 & 0 & 0 & 0 & 0 & 0 & & 1 \\
\hline & 0 & & 0 & 0 & 0 & 10 & 2 & 2 & & 2 & $?$ & ? & $?$ & 2 & 1 & 0 & 00 & 0 & 0 & 1 & 0 & 1 & 0 & 0 & 0 & 02 & & 0 & 1 & 0 & 0 & 0 & 0 & 0 & . & 1 \\
\hline & & & 0 & 0 & 0 & 1 & 2 & 2 & & 2 & $?$ & ? & ? & 2 & 1 & 0 & 00 & 0 & 0 & 1 & 0 & 1 & 0 & 0 & 0 & 02 & & 0 & 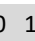 & 0 & 0 & 0 & 0 & 0 & - & 1 \\
\hline & 0 & & 0 & 0 & 0 & 10 & 2 & 2 & & 2 & $?$ & ? & ? & 2 & 1 & 0 & 00 & 00 & 0 & 1 & 0 & 1 & 0 & 0 & 0 & 01 & & 0 & & 0 & 0 & 0 & 0 & 0 & - & 1 \\
\hline & 0 & & 0 & 0 & 0 & 10 & 2 & 2 & & 2 & $?$ & ? & ? & 2 & 1 & 0 & 00 & 00 & 0 & 1 & 0 & 1 & 0 & 0 & 0 & 01 & & 0 & & 0 & 0 & 0 & 0 & 0 & & 1 \\
\hline$A$ & 0 & & 0 & 0 & 01 & 10 & 2 & 2 & 1 & 2 & $?$ & $?$ & $?$ & 2 & 1 & 0 & 00 & 0 & 0 & 1 & 0 & 1 & 0 & 0 & 0 & 0 & & 0 & & 0 & 0 & 0 & 0 & 0 & - & 1 \\
\hline & 0 & & 0 & 0 & 0 & 10 & 2 & 2 & & 2 & ? & ? & ? & 2 & 1 & 0 & 00 & 00 & 0 & 1 & 0 & 1 & 0 & 0 & 0 & 0 & & 0 & & 0 & 0 & 0 & 0 & 0 & . & \\
\hline & 0 & & 0 & 0 & 0 & 10 & 2 & 2 & & 2 & ? & ? & ? & 2 & 1 & 0 & 00 & 00 & 0 & 1 & 0 & 1 & 0 & 0 & 0 & 0 & & 0 & & 0 & 0 & 0 & 0 & 0 & - & \\
\hline$P$ & 0 & & 0 & 0 & 0 & 10 & 2 & 2 & & 2 & $?$ & ? & $?$ & 2 & 1 & 0 & 00 & 0 & 0 & 1 & 0 & 1 & 0 & 0 & 0 & 0 & & 0 & & 0 & 0 & 0 & 0 & & - & 1 \\
\hline & 0 & & 0 & & 0 & 10 & 2 & 2 & & 2 & $?$ & ? & ? & 2 & 1 & 0 & 00 & 00 & 0 & 1 & 0 & 1 & 0 & 0 & 0 & 0 & & 0 & & 0 & 0 & 0 & 0 & & - & 1 \\
\hline & 0 & & 0 & & 0 & 1 & 2 & 2 & & 2 & $?$ & ? & ? & 2 & 1 & 0 & 00 & 0 & 0 & 1 & 0 & 1 & 0 & 0 & 0 & 0 & & 0 & & 0 & 0 & 0 & 0 & 0 & 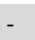 & 1 \\
\hline & 0 & & 0 & 0 & 0 & 1 & 2 & 2 & & 2 & ? & ? & ? & 2 & 1 & 0 & 00 & 0 & 0 & 1 & 0 & 1 & 0 & 0 & 0 & 0 & & 0 & D & 0 & 0 & 0 & 0 & 0 & & 1 \\
\hline & 0 & & 0 & 0 & 0 & 1 & 2 & 2 & & 2 & ? & $?$ & ? & 2 & 1 & 0 & 00 & 00 & 0 & 1 & 0 & 1 & 0 & 0 & 0 & 0 & & 0 & 1 & 0 & 0 & 0 & 0 & 0 & & 1 \\
\hline & 0 & & 0 & 0 & 0 & 1 & 2 & 2 & 1 & 2 & $?$ & $?$ & ? & 2 & 1 & 0 & 00 & 00 & 0 & 1 & 0 & 1 & 0 & 0 & 0 & 0 & & 0 & ) & 0 & 0 & 0 & 0 & 0 & . & 1 \\
\hline & 0 & & 0 & 0 & 0 & 1 & 2 & 2 & & 2 & 2 & $?$ & ? & 2 & 1 & 0 & 00 & 0 & 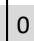 & 1 & 0 & 1 & 0 & 0 & 0 & 0 & & 0 & 1 & 0 & 0 & 0 & 0 & 0 & & \\
\hline & 0 & & 0 & 0 & 0 & 10 & 2 & 2 & & 2 & ? & ? & ? & 2 & 1 & 0 & 00 & 00 & 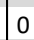 & 1 & 0 & 1 & 0 & 0 & 0 & 0 & & 0 & D & 0 & 0 & 0 & 0 & ( & & 1 \\
\hline & 0 & & 0 & & 0 & 1 & 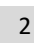 & 2 & & 2 & ? & $?$ & $?$ & 2 & 1 & 0 & 00 & 00 & 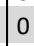 & 1 & 0 & 1 & 0 & 0 & 0 & 0 & & 0 & 1 & 0 & 0 & ) & 0 & 0 & & 1 \\
\hline & 0 & & 0 & & 0 & 1 & 2 & 2 & & 2 & ? & $?$ & ? & 2 & 1 & 0 & 00 & 00 & 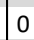 & 1 & 0 & 1 & 0 & 0 & 0 & 0 & & & 1 & . & 0 & 0 & 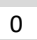 & ( & & 1 \\
\hline Leuc & 0 & & 0 & & 0 & 1 & 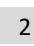 & 2 & & 2 & ? & ? & ? & 2 & ( & 0 & 00 & 00 & 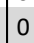 & 1 & 0 & 1 & 0 & 0 & 0 & 0 & & & & 0 & 0 & 0 & 0 & 0 & & \\
\hline 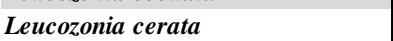 & 0 & & 0 & & 0 & 1 & 2 & 2 & & 2 & ? & $?$ & ? & 2 & 1 & & 00 & 00 & 0 & 1 & 0 & 1 & 0 & 0 & 0 & 02 & & & & 0 & 0 & 0 & 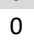 & 0 & & \\
\hline & 0 & & 0 & 0 & 0 & 1 & 2 & 2 & & 2 & ? & $?$ & ? & 2 & 1 & 0 & 00 & 0 & 0 & 1 & 0 & 1 & 0 & 0 & 0 & 0 & & 0 & & 0 & 0 & 0 & 1 & 0 & . & 1 \\
\hline & 0 & & 0 & 0 & 0 & 1 & 2 & 2 & 1 & 2 & ? & $?$ & ? & 2 & 1 & 0 & 0 & 00 & 0 & 1 & 0 & 1 & 0 & 0 & 0 & 0 & & 0 & ) & 0 & 0 & D & 0 & 0 & - & 1 \\
\hline & 0 & & 0 & & 0 & 1 & 2 & 2 & & 2 & ? & $?$ & ? & 2 & & & 0 & 00 & 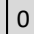 & 1 & 0 & 1 & 0 & 0 & 0 & 0 & & 0 & & . & 0 & & D & & & \\
\hline & 0 & & 0 & & 0 & & & 2 & & 2 & ? & $?$ & ? & 2 & & & 00 & & 0 & 1 & 0 & 1 & 0 & 0 & 0 & 0 & & & & 0 & 0 & 0 & 0 & $c$ & . & 1 \\
\hline & 0 & & 0 & & 0 & 10 & & 2 & & 2 & & & & 2 & & & & & 0 & & 0 & & & & & & & & & & & & & & & \\
\hline
\end{tabular}




\begin{tabular}{|c|c|c|c|c|c|c|c|c|c|c|c|c|c|c|c|c|c|c|c|c|c|c|c|c|c|c|c|c|c|c|c|c|c|c|c|c|c|c|c|c|c|}
\hline TAXON & & & & 3 & & & 6 & 7 & 8 & 9 & & & & 3 & & 5 & 6 & & & & & 1 & & & & & & 6 & & 8 & 9 & 0 & & & & & & & & & \\
\hline Monetaria annulus & 5 & 2 & 3 & 0 & 0 & 1 & 2 & 2 & 1 & 3 & & 0 & & 0 & 0 & 2 & 1 & 1 & 0 & 3 & 1 & 0 & 8 & $\overline{5}$ & & 0 & 0 & 1 & 0 & - & & 0 & 2 & 1 & 1 & 0 & 1 & 0 & 1 & 1 & \\
\hline Thais speciosa & 0 & 0 & 0 & 0 & 0 & 0 & 1 & 0 & 0 & - & & - & & 4 & 1 & 1 & 2 & 1 & 0 & 3 & 1 & 0 & 1 & 0 & & 0 & 0 & 1 & 0 & - & - & 0 & 1 & 0 & 0 & 0 & 1 & 0 & 1 & 1 & 1 \\
\hline Pugilina tupiniquim & 0 & 0 & 0 & 0 & 1 & 0 & 1 & 0 & 0 & - & & - & & 4 & 0 & 0 & 2 & 2 & 0 & 3 & 2 & 0 & 1 & 0 & & 0 & 0 & 1 & 0 & - & - & 0 & 1 & 0 & 0 & 1 & 1 & 0 & & 1 & \\
\hline engoniophos unicinct & 0 & 0 & 0 & 0 & 0 & 0 & 1 & 0 & 0 & - & & - & & 0 & 0 & 0 & 2 & 2 & 0 & 3 & 2 & 0 & 1 & 0 & & 0 & 0 & 1 & 0 & - & - & 0 & 1 & 0 & 0 & 0 & 1 & & & & \\
\hline Nass & 0 & 0 & 0 & 0 & 0 & 0 & 1 & 0 & 0 & - & & - & & 0 & 0 & 0 & 2 & 1 & 0 & 3 & 2 & 0 & 1 & 0 & & 0 & U & 1 & 0 & - & - & 0 & 1 & 0 & 0 & 0 & 1 & & & 1 & \\
\hline Bullia lc & 0 & 0 & 0 & 0 & 1 & 0 & 1 & 0 & 0 & - & & - & & 4 & 0 & 0 & 2 & 1 & 0 & 3 & 3 & 0 & 1 & & 0 & 0 & 0 & 1 & 0 & - & - & 0 & 1 & 0 & 0 & 0 & 1 & 1 & & 1 & \\
\hline Buccinun & 0 & 0 & 0 & 0 & 1 & 0 & 1 & 0 & 0 & - & & - & & 4 & 0 & 0 & 2 & 2 & 0 & 3 & 2 & 0 & 1 & 0 & 0 & 0 & 0 & 1 & 0 & - & - & 0 & 1 & 0 & 0 & 0 & 1 & 0 & 1 & 1 & \\
\hline Pisania pusio & 0 & 0 & 0 & 0 & 1 & 0 & 1 & 0 & 0 & - & & - & & 4 & 0 & 0 & 2 & 2 & 0 & 3 & 2 & 0 & 1 & 0 & 0 & 0 & 0 & 1 & 0 & - & - & 0 & 1 & 0 & 0 & 0 & 1 & 0 & 1 & 11 & 1 \\
\hline Dolicholatirus & 0 & 0 & 0 & 0 & 0 & 0 & 1 & 0 & 0 & - & & - & & 0 & 0 & 0 & 2 & 2 & 0 & 3 & 1 & 0 & 1 & 0 & 0 & 0 & 0 & 1 & 0 & - & - & 0 & 1 & 0 & 0 & 1 & 1 & 1 & & 1 & 1 \\
\hline Teralatirus & 0 & 0 & 0 & 0 & 0 & 0 & 1 & 0 & 0 & - & & - & & 0 & 0 & 0 & 2 & 2 & 0 & 3 & 1 & 0 & 1 & 0 & 0 & 0 & 0 & 1 & 0 & - & - & 0 & 1 & 0 & 0 & 1 & 1 & 1 & 1 & 1 & 1 \\
\hline Dolicholatirus a & 0 & 0 & 0 & 0 & 0 & 0 & 1 & 0 & 0 & - & & - & - & 0 & 0 & 0 & 2 & 2 & 0 & 3 & 1 & 0 & 1 & 0 & 0 & 0 & 0 & 1 & 0 & - & - & 0 & 1 & 0 & 0 & 1 & 1 & 1 & & 1 & \\
\hline dae & 0 & 0 & 0 & 0 & 0 & 0 & 1 & 0 & 0 & - & & - & - & 0 & 0 & 0 & 2 & 2 & 0 & 3 & 2 & 0 & 1 & & 0 & 0 & 0 & 1 & 0 & - & - & 0 & 1 & 0 & 0 & 0 & 2 & 1 & & 1 & \\
\hline Pset & 0 & 0 & 0 & 0 & 0 & 0 & 1 & 0 & 0 & - & & - & & 0 & 0 & 0 & 2 & 2 & 0 & 3 & 2 & 0 & 1 & 0 & b & 0 & 0 & 1 & 0 & - & . & 0 & 1 & 0 & 0 & 0 & 2 & 1 & 1 & 1 & 1 \\
\hline$A m i$ & 0 & 0 & 0 & 0 & 0 & 0 & 1 & 0 & 0 & - & & - & & 0 & 0 & 0 & 2 & 2 & 0 & 3 & 2 & 0 & 1 & & 0 & 0 & 0 & 1 & 0 & - & - & 0 & 1 & 0 & 0 & 0 & 2 & 1 & 1 & 1 & 1 \\
\hline andoris & 0 & 0 & 0 & 0 & 0 & 0 & 1 & 0 & 0 & - & & - & & 0 & 0 & 0 & 2 & 2 & 0 & 3 & 2 & 0 & 1 & 0 & 0 & 0 & 0 & 1 & 0 & - & - & 0 & 1 & 0 & 0 & 0 & 2 & 1 & 1 & 1 & 10 \\
\hline lidus & 0 & 0 & 0 & 0 & 0 & 0 & 1 & 0 & 0 & - & & - & - & 0 & 0 & 0 & 2 & 2 & 0 & 3 & 2 & 0 & 1 & 0 & 0 & 0 & 0 & 1 & 0 & - & - & 0 & 1 & 0 & 0 & 0 & 2 & 0 & ) 1 & 1 & 10 \\
\hline Chr & 0 & 0 & 0 & 0 & 0 & 0 & 1 & 0 & 0 & - & & - & - & 0 & 0 & 0 & 2 & 2 & 0 & 3 & 2 & 0 & 1 & & 0 & 0 & 0 & 1 & 0 & - & - & 0 & 1 & 0 & 0 & 0 & 2 & 0 & & 1 & 1 \\
\hline Chry & 0 & 0 & 0 & 0 & 0 & 0 & 1 & 0 & 0 & - & & - & 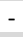 & 0 & 0 & 0 & 2 & 2 & 0 & 3 & 2 & 0 & 1 & & 0 & 0 & 0 & 1 & 0 & - & - & 0 & 1 & 0 & 0 & 0 & 2 & 0 & 1 & 1 & 1 \\
\hline$F u s$ & 0 & 0 & 0 & 0 & 0 & 0 & 1 & 0 & 0 & - & - & - & & 0 & 0 & 0 & 2 & 2 & 0 & 3 & 1 & 0 & 1 & & o & 0 & 0 & 1 & 0 & - & - & 0 & 1 & 0 & 0 & 0 & 2 & 0 & 1 & 1 & 1 \\
\hline Fusinus brasiliensis & 0 & 0 & 0 & 0 & 0 & 0 & 1 & 0 & 0 & - & & - & & 0 & 0 & 0 & 2 & 2 & 0 & 3 & 1 & 0 & 1 & 0 & 0 & 0 & 0 & 1 & 0 & - & - & 0 & 1 & 0 & 0 & 0 & 2 & 0 & ) & 11 & 1 \\
\hline Fusinus sp. & 0 & 0 & 0 & 0 & 0 & 0 & 1 & 0 & 0 & - & - & - & - & 0 & 0 & 0 & 2 & 2 & 0 & 3 & 1 & 0 & 1 & 0 & 0 & 0 & 0 & 1 & 0 & - & - & 0 & 1 & 0 & 0 & 0 & 2 & 0 & 1 & 11 & 10 \\
\hline us fren & 0 & 0 & 0 & 0 & 0 & 0 & 1 & 0 & 0 & - & - & - & - & 0 & 0 & 0 & 2 & 2 & 0 & 3 & 1 & 0 & 1 & & 0 & 0 & 0 & 1 & 0 & - & - & 0 & 1 & 0 & 0 & 0 & 2 & 0 & & 1 & 10 \\
\hline Fus & 0 & 0 & 0 & 0 & 0 & 0 & 1 & 0 & 0 & - & & - & 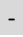 & 0 & 0 & 0 & 2 & 2 & 0 & 3 & 1 & 0 & 1 & & 0 & 0 & 0 & 1 & 0 & - & - & 0 & 1 & 0 & 0 & 0 & 2 & U & 1 & 1 & 1 \\
\hline & 0 & 0 & 0 & 0 & 0 & 0 & 1 & 0 & 0 & - & & - & & 0 & 0 & 0 & 2 & 2 & 0 & 3 & 2 & 0 & 1 & & b & 0 & 0 & 1 & 0 & - & - & 0 & 1 & 0 & 0 & 0 & 2 & & 1 & 1 & 0 \\
\hline ifusu & 0 & 0 & 0 & 0 & 0 & 0 & 1 & 0 & 0 & - & & - & & 0 & 0 & 0 & 2 & 2 & 0 & 3 & 2 & 0 & 1 & & 0 & 0 & 0 & 1 & 0 & - & - & 0 & 1 & 0 & 0 & 0 & 2 & 0 & ) & 1 & 1 \\
\hline Granulifusu & 0 & 0 & 0 & 0 & 0 & 0 & 1 & 0 & 0 & - & - & - & - & 0 & 0 & 0 & 2 & 2 & 0 & 3 & 2 & 0 & 1 & & 0 & 0 & 0 & 1 & 0 & - & - & 0 & 1 & 0 & 0 & 0 & 2 & 0 & 1 & 1 & 10 \\
\hline olatirus & 0 & 0 & 0 & 0 & 0 & 0 & 1 & 0 & 0 & - & - & - & - & 0 & 0 & 0 & 2 & 2 & 0 & 3 & 2 & 0 & 1 & 0 & 0 & 0 & 0 & 1 & 0 & - & - & 0 & 1 & 0 & 0 & 0 & 2 & 0 & 1 & 11 & 10 \\
\hline Granulifusus & 0 & 0 & 0 & 0 & 0 & 0 & 1 & 0 & 0 & - & - & - & - & 0 & 0 & 0 & 2 & 2 & 0 & 3 & 2 & 0 & 1 & & D & 0 & 0 & 1 & 0 & - & - & 0 & 1 & 0 & 0 & 0 & 2 & 0 & ) & 11 & 10 \\
\hline Fus & 0 & 0 & 0 & 0 & 0 & 0 & 1 & 0 & 0 & - & & - & 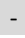 & 0 & 0 & 0 & 2 & 2 & 0 & 3 & 2 & 0 & 1 & & 0 & 0 & 0 & 1 & 0 & - & - & 0 & 1 & 0 & 0 & 0 & 2 & U & 1 & 1 & 1 \\
\hline Per & 0 & 0 & 0 & 0 & 0 & 0 & 1 & 0 & 0 & - & & - & & 0 & 0 & 0 & 2 & 2 & 0 & 3 & 2 & 0 & 1 & & 0 & 0 & 0 & 1 & 0 & - & - & 0 & 1 & 0 & 0 & 0 & 2 & & 1 & 1 & 1 \\
\hline satula & 0 & 0 & 0 & 0 & 0 & 0 & 1 & 0 & 0 & - & & - & & 0 & 0 & 0 & 2 & 2 & 0 & 3 & 2 & 0 & 1 & & 0 & 0 & 0 & 1 & 0 & - & - & 0 & 1 & 0 & 0 & 0 & 2 & 0 & ) & 1 & 10 \\
\hline Nod & 0 & 0 & 0 & 0 & 0 & 0 & 1 & 0 & 0 & - & - & - & - & 0 & 0 & 0 & 2 & 2 & 0 & 3 & 2 & 0 & 1 & & 0 & 0 & 0 & 1 & 0 & - & - & 0 & 1 & 0 & 0 & 1 & 2 & 0 & ) & 1 & 11 \\
\hline Latir & 0 & 0 & 0 & 0 & 0 & 0 & 1 & 0 & 0 & - & - & - & - & 0 & 0 & 0 & 2 & 2 & 0 & 3 & 2 & 0 & 1 & 0 & 0 & 0 & 0 & 1 & 0 & - & - & 0 & 1 & 0 & 0 & 1 & 2 & 0 & 1 & 11 & 11 \\
\hline Aur & 0 & 0 & 0 & 0 & 0 & 0 & 1 & 0 & 0 & - & - & - & - & 0 & 0 & 0 & 2 & 2 & 0 & 3 & 2 & 0 & 1 & & D & 0 & 0 & 1 & 0 & - & - & 0 & 1 & 0 & 0 & 1 & 2 & U & 1 & 1 & 1 \\
\hline$F a$ & 0 & 0 & 0 & 0 & 0 & 0 & 1 & 0 & 0 & - & & - & 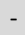 & 0 & 0 & 0 & 2 & 2 & 0 & 3 & 2 & 0 & 1 & & o & 0 & 0 & 1 & 0 & - & - & 0 & 1 & 0 & 0 & 1 & 2 & U & 1 & 1 & 1 \\
\hline Aust & 0 & 0 & 0 & 0 & 0 & 0 & 1 & 0 & 0 & . & & - & & 0 & 0 & 0 & 2 & 2 & 0 & 3 & 2 & 0 & 1 & & 0 & 0 & 0 & 1 & 0 & - & - & 0 & 1 & 0 & 0 & 1 & 2 & 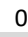 & 1 & 1 & 1 \\
\hline Pleu & 0 & 0 & 0 & 0 & 0 & 0 & 1 & 0 & 0 & - & & - & - & 0 & 0 & 0 & 2 & 2 & 0 & 3 & 2 & 0 & 1 & & o & 0 & 0 & 1 & 0 & - & - & 0 & 1 & 0 & 0 & 1 & 2 & 0 & ) & 1 & 11 \\
\hline Filifusus filamentosus & 0 & 0 & 0 & 0 & 0 & 0 & 1 & 0 & 0 & - & - & - & - & 0 & 0 & 0 & 2 & 2 & 0 & 3 & 2 & 0 & 1 & & 0 & 0 & 0 & 1 & 0 & - & - & 0 & 1 & 0 & 0 & 1 & 2 & 0 & 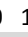 & 11 & 11 \\
\hline Hemipolygon & 0 & 0 & 0 & 0 & 0 & 0 & 1 & 0 & 0 & - & - & - & - & 0 & 0 & 0 & 2 & 2 & 0 & 3 & 2 & 0 & 1 & & 0 & 0 & 0 & 1 & 0 & - & - & 0 & 1 & 0 & 0 & 0 & 2 & 0 & ) & 11 & 1 \\
\hline Pustulatirus mediam & 0 & 0 & 0 & 0 & 0 & 0 & 1 & 0 & 0 & - & - & - & - & 0 & 0 & 0 & 2 & 2 & 0 & 3 & 2 & 0 & 1 & & 0 & 0 & 0 & 1 & 0 & - & - & 0 & 1 & 0 & 0 & 0 & 2 & 0 & 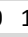 & 11 & 10 \\
\hline Pustulatirus ogum & 0 & 0 & 0 & 0 & 0 & 0 & 1 & 0 & 0 & - & & - & 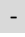 & 0 & 0 & 0 & 2 & 2 & 0 & 3 & 2 & 0 & 1 & & & 0 & 0 & 1 & 0 & - & - & 0 & 1 & 0 & 0 & 0 & 2 & 0 & 1 & 1 & j \\
\hline Poly & 0 & 0 & 0 & 0 & 0 & 0 & 1 & 0 & 0 & - & & - & - & 0 & 0 & 0 & 2 & 2 & 0 & 3 & 2 & 0 & 1 & & b & 0 & 0 & 1 & 0 & - & - & 0 & 1 & 0 & 0 & 0 & 2 & 0 & ) & 1 & 10 \\
\hline Latir & 0 & 0 & 0 & 0 & 0 & 0 & 1 & 0 & 0 & - & & - & & 0 & 0 & 0 & 2 & 2 & 0 & 3 & 2 & 0 & 1 & & b & 0 & 0 & 1 & 0 & - & - & 0 & 1 & 0 & 0 & 0 & 2 & 0 & ) & 1 & 10 \\
\hline Polygona infundibulum & 0 & 0 & 0 & 0 & 0 & 0 & 1 & 0 & 0 & - & & - & & 0 & 0 & 0 & 2 & 2 & 0 & 3 & 2 & 0 & 1 & & 0 & 0 & 0 & 1 & 0 & - & - & 0 & 1 & 0 & 0 & 0 & 2 & 0 & 1 & 1 & 10 \\
\hline Hemipolygona beckyae & 0 & 0 & 0 & 0 & 0 & 0 & 1 & 0 & 0 & - & & - & & 0 & 0 & 0 & 2 & 2 & 0 & 3 & 2 & 0 & 1 & & 0 & 0 & 0 & 1 & 0 & - & - & 0 & 1 & 0 & 0 & 0 & 2 & 0 & ) & 1 & 10 \\
\hline Latirus pictus & 0 & 0 & 0 & 0 & 0 & 0 & 1 & 0 & 0 & - & & - & 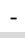 & 0 & 0 & 0 & 2 & 2 & 0 & 3 & 2 & 0 & 1 & 0 & 0 & 0 & 0 & 1 & 0 & - & - & 0 & 1 & 0 & 0 & 0 & 2 & 0 & 1 & 1 & 1 \\
\hline Leuc & 0 & 0 & 0 & 0 & 0 & 0 & 1 & 0 & 0 & - & & - & & 0 & 0 & 0 & 2 & 2 & 0 & 3 & 2 & 0 & 1 & & J & 0 & 0 & 1 & 0 & - & - & 0 & 1 & 0 & 0 & 1 & 2 & U & 1 & 1 & 0 \\
\hline onia cerata & 0 & 0 & 0 & 0 & 0 & 0 & 1 & 0 & 0 & - & & - & & 0 & 0 & 0 & 2 & 2 & 0 & 3 & 2 & 0 & 1 & & 0 & 0 & 0 & 1 & 0 & - & - & 0 & 1 & 0 & 0 & 1 & 2 & 0 & 1 & 1 & 10 \\
\hline Opeatostoma pseud & 0 & 0 & 0 & 0 & 0 & 0 & 1 & 0 & 0 & - & & - & & 0 & 0 & 0 & 2 & 2 & 0 & 3 & 2 & 0 & 1 & & & 0 & 0 & 1 & 0 & - & - & 0 & 1 & 0 & 0 & 1 & 2 & 0 & 1 & 1 & 10 \\
\hline Leucozonia nassa nassa & 0 & 0 & 0 & 0 & 0 & 0 & 1 & 0 & 0 & - & & - & & 0 & 0 & 0 & 2 & 2 & 0 & 3 & 2 & 0 & 1 & 0 & b & 0 & 0 & 1 & 0 & - & - & 0 & 1 & 0 & 0 & 1 & 2 & 0 & 1 & 1 & 10 \\
\hline a cinguli & 0 & 0 & 0 & 0 & 0 & 0 & 1 & 0 & 0 & - & & - & & 0 & 0 & 0 & 2 & 2 & 0 & 3 & 2 & 0 & 1 & 0 & & 0 & 0 & 1 & 0 & - & - & 0 & 1 & 0 & 0 & 1 & 2 & 0 & 1 & 1 & 1 \\
\hline Leuc & 0 & 0 & 0 & 0 & 0 & 0 & 1 & 0 & 0 & - & & - & & 0 & 0 & 0 & 2 & 2 & 0 & 3 & 2 & 0 & 1 & 10 & & 0 & 0 & 1 & 0 & - & - & 0 & 1 & 0 & 0 & 1 & 2 & 0 & 1 & 1 & 1 \\
\hline Leucozonia ponderosa & 0 & 0 & 0 & 0 & 0 & 0 & 1 & 0 & 0 & [ & & - & & 0 & 0 & 0 & 2 & 2 & 0 & 3 & 2 & 0 & 1 & & & 0 & 0 & 1 & 0 & - & - & 0 & 1 & 0 & 0 & 1 & 2 & 0 & & 1 & \\
\hline
\end{tabular}




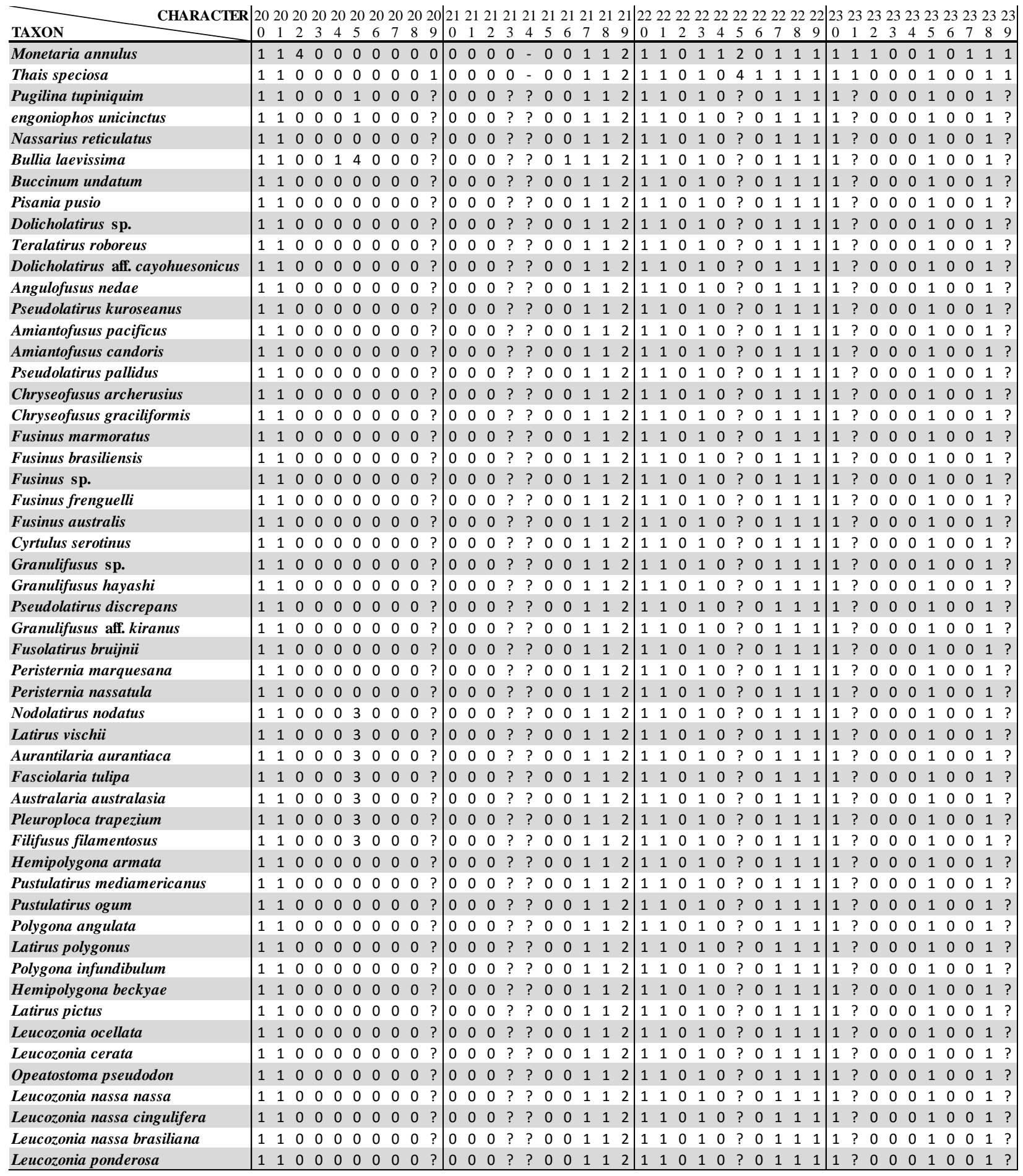




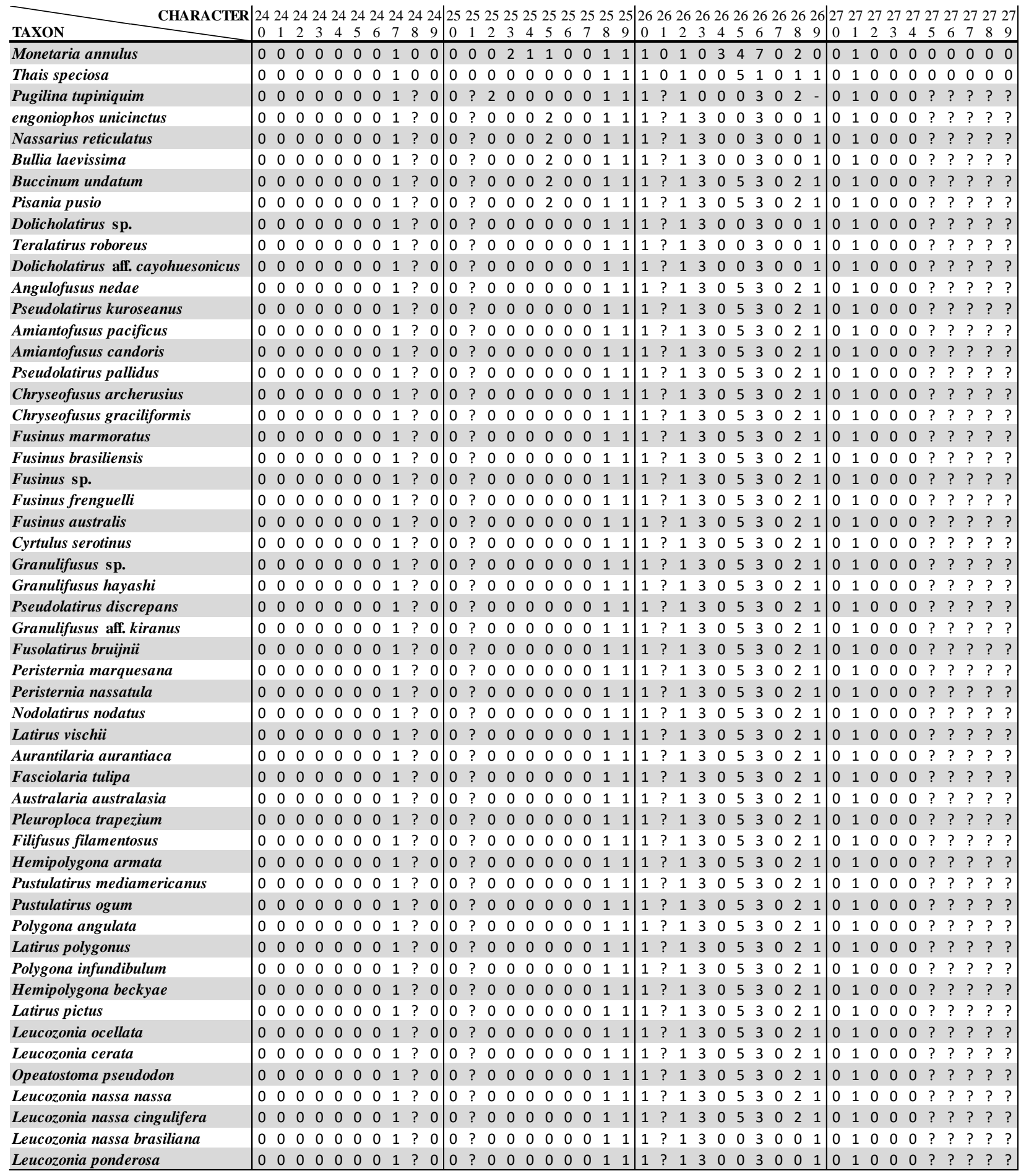




\begin{tabular}{|c|c|c|c|c|c|c|c|c|c|c|c|c|c|c|c|c|c|c|c|c|c|c|c|c|c|c|c|c|c|c|c|c|c|c|c|c|c|c|c|c|c|}
\hline XON & $\begin{array}{c}20 \\
0\end{array}$ & & 2 & 3 & 4 & 5 & 6 & 7 & 8 & 9 & & & & & & & 6 & 7 & & 9 & & 1 & & & 4 & & & & & 9 & & & 2 & & & & & & & & \\
\hline annulus & 0 & 0 & 0 & 8 & 1 & 1 & 0 & 0 & 2 & 2 & 0 & 0 & 0 & 0 & 0 & 0 & 0 & 0 & 1 & 0 & 1 & 0 & 2 & 0 & 0 & 2 & - & 0 & 0 & 1 & 1 & 2 & & & 1 & 2 & T & & & & \\
\hline Thai & 0 & 0 & 0 & 0 & 1 & 1 & 0 & 0 & 0 & 2 & 0 & 0 & 0 & U & 0 & 0 & 0 & 0 & 1 & 0 & 1 & 0 & 2 & 0 & 0 & 0 & 0 & 0 & U & 1 & 1 & 2 & & & & 0 & 0 & ) & & & \\
\hline Pugilina tupiniq & ? & ? & ? & 0 & 1 & 1 & 4 & ? & ? & 2 & 0 & 0 & 0 & 0 & 0 & 0 & 0 & 0 & 3 & 0 & 2 & 0 & 2 & 0 & 0 & 0 & 0 & 0 & 0 & 0 & 1 & ! & & & & - & U & 0 & & 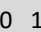 & \\
\hline engoniopho & ? & ? & ? & 0 & 1 & 1 & 4 & ? & ? & 2 & 0 & $u$ & 0 & 0 & 0 & 0 & 0 & 0 & 3 & 0 & 2 & 0 & 2 & 0 & 0 & 0 & 0 & 0 & 0 & 1 & 0 & $?$ & ? & & & - & & c & ) & & \\
\hline Nass & ? & ? & ? & 0 & 1 & 1 & 4 & ? & ? & 2 & 0 & 0 & 0 & 0 & 0 & 0 & 0 & 0 & 2 & 0 & 2 & 0 & 2 & 0 & 0 & 0 & 0 & 0 & 0 & 1 & 0 & $?$ & ? & & & - & & & & & \\
\hline Bullia laev & ? & ? & ? & 0 & 1 & 1 & 4 & ? & $?$ & 2 & 0 & 0 & 0 & 0 & 0 & 0 & 0 & 0 & 3 & 0 & 2 & 0 & 2 & 0 & 0 & 0 & 0 & 0 & 0 & 1 & 1 & $?$ & ? & & & - & 0 & & ) & & \\
\hline Buccinum & ? & ? & ? & 0 & 1 & 1 & 4 & ? & ? & 2 & 0 & 0 & 0 & 0 & 0 & 0 & 0 & 0 & 1 & 0 & 2 & 0 & 2 & 0 & 0 & 0 & 0 & 0 & 0 & 1 & 0 & $?$ & ? & 0 & - & - & 0 & C & כ & 0 & \\
\hline Pisania pusio & ? & ? & ? & 0 & 1 & 1 & 4 & ? & ? & 2 & 0 & 0 & 0 & 0 & 0 & 0 & 0 & 0 & 1 & 0 & 2 & 0 & 2 & 0 & 0 & 0 & 0 & 0 & 0 & 1 & 0 & $?$ & ? & 0 & - & - & 0 & c & כ & 0 & 2 \\
\hline Dolicholatirus sp. & ? & ? & ? & 0 & 1 & 1 & 4 & ? & ? & 2 & 0 & 0 & 0 & 0 & 0 & 0 & 0 & 0 & 2 & 0 & 2 & 0 & 2 & 0 & 0 & 0 & 0 & 0 & 0 & 1 & 0 & $?$ & ? & 0 & & - & 0 & & כ & 0 & 1 \\
\hline Teralatirus roboreus & ? & $?$ & ? & 0 & 1 & 1 & 4 & ? & ? & 2 & 0 & 0 & 0 & 0 & 0 & 0 & 0 & 0 & 2 & 0 & 2 & 0 & 2 & 0 & 0 & 0 & 0 & 0 & 0 & 1 & 0 & $?$ & ? & & & - & 0 & c & ( & 0 & 1 \\
\hline Dolicholatirus a & $?$ & ? & ? & 0 & 1 & 1 & 4 & ? & ? & 2 & 0 & 0 & 0 & 0 & 0 & 0 & 0 & 0 & 2 & 0 & 2 & 0 & 2 & 0 & 0 & 0 & 0 & 0 & 0 & 1 & 0 & $?$ & ? & & & - & 0 & & $\mathrm{~J}$ & 0 & 1 \\
\hline edae & ? & ? & ? & 0 & 1 & 1 & 4 & ? & ? & 2 & 0 & 0 & 0 & 0 & 0 & 0 & 0 & 0 & 2 & 0 & 2 & 0 & 2 & 0 & 0 & 0 & 0 & 0 & 0 & 1 & 0 & $?$ & ? & & & - & 0 & & 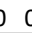 & & 2 \\
\hline Pseu & ? & ? & ? & 0 & 1 & 1 & 4 & ? & ? & 2 & 0 & 0 & 0 & 0 & 0 & 0 & 0 & 0 & 2 & 0 & 2 & 0 & 2 & 0 & 0 & 0 & 0 & 0 & 0 & 1 & 0 & ? & ? & 0 & & - & 0 & c & כ) & 0 & 2 \\
\hline Amiantofusu & ? & $?$ & ? & 0 & 1 & 1 & 4 & ? & $?$ & 2 & 0 & 0 & 0 & 0 & 0 & 0 & 0 & 0 & 2 & 0 & 2 & 0 & 2 & 0 & 0 & 0 & 0 & 0 & 0 & 1 & 0 & $?$ & $?$ & 0 & & - & 0 & c & ) & 0 & 2 \\
\hline Amiantofusu & $?$ & ? & ? & 0 & 1 & 1 & 4 & ? & ? & 2 & 0 & 0 & 0 & 0 & 0 & 0 & 0 & 0 & 2 & 0 & 2 & 0 & 2 & 0 & 0 & 0 & 0 & 0 & 0 & 1 & 0 & $?$ & ? & 0 & & - & 0 & c & ) & 0 & 2 \\
\hline allidus & ? & ? & ? & 0 & 1 & 2 & 4 & ? & ? & 2 & 0 & 0 & 0 & 0 & 0 & 0 & 0 & 0 & 2 & 0 & 2 & 0 & 2 & 0 & 1 & 0 & 0 & 0 & 0 & 1 & 0 & $?$ & ? & & - & - & 0 & C & 0 & 0 & 2 \\
\hline Chr & ? & ? & ? & 0 & 1 & 2 & 4 & ? & ? & 2 & 0 & 0 & 0 & 0 & 0 & 0 & 0 & 0 & 2 & 0 & 2 & 0 & 2 & 0 & 1 & 0 & 0 & 0 & 0 & 1 & 0 & ? & $?$ & & - & - & & & כ & 0 & 2 \\
\hline Chry & ? & ? & ? & 0 & 1 & 2 & 4 & ? & ? & 2 & 0 & 0 & 0 & 0 & 0 & 0 & 0 & 0 & 2 & 0 & 2 & 0 & 2 & 0 & 1 & 0 & 0 & 0 & 0 & 1 & 0 & $?$ & ? & & & - & 0 & C & כ & 0 & 2 \\
\hline Fusi & ? & ? & ? & 0 & 1 & 2 & 4 & ? & ? & 2 & 0 & 0 & 0 & 0 & 0 & 0 & 0 & 0 & 2 & 0 & 2 & 0 & 2 & 0 & 1 & 0 & 0 & 0 & 0 & 1 & 0 & $?$ & ? & 0 & & - & 0 & C & כ) & 2 & 2 \\
\hline Fusinus bras & $?$ & $?$ & ? & 0 & 1 & 2 & 4 & ? & ? & 2 & 0 & 0 & 0 & 0 & 0 & 0 & 0 & 0 & 2 & 0 & 2 & 0 & 2 & 0 & 1 & 0 & 0 & 0 & 0 & 1 & 0 & $?$ & $?$ & 0 & & - & 0 & $c$ & b & 0 & 2 \\
\hline Fusinus sp. & $?$ & ? & ? & 0 & 1 & 2 & 4 & ? & ? & 2 & 0 & 0 & 0 & 0 & 0 & 0 & 0 & 0 & 2 & 0 & 2 & 0 & 2 & 0 & 1 & 0 & 0 & 0 & 0 & 1 & 0 & $?$ & $?$ & 0 & & - & 0 & $c$ & כ & 02 & 2 \\
\hline Fusinus freng & $?$ & ? & ? & 0 & 1 & 2 & 4 & ? & ? & 2 & 0 & 0 & 0 & 0 & 0 & 0 & 0 & 0 & 2 & 0 & 2 & 0 & 2 & 0 & 1 & 0 & 0 & 0 & 0 & 1 & 0 & $?$ & ? & 0 & - & - & 0 & & J & 0 & 2 \\
\hline Fus & $?$ & ? & ? & 0 & 1 & 2 & 4 & ? & ? & 2 & 0 & 0 & 0 & 0 & 0 & 0 & 0 & 0 & 2 & 0 & 2 & 0 & 2 & 0 & 1 & 0 & 0 & 0 & 0 & 1 & 0 & ? & ? & 0 & 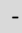 & - & U & C & כ) & 0 & 2 \\
\hline Cy & ? & ? & ? & 0 & 1 & 2 & 4 & ? & ? & 2 & 0 & 0 & 0 & 0 & 0 & 0 & 0 & 0 & 2 & 0 & 2 & 0 & 2 & 0 & 1 & 0 & 0 & 0 & 0 & 1 & 0 & ? & $?$ & & - & 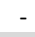 & 0 & 0 & 0 & 0 & 2 \\
\hline Gro & ? & ? & ? & 0 & 1 & 2 & 4 & ? & ? & 2 & 0 & 0 & 0 & 0 & 0 & 0 & 0 & 0 & 2 & 0 & 2 & 0 & 2 & 0 & 0 & 0 & 0 & 0 & 0 & 1 & 0 & ? & ? & 0 & - & - & 0 & C & J & 2 & 2 \\
\hline Granulifusus hayashi & $?$ & ? & ? & 0 & 1 & 2 & 4 & ? & ? & 2 & 0 & 0 & 0 & 0 & 0 & 0 & 0 & 0 & 2 & 0 & 2 & 0 & 2 & 0 & 0 & 0 & 0 & 0 & 0 & 1 & 0 & $?$ & $?$ & 0 & & - & 0 & 0 & J & 0 & 2 \\
\hline Pseudolatirus & ? & ? & ? & 0 & 1 & 2 & 4 & ? & ? & 2 & 0 & 0 & 0 & 0 & 0 & 0 & 0 & 0 & 2 & 0 & 2 & 0 & 2 & 0 & 0 & 0 & 0 & 0 & 0 & 1 & 0 & ? & ? & 0 & - & - & 0 & ) & 0 & 02 & 2 \\
\hline Granulifusus aff. kir & ? & ? & ? & 0 & 1 & 2 & 4 & ? & ? & 2 & 0 & 0 & 0 & 0 & 0 & 0 & 0 & 0 & 2 & 0 & 2 & 0 & 2 & 0 & 0 & 0 & 0 & 0 & 0 & 1 & 0 & $?$ & ? & 0 & - & - & 0 & $c$ & D & 02 & 2 \\
\hline$F u$ & ? & ? & ? & 0 & 1 & 2 & 4 & ? & $?$ & 2 & 0 & 0 & 0 & 0 & 0 & 0 & 0 & 0 & 2 & 0 & 2 & 0 & 2 & 0 & 0 & 0 & 0 & 0 & 0 & 1 & 0 & ? & ? & U & - & - & U & $C$ & J & 0 & 2 \\
\hline Peris & $?$ & ? & ? & 0 & 1 & 2 & 4 & ? & ? & 2 & 0 & 0 & 0 & 0 & 0 & 0 & 0 & 0 & 2 & 0 & 2 & 0 & 2 & 0 & 0 & 0 & 0 & 0 & 0 & 1 & 0 & $?$ & ? & & & - & 0 & c & b & & 2 \\
\hline satula & $?$ & $?$ & ? & 0 & 1 & 2 & 4 & ? & ? & 2 & 0 & 0 & 0 & 0 & 0 & 0 & 0 & 0 & 2 & 0 & 2 & 0 & 2 & 0 & 0 & 0 & 0 & 0 & 0 & 1 & 0 & $?$ & ? & 0 & & - & 0 & C & כ & 2 & 2 \\
\hline Nodo & ? & ? & ? & 0 & 1 & 2 & 4 & ? & ? & 2 & 0 & 0 & 0 & 0 & 0 & 0 & 0 & 0 & 1 & 0 & 2 & 0 & 2 & 0 & 0 & 0 & 0 & 0 & 0 & 1 & 1 & ? & ? & 0 & - & - & 0 & C & D & $\begin{array}{ll}0 & 1\end{array}$ & 1 \\
\hline ischii & ? & ? & ? & 0 & 1 & 2 & 4 & ? & ? & 2 & 0 & 0 & 0 & 0 & 0 & 0 & 0 & 0 & 1 & 0 & 2 & 0 & 2 & 0 & 0 & 0 & 0 & 0 & 0 & 1 & 1 & $?$ & ? & 0 & - & - & 0 & ) & J & 01 & 1 \\
\hline Aurc & $?$ & ? & ? & 1 & 1 & 2 & 4 & ? & ? & 2 & 0 & 0 & 0 & 0 & 0 & 0 & 0 & 0 & 1 & 0 & 2 & 0 & 2 & 0 & 0 & 0 & 0 & 0 & 0 & 1 & 1 & $?$ & $?$ & 0 & - & - & 0 & c & D & 0 & 1 \\
\hline Fas & $?$ & ? & ? & 1 & 1 & 2 & 4 & ? & ? & 2 & 0 & 0 & 0 & 0 & 0 & 0 & 0 & 0 & 1 & 0 & 2 & 0 & 2 & 0 & 0 & 0 & 0 & 0 & 0 & 1 & 1 & $?$ & ? & & & - & U & $c$ & J & & 1 \\
\hline Aust & $?$ & $?$ & ? & 1 & 1 & 2 & 4 & ? & ? & 2 & 0 & 0 & 0 & 0 & 0 & 0 & 0 & 0 & 1 & 0 & 2 & 0 & 2 & 0 & 0 & 0 & 0 & 0 & 0 & 1 & 1 & $?$ & $?$ & & & - & U & $c$ & 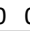 & & 1 \\
\hline Pleur & ? & ? & ? & 1 & 1 & 2 & 4 & ? & ? & 2 & 0 & 0 & 0 & 0 & 0 & 0 & 0 & 0 & 1 & 0 & 2 & 0 & 2 & 0 & 0 & 0 & 0 & 0 & 0 & 1 & 1 & ? & ? & O & & - & 0 & C & J & 0 & 1 \\
\hline Filifusus filamentosus & $?$ & ? & ? & 1 & 1 & 2 & 4 & ? & ? & 2 & 0 & 0 & 0 & 0 & 0 & 0 & 0 & 0 & 1 & 0 & 2 & 0 & 2 & 0 & 0 & 0 & 0 & 0 & 0 & 1 & 1 & ? & ? & 0 & - & - & 0 & C & 0 & 01 & 1 \\
\hline Hemipolygona armata & $?$ & ? & $?$ & 0 & 1 & 2 & 4 & ? & $?$ & 2 & 0 & 0 & 0 & 0 & 0 & 0 & 0 & 0 & 2 & 0 & 2 & 0 & 2 & 0 & 0 & 0 & 0 & 0 & 0 & 1 & 0 & $?$ & ? & 0 & - & - & 0 & C & o & 02 & 2 \\
\hline Pustulatirus media & $?$ & ? & ? & 0 & 1 & 2 & 4 & ? & ? & 2 & 0 & 0 & 0 & 0 & 0 & 0 & 0 & 0 & 2 & 0 & 2 & 0 & 2 & 0 & 0 & 0 & 0 & 0 & 0 & 1 & 0 & $?$ & $?$ & 0 & - & - & 0 & $c$ & כ & 0 & 2 \\
\hline Pust & ? & ? & ? & 0 & 1 & 2 & 4 & ? & ? & 2 & 0 & 0 & 0 & 0 & 0 & 0 & 0 & 0 & 2 & 0 & 2 & 0 & 2 & 0 & 0 & 0 & 0 & 0 & 0 & 1 & 0 & ? & ? & & & - & 0 & C & J & & 2 \\
\hline Polyg & ? & $?$ & $?$ & 0 & 1 & 2 & 4 & ? & $?$ & 2 & 0 & 0 & 0 & 0 & 0 & 0 & 0 & 0 & 2 & 0 & 2 & 0 & 2 & 0 & 0 & 0 & 0 & 0 & 0 & 1 & 0 & $?$ & $?$ & & 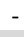 & - & 0 & c & D & 2 & 2 \\
\hline Latirus polygonus & ? & ? & ? & 0 & 1 & 2 & 4 & ? & ? & 2 & 0 & 0 & 0 & 0 & 0 & 0 & 0 & 0 & 2 & 0 & 2 & 0 & 2 & 0 & 0 & 0 & 0 & 0 & 0 & 1 & 0 & ? & ? & 0 & - & - & 0 & C & 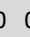 & 2 & 2 \\
\hline Polygona infundibulum & ? & ? & ? & 0 & 1 & 2 & 4 & ? & ? & 2 & 0 & 0 & 0 & 0 & 0 & 0 & 0 & 0 & 2 & 0 & 2 & 0 & 2 & 0 & 0 & 0 & 0 & 0 & 0 & 1 & 0 & ? & ? & 0 & - & - & 0 & C & 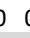 & 02 & 2 \\
\hline Hemipolygona bec & $?$ & $?$ & $?$ & 0 & 1 & 2 & 4 & ? & $?$ & 2 & 0 & 0 & 0 & 0 & 0 & 0 & 0 & 0 & 2 & 0 & 2 & 0 & 2 & 0 & 0 & 0 & 0 & 0 & 0 & 1 & 0 & $?$ & $?$ & 0 & - & - & 0 & c & 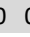 & 02 & 2 \\
\hline Latirus pictus & $?$ & ? & ? & 0 & 1 & 2 & 4 & ? & $?$ & 2 & 0 & 0 & 0 & 0 & 0 & 0 & 0 & 0 & 2 & 0 & 2 & 0 & 2 & 0 & 0 & 0 & 0 & 0 & 0 & 1 & 0 & $?$ & $?$ & 0 & - & - & 0 & C & b & 0 & 2 \\
\hline onia oce & $?$ & ? & ? & 0 & 1 & 2 & 4 & $?$ & ? & 2 & 0 & 0 & 0 & 0 & 0 & 0 & 0 & 0 & 2 & 0 & 2 & 0 & 2 & 0 & 0 & 0 & 0 & 0 & 0 & 1 & 0 & $?$ & ? & & 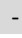 & - & U & C & J & 1 & 1 \\
\hline Leuc & ? & ? & ? & 0 & 1 & 2 & 4 & ? & ? & 2 & 0 & 0 & 0 & 0 & 0 & 0 & 0 & 0 & 2 & 0 & 2 & 0 & 2 & 0 & 0 & 0 & 0 & 0 & 0 & 1 & 0 & ? & ? & & - & - & U & C & 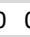 & 0 & 1 \\
\hline Opeatostoma pseud & $?$ & $?$ & ? & 0 & 1 & 2 & 4 & 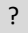 & ? & 2 & 0 & 0 & 0 & 0 & 0 & 0 & 0 & 0 & 2 & 0 & 2 & 0 & 2 & 0 & 0 & 0 & 0 & 0 & 0 & 1 & 0 & $?$ & ? & 0 & - & - & 0 & C & 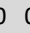 & 1 & 1 \\
\hline onia nassa na & $?$ & ? & ? & 0 & 1 & 2 & 4 & ? & ? & 2 & 0 & 0 & 0 & 0 & 0 & 0 & 0 & 0 & 2 & 0 & 2 & 0 & 2 & 0 & 0 & 0 & 0 & 0 & 0 & 1 & 0 & ? & ? & 0 & - & - & 0 & C & D & 0 & 1 \\
\hline onia nassa cingul & $?$ & ? & ? & 0 & 1 & 2 & 4 & ? & ? & 2 & 0 & 0 & 0 & 0 & 0 & 0 & 0 & 0 & 2 & 0 & 2 & 0 & 2 & 0 & 0 & 0 & 0 & 0 & 0 & 1 & 0 & ? & ? & 0 & & - & 0 & C & D & 01 & 1 \\
\hline Leucozonia nassa brasiliana & $?$ & ? & ? & 0 & 1 & 2 & 4 & ? & ? & 2 & 0 & 0 & 0 & 0 & 0 & 0 & 0 & 0 & 2 & 0 & 2 & 0 & 2 & 0 & 0 & 0 & 0 & 0 & 0 & 1 & 0 & $?$ & ? & U & & - & 0 & & 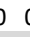 & 0 & 1 \\
\hline Leucozonia ponderosa & $?$ & $?$ & ? & 0 & 1 & 2 & 4 & ? & ? & 2 & 0 & 0 & 0 & 0 & 0 & 0 & 0 & 0 & 2 & 0 & 2 & 0 & 2 & 0 & 0 & 0 & 0 & 0 & 0 & 1 & 0 & $?$ & $?$ & & & - & 0 & & 0 & & 1 \\
\hline
\end{tabular}




\begin{tabular}{|c|c|c|c|c|c|c|c|c|c|c|c|c|c|c|c|c|c|c|c|c|c|c|c|c|c|c|c|c|c|c|c|c|c|c|c|c|}
\hline & & & & & & & & & & & & & & & & & & & & & & & & & & & & & & & & & & & & \\
\hline & 0 & 2 & & 4 & & 6 & & & & & & & 4 & & 6 & & & & 0 & & & & & 6 & & & & & & & & & & & & \\
\hline on & 0 & 0 & 0 & 0 & 0 & 0 & 0 & 2 & & 2 & 0 & 3 & 1 & 3 & 1 & 0 & & 0 & 0 & 0 & - & 0 & & 2 & 3 & & 1 & 1 & & 0 & 0 & 0 & & & & \\
\hline Thais $s_{t}$ & 0 & 0 & 0 & 1 & 0 & 0 & & 4 & & 1 & & 0 & 1 & 3 & 1 & 2 & & 0 & 0 & 0 & - & 0 & & 2 & & 0 & 2 & 0 & & & 1 & 0 & & & & \\
\hline piniquim & 0 & & 0 & 0 & & 0 & & & & 1 & & & 2 & 3 & 1 & ? & & & 0 & & & 0 & & & 1 & & 2 & 0 & & & 0 & & & & & \\
\hline ngoniophos unicinctus & 0 & & 0 & 0 & - & 0 & 0 & 3 & & 1 & & & 2 & 3 & 1 & ? & & & 0 & 0 & - & 0 & & & & & 2 & 0 & & 0 & 0 & & & & 1 & \\
\hline Nassarius reticulatus & 0 & & 0 & 0 & - & 0 & 0 & 3 & & 1 & & 00 & 2 & 3 & 1 & ? & & & 0 & 0 & & & & & & ? & 2 & 0 & & 0 & 1 & & & & 1 & \\
\hline Bullia laevissima & 0 & & 0 & 0 & - & 0 & 0 & 3 & & 1 & & 00 & 2 & 3 & 1 & ? & & & 0 & 0 & & 0 & & & & ? & 2 & 0 & & 0 & 1 & 1 & 2 & & 1 & \\
\hline Buccinun & 0 & & 0 & 0 & - & 0 & 0 & 3 & & 1 & & 00 & 2 & 3 & 1 & ? & & & 0 & 0 . & & 0 & & & 1 & ? & 2 & 0 & & 0 & 1 & 1 & 2 & & 1 & \\
\hline Pisan & 0 & & 0 & 0 & - & 0 & 0 & 3 & & 1 & & 00 & 2 & 3 & 1 & ? & & & 0 & 0 . & - & & & & & ? & 2 & 0 & & 0 & 1 & & & & 1 & \\
\hline is sp. & 0 & & 0 & 0 & - & 0 & 0 & 3 & & 1 & 0 & 00 & 2 & 3 & 1 & ? & & & $?$ & 0 . & - & & & & & & 2 & 0 & & 0 & 0 & & 2 & & & \\
\hline Teralati & 0 & & 0 & 0 & - & 0 & 0 & 3 & & 1 & & 00 & 2 & 3 & 1 & ? & 1 & & ? & 0 . & - & 0 & & & & & 2 & 0 & & 0 & 0 & 1 & 2 & & 1 & \\
\hline 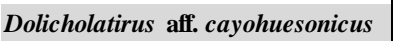 & 0 & ? & 0 & 0 & - & 0 & 0 & 3 & & 1 & 0 & 00 & 2 & 3 & 1 & ? & 1 & & ? & 0 & - & 0 & ? 2 & 2 & 1 & ? & 2 & 0 & & 0 & 0 & 1 & & 0 & 1 & 0 \\
\hline$a e$ & 00 & ? & 0 & 0 & - & 0 & 0 & 3 & & 1 & 0 & $0 \mathrm{c}$ & 2 & 3 & 1 & ? & 1 & - & 0 & 0 . & - & 0 & ? 2 & 22 & 1 & ? & 2 & 0 & & 0 & 1 & 1 & 2 & 1 & 1 & 0 \\
\hline 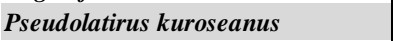 & c & ? & 0 & 0 & - & 0 & 0 & 3 & & 1 & & 0 & 2 & 3 & 1 & $?$ & 1 & & 0 & 0 & - & 0 & ? 2 & & 21 & ? & 2 & 0 & & 0 & 1 & 1 & 2 & & 1 & 0 \\
\hline ificus & 0 & ? & 0 & 0 & - & 0 & 0 & 3 & & 1 & 0 & 00 & 2 & 3 & 1 & $?$ & 1 & & 0 & 0 & - & 0 & ? 2 & 2 & 2 & 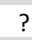 & 2 & 0 & 2 & 0 & 1 & 1 & 2 & 1 & 1 & 0 \\
\hline ris & 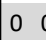 & ? & 0 & 0 & - & 0 & 0 & 3 & & 1 & 0 & 0 & 2 & 3 & 1 & $?$ & 1 & & 0 & 0 & - & 0 & ? 2 & 2 & 1 & . & 2 & 0 & 2 & 0 & 1 & 1 & 2 & 1 & 1 & 0 \\
\hline seuc & 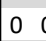 & ? & 0 & 0 & - & 0 & 0 & 3 & & 1 & 0 & 0 & 2 & 3 & 1 & ? & 1 & & 0 & 0 & - & 0 & ? 2 & 22 & 1 & ? & 2 & 0 & 2 & 0 & 1 & 1 & 2 & & 1 & \\
\hline herusius & 0 & & 0 & 0 & - & 0 & 0 & 3 & & 1 & 0 & 00 & 2 & 3 & 1 & ? & 1 & & 0 & 0 & - & 0 & ? 2 & & 1 & ? & 2 & 0 & 2 & 0 & 1 & & 2 & & 1 & 0 \\
\hline ilij & 0 & ? & 0 & 0 & - & 0 & 0 & 3 & & 1 & 0 & 0 & 2 & 3 & 1 & ? & 1 & & 0 & 0 & - & 0 & ? 2 & 22 & 1 & ? & 2 & 0 & & 0 & 1 & & 2 & 1 & 1 & \\
\hline us & 0 & ? & 0 & 0 & - & 0 & 0 & 3 & & 1 & 0 & 00 & 2 & 3 & 1 & ? & . & & 0 & 0 & - & 0 & $? 2$ & 22 & 1 & ? & 2 & 0 & & 0 & 1 & 1 & 2 & & 1 & \\
\hline$\therefore$ & 0 & ? & 0 & 0 & - & 0 & 0 & 3 & & 1 & 0 & 00 & 2 & 3 & 1 & ? & 1 & & 0 & 0 & - & 0 & ? 2 & 22 & 1 & ? & 2 & 0 & & 0 & 1 & 1 & 2 & & 1 & \\
\hline usin & 0 & ? & 0 & 0 & & 0 & 0 & 3 & & 1 & 0 & 0 & 2 & 3 & 1 & ? & & & 0 & 0 & 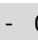 & 0 & ? 2 & 22 & 1 & ? & 2 & 0 & & 0 & 1 & 1 & 2 & & 1 & \\
\hline$F$ & 0 & ? & 0 & 0 & - & 0 & 0 & 3 & & 1 & 0 & 00 & 2 & 3 & 1 & ? & 1 & & 0 & 0 & - & 0 & & 22 & 1 & ? & 2 & 0 & & 0 & 1 & 1 & & & 1 & \\
\hline Fusi & 0 & ? & 0 & 0 & - & 0 & 0 & 3 & & 1 & 0 & 0 & 2 & 3 & 1 & ? & 1 & & 0 & 0 & - & 0 & & 22 & 1 & ? & 2 & 0 & & 0 & 1 & 1 & & & 1 & \\
\hline & 0 & ? & 0 & 0 & - & 0 & 0 & 3 & & 1 & 0 & 0 & 2 & 3 & 1 & ? & 1 & & 0 & 0 & - & 0 & & & 1 & & 2 & 0 & & 0 & 1 & 1 & 2 & & & \\
\hline & 0 & ? & 0 & 0 & - & 0 & 0 & 3 & & 1 & & 0 & 2 & 3 & 1 & ? & 1 & & 0 & 0 & - & 0 & & & 1 & & 2 & 0 & & 0 & 1 & 1 & 2 & & & 0 \\
\hline & 00 & 0 ? & 0 & 0 & - & 0 & 0 & 3 & 1 & 1 & & 0 & 2 & 3 & 1 & ? & 1 & & 0 & 0 & - & 0 & ? & 22 & 1 & ? & 2 & 0 & & 0 & 1 & 1 & 2 & & 1 & 0 \\
\hline & 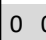 & 0 ? & 0 & 0 & - & 0 & 0 & 3 & 1 & 1 & 0 & 0 & 2 & 3 & 1 & ? & 1 & & 0 & 0 & - & 0 & ? & 22 & 21 & & 2 & 0 & & 0 & 1 & 1 & 2 & 1 & 1 & 0 \\
\hline & 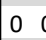 & 0 ? & 0 & 0 & - & 0 & 0 & 3 & 1 & 1 & & 00 & 2 & 3 & 1 & ? & 1 & & 0 & 0 & - & 0 & ? & 22 & 21 & ? & 2 & 0 & 2 & 0 & 1 & 1 & 2 & 1 & 1 & 0 \\
\hline ii & 0 & 0 ? & 0 & 0 & - & 0 & 0 & 3 & & 1 & 0 & 0 & 2 & 3 & 1 & ? & 1 & & 0 & 0 & - & 0 & 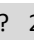 & 22 & 21 & . & 2 & 0 & 2 & 0 & 1 & 1 & 2 & 1 & 1 & 0 \\
\hline & 0 & 0 ? & 0 & 0 & - & 0 & 0 & 3 & & 1 & 0 & 00 & 2 & 3 & 1 & ? & 1 & & 0 & 0 & - & 0 & 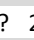 & 22 & 21 & 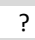 & 2 & 0 & 2 & 0 & 1 & 1 & 2 & 1 & 1 & 0 \\
\hline & 0 & 0 ? & 0 & 0 & - & 0 & 0 & 3 & & 1 & 0 & 0 & 2 & 3 & 1 & ? & 1 & & 0 & 0 & - & 0 & ? & 22 & 21 & ? & 2 & 0 & 2 & 0 & 1 & 1 & 2 & 1 & 1 & 0 \\
\hline & 0 & 0 ? & 0 & 0 & - & 0 & 0 & 3 & & 1 & 0 & 0 & 2 & 3 & 1 & ? & 1 & & 0 & 0 & - & 0 & ? & 22 & 2 & ? & 2 & 0 & 2 & 0 & 0 & 1 & 2 & & 1 & 0 \\
\hline & 0 & 0 ? & 0 & 0 & - & 0 & 0 & 3 & & 1 & 0 & 0 & 2 & 3 & 1 & ? & 1 & & 0 & 0 & - & 0 & ? & 22 & 21 & . & 2 & 0 & 2 & 0 & 0 & 1 & 2 & U & 1 & 0 \\
\hline$A \boldsymbol{A}$ & 0 & 0 ? & 0 & 0 & - & 0 & 0 & 3 & 1 & 1 & 0 & 0 & 2 & 3 & 1 & ? & 1 & & 0 & 0 & - & 0 & ? & 22 & 1 & ? & 2 & 0 & & 0 & 0 & 1 & 2 & 0 & 1 & 0 \\
\hline & 0 & 0 ? & 0 & 0 & - & 0 & 0 & 3 & & 1 & 0 & 0 & 2 & 3 & 1 & ? & 1 & & 0 & 0 & - & 0 & ? & 22 & ? & ? & 2 & 0 & & 0 & 0 & 1 & 2 & 0 & 1 & 0 \\
\hline $\boldsymbol{A}$ & 0 & 0 ? & 0 & 0 & 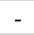 & 0 & 0 & 3 & & 1 & 0 & 0 & 2 & 3 & 1 & ? & 1 & & 0 & 0 & - & 0 & ? & 22 & 1 & ? & 2 & 0 & & 0 & 0 & 1 & 2 & & 1 & 0 \\
\hline$P$ & 0 & 0 ? & 0 & ) & - & 0 & 0 & 3 & & 1 & 0 & 0 & 2 & 3 & 1 & ? & 1 & & 0 & 0 & - & 0 & ? & 22 & 1 & ? & 2 & 0 & & 0 & 0 & 1 & 2 & & 1 & 0 \\
\hline & 0 & 0 ? & 0 & D & 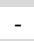 & 0 & 0 & 3 & & 1 & 0 & 0 & 2 & 3 & 1 & ? & 1 & & 0 & 0 & - & 0 & & 22 & 1 & ? & 2 & 0 & & 0 & 0 & 1 & 2 & & 1 & 0 \\
\hline & 0 & 0 ? & 0 & 0 & - & 0 & 0 & 3 & & 1 & 0 & 0 & 2 & 3 & 1 & ? & & & 0 & 0 & - & 0 & ? & 22 & 1 & ? & 2 & 0 & & 0 & 1 & 1 & 2 & & 1 & 0 \\
\hline & 0 & 0 & 0 & 0 & - & 0 & 0 & 3 & & 1 & 0 & 0 & 2 & 3 & 1 & ? & L & & 0 & 0 & - & 0 & 2 & 22 & 1 & ? & 2 & ( & 2 & 0 & 1 & 1 & 2 & & 1 & 0 \\
\hline & 0 & 0 & 0 & 0 & - & 0 & 0 & 3 & 1 & 1 & 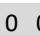 & 0 & 2 & 3 & 1 & ? & 1 & & 0 & 0 & - & 0 & 2 & 2 & 1 & . & 2 & 0 & 2 & 0 & 1 & 1 & 2 & & 1 & 0 \\
\hline & 0 & 0 & 0 & 0 & - & 0 & 0 & 3 & 1 & 1 & 0 & 0 & 2 & 3 & 1 & ? & 1 & & 0 & 0 & - & 0 & 2 & 22 & 21 & ? & 2 & 0 & 2 & 0 & 1 & 1 & 2 & 1 & 1 & 0 \\
\hline & 0 & 0 & 0 & 0 & - & 0 & 0 & 3 & 1 & 1 & 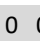 & 0 & 2 & 3 & 1 & ? & 1 & & 0 & 0 & - & 0 & 2 & 22 & 21 & . & 2 & 0 & 2 & 0 & 1 & 1 & 2 & 1 & 1 & 0 \\
\hline & 0 & 0 & 0 & 0 & - & 0 & 0 & 3 & & 1 & 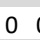 & 0 & 2 & 3 & 1 & ? & 1 & & 0 & 0 & - & 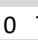 & 2 & 22 & 21 & . & 2 & 0 & 2 & 0 & 1 & 1 & 2 & 1 & 1 & 0 \\
\hline & 0 & 0 & 0 & 0 & - & 0 & 0 & 3 & & 1 & 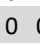 & 0 & 2 & 3 & 1 & ? & 1 & & 0 & 0 & - & 0 & 2 & 22 & 21 & & 2 & 0 & 2 & 0 & 1 & 1 & 2 & 1 & 1 & 0 \\
\hline tir & 0 & 0 & 0 & 0 & - & ) & 0 & 3 & & 1 & 0 & 0 & 2 & 3 & 1 & ? & 1 & & 0 & 0 & - & 0 & 2 & 22 & 21 & . & 2 & 0 & 2 & 0 & 1 & 1 & 2 & 1 & 1 & 0 \\
\hline & 0 & & 0 & 0 & - & 0 & 0 & 3 & & 1 & 0 & 0 & 22 & 3 & 1 & ? & 1 & & 0 & 0 & - & 0 & ? & 2 & 2 1 & . & 2 & 0 & 2 & 0 & 1 & 1 & 2 & 1 & 1 & 0 \\
\hline$L$ & 0 & & 0 & 0 & & 0 & 0 & 3 & & 1 & & 0 & 2 & 3 & 1 & ? & 1 & & 0 & 0 & - & 0 & 2 & 22 & 21 & . & 2 & 0 & & 0 & 1 & 1 & 2 & & & 0 \\
\hline & 0 & & 0 & 0 & - & 0 & 0 & 3 & & 1 & 0 & 0 & 2 & 3 & 1 & ? & & & 0 & 0 & 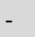 & 0 & 2 & 22 & 2 & & 2 & 0 & & 0 & 1 & 1 & & & & 0 \\
\hline & 0 & & 0 & 0 & - & 0 & 0 & 3 & & 1 & 0 & 0 & 02 & 3 & 1 & ? & & & 0 & 0 & - & 0 & ? & 22 & 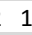 & . & 2 & 0 & & 0 & 1 & 1 & & & & 0 \\
\hline & 0 & & 0 & 0 & & 0 & 0 & 3 & & 1 & & 0 & o & 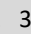 & 1 & ? & & & 0 & 0 & - & 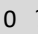 & 2 & $?$ & ? & & ? & 0 & & 0 & 1 & 1 & & & & 0 \\
\hline & 0 & & 0 & 0 & & 0 & 0 & 3 & & 1 & & 0 & 0 & 3 & 1 & ? & & & ? & 0 & & 0 & & 22 & 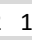 & ? & 2 & 0 & & 0 & 0 & 1 & & & 1 & 0 \\
\hline & 0 & & & 0 & & 0 & & 3 & & 1 & & & 2 & 3 & 1 & ? & & & ? & & & 0 & & & & & & 0 & & & & & & & & \\
\hline
\end{tabular}




\begin{tabular}{|c|c|c|c|c|c|c|c|c|c|c|c|c|c|c|c|c|c|c|c|c|c|c|c|c|c|c|c|c|c|c|c|c|c|c|c|c|}
\hline & & & & & & & & & & & & & & & & & & & & & & & & & & & & & & & & & & & & \\
\hline XON & & & & 3 & & 6 & 7 & 8 & 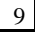 & 0 & & & & & & & & 9 & 0 & 1 & & & & & & 8 & 9 & 0 & & & & & & & & \\
\hline Monetaria annulus & 1 & & 0 & 1 & & 0 & 1 & ? & 0 & 0 & 0 & ? & 1 & 1 & & 0 & & 1 & 3 & 0 & 0 & 1 & & 0 & 0 & 5 & 0 & 0 & 1 & c & 0 & 0 & 0 & & & \\
\hline Thais speciosa & 0 & & 0 & $3-$ & & 0 & 1 & 1 & & 0 & 0 & 0 & & & & 0 & & 1 & 0 & 0 & 0 & 0 & & 0 & & 0 & 0 & 0 & 1 & & 0 & & & & & \\
\hline piniquim & 1 & & & 3 & & & 1 & ? & & 0 & ? & ? & & & & & & 1 & 0 & 0 & & & & 0 & & 0 & ? & ? & ? & ? & & & & 1 & 2 & \\
\hline inctu & 1 & & 0 & $3-$ & & 0 & 1 & ? & & 0 & $?$ & $?$ & & & & & & 1 & 4 & 0 & & & & 0 & & 0 & $?$ & ? & $?$ & $?$ & $?$ & & & 01 & & \\
\hline eticulatus & 1 & & & $3-$ & & & 1 & ? & & 0 & $?$ & $?$ & ? & & & 00 & & 1 & 4 & 0 & & & & 0 ? & & 0 & ? & ? & ? & ? & $?$ & & 0 & 1 & & \\
\hline Bullia lae & 1 & & & $3-$ & & & 1 & ? & & 0 & $?$ & $?$ & $?$ & & & 0 & & & 4 & 0 & 0 & 0 & & 0 ? & & 0 & $?$ & ? & ? & $?$ & $?$ & & & 01 & & \\
\hline Buccin & . & & & 3 & & & 1 & ? & & 0 & $?$ & $?$ & $?$ & & 3 & 0 & & & 4 & 0 & 0 & 0 & & 0 ? & & 0 & ? & ? & ? & $?$ & $?$ & & & 0 & & \\
\hline is a & 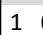 & & & $3-$ & & & 1 & ? & ? & 0 & ? & $?$ & ? & & & & & & 4 & 0 & 00 & & & 0 ? & & 0 & ? & ? & ? & $?$ & ? & & & & & \\
\hline us $\mathrm{s}$ & ( & & & $3-$ & & & 1 & ? & & 0 & ? & $?$ & ? & & & & & 1 & 0 & 0 & & & & 0 ? & & 0 & ? & ? & & $?$ & ? & & & 0 & & \\
\hline Teral & 1 & & & $3-$ & & & 1 & ? & & 0 & ? & ? & & & & & & 1 & 0 & 0 & & & & 0 ? & & 0 & ? & ? & ? & $?$ & $?$ & & & & & \\
\hline & ( & & 0 & $3-$ & - & 0 & 1 & ? & & 0 & $?$ & $?$ & ? & ? & 3 & & 01 & 11 & 0 & 0 & 0 & 0 & & 0 ? & 0 & 0 & ? & ? & $?$ & $?$ & $?$ & ? & 0 & 0 & & \\
\hline $\boldsymbol{e}$ & ( & & 0 & $3-$ & - & 0 & 1 & ? & $?$ & 0 & $?$ & $?$ & $?$ & ? & 3 & 0 & 01 & 1 & 0 & 0 & 0 & 0 & & 0 ? & 0 & 0 & $?$ & ? & $?$ & $?$ & $?$ & ? & 0 & 01 & & \\
\hline Psen & 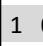 & & 0 & $3-$ & 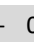 & 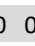 & 1 & ? & $?$ & 0 & $?$ & $?$ & ? & $?$ & 3 & 0 & 01 & 1 & 0 & 0 & 0 & 0 & & 0 ? & 0 & 0 & ? & ? & $?$ & $?$ & ? & ? & 0 & & 12 & \\
\hline ificus & 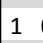 & & 0 & 3 & -0 & 0 & 1 & ? & & 0 & $?$ & $?$ & ? & ? & 3 & 0 & 01 & 1 & 0 & 0 & 0 & 0 & & 0 ? & 0 & 0 & $?$ & ? & $?$ & $?$ & $?$ & ? & 0 & 01 & 12 & \\
\hline oris & 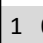 & & 0 & $3-$ & 0 & 0 & 1 & ? & $?$ & 0 & $?$ & $?$ & $?$ & $?$ & 3 & & 01 & 1 & 0 & 0 & 0 & 0 & & 0 ? & 0 & 0 & ? & ? & $?$ & $?$ & $?$ & ? & 0 & 01 & & \\
\hline seuc & ( & & 0 & $3-$ & & & 1 & ? & : & 0 & $?$ & $?$ & ? & ? & 3 & & 01 & 1 & 0 & 0 & 0 & 0 & & 0 ? & 0 & 0 & $?$ & ? & ? & $?$ & $?$ & ? & 0 & 0 & & \\
\hline Chry & ( & & 0 & $3-$ & 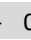 & 0 & 1 & ? & & 0 & $?$ & $?$ & $?$ & $?$ & 3 & 0 & 1 & 1 & 0 & 0 & 0 & 0 & & 0 ? & 0 & 0 & ? & ? & ? & ? & ? & ? & 0 & 0 & & \\
\hline Chrys & 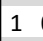 & & 0 & $3-$ & 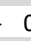 & 0 & 1 & ? & & 0 & $?$ & $?$ & ? & $?$ & 3 & 0 & 1 & 1 & 0 & 0 & 0 & 0 & & 0 ? & 0 & 0 & $?$ & ? & ? & ? & $?$ & ? & 0 & 0 & & \\
\hline Fusi & . & & 0 & $3-$ & . & 0 & 1 & ? & & 0 & $?$ & $?$ & ? & ? & 3 & 0 & 01 & 11 & 0 & 0 & 0 & 0 & & 0 ? & 0 & 0 & ? & ? & ? & $?$ & ? & ? & & 0 & & \\
\hline Fusi & 1 & & 0 & $3-$ & . & 0 & 1 & ? & $?$ & 0 & $?$ & $?$ & $?$ & $?$ & 3 & 0 & 01 & 1 & 0 & 0 & 0 & 0 & & 0 ? & 0 & 0 & $?$ & ? & $?$ & ? & $?$ & ? & 0 & & & \\
\hline$F$ & 1 & & 0 & $3-$ & c & ) & 1 & ? & & 0 & $?$ & $?$ & $?$ & ? & 3 & 0 & 1 & 1 & 0 & 0 & 0 & 0 & & 0 & & 0 & $?$ & ? & ? & ? & ? & ? & & & & \\
\hline$F$ & 1 & & 0 & $3-$ & c & 0 & 1 & ? & $?$ & 0 & $?$ & $?$ & ? & $?$ & 3 & 0 & 1 & 1 & 0 & 0 & 0 & 0 & & 0 & & 0 & $?$ & ? & ? & ? & ? & ? & 0 & & & \\
\hline$F u$ & 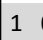 & & 0 & $3-$ & . & 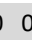 & 1 & ? & & 0 & $?$ & $?$ & $?$ & $?$ & 3 & & 1 & 1 & 0 & 0 & 0 & 0 & & 0 & & 0 & ? & ? & ? & ? & ? & ? & 0 & & & \\
\hline & 1 & & 0 & $3-$ & c & & 1 & ? & ? & 0 & ? & $?$ & ? & $?$ & 3 & & & 1 & 0 & 0 & & 0 & & 0 & & 0 & ? & ? & ? & ? & ? & ? & & & & \\
\hline & 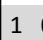 & & 0 & $3-$ & c & 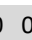 & 1 & ? & : & 0 & ? & ? & ? & ? & 3 & 0 & 01 & 1 & 0 & 0 & 0 & 0 & & 0 ? & 0 & 0 & ? & ? & ? & ? & ? & ? & & & & \\
\hline & 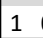 & & 0 & $3-$ & c & 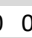 & 1 & ? & ? & 0 & ? & ? & ? & ? & 3 & 0 & 01 & 1 & 0 & 0 & 0 & 0 & & 0 ? & 0 & 0 & ? & $?$ & ? & ? & $?$ & ? & 0 & & & \\
\hline & 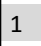 & & 0 & $3-$ & - & 0 & 1 & ? & ? & 0 & $?$ & $?$ & $?$ & ? & 3 & 0 & 01 & 1 & 0 & 0 & 0 & 0 & 0 & 0 ? & 0 & 0 & ? & ? & ? & ? & ? & ? & 0 & 0 & 12 & \\
\hline & 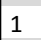 & & 0 & $3-$ & - & 0 & 1 & ? & $?$ & 0 & $?$ & $?$ & $?$ & ? & 3 & 0 & 01 & 1 & 0 & 0 & 0 & 0 & 0 & 0 ? & 0 & 0 & ? & ? & ? & $?$ & ? & ? & 0 & 01 & 12 & \\
\hline & 1 & & 0 & 3 & 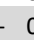 & 0 & 1 & ? & ? & 0 & ? & $?$ & $?$ & ? & 3 & 0 & 1 & 1 & 0 & 0 & 0 & 0 & 0 & 0 ? & 0 & 0 & ? & ? & ? & $?$ & ? & ? & 0 & 01 & 12 & \\
\hline & 1 & & 0 & $3-$ & - & 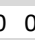 & 1 & ? & ? & 0 & $?$ & $?$ & $?$ & $?$ & 3 & 0 & 1 & 1 & 0 & 0 & 0 & 0 & 0 & 0 ? & 0 & 0 & ? & ? & ? & $?$ & ? & ? & 0 & 01 & 12 & \\
\hline & 1 & & 0 & $3-$ & -0 & 0 & 1 & ? & ? & 0 & $?$ & $?$ & $?$ & ? & 3 & 0 & 1 & 1 & 0 & 0 & 0 & 0 & 0 & 0 ? & 0 & 0 & ? & ? & ? & $?$ & ? & ? & 0 & 01 & 12 & \\
\hline & 1 & & 0 & $3-$ & c & 0 & 1 & ? & & 0 & $?$ & $?$ & ? & ? & 3 & 0 & 01 & 1 & 0 & 0 & 0 & 0 & 0 & 0 ? & 0 & 0 & ? & ? & ? & ? & ? & ? & 0 & 1 & 12 & \\
\hline & 1 & & 0 & $3-$ & c & 0 & 1 & ? & & 0 & $?$ & $?$ & $?$ & ? & 3 & 0 & 01 & 1 & 0 & 0 & 0 & 0 & 0 & 0 ? & 0 & 0 & ? & ? & ? & ? & ? & ? & 0 & 01 & 2 & \\
\hline & 1 & & 0 & $3-$ & c & 0 & 1 & ? & ? & 0 & $?$ & $?$ & $?$ & ? & 3 & 0 & 01 & L 1 & 0 & 0 & 0 & 0 & 0 & 0 & 0 & 0 & ? & ? & ? & ? & ? & ? & 0 & 01 & 12 & \\
\hline & & & 0 & $3-$ & . & 0 & 1 & ? & & 0 & ? & $?$ & $?$ & ? & 3 & 0 & 01 & L 1 & 0 & 0 & 0 & 0 & 0 & 0 & 0 & 0 & ? & ? & ? & ? & ? & ? & 0 & 0 & 12 & \\
\hline & 1 & & 0 & $3-$ & c & 0 & 1 & ? & & 0 & $?$ & $?$ & $?$ & $?$ & 3 & 0 & 1 & 1 & 0 & 0 & 0 & 0 & 0 & 0 ? & 0 & 0 & ? & ? & ? & ? & ? & ? & 0 & 01 & 12 & \\
\hline$P$ & 1 & & 0 & $3-$ & 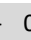 & 0 & 1 & ? & & 0 & $?$ & $?$ & $?$ & ? & 3 & 0 & 1 & 1 & 0 & 0 & 0 & 0 & & 0 & & 0 & ? & ? & ? & ? & ? & ? & 0 & & & \\
\hline & 1 & & 0 & $3-$ & 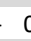 & ) & 1 & ? & ? & 0 & $?$ & $?$ & $?$ & ? & 3 & 0 & 01 & 1 & 0 & 0 & 0 & 0 & & 0 & 0 & 0 & ? & ? & ? & ? & ? & ? & 0 & & & \\
\hline & 1 & & 0 & $3-$ & . & ) & 1 & ? & ? & 0 & $?$ & $?$ & $?$ & ? & 3 & 0 & 01 & 1 & 0 & 0 & 0 & 0 & 0 & 0 ? & 0 & 0 & ? & ? & ? & ? & ? & ? & 0 & 0 & 12 & \\
\hline & 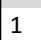 & & 0 & 3 & c & ) & 1 & ? & ? & 0 & ? & ? & $?$ & ? & 3 & 0 & 01 & 1 & 0 & 0 & 0 & 0 & 0 & 0 ? & 0 & 0 & ? & ? & ? & 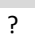 & ? & ? & 0 & & 12 & \\
\hline & 1 & & 0 & 3 & c & ) & 1 & ? & ? & 0 & ? & $?$ & ? & ? & 3 & 0 & 01 & 1 & 0 & 0 & 0 & 0 & 0 & 0 & 0 & 0 & ? & ? & ? & 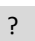 & ? & ? & 0 & 1 & 2 & \\
\hline & 1 & & 0 & $3-$ & - & ) & 1 & ? & ? & 0 & $?$ & $?$ & $?$ & ? & 3 & 0 & 01 & 1 & 0 & 0 & 0 & 0 & 0 & 0 ? & 0 & 0 & ? & ? & ? & ? & ? & ? & 0 & U & 2 & \\
\hline & 1 & & 0 & $3-$ & c & D & 1 & ? & ? & 0 & $?$ & $?$ & $?$ & ? & 3 & 0 & 01 & 1 & 0 & 0 & 0 & 0 & 0 & 0 ? & 0 & 0 & ? & ? & ? & $?$ & ? & ? & 0 & 1 & 12 & \\
\hline & 1 & & 0 & 3 & c & D & 1 & ? & ? & 0 & ? & ? & $?$ & ? & 3 & 0 & 01 & 1 & 0 & 0 & 0 & 0 & 0 & 0 ? & 0 & 0 & ? & ? & ? & ? & $?$ & ? & 0 & 1 & 12 & \\
\hline & & & 0 & 3 & - & b & 1 & ? & ? & 0 & ? & $?$ & $?$ & $?$ & 3 & 0 & 1 & 1 & 0 & 0 & 0 & 0 & & 0 ? & 0 & 0 & ? & ? & ? & ? & ? & ? & 0 & 1 & 2 & \\
\hline & 1 & & 0 & 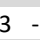 & - & 0 & ) & ? & ? & 0 & ? & $?$ & $?$ & ? & 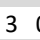 & 0 & 01 & 1 & 0 & 0 & 0 & 0 & & 0 ? & 0 & 0 & ? & ? & ? & ? & ? & ? & 0 & 1 & 2 & \\
\hline Leuc & & & 0 & $3-$ & - & 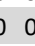 & ) & ? & & 0 & ? & ? & ? & ? & 3 & 0 & D & 1 & 0 & 0 & 0 & 0 & & 0 ? & 0 & 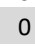 & ? & ? & ? & ? & ? & ? & 0 & 1 & 2 & \\
\hline (u) & 1 & & 0 & 3 & c & & ) 1 & ? & & 0 & ? & $?$ & $?$ & ? & 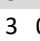 & & 01 & 1 & 0 & 0 & 0 & 0 & & 0 ? & 0 & 0 & ? & ? & ? & 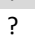 & ? & ? & 0 & 1 & 2 & \\
\hline & 1 & & 0 & $3-$ & c & ) & 1 & ? & & 0 & ? & $?$ & $?$ & ? & . & & 1 & 1 & 0 & 0 & 0 & 0 & & 0 & 0 & 0 & ? & ? & ? & ? & ? & ? & 0 & 1 & 2 & \\
\hline & 1 & & 0 & 3 & - & ) & 1 & ? & ? & 0 & ? & $?$ & $?$ & ? & 3 & 0 & 0 & L 1 & 0 & 0 & 0 & 0 & 0 & 0 & 0 & 0 & ? & ? & ? & ? & ? & ? & 0 & 0 & 2 & \\
\hline & & & 0 & & c & ) & 1 & ? & & 0 & ? & $?$ & $?$ & ? & 3 & & 0 & & 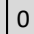 & 0 & 0 & 0 & & 0 & 0 & 0 & ? & ? & ? & ? & ? & ? & 0 & & 12 & \\
\hline & 1 & & 0 & & c & & & ? & & 0 & ? & $?$ & $?$ & $?$ & 3 & & & & 0 & 0 & 0 & 0 & & 0 & 0 & 0 & ? & ? & 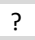 & ? & ? & ? & 0 & 0 & 12 & \\
\hline & 1 & & 0 & 3. & -0 & 0 & & ? & & 0 & & $?$ & & & & & 01 & & & 0 & & & & & & 0 & & & & & & & & & & \\
\hline
\end{tabular}




\begin{tabular}{|c|c|c|c|c|c|c|c|c|c|c|c|c|c|c|c|c|c|c|c|c|c|c|c|c|c|c|c|c|c|c|c|c|c|c|c|c|c|c|c|c|c|c|}
\hline TAXON & & & 2 & & 4 & 5 & 6 & 7 & & 9 & 0 & & & 3 & 4 & & & & & & & & & 2 & 3 & 4 & & & & & & 9 & & & & & & & & & & \\
\hline Monetaria annulus & 0 & 0 & 0 & 1 & 0 & 0 & 0 & 1 & 3 & 0 & 2 & 1 & 1 & 1 & 2 & $\overline{0}$ & 4 & +8 & ) & 1 & 0 & 0 & 0 & 1 & 3 & 1 & $\overline{0}$ & $\overline{0}$ & & & & 0 & & 0 & & 3 & 0 & 2 & 2 & 0 & & 0 \\
\hline Thais speciosa & 1 & 0 & 0 & 1 & 0 & 0 & 0 & 2 & 3 & 0 & 3 & 1 & 1 & 1 & 2 & 5 & 7 & 70 & D & 0 & 0 & 0 & U & 1 & 5 & 0 & 5 & 0 & ) & 2 & 1 & 0 & 0 & & & - & & - & - & & - & \\
\hline Pugilina tupiniquim & 1 & 0 & 0 & 2 & 0 & 0 & 0 & 2 & 0 & 0 & 3 & 1 & 1 & 1 & 2 & 0 & 0 & 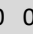 & ) & 0 & 0 & 0 & 0 & 1 & 5 & 0 & 5 & 0 & & & 1 & 0 & 0 & - & & - & - & - & - & & & \\
\hline engoniophos unicinctus & 1 & 0 & 0 & 2 & 0 & 0 & 0 & 2 & 0 & 0 & 3 & 1 & 1 & 1 & 2 & 5 & 1 & 10 & 00 & 0 & ( & 0 & 0 & 1 & J & 0 & 5 & 0 & & 2 & & 0 & 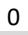 & & & 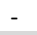 & & - & - & & & \\
\hline culatus & 1 & 0 & 0 & 2 & 0 & 0 & 0 & 2 & 0 & 0 & 3 & 1 & 1 & 1 & 2 & 5 & 1 & 10 & 0 & 0 & 0 & 0 & 0 & 1 & 5 & 0 & 5 & 0 & & 2 & 1 & 0 & & - & - & - & & 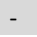 & - & - & - & \\
\hline Bullia laevissima & 1 & 0 & 0 & 2 & 0 & 0 & 0 & 2 & 0 & 0 & 3 & 1 & 1 & 1 & 2 & 5 & 1 & 10 & 00 & 0 & 0 & 0 & 0 & 1 & 5 & 0 & 5 & 0 & & 2 & 1 & 0 & 0 & - & - & - & - & - & - & - & - & \\
\hline Buccinum undatum & 1 & 0 & 0 & 2 & 0 & 0 & 0 & 2 & 0 & 0 & 3 & 1 & 1 & 1 & 2 & 5 & 1 & 10 & 0 & 0 & 0 & 0 & 0 & 1 & 5 & 0 & 5 & 0 & & 2 & 1 & 0 & 0 & - & - & - & - & - & - & - & - & \\
\hline Pisania pusio & 1 & 0 & 0 & 2 & 0 & 0 & 0 & 2 & 0 & 0 & 3 & 1 & 1 & 1 & 2 & ? & ? & 0 & 00 & 0 & 0 & 0 & 0 & 1 & 5 & 0 & 5 & 0 & & 2 & 1 & 0 & 0 & - & - & - & - & - & - & - & - & \\
\hline Dolicholatirus sp. & 1 & 0 & 0 & 2 & 0 & 0 & 0 & 2 & 0 & 0 & 3 & 1 & 1 & 1 & 2 & 0 & 0 & 0 & 0 & 0 & 0 & 0 & 0 & 1 & 1 & 1 & 2 & 0 & & 2 & 1 & 0 & 0 & - & - & - & - & - & - & - & 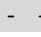 & \\
\hline Teralatirus & 1 & 0 & 0 & 2 & 0 & 0 & 0 & 2 & 0 & 0 & 3 & 1 & 1 & 1 & 2 & 0 & 0 & 0 & 0 & 0 & 0 & 0 & 0 & 1 & 1 & 1 & 2 & 0 & & 2 & 1 & 0 & ( & - & - & - & - & - & - & - & - & \\
\hline Dolicholatirus aff. $c$ & 1 & 0 & 0 & 2 & 0 & 0 & 0 & 2 & 0 & 0 & 3 & 1 & 1 & 1 & 2 & 0 & 0 & 0 & 0 & 0 & 0 & 0 & 0 & 1 & 1 & 1 & 2 & 0 & & 2 & 1 & 0 & & - & - & - & - & 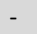 & - & - & - & \\
\hline dae & 1 & 0 & 0 & 2 & 0 & 0 & 0 & 2 & 0 & 0 & 3 & 1 & 1 & 1 & 2 & 0 & 4 & +0 & 01 & 1 & 0 & 0 & 0 & 1 & 0 & 0 & 2 & 0 & & 2 & 1 & 0 & 0 & - & - & - & - & - & - & ${ }^{-}$ & - & \\
\hline Pset & 1 & 0 & 0 & 2 & 0 & 0 & 0 & 2 & 0 & 0 & 3 & 1 & 1 & 1 & 2 & 0 & 4 & +0 & 0 & 1 & 0 & 0 & 0 & 1 & 0 & 0 & 2 & 0 & & 2 & 1 & 0 & 0 & - & - & - & - & - & - & - & - & \\
\hline Amiantofusu & 1 & 0 & 0 & 2 & 0 & 0 & 0 & 2 & 0 & 0 & 3 & 1 & 1 & 1 & 2 & 0 & 4 & +0 & 0 & 1 & 0 & 0 & 0 & 1 & 0 & 0 & 2 & 0 & & 2 & 1 & 0 & 0 & - & - & - & - & - & - & - & - & \\
\hline Amiantofusu & 1 & 0 & 0 & 2 & 0 & 0 & 0 & 2 & 0 & 0 & 3 & 1 & 1 & 1 & 2 & 0 & 4 & +0 & 0 & 1 & 0 & 0 & 0 & 1 & 0 & 0 & 2 & 0 & & 2 & 1 & 0 & 0 & - & - & - & - & - & - & - & - & \\
\hline allidus & 1 & 0 & 0 & 2 & 0 & 0 & 0 & 2 & 0 & 0 & 3 & 1 & 1 & 1 & 2 & 0 & 4 & +0 & 0 & 0 & 0 & 0 & 0 & 1 & 0 & 0 & 2 & 0 & & 2 & 1 & 0 & 0 & - & - & - & - & - & - & - & - & \\
\hline Chr & 1 & 0 & 0 & 2 & 0 & 0 & 0 & 2 & 0 & 0 & 3 & 1 & 1 & 1 & 2 & 0 & 4 & & 0 & 0 & 0 & 0 & 0 & 1 & 0 & 0 & 2 & 0 & & 2 & 1 & 0 & 0 & - & - & - & - & - & - & - & - & \\
\hline Chry & 1 & 0 & 0 & 2 & 0 & 0 & 0 & 2 & 0 & 0 & 3 & 1 & 1 & 1 & 2 & 0 & 4 & +0 & 0 & 0 & 0 & 0 & 0 & 1 & 0 & 0 & 2 & 0 & & 2 & 1 & 0 & 0 & - & - & - & - & - & - & _ & - & \\
\hline Fusinus mar & 1 & 0 & 0 & 2 & 0 & 0 & 0 & 2 & 0 & 0 & 3 & 1 & 1 & 1 & 2 & 0 & 4 & & 0 & 0 & 0 & 0 & 0 & 1 & 0 & 0 & 2 & 0 & & 2 & 1 & 0 & 0 & - & - & - & - & - & - & - & - & \\
\hline Fusinus brasiliensis & 1 & 0 & 0 & 2 & 0 & 0 & 0 & 2 & 0 & 0 & 3 & 1 & 1 & 1 & 2 & 0 & 4 & & 0 & 0 & 0 & 0 & 0 & 1 & 0 & 0 & 2 & 0 & & 2 & 1 & 0 & 0 & - & - & - & - & - & - & - & - & \\
\hline Fusinus sp. & 1 & 0 & 0 & 2 & 0 & 0 & 0 & 2 & 0 & 0 & 3 & 1 & 1 & 1 & 2 & 0 & 4 & +0 & 0 & 0 & 0 & 0 & 0 & 1 & 0 & 0 & 2 & 20 & & 2 & 1 & 0 & 0 & - & - & - & - & - & - & - & - & 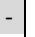 \\
\hline Fusinus frenguelli & 1 & 0 & 0 & 2 & 0 & 0 & 0 & 2 & 0 & 0 & 3 & 1 & 1 & 1 & 2 & 0 & 4 & & 0 & 0 & 0 & 0 & 0 & 1 & 0 & 0 & 2 & 0 & & 2 & 1 & 0 & 0 & - & - & - & - & - & - & - & - & \\
\hline Fus & 1 & 0 & 0 & 2 & 0 & 0 & 0 & 2 & 0 & 0 & 3 & 1 & 1 & 1 & 2 & 0 & 4 & & 0 & 0 & 0 & 0 & 0 & 1 & 0 & 0 & 2 & 0 & & 2 & 1 & 0 & 0 & - & - & - & - & - & - & - & - & \\
\hline inor & 1 & 0 & 0 & 2 & 0 & 0 & 0 & 2 & 0 & 0 & 3 & 1 & 1 & 1 & 2 & 0 & 4 & +0 & 0 & 0 & 0 & 0 & 0 & 1 & 0 & 0 & 2 & 0 & & 2 & 1 & 0 & 0 & - & - & - & - & - & - & - & 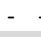 & \\
\hline Granulifusus sp. & 1 & 0 & 0 & 2 & 0 & 0 & 0 & 2 & 0 & 0 & 3 & 1 & 1 & 1 & 2 & 0 & 4 & +0 & 0 & 0 & 0 & 0 & 0 & 1 & 0 & 0 & 2 & 0 & & 2 & 1 & 0 & 0 & - & - & - & - & - & - & - & - & \\
\hline Granulifusus hayashi & 1 & 0 & 0 & 2 & 0 & 0 & 0 & 2 & 0 & 0 & 3 & 1 & 1 & 1 & 2 & 0 & 4 & +0 & 0 & 0 & 0 & 0 & 0 & 1 & 0 & 0 & 2 & 0 & & 2 & 1 & 0 & 0 & - & - & - & - & - & - & - & - & 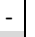 \\
\hline lolatirus discr & 1 & 0 & 0 & 2 & 0 & 0 & 0 & 2 & 0 & 0 & 3 & 1 & 1 & 1 & 2 & 0 & 4 & +0 & 0 & 0 & 0 & 0 & 0 & 1 & 0 & 0 & 2 & -0 & & 2 & 1 & 0 & 0 & - & - & - & - & - & - & - & - & 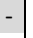 \\
\hline Graı & 1 & 0 & 0 & 2 & 0 & 0 & 0 & 2 & 0 & 0 & 3 & 1 & 1 & 1 & 2 & 0 & 4 & +0 & 0 & 0 & 0 & 0 & 0 & 1 & 0 & 0 & 2 & 0 & & 2 & 1 & 0 & 0 & - & - & - & - & - & - & - & - & \\
\hline Fus & 1 & 0 & 0 & 2 & 0 & 0 & 0 & 2 & 0 & 0 & 3 & 1 & 1 & 1 & 2 & 0 & 4 & & 0 & 0 & 0 & 0 & 0 & 1 & 0 & 0 & 2 & 0 & & 2 & 1 & 0 & 0 & - & - & - & - & - & - & - & - & \\
\hline ia marques & 1 & 0 & 0 & 2 & 0 & 0 & 0 & 2 & 0 & 0 & 3 & 1 & 1 & 1 & 2 & 0 & 4 & +0 & 0 & 0 & 0 & 0 & 0 & 1 & 0 & 0 & 2 & 0 & ) & 2 & 1 & 0 & 0 & - & - & - & - & - & - & - & - & \\
\hline satula & 1 & 0 & 0 & 2 & 0 & 0 & 0 & 2 & 0 & 0 & 3 & 1 & 1 & 1 & 2 & 0 & 4 & +0 & 0 & 0 & 0 & 0 & 0 & 1 & 0 & 0 & 2 & 0 & & 2 & 1 & 0 & 0 & - & - & - & - & - & - & - & - & 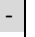 \\
\hline Nodolatirus & 1 & 0 & 0 & 2 & 0 & 0 & 0 & 2 & 0 & 0 & 3 & 1 & 1 & 1 & 2 & 0 & 0 & 0 & 0 & 0 & 0 & 0 & 0 & 1 & 0 & 0 & 2 & 0 & & 2 & 1 & 0 & 0 & - & - & - & - & - & - & - & - & - \\
\hline Latir & 1 & 0 & 0 & 2 & 0 & 0 & 0 & 2 & 0 & 0 & 3 & 1 & 1 & 1 & 2 & 0 & 0 & & 0 & 0 & 0 & 0 & 0 & 1 & 0 & 0 & 2 & 0 & ) & 2 & 1 & 0 & 0 & - & - & - & - & - & - & - & - & - \\
\hline Aur & 1 & 0 & 0 & 2 & 0 & 0 & 0 & 2 & 0 & 0 & 3 & 1 & 1 & 1 & 2 & 0 & 0 & & 0 & 0 & 0 & 0 & 0 & 1 & 0 & 0 & 2 & 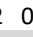 & & $\mathbf{L}$ & 1 & 0 & 0 & - & - & - & - & - & $\begin{array}{ll}- \\
-\end{array}$ & - & - & \\
\hline laria tulipa & 1 & 0 & 0 & 2 & 0 & 0 & 0 & 2 & 0 & 0 & 3 & 1 & 1 & 1 & 2 & 0 & 0 & & 0 & 0 & 0 & 0 & 0 & 1 & 0 & 0 & 2 & 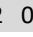 & & 2 & 1 & 0 & & - & - & - & - & - & - & - & - & \\
\hline Aust & 1 & 0 & 0 & 2 & 0 & 0 & 0 & 2 & 0 & 0 & 3 & 1 & 1 & 1 & 2 & 0 & 0 & 0 & 0 & 0 & 0 & 0 & 0 & 1 & 0 & 0 & 2 & 0 & & 2 & 1 & 0 & & - & - & - & - & - & - & - & - & \\
\hline Pleuroploca trapezium & 1 & 0 & 0 & 2 & 0 & 0 & 0 & 2 & 0 & 0 & 3 & 1 & 1 & 1 & 2 & 0 & 0 & & 0 & 0 & 0 & 0 & 0 & 1 & 0 & 0 & 2 & 0 & & 2 & 1 & 0 & 0 & - & - & - & - & - & - & - & - & 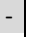 \\
\hline Filifusus filamentosus & 1 & 0 & 0 & 2 & 0 & 0 & 0 & 2 & 0 & 0 & 3 & 1 & 1 & 1 & 2 & 0 & 0 & & 0 & 0 & 0 & 0 & 0 & 1 & 0 & 0 & 2 & 0 & 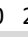 & 2 & 1 & 0 & 0 & - & - & - & - & - & - & - & - & 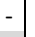 \\
\hline Hemipolygona armata & 1 & 0 & 0 & 2 & 0 & 0 & 0 & 2 & 0 & 0 & 3 & 1 & 1 & 1 & 2 & ? & ? & 0 & 0 & 0 & 0 & 0 & 0 & 1 & 0 & 0 & 2 & 0 & & 2 & 1 & 0 & 0 & - & - & - & - & - & - & - & - & \\
\hline Pustulatirus mediamer & 1 & 0 & 0 & 2 & 0 & 0 & 0 & 2 & 0 & 0 & 3 & 1 & 1 & 1 & 2 & ? & ? & & 0 & 0 & 0 & 0 & 0 & 1 & 0 & 0 & 2 & $=0$ & ) & 2 & 1 & 0 & 0 & - & - & - & - & - & - & - & - & \\
\hline Pustulatirus & 1 & 0 & 0 & 2 & 0 & 0 & 0 & 2 & 0 & 0 & 3 & 1 & 1 & 1 & 2 & ? & ? & & 0 & 0 & 0 & 0 & 0 & 1 & 0 & 0 & 2 & - & ) & 2 & 1 & 0 & & - & - & - & - & - & - & - & - & \\
\hline Polygona angulata & 1 & 0 & 0 & 2 & 0 & 0 & 0 & 2 & 0 & 0 & 3 & 1 & 1 & 1 & 2 & ? & ? & & 0 & 0 & 0 & 0 & 0 & 1 & 0 & 0 & 2 & 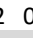 & 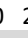 & 2 & 1 & 0 & 0 & - & - & - & - & - & - & - & - & 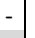 \\
\hline Latirus polygonus & 1 & 0 & 0 & 2 & 0 & 0 & 0 & 2 & 0 & 0 & 3 & 1 & 1 & 1 & 2 & ? & ? & & 0 & 0 & 0 & 0 & 0 & 1 & 0 & 0 & 2 & 20 & o & 2 & 1 & 0 & 0 & - & - & - & - & - & - & - & - & 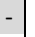 \\
\hline Polygona infundibulum & 1 & 0 & 0 & 2 & 0 & 0 & 0 & 2 & 0 & 0 & 3 & 1 & 1 & 1 & 2 & ? & ? & & 0 & 0 & 0 & 0 & 0 & 1 & 0 & 0 & 2 & 20 & ) & 2 & 1 & 0 & 0 & - & - & - & - & - & - & - & - & 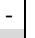 \\
\hline Hemipolygona beckyae & 1 & 0 & 0 & 2 & 0 & 0 & 0 & 2 & 0 & 0 & 3 & 1 & 1 & 1 & 2 & ? & ? & & 0 & 0 & 0 & 0 & 0 & 1 & 0 & 0 & 2 & 20 & o & 2 & 1 & 0 & 0 & - & - & - & - & - & - & - & - & \\
\hline Latir & 1 & 0 & 0 & 2 & 0 & 0 & 0 & 2 & 0 & 0 & 3 & 1 & 1 & 1 & 2 & ? & ? & & 0 & 0 & 0 & 0 & 0 & 1 & 0 & 0 & 2 & -0 & 0 & 2 & 1 & 0 & 0 & - & - & - & - & - & - & - & - & \\
\hline Leuc & 1 & 0 & 0 & 2 & 0 & 0 & 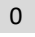 & 2 & 0 & 0 & 3 & 1 & 1 & 1 & 2 & 0 & 0 & & 0 & 0 & 0 & 0 & 0 & 1 & 0 & 0 & 2 & 0 & 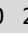 & 2 & 1 & 0 & ( & - & - & - & - & - & - & - & - & \\
\hline nia cerata & 1 & 0 & 0 & 2 & 0 & 0 & 0 & 2 & 0 & 0 & 3 & 1 & 1 & 1 & 2 & 0 & 0 & & 0 & 0 & 0 & 0 & 0 & 1 & 0 & 0 & 2 & $=0$ & ) & 2 & $\perp$ & 0 & 0 & - & - & - & - & - & - & - & - & 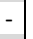 \\
\hline Opeatostoma pseudodon & 1 & 0 & 0 & 2 & 0 & 0 & 0 & 2 & 0 & 0 & 3 & 1 & 1 & 1 & 2 & 0 & 0 & & 0 & 0 & 0 & 0 & 0 & 1 & 0 & 0 & 2 & 0 & ) & 2 & 1 & 0 & 0 & - & - & - & - & - & - & - & - & \\
\hline Leucozonia nassa nassa & 1 & 0 & 0 & 2 & 0 & 0 & 0 & 2 & 0 & 0 & 3 & 1 & 1 & 1 & 2 & 0 & 0 & & 0 & 0 & 0 & 0 & 0 & 1 & 0 & 0 & 2 & 20 & b & 2 & 1 & 0 & 0 & - & - & - & - & - & - & - & - & \\
\hline a cingul & 1 & 0 & 0 & 2 & 0 & 0 & 0 & 2 & 0 & 0 & 3 & 1 & 1 & 1 & 2 & 0 & 0 & & 0 & 0 & 0 & 0 & 0 & 1 & 0 & 0 & 2 & 20 & J & 2 & 1 & 0 & 0 & - & - & - & - & - & - & - & - & \\
\hline i & 1 & & 0 & 2 & 0 & 0 & 0 & 2 & 0 & 0 & 3 & 1 & 1 & 1 & 2 & 0 & 0 & & 0 & 0 & 0 & 0 & 0 & 1 & 0 & 0 & 2 & 20 & & $\mathbf{L}$ & 1 & 0 & 0 & - & - & - & - & - & - & $\begin{array}{ll}- \\
-\end{array}$ & - & \\
\hline Leucozonia ponderosa & 1 & 0 & 0 & 2 & 0 & 0 & 0 & 2 & 0 & $0 \mid$ & 3 & 1 & 1 & 1 & 2 & 0 & 0 & & 0 & 0 & 0 & 0 & 0 & 1 & 0 & 0 & 2 & 20 & & 2 & 1 & 0 & 然 & - & - & - & - & - & - & - & - & \\
\hline
\end{tabular}




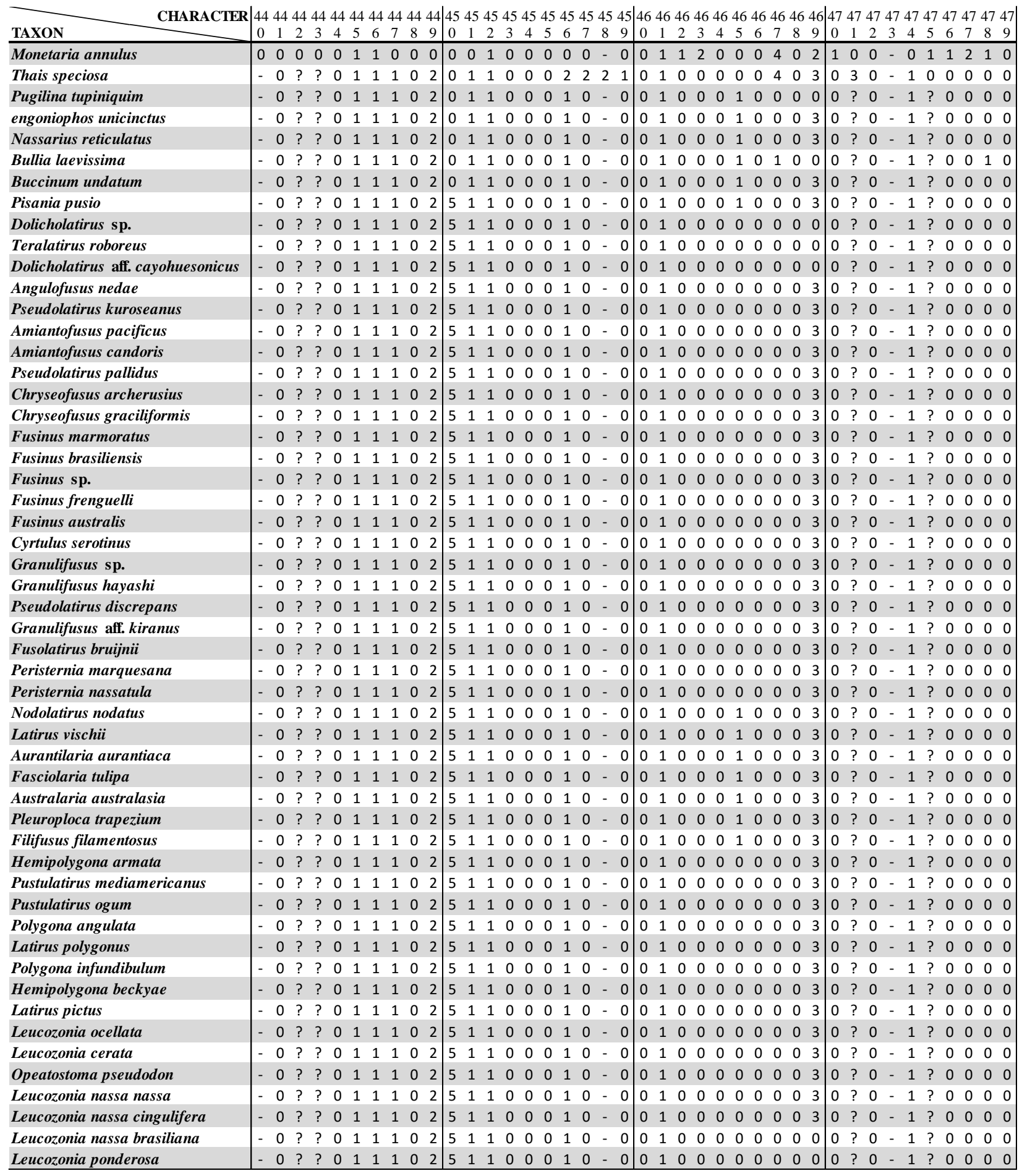




\begin{tabular}{|c|c|c|c|c|c|c|c|c|c|c|c|c|c|c|c|c|c|c|c|c|c|c|c|c|c|c|c|c|c|c|c|c|c|c|c|c|c|c|c|c|c|}
\hline TAXON & $\begin{array}{l}+0 \\
0\end{array}$ & & & & 4 & 5 & 6 & 7 & 8 & 9 & 0 & 1 & & 3 & & 5 & & & 8 & & & & 2 & & & 5 & 6 & & & & & & & & & & & & & & \\
\hline Monetaria annulus & - & - & 0 & - & 0 & - & 0 & - & - & 1 & 0 & 0 & 0 & 1 & 0 & 0 & 1 & 0 & 0 & 0 & & 0 & U & 0 & & & & 0 & 0 & 2 & U & & & & 0 & 0 & 1 & 1 & 0 & 1 & \\
\hline Thais speciosa & - & - & 0 & - & 1 & 1 & 1 & 0 & ? & 1 & 0 & 0 & 4 & 1 & 0 & 0 & 0 & 0 & 0 & 0 & & 0 & 0 & 0 & & & - & 0 & 0 & 0 & 0 & & & & 2 & & 1 & 1 & 0 & 1 & \\
\hline Pugilina tupiniquim & - & - & 0 & - & 0 & 0 & 0 & - & - & ? & $?$ & ? & $?$ & ? & $?$ & ? & ? & ? & $?$ & ? & ? & ? & ? & 0 & & - & - & - & ? & ? & & ? & ? & & 2 & ? & ? & ? & 0 & ? & \\
\hline engoniophos unicinctus & - & - & 0 & - & 1 & 0 & 1 & 1 & 2 & ? & $?$ & ? & $?$ & ? & $?$ & ? & $?$ & $?$ & $?$ & $\cdot 1$ & ? & $?$ & ? & r & & & - & - & ? & ? & $?$ & & ? & & 2 & $?$ & $?$ & ? & 0 & & \\
\hline Nassarius & - & - & 0 & - & 1 & 0 & 1 & 1 & 2 & ? & $?$ & ? & $?$ & $?$ & $?$ & $?$ & $?$ & $?$ & $?$ & $?$ & ? & $?$ & $?$ & 0 & & & - & - & $?$ & S & ? & ? & ? & $?$ & 2 & ? & $?$ & ? & 0 & ? & \\
\hline Bullia laev & - & - & 0 & - & 1 & 0 & 1 & 0 & 2 & ? & ? & ? & ? & ? & $?$ & $?$ & $?$ & ? & ? & ? & ? & ? & $?$ & 0 & - & - & - & - & ? & $?$ & ? & $?$ & ? & ? & 2 & ? & $?$ & ? & 0 & ? & \\
\hline Buccinum undatum & - & - & 0 & - & 1 & 0 & 1 & 1 & 2 & ? & $?$ & ? & $?$ & ? & $?$ & ? & $?$ & $?$ & ? & $?$ & ? & ? & ? & 0 & - & - & - & - & $?$ & $?$ & ? & ? & ? & ? & 2 & ? & ? & ? & 0 & ? & \\
\hline Pisania pusio & - & - & 0 & - & 1 & 0 & 1 & 0 & 2 & ? & ? & ? & ? & ? & $?$ & ? & $?$ & ? & ? & ? & $?$ & ? & ? & 0 & - & - & - & - & ? & $?$ & ? & ? & ? & ? & 2 & ? & $?$ & ? & 0 & ? & \\
\hline Dolicholatirus sp. & - & - & 0 & - & 1 & 0 & 0 & 1 & 2 & ? & $?$ & ? & $?$ & $?$ & $?$ & $?$ & $?$ & ? & $?$ & $?$ & $?$ & $?$ & $?$ & 0 & - & 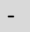 & - & - & $?$ & $?$ & : & ? & ? & & 2 & $?$ & $?$ & ? & 0 & $?$ & \\
\hline Teralatirus & - & - & 0 & - & 0 & 0 & 0 & 1 & 2 & ? & $?$ & $?$ & $?$ & $?$ & $?$ & $?$ & $?$ & $?$ & $?$ & $?$ & $?$ & $?$ & $?$ & 0 & - & - & - & - & $?$ & $?$ & $?$ & & ? & & 2 & ? & $?$ & ? & 0 & ? & \\
\hline Dolicholatirt & - & - & 0 & - & 1 & 0 & 0 & 1 & 2 & ? & $?$ & ? & $?$ & $?$ & $?$ & $?$ & $?$ & $?$ & $?$ & ? & $?$ & ? & $?$ & 0 & - & - & - & - & ? & ? & $?$ & & ? & & 2 & ? & $?$ & ? & 0 & ? & \\
\hline dae & - & - & 0 & - & 1 & 0 & 1 & 1 & 2 & ? & $?$ & ? & $?$ & ? & $?$ & $?$ & ? & $?$ & $?$ & ? & ? & $?$ & $?$ & 0 & - & - & - & - & ? & ? & $?$ & ? & ? & ? & 2 & $?$ & $?$ & ? & 0 & ? & \\
\hline Pse & - & - & 0 & - & 1 & 0 & 1 & 1 & 2 & ? & $?$ & $?$ & $?$ & ? & $?$ & $?$ & $?$ & $?$ & $?$ & $?$ & ? & ? & $?$ & 0 & - & - & - & - & $?$ & $?$ & ? & & ? & ? & 2 & $?$ & $?$ & ? & 0 & ? & $?$ \\
\hline Amiantofusu & - & - & 0 & - & 1 & 0 & 1 & 1 & 2 & $?$ & $?$ & $?$ & $?$ & $?$ & $?$ & $?$ & $?$ & $?$ & $?$ & ? & ? & $?$ & $?$ & 0 & - & - & - & - & $?$ & $?$ & ? & $?$ & ? & ? & 2 & ? & $?$ & $?$ & 0 & ? & \\
\hline Amiantofusu & - & - & 0 & - & 1 & 0 & 1 & 1 & 2 & $?$ & $?$ & $?$ & $?$ & $?$ & $?$ & $?$ & $?$ & $?$ & $?$ & $?$ & $?$ & $?$ & $?$ & 0 & - & - & - & - & ? & ? & ? & & ? & ? & 2 & $?$ & $?$ & ? & 0 & ? & $:$ \\
\hline Pse & - & - & 0 & - & 1 & 0 & 1 & 1 & 2 & ? & $?$ & ? & $?$ & $?$ & $?$ & $?$ & $?$ & ? & $?$ & $?$ & ? & ? & $?$ & 0 & - & - & - & - & ? & ? & ? & & ? & ? & 2 & ? & $?$ & $?$ & 0 & $?$ & \\
\hline Chr & - & - & 0 & - & 1 & 0 & 1 & 1 & 2 & $?$ & $?$ & ? & $?$ & ? & $?$ & $?$ & ? & ? & $?$ & ? & ? & ? & $?$ & 0 & - & - & - & - & ? & ? & i & $?$ & ? & ? & 2 & $?$ & $?$ & ? & 0 & ? & \\
\hline Chry & - & - & 0 & - & 1 & 0 & 1 & 1 & 2 & $?$ & $?$ & ? & $?$ & ? & ? & $?$ & ? & $?$ & $?$ & ? & $?$ & ? & $?$ & 0 & - & - & - & - & $?$ & $?$ & ? & $?$ & ? & ? & 2 & $?$ & $?$ & ? & 0 & $?$ & $?$ \\
\hline Fusinus mar & - & - & 0 & - & 1 & 0 & 1 & 1 & 2 & $?$ & $?$ & $?$ & $?$ & $?$ & $?$ & $?$ & $?$ & $?$ & $?$ & $?$ & $?$ & $?$ & $?$ & 0 & - & - & - & - & $?$ & $?$ & ? & ? & ? & ? & 2 & $?$ & $?$ & ? & 0 & ? & ? \\
\hline Fusinus brasiliensis & - & - & 0 & - & 1 & 0 & 1 & 1 & 2 & $?$ & $?$ & $?$ & $?$ & $?$ & $?$ & $?$ & $?$ & $?$ & $?$ & $?$ & ? & $?$ & $?$ & 0 & - & - & - & - & ? & $?$ & ? & & $?$ & ? & 2 & $?$ & $?$ & $?$ & 0 & $?$ & ? \\
\hline Fusinus sp. & - & - & 0 & - & 1 & 0 & 1 & 1 & 2 & ? & $?$ & $?$ & $?$ & $?$ & $?$ & $?$ & $?$ & ? & ? & $?$ & ? & $?$ & $?$ & 0 & - & - & - & - & ? & ? & ? & ? & ? & ? & 2 & ? & $?$ & ? & 0 & $?$ & ? \\
\hline Fusinus frenguelli & - & - & 0 & - & 1 & 0 & 1 & 1 & 2 & ? & $?$ & ? & $?$ & $?$ & $?$ & $?$ & $?$ & ? & $?$ & $?$ & ? & $?$ & ? & 0 & - & - & - & - & ? & ? & $?$ & 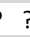 & ? & : & 2 & $?$ & $?$ & ? & 0 & ? & $\cdot$ \\
\hline Fus & - & - & 0 & - & 1 & 0 & 1 & 1 & 2 & $?$ & $?$ & ? & $?$ & ? & $?$ & $?$ & ? & $?$ & $?$ & $?$ & $?$ & $?$ & $?$ & 0 & - & - & - & - & $?$ & $?$ & $?$ & ? & ? & & 2 & $?$ & $?$ & ? & & $?$ & $\cdot$ \\
\hline$C$ & - & - & 0 & - & 1 & 0 & 1 & 1 & 2 & $?$ & ? & ? & $?$ & ? & ? & $?$ & ? & $?$ & $?$ & ? & $?$ & ? & $?$ & 0 & 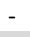 & - & - & - & $?$ & $?$ & $?$ & ? & " & $?$ & 2 & ? & $?$ & ? & 0 & ? & \\
\hline Granulifusus sp. & - & - & 0 & - & 1 & 0 & 1 & 1 & 2 & $?$ & $?$ & $?$ & $?$ & $?$ & $?$ & $?$ & $?$ & $?$ & $?$ & $?$ & ? & $?$ & $?$ & 0 & - & - & - & - & $?$ & $?$ & ? & ? & ? & ? & 2 & $?$ & $?$ & $?$ & 0 & $?$ & ? \\
\hline Granulifusus hayashi & - & - & 0 & - & 1 & 0 & 1 & 1 & 2 & ? & $?$ & $?$ & $?$ & ? & $?$ & $?$ & $?$ & $?$ & $?$ & $?$ & ? & $?$ & $?$ & 0 & - & - & - & - & ? & ? & ? & ? & ? & ? & 2 & $?$ & $?$ & $?$ & 0 & $?$ & ? \\
\hline Pset & - & - & 0 & - & 1 & 0 & 1 & 1 & 2 & ? & ? & ? & $?$ & ? & $?$ & ? & $?$ & ? & ? & ? & ? & ? & ? & 0 & - & - & - & - & ? & ? & ? & & ? & ? & 2 & ? & ? & $?$ & 0 & $?$ & $: 1$ \\
\hline Gra & - & - & 0 & - & 1 & 0 & 1 & 1 & 2 & $?$ & $?$ & ? & $?$ & ? & $?$ & $?$ & $?$ & $?$ & $?$ & $?$ & ? & $?$ & $?$ & 0 & - & - & - & - & $?$ & $?$ & ! & 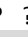 & ? & ? & 2 & ? & $?$ & ? & U & $?$ & $!$ \\
\hline & - & - & 0 & - & 1 & 0 & 1 & 1 & 2 & $?$ & $?$ & $?$ & $?$ & $?$ & $?$ & $?$ & ? & $?$ & $?$ & ? & ? & ? & $?$ & 0 & - & - & - & - & $?$ & $?$ & & & : & & 2 & $\cdot$ & $?$ & ? & 0 & $?$ & . \\
\hline Peri & - & - & 0 & - & 1 & 0 & 1 & 1 & 2 & $?$ & $?$ & $?$ & $?$ & $?$ & $?$ & $?$ & $?$ & $?$ & $?$ & $?$ & ? & $?$ & $?$ & 0 & - & - & - & - & $?$ & $?$ & ? & $?$ & ? & ? & 2 & ? & $?$ & $?$ & 0 & $?$ & ? \\
\hline satula & - & - & 0 & - & 1 & 0 & 1 & 1 & 2 & ? & $?$ & $?$ & $?$ & $?$ & $?$ & $?$ & $?$ & ? & $?$ & $?$ & $?$ & $?$ & $?$ & 0 & - & - & - & - & ? & ? & ? & , & $?$ & ? & 2 & $?$ & $?$ & $?$ & 0 & $?$ & $?$ \\
\hline Nodolatiru & - & - & 0 & - & 1 & 0 & 1 & 1 & 2 & $?$ & $?$ & $?$ & $?$ & $?$ & $?$ & $?$ & $?$ & $?$ & $?$ & $?$ & $?$ & $?$ & $?$ & 0 & - & - & - & - & ? & ? & ? & ? & $?$ & ? & 2 & $?$ & $?$ & $?$ & 0 & $?$ & $?$ \\
\hline Lati & - & - & 0 & - & 1 & 0 & 1 & 1 & 2 & ? & ? & ? & $?$ & ? & $?$ & $?$ & $?$ & ? & $?$ & $?$ & ? & ? & ? & 0 & - & - & - & - & $?$ & ? & ? & 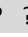 & ? & ? & 2 & ? & $?$ & $?$ & 0 & $?$ & ? \\
\hline Aur & - & - & 0 & - & 1 & 0 & 1 & 1 & 2 & $?$ & ? & ? & $?$ & ? & $?$ & $?$ & $?$ & $?$ & $?$ & ? & $?$ & $?$ & $?$ & 0 & - & - & - & - & ? & ? & : & 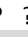 & ! & & 2 & ? & $?$ & ? & 0 & $?$ & $:$ \\
\hline Fas & - & - & 0 & - & 1 & 0 & 1 & 1 & 2 & $?$ & $?$ & ? & $?$ & $?$ & $?$ & $?$ & $?$ & $?$ & $?$ & $?$ & ? & $?$ & $?$ & 0 & - & 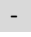 & - & - & ? & ? & & 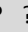 & ? & & 2 & ? & $?$ & ? & 0 & $?$ & \\
\hline Aust & - & - & 0 & - & 1 & 0 & 1 & 1 & 2 & $?$ & $?$ & ? & $?$ & $?$ & $?$ & $?$ & $?$ & $?$ & $?$ & $?$ & $?$ & $?$ & $?$ & 0 & - & - & - & - & $?$ & $?$ & ? & 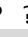 & ? & ? & 2 & $?$ & $?$ & $?$ & 0 & $?$ & $?$ \\
\hline Pleuroploca $t$ & - & - & 0 & - & 1 & 0 & 1 & 1 & 2 & ? & $?$ & $?$ & $?$ & $?$ & $?$ & $?$ & $?$ & $?$ & $?$ & $?$ & ? & $?$ & $?$ & 0 & - & - & - & - & $?$ & $?$ & ? & ? & ? & ? & 2 & $?$ & $?$ & $?$ & 0 & $?$ & $?$ \\
\hline Filifusus filamentosus & - & - & 0 & - & 1 & 0 & 1 & 1 & 2 & $?$ & $?$ & ? & $?$ & $?$ & $?$ & $?$ & $?$ & $?$ & $?$ & $?$ & ? & ? & $?$ & 0 & - & - & - & - & $?$ & $?$ & ? & ? & $?$ & ? & 2 & $?$ & $?$ & $?$ & 0 & $?$ & $?$ \\
\hline Hemipolygona armata & - & - & 0 & - & 1 & 0 & 1 & 1 & 2 & $?$ & $?$ & ? & $?$ & $?$ & $?$ & $?$ & $?$ & $?$ & $?$ & $?$ & $?$ & $?$ & $?$ & 0 & - & - & - & - & $?$ & $?$ & ? & 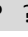 & ? & ? & 2 & $?$ & $?$ & ? & 0 & $?$ & $?$ \\
\hline latirus mediame & - & - & 0 & - & 1 & 0 & 1 & 1 & 2 & $?$ & $?$ & $?$ & $?$ & $?$ & $?$ & $?$ & $?$ & $?$ & $?$ & $?$ & $?$ & $?$ & $?$ & 0 & - & - & - & - & $?$ & $?$ & : & 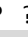 & $?$ & ? & 2 & ? & $?$ & $?$ & 0 & $?$ & ? \\
\hline Pustulatirus & - & - & 0 & - & 1 & 0 & 1 & 1 & 2 & $?$ & $?$ & ? & $?$ & ? & $?$ & $?$ & $?$ & ? & $?$ & $?$ & $?$ & $?$ & $?$ & 0 & - & - & - & - & ? & ? & : & ( & ? & ? & 2 & $?$ & $?$ & ? & 0 & $?$ & $\cdot 1$ \\
\hline a angulata & - & - & 0 & - & 1 & 0 & 1 & 1 & 2 & $?$ & $?$ & $?$ & $?$ & $?$ & $?$ & $?$ & $?$ & $?$ & $?$ & $?$ & ? & ? & $?$ & 0 & - & - & - & - & $?$ & $?$ & ? & 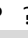 & ? & ? & 2 & $?$ & $?$ & $?$ & 0 & $?$ & ? \\
\hline Latirus polygonus & - & - & 0 & - & 1 & 0 & 1 & 1 & 2 & ? & $?$ & ? & $?$ & $?$ & $?$ & $?$ & $?$ & ? & $?$ & $?$ & ? & ? & $?$ & 0 & - & - & - & - & ? & ? & ? & ? & ? & ? & 2 & $?$ & $?$ & $?$ & 0 & $?$ & $?$ \\
\hline Polygona infundibulum & - & - & 0 & - & 1 & 0 & 1 & 1 & 2 & $?$ & ? & $?$ & $?$ & $?$ & $?$ & $?$ & $?$ & $?$ & $?$ & $?$ & $?$ & $?$ & $?$ & 0 & - & - & - & - & $?$ & $?$ & ? & P & ? & ? & 2 & $?$ & $?$ & $?$ & 0 & $?$ & $?$ \\
\hline Hemipolygona beckyae & - & - & 0 & - & 1 & 0 & 1 & 1 & 2 & ? & $?$ & $?$ & $?$ & $?$ & $?$ & $?$ & $?$ & $?$ & $?$ & $?$ & $?$ & $?$ & $?$ & 0 & - & - & - & - & ? & $?$ & ? & 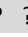 & $?$ & ? & 2 & ? & $?$ & ? & 0 & $?$ & $?$ \\
\hline Latirus & - & - & 0 & - & 1 & 0 & 1 & 1 & 2 & $?$ & $?$ & ? & $?$ & $?$ & ? & $?$ & $?$ & ? & $?$ & $?$ & ? & $?$ & ? & 0 & - & - & - & - & ? & $?$ & ? & 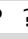 & ? & ? & 2 & $?$ & $?$ & $?$ & 0 & $?$ & ? \\
\hline Leuc & - & - & 0 & - & 1 & 0 & 1 & 0 & 2 & $?$ & $?$ & ? & $?$ & $?$ & $?$ & $?$ & $?$ & $?$ & $?$ & $?$ & $?$ & ? & $?$ & 0 & - & - & - & - & $?$ & $?$ & ? & , & ? & : & 2 & $?$ & $?$ & $?$ & 0 & $?$ & ? \\
\hline nia cerata & - & - & 0 & - & 1 & 0 & 1 & 0 & 2 & $?$ & $?$ & ? & $?$ & ? & ? & $?$ & ? & ? & $?$ & $?$ & $?$ & ? & $?$ & 0 & - & - & - & - & ? & ? & : & & ? & & 2 & $?$ & $?$ & $?$ & 0 & $?$ & ? \\
\hline oma pseudodon & - & - & 0 & - & 1 & 0 & 1 & 0 & 2 & $?$ & $?$ & ? & $?$ & $?$ & $?$ & $?$ & $?$ & $?$ & $?$ & $?$ & $?$ & ? & $?$ & 0 & - & - & - & - & $?$ & $?$ & ? & ? & ? & ? & 2 & $?$ & $?$ & $?$ & 0 & $?$ & $\cdot$ \\
\hline Leucozonia nassa nassa & - & - & 0 & - & 1 & 0 & 1 & 0 & 2 & $?$ & $?$ & $?$ & $?$ & $?$ & $?$ & $?$ & $?$ & $?$ & $?$ & $?$ & $?$ & $?$ & $?$ & 0 & - & - & - & - & $?$ & $?$ & ? & ? & ? & ? & 2 & $?$ & $?$ & $?$ & 0 & $?$ & $?$ \\
\hline Leuc & - & - & 0 & - & 1 & 0 & 1 & 0 & 2 & $?$ & $?$ & ? & $?$ & ? & $?$ & ? & $?$ & $?$ & ? & $?$ & ? & $?$ & ? & 0 & - & - & - & - & $?$ & $?$ & ? & 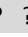 & ? & ? & 2 & ? & $?$ & ? & 0 & $?$ & ! \\
\hline 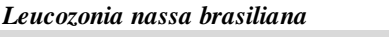 & - & - & 0 & - & 1 & 0 & 0 & 1 & 2 & ? & $?$ & ? & $?$ & $?$ & $?$ & $?$ & $?$ & $?$ & ! & $?$ & $?$ & ? & ? & 0 & - & - & - & - & $?$ & $?$ & ? & ? & ? & : & 2 & $?$ & $?$ & $?$ & 0 & $?$ & ? \\
\hline Leucozonia ponderosa & - & - & 0 & - & 1 & 0 & 0 & 1 & 2 & ? & $?$ & $?$ & $?$ & ? & $?$ & ? & $?$ & ? & $?$ & $?$ & ? & $?$ & $?$ & 0 & - & - & - & - & ? & ? & ? & & $?$ & ? & 2 & ? & $?$ & $?$ & 0 & $?$ & \\
\hline
\end{tabular}




\begin{tabular}{|c|c|c|c|c|c|c|c|c|c|c|c|c|c|c|c|c|c|c|c|c|c|c|c|c|c|c|c|c|c|c|c|c|c|c|c|c|}
\hline & & & & & & & & & & & & & & & & & & & & & & & & & & & & & & & & & & & & \\
\hline XON & 0 & & & & & 6 & & 8 & 9 & 0 & & & & & & & & & 0 & & 2 & & 4 & & & & & & & & & & & & & \\
\hline Monetaria annulus & 1 & & 0 & & 10 & 0 & 1 & ) & 0 & 1 & & 0 & 1 & 0 & 0 & 2 & & 00 & 0 & 1 & 1 & 1 & 2 & 4 & 0 & 0 & & & 0 & & 0 & 1 & 0 & & $\begin{array}{ll}0 & 1\end{array}$ & \\
\hline Thais speciosa & 1 & & 0 & & 10 & 0 & & 0 & 0 & 1 & & 0 & 0 & 0 & 0 & & 00 & 00 & 0 & 1 & 1 & 1 & 2 & 2 & 0 & & & & & & 0 & 0 & 1 & & 01 & \\
\hline Pugilin & 1 & & 0 & & ? ? & 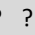 & & ? & 0 & 1 & & 0 & & & & & & 00 & 0 & ? & 1 & 1 & 3 & 2 & & 0 & & & & & 0 & 0 & 1 & 10 & 0 ? & \\
\hline inctu: & 1 & & 0 & & ? ? & ? & & ? & 0 & 1 & 0 & 0 & & 0 & & & & 0 & 0 & ? & 1 & 1 & 3 & 2 & 0 & 0 & & & 0 & & 0 & 0 & 1 & 10 & $0 ?$ & \\
\hline Nassarius & 1 & & 0 & & ? ? & ? & & ? & 0 & 1 & 0 & 0 & & 0 & & 00 & 00 & & 0 & ? & 1 & 1 & 3 & 2 & 0 & 0 & & & & & 0 & 0 & 1 & 10 & 0 ? & \\
\hline Bullia laevissima & 1 & & & & ? ? & ? & & ? & 0 & 1 & 0 & 0 & & 0 & & 0 & & & 0 & ? & 1 & 1 & 3 & 2 & & $0 ?$ & & & 0 & & 0 & 0 & 1 & & 0 ? & \\
\hline Buccin & 1 & & & 1 & ? ? & ? & & ? & 0 & 1 & 0 & 0 & 0 & 0 & 0 & 0 & 00 & 0 & 0 & ? & 1 & 1 & 3 & 2 & 0 & 0 & & & 0 & & 0 & 0 & 1 & & 0 ? & \\
\hline is a & 1 & & 0 & & ? ? & ? & & ? & 0 & 1 & 0 & 0 & 0 & 0 & & & 00 & & 0 & ? & 1 & 1 & 3 & 2 & 0 & & & & & & 0 & 0 & 1 & & 0 ? & \\
\hline us sp. & 1 & & & & ? ? & ? & & ? & 0 & 1 & 0 & 0 & 0 & 0 & & & 00 & 0 & 0 & ? & 1 & & 3 & 2 & & & & & & & 0 & 0 & 1 & & 0 ? & \\
\hline Teralat & 1 & & & & ? ? & ? & & ? & 0 & 1 & 0 & 0 & & 0 & 0 & & & 0 & 0 & ? & 1 & 1 & 3 & 2 & & & & & & & 0 & 0 & 1 & & 0 ? & \\
\hline & 1 & & 0 & 1 & ? ? & ? & & ? & 0 & 1 & 0 & 0 & & 0 & 0 & 0 & 00 & 0 & 0 & ? & 1 & 1 & 3 & 2 & 0 & 0 & & ? ? & 0 & & 0 & 0 & 1 & 10 & 0 ? & \\
\hline $\boldsymbol{e}$ & 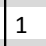 & & 0 & 1 & ? ? & ? & & ? & 0 & 1 & 0 & 0 & 0 & 0 & 0 & 0 & 00 & 00 & 0 & ? & 1 & 1 & 3 & 2 & 0 & 0 & & ? ? & 0 & ? & 0 & 0 & 1 & & 0 ? & ? \\
\hline Psen & 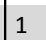 & & 0 & 1 & ? ? & ? & & ? & 0 & 1 & 0 & 0 & 0 & 0 & 0 & 0 & 00 & 00 & 0 & ? & 1 & 1 & 3 & 2 & 0 & 0 & & ? & 0 & & 0 & 0 & 1 & 10 & 0 ? & ? \\
\hline ificus & 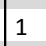 & & 0 & 1 & ? ? & ? & & ? & 0 & 1 & 0 & 0 & 0 & 0 & 0 & 0 & 00 & 00 & 0 & ? & 1 & 1 & 3 & 2 & 0 & 0 & & ? ? & 0 & & 0 & 0 & 1 & 10 & 0 ? & ? \\
\hline doris & 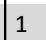 & & 0 & 1 & ? ? & ? & & ? & 0 & 1 & 0 & 0 & 0 & 0 & 0 & & 00 & 0 & 0 & ? & 1 & 1 & 3 & 2 & 0 & 0 & ? & ? & 0 & & 0 & 0 & 1 & 1 & 0 ? & ? \\
\hline Pseuc & 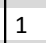 & & 0 & 1 & ? ? & ? & & ? & 0 & 1 & 0 & 0 & 0 & 0 & 0 & & 00 & 00 & 0 & ? & 1 & 1 & 3 & 2 & 0 & 0 & & & 0 & & 0 & 0 & 1 & c & 0 ? & ? \\
\hline Chry & 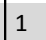 & & 0 & 1 & ? ? & ? & & ? & 0 & 1 & 0 & 0 & 0 & 0 & 0 & 0 & 00 & 0 & 0 & ? & 1 & 1 & 3 & 2 & 0 & 0 & & ? & 0 & & 0 & 0 & 1 & c & 0 ? & \\
\hline Chrys & 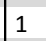 & & 0 & 1 & ? ? & ? & & ? & 0 & 1 & 0 & 0 & 0 & 0 & 0 & 0 & 00 & 0 & 0 & ? & 1 & 1 & 3 & 2 & 0 & 0 & ? & ? & 0 & & 0 & 0 & 1 & 10 & 0 ? & ? \\
\hline Fusi & 1 & & 0 & 1 & ? ? & ? & & ? & 0 & 1 & 0 & 0 & 0 & 0 & 0 & 0 & 00 & 0 & 0 & ? & 1 & 1 & 3 & 2 & 0 & 0 & ? & ? & 0 & & 0 & 0 & 1 & & 0 ? & \\
\hline Fusi & 1 & & 0 & 1 & ? ? & ? & & ? & 0 & 1 & 0 & 0 & 0 & 0 & 0 & 0 & 00 & 00 & 0 & ? & 1 & 1 & 3 & 2 & 0 & 0 & ? & ? & 0 & & 0 & 0 & 1 & & 0 ? & \\
\hline$F$ & 1 & & 0 & 1 & ? ? & ? & & ? & 0 & 1 & 0 & 0 & 0 & 0 & 0 & 0 & 00 & 0 & 0 & $?$ & 1 & 1 & 3 & 2 & 0 & 0 & & ? & 0 & & 0 & 0 & 1 & & 0 ? & \\
\hline$F$ & 1 & & 0 & 1 & ? ? & ? & & ? & 0 & 1 & 0 & 0 & 0 & 0 & 0 & 0 & 00 & 00 & 0 & ? & 1 & 1 & 3 & 2 & 0 & 0 & & ? & 0 & & 0 & 0 & 1 & & 0 ? & \\
\hline Fus & 1 & & 0 & 1 & ? ? & ? & & ? & 0 & 1 & 0 & 0 & 0 & 0 & 0 & & 00 & 0 & 0 & ? & 1 & 1 & 3 & 2 & 0 & 0 & & ? & & & 0 & 0 & 1 & & 0 ? & \\
\hline & 1 & & 0 & 1 & ? ? & ? & & ? & 0 & 1 & 0 & 0 & 0 & 0 & 0 & & 00 & 0 & 0 & ? & 1 & 1 & 3 & 2 & 0 & & & & & & 0 & 0 & 1 & & ? & \\
\hline & 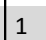 & & 0 & 1 & ? ? & ? & & ? & 0 & 1 & 0 & 0 & 0 & 0 & 0 & & 00 & 00 & 0 & ? & 1 & 1 & 3 & 2 & 0 & 0 & & ? & 0 & & 0 & 0 & 1 & & 0 ? & \\
\hline & 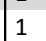 & & 0 & 1 & ? ? & ? & & ? & 0 & 1 & 0 & 0 & 0 & 0 & 0 & 0 & 00 & 00 & 0 & ? & 1 & 1 & 3 & 2 & 0 & 0 & & ? & 0 & & 0 & 0 & 1 & 10 & 0 ? & ? \\
\hline & 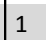 & & 0 & 1 & ? ? & ? & & ? & 0 & 1 & 0 & 0 & 0 & 0 & 0 & 0 & 00 & 0 & 0 & ? & 1 & 1 & 3 & 2 & 0 & 0 & & ? & 0 & & 0 & 0 & 1 & 10 & 0 ? & ? \\
\hline & 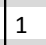 & & 0 & 1 & ? ? & ? ? & - & ? & 0 & 1 & 0 & 0 & 0 & 0 & 0 & 0 & 00 & 00 & 0 & ? & 1 & 1 & 3 & 2 & 0 & 0 & $?$ & $?$ & 0 & & 0 & 0 & 1 & 10 & 0 ? & ? \\
\hline & 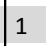 & & 0 & 1 & ? ? & ? & & ? & 0 & 1 & 0 & 0 & 0 & 0 & 0 & 0 & 00 & 00 & 0 & ? & 1 & 1 & 3 & 2 & 0 & 0 & & ? & 0 & & 0 & 0 & 1 & 10 & 0 ? & ? \\
\hline & 1 & & 0 & 1 & ? ? & ? & & ? & 0 & 1 & 0 & 0 & 0 & 0 & 0 & 0 & 00 & 0 & 0 & ? & 1 & 1 & 3 & 2 & 0 & 0 & ? & ? & 0 & & 0 & 0 & 1 & 10 & 0 ? & ? \\
\hline & 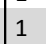 & & 0 & 1 & ? ? & ? ? & 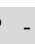 & ? & 0 & 1 & 0 & 0 & 0 & 0 & 0 & 0 & 00 & 00 & 0 & ? & 1 & 1 & 3 & 2 & 0 & 0 & ? & ? & 0 & & 0 & 0 & 1 & 1 & 0 ? & ? \\
\hline & 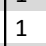 & & 0 & 1 & ? ? & ? ? & & ? & 0 & 1 & 0 & 0 & 0 & 0 & 0 & & 00 & 00 & 0 & ? & 1 & 1 & 3 & 2 & 0 & 0 & ? & ? & 0 & & 0 & 0 & 1 & c & 0 ? & ? \\
\hline & 1 & & 0 & 1 & ? ? & ? & & ? & 0 & 1 & 0 & 0 & 0 & 0 & 0 & 0 & 00 & 00 & 0 & ? & 1 & 1 & 3 & 2 & 0 & 0 & ? & ? & 0 & ) & 0 & 0 & 1 & 1 & 0 ? & ? \\
\hline & 1 & & 0 & 1 & ? ? & ? ? & & ? & 0 & 1 & 0 & 0 & 0 & 0 & 0 & 0 & 00 & 00 & 0 & ? & 1 & 1 & 3 & 2 & 0 & 0 & ? & ? & 0 & ? ? & 0 & 0 & 1 & 10 & 0 ? & ? \\
\hline & 1 & & 0 & 1 & ? ? & ? ? & & ? & 0 & 1 & 0 & 0 & 0 & 0 & 0 & 0 & 00 & 00 & 0 & ? & 1 & 1 & 3 & 2 & 0 & 0 & ? & ? & 0 & & 0 & 0 & 1 & & 0 ? & \\
\hline & 1 & & 0 & 1 & ? ? & ? ? & & ? & 0 & 1 & 0 & 0 & 0 & 0 & 0 & 0 & 00 & 00 & 0 & ? & 1 & 1 & 3 & 2 & 0 & 0 & ? & ? & 0 & & 0 & 0 & 1 & & 0 ? & ? \\
\hline & 1 & & 0 & 1 & ? ? & ? ? & - & ? & 0 & 1 & 0 & 0 & 0 & 0 & 0 & & 00 & 0 & 0 & ? & 1 & 1 & 3 & 2 & 0 & 0 & & ? & 0 & & 0 & 0 & 1 & & 0 ? & \\
\hline & 1 & & 0 & 1 & ? ? & $?$ & & ? & 0 & 1 & 0 & 0 & 0 & 0 & 0 & 0 & 00 & 00 & 0 & ? & 1 & 1 & 3 & 2 & 0 & 0 & & ? & 0 & & 0 & 0 & 1 & & 0 & ? \\
\hline & 1 & & 0 & 1 & ? ? & ? & - & ? & 0 & 1 & 0 & 0 & 0 & 0 & 0 & 0 & 00 & 0 & 0 & ? & 1 & 1 & 3 & 2 & 0 & 0 & ? & ? & 0 & & 0 & 0 & 1 & & 0 ? & \\
\hline & 1 & & 0 & 1 & ? ? & ? & & ? & 0 & 1 & 0 & 0 & 0 & 0 & 0 & 0 & 00 & 0 & 0 & ? & 1 & 1 & 3 & 2 & 0 & 0 & ? & ? & 0 & & 0 & 0 & 1 & & ? & \\
\hline & 1 & & 0 & 1 & ? ? & $?$ & ? & ? & 0 & 1 & 0 & 0 & 0 & 0 & 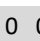 & 0 & 00 & 00 & 0 & ? & 1 & 1 & 3 & 2 & 0 & 0 & ? & 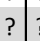 & 0 & & 0 & 0 & 1 & & 0 ? & ? \\
\hline & 1 & & 0 & 1 & ? ? & $?$ & ? & ? & 0 & 1 & 0 & 0 & 0 & 0 & 0 & 0 & 00 & 00 & 0 & ? & 1 & 1 & 3 & 2 & 0 & 0 & ? & $?$ & 0 & J & 0 & 0 & 1 & & 0 ? & ? \\
\hline & 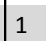 & & 0 & 1 & ? ? & ? & & ? & 0 & 1 & 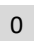 & 0 & 0 & 0 & 0 & 0 & 00 & 0 & 0 & ? & 1 & 1 & 3 & 2 & 0 & 0 & & ? & 0 & ) & 0 & 0 & 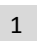 & 10 & 0 ? & \\
\hline & 1 & & 0 & 1 & ? ? & ? & & ? & 0 & 1 & 0 & 0 & 0 & 0 & 0 & 0 & 00 & 00 & D & ? & 1 & 1 & 3 & 2 & 0 & 0 & ? & ? & 0 & & 0 & 0 & 1 & 10 & 0 ? & ? \\
\hline & 1 & & 0 & 1 & ? ? & & & ? & 0 & 1 & 0 & 0 & 0 & 0 & 0 & & 00 & 00 & ) & ? & 1 & 1 & 3 & 2 & 0 & 0 & 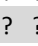 & $?$ & 0 & & 0 & 0 & 1 & 10 & 0 ? & ? \\
\hline & 1 & & 0 & 1 & ? ? & & & ? & D & 1 & 0 & 0 & 0 & 0 & 0 & & 00 & 00 & ) & ? & 1 & 1 & 3 & 2 & 0 & 0 & ? & ? & 0 & & 0 & 0 & 1 & 10 & 0 ? & ? \\
\hline $\boldsymbol{L}$ & 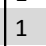 & & 0 & 1 & ? ? & & & ? & ) & 1 & 0 & 0 & 0 & 0 & 列 & & 00 & 00 & 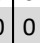 & ? & 1 & 1 & 3 & 2 & 0 & 0 & ? & ? & 0 & & 0 & 0 & 1 & 10 & 0 ? & ? \\
\hline$L$ & 1 & & 0 & 1 & ? ? & & & ? & 0 & 1 & 0 & 0 & 0 & 0 & 0 & & 00 & 00 & 0 & ? & 1 & 1 & 3 & 2 & 0 & 0 & & $?$ & 0 & & 0 & 0 & 1 & 10 & 0 ? & ? \\
\hline & 1 & & 0 & 1 & ? ? & & & ? & 0 & 1 & 0 & 0 & 0 & 0 & 0 & 0 & 00 & 0 & 0 & ? & 1 & 1 & 3 & 2 & 0 & 0 & & ? & 0 & & 1 & 0 & 1 & & 0 ? & ? \\
\hline & 1 & & 0 & 1 & ? ? & & ? & ? & 0 & 1 & 0 & 0 & 0 & 0 & 0 & 0 & 0 & 00 & 0 & ? & 1 & 1 & 3 & 2 & 0 & 0 & & : & 0 & & 0 & 0 & 1 & & 0 ? & ? \\
\hline & 1 & & 0 & 1 & ? & & & ? & 0 & 1 & 0 & 0 & 0 & 0 & 0 & & 00 & 00 & 0 & ? & 1 & 1 & 3 & 2 & 0 & 0 & & ? & 0 & & 0 & 0 & 1 & & 0 ? & ? \\
\hline & 1 & & 0 & & ? ? & & & ? & & 1 & 0 & 0 & 0 & 0 & 0 & & 00 & & 0 & ? & 1 & & 3 & 2 & 0 & 0 & & ? & 0 & & 0 & 0 & 1 & & $0 ?$ & ? \\
\hline & 1 & & 0 & 1 & & & & ? & & 1 & & & 0 & & 0 & & & & & ? & 1 & & & & & & & & 0 & & & & & & & \\
\hline
\end{tabular}




\begin{tabular}{|c|c|c|c|c|c|c|c|c|c|c|c|c|c|c|c|c|c|c|c|c|c|c|c|c|c|c|c|c|c|c|c|c|c|c|c|c|}
\hline & & & & & & & & & & & & & & & & & & & & & & & & & & & & & & & & & & & & \\
\hline & 0 & & & & & & & & & 0 & & & & & & & & & & 12 & & & & & & & & & 2 & & & & & & & \\
\hline Ionetaria annulus & 0 & -1 & 10 & 0 & 0 & - & & - & & 3 & & 0 & 0 & 0 & & 0 & $\overline{0 C}$ & & & 1 & 0 & 1 & - & 0 & 1 & 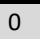 & 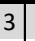 & & 0 & $\overline{1}$ & 0 & \pm & & & & \\
\hline ais & 0 & 1 & 10 & 0 & 0 & 0 & & - & & 3 & & 0 & 0 & 0 & 1 & 0 & 00 & $0 \mid 0$ & 00 & 1 & 0 & 1 & 0 & 0 & 0 & 0 & 3 & 2 & +0 & 1 & 0 & 2 & 0 & 0 & & \\
\hline ıgilin & 0 & 1 & 1 & 0 & 0 & 0 & & & & ? & 0 & 0 & 0 & 0 & 1 & 0 & $0 \mathrm{c}$ & & $? 0$ & 1 & 0 & 1 & 0 & 0 & 0 & 0 & 3 & 2 & +0 & 1 & 0 & 2 & 0 & 0 & 0 & \\
\hline goniophos unicinctus & 0 & -1 & 10 & 0 & 0 & 0 & - & 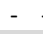 & & - ? & 0 & 0 & 0 & 0 & 1 & & & & & & 0 & 1 & 0 & 0 & 0 & 0 & & 2 & +0 & 1 & 0 & & 0 & & & \\
\hline issaruus & 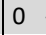 & -1 & 10 & 0 & 0 & 0 & - & - & & - ? & 0 & 0 & 0 & 0 & 1 & & & & & & 0 & 1 & 0 & 0 & & 0 & & 2 & +2 & 1 & 0 & & 0 & & & \\
\hline ullia laevissima & 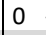 & -1 & 10 & 0 & 0 & 0 & - & 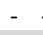 & & - ? & 0 & 0 & 0 & 0 & 1 & & & & & & 0 & 1 & 0 & 0 & 0 & 0 & & 2 & 0 & 1 & 0 & 2 & 0 & & & \\
\hline Buccin & . & -1 & 11 & 0 & 0 & 0 & - & - & & - ? & 0 & 0 & 0 & 0 & 1 & & & & & & 0 & 1 & 0 & 0 & 0 & 0 & & 2 & 2 & 1 & 0 & & 0 & 0 & & \\
\hline san & 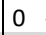 & -1 & 10 & 0 & 0 & 0 & - & - & & - ? & 0 & 0 & 0 & 0 & 1 & 0 & 00 & & & 1 & 0 & 1 & 0 & 0 & 0 & 0 & & 2 & 42 & 1 & 0 & 2 & 0 & 0 & & \\
\hline p. & 0 & -1 & 10 & 0 & 0 & 0 & - & - & & ? & & 0 & 0 & 0 & 1 & 0 & 0 & & & & 0 & 1 & 0 & 0 & 0 & 0 & & 2 & 2 & 1 & 0 & & 0 & 0 & 0 & \\
\hline reus & 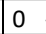 & -1 & 10 & 0 & 0 & 0 & - & 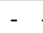 & & - ? & 0 & 0 & 0 & 0 & 1 & 0 & 00 & & ? 0 & & 0 & 1 & 0 & 0 & 0 & 0 & & 2 & 42 & & 0 & & 0 & 0 & & \\
\hline 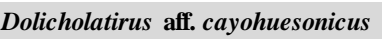 & 0 & -1 & 10 & 0 & 0 & 0 & - & - & & - ? & 0 & 0 & 0 & 0 & 1 & 0 & 0 & & & & 0 & 1 & 0 & 0 & 0 & 0 & & 2 & 2 & & 0 & & 0 & & & \\
\hline 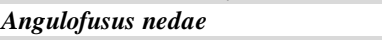 & 0 & & 10 & 0 & 0 & 0 & - & 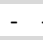 & & - ? & 0 & 0 & 0 & 0 & 1 & & & & & & 0 & 1 & 0 & 0 & 0 & 0 & & 2 & & & 0 & & 0 & & & \\
\hline seuc & 0 & -1 & 10 & 0 & 0 & 0 & - & - & & - ? & 0 & 0 & 0 & 0 & 1 & & & & & & 0 & 1 & 0 & 0 & 0 & 0 & & 2 & 42 & 1 & 0 & & 0 & & & \\
\hline & 0 & -1 & 10 & 0 & 0 & 0 & - & - & & - ? & 0 & 0 & 0 & 0 & 1 & 0 & 0 & 0 & $? 0$ & 1 & 0 & 1 & 0 & 0 & 0 & 0 & 3 & 2 & 42 & 1 & 0 & 2 & 0 & 0 & 0 & \\
\hline loris & 0 & -1 & 10 & 0 & 0 & 0 & - & - & & - ? & 0 & 0 & 0 & 0 & 1 & 0 & 0 & $0 ?$ & $? 0$ & 1 & 0 & 1 & 0 & 0 & 0 & 0 & 3 & 2 & 2 & 21 & 0 & 2 & 0 & & & \\
\hline dus & 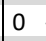 & -1 & 10 & 0 & 0 & 0 & - & - & & - ? & 0 & 0 & 0 & 0 & 1 & 0 & 0 & $0 ?$ & $? 0$ & 1 & 0 & 1 & 0 & 0 & 0 & 0 & 3 & 2 & 2 & 21 & 0 & 2 & 0 & 0 & 0 & \\
\hline & 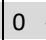 & -1 & 10 & 0 & 0 & 0 & & - & & - ? & 0 & 0 & 0 & 0 & 1 & 0 & 0 & $0 ?$ & $? 0$ & 1 & 0 & 1 & 0 & 0 & 0 & 0 & 3 & 2 & 42 & 2 1 & 0 & & 0 & & 0 & \\
\hline Chr & 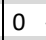 & -1 & 10 & 0 & 0 & 0 & & - & & - ? & 0 & 0 & 0 & 0 & 1 & 0 & 0 & $0 ?$ & ? 0 & 1 & 0 & 1 & 0 & 0 & 0 & 0 & 3 & 2 & 42 & 1 & 0 & & 0 & & 0 & \\
\hline is & 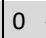 & -1 & 10 & 0 & 0 & 0 & - & - & & - ? & 0 & 0 & 0 & 0 & 1 & 0 & 0 & & ? 0 & & 0 & 1 & 0 & 0 & 0 & 0 & & 2 & +2 & 1 & 0 & 2 & 0 & & 0 & \\
\hline isi & 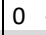 & -1 & 10 & 0 & 0 & 0 & - & - & & - ? & 0 & 0 & 0 & 0 & 1 & 0 & 0 & $\begin{array}{lll}0 & ?\end{array}$ & ? 0 & 1 & 0 & 1 & 0 & 0 & 0 & 0 & 3 & 2 & 2 & 1 & 0 & 2 & 0 & & 0 & \\
\hline$F$ & 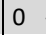 & -1 & 10 & 0 & 0 & 0 & - & 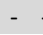 & & - ? & 0 & 0 & 0 & 0 & 1 & 0 & & & & & 0 & 1 & 0 & 0 & 0 & 0 & & 2 & 2 & 1 & 0 & 2 & 0 & 0 & 0 & \\
\hline elli & 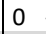 & -1 & 10 & 0 & 0 & 0 & - & - & & - ? & 0 & 0 & 0 & 0 & 1 & 0 & 0 & 0 & ? 0 & & 0 & 1 & 0 & 0 & 0 & 0 & 3 & 2 & 2 & 1 & 0 & 2 & 0 & 0 & 0 & \\
\hline is & (t) & -1 & 10 & 0 & 0 & 0 & - & 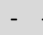 & & - ? & 0 & 0 & 0 & 0 & 1 & 0 & 0 & 0 & ? 0 & 1 & 0 & 1 & 0 & 0 & 0 & 0 & & 2 & 2 & 1 & 0 & 2 & 0 & 0 & 0 & \\
\hline & 0 & -1 & 10 & 0 & 0 & 0 & - & - & & - ? & 0 & 0 & 0 & 0 & 1 & 0 & 0 & 0 & ? 0 & 1 & 0 & 1 & 0 & 0 & 0 & 0 & & 2 & 2 & 2 1 & 0 & & 0 & 0 & 0 & \\
\hline$G$ & 0 & -1 & 10 & 0 & 0 & 0 & & - & & - ? & 0 & 0 & 0 & 0 & 1 & 0 & 0 & & $? 0$ & 1 & 0 & 1 & 0 & 0 & 0 & 0 & & 2 & 2 & 1 & 0 & & 0 & & 0 & \\
\hline Gra & 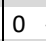 & -1 & 10 & 0 & 0 & 0 & - & - & & - ? & 0 & 0 & 0 & 0 & 1 & 0 & & & $? 0$ & 1 & 0 & 1 & 0 & 0 & 0 & 0 & & 2 & 2 & 1 & 0 & 2 & 0 & & 0 & \\
\hline$P$ & 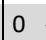 & -1 & 10 & 0 & 0 & 0 & - & - & & - ? & 0 & 0 & 0 & 0 & 1 & 0 & & & $? 0$ & 1 & 0 & 1 & 0 & 0 & 0 & 0 & & 2 & 2 & 1 & 0 & 2 & 0 & & 0 & \\
\hline & 0 & -1 & 10 & 0 & 0 & 0 & 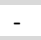 & - & & - ? & 0 & 0 & 0 & 0 & 1 & 0 & & 0 & ? 0 & 1 & 0 & 1 & 0 & 0 & 0 & 0 & 3 & 2 & 2 & 1 & 0 & 2 & 0 & 0 & 0 & \\
\hline & 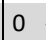 & -1 & 10 & 0 & 0 & 0 & - & - & & - ? & 0 & 0 & 0 & 0 & 1 & 0 & 0 & $0 ?$ & $? 0$ & 1 & 0 & 1 & 0 & 0 & 0 & 0 & 3 & 2 & 2 & 2 1 & 0 & 2 & 0 & 0 & 0 & \\
\hline & 0 & -1 & 10 & 0 & 0 & 0 & - & - & - & - ? & 0 & 0 & 0 & 0 & 1 & 0 & 0 & $\begin{array}{ll}0 \\
\end{array}$ & ? 0 & 1 & 0 & 1 & 0 & 0 & 0 & 0 & 3 & 2 & 2 & 21 & 0 & 2 & 0 & 0 & 0 & \\
\hline & 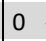 & -1 & 10 & 0 & 0 & 0 & 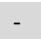 & - & & - ? & 0 & 0 & 0 & 0 & 1 & 0 & 0 & $0 ?$ & $? 0$ & 1 & 0 & 1 & 0 & 0 & 0 & 0 & 3 & 2 & 2 & 21 & 0 & 2 & 0 & 0 & 0 & \\
\hline & 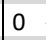 & -1 & 10 & 0 & 0 & 0 & - & - & & - ? & 0 & 0 & 0 & 0 & 1 & 0 & 0 & $0 ?$ & ? 0 & 1 & 0 & 1 & 0 & 0 & 0 & 0 & 3 & 2 & 2 & 1 & 0 & 2 & 0 & 0 & 0 & \\
\hline$L$ & 0 & -1 & 10 & 0 & 0 & 0 & - & - & & - ? & 0 & 0 & 0 & 0 & 1 & 0 & 0 & & ? 0 & 1 & 0 & 1 & 0 & 0 & 0 & 0 & 3 & 2 & 2 & 21 & 0 & 2 & 0 & 0 & 0 & \\
\hline & 0 & -1 & 10 & 0 & 0 & 0 & - & - & & - ? & 0 & 0 & 0 & 0 & 1 & 0 & 0 & 0 & $? 0$ & 1 & 0 & 1 & 0 & 0 & 0 & 0 & 3 & 2 & 2 & 1 & 0 & 2 & 0 & 0 & 0 & \\
\hline & 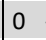 & -1 & 10 & 0 & 0 & 0 & - & - & & - ? & 0 & 0 & 0 & 0 & 1 & 0 & 0 & 0 & $? 0$ & 1 & 0 & 1 & 0 & 0 & 0 & 0 & 3 & 2 & 2 & 1 & 0 & 2 & 0 & 0 & 0 & \\
\hline & 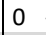 & -1 & 10 & 0 & 0 & 0 & - & 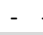 & & - ? & 0 & 0 & 0 & 0 & 1 & 0 & 0 & 0 & ? 0 & 1 & 0 & 1 & 0 & 0 & 0 & 0 & & 2 & 2 & 1 & 0 & 2 & 0 & 0 & 0 & \\
\hline & t & -1 & 10 & 0 & 0 & 0 & - & - & & - ? & 0 & 0 & 0 & 0 & 1 & 0 & & & ? 0 & 1 & 0 & 1 & 0 & 0 & 0 & 0 & & 2 & +2 & 1 & 0 & 2 & 0 & 0 & & \\
\hline$F$ & 0 & -1 & 10 & 0 & 0 & 0 & - & - & & - ? & 0 & 0 & 0 & 0 & 1 & 0 & & & ? 0 & 1 & 0 & 1 & 0 & 0 & 0 & 0 & & 2 & 2 & 1 & 0 & 2 & 0 & 0 & 0 & \\
\hline$H$ & 0 & -1 & 10 & 0 & 0 & 0 & - & 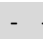 & & - ? & 0 & 0 & 0 & 0 & 1 & 0 & 0 & & ? 0 & 1 & 0 & 1 & 0 & 0 & 0 & 0 & & 2 & 2 & 1 & 0 & 2 & 0 & 0 & 0 & \\
\hline$P$ & 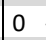 & -1 & 10 & 0 & 0 & 0 & - & - & & - ? & 0 & 0 & 0 & 0 & 1 & 0 & & & ? 0 & 1 & 0 & 1 & 0 & 0 & 0 & 0 & & 2 & 2 & 1 & 0 & 2 & 0 & 0 & 0 & \\
\hline & . & -1 & 10 & 0 & 0 & 0 & - & - & & - ? & 0 & 0 & 0 & 0 & 1 & 0 & & & $? 0$ & 1 & 0 & 1 & 0 & 0 & 0 & 0 & 3 & 2 & 2 & 1 & 0 & 2 & c & 0 & 0 & \\
\hline & . & -1 & 10 & 0 & 0 & 0 & - & - & & - ? & 0 & 0 & 0 & 0 & 1 & 0 & & 0 & $? 0$ & 1 & 0 & 1 & 0 & 0 & 0 & 0 & 3 & 2 & 2 & 1 & 0 & 2 & $c$ & 0 & 0 & \\
\hline & t & -1 & 10 & 0 & 0 & 0 & & - & & - ? & 0 & 0 & 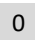 & 0 & 1 & 0 & 0 & 0 & $? 0$ & 1 & 0 & 1 & 0 & 0 & 0 & 0 & 3 & 2 & 2 & 1 & 0 & 2 & 0 & 0 & 0 & \\
\hline & 0 & -1 & 10 & 0 & 0 & 0 & - & - & & - ? & 0 & 0 & 0 & 0 & 1 & 0 & 0 & 0 & $? 0$ & 1 & 0 & 1 & 0 & 0 & 0 & 0 & 3 & 2 & 2 & 1 & 0 & 2 & 0 & 0 & 0 & \\
\hline & 0 & -1 & 10 & 0 & 0 & 0 & - & - & & - ? & 0 & 0 & 0 & 0 & 1 & 0 & 0 & 0 & $? 0$ & 1 & 0 & 1 & 0 & 0 & 0 & 0 & 3 & 2 & 2 & 1 & 0 & 2 & 0 & 0 & 0 & \\
\hline & 0 & -1 & 10 & 0 & 0 & 0 & & - & & - ? & 0 & 0 & 0 & 0 & 1 & 0 & 0 & 0 & ? 0 & 1 & 0 & 1 & 0 & 0 & 0 & 0 & 3 & 2 & 2 & 1 & 0 & 2 & 0 & 0 & ( & \\
\hline Leucc & 0 & -1 & 10 & 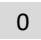 & 0 & 0 & & - & & - ? & 0 & 0 & 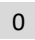 & 0 & 1 & 0 & 0 & & $? 0$ & 1 & 0 & 1 & 0 & 0 & 0 & 0 & 3 & 2 & 2 & 1 & 0 & 2 & C & 0 & C & \\
\hline Leuct & 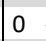 & -1 & 10 & 0 & 0 & 0 & - & - & & - ? & 0 & 0 & 0 & 0 & 1 & 0 & & & $? 0$ & 1 & 0 & 1 & 0 & 0 & 0 & 0 & 3 & 2 & 2 & 1 & 0 & 2 & 0 & 0 & 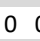 & \\
\hline Ореа & . & -1 & 10 & 0 & 0 & 0 & - & - & & - ? & 0 & 0 & 0 & 0 & 1 & 0 & 0 & & ? 0 & 1 & 0 & 1 & 0 & 0 & 0 & 0 & 3 & 2 & 2 & 1 & 0 & 2 & 0 & 0 & 0 & \\
\hline (2) & 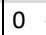 & -1 & 10 & 0 & 0 & 0 & & - & & - ? & 0 & 0 & 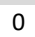 & 0 & 1 & 0 & & & ? 0 & 1 & 0 & 1 & 0 & 0 & 0 & 0 & 3 & 2 & 2 & 1 & 0 & 2 & 0 & 0 & 0 & \\
\hline & . & -1 & 10 & 0 & 0 & 0 & & - & & ? & 0 & 0 & 0 & 0 & 1 & 0 & & & $? 0$ & 1 & 0 & 1 & 0 & 0 & $c$ & 0 & 3 & 2 & & & 0 & 2 & c & $c$ & 0 & \\
\hline & 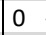 & -1 & 10 & 0 & 0 & 0 & & - & & - ? & 0 & 0 & 0 & 0 & 1 & 0 & & 0 & ? 0 & 1 & 0 & 1 & 0 & 0 & 0 & 0 & 3 & 2 & & & & 2 & $c_{-}$ & 0 & 0 & \\
\hline & 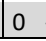 & -1 & 10 & 0 & 0 & 0 & & & & $-\quad$ ? & 0 & 0 & 0 & 0 & 1 & 0 & & & $? 0$ & & 0 & & 0 & 0 & & 0 & & & & & & - & 0 & & & \\
\hline
\end{tabular}




\begin{tabular}{|c|c|c|c|c|c|c|c|c|c|c|c|c|c|c|c|c|c|c|c|c|c|c|c|c|c|c|c|c|c|c|c|c|c|c|c|c|}
\hline XON & & & & & & & & & & & & & & & & & & & & & & & & & & & & & & & & & & & & \\
\hline AXON & 0 & & & & & & & & & & & & & & & & & & 0 & & & & & & & & & & & & & & & & & \\
\hline onet & 0 & & 0 & 0 & 0 & 0 & 0 & & 1 & 0 & 1 & 0 & 0 & 3 & 2 & 0 & 5 & 0 & 0 & . & 0 & 1 & 0 & 2 & 0 & 0 & 0 & & & 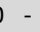 & 1 & 0 & 0 & & - & \\
\hline hals & 0 & & 00 & 0 & 0 & 0 & 0 & 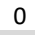 & 0 & 0 & 1 & 1 & 0 & \pm & 0 & 00 & 01 & 0 & 0 & 0 & 0 & 0 & 4 & 2 & 0 & & 00 & & & 0 & 1 & 0 & 0 & 0 & - & 0 \\
\hline gig & 0 & & 00 & 0 & 00 & 0 & 0 & 0 & 0 & 0 & 1 & $?$ & 0 & 1 & 0 & 00 & D 1 & 10 & 0 & & 0 & 0 & 0 & 0 & ? & 0 & 00 & & & ) 1 & 1 & 0 & 0 & 0 & - & 0 \\
\hline go & 0 & 0 & 00 & 0 & 00 & 0 & 0 & 0 & 0 & 0 & 1 & $?$ & 0 & 1 & 0 & 00 & & 10 & 0 & 0 & 0 & 0 & 0 & 2 & $?$ & & 00 & \begin{tabular}{l|l}
0 & 0
\end{tabular} & 0 & ) 1 & 1 & 0 & 0 & 0 & - & 0 \\
\hline issa & 0 & & & 0 & 00 & 0 & 0 & 0 & 0 & 0 & 1 & $?$ & 0 & 1 & 0 & 00 & 1 & 10 & 0 & 0 & 0 & 0 & 0 & 2 & ? & 0 & 00 & \begin{tabular}{l|l}
0 & 0
\end{tabular} & 0 & ) 1 & 1 & 0 & 0 & 0 & - & 0 \\
\hline Bullic & 0 & 0 & 00 & 0 & 00 & 0 & 0 & 0 & 0 & 0 & 1 & $?$ & 0 & 1 & 0 & 00 & b 1 & 10 & 0 & 0 & 0 & 0 & 0 & 0 & ? & 0 & 00 & \begin{tabular}{l|l}
0 & 0
\end{tabular} & 0 & ) 1 & 1 & 0 & 0 & 0 & - & \\
\hline cet & 0 & 0 & 00 & 0 & 00 & 0 & 0 & 0 & 0 & 0 & 1 & ? & 0 & 1 & 0 & 00 & D 1 & 10 & 0 & 0 & 0 & 0 & 0 & 0 & ? & 0 & 00 & & 0 & ) 1 & 1 & 0 & 0 & 0 & & 0 \\
\hline sania & 0 & 0 & $\begin{array}{lll}0 & 0\end{array}$ & 0 & 00 & 0 & 0 & 0 & 0 & 0 & 1 & $?$ & 0 & 1 & 0 & 00 & D 1 & 10 & 0 & 0 & 0 & 0 & 0 & 0 & $?$ & 0 & 00 & & 0 & 1 & 1 & 0 & 0 & 0 & - & \\
\hline Doulct & 0 & & 00 & 0 & 00 & 0 & 0 & 0 & 0 & 0 & 1 & $?$ & 0 & 1 & 0 & 00 & 1 & 10 & 0 & 0 & 0 & 0 & 0 & 2 & ? & & 00 & & & ) 1 & 1 & 0 & 0 & & - & \\
\hline Teralc & 0 & & 00 & 0 & 00 & 0 & 0 & 0 & 0 & 0 & 1 & $?$ & 0 & 1 & & 00 & D 1 & 10 & 0 & 0 & 0 & 0 & 0 & 2 & ? & 0 & 00 & & 0 & ) 1 & 1 & 0 & 0 & 0 & - & \\
\hline Dolich & 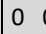 & & & 0 & 00 & & 0 & 0 & 0 & 0 & 1 & $?$ & 0 & 1 & & 00 & & 10 & 0 & & 0 & 0 & 0 & 2 & ? & 0 & & & & 1 & 1 & 0 & 0 & & - & \\
\hline e & 0 & & 00 & 0 & 00 & 0 & 0 & 0 & 0 & 0 & 1 & $?$ & 0 & 1 & & 00 & & 10 & 0 & 0 & 0 & 0 & 0 & 0 & ? & 0 & 00 & & & & & 0 & 0 & 0 & - & \\
\hline $\boldsymbol{e t}$ & 0 & 0 & 00 & 0 & 00 & 0 & 0 & 0 & 0 & 0 & 1 & $?$ & 0 & 1 & & 00 & & 10 & 0 & 0 & 0 & 0 & 0 & 0 & ? & 0 & 00 & & & 1 & 1 & 0 & 0 & 0 & . & 0 \\
\hline Amia & 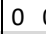 & & 00 & 0 & 00 & 0 & 0 & 0 & 0 & 0 & 1 & $?$ & 0 & 1 & & 00 & & 10 & 0 & 0 & 0 & 0 & 0 & 0 & $?$ & 0 & 00 & & & ) 1 & 1 & 0 & 0 & 0 & - & \\
\hline & 0 & 0 & 00 & 0 & 00 & 0 & 0 & 0 & 0 & 0 & 1 & ? & 0 & 1 & & 00 & & 10 & 0 & 0 & 0 & 0 & 0 & 0 & ? & 0 & 00 & & & ) 1 & 1 & 0 & 0 & 0 & - & 0 \\
\hline & 0 & 0 & 00 & 0 & 00 & 0 & 0 & 0 & 0 & 0 & 1 & ? & 0 & 1 & ? & 00 & D 1 & 10 & 0 & 0 & 0 & 0 & 0 & 0 & ? & 0 & 00 & \begin{tabular}{l|l}
0 & 0
\end{tabular} & & ) 1 & 1 & 0 & 0 & 0 & - & 0 \\
\hline$C$ & 0 & 0 & 00 & 0 & 00 & 0 & 0 & 0 & 0 & 0 & 1 & ? & 0 & 1 & ? & 00 & 1 & 10 & 0 & 0 & 0 & 0 & 0 & 0 & ? & 0 & 00 & & & ) 1 & 1 & 0 & 0 & 0 & - & 0 \\
\hline & 0 & 0 & 00 & 0 & 00 & 0 & 0 & 0 & 0 & 0 & 1 & ? & 0 & 1 & ? & $\begin{array}{ll}0 & 0\end{array}$ & 1 & 10 & 0 & 0 & 0 & 0 & 0 & 0 & $?$ & 0 & 00 & & & 1 & 1 & 0 & 0 & 0 & - & 0 \\
\hline & 0 & 0 & 00 & 0 & 00 & 0 & 0 & 0 & 0 & 0 & 1 & $?$ & 0 & 1 & ? & 00 & 1 & 10 & 0 & 0 & 0 & 0 & 0 & 0 & ? & 0 & 00 & & & ) 1 & 1 & 0 & & 0 & - & 0 \\
\hline Fusin & 0 & 0 & 00 & 0 & 00 & 0 & 0 & 0 & 0 & 0 & 1 & $?$ & 0 & 1 & ? & 00 & 0 1 & 10 & 0 & 0 & 0 & 0 & 0 & 0 & ? & 0 & 00 & & & ) 1 & 1 & 0 & & 0 & - & \\
\hline & 0 & 0 & 00 & 0 & 00 & 0 & 0 & 0 & 0 & 0 & 1 & ? & 0 & 1 & ? & 00 & 0 1 & 10 & 0 & 0 & 0 & 0 & 0 & 0 & ? & 0 & 00 & & 0 & ) 1 & 1 & 0 & 0 & & - & \\
\hline & 0 & 0 & 00 & 0 & 00 & 0 & 0 & 0 & 0 & 0 & 1 & $?$ & 0 & 1 & ? & 00 & 0 1 & 10 & 0 & 0 & 0 & 0 & 0 & 0 & $?$ & 0 & 00 & & & ) 1 & 1 & 0 & 0 & & - & 0 \\
\hline & 0 & 0 & 00 & 0 & 00 & 0 & 0 & 0 & 0 & 0 & 1 & ? & 0 & 1 & ? & 00 & 1 & 10 & 0 & 0 & 0 & 0 & 0 & 0 & ? & 0 & 00 & & & ) 1 & 1 & 0 & 0 & 0 & 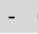 & 0 \\
\hline Cyrtu & 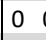 & 0 & $\begin{array}{ll}0 & 0\end{array}$ & 0 & $\begin{array}{ll}0 & 0\end{array}$ & 0 & 0 & 0 & 0 & 0 & 1 & $?$ & 0 & 1 & & $\begin{array}{ll}0 & 0\end{array}$ & 1 & 10 & 0 & 0 & 0 & 0 & 0 & 0 & $?$ & 0 & 00 & & & 1 & 1 & 0 & 0 & 0 & 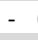 & 0 \\
\hline $\boldsymbol{G}$ & s & 0 & & 0 & 00 & 0 & 0 & 0 & 0 & 0 & 1 & $?$ & 0 & 1 & & 00 & & 10 & 0 & 0 & 0 & 0 & 0 & 0 & ? & 0 & 00 & & & ) 1 & 1 & 0 & 0 & 0 & - & \\
\hline $\boldsymbol{G}$ & ( & 0 & 00 & 0 & 00 & 0 & 0 & 0 & 0 & 0 & 1 & $?$ & 0 & 1 & ? & 00 & 01 & 10 & 0 & 0 & 0 & 0 & 0 & 0 & ? & 0 & 00 & & 00 & ) 1 & 1 & 0 & 0 & 0 & - & 0 \\
\hline & 0 & 0 & 00 & 0 & 00 & 0 & 0 & 0 & 0 & 0 & 1 & $?$ & 0 & 1 & ? & 00 & 1 & 10 & 0 & 0 & 0 & 0 & 0 & 0 & ? & 0 & 00 & & & ) 1 & 1 & 0 & 0 & 0 & -5 & 0 \\
\hline & 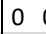 & 0 & 00 & 0 & 00 & 0 & 0 & 0 & 0 & 0 & 1 & $?$ & 0 & 1 & ? & 00 & 0 1 & 10 & 0 & 0 & 0 & 0 & 0 & 0 & $?$ & 0 & 00 & & & ) 1 & 1 & 0 & 0 & 0 & - & 0 \\
\hline Fusol & 0 & 0 & 00 & 0 & 00 & 0 & 0 & 0 & 0 & 0 & 1 & ? & 0 & 1 & ? & 00 & 1 & 10 & 0 & 0 & 0 & 0 & 0 & 0 & ? & 0 & 00 & & & ) 1 & 1 & 0 & 0 & & - & 0 \\
\hline & 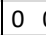 & 0 & 00 & 0 & 00 & 0 & 0 & 0 & 0 & 0 & 1 & ? & 0 & 1 & ? & 00 & D 1 & 10 & 0 & 0 & 0 & 0 & 0 & 0 & ? & 0 & 00 & & 0 & ) 1 & 1 & 0 & 0 & 0 & - & 0 \\
\hline & 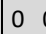 & 0 & 00 & 0 & 00 & 0 & 0 & 0 & 0 & 0 & 1 & ? & 0 & 1 & ? & 00 & 1 & 10 & 0 & 0 & 0 & 0 & 0 & 0 & ? & 0 & $\begin{array}{lll}0 & 0\end{array}$ & & 0 & ) 1 & 1 & 0 & 0 & 0 & - & 0 \\
\hline & s & 0 & 00 & 0 & 00 & 0 & 0 & 0 & 0 & 0 & 1 & $?$ & 0 & 1 & 0 & 00 & 1 & 10 & 0 & 0 & 0 & 0 & 0 & 2 & ? & 0 & 00 & & & ) 1 & 1 & 0 & 0 & 0 & - & 0 \\
\hline & s & 0 & 00 & 0 & 00 & 0 & 0 & 0 & 0 & 0 & 1 & $?$ & 0 & 1 & 0 & 00 & 1 & 10 & 0 & 0 & 0 & 0 & 0 & 2 & ? & 0 & 00 & & & 1 & 1 & 0 & 0 & & - & 0 \\
\hline & 0 & 0 & 00 & 0 & 00 & 0 & 0 & 0 & 0 & 0 & 1 & ? & 0 & 1 & 0 & 00 & 1 & 10 & 0 & 0 & 0 & 0 & 0 & 2 & ? & 0 & 00 & & 0 & ) 1 & 1 & 0 & 0 & 0 & - & 0 \\
\hline & 0 & 0 & 00 & 0 & 00 & 0 & 0 & 0 & 0 & 0 & 1 & ? & 0 & 1 & 0 & 00 & 1 & 10 & 0 & 0 & 0 & 0 & 0 & 2 & ? & 0 & 00 & & & ) 1 & 1 & 0 & 0 & & $-5+2>$ & 0 \\
\hline & 0 & 0 & 00 & 0 & 00 & 0 & 0 & 0 & 0 & 0 & 1 & $?$ & 0 & 1 & 0 & 00 & 01 & 10 & 0 & 0 & 0 & 0 & 0 & 2 & $?$ & 0 & 00 & & 0 & ) 1 & 1 & 0 & 0 & 0 & - & 0 \\
\hline & 0 & 0 & 00 & 0 & 00 & 0 & 0 & 0 & 0 & 0 & 1 & ? & 0 & 1 & 0 & 00 & 01 & 10 & 0 & 0 & 0 & 0 & 0 & 2 & ? & 0 & 00 & 0 & 0 & ) 1 & 1 & 0 & 0 & 0 & - & 0 \\
\hline & 0 & 0 & 00 & 0 & 00 & 0 & 0 & 0 & 0 & 0 & 1 & ? & 0 & 1 & & 00 & & 10 & 0 & 0 & 0 & 0 & 0 & 2 & ? & 0 & 00 & & & ) 1 & 1 & 0 & 0 & 0 & 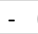 & 0 \\
\hline & 0 & 0 & 00 & 0 & 00 & 0 & 0 & 0 & 0 & 0 & 1 & $?$ & 0 & 1 & & 00 & & 10 & 0 & 0 & 0 & 0 & 0 & 0 & ? & 0 & 00 & & 0 & ) 1 & 1 & 0 & 0 & 0 & - & \\
\hline Pustu & 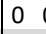 & 0 & 00 & 0 & 00 & 0 & 0 & 0 & 0 & 0 & 1 & $?$ & 0 & 1 & ? & 00 & 1 & 10 & 0 & 0 & 0 & 0 & 0 & 0 & ? & 0 & 00 & & & 1 & 1 & 0 & 0 & 0 & - & 0 \\
\hline & 列 & 0 & 00 & 0 & 00 & 0 & 0 & 0 & 0 & 0 & 1 & ? & 0 & 1 & ? & 00 & 1 & 10 & 0 & 0 & 0 & 0 & 0 & 0 & ? & 0 & 00 & & & ) 1 & 1 & 0 & 0 & 0 & . & 0 \\
\hline & 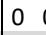 & 0 & 00 & 0 & 00 & 0 & 0 & 0 & 0 & 0 & 1 & ? & 0 & 1 & ? & 00 & 01 & 10 & 0 & 0 & 0 & 0 & 0 & 0 & ? & 0 & 00 & & & ) 1 & 1 & 0 & 0 & 0 & - & 0 \\
\hline & 0 & 0 & 00 & 0 & 00 & 0 & 0 & 0 & 0 & 0 & 1 & ? & 0 & 1 & ? & 00 & 1 & 10 & 0 & 0 & 0 & 0 & 0 & 0 & ? & 0 & 00 & & & ) 1 & 1 & 0 & 0 & 0 & - & 0 \\
\hline & 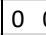 & 0 & 00 & 0 & 00 & 0 & 0 & 0 & 0 & 0 & 1 & ? & 0 & 1 & ? & 00 & 01 & 10 & 0 & 0 & 0 & 0 & 0 & 0 & ? & 0 & 00 & & 0 & ) 1 & 1 & 0 & 0 & 0 & - & 0 \\
\hline & 0 & 0 & 00 & 0 & 00 & 0 & 0 & 0 & 0 & 0 & 1 & ? & 0 & 1 & ? & $\begin{array}{ll}0 & 0\end{array}$ & 1 & 10 & 0 & 0 & 0 & 0 & 0 & 0 & $?$ & 0 & 00 & 0 & 0 & 1 & 1 & 0 & 0 & 0 & - & 0 \\
\hline & 0 & 0 & 00 & 0 & 00 & 0 & 0 & 0 & 0 & 0 & 1 & $?$ & 0 & 1 & ? & 00 & 1 & 10 & 0 & 0 & 0 & 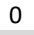 & 0 & 0 & ? & 0 & 00 & & 0 & ) 1 & 1 & 0 & 0 & 0 & - & 0 \\
\hline & 0 & 0 & 00 & 0 & 0 & 0 & 0 & 0 & 0 & 0 & 1 & $?$ & 0 & 1 & 0 & 00 & 1 & 10 & 0 & 0 & 0 & 0 & 0 & 2 & ? & 0 & 00 & 0 & D & . 1 & 1 & 0 & 0 & 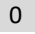 & - & 0 \\
\hline & 0 & 0 & 00 & 0 & 0 & 0 & 0 & 0 & 0 & 0 & 1 & ? & 0 & 1 & & 00 & & 10 & | & & 0 & 0 & 0 & 2 & ? & 0 & 00 & & o ? & 1 & 1 & 0 & 0 & 0 & 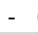 & 0 \\
\hline & 0 & 0 & 0 & 0 & 0 & 0 & 0 & 0 & 0 & 0 & 1 & ? & 0 & 1 & 0 & 00 & & 10 & 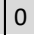 & & 0 & 0 & 0 & 2 & : & & 00 & & o ? & 1 & 1 & 0 & 0 & ( & - & 0 \\
\hline$u$ & 0 & 0 & 00 & 0 & 0 & 0 & 0 & 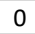 & 0 & 0 & 1 & ? & 0 & 1 & 0 & 00 & 01 & 10 & ( & & 0 & 0 & 0 & 2 & ? & 0 & 00 & & & 1 & 1 & ) & 0 & ( & & \\
\hline Leuc & 0 & 0 & & & & 0 & 0 & 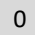 & 0 & 0 & 1 & & & 1 & & 00 & & 10 & 0 & & 0 & 0 & 0 & 2 & ? & 0 & 00 & & & , 1 & 1 & 0 & 0 & ( & & 0 \\
\hline Lucozania nas & 0 & & 0 & 0 & 0 & 0 & 0 & 0 & 0 & 0 & 1 & ? & 0 & 1 & 0 & $\begin{array}{ll}0 & 0\end{array}$ & & 10 & 0 & 0 & 0 & 0 & 0 & 2 & ? & & 00 & 0 & & 1 & 1 & 0 & 0 & ( & & \\
\hline$u c e$ & 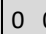 & 0 & & & 0 & & & 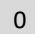 & & & 1 & & 0 & 1 & & 00 & & & 0 & 0 & 0 & & 0 & & & & 00 & & & ) 1 & & & & 0 & & \\
\hline
\end{tabular}




\begin{tabular}{|c|c|c|c|c|c|c|c|c|c|c|c|c|c|c|c|c|c|c|c|c|c|c|c|c|c|c|c|c|c|c|c|c|c|c|c|}
\hline AXON & & & & & & 6 & & 8 & & & & & & & & & & & & & & & & & & & & 9 & & & & & & & \\
\hline$a$ ann & 00 & 01 & 0 & 6 & 0 & 0 & 0 & -1 & & & & 1 & 2 & & & & & & & & & & & & & 0 & & 0 & & & & & & & \\
\hline$h a$ & $\begin{array}{ll}0 & 1\end{array}$ & 11 & 0 & 6 & 0 & 0 & 0 & 1 & 2 & & 2 & & & & & 3 & 1 & 1 & 4 & 0 & & 0 & 1 & 0 & & 0 & & 0 & 1 & 1 & 1 & 0 & & 0 & \\
\hline niquim & $\begin{array}{ll}0 & 1\end{array}$ & 11 & 0 & 6 & 0 & 0 & 0 & 1 & 2 & 1 & 2 & 1 & 3 & 2 & ? & ? & 1 & 1 & & 0 & 10 & 0 & 10 & 0 & 1 & ? 1 & & ? & 0 & 1 & 1 & 0 & - & 0 & \\
\hline goniophos unicinct & 01 & 11 & 0 & 6 & 0 & 0 & 0 & 1 & & 1 & 2 & 1 & 3 & 2 & ? & ? & 1 & 1 & & 0 & & & & & & ? 1 & & ? & 0 & 1 & 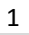 & 0 & & & \\
\hline as & $\begin{array}{ll}0 & 1\end{array}$ & 11 & 0 & 6 & 0 & 0 & 0 & 1 & 2 & 1 & 2 & 1 & 3 & 2 & ? & ? & 1 & 1 & 5 & 0 & 1 & 0 & 1 & & & ? & 2 & ? & 0 & 1 & 1 & 0 & & & \\
\hline Bulli & $\begin{array}{ll}0 & 1\end{array}$ & 11 & 0 & 6 & 0 & 0 & 0 & 1 & 2 & 1 & 2 & 1 & 3 & 2 & ? & ? & 1 & 1 & 5 & 0 & 1 & 0 & 10 & 0 & $1 ?$ & ? 1 & & ? & 0 & 1 & 1 & 0 & - & 0 & \\
\hline$u c$ & 00 & 01 & 0 & 6 & 0 & 0 & 0 & 1 & 2 & 1 & 2 & ? & 3 & 2 & ? & ? & 1 & 1 & 5 & 0 & 10 & & & & & ? 1 & & ? & 0 & 1 & 1 & 0 & & & \\
\hline sa & 00 & 01 & 0 & 6 & 0 & 0 & 0 & 1 & 2 & 1 & 2 & 1 & 3 & 2 & ? & ? & 1 & 1 & 5 & 0 & & & & & $1 ?$ & ? 1 & & ? & 0 & 1 & 1 & 0 & - & & \\
\hline p. & 01 & 11 & 0 & 6 & 0 & 0 & 0 & 1 & 2 & 1 & 2 & 1 & 3 & 2 & ? & ? & 1 & 1 & 5 & 0 & 10 & 0 & 10 & 0 & $1 ?$ & ? 1 & 2 & ? & 0 & 1 & 1 & 0 & & 0 & \\
\hline us & $\begin{array}{ll}0 & 1\end{array}$ & $\begin{array}{ll}11\end{array}$ & 0 & 6 & 0 & 0 & 0 & 1 & 2 & 1 & 2 & 1 & 3 & 2 & ? & ? & 1 & 1 & 5 & 0 & 1 & 0 & 10 & 01 & $1 ?$ & ? & & ? & & 1 & 1 & 0 & - & 0 & \\
\hline Dol & $\begin{array}{ll}0 & 1\end{array}$ & 11 & 0 & 6 & 0 & 0 & 0 & 1 & 2 & 1 & 2 & 1 & 3 & 2 & ? & ? & 1 & 1 & 5 & 0 & 1 & & & & & ? 1 & & ? & 0 & 1 & 1 & 0 & & 0 & \\
\hline ae & 1 & $\begin{array}{ll}11\end{array}$ & 0 & 6 & 0 & 0 & 0 & 1 & 2 & 1 & 2 & 1 & 3 & 2 & $?$ & ? & 1 & 1 & 5 & 0 & 1 & 0 & 10 & 0 & $1 ?$ & ? 1 & & ? & 0 & 1 & 1 & 0 & - & & \\
\hline uros & $\begin{array}{ll}0 & 1\end{array}$ & 11 & 0 & 6 & 0 & 0 & 0 & 1 & 2 & 1 & 2 & 1 & 3 & 2 & ? & ? & 1 & 1 & 5 & 0 & 1 & 0 & 1 & 0 & $1 ?$ & ? 1 & 2 & ? & 0 & 1 & 1 & 0 & - & 0 & \\
\hline & $\begin{array}{ll}01 \\
0\end{array}$ & 11 & 0 & 6 & 0 & 0 & 0 & 1 & 2 & 1 & 2 & 1 & 3 & 2 & ? & ? & 1 & 1 & 5 & 0 & 1 & 0 & 1 & 0 & $1 ?$ & ? 1 & & ? & & 1 & 1 & 0 & - & 0 & \\
\hline & $\begin{array}{ll}0 & 1\end{array}$ & 11 & 0 & 6 & 0 & 0 & 0 & 1 & 2 & 1 & 2 & 1 & 3 & 2 & ? & ? & 1 & 1 & 5 & 0 & 1 & 0 & 1 & 0 & $1 ?$ & ? 1 & & ? & 0 & 1 & 1 & 0 & & 0 & \\
\hline Pse & 01 & $\begin{array}{ll}11 \\
\end{array}$ & 0 & 6 & 0 & 0 & 0 & 1 & 2 & 1 & 2 & 1 & 3 & 2 & $?$ & ? & 1 & 1 & 5 & 0 & 1 & 0 & 1 & 0 & $1 ?$ & ? 1 & & ? & 0 & 1 & 1 & 0 & - & & \\
\hline Chr & $\begin{array}{ll}0 & 1\end{array}$ & 11 & 0 & 6 & 0 & 0 & 0 & 1 & 2 & 1 & 2 & 1 & 3 & 2 & ? & ? & 1 & 1 & 5 & 0 & 1 & 0 & 1 & 0 & $1 ?$ & ? 1 & 2 & ? & 0 & 1 & 1 & 0 & & 0 & \\
\hline Chr & $\begin{array}{ll}01 \\
0\end{array}$ & 11 & 0 & 6 & 0 & 0 & 0 & 1 & 2 & 1 & 2 & 1 & 3 & 2 & $?$ & ? & 1 & 1 & 5 & 0 & 1 & 0 & 1 & 0 & $1 ?$ & ? 1 & & ? & 0 & 1 & 1 & 0 & - & 0 & \\
\hline & $\begin{array}{ll}0 & 1\end{array}$ & 11 & 0 & 6 & 0 & 0 & 0 & 1 & 2 & 1 & 2 & 1 & 3 & 2 & ? & ? & 1 & 1 & 5 & 0 & 1 & 0 & 1 & 0 & $1 ?$ & ? 1 & & ? & 0 & 1 & 1 & 0 & & 0 & \\
\hline us & 1 & 11 & 0 & 6 & 0 & 0 & 0 & 1 & 2 & 1 & 2 & 1 & 3 & 2 & $?$ & ? & 1 & 1 & 5 & 0 & 1 & 0 & 1 & 01 & $1 ?$ & ? 1 & 2 & ? & 0 & 1 & 1 & 0 & & 0 & \\
\hline Fusi & $\begin{array}{ll}0 & 1\end{array}$ & 11 & 0 & 6 & 0 & 0 & 0 & 1 & 2 & 1 & 2 & 1 & 3 & 2 & $?$ & ? & 1 & 1 & 5 & 0 & 1 & 0 & 1 & 0 & $1 ?$ & ? 1 & 2 & ? & 0 & 1 & 1 & 0 & & 0 & \\
\hline & 01 & 11 & 0 & 6 & 0 & 0 & 0 & 1 & 2 & 1 & 2 & 1 & 3 & 2 & $?$ & ? & 1 & 1 & 5 & 0 & 1 & 0 & 1 & 0 & $1 ?$ & ? 1 & 12 & ? & 0 & 1 & 1 & 0 & 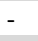 & 0 & \\
\hline & $\begin{array}{ll}0 & 1\end{array}$ & 11 & 0 & 6 & 0 & 0 & 0 & 1 & 2 & 1 & 2 & 1 & 3 & 2 & ? & ? & 1 & 1 & 5 & 0 & 1 & 0 & 1 & 01 & $1 ?$ & ? 1 & 12 & ? & 0 & 1 & 1 & 0 & & 0 & \\
\hline Cyrt & $\begin{array}{ll}0 & 1\end{array}$ & $\begin{array}{ll}11 \\
\end{array}$ & 0 & 6 & 0 & 0 & 0 & 1 & 2 & 1 & 2 & 1 & 3 & 2 & $?$ & ? & 1 & 1 & 5 & 0 & 1 & 0 & 1 & 01 & $1 ?$ & ? 1 & 2 & ? & 0 & 1 & 1 & 0 & & 0 & \\
\hline & 1 & 11 & 0 & 6 & 0 & 0 & 0 & 1 & 2 & 1 & 2 & 1 & 3 & 2 & $?$ & ? & 1 & 1 & 5 & 0 & 1 & 0 & 1 & 0 & $1 ?$ & ? 1 & 2 & ? & 0 & 1 & 1 & 0 & & 0 & \\
\hline & $\begin{array}{ll}0 & 1\end{array}$ & 11 & 0 & 6 & 0 & 0 & 0 & 1 & 2 & 1 & 2 & 1 & 3 & 2 & $?$ & ? & 1 & 1 & 5 & 0 & 1 & 0 & 1 & 01 & $1 ?$ & ? 1 & 12 & ? & 0 & 1 & 1 & 0 & - & 0 & \\
\hline & $\begin{array}{ll}0 & 1\end{array}$ & 11 & 0 & 6 & 0 & 0 & 0 & 1 & 2 & 1 & 2 & 1 & 3 & 2 & ? & ? & 1 & 1 & 5 & 0 & 1 & 0 & 1 & 01 & $1 ?$ & ? 1 & & ? & 0 & 1 & 1 & 0 & - & 0 & \\
\hline Gro & $\begin{array}{ll}0 & 1\end{array}$ & $\begin{array}{ll}11 \\
\end{array}$ & 0 & 6 & 0 & 0 & 0 & 1 & 2 & 1 & 2 & 1 & 3 & 2 & ? & $?$ & 1 & 1 & 5 & 0 & 1 & 0 & 1 & 01 & $1 ?$ & ? 1 & 2 & ? & 0 & 1 & 1 & 0 & - & 0 & \\
\hline & 1 & 11 & 0 & 6 & 0 & 0 & 0 & 1 & 2 & 1 & 2 & 1 & 3 & 2 & ? & ? & 1 & 1 & 5 & 0 & 1 & 0 & 1 & 0 & $1 ?$ & ? 1 & 12 & ? & 0 & 1 & 1 & 0 & & 0 & \\
\hline & $\begin{array}{ll}01 \\
0\end{array}$ & 11 & 0 & 6 & 0 & 0 & 0 & 1 & 2 & 1 & 2 & 1 & 3 & 2 & $?$ & ? & 1 & 1 & 5 & 0 & 1 & 0 & 1 & 01 & $1 ?$ & ? 1 & 12 & ? & 0 & 1 & 1 & 0 & - & 0 & \\
\hline & 0 & 11 & 0 & 6 & 0 & 0 & 0 & 1 & 2 & 1 & 2 & 1 & 3 & 2 & ? & ? & 1 & 1 & 5 & 0 & 1 & 0 & 1 & 01 & $1 ?$ & ? 1 & 12 & ? & 0 & 1 & 1 & 0 & 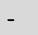 & 0 & \\
\hline$N$ & 1 & 11 & 0 & 6 & 0 & 0 & 0 & 1 & 2 & 1 & 2 & 1 & 3 & 2 & ? & ? & 1 & 1 & & 0 & 1 & 0 & 1 & 0 & $1 ?$ & ? 1 & 2 & ? & 0 & 1 & 1 & 0 & & 0 & \\
\hline & 1 & 11 & 0 & 6 & 0 & 0 & 0 & 1 & 2 & 1 & 2 & 1 & 3 & 2 & $?$ & ? & 1 & 1 & 5 & 0 & 1 & 0 & 1 & 0 & $1 ?$ & ? 1 & 2 & ? & 0 & 1 & 1 & 0 & & 0 & \\
\hline & $\begin{array}{ll}0 & 1\end{array}$ & $\begin{array}{ll}11 \\
\end{array}$ & 0 & 6 & 0 & 0 & 0 & 1 & 2 & 1 & 2 & 1 & 3 & 2 & $?$ & ? & 1 & 1 & 5 & 0 & 1 & 0 & 1 & 0 & $1 ?$ & ? 1 & & ? & 0 & 1 & 1 & 0 & - & 0 & \\
\hline & 0 & 1 & 0 & 6 & 0 & 0 & 0 & 1 & 2 & 1 & 2 & 1 & 3 & 2 & ? & ? & 1 & 1 & & 0 & 1 & 0 & 1 & 0 & $1 ?$ & ? 1 & & ? & 0 & 1 & 1 & 0 & 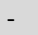 & 0 & \\
\hline & 1 & 11 & 0 & 6 & 0 & 0 & 0 & 1 & 2 & 1 & 2 & 1 & 3 & 2 & ? & ? & 1 & 1 & & 0 & 1 & 0 & 1 & 0 & $1 ?$ & ? 1 & 2 & ? & 0 & 1 & 1 & 0 & - & 0 & \\
\hline & 1 & 11 & 0 & 6 & 0 & 0 & 0 & 1 & 2 & 1 & 2 & 1 & 3 & 2 & ? & ? & 1 & 1 & 5 & 0 & 1 & 0 & 1 & 0 & $1 ?$ & ? 1 & 2 & ? & 0 & 1 & 1 & 0 & - & 0 & \\
\hline & $\begin{array}{ll}0 & 1\end{array}$ & 11 & 0 & 6 & 0 & 0 & 0 & 1 & 2 & 1 & 2 & 1 & 3 & 2 & ? & ? & 1 & 1 & 5 & 0 & 1 & 0 & 1 & 0 & $1 ?$ & ? 1 & 12 & ? & 0 & 1 & 1 & 0 & - & 0 & \\
\hline & 0 & 1 & 0 & 6 & 0 & 0 & 0 & 1 & 2 & 1 & 2 & 1 & 3 & 2 & ? & ? & 1 & 1 & 5 & 0 & 1 & 0 & 1 & 0 & $1 ?$ & ? 1 & & ? & 0 & 1 & 1 & 0 & - & 0 & \\
\hline$P l$ & 1 & 11 & 0 & 6 & 0 & 0 & 0 & 1 & 2 & 1 & 2 & 1 & 3 & 2 & ? & ? & 1 & 1 & & 0 & 1 & 0 & 1 & 0 & $1 ?$ & ? 1 & & ? & 0 & 1 & 1 & 0 & 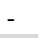 & 0 & \\
\hline & 1 & $\begin{array}{ll}1 & 1\end{array}$ & 0 & 6 & 0 & 0 & 0 & 1 & 2 & 1 & 2 & 1 & 3 & 2 & ? & $?$ & 1 & 1 & 5 & 0 & 1 & 0 & 1 & 0 & $1 ?$ & ? 1 & 2 & ? & 0 & 1 & 1 & 0 & 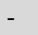 & 0 & \\
\hline & $\begin{array}{ll}0 & 1\end{array}$ & 11 & 0 & 6 & 0 & 0 & 0 & 1 & 2 & 1 & 2 & 1 & 3 & 2 & ? & $?$ & 1 & 1 & 5 & 0 & 1 & 0 & 1 & 01 & $1 ?$ & ? 1 & 2 & ? & 0 & 1 & 1 & 0 & - & 0 & 1 \\
\hline & $\begin{array}{ll}0 & 1\end{array}$ & 11 & 0 & 6 & 0 & 0 & 0 & 1 & 2 & 1 & 2 & 1 & 3 & 2 & ? & ? & 1 & 1 & 5 & 0 & 1 & 0 & 1 & 0 & $1 ?$ & ? 1 & & ? & 0 & 1 & 1 & 0 & 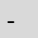 & 0 & \\
\hline Polyg & $\begin{array}{ll}0 & 1\end{array}$ & 11 & 0 & 6 & 0 & 0 & 0 & 1 & 2 & 1 & 2 & 1 & 3 & 2 & ? & ? & 1 & 1 & & 0 & 1 & 0 & 1 & 0 & $1 ?$ & ? 1 & 2 & ? & 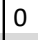 & 1 & 1 & 0 & - & 0 & \\
\hline & 0 & 11 & 0 & 6 & 0 & 0 & 0 & 1 & 2 & 1 & 2 & 1 & 3 & 2 & ? & $?$ & 1 & 1 & 5 & 0 & 1 & 0 & 1 & 01 & $1 ?$ & ? 1 & L & ? & 0 & 1 & 1 & 0 & - & 0 & \\
\hline & $\begin{array}{ll}0 & 1\end{array}$ & 11 & 0 & 6 & 0 & 0 & 0 & 1 & 2 & 1 & 2 & 1 & 3 & 2 & ? & $?$ & 1 & 1 & 5 & 0 & 1 & 0 & 1 & 0 & $1 ?$ & ? 1 & 1 & ? & 0 & 1 & 1 & 0 & - & 0 & 1 \\
\hline & $\begin{array}{ll}0 & 1\end{array}$ & & 0 & 6 & 0 & 0 & 0 & 1 & 2 & 1 & 2 & 1 & 3 & 2 & ? & $?$ & 1 & 1 & & 0 & 1 & 0 & 1 & 0 & $1 ?$ & ? 1 & & ? & 0 & 1 & 1 & 0 & - & 0 & \\
\hline Leuc & $\begin{array}{ll}0 & 1\end{array}$ & 11 & 0 & 6 & 0 & 0 & 0 & 1 & 2 & 1 & 2 & 1 & 3 & 2 & ? & ? & 1 & 1 & & 0 & 1 & 0 & 1 & 0 & $1 ?$ & ? 1 & & ? & 0 & 1 & 1 & 0 & 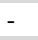 & 0 & \\
\hline & $\begin{array}{lll}0 & 1\end{array}$ & $\begin{array}{ll}1 & 1\end{array}$ & 0 & 6 & 0 & 0 & 0 & 1 & 2 & 1 & 2 & 1 & 3 & 2 & ? & ? & 1 & 1 & 5 & 0 & 1 & 0 & 1 & 0 & 1 & ? 1 & 2 & ? & 0 & 1 & 1 & 0 & - & 0 & \\
\hline & 01 & 11 & 0 & 6 & 0 & 0 & 0 & 1 & 2 & 1 & 2 & 1 & 3 & 2 & ? & ? & 1 & 1 & 5 & 0 & 1 & 0 & 1 & 0 & 1 & ? & & ? & 0 & 1 & 1 & 0 & 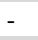 & 0 & \\
\hline & $\begin{array}{ll}0 & 1\end{array}$ & & & 6 & 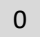 & 0 & 0 & 1 & 2 & 1 & 2 & 1 & & 2 & & ? & 1 & & & & & & & & & & & $?$ & 0 & 1 & 1 & 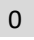 & & 0 & \\
\hline eucs & $\begin{array}{ll}0 & 1\end{array}$ & & 0 & 6 & 0 & 0 & 0 & 1 & 2 & 1 & 2 & 1 & 3 & 2 & ? & ? & 1 & & & 0 & 1 & 0 & 1 & 0 & 1 & ? 1 & & & 0 & 1 & 1 & 0 & - & 0 & \\
\hline eucozonia ponderosa & 1 & & & & & & & & & & & & & & & & & & & & & & & & & & & & & & & & & & \\
\hline
\end{tabular}




\section{References}

Bouchet P. \& Rocroi J.P. 2005. Classification and nomenclator of gastropod families. Malacologia, 47: 1-397.

Kantor Y.I. \& Fedosov A. 2009. Morphology and development of the valve of Leiblein in Neogastropoda: possible evidence for paraphyly of the Neogastropoda. The Nautilus, 123(3): 73-82.

Ponder W.F., Colgan D.J., Healy J.M., Nützel A., Simone L.R.L. \& Strong E.E. 2008. Caenogastropoda. In: Ponder W.F. \& Lindberg D.R. (Eds.). Phylogeny and Evolution of the Mollusca. University of California Press. p. 331-383.

Simone L.R.L. 2011. Phylogeny of the Caenogastropoda (mollusca), based on comparative morphology. Arquivos de Zoologia, São Paulo, 42(4): 161-323.

WoRMS 2016. World Register of Marine Species. http://www.marinespecies.org/ (accessed November 22, 2016). 
APPENDIX 
(*script for POY parameter set 1110*)

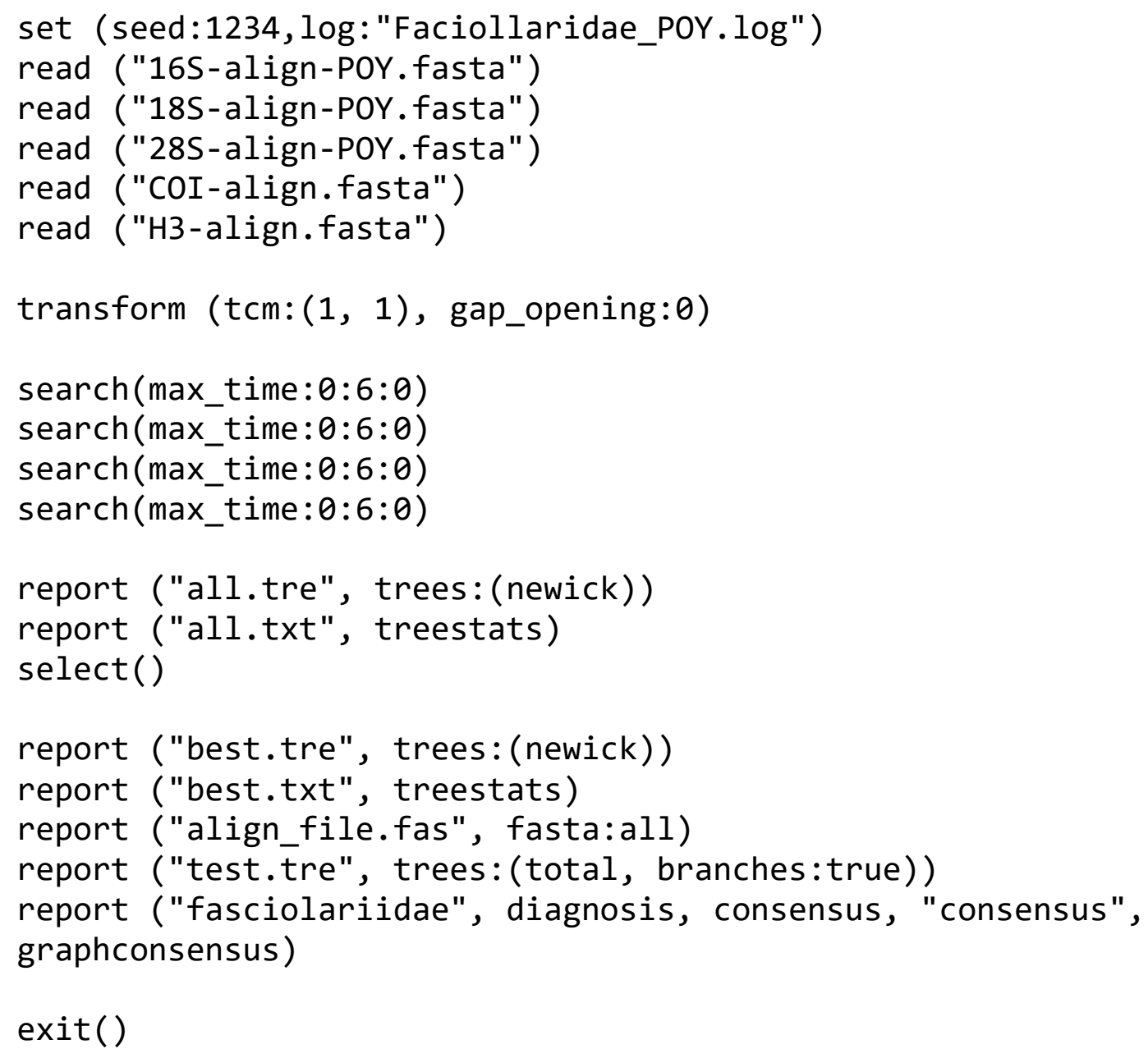


(*script for POY parameter set 2110*)

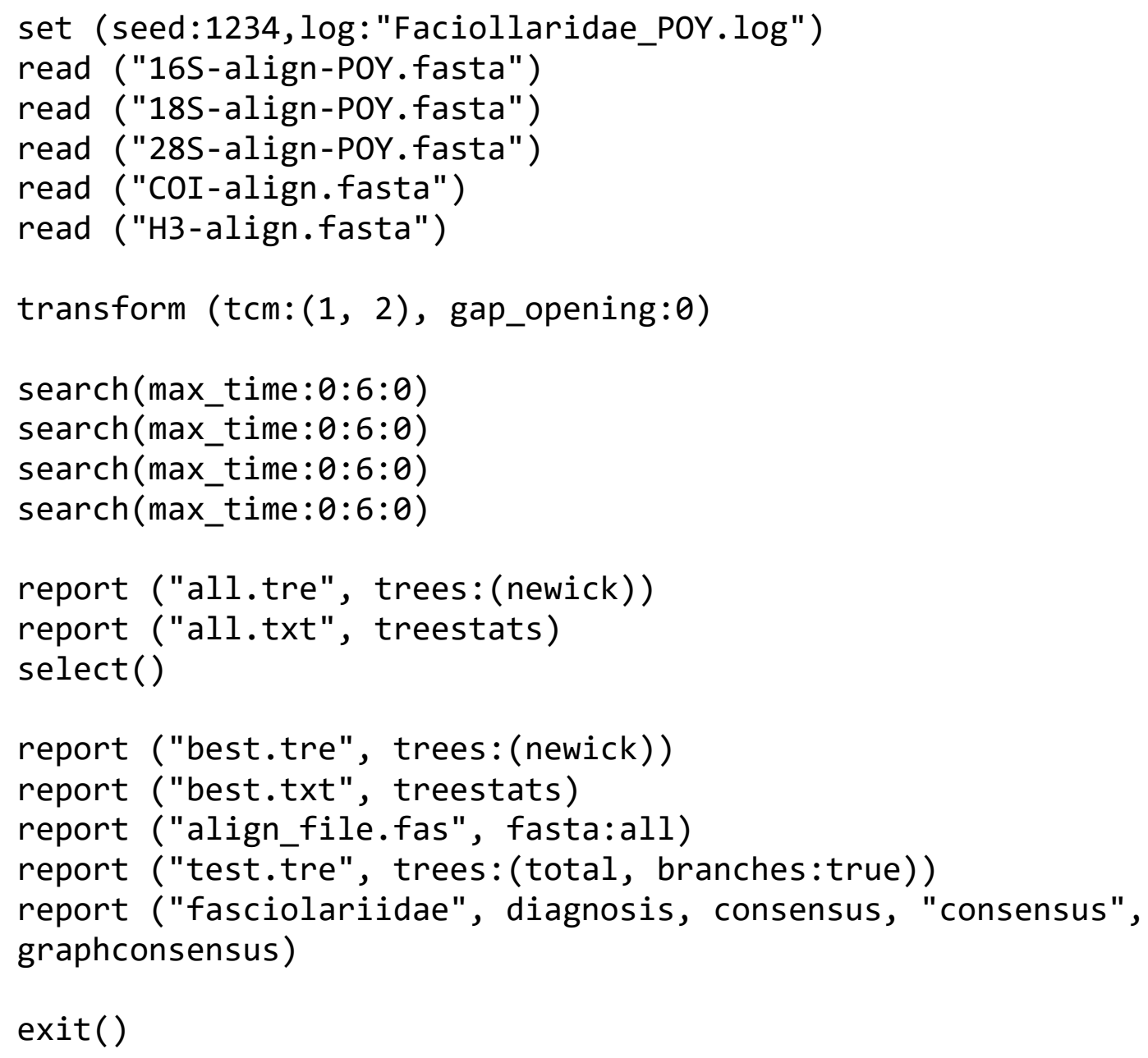


(*script for POY parameter set $3221 *$ )

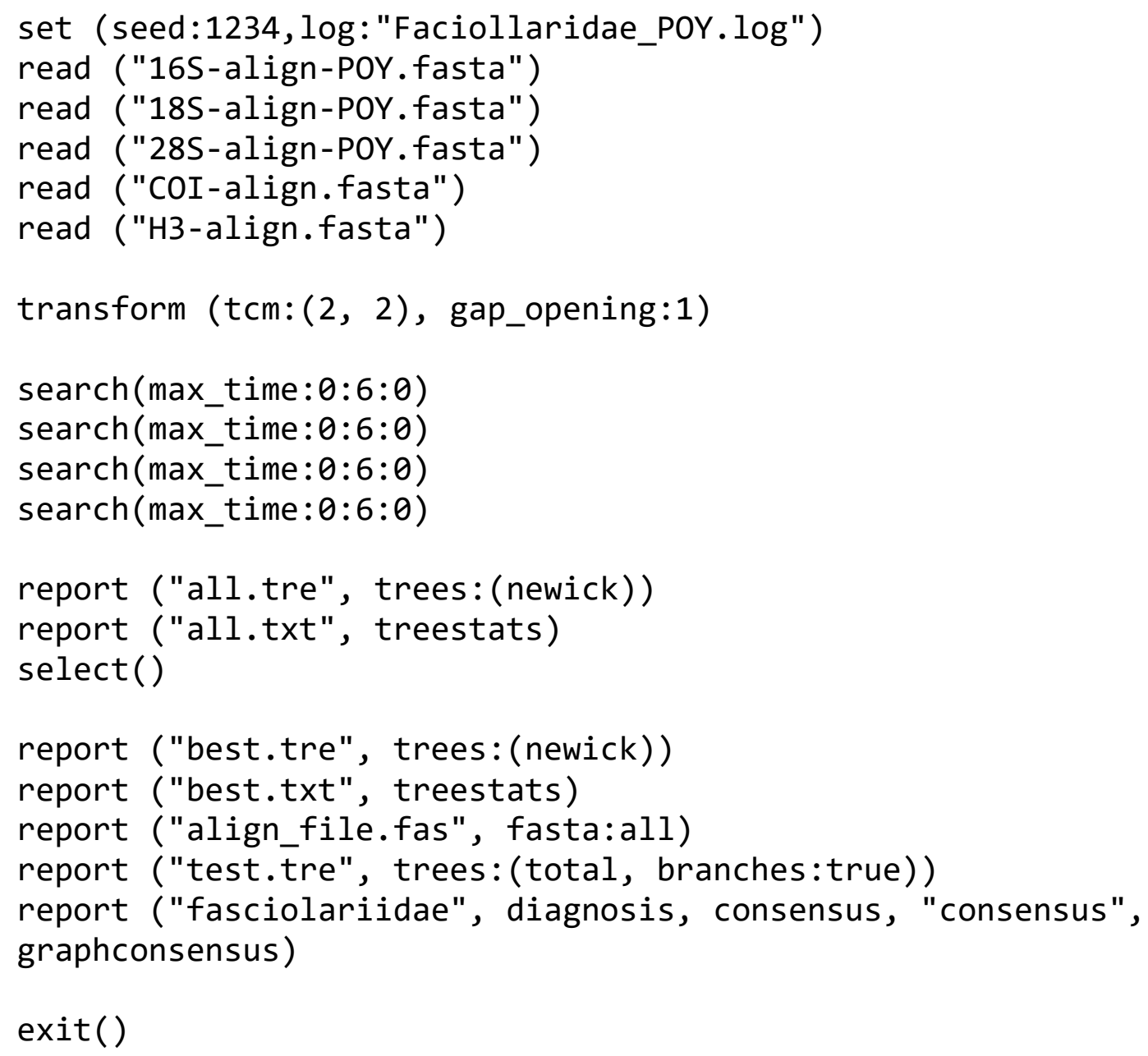


(*script for POY parameter set 1210*)

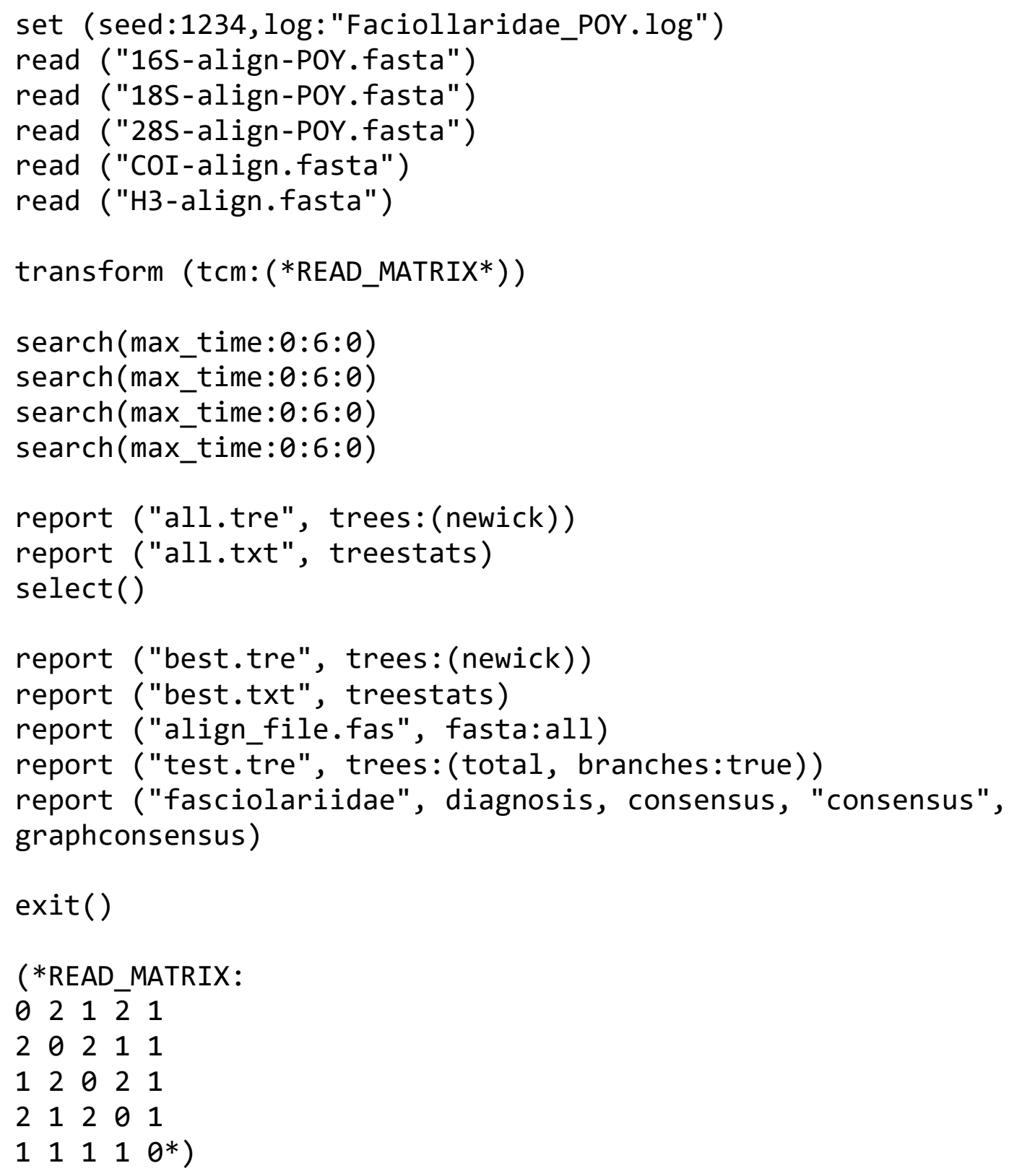


(*script for POY parameter set 2210*)

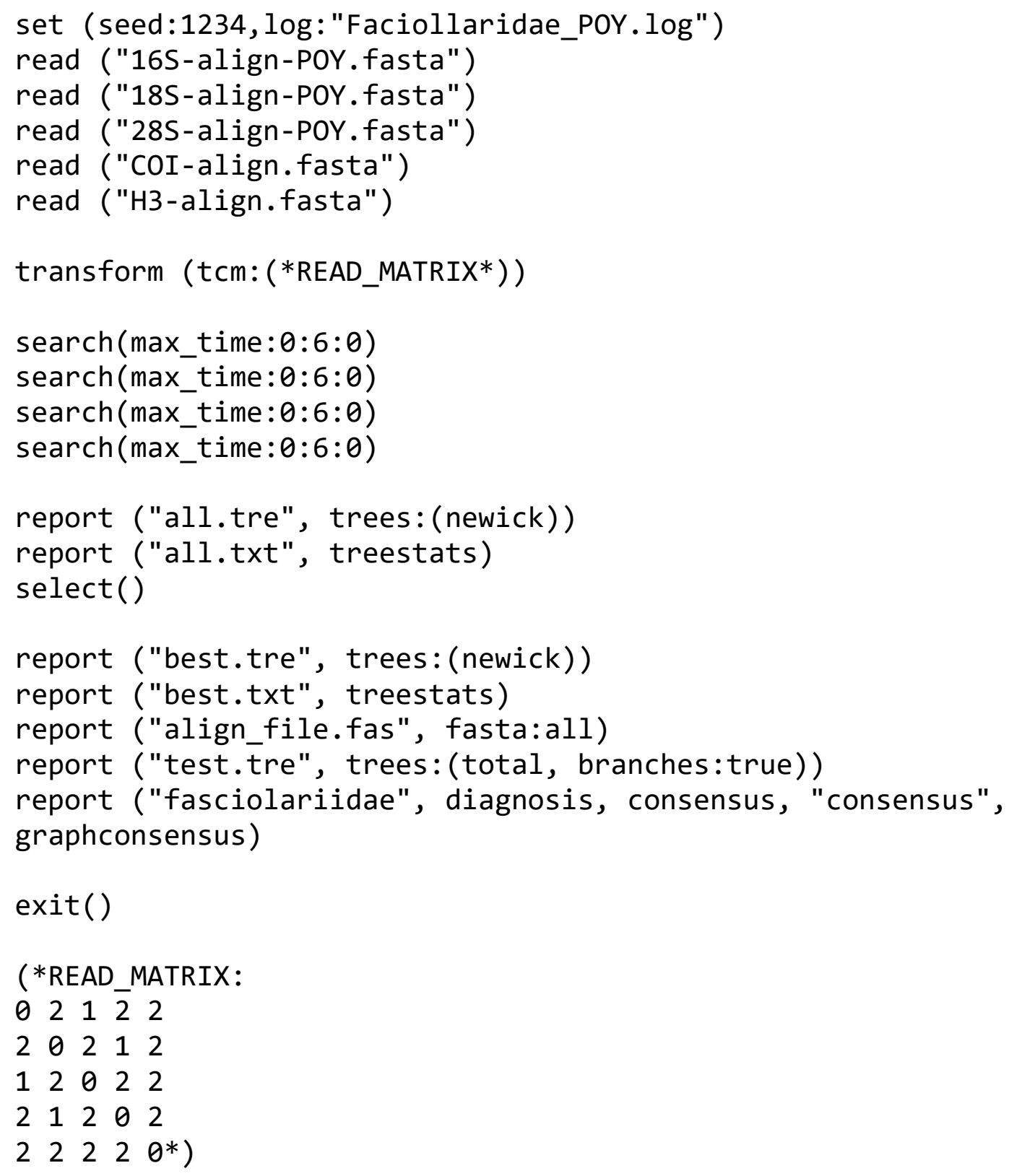


(*script for POY parameter set $3211 *$ )

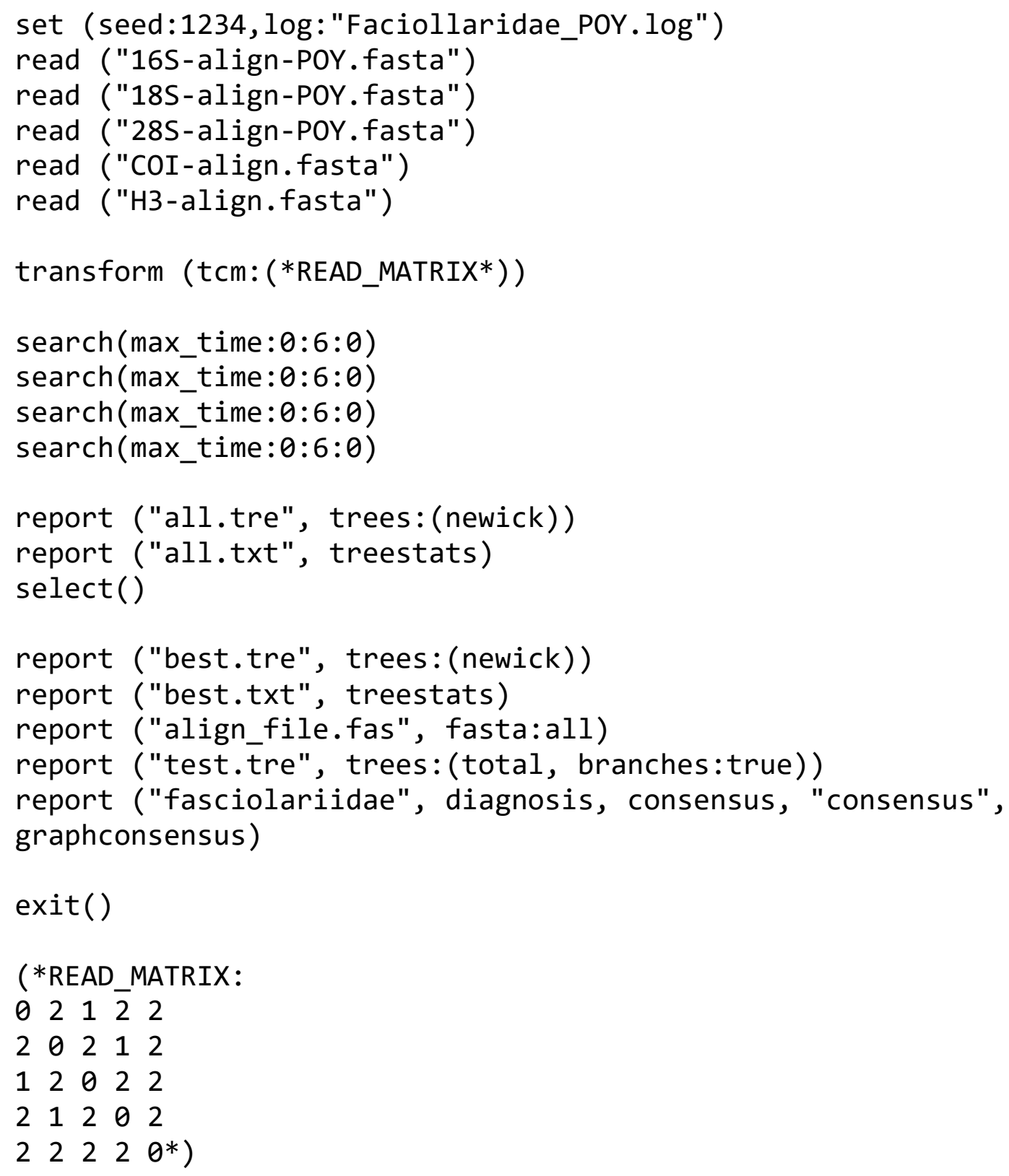




\title{
Comparative anatomy of the fasciolariids Pustulatirus ogum and Hemipolygona beckyae from Brazil (Gastropoda: Buccinoidea: Peristerniinae)
}

\author{
Diogo R. Couto ${ }^{1}$, Luiz R. L. R. Simone ${ }^{1}$, Alexandre D. Pimenta ${ }^{2}$ \\ ${ }^{1}$ Laboratório de Malacologia, Museu de Zoologia da Universidade de São Paulo. Avenida Nazaré, 481, Ipiranga. CEP \\ 04263-000 São Paulo, SP, Brazil. E-mail: diogoaut@gmail.com \\ ${ }^{2}$ Setor de Malacologia, Departamento de Invertebrados, Museu Nacional, Universidade Federal do Rio de Janeiro. Quinta \\ da Boa Vista s/n, São Cristóvão. CEP 20940-040 Rio de Janeiro, RJ, Brazil.
}

\begin{abstract}
Summary: The Brazilian species Pustulatirus ogum and Hemipolygona beckyae were examined, and certain morphological characters were described. Both species were originally assigned to the genus Latirus, considered as a heterogeneous complex. The radulae of both species are like that which characterizes Latirus, in which the innermost cusp of the rachidian tooth is well developed but always smaller than the other cusps. This feature differs from Leucozonia, in which this cusp is reduced or absent. The penis tapers terminally, and the tapered part may be long (more than half the total penis length), as in $H$. beckyae, or very short (less than half the total penis length), as in P. ogum. The anatomical data observed in both species are discussed under the framework of fasciolariid systematics and they appear to be widespread among other fasciolariid species. For this reason, to date, the soft-part features here provided and those known from previously studied species of Latirus are not useful for delineating precise generic diagnoses.
\end{abstract}

Keywords: morphology; Caenogastropoda; Fasciolariidae; Latirus; western Atlantic.

Anatomía comparada de los fascioláridos Pustulatirus ogum y Hemipolygona beckyae de Brasil (Gastropoda: Buccinoidea: Peristerniinae)

Resumen: Se describe la morfología y anatomía de las especies brasileñas Pustulatirus ogum y Hemipolygona beckyae. Ambas especies han sido tradicionalmente asignadas al género Latirus, que en la actualidad se considera que agrupa a un conjunto heterogéneo de especies. Las rádulas de ambas especies son como la que caracteriza a Latirus, con la cúspide más interna del diente raquídeo bien desarrollada y siempre menor que las otras cúspides. Esta característica difiere de la que presentan las especies del género Leucozonia, en las que esta cúspide está reducida o ausente. El pene se estrecha en su parte terminal, y la parte cónica puede ser larga (más de la mitad de la longitud total del pene), como en $H$. beckyae, o muy corta (menos de la mitad de la longitud total del pene), como en P. ogum. Los caracteres morfológicos observados en ambas especies se discuten en el marco de la sistemática de los Fasciolariidae y parecen estar ampliamente distribuidos en otras especies de fascioláridos. Por ello, hasta la fecha, las características de las partes blandas del animal aquí descritas y las conocidas previamente de otras especies de Latirus no se consideran de utilidad para la diagnosis de los géneros en esta familia.

Palabras clave: morfología; Caenogastropoda; Fasciolariidae; Latirus; Atlántico occidental.

Citation/Como citar este artículo: Couto D.R., Simone L.R.L.R., Pimenta A.D. 2015. Comparative anatomy of the fasciolariids Pustulatirus ogum and Hemipolygona beckyae from Brazil (Gastropoda: Buccinoidea: Peristerniinae). Sci. Mar. 79(1): 000-000. doi: http://dx.doi.org/10.3989/scimar.04144.08A

Editor: J. Templado.

Received: September 1, 2014. Accepted: December 16, 2014. Published: February 12, 2015.

Copyright: (0) 2015 CSIC. This is an open-access article distributed under the Creative Commons Attribution-Non Commercial Lisence (by-nc) Spain 3.0.

\section{INTRODUCTION}

The neogastropod family Fasciolariidae comprises more than 1300 living species, distributed in the tropics and subtropics (Gofas 2014), and divided into three subfamilies, Fasciolariinae, Fussininae and Peristerni- inae. Members of the subfamily Peristerniinae inhabit hard bottoms, although other fasciolariids dwell mostly in soft and muddy substrates (Harasewych 1998, Vermeij and Snyder 2006).

Members of the Peristerniinae are represented in Brazil by at least 16 species, in the genera Polygona 
Schumacher, 1817 (7 spp.), Hemipolygona Rovereto, 1899 (2 spp.), Pustulatirus Vermeij and Snyder, 2006 (3 spp.) and Leucozonia Gray, 1847 (4 spp.) (Rosenberg 2009). Most species included in Hemipolygona and Pustulatirus were previously grouped in Latirus. However, this genus is now restricted to the Indo-West Pacific (Vermeij and Snyder, 2006); it was previously regarded as a heterogeneous assemblage, and was recently the target of some taxonomic revisions (Vermeij and Snyder 2002, 2006).

Pustulatirus ogum and Hemipolygona beckyae, which occur in Brazilian waters, were treated in the most recent bibliographic records as subgenera of Latirus (Rios 1994, 2009).The former species occurs from Espírito Santo to Bahia state, and the latter only in Espírito Santo; P. ogum inhabits tide pools, while $H$. beckyae occurs at depths of about $30 \mathrm{~m}$.

Kosyan et al. (2009) studied the anatomy of some species of Fasciolariidae, including Turrilatirus turritus (Gmelin, 1791), Pustulatirus mediamericanus (Hertlein and Strong, 1951) and Latirus polygonus (Gmelin, 1791), all of which were previously regarded as members of Latirus. In Brazil, only the anatomy of species belonging to Leucozonia has been studied: $L$. nassa (Gmelin, 1791) by Marcus and Marcus (1962); L. nassa (Gmelin, 1791), L. ocellata (Gmelin, 1791) and L. ponderosa (Vermeij and Snyder 1998) by Couto and Pimenta (2012); and Teralatirus roboreus by $\mathrm{Si}$ mone et al. (2013).

Fraussen et al. (2007) reported that a combination of traits is diagnostic for Fasciolariidae: multicuspidate lateral teeth and straight rachidian teeth, proboscis retractor muscle as a single or paired tuft of fibres, ducts of the salivary glands embedded in the esophagus wall, and a stomach without a posterior mixing area. Kosyan et al. (2009) studied the anatomy of eight fasciolariid species belonging to seven genera. These authors distinguished fasciolariids from buccinids studied by them and by Kosyan and Kantor (2009), based on the stomach morphology: low folds with transverse striations, absence of differentiation of the gastric chamber, absence of a posterior mixing area (Kantor 2003), and proboscis retractor muscles as a single muscle or paired (Fraussen et al. 2007). The orange-red colour of the foot and head-foot mass is typical for fasciolariids.

Morphological characters may prove useful in validating phylogenetic relationships and may help to resolve internal clades (Strong 2003, Simone 2011). However, no formal anatomical characterization within Latirus and related species exists. They are presently distinguished solely on shell features (Vermeij and Snyder 2006, Lyons and Snyder 2013), and hence prone to hypotheses of polymorphism and convergence. The present contribution provides morphological descriptions and comparisons of Pustulatirus ogum and Hemipolygona beckyae.

\section{MATERIALS AND METHODS}

The material used for this study is deposited in the Museu Nacional / Universidade Federal do Rio de Ja- neiro (MNRJ) and Museu de Zoologia / Universidade de São Paulo (MZSP).

The specimens collected were fixed in $70 \%$ ethanol. Shells were measured with a caliper, and photographs of individuals were taken with a digital camera. The anatomical dissections were done under a stereomicroscope. All drawings were made using a camera lucida. Radulae were manually extracted and prepared by immersion in $\mathrm{KOH}$, followed by ultrasonic cleaning and subsequent immersion in distilled water for scanning electron microscope photography.

\section{RESULTS}

Genus Pustulatirus Schumacher, 1817

Pustularitus Vermeij and Snyder, 2006. Type species: Latirus mediamericanus Hertlein and Strong, 1951 by original designation.

Diagnosis. See Vermeij and Snyder (2006).

Pustulatirus ogum (Petuch, 1979) (Figs 1-5)

Latirus ogum: Petuch 1979: 519 (Figs 3A-B); Rios 1985: 107 (pl. 36, Fig. 470); Mallard and Robin 2005: 18 (pl. 47).

Latirus (Polygona) ogum: Petuch 1987: 140 (pl. 27, Figs 1-2); Rios 1994: 133, (pl. 42, Fig. 574); Snyder 2003: 152, 306; Rios 2009: 253.

Benimakia ogum: Vermeij and Snyder 2003: 17 (Figs 6A-B).

Polygona ogum: Rosenberg 2009.

Pustulatirus ogum: Landau and Vermeij 2012: 88; Lyons and Snyder 2013: 49 (Figs 52-62).

Type locality. West of Coroa Vermelha, in tide pool, Abrolhos reef, Bahia state, Brazil, $17^{\circ} 57^{\prime} \mathrm{S}, 39^{\circ} 13^{\prime} \mathrm{W}$.

Types. Holotype: USNM 780654.

Examined material. Brazil: Bahia, Alcobaça (20-25 m), MZSP 68475, 16 specimens (vi/2006), MZSP 68835, 1 specimen (viii/2005); Espírito Santo, Guarapari (A. Bodart col., 20-25 m, i/2006), MZSP 69477, 6 especimens, MZSP 69481, 10 specimens; Rio de Janeiro, Arraial do Cabo, 30-35 m, MZSP 69301, 2 specimens (P. Conçalves col., i/2005).

Distribution. Abrolhos reef, Bahia state; Espírito Santo to Rio de Janeiro states, southeast coast of Brazil.

Shell (Fig. 1A-F). Shell elliptical, fusiform, height up to $39.2 \mathrm{~mm}$, width $2 / 5-1 / 2$ of height. Colour chestnut to dark brown. Spire high, angle $45^{\circ}-50^{\circ}, \sim 1 / 2$ of total shell height. Protoconch small with 2 whorls, smooth, terminal varix low. Teleoconch with 7-8 rounded whorls; subsutural ramp slightly concave, suture deep, base of shell concave. Spiral sculpture of 6-7 continuous spiral cords along entire teleoconch, 3 in abapical half of each whorl, more evidenced in first whorls, 3-4 strong spiral cords marking siphonal canal; several secondary spiral cords along entire teleoconch. Axial sculpture of 7-8 strong rounded ribs. Aperture elliptical to pyriform, height $\sim 3 \times$ width. Columella bearing 3 folds medially. Outer lip crenulated, marked internally by 10 discontinuous lirae. Siphonal canal moderately long, length $\sim 1 / 2$ of length of aperture. Siphonal fasciole indistinct. Pseudoumbilicus as shallow slit. 


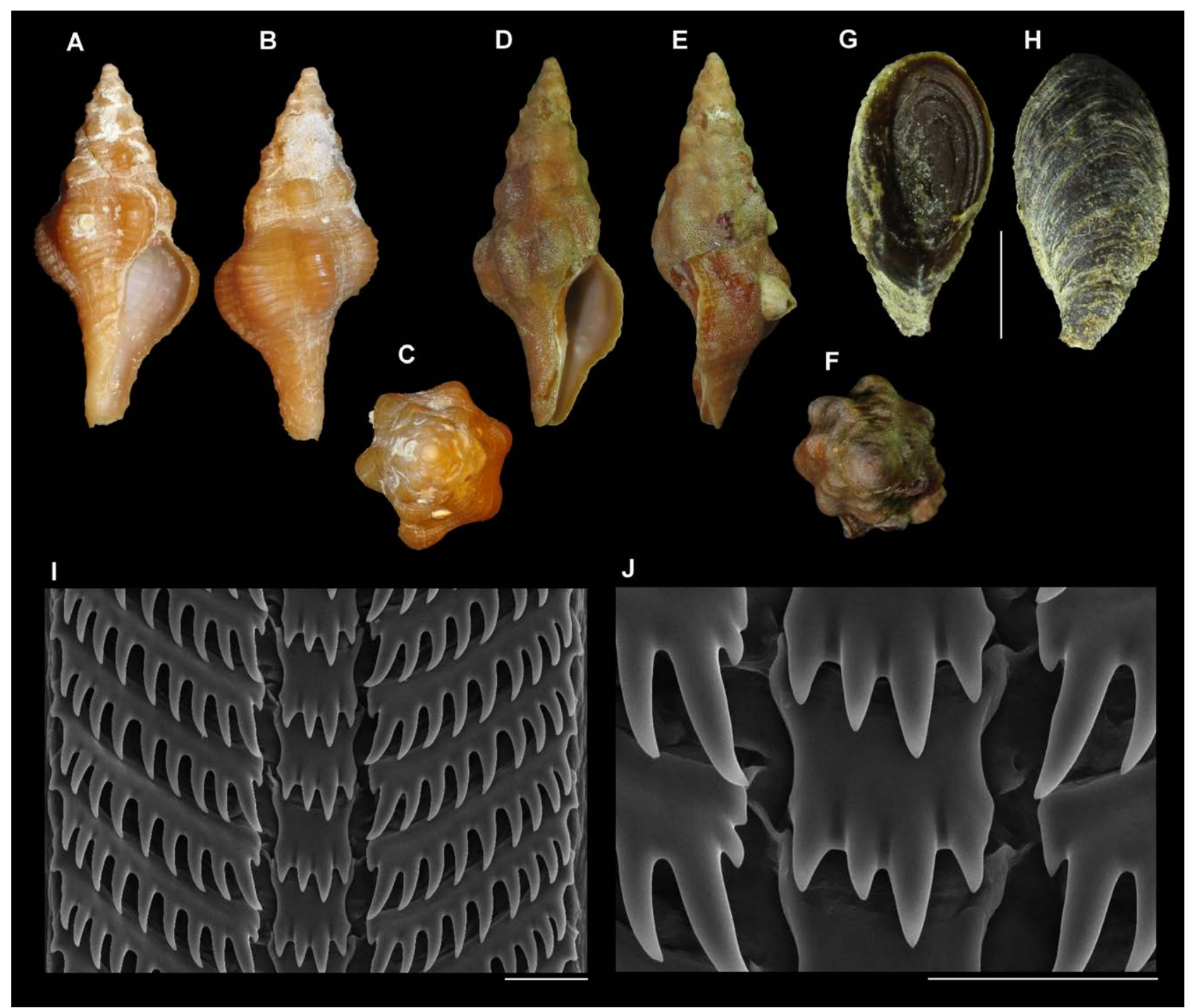

Fig. 1. - Pustulatirus ogum. A-C, 22.2 mm (MZSP 68475); D-F, 39.2 mm (MZSP 69301); G, operculum internal view; H, operculum external view; I, radula; J, detail of rachidian tooth. Scale bars: G-H, $3 \mathrm{~mm}$; I-J, $30 \mathrm{~mm}$.

Head-foot (Fig. 2A-B). colour cream in fixed species. Head prominent, of medium size (width $\sim 1 / 3$ of adjacent width of head-foot), cephalic tentacles blunt and short (length $\sim 1 / 2$ of anterior width of head), situated very close to each other; bases lying side by side. Eyes dark, small, rounded, situated in middle region of outer edge of tentacles. Foot short, rounded, anterior region bifid. Pedal gland as shallow median anterior slit, with anterior furrow extending along entire anterior edge. Columellar muscle thick, with $\sim 1.25$ whorls in length.

Operculum (Fig. 1G-H). Operculum corneous, unguiculate (width $\sim 2 / 3$ of length), filling entire aperture; outer surface opaque, with anterior nucleus inner surface with attachment scar elongated, elliptical, situated posteriorly, occupying $~ 2 / 3$ of inner area.

Pallial complex (Fig. 2C-D). Pallial cavity wide, of one whorl. Mantle border simple, thickened. Siphon short (length about 1/4 of free portion of mantle edge), its margin smooth; right fold of siphon base extend- ing into pallial cavity, ending close to anterior end of ctenidium. Osphradium elongated, tapering anteriorly; length $\sim 1 / 2$ of ctenidium; almost symmetrical longitudinally; osphradium leaflets rounded, short (height $\sim 1 / 2$ of ctenidial filament height at middle region of pallial cavity), equal in size. Ctenidium curved, 1/4 of total pallial cavity area, width slightly larger than osphradium; anterior and posterior region pointed, posterior end situated close to pericardium; filaments triangular; ctenidial vein (efferent branchial vessel) uniformly narrow along its length. Hypobranchial gland thin and loosely fixed, situated between gill and rectum, except for posterior $1 / 2$ of pallial cavity. Rectum elongated. Anus elliptical, situated at 1/4 of mantle edge.

Circulatory and excretory systems (Fig. 4G). Pericardium spanning $\sim 1 / 5$ of total renal cavity area. Auricle pyriform, wall thin, translucent; ventricle large and rounded ( larger than auricle), triangular in shape, with thick walls. Aorta bifurcate immediately after leaving ventricle; posterior aorta following visceral mass close to stomach; anterior aorta crossing diaphragmatic sep- 


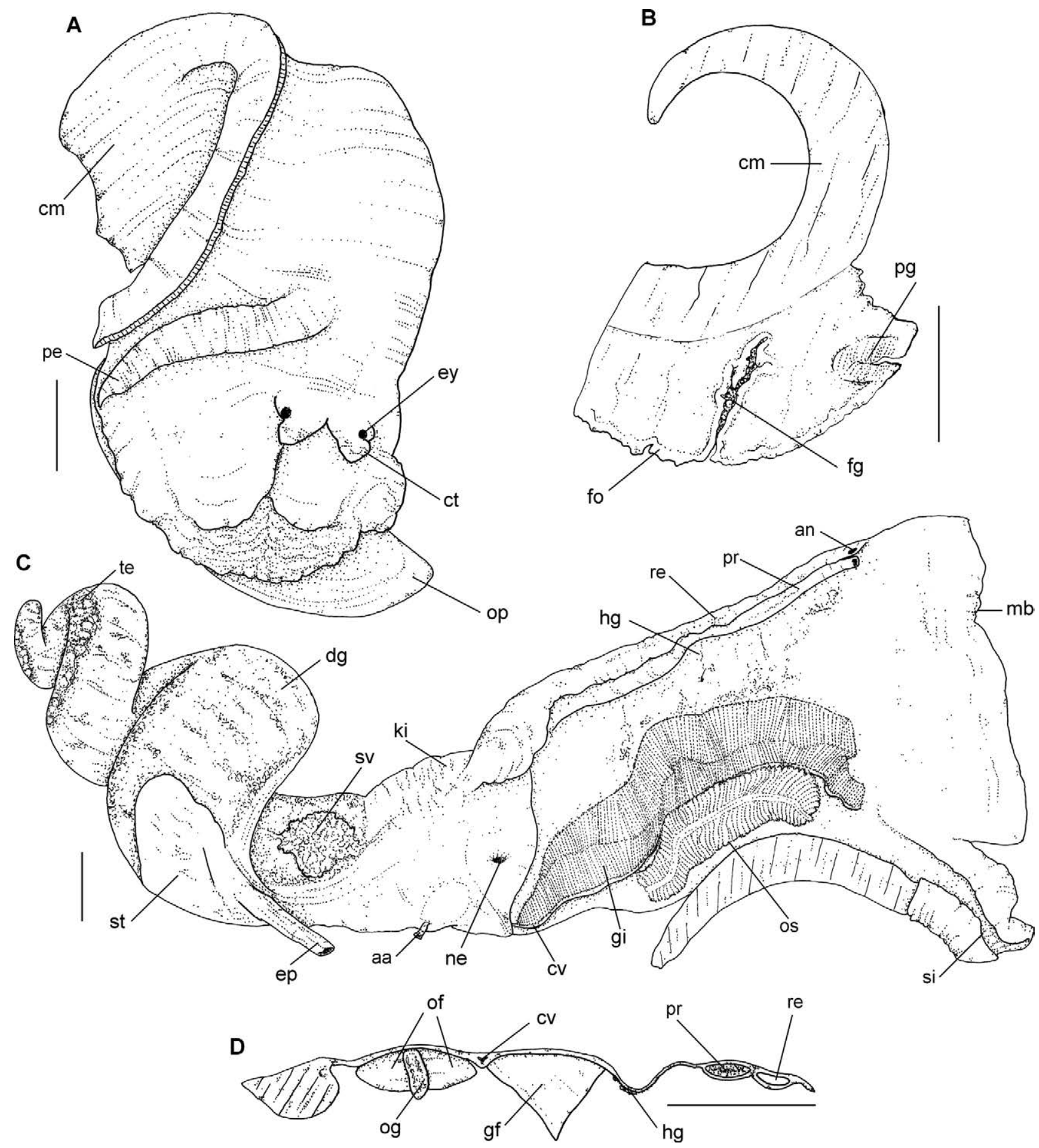

Fig. 2. - Pustulatirus ogum. A, head-foot mass in dorsal view; B, longitudinal section of head-foot mass, female; C, roof of pallial cavity in ventral view, male; D, transverse section of roof of pallial cavity. Abbreviations: aa, anterior aorta; an, anus; cm, columellar muscle; ct, cephalic tentacle; cv, ctenidial vein; dg, digestive gland; ep, posterior esophagus; ey, eye; fg, female cement gland; fo, foot; gf, gill filament gi, gill; hg, hypobranchial gland; ki, kidney; mb, mantle border; ne, nephrostome; of, osphradium filament; og, osphradium ganglia; op, operculum; os, osphradium; pe, penis; pg, pedal gland; pr, prostate; re, rectum; si, siphon; st, stomach; sv, seminal vesicle; te; testis. Scale bars: 2 mm.

tum anteriorly. Anterior aorta running anteriorly along whole length of posterior esophagus, crossing gland of Leiblein in mid-esophagus, with branches forming sinus surrounding nerve ring. Anterior aorta bifurcating anteriorly to nerve ring; one branch following anteriorly to pedal ganglia as pedal aorta, another branch accompanying anterior esophagus, following anteriorly to buccal mass and odontophore. Kidney bearing ventral and dorsal lamellar lobes similar in shape; nephridial gland situated on dorsal side of membrane between renal cavity and pericardium; renal aperture as slit in membrane between pallial and renal cavities, flanked on its right side by transversal folds, longitudinal to roof of pallial cavity. Part of intestine running longitudinally on inner side of kidney, ventrally adhered to its membrane 


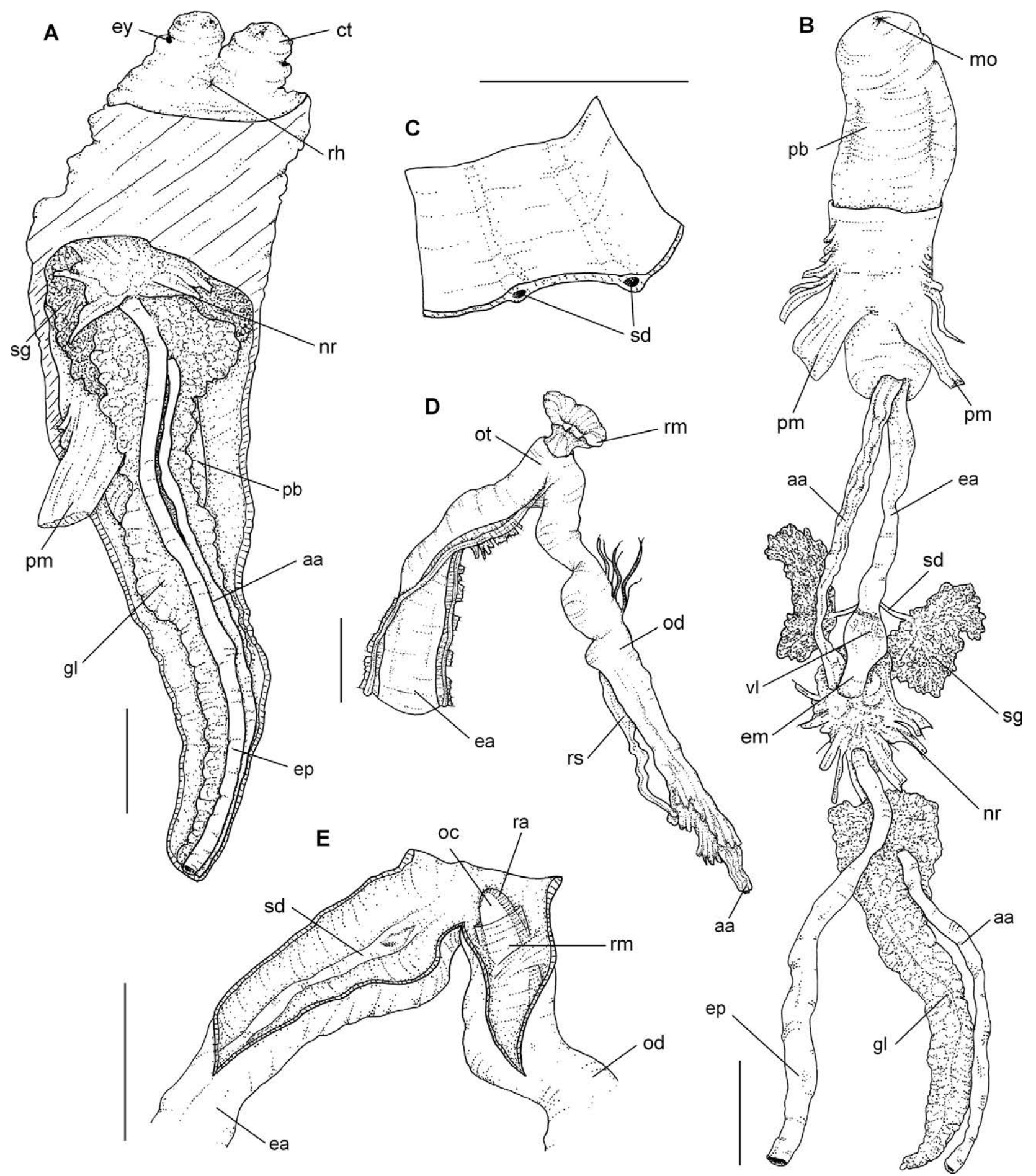

Fig. 3.- Pustulatirus ogum. A, haemocoel in ventral view; B, anterior digestive system; C, lumen of anterior esophagus; D, buccal mass in lateral view; E, buccal mass in lateral view, opened longitudinally. Abbreviations: aa, anterior aorta; ct, cephalic tentacle; ea, anterior esophagus; ep, posterior esophagus; ey, eye; gl, gland of Leiblein; mo, mouth opening; nr, nerve ring; oc, odontophore cartilage; od, odontophore tube; ot, oral tube; pb, proboscis; pm, proboscis retractor muscles; ra, radula; rh, rhynchostoma; rm, subradular membrane; rs, radular sac; sd, salivary gland duct; sg, salivary gland; vl, valve of Leiblein. Scale bars: A-B, 2 mm; C-E, 1 mm.

Digestive system (Figs 3A-E, 4A-E). Rhynchostome as small longitudinal slit, located between and below cephalic tentacles. Proboscis straight, of moderate length ( 2/3 of haemocoel length), with thick muscular walls bearing 2 lateral grooves. Pair of proboscis retractor muscles originating in ventral posterior wall of proboscis; series of short lateral muscle fibres connected to inner walls of haemocoel. Mouth small, circular. Odontophore long, slender ( $\sim$ same length as proboscis), pair of odontophore cartilages dorsally concave, fused anteriorly at $\sim 1 / 4$ of total cartilage length. Series of transversal muscle fibres connecting odontophore tube with anterior esophagus; superficial circular muscles (m3) enveloping entirely odontophore, except for most posterior end; horizontal muscle (m6), originating on ventral surface of odontophore 

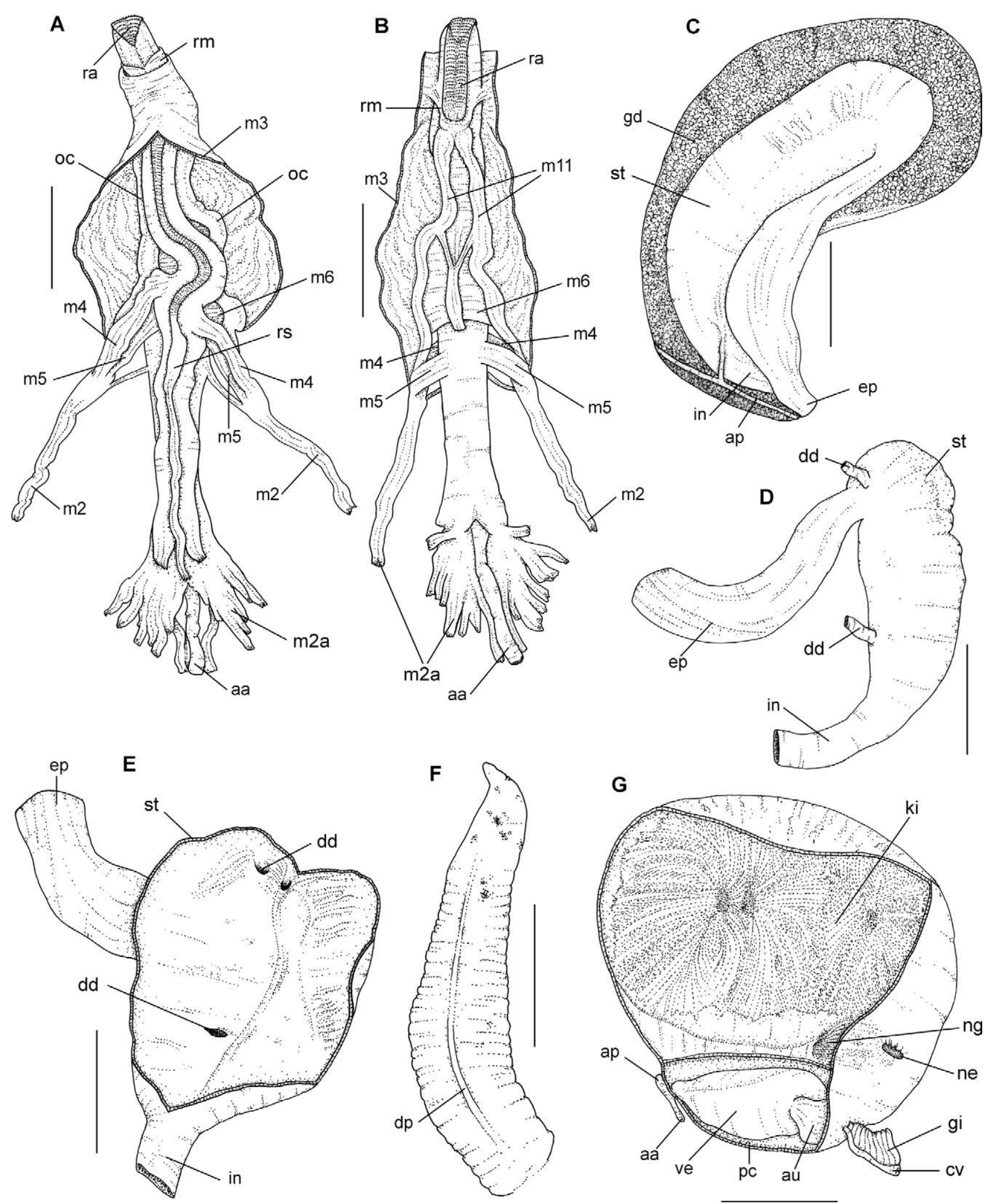

Fig. 4. - Pustulatirus ogum. A, odontophore in dorsal view; B, odontophore in ventral view; $\mathrm{C}$, stomach in dorsal view; $\mathrm{D}$, stomach in ventral view; E, stomach shown internally; F, penis in dorsal; G, renal cavity and pericardium in ventral view. Abbreviations: aa, anterior aorta; ap, posterior aorta; au, auricle; bu, bursa; cv, ctenidial vein; dd, duct of digestve gland; dg, digestive gland; dp, duct of penis; ep, posterior esophagus; in, intestine; ki, kidney; $\mathrm{m} 11$, ventral tensor muscles of radula; $\mathrm{m} 2$, odontophore retractor muscles; m2a, accessory odontophore retractor muscles; $\mathrm{m} 3$, superficial circular muscles; $\mathrm{m} 4$, dorsal tensor muscles of radula; $\mathrm{m} 5$, auxiliary dorsal tensor muscles of radula; m6, horizontal muscle; ne, nephrostome; ng, nephridial gland; oc, odontophore cartilage; pc, pericardium; ra, radula; re, rectum; rm, subradular membrane; rs, radular sac; ve, ventricle. Scale bars: A-B, $1 \mathrm{~mm}$; C-G, 2 mm. 

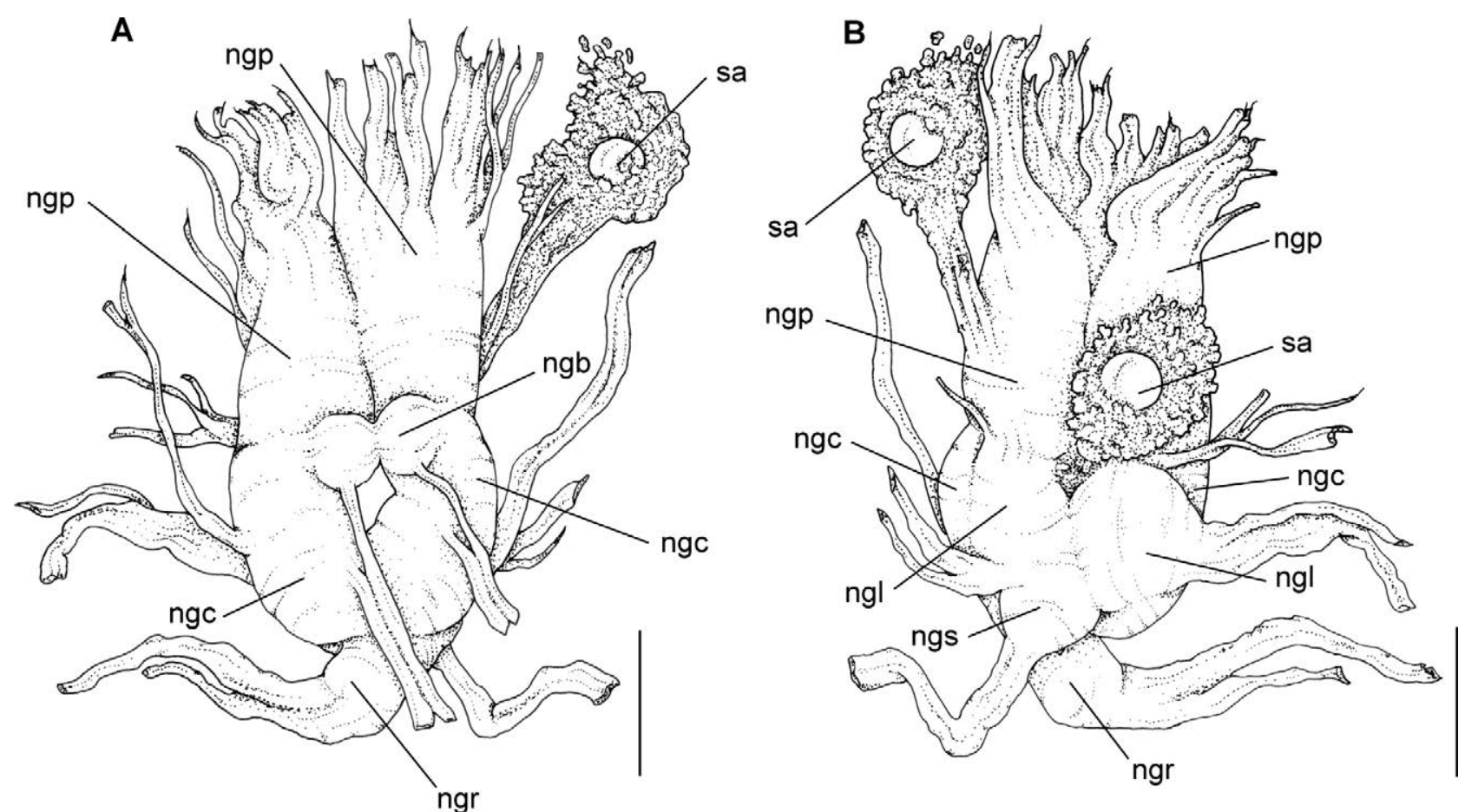

Fig. 5. - Pustulatirus ogum. A, nerve ring in dorsal view; B, nerve ring in ventral view. Abbreviations: ngb, buccal ganglion; ngc, cerebral ganglion; nbl, pleural ganglion; ngp, pedal ganglion; ngr, supra-esophageal ganglion; ngs, subesophageal ganglion; sa, statocyst. Scale bars: $0.5 \mathrm{~mm}$.

cartilages, except for most posterior region $(\sim 1 / 5$ of total odontophore length). Pair of odontophore retractor muscles $(\mathrm{m} 2)$ originating from posterior end of odontophore cartilages, near to radular sac, inserted in inner wall of proboscis; pair of accessory odontophore retractor muscles $(\mathrm{m} 2 \mathrm{a})$, originating from inner surface of proboscis, near origin of $\mathrm{m} 2$, runnind adjacent to esophagus, insertion enveloping enveloping radular sac; pair of secondary, long branch of m2a accompanying anterior aorta reaching up to posterior level of nerve ring. Pair of dorsal tensor muscles of radula (m4) originating from posterior dorsal end of odontophore, covering its dorsal surface, inserting $\mathrm{m} 2 \mathrm{a}$; pair of auxiliary dorsal tensor muscles of radula (m5) originating from posterior end of odontophore, covering its ventral surface, inserting in $\mathrm{m} 2 \mathrm{a}$; pair of ventral tensor muscles of radula (m11), inserting anteriorly in subradular membrane, running, ventrally adhered ( $\sim 3 / 4$ of total odontophore length), origin bifid: main branch originating in ventral posterior cartilage of odontophore near origin of $\mathrm{m} 2$, secondary branch originating ventrally in $\mathrm{m} 2 \mathrm{a}$, crossing dorsally $\mathrm{m} 6$, connecting in main branch ( at $\sim 1 / 2$ of total m11 length). Radula long and thin; radular sac extending beyond posterior end of odontophore; Radular teeth (Fig. 1I-J): rachidian tooth straight, slightly rectangular, their base with concave outline, cusped margin convex, bearing 4 sharp cusps of equal size, except for right central, slightly larger than others; lateral tooth wider than long, bearing 11 prominent, centrally recurved cusps of approximately same size, except for innermost $\sim 1 / 5$ smaller, and outermost $\sim 1 / 4$ smaller and separated from rest. Anterior esophagus moderately long and broad ( $2 \times$ proboscis length), dorsally-ventrally compressed, originating in oral tube. Valve of Leiblein pyriform, forming orange ring around esophagus, $\sim 1.5$ of esophagus width. Salivary glands just anterior to valve of Leiblein, forming pair of branching and amorphous masses; free portion of salivary ducts short, extending along esophagus, anteriorly to valve of Leiblein, becoming embedded with esophageal wall, running immersed anteriorly, opening in oral lumen, immediately before oral tube. Accessory salivary glands absent. Middle esophagus short. Duct of gland of Leiblein short and narrow, inserted posterior to nerve ring. Gland of Leiblein brownish, long, of same length as posterior esophagus, posterior end acute. Posterior and anterior esophagus of $\sim$ same width. Inner wall of anterior esophagus smooth, salivary ducts immersed in marked lateral folds. Stomach wide, walls thin, bearing many internal folds. Digestive gland dark brown, occupying all whorls of visceral mass, from apex to kidney/pericardium area, surrounding stomach, emitting two narrow, branching ducts discharging near esophagus and intestine apertures. Intestine bearing expansion near posterior region of pallial cavity in region preceding rectum, internally bearing many longitudinal folds.

Male genital system (Fig. 4F). Testis brownish, occupying all whorls of visceral mass, except for last one; surrounding apically entire length of digestive gland. Visceral vas deferens running from testis. Seminal vesicle coiled, located on mid-ventral region of last whorl of visceral mass; vas deferens narrow, simple, running along ventral wall of kidney. Prostate thin and long, tubular, located along right side of roof of pallial cavity, next to rectum and equal in width. Penis long, close to head-foot, circular in transverse section; penis becoming narrower at middle of its length, terminating in extension of $\sim 1 / 2$ of total penis length; duct of penis linear, simple. 
Female genital system (Fig. 2B). Ovaries brownish, with same texture and length as testis. Female cement gland opening at $\sim 1 / 2$ from anterior edge of foot, forming somewhat elongated and deep sac of $\sim$ same depth as foot thickness, recurved anteriorly. Pallial oviduct not observed.

Nervous system (Fig. 5A-B). Nerve ring highly concentrated, occupying $\sim 1 / 6$ of total haemocoel area, surrounding mid-esophagus posteriorly. All commissures internal. Cerebral ganglia bean-shaped, occupying $\sim 1 / 2$ of total nerve ring volume, right ganglion slightly larger and more dorsal than left ganglion, its posterior halves broadly connected with each other; pair of lateral tentacular nerves following anteriorly to pedal aorta. Pleural ganglia as pair of bulges ventral to cerebral ganglia, strongly attached to these; left pleural ganglia emitting thick nerve accompanying proboscis anteriorly. Pedal ganglia anterior, elongated, $\sim 1 / 2$ of total nerve ring volume; bearing anterior nerves; right pedal ganglion slightly larger and dorsal than left pedal ganglion. Buccal ganglia circular, small, 1/5 of cerebral ganglia and dorsal to these, emitting pair of cerebro-buccal nerves, following anteriorly to anterior aorta. Supra-esophageal ganglion posterior to cerebropleural ganglia complex, slightly larger than buccal ganglia, emitting thick osphradial nerve. Subesophageal ganglion as ventral bulge in left cerebro-pleural ganglia complex emitting thick pallial-siphon nerve. Pair of vitreous statocysts with one anterior and associated with right pedal ganglion; and one posterior, associated with left pedal ganglion.

\section{Genus Hemipolygona Rovereto, 1899}

Hemipolygona Rovereto, 1899: 104. New name for Chascax Watson, 1873, non Ritgen 1828 (Reptilia). Type species: Chascax maderensis Watson, 1873 by monotypy.

Diagnosis. Shell extremely nodulose with blunt to sharp nodes where axial ribs cross spiral cords, especially on shoulder angulation and central cord, but also on base of shell and subsutural ramp; columella bearing up to 3 weak to strong folds medially; outer lip crenulated, marked internally by several beaded lirae; siphonal fasciole and pseudoumbilicus usually present.

Hemipolygona beckyae (Snyder, 2000) (Figs 6-9)

Latirus beckyae: Snyder 2000: 161 (Figs 1-2); Snyder 2003: 48, 300; Mallard and Robin 2005: 17 (pl. 40).

Hemipolygona beckyae: Vermeij and Snyder 2006: 417 (Fig. 2D); Rosenberg 2009.

Type locality. Off Vitória, 30-50 m depth, Espírito Santo state, Brazil.

Types. Holotype: USNM 880231; Paratypes: USNM 880232; IBUFRJ 9121; MORG 39008; MNRJ 7696.

Examined material. Brazil: Espírito Santo, Vitória (30-50 m, v/1994), MNRJ 7696, paratype, 1 shell; (viii/2005) MZSP 68835, 1 specimen; Vitória (viii/2003, 30-35 m), MZSP 69482, 3 specimens; Guarapari, MZSP 57053, 1 specimen, (30-35 m, viii/2000), MZSP 69764, 1 specimen.
Distribution. Espírito Santo to São Paulo states, southeast coast of Brazil.

Shell (Fig. 6A-G). Shell elliptical, fusiform, height up to $55.4 \mathrm{~mm}$, width $\sim 1 / 3$ of height. Colour light orange with spiral cords whitish. Spire high, angle $50^{\circ}$ $55^{\circ}, \sim 1 / 2$ of total shell height. Protoconch small with 1,5 whorls, smooth, terminal varix low. Teleoconch with 6-9 rounded whorls; suture raised, subsutural lamellar spiral cord, base of shell concave. Spiral sculpture of 8-9 continuous whitish spiral cords per whorl, more prominent in shoulder angulation; 14-18 whitish spiral in base; several secondary spiral cords along teleoconch. Axial sculpture of 7-8 strong, wide, rounded ribs; lamellar striae occurring between spiral cords, eroded in early whorls. Aperture elliptical, height $\sim 3 \times$ width. Columella bearing 3 folds medially. Outer lip crenulated, marked internally by 10-11 discontinuous lirae, not present where they cross outer lip growth scars. Siphonal canal moderately long, length $\sim 1 / 2$ of length of aperture. Siphonal fasciole present. Pseudoumbilicus as shallow slit.

Head-foot (Fig. 7A-B). Colour cream in fixed species, Head prominent, small (width $\sim 1 / 4$ of adjacent width of head-foot), cephalic tentacles blunt and of medium size (length $\sim$ same as anterior width of head), situated very close to each other, bases lying side by side. Eyes dark, small, rounded, situated in middle region of outer edge of tentacles. Foot short, rounded, its anterior region bifid. Pedal gland as shallow median anterior slit, with anterior furrows extending along entire anterior edge.

Operculum (Fig. 6H-I). Corneous, unguiculate (width $~ 2 / 3$ of length), filling entire aperture; outer surface opaque, with anterior nucleus; inner surface with attachment scar elongated, elliptical, situated posteriorly, occupying $\sim 2 / 3$ of inner area. Columellar muscle thick, with $\sim 1$ whorl in length.

Pallial complex. Pallial cavity of 3/4 whorl; mantle border simple, thickened. Siphon short (length about $1 / 4$ of free portion of mantle edge), margin smooth. Gill, hypobranchial gland osphradium and pallial portion of digestive system not observed.

\section{Circulatory and excretory systems. Not analysed.}

Digestive system (Figs 7C-D, 8, 9A-C). Rhynchostome as transversal slit, located slightly below right cephalic tentacle. Proboscis straight, of moderate length ( $2 / 3$ of haemocoel length), with thick muscular walls; strong proboscis retractor muscles originating in right ventral posterior wall of proboscis; laterally to proboscis, series of short muscle fibres connect to inner walls of haemocoel. Mouth small, circular. Odontophore long, very slender $(\sim 1 / 2$ total length of proboscis). Pair of odontophore cartilages dorsally concave, fused anteriorly at $\sim 1 / 5$ of total cartilage length; series of transversal muscle fibres connect odontophore tube with anterior esophagus, and series of 


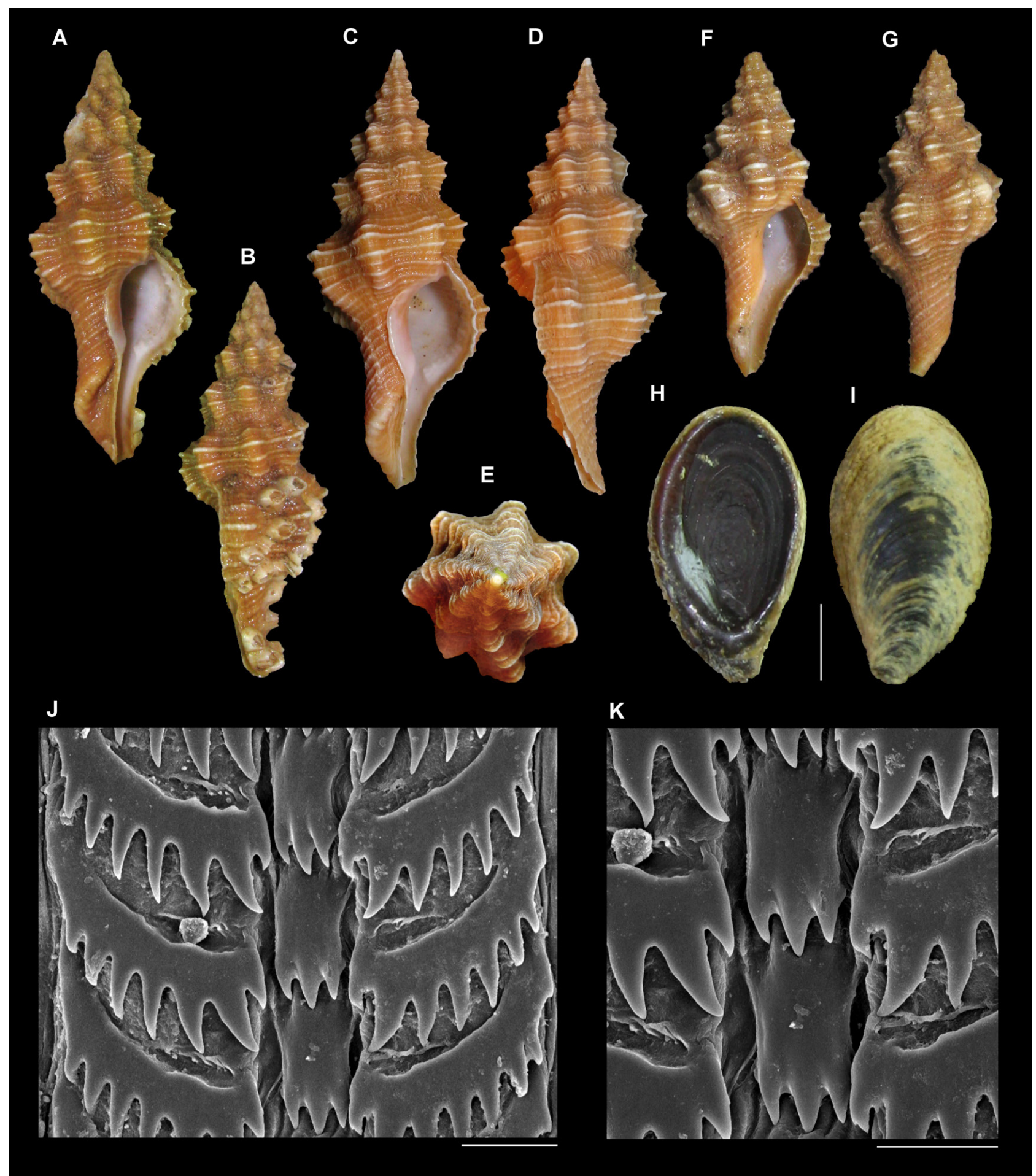

Fig. 6. - Hemipolygona beckyae. A-B, 55.4 mm (MZSP 69764); C-E, 52.4 mm (MZSP 57053); F-G, 38.2 mm (MZSP 69482); H, operculum internal view; I, operculum external view; J, radula; K, detail of rachidian tooth. Scale bars: H-I, $3 \mathrm{~mm}$; J-K, $30 \mathrm{~mm}$.

thin muscle fibres, superficial circular muscles (m3) entirely envelope odontophore, except for most posterior end. Horizontal muscle (m6), on ventral surface of odontophore cartilages, except for most posterior region ( 1/6 of total odontophore length). Pair of odontophore retractor muscles $(\mathrm{m} 2)$ originating from posterior end of odontophore cartilages, near to radular sac, inserted in inner wall of proboscis. Pair of accessory odontophore retractor muscles $(\mathrm{m} 2 \mathrm{a})$, originating from inner surface of proboscis, near origin of $\mathrm{m} 2$, running adjacent to esophagus, insertion enveloping radular sac; pair of secondary, long branches of $\mathrm{m} 2 \mathrm{a}$ accompanying anterior aorta reaching up to posterior level of nerve ring. Pair of dorsal tensor muscles of radula (m4) originating from posterior dorsal end of odontophore, covering its dorsal surface, inserting m2a. Pair of auxiliary dorsal tensor muscles of radula (m5) originating from posterior end of odontophore, covering its ventral 

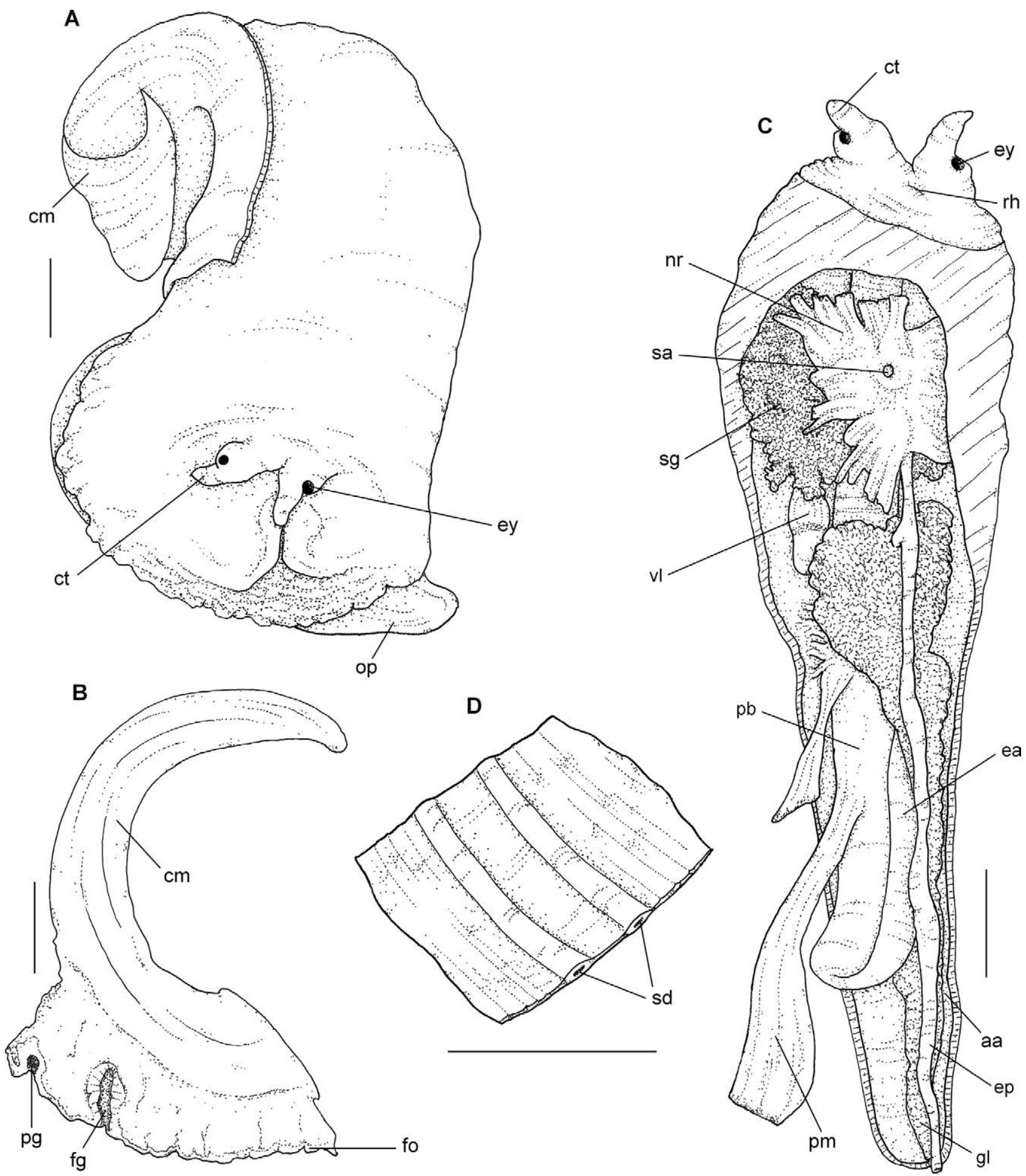

Fig. 7. - Hemipolygona beckyae. A, head-foot mass in dorsal view; B, longitudinal section of head-foot mass, female; C, haemocoel in ventral view; D, lumen of anterior esophagus. Abbreviations: aa, anterior aorta; cm, columellar muscle; ct, cephalic tentacle; ea, anterior esophagus; ep, posterior esophagus; ey, eye; fg, female cement gland; fo, foot; gl, gland of Leiblein; nr, nerve ring; op, operculum; pb, proboscis; pg, pedal gland; rh, rhynchostoma; sa, statocyst; sd, salivary gland duct; sg, salivary gland. Scale bars: A-C, 2 mm; D, 0.5 mm.

surface, inserting in m2a. Pair of ventral tensor muscles of radula (m11), inserting anteriorly in subradular membrane, running ventrally adhered $(\sim 2 / 3$ of total odontophore length), their origin bifid: main branch originating in ventral posterior cartilage of odontophore near origin of $\mathrm{m} 2$; secondary branch originating ventrally in $\mathrm{m} 2 \mathrm{a}$, crossing $\mathrm{m} 6$ dorsally, connecting in main branch, (at $\sim 2 / 3$ of total m11 length). Radula long and thin; radular sac extending beyond posterior end of odontophore. Radular teeth (Fig. 6J-K): rachidian tooth straight, rectangular, its base with concave outline and its cusped margin slight convex outline, with 3 sharp cusps of equal size; lateral tooth wider than long, bearing 8-9 prominent and centrally recurved cusps of 

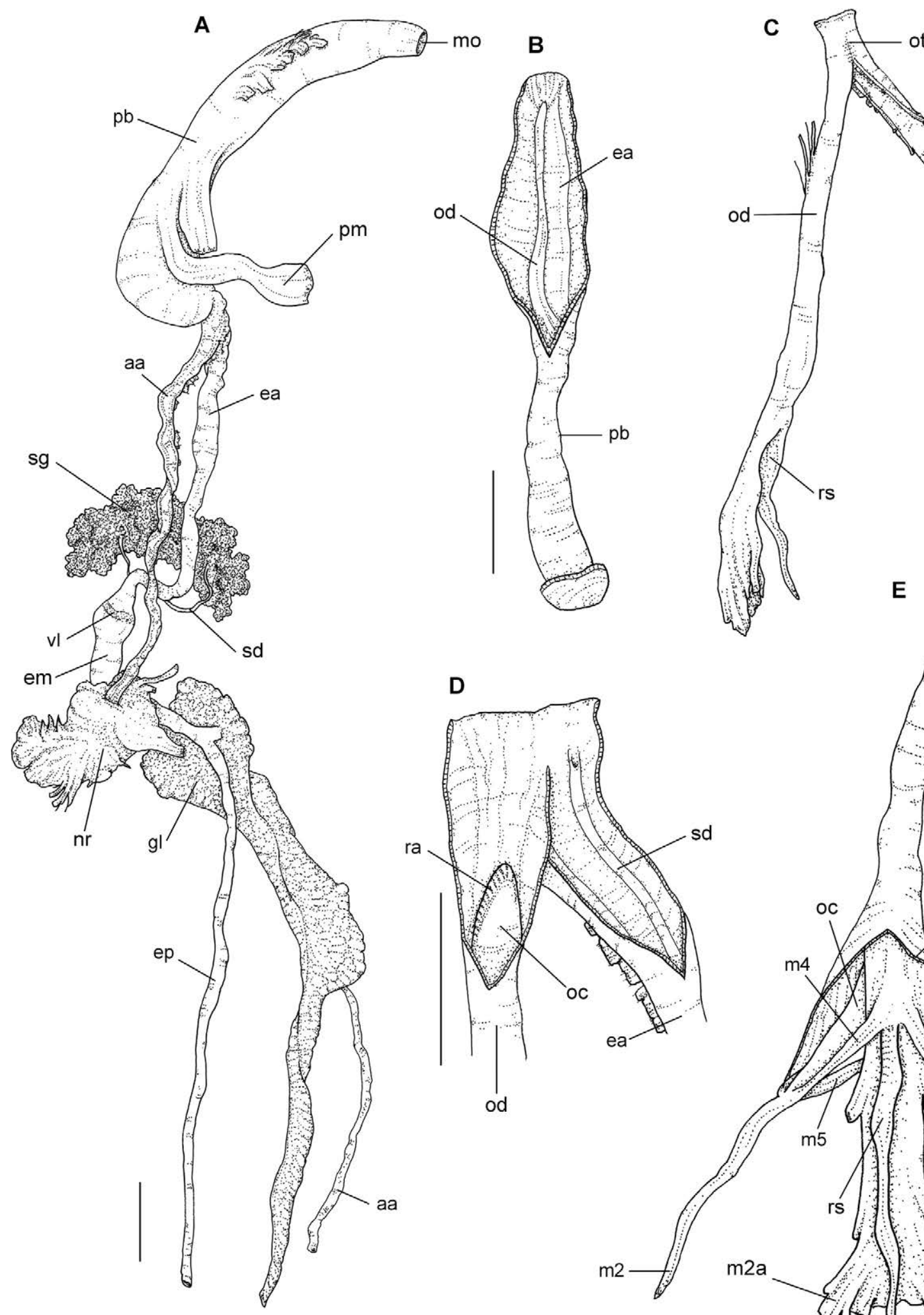

Fig. 8. - Hemipolygona beckyae. A, anterior digestive system; $\mathrm{B}$, proboscis opened anteriorly in lateral view; C, buccal mass in lateral view; $\mathrm{D}$, buccal mass in lateral view, opened longitudinally; E, odontophore in dorsal view. Abbreviations: aa, anterior aorta; ea, anterior esophagus; ep, posterior esophagus; gl, gland of Leiblein; m2, odontophore retractor muscles; $\mathrm{m} 2 \mathrm{a}$, accessory odontophore retractor muscles; m3, superficial circular muscles; m4, dorsal tensor muscles of radula; m5, auxiliary dorsal tensor muscles of radula; m6, horizontal muscle; mo, mouth opening; nr, nerve ring; oc, odontophore cartilage; od, odontophore tube; ot, oral tube; ra, radula; rm, subradular membrane; rs, radular sac; sd, salivary gland duct; sg, salivary gland; vl, valve of Leiblein. Scale bars: A-B, $2 \mathrm{~mm}$; C-E, $1 \mathrm{~mm}$. 

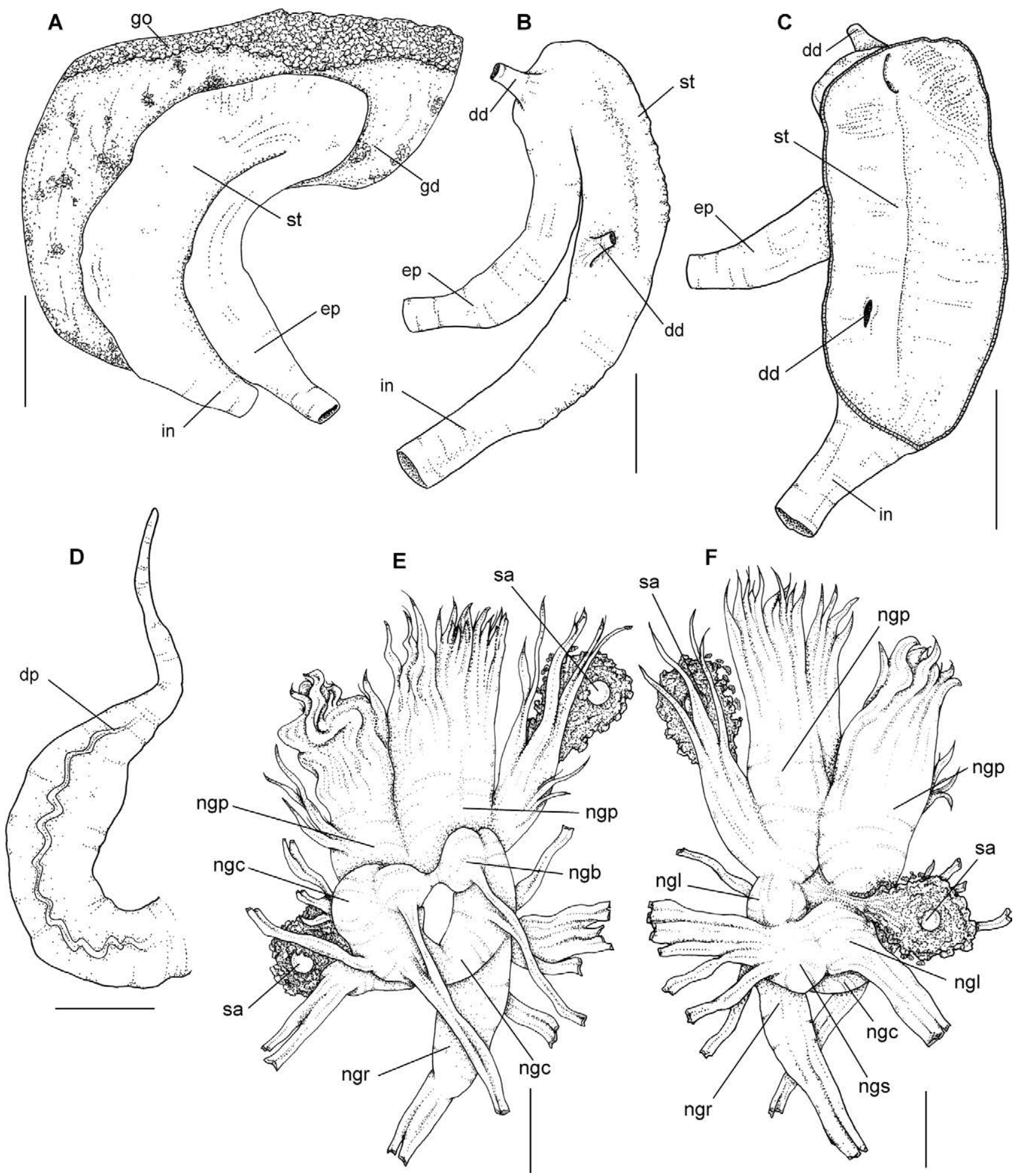

Fig. 9. - Hemipolygona beckyae. A, stomach in dorsal view; B, stomach in ventral view; C, stomach shown internally; D, penis in dorsal; E, nerve ring in dorsal view; F, nerve ring in ventral view. Abbreviations: dd, duct of digestive gland; dp, duct of penis; ep, posterior esophagus; in, intestine; nbl, pleural ganglion; ngb, buccal ganglion; ngc, cerebral ganglion; ngp, pedal ganglion; ngr, supra-esophageal ganglion; ngs, subesophageal ganglion; sa, statocyst. Scale bars: A-D, 2 mm; E-F, $0.5 \mathrm{~mm}$.

approximately same size, except for innermost $\sim 1 / 2$ smaller than rest, lateral margin acute, terminating in external cusp. Anterior esophagus moderately long and broad ( $2 \times$ proboscis length), dorsally-ventrally compressed, originating in oral tube. Valve of Leiblein pyriform, as an orange ring around esophagus, $\sim 2 \times$ esophagus width. Salivary glands just anterior to valve of Leinblein, as pair of amorphous masses; free portion of salivary ducts short, extending to esophagus anteriorly to valve of Leiblein, where ducts become embedded with esophagus wall, following anteriorly and opening in esophagus lumen, immediately before 
oral tube. Accessory salivary glands absent. Middle esophagus short; duct of gland of Leiblein short, situated after nerve ring. Gland of Leiblein brownish, long, of $\sim$ same length as posterior esophagus, posterior end acute. Posterior and anterior esophagus of $\sim$ same width. Inner wall of anterior esophagus with thin dorsal longitudinal folds, salivary ducts immersed in marked lateral folds. Stomach as wide sac with thin walls bearing many internal folds. Digestive gland dark brown, occupying all whorls of visceral mass, from apex to kidney/pericardium area, surrounding stomach and emitting two narrow ducts that discharge into stomach near esophagus and intestine apertures. Pallial portion of digestive system not analysed.

Male genital system (Fig. 9D). Testis brownish. Visceral and pallial portion of male genital system not observed. Penis long and thin, close to head-foot mass, $\sim$ circular in transverse section; at $\sim 2 / 3$ of its length penis becomes narrower ( 1/4 diameter), terminating in short, blunt extension; duct of penis linear.

Female genital system (Fig. 7B). Ovaries same colour and texture as testis. Female cement gland opening at $\sim 1 / 3$ from anterior edge of foot, forming shallow sac ( 1/2 foot thickness).

Nervous system (Fig. 9E-F). Nerve ring highly concentrated, occupying $\sim 1 / 4$ of total hemocoel area, surrounding mid-esophagus posteriorly. All commissures and internal. Cerebral ganglia bean-shaped, occupying $\sim 1 / 3$ of total nerve ring volume, of about same size, posterior halves broadly connected; pair of lateral tentacular nerves follow pedal aorta anteriorly. Pleural ganglia as pair of bulges ventral to cerebral ganglia, strongly attached to these; left pleural ganglia emits thick nerve that accompanies proboscis anteriorly. Pedal ganglia anterior, elongated, $\sim 1 / 2$ of total nerve ring volume, emitting anterior zigzag nerves; right pedal ganglion slightly larger and dorsal than left. Buccal ganglia subcircular, $\sim 1 / 3$ of cerebral ganglia and dorsal to these, emitting pair of nerves that form cerebro-buccal nerves, that follow anterior aorta anteriorly. Supra-esophageal ganglion posterior to cerebro-pleural ganglia complex, elongated, same volume as cerebral ganglion, emitting thick osphradial nerve. Subesophageal ganglion as ventral bulge in left cerebro-pleural ganglia complex that emits thick branching pallialsiphon. Pair of vitreous statocysts with one anterior and associated with right pedal ganglion, and one posterior, associated with left pedal ganglion.

\section{DISCUSSION}

Ponder (1973) pointed out the anatomical similarity among members of the Buccinoidea, concluding that there are no consistent differences among the families; hence they could be treated as subfamilies (e.g. Buccininae, Fasciolariinae). However, later taxonomic studies (e.g. Bouchet and Rocroi 2005) recognized family entities within the superfamily Buccinoidea. The morphological results obtained in this study are in agreement with the diagnostic characteristics established by Fraussen et al. (2007) for Fasciolariidae. These are the multicuspidate lateral teeth, the straight shape of the rachidian teeth of the radula, the proboscis retractor muscle as a single or paired tuft of fibres, ducts of the salivary glands embedded in the esophagus wall, and the stomach without a posterior mixing area.

The taxonomy of fasciolariids is based on the shell and radula (e.g. Tryon 1880, Thiele 1929-1935, Vermeij and Snyder 2002, 2006), and taxonomic approaches based on soft-part anatomy are few. Anatomical data for the buccinoideans, particularly the stomach (e.g. Kosyan and Kantor 2013, Kantor 1996, Strong 2003), the anterior digestive system including the radula (e.g. Kosyan et al. 2009, Simone 1996) and the reproductive system (Fraussen et al. 2007), suggest that they are highly advanced Neogastropoda that lack accessory salivary glands and anal glands.

The accessory salivary glands and anal glands are synapomorphic to neogastropods (Ponder and Lindberg 1997, Harasewych 1998, Strong 2003, Simone 2011), although these organs are lacking in buccinoideans. Kantor and Fedosov (2009) asserted the dual appearance of the valve of Leiblein in Buccinoidea; therefore, this clade shares none of the previously hypothesized autapomorphies with other neogastropods; and in this case, Neogastropoda is a paraphyletic group.

Historically, the taxonomy of the subfamily Peristerniinae, especially that of Latirus, has been confused, because the genus was used indiscriminately to include several species, some of them doubtfully related. Latirus was initially considered to have a worldwide distribution. However, Vermeij and Snyder (2006) considered the known geographic range of the genus to be restricted to the western Indo-Pacific, and consequently raised several taxa previously considered as subgenera to genus rank (e.g. Hemipolygona) and proposed new genera (e.g. Pustulatirus, Turrilatirus).

Vermeij and Snyder (2003) transferred several species to the genus Benimakia Habe, 1958, including Benimakia ogum, originally described in Latirus. These authors characterized Benimakia as high-spired fasciolariids with prominent axial ribs and a labral tooth at the end of the central cord of the outer lip. Benimakia ogum differs from other species of the genus in having a discontinuous beaded lira on the inner side of the outer lip (Fig. 1A, D), in this respect resembling Latirus (Vermeij and Snyder 2003) and Pustulatirus (Vermeij and Snyder 2006). Species included in Benimakia by Habe (1958) and Vermeij and Snyder (2003) occur in the western Pacific, with the exception of $B$. ogum, which putatively differs from other members of Peristerniinae related to Latirus in having a small labral tooth at the end of the basal cord. However, the presence of this tooth is questionable. A labral tooth is not mentioned in the original description by Petuch (1979), nor was it found in the present study (Fig. 1AF). A pseudoumbilicus is also present, differentiating it from Benimakia, although it occurs in Pustulatirus. Therefore B. ogum clearly belongs to the genus Pustulatirus, in agreement with Landau and Vermeij (2012) and Lyons and Snyder (2013). 
Table 1. - Main comparative radular features of the Peristerniinae based on our data and those of ${ }^{1}$ Couto and Pimenta (2012), ${ }^{2}$ Kosyan et al. (2009), ${ }^{3}$ Bandel (1984) and ${ }^{4}$ Snyder and Bouchet (2006).

\begin{tabular}{|c|c|c|c|c|}
\hline & Raquid & cusps & first cusp & Lateral \\
\hline Pustulatirus ogum & square, base broad & 4 & developed & 11 curved \\
\hline Hemipolygona beckyae & rectangular, thin, base broad & 3 & developed & 8-9 somewhat curved \\
\hline Leucozonia nassa ${ }^{1}$ & square, broad, base broad & 3 & vestigial & $7-8$ curved \\
\hline Leucozonia ocellata $^{1}$ & square, broad, base broad & 3 & reduced & 5-6 curved \\
\hline Pustulatirus mediamericanus ${ }^{2}$ & square, broad, base broad & 4 & developed & $11-12$ \\
\hline Peristernia nassatula ${ }^{2}$ & Trapezoidal, thin, base thin & 3 laterally recurved & well developed & $11-12$ alternating smaller/larger \\
\hline Peristernia ustulata $^{2}$ & Trapezoidal, thin, base thin & 3 laterally recurved & well developed & $11-12$ alternating smaller/larger \\
\hline Opeatostoma pseudodon $^{2}$ & square, broad, base broad & 5 & absent & 8 , central larger \\
\hline Tarantinae lignaria ${ }^{2}$ & square, broad, base broad & 3 & developed & 9 curved \\
\hline Latirus polygonus 2,3 & square, broad, base broad & 3 , central longer & developed & $11-12$ curved \\
\hline Turrilatirus turritus ${ }^{2,3}$ & rectangular, base broad & 3 & well developed & 7 curved \\
\hline Latirus infundibulum ${ }^{3}$ & rectangular, thin, base broad & 3 centrally recurved & well developed & $7-8$ curved \\
\hline Latirolagena smaragdula ${ }^{3}$ & square, base broad & 3 , central longer & reduced & $15-16$ \\
\hline Polygona angulata ${ }^{3}$ & Trapezoidal, thin, base thin & 3 & well developed & 8-9 curved \\
\hline Fusolatirus elsiae $^{4}$ & Trapezoidal, thin, base thin & 3 & well developed & $12-13$ alternating smaller/larger \\
\hline
\end{tabular}

Hemipolygona beckyae was originally included in Latirus by Petuch (1979), and was later allocated to Hemipolygona by Snyder (2003), as agreed to by Vermeij and Snyder (2006), due to the highly nodulose shell with a deep slit-like pseudoumbilicus and whitish spiral cords (Fig. 6A-G).

The morphology of the two species is similar and in accordance with other descriptions of fasciolariids (Fraussen et al. 2007, Kosyan et al. 2009, Couto and Pimenta 2012), with the main differences occurring in the anterior digestive and male reproductive systems. Details of the anatomy, histology and ultrastructure of the anterior digestive system (including the radula) have been noted as useful traits for phylogenetic analyses (Ponder and Lindberg 1997), and the anterior structures of the foregut are generally used to distinguish neogastropod families (Fraussen et al. 2007). A recent phylogenetic analysis based on comparative morphology (Simone 2011) consistently recovered all the major caenogastropod clades.

The rhynchostome occurs as a lip-like slit bearing longitudinal lamellar folds, which may be longitudinal to the adjacent head-foot mass as in P. ogum (Fig. 3A) or transverse, although located slightly to the right side of the animal, not between its cephalic tentacles as in H. beckyae (Fig. 7C).

Golding et al. (2009a) studied the snout and proboscis morphology in species belonging to 33 caenogastropod families, among them a buccinoidean (Columbellidae), but included no fasciolariid. In their study they reported the ventro-lateral insertion of the proboscis retractor muscles as occurring in all Neogastropoda, and the presence of aortic muscles that flank the aorta in the anterior esophagus; both characters are confirmed for members of Fasciolariidae so far studied. On the other hand, Goulding et al. (2009b) studied the anatomy of odontophoral cartilages in Caenogastropoda through the use of micro-CT scanning, although none of the species studied were buccinoideans. This method allows observation of the cartilages in their natural orientation, without anatomical dissections that would otherwise cut or displace structures. Despite the methodological differences, Pustulatirus ogum and $H$. beckyae showed a close resemblance to the muricoidean studied by Golding et al. (2009b) in having greatly elongated anterior cartilages and lacking subradular cartilages. As noted by these authors, the Neogastropoda possess the most dramatic modifications of the plesiomorphic odontophoral cartilage morphology. Also, the morphology of the odontophoral cartilages may be conserved within families and superfamilies: hence the resemblance of these structures among the Fasciolariidae (Couto and Pimenta 2012) and to other buccinoideans (Simone 1996, 2011)

The lateral teeth of the radula of the Peristerniinae observed in this study and in Leucozonia (Couto and Pimenta 2012) have the innermost cusp (defined as a 'denticle' by Bullock, 1974) as a small projection at its base, next to the rachidian tooth. This projection may vary considerably in size and shape. In Leucozonia, it is reduced or even absent (Couto and Pimenta 2012: 1Q, 5G and 9O), while in P. ogum (Fig. 1A-J) and Hemipolygona beckyae (Fig. 6J-K) it is developed, although smaller than the outer cusps, and recurved outward. All species of Peristerniinae studied by Bullock (1974) and Bandel (1984) have this same conformation, and Bullock (1974) also noted that this feature distinguishes Latirus and related species from Leucozonia.

Within the Fasciolariidae, members of Peristerniinae possess fewer cusps of the lateral teeth than members of other subfamilies (Bandel 1984, Taylor and Lewis 1995, Snyder and Bouchet 2006). However, recent findings from moderate/deep-sea regions of the Indo-West Pacific led to the description of several species and genera that deviate from this pattern (e.g. Amiantofusus, Fraussen et al. 2007; Chryseofusus, Hadorn et al. 2008; and Angulofusus, Fedosov and Kantor 2012). All aforementioned genera have the radula closer to Peristerniinae than to Fusininae. Table 1 lists relevant radular features of $P$. ogum and $H$. beckyae, as well as those of other members of Peristerniinae compiled from the literature.

According to Fraussen et al. (2007), the ducts of the salivary glands embedded in the esophagus wall is diagnostic for the family; this feature was reported for Latirus polygonus, but not for Pustulatirus mediamericanus, Turrilatirus turritus, Peristernia nassatula, $P$. ustulata, Opeatostoma pseudodon and Tarantinae lignaria studied by Kosyan et al. (2009), and therefore a reinvestigation is needed in these species. In the species 


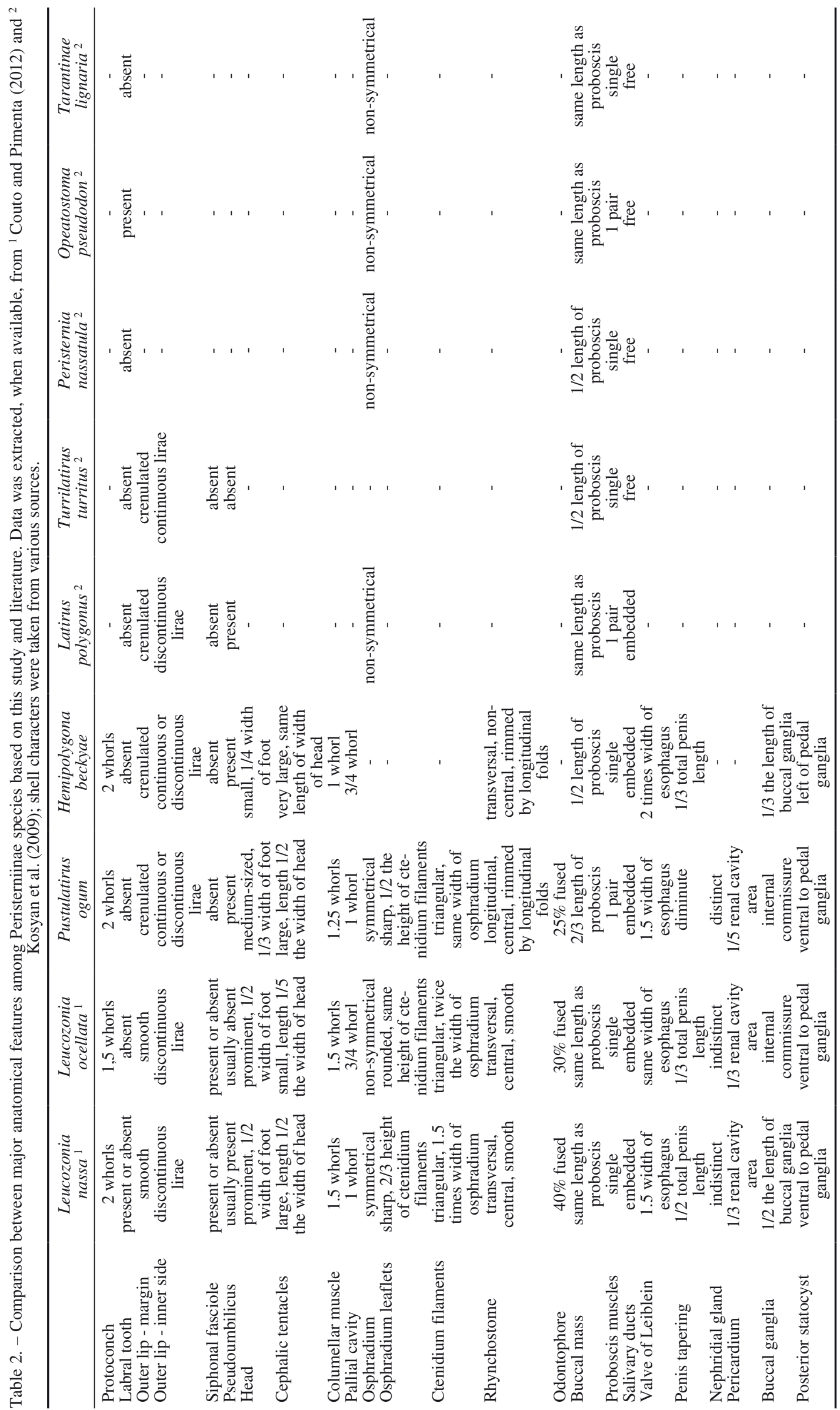


studied here and those reported by other authors (e.g. Marcus and Marcus 1962, Couto and Pimenta 2012, Fedosov and Kantor 2012), this feature also occurs.

Hemipolygona beckyae has a single powerful proboscis retractor muscle, which emerges posteriorly and ventrally from the proboscis (Fig. 8A). Pustulatirus ogum has a pair of muscles (Fig. 3B). In the species studied by Kosyan et al. (2009), all fasciolariids but Latirus polygonus and Fusinus tenerifensis have a single muscle, while in the buccinids multiple fibres occur posteriorly to the proboscis. Golding et al. (2009a) distinguished different proboscis types among caenogastropods, although they studied only one species of Buccinoidea, the columbellid Euplica scripta, which possesses two ventro-lateral proboscis retractors, resembling those of $H$. beckyae. Both fasciolariids have the proboscis retractor passing outside the nerve ring and originating in the posterior hemocoel floor, near the diaphragm septum.

Kantor (2003) distinguished species of Fasciolariidae from other buccinoideans by the low relief of the folds on the inner stomach wall; presence of transverse striations on the low longitudinal fold; absence of clear differentiation of the gastric chamber into dorsal and ventral parts; absence of a posterior mixing area; and a shallow lateral sulcus. Despite this thorough examination of representatives of the three subfamilies (Fasciolariinae: Fasciolaria lilium, F. filamentosa; Fusininae: Fusinus nicobaricus and Peristerniinae: Leucozonia nassa), Kantor (2003) noted the difficulties of examination and the necessity of specially preserved specimens for stomach analysis, although the differences observed are likely due to phylogenetic relationships. While both $P$. ogum and $H$. beckyae have stomach morphology similar to the fasciolariids cited by Kantor (2003), species-level differentiation is unlikely.

Both species, as well as Leucozonia (Marcus and Marcus 1962, Couto and Pimenta 2012), have penises with terminal tapering. In Leucozonia (Couto and Pimenta 2012: Figs 4E and 8F) and H. beckyae (Fig. 9D) the terminal extension extends for more than half of the total penis length, while in $P$. ogum it extends less than half of its length (Fig. 4F).

Several morphological characters occur in both species and also occur diffused among other fasciolariids (Fraussen et al. 2007, Kosyan et al. 2009, Couto and Pimenta 2012). These include the outline of the gill lamellae, the length and anterior fusion of the odontophore cartilages, and the extension of the anus to the edge of the pallial cavity. For this reason, the soft-part traits of Latirus and related species studied so far do not allow a precise anatomical diagnosis. Table 2 lists the main differentiating characteristics.

\section{ACKNOWLEDGEMENTS}

The authors are grateful to two anonymous reviewers who made insightful comments and suggestions on this manuscript. Dr. J. Reid, from Virginia Museum of Natural History for revising the English text. This work was funded in part by the Conselho de Desenvolvimento Científico e Tecnológico (CNPq) for a M.S. scholar- ship and Fundação de Amparo à Pesquisa do Estado de São Paulo (FAPESP) for a PhD scholarship.

\section{REFERENCES}

Bandel K. 1984. The Radulae of Caribbean and other Mesogastropoda and Neogastropoda. Riiksmuseum van Natuurlijke Historie, 346 pp. 22 pls.

Bouchet P., Rocroi J.P. 2005. Classification and nomenclator of gastropod families. Malacologia 47(1-2): $397 \mathrm{pp}$.

Bullock R.C. 1974. A contribution to the systematics of some West Indian Latirus (Gastropoda: Fasciolariidae). Nautilus 88(3): 69-79.

Couto D.R., Pimenta A.D. 2012. Comparative morphology of Leucozonia from Brazil (Neogastropoda: Buccinoidea: Fasciolariidae). Am. Malacol. Bull. 30(1): 103-116. http://dx.doi.org/10.4003/006.030.0108

Fedosov A.E., Kantor Y.I. 2012. A new species and genus of enigmatic turriform Fasciolariidae from the Central Indo-Pacific (Gastropoda: Neogastropoda). Arch. Molluskenkunde 141(2): 137-144.

Fraussen K., Kantor Y.I., Hadorn R. 2007. Amiantofusus gen. nov. for Fusus amiantus Dall, 1889 (Mollusca: Gastropoda: Fasciolariidae) with description of a new and extensive Indo-West Pacific radiation. Novapex 8(3-4): 79-101.

Gofas S. 2014. Fasciolariidae Gray, 1853. Accessed through: World Register of Marine Species on 2014-07-15, at http://www.marinespecies.org/aphia.php? $\mathrm{p}=$ taxdetails \&id= 23038

Golding R.E., Ponder W.F., Byrne M. 2009a. The evolutionary and biomechanical implications of snout and proboscis morphology in Caenogastropoda (Mollusca: Gastropoda). J. Nat Hist. 43(4344): 2723-2763 http://dx.doi.org/10.1080/00222930903219954

Golding R.E., Ponder W.F., Byrne M. 2009b. Three-Dimensional Reconstruction of the Odontophoral Cartilages of Caenogastropoda (Mollusca: Gastropoda) Using Micro-CT: Morphology and Phylogenetic Significance. J. Morphol. 270: 558-587.

Habe T. 1958. On the radulae of Japanese marine gastropods. Venus 20: $43-60$.

Hadorn R., Snyder M.A., Fraussen K. 2008. A new Chryseofusus (Gastropoda: Fasciolariidae: Fusinus) from South and Western Australia. Novapex 9(2-3): 95-99.

Harasewych M.G. 1998. Family Fasciolariidae. In: Beesley P.L., Ross G.J.B., Wells A. (eds), Mollusca: The Southern Synthesis. Fauna of Australia. CSIRO publishing, Melbourne, pp 832-833.

Kantor Y.I. 1996. Phylogeny and relationships of Neogastropoda. In: Taylor J.D. Origin and evolutionary radiation of the Mollusca. Oxford Univ. Press, pp 221-230.

Kantor Y.I. 2003. Comparative anatomy of the stomach of Buccinoidea (Neogastropoda). J. Moll. Stud. 69(3): 203-220. http://dx.doi.org/10.1093/mollus/69.3.203

Kantor Y.I., Fedosov A. 2009. Morphology and development of the valve of Leiblein: possible evidence for paraphyly of the Neogastropoda. Nautilus 123(3): 1-73.

Kosyan A.R., Kantor Y.I. 2009. Phylogenetic analysis of the subfamily Colinae (Neogastropoda, Buccinidae) based on morphological characters. Nautilus 123: 83-94.

Kosyan A.R., Kantor Y.I. 2013. Revision of the genus Aulacofusus Dall, 1918 (Gastropoda: Buccinidae). Ruthenica 23(1): 1-33.

Kosyan A.R., Modica M.V., Oliverio M. 2009. The anatomy and relationships of Troschelia (Neogastropoda, Buccinidae): New evidence for a closer fasciolariid-buccinid relationship? Nautilus 123: 95-105

Landau B., Vermeij G.J. 2012. The Peristerniinae (Mollusca: Gastropoda, Buccinoidea, Fasciolariidae) from the Neogene of Venezuela. Cainozoic Res. 9(1): 87-99.

Lyons W.G., Snyder M.A. 2013. The genus Pustulatirus Vermeij and Snyder, 2006 (Gastropoda: Fasciolariidae: Peristerniinae) in the western Atlantic, with descriptions of three new species. Zootaxa 3636(1): 35-58. http://dx.doi.org/10.11646/zootaxa.3636.1.2

Mallard D., Robin A. 2005. Fasciolariidae. La Mothe Achard, Les Sables-d'Olonne, France, 27 pp. 70 pls

Marcus E., Marcus E. 1962. On Leucozonia nassa. Bol. Fac. Fil Cienc. Letr. Univ. São Paulo, Zool. 24: 11-30.

Petuch E.J. 1979. New Gastropods from the Abrolhos reef archipelago and reef complex, Brazil. Proc. Biol. Soc. Wash. 92(3): 520-526. 
Petuch E.J. 1987. New Caribbean Molluscan Faunas. The Coastal education and Research foundation [CERF], Charlottesville, Virginia. 154 pp. A1-A4.

Ponder W.F. 1973. The Origin and Evolution of the Neogastropoda. Malacologia 12(2): 295-338.

Ponder W.F., Lindberg D.R. 1997. Towards a phylogeny of gastropod molluscs: an analysis using morphological characters. Zool. J. Linn. Soc. 119: 83-265. http://dx.doi.org/10.1111/j.1096-3642.1997.tb00137.x

Rios E.C. 1985. Seashells of Brazil. Museu Oceanográfico, Fundação Univesidade do Rio Grande, Rio Grande, 328 pp.

Rios E.C. 1994. Seashells of Brazil. Museu Oceanográfico Prof. E. C. Rios, Fundação Universidade do Rio Grande, Rio Grande, 368 pp. 113 pls

Rios E.C. 2009. Compendium of Brazilian Sea Shells. Museu Oceanográfico Prof. E. C. Rios, Fundação Universidade do Rio Grande, Rio Grande, 668 pp.

Rosenberg G. 2009. Malacolog 4.1.0: A Database of Western Atlantic Marine Mollusca http://www.malacolog.org/

Simone L.R.L. 1996. Anatomy and systematics of Buccinanops gradatus (Deshayes, 1844) and Buccinanops moniliferus (Kiener, 1834) (Neogastropoda, Muricoidea) from the Southeastern coast of Brazil. Malacologia 38(1-2): 87-102.

Simone L.R.L. 2011. Phylogeny of the Caenogastropoda (Mollusca), based on comparative morphology. Arq. Zool. Mus. Zoo. Univ. São Paulo 42(2-4): 83-323.

Simone L.R.L., Cavallari D.C., Abbate D. 2013. Revision of the genus Teralatirus Coomans 1965 in the Western Atlantic, with an anatomical description of $T$. roboreus (Reeve 1845) (Gastropoda: Neogastropoda: Fasciolariidae). Arch. Molluskenkunde 142(2): 215-226.

Snyder M.A. 2000. Latirus beckyae, a new species of Fasciolariidae (Gastropoda: Neogastropoda) from Brazil. Nautilus 114(4): 161-163.

Snyder M.A. 2003. Catalogue of the marine gastropod family Fas- ciolariidae. Acad. Nat. Sci. Phila. Spec. Publ. 21. Philadelphia, iv $+431 \mathrm{pp}$.

Snyder M.A., Bouchet P. 2006. New species and new records of deep-water Fusolatirus (Neogastropoda: Fasciolariidae) from the West Pacific. J. Conchology 39: 1-12.

Strong E.E. 2003. Refining molluscan characters: morphology, character coding and a phylogeny of the Caenogastropod. Zool. J. Linn. Soc. 137: 447-554. http://dx.doi.org/10.1046/j.1096-3642.2003.00058.x

Taylor J.D., Lewis A. 1995. Diet and radular morphology of Peristernia and Latirolagena (Gastropoda: Fasciolariidae) from Indo-Pacific coral reefs. J. Nat. Hist. 29(5): 1143-1154. http://dx.doi.org/10.1080/00222939500770481

Thiele J. 1929-1935. Handbuch der Systematischen Weichtierkunde. Gustav Fischer, Jena vol 1: vi + 778 pp. vol. 2: v + 779-1134 pp.

Tryon G.W. 1880. Manual of Conchology, Structural and Systematic, with Illustrations of the Species. Philiadelphia. 310 pp. 87 pls.

Vermeij G.J., Snyder M.A. 1998. Leucozonia ponderosa, a new fasciolariid gastropod from Brazil. Nautilus 112: 117-119.

Vermeij G.J., Snyder M.A. 2002. Leucozonia and related genera of Fasciolariid Gastropods: shell-based taxonomy and relationships. Proc. Acad. Nat. Sci. Phila. 152: 23-44. http://dx.doi.org/10.1635/0097-3157(2002)152[0023:LARGO F]2.0.CO;2

Vermeij G.J., Snyder M.A. 2003. The fasciolariid gastropod genus Benimakia: new species and a discussion of Indo-Pacific genera in Brazil. Proc. Acad. Nat. Sci. Phila. 153: 15-22. http://dx.doi.org/10.1635/0097-3157(2003)153[0015:TFGGB $\mathrm{N}] 2.0 . \mathrm{CO} ; 2$

Vermeij G.J., Snyder M.A. 2006. Shell characters and taxonomy of Latirus and related fasciolariid groups. J. Moll. Stud. 72(4): 413-424.

http://dx.doi.org/10.1093/mollus/ey1020 


\title{
MORPHOLOGY OF FASCIOLARIA TULIPA FROM VENEZUELA (GASTROPODA: BUCCINOIDEA: FASCIOLARIIDAE)
}

\author{
Diogo R. Couto ${ }^{1}$, Luiz Ricardo L. Simone ${ }^{1}$, Alexandre D. Pimenta ${ }^{2}$ \\ ${ }^{1}$ Laboratório de Malacologia, Museu de Zoologia da Universidade de São Paulo. Avenida Nazaré, 481, Ipiranga. \\ CEP 04263-000 São Paulo, SP, Brazil \\ ${ }^{2}$ Setor de Malacologia, Departamento de Invertebrados, Museu Nacional, Universidade Federal do Rio de Janeiro. Quinta da \\ Boa Vista s/n, São Cristóvão. CEP 20940-040 Rio de Janeiro, RJ, Brazil
}

\begin{abstract}
The morphology of Fasciolaria tulipa, type species for the genus, is described and illustrated. Features of the shell, head-foot, pallial organs, circulatory, excretory, digestive and reproductive systems are presented, along with comparisons of published descriptions of other members of Fasciolariidae. The anatomical features concord with previous characterizations of the family: proboscis retractor as a single and powerful muscle, lateral teeth of the radula wide and multicuspidate, ducts of the salivary glands immersed in the esophagus wall, and stomach without a posterior sorting area. Fasciolaria tulipa is notable for a large, thin walled auricle, a conspicuous nephridial gland, and a renal aperture sited close to the pericardium; also the odontophore cartilages are fused anteriorly in only 10\% of their length, and the radula has the central side of the base of the lateral tooth rounded, a trait that is shared with other species of the subfamily Fasciolariinae. As the type of the genus, the soft-parts anatomy of F. tulipa is of great importance, especially because recent taxonomic revisions of the Fasciolariinae have not considered anatomical data.
\end{abstract}

Key words Fasciolariidae, Fasciolaria tulipa, anatomy, morphology

\section{INTRODUCTION}

The Neogastropod family Fasciolariidae comprises more than 1300 living species distributed in the tropics and subtropics (Gofas, 2014). Members of the subfamily Fasciolariinae are usually easily recognized by their ample shell, sinuous columella, and oblique columellar folds. The genus Fasciolaria is restricted to the western Atlantic and its fossil record dates from the early Pliocene, which is relatively late in comparison with other fasciolariids (Snyder et al. 2012).

Two species of Fasciolariinae are recognized from Brazil: Pleuroploca aurantiaca (Lamarck, 1816) and Fasciolaria tulipa (Linnaeus, 1758) (Rosenberg, 2009). Although the former species was allocated to the new genus Aurantilaria by Snyder et al. (2012), no recent taxonomic rearrangement has been undertaken for the latter species, as it is the type for the genus Fasciolaria. Although F. tulipa occurs on virtually every Caribbean island, despite its non-planktotrophic mode of development, in Brazil this species is restricted to the northern border of Amapá state (Rosenberg, 2009; Snyder et al. 2012), implying the possible presence of a geographic barrier formed by the Amazon River mouth.

Contact author : diogoaut@gmail.com
Present knowledge on the anatomy of the Fasciolariidae is as described by Fraussen et al. (2007), with a combination of traits diagnostic for the family: multicuspidate lateral teeth and straight rachidian teeth, proboscis retractor muscle as a single or paired tuft of fibres, ducts of the salivary glands immersed in the esophagus wall, and the stomach without a posterior caecum. However, anatomical diagnoses of species within Fasciolariidae have not been developed.

In Brazil, few species of Fasciolariidae have undergone a thorough anatomical study. The anatomy of some species belonging to Leucozonia has been studied in detail: L. nassa (Gmelin, 1791) by Marcus \& Marcus (1962), and L. nassa (Gmelin, 1791), L. ocellata (Gmelin, 1791) and L. ponderosa (Vermeij \& Snyder, 1998) by Couto \& Pimenta (2012). Recently, Simone et al. (2013) thoroughly described the anatomy of Teralatirus roboreus (Reeve, 1845). Matthews-Cascon et al. (1989) contributed a superficial characterization of Aurantilaria aurantiaca; however, no other member of Fasciolariinae from Brazil has had its anatomy studied. Kosyan et al. (2009) studied the anatomy of eight species of Fasciolariidae, including Fasciolaria lignaria (Linnaeus, 1758), although none of these occurs in Brazil.

The taxonomy of gastropod groups is based mainly on shell and radula features (e.g., Tryon, 
1880; Thiele, 1929-1935; Snyder et al., 2012). Therefore, approaches using soft-part anatomy will prove useful in delimiting groups that have similar conchological features and/or those prone to polymorphisms and convergences. Also, morphological data will prove useful in validating phylogenetic relationships and resolve internal clades (Ponder \& Lindberg, 2008; Simone, 2011). This study provides a thorough morphological description of the type species for the genus Fasciolaria, F. tulipa, from Venezuela, in order to provide supporting information for future comparative analyses.

\section{Material And Methods}

Material for this study is deposited in the Museu de Zoologia da Universidade de São Paulo (MZSP).

The specimens collected were fixed in $70 \%$ ethanol. Shells were measured with a caliper, and photographs of individuals were taken with a digital camera. The anatomical dissections were made with the aid of a stereomicroscope. All drawings were done using a camera lucida. Radulae were extracted manually and prepared by immersion in $\mathrm{KOH}$, followed by ultrasonic cleaning and rinsing in distilled water for SEM photography.

\section{Results}

Fasciolaria tulipa (Linnaeus, 1758)

(figs 1-30)

Murex tulipa Linnaeus, 1758: 754.

Colus achatinus Röding, 1798: 117.

Colus marmoratus Röding, 1798: 117.

Neptunea laevigata Link, 1807: 117-118.

Fasciolaria canaliculata Valenciennes, 1832: 286.

Fasciolaria tulipa var. concolor Kobelt, 1875: 362.

Fasciolaria tulipa var. rugosa Kobelt, 1875: 362.

Fasciolaria scheepmakeri Kobelt, 1875: 362.

Fasciolaria rugosa: Dall (1885:115).

Fasciolaria var. obsoleta Dall, 1890: 102.

Fasciolaria tulipa: Warmke \& Abbott, 1961: 119 (pl. 2d); Rios, 1970: 96; 1975: 102 (pl. 29, fig. 431); 1985: 106 (pl. 36, fig. 465); 1994: 131(pl. 42, fig. 564); 2009: 248; Abbott, 1974: 227-228 (fig. 2500); (Vokes \& Vokes, 1983: 26, (pl. 16, fig. 6); Bandel, 1984: 144, (pl. 17, figs 9, 10); Abbott \& Morris, 1995: 233 (pl. 56, fig. 1); Redfern, 2001: 101, (pl. 46, fig. 428A-B); Snyder, 2003: 211, 235; Mallard
\& Robin, 2005: 8 (pl. 2); Jensen \& Pearce, 2009: 143; Rosenberg, 2009; Tunnel et al., 2010: 221; Snyder et al., 2012: 40 (fig. 1).

Type locality Not given.

Type material Murex Tulipa P-Z 0010859. Linnean Society of London Collection, 3 specimens. Available online: http://linnean-online. org/17116/

Examined material HONDURAS; Roatan Island, $16^{\circ} 22^{\prime} 49.2^{\prime \prime} \mathrm{N}, \quad 86^{\circ} 24^{\prime} 39.6^{\prime \prime} \mathrm{W}$ (80-100m depth, Femorale col. iii/2006), MZSP 69277, 1 specimen. VENEZUELA; Marguerite Island, 1056'38.9”N, 6401'31.1”W, (L. R. Simone col.), MZSP 35530, 2 specimens; 1053'51.3"N, 6358'11.9”'W, (El Yaque, $2 \mathrm{~m}$ depth, Simone col. 28/i/1998), MZSP 56870, 2 specimens.

Geographic distribution North Carolina, USA; Caribbean islands; west coast of central America to Amapá state, Brazil.

Description Shell (figs 1-9) Elliptical and moderately fusiform, height up to $106 \mathrm{~mm}$, width usually less than $1 / 2$ of height. Colour chestnut to brown, with darker blotches. Spire moderately high, angle $55^{\circ}-65^{\circ}, \sim 2 / 5$ of total shell height. Protoconch small with $11 / 2$ whorls, sculptured with axial ribs in last $1 / 2$ whorl, terminal varix low. Teleoconch with 5-7 rounded whorls; suture slightly raised. Spiral sculpture of 17-27 main spiral cords, color dark brown, usually grouped in pairs, along entire teleoconch but usually obsolete in siphonal canal. Axial sculpture indistinct. Aperture elliptical, ample, height $\sim 3 x$ width. Columella bearing 3 folds medially, close to siphonal canal. Outer lip thin, marked internally by $45-50$ discontinuous lirae, crenulated by spiral sculpture and forming brownish sharp protuberances. Siphonal canal short, length $\sim 1 / 3$ of length of aperture. Siphonal fasciole indistinct. Pseudoumbilicus indistinct.

Head-foot (figs 15, 16) Colour cream in fixed species. Head prominent, of medium size, width $\sim 1 / 3$ of adjacent width of head-foot; cephalic tentacles blunt and medium-sized, length $\sim 2 / 3$ of anterior width of head, situated very close to each other; bases lying side by side. Eyes dark, small, rounded, situated in middle region of outer edge of tentacles. Foot short, rounded, anterior region 


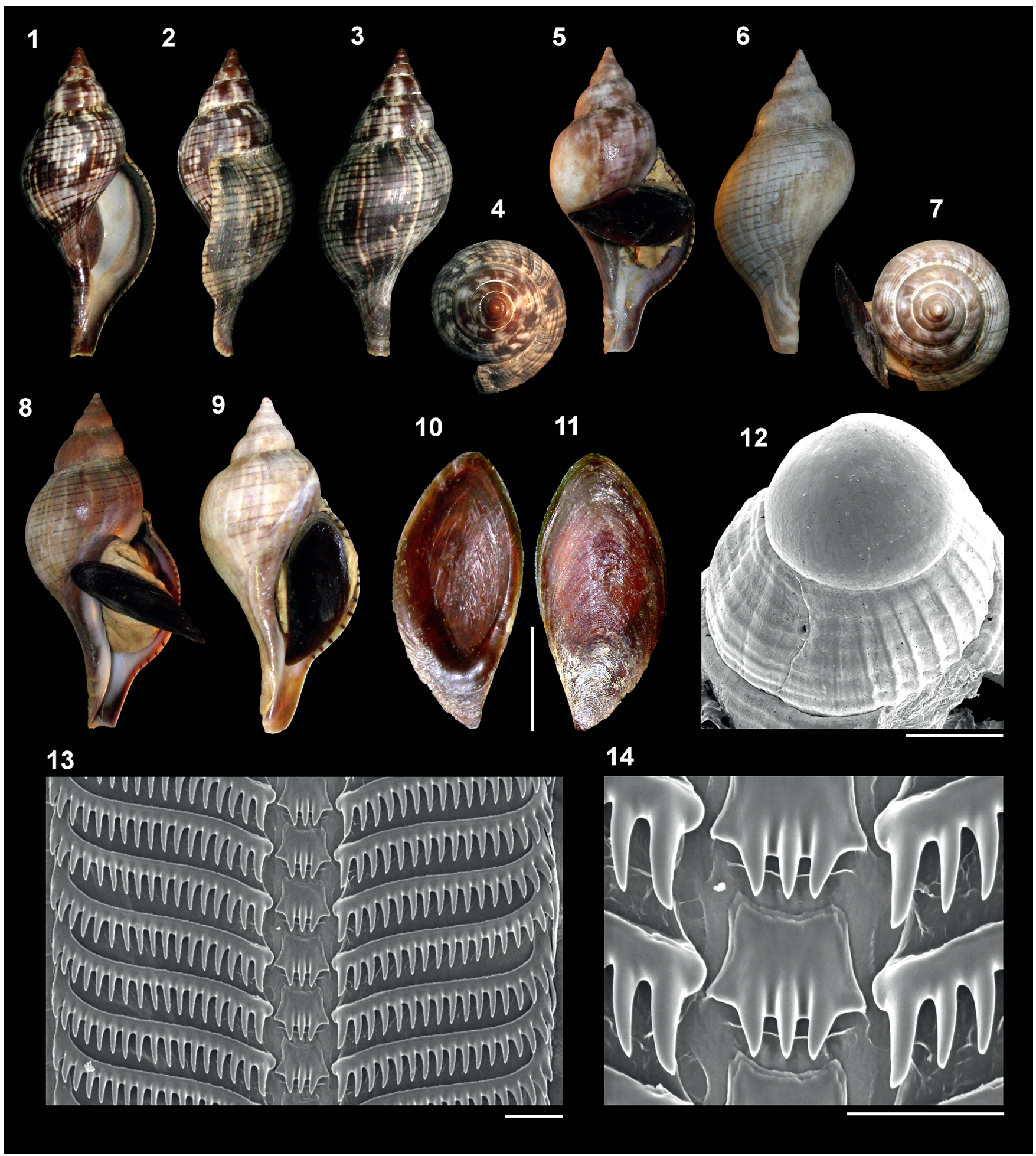

Figures 1-14 Fasciolaria tulipa. 1-4: 69,5mm (MZSP 69277); 5-7: 92,3mm (MZSP 56870); 8: 77,5mm (MZSP 35530); 9: 107,9mm (MZSP 35530); 10: operculum, internal view; 11: operculum, external view; 12: detail of protoconch, lateral view; 13: radula; 14: detail of rachidian tooth of radula. Scale bars: 10-11: 10mm; 12: 1mm; 13-14: 100 $10 \mathrm{~m}$.

bifid. Pedal gland as a shallow median anterior slit, with anterior furrow extending along entire anterior edge. Columellar muscle thick, $\sim 1$ 1/2 whorls in length.
Operculum (figs 10, 11) Corneous, unguiculated (width $\sim 2 / 3$ of length), filling entire aperture; outer surface opaque, with anterior nucleus; inner surface with attachment scar elongated, 
elliptical, situated posteriorly, occupying $~ 2 / 3$ of inner area.

Pallial complex (figs 17,18 ) Pallial cavity wide than longer, of $1 / 2$ whorl. Mantle border simple, thickened. Siphon short (length $\sim 1 / 4$ of free portion of mantle edge), its margin smooth; right fold of siphon base extending into pallial cavity, ending as a thickened transversal flap, close to anterior end of ctenidium and osphradium. Osphradium elongated, tapering posteriorly; length $\sim 2 / 3$ of ctenidium; almost symmetrical longitudinally; osphradium leaflets rounded, short (height $\sim 1 / 2$ of ctenidial filament height at middle region of pallial cavity), equal in size. Ctenidium curved, $\sim 1 / 3$ of total pallial cavity area, width $\sim$ twice than osphradium; anterior and posterior region pointed, posterior end situated close to pericardium; filaments triangular; ctenidial vein (efferent branchial vessel) uniformly narrow along its length. Hypobranchial gland thin, loosely fixed, situated in all the area between gill and rectum. Rectum elongated. Anus elliptical, situated at $\sim 1 / 3$ of mantle edge.

Circulatory and excretory systems (fig. 30) Pericardium ample, spanning $\sim 1 / 3$ of total renal cavity area. Auricle large, translucent, walls thin, posterior wall elongated ending close to renal aperture; ventricle large and rounded ( larger than auricle), rounded, with thick walls. Aorta bifurcating immediately after ventricle; posterior aorta following visceral mass close to stomach; anterior aorta crossing diaphragmatic septum anteriorly. Kidney small, $\sim 1 / 4$ whorl, bearing ventral and dorsal lamellar lobes similar in shape; nephridial gland prominent, situated on dorsal side of membrane between renal cavity and pericardium; renal aperture sub-circular, situated in membrane closer to pericardium, flanked by thick folds, longitudinal to roof of pallial cavity. Part of intestine running longitudinally on inner side of kidney, ventrally adhered to its membrane.

Digestive system (figs 19-28) Rhynchostome as ample transversal slit, located between and below cephalic tentacles, flanked by lip-like folds bearing longitudinal lamellae. Proboscis straight, of moderate length ( 2/3 of haemocoel length), with thick muscular walls bearing 2 lateral grooves; a single proboscis retractor muscles originating in ventral posterior wall of the proboscis; series of short lateral muscles fibers connected to inner walls of haemocoel. Mouth small, circular. Odontophore long, slender, same length as proboscis; pair of odontophore cartilages dorsally concave, fused anteriorly at $\sim 1 / 10$ of total cartilage length; series of transversal muscle fibers connecting odontophore tube with anterior esophagus; superficial circular muscles $\left(\mathrm{m}^{3}\right)$ enveloping entirely odontophore, except for most posterior end; horizontal muscle $\left(\mathrm{m}^{6}\right)$, originating on ventral surface of odontophore cartilages, except for most posterior region, $\sim 1 / 6$ of total odontophore length; pair of odontophore retractor muscles $\left(\mathrm{m}^{2}\right)$ originating from posterior end of odontophore cartilages, near to radular sac, inserted in inner wall of proboscis; pair of accessory odontophore retractor muscles $\left(m^{2} a\right)$, originating from inner surface of proboscis, near origin of $\mathrm{m}^{2}$, enveloping radular sac, a long branch of $\mathrm{m}^{2} \mathrm{a}$ accompanies anterior aorta posteriorly to nerve ring; pair of dorsal tensor muscles of radula $\left(\mathrm{m}^{4}\right)$ originating from posterior dorsal end of odontophore, covering its dorsal surface, inserting $\mathrm{m}^{2} \mathrm{a}$; pair of auxiliary dorsal tensor muscles of radula $\left(\mathrm{m}^{5}\right)$ originating from posterior end of odontophore, covering its ventral surface, inserting in $\mathrm{m}^{2} \mathrm{a}$; pair of ventral tensor muscles of radula $\left(\mathrm{m}^{11}\right)$, inserting anteriorly in sub-radular membrane, running, ventrally adhered $(\sim 2 / 3$ of total odontophore length), its origin bifid: main branch originating in ventral posterior cartilage of odontophore near origin of $\mathrm{m}^{2}$, secondary branch originating ventrally in $\mathrm{m}^{2} \mathrm{a}$, crossing $\mathrm{m}^{6}$ dorsally , connecting in main branch, at $\sim 2 / 3$ of total $\mathrm{m}^{11}$ length. Radula long and thin; radular sac extending to posterior end of odontophore; Radular teeth (figs 13, 14): rachidian tooth straight, trapezoidal, its base with concave outline, cusped margin convex, bearing 3 sharp cusps of equal size; lateral tooth wider than long, bearing 17-18 prominent, slightly centrally recurved cusps of approximately same size, central side of base rounded. Anterior esophagus moderately long and broad ( 2x proboscis length), dorsallyventrally compressed, originating in oral tube. Valve of Leiblein pyriform, forming orange ring around esophagus, of same width. Salivary glands just anterior to valve of Leiblein, forming pair of branching and amorphous masses; free portion of salivary ducts short, extending along esophagus, anteriorly to valve of Leiblein, becoming merged with esophageal wall, running 

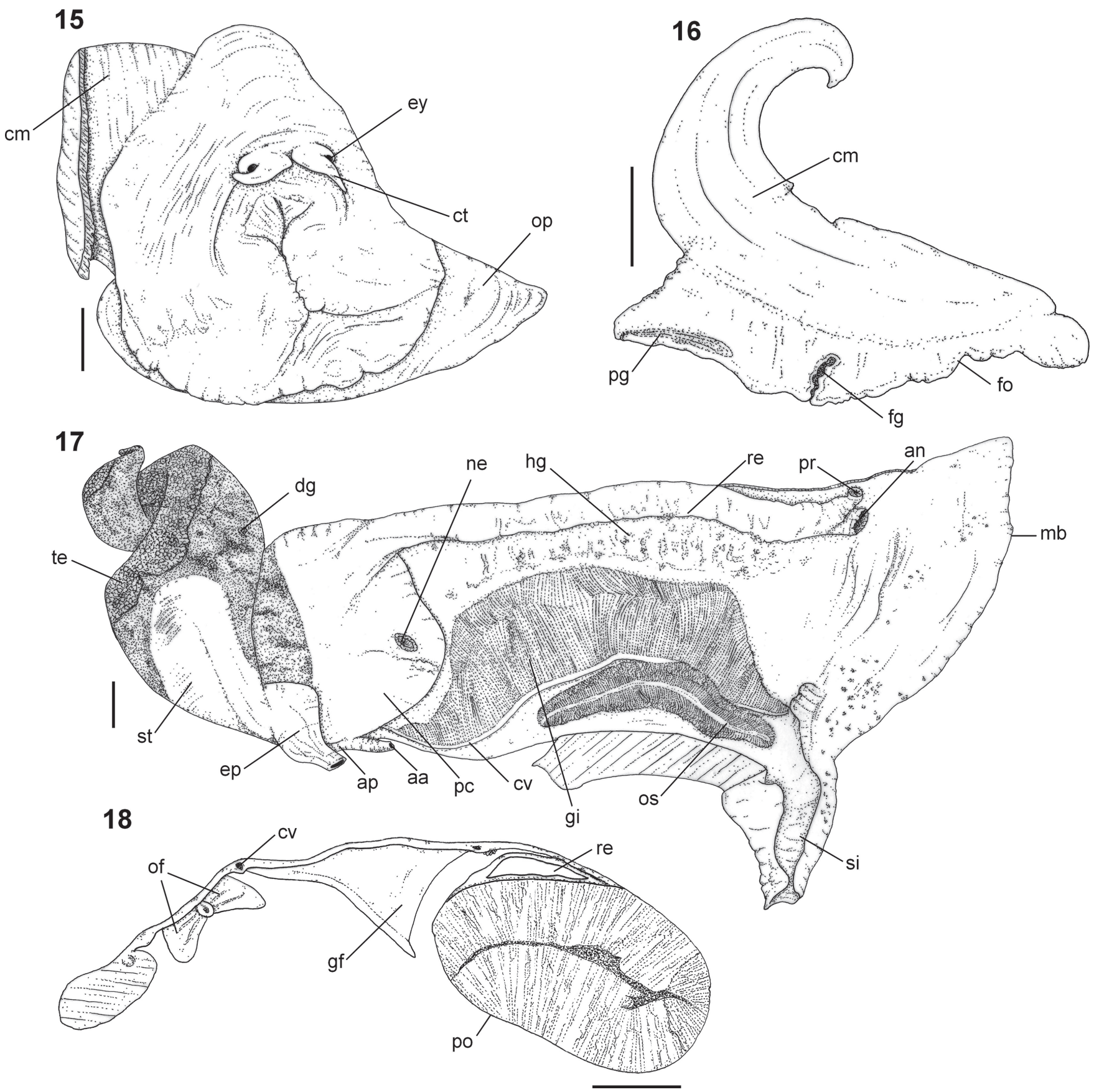

Figures 15-18 Fasciolaria tulipa. 15: head-foot mass in dorsal view; 16: longitudinal section of foot, female; 17: roof of pallial cavity in ventral view, male 18: transversal section of roof of pallial cavity, female. Abbreviations: aa, anterior aorta; an, anus; cm, columellar muscle; ct, cephalic tentacle; cv, ctenidial vein; dg, digestive gland; ep, posterior esophagus; ey, eye; fg, female cement gland; fo, foot; gf, gill filament; gi, gill; hg, hypobranchial gland; ki, kidney; mb, mantle border; ne, nephrostome; of, osphradium filament; op, operculum; os, osphradium; pc, pericardium; pe, penis; pg, pedal gland; po, pallial oviduct; pr, prostate; re, rectum; si, siphon; st, stomach; sv, seminal vesicle; te; testis. Scale bars: $4 \mathrm{~mm}$.

immersed anteriorly, opening in oral lumen, immediately before oral tube. Accessory salivary glands absent. Middle esophagus short. Duct of gland of Leiblein short and narrow, inserted posterior to nerve ring. Gland of Leiblein brownish, long, of same length as posterior esophagus, posterior end acute. Posterior and anterior esophagus of $\sim$ same width. Inner wall of anterior esophagus bearing many longitudinal folds, salivary ducts immersed in marked lateral folds. 


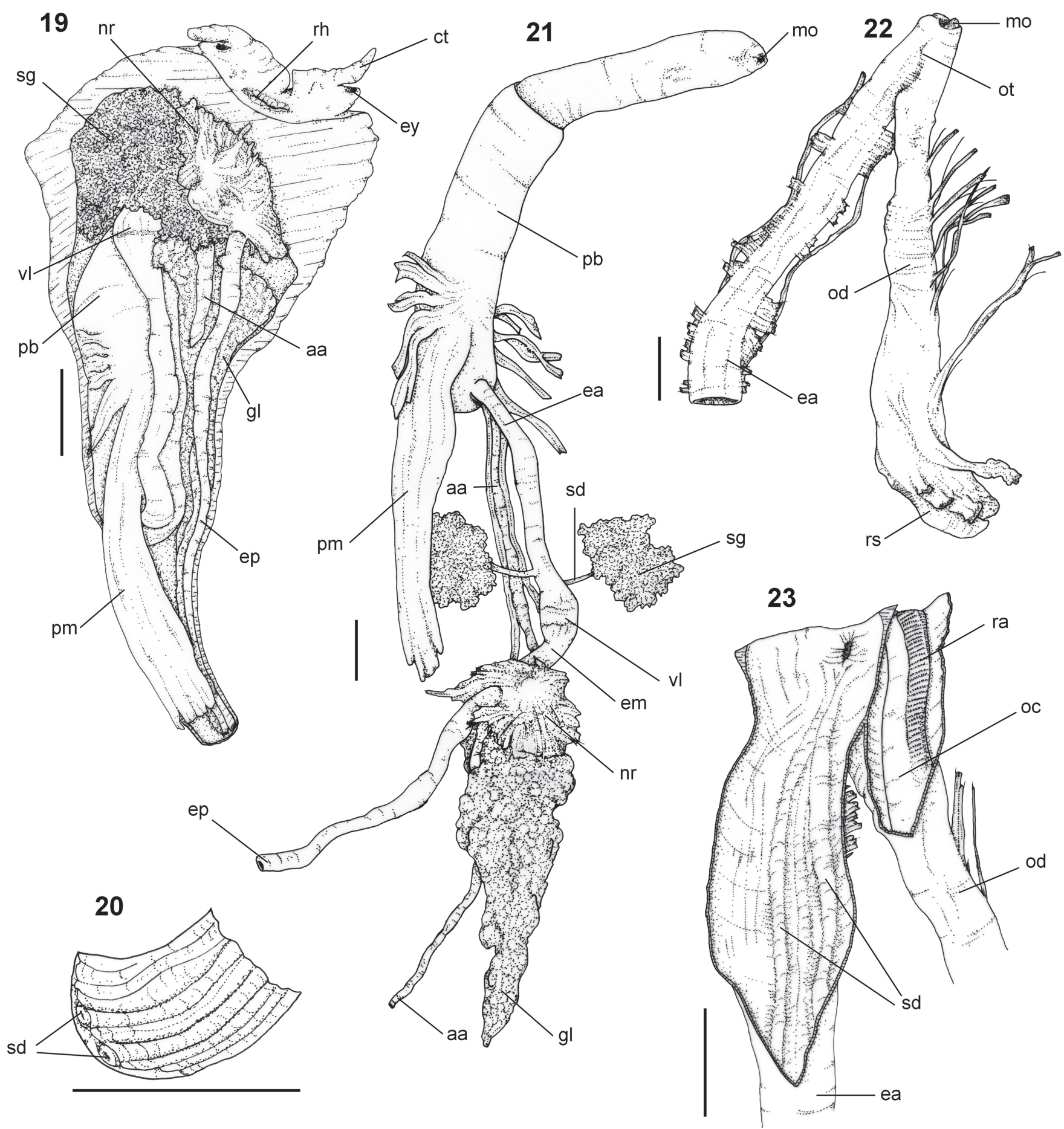

Figures 19-23 Fasciolaria tulipa. 19: hemocoel in ventral view; 20: longitudinal section of anterior esophagus; 21: anterior digestive system; 22: buccal mass in lateral view; 23: buccal mass in lateral view opened longitudinally. Abbreviations: aa, anterior aorta; ct, cephalic tentacle; ea, anterior esophagus; ep, posterior esophagus; ey, eye; gl, gland of leiblein; mo, mouth opening; $\mathbf{n r}$, nerve ring; oc, odontophore cartilage; od, odontophore tube; ot, oral tube; ra, radula; rh, rhynchostoma; rs, radular sac; sd, salivary gland duct; sg, salivary gland; vl, valve of leiblein. Scale bars: 19-20: 4mm; 21-23: $2 \mathrm{~mm}$.

Sudden broadening of posterior esophagus anteriorly to stomach. Stomach wide, walls thin, bearing many internal folds. Digestive gland dark-brown, occupying all whorls of visceral mass, from apex to kidney/pericardium area, surrounding stomach, emitting two narrow, branching ducts discharging near esophagus and intestine apertures. Intestine $\sim$ same width 
of posterior esophagus and rectum, with smooth lumen.

Male genital system (fig. 29) Testis cream colored, occupying all whorls of visceral mass; surrounding apically entire length of digestive gland. Visceral vas deferens running along testis. Seminal vesicle indistinct; vas deferens narrow, simple, running along ventral wall of kidney. Prostate thin and long, tubular, located along right side of roof of pallial cavity, next to rectum and of its equal width. Penis mediumsized, close to head-foot, circular in transverse section; penis becoming narrower at mid of its length, terminating in tip-like extension; duct of penis sinuous.

Female genital system (fig. 18) Ovaries brownish, with same texture and length as testis. Cement gland opening centrally on foot, forming somewhat elongated and deep sac of depth of $\sim 2 / 3$ of foot thickness. Pallial oviduct ample, occupying $~ 1 / 2$ of total pallial cavity area, covering part of ctenidium and renal aperture. Pallial oviduct glands not analyzed due to poor preservation.

\section{DisCUSSION}

The anatomy of the fasciolariid Fasciolaria tulipa is consistent with the framework within the Neogastropoda, as well as Buccinoidea, in lacking accessory salivary glands and an anal gland. The proboscis retractor as a single and powerful muscle, the multicuspidate lateral teeth of the radula, the stomach without a posterior sorting area (caecum), and the ducts of the salivary glands immersed in the esophagus wall confirm the species as a member of the Fasciolariidae in the context of Buccinoidea as diagnosed by Fraussen et al. (2007).

Snyder et al. (2012) noted that the distributions of both species of Fasciolariinae (F. tulipa and Aurantilaria aurantiaca) overlap in northern Brazil. Fasciolariinae have a free-swimming larval stage of up to six days, allowing some species to occur over a wide range, supposedly because the veligers gain access to floating objects and disperse to areas inaccessible to crawlers (Snyder et al., 2012). Juveniles of A. aurantiaca hatch from egg capsules attached to the bottom and crawl directly onto the surrounding substrate (Meirelles \& Matthews-Cascon, 2005); the protoconch morphology also indicates a direct mode of development. However, F. tulipa has a wide distribution and probably has a free-swimming larva during its development, albeit briefly (Leal, 1991), and its protoconch indicates this. The distinction of the Fasciolaria species from the West Atlantic is problematic (Lyons, 1972); Rosenberg (2009) argued for the occurrence of at least seven distinct species occurring in sympatry in the Caribbean Sea: Fasciolaria tulipa (Linnaeus, 1758); F. bullisi Lyons, 1972; F. hollisteri Weisbord, 1962; F. tephrina de Souza, 2002; F. branhamae Rehder \& Abbott, 1951; F. hunteria (G. Perry, 1811) and F. lilium G. Fischer, 1807. However, Snyder et al. (2012) recognized only the first four of these as belonging to this genus.

Shells of members of Fasciolariinae are morphologically similar to those of Peristerniinae: both groups are characterized by the presence of folds in the columella, with one fold marking the entrance to the siphonal canal, and an outer lip with lirae internally. The folds in Fasciolariinae, however, are orientated obliquely, whereas in Peristerniinae they are transverse (Snyder et al. 2012).

The central side of the base of the lateral tooth with a rounded outline is unique for Fasciolariinae. Bandel (1984) illustrated many fasciolariid radulae, with three species of Fasciolaria, including F. tulipa; all the radulae that he described agree with this pattern. All the cusps of the laterals are more or less equal in size, and the number of these is generally larger than in other fasciolariids (see Bandel, 1984, figs 257-268, for examples of radulae of Peristerniinae and Fusininae). The radula of Fasciolaria lignaria (Küster \& Kobelt, 1876; Kosyan et al., 2009) resembles that of many Latirus-like species in having a minute cusp on the inner side of the base of the lateral tooth, as well as fewer, shorter and more strongly curved cusps. Snyder et al. (2012) tentatively placed the species in the genus Tarantinae Monterosato (1917) (see also Gofas \& Bouchet, 2014), previously a subgenus of Fasciolaria, due to the presence of an adapical sinus on the outer lip. Moreover, this species was considered a member of Peristerniinae "pending molecular confirmation" by these same authors.

Two other features of the anterior digestive system are noteworthy for F. tulipa. The odontophore cartilages are fused anteriorly along only $10 \%$ of their length, less than in other fasciolariids: $30-40 \%$ in Leucozonia (Couto \& Pimenta, 2012) and $25 \%$ in Polygona. The posterior esophagus 

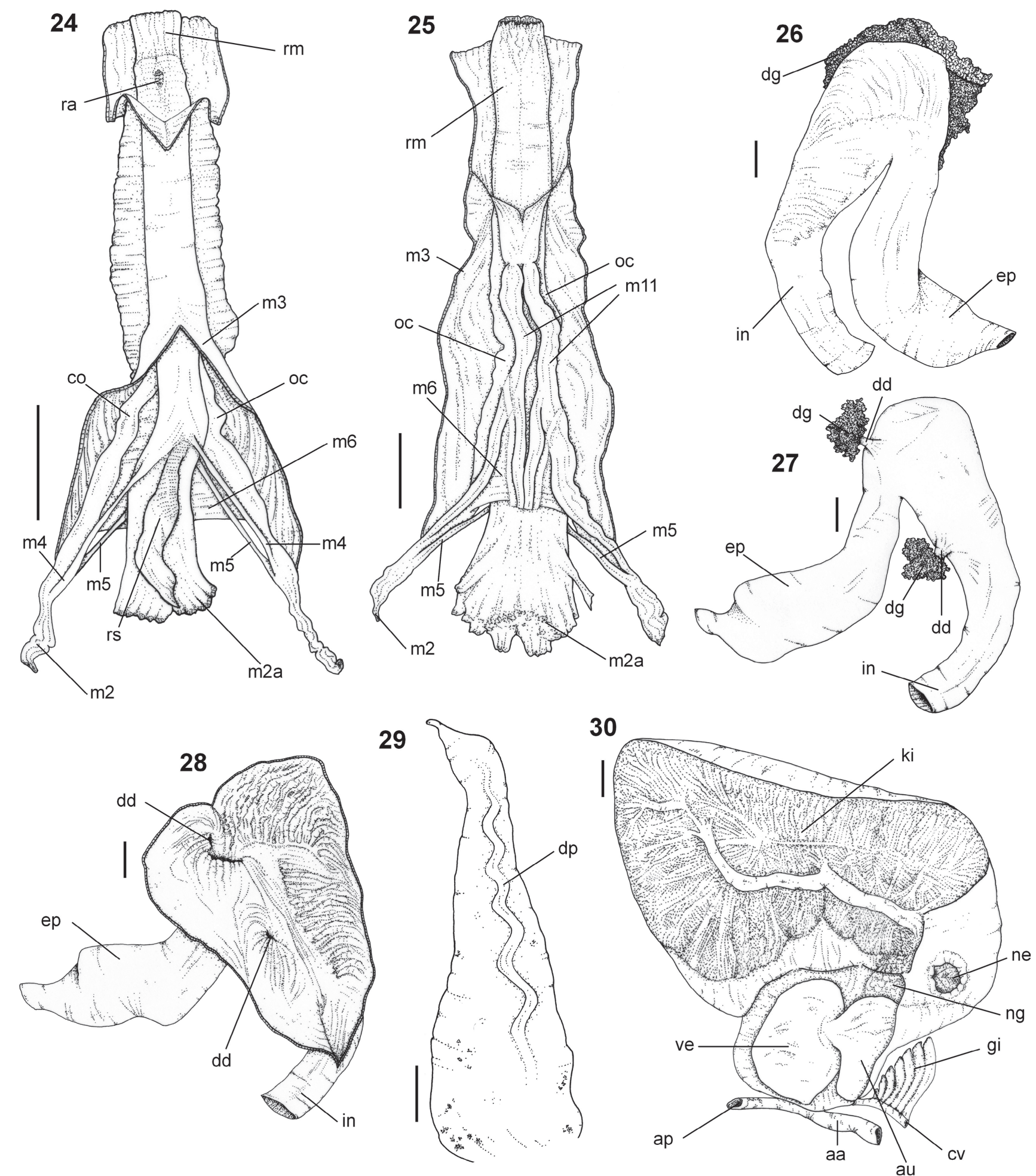

Figures 24-30 Fasciolaria tulipa. 24: odontophore in dorsal view; 25: odontophore in ventral view; 26: stomach in dorsal view; 27: stomach in ventral view; 28: stomach opened longitudinally; 29: penis in dorsal view; 30: renal cavity and pericardium opened ventrally. Abbreviations: aa, anterior aorta; ap, posterior aorta; au, auricle; $\mathbf{c v}$, ctenidial vein; dd, duct of digestve gland; dg, digestive gland; dp, duct of penis; ep, posterior esophagus; in, intestine; $\mathbf{k i}$, kidney; $\mathbf{m}^{11}$, ventral tensor muscles of radula; $\mathbf{m}^{2}$, odontophore retractor muscles; $\mathbf{m}^{2} \mathbf{a}$, accessory odontophore retractor muscles; $\mathbf{m}^{3}$, superficial circular muscles; $\mathbf{m}^{4}$, dorsal tensor muscles of radula; $\mathbf{m}^{5}$, auxiliary dorsal tensor muscles of radula; $\mathbf{m}^{6}$, horizontal muscle; ne, nephrostome; $\mathbf{n g}$, nephridial gland; oc, odontophore cartilage; pc, pericardium; ra, radula; re, rectum; rm, sub-radular membrane; rs, radular sac; ve, ventricle. Scale bars: $2 \mathrm{~mm}$. 
broadens anteriorly to the entrance of the stomach; this suggests a premature digestion in this part of the esophagus, although histological procedures are required to verify this statement.

As in many groups, the morphology of the anterior digestive and male reproductive systems is more informative for species-level taxonomy, and this is also true for Fasciolariidae (Fraussen et al. 2007; Kosyan et al. 2009; Couto \& Pimenta, 2012; Couto et al. 2015). The radula is especially important, as an easily preserved structure that distinguishes fairly well the families of Neogastropoda (Fraussen et al. 2007).

A renal aperture of F. tulipa is situated very close to the pericardium, instead of being located centrally in the membrane; this is not seen in any other fasciolariid (e.g., Marcus \& Marcus, 1962; Couto \& Pimenta 2012, Couto et al. submitted). This occurs together with two other unique features: a large auricle with thin, translucent walls, its posterior end elongated and terminating close to the renal aperture; and a very conspicuous nephridial gland. The posterior end of the auricle seems to be attached to the roof of the pericardium wall, hence the elongation of its wall; the nephridial gland is conspicuous, visible through the transparent wall between the pericardium and renal cavity. No other member of Fasciolariidae is so far known to present these features (Marcus \& Marcus, 1962; Couto \& Pimenta, 2012), whereas both occur in A aurantiaca (Couto, pers. obs.).

Fraussen et al. (2007) defined a diagnostic character for F. tulipa: the ducts of the salivary gland do not run free alongside the anterior esophagus, as they do in other fasciolariids (Marcus \& Marcus, 1962; Couto \& Pimenta, 2012; Fedosov \& Kantor, 2012), but are merged in its wall anteriorly to the valve of Leiblein. This feature was reported only for Latirus polygonus, among the fasciolariids examined by Kosyan et al. (2009).

An important diagnostic feature for the family sensu Fraussen et al. (2007) is the proboscis retractor as a single ventral-lateral muscle. All fasciolariids except Latirus polygonus and Fusinus tenerifensis have a single muscle, while in the buccinids, multiple fibers occur posteriorly to the proboscis, distinguishing the Fasciolariidae from the Buccinidae (Kosyan et al., 2009). Other studies that mention the proboscis retractor for Fasciolariidae agree on this (Marcus \& Marcus,
1962; Couto \& Pimenta, 2012; Fedosov \& Kantor, 2012; Couto et al., submitted).

Fasciolaria tulipa is the type species of the genus, so the study of its anatomy is fundamental in resolving species-level taxonomy, particularly because the subfamily Fasciolariinae has undergone a thorough taxonomic revision in recent years, albeit only conchologically (Snyder et al. 2012). A more detailed understanding of the morphology of soft-parts will be able to provide further data, and possibly help to define groups that are currently doubtful, as is the case for many Latirus- and Fusinus-like species. Moreover, knowledge of anatomical characters is imperative for phylogenetic analysis, as the relationships of most groups within the Buccinoidea, including family and genus level are still unknown. This analysis is in effect a permanent work in progress, of which the present study is a part.

\section{ACKNOWLeDgments}

The authors are grateful to Lara Guimarães for helping with the SEM. This work was funded in part by the Conselho de Desenvolvimento Científico e Tecnológico (CNPq) for a M.S. scholarship and Fundação de Amparo à Pesquisa do Estado de São Paulo (FAPESP) for a Ph.D scholarship.

\section{REFERENCES}

AввотT RT \& MORRIS PA 1995 A field guide to shells: Atlantic and Gulf Coasts and the West Indies. Houghton Mifflin Co. Boston, MA. 350p.

Aввотт RT 1974 American Seashells. second edition. Van Nostrand Reinhold Co, New York. 663p. 24pls.

BANDEL K 1984 The Radulae of Caribbean and other Mesogastropoda and Neogastropoda. Riiksmuseum van Natuurlijke Historie, 346p. 22pls.

Couto DR \& PimentA AD 2012 Comparative morphology of Leucozonia from Brazil (Neogastropoda: Buccinoidea: Fasciolariidae). American Malacological Bulletin 30(1): 103-116.

Couto DR, Simone LRL \& PimentA, AD 2015 Comparative anatomy of the fasciolariids Pustulatirus ogum and Hemipolygona beckyae from Brazil (Gastropoda: Buccinoidea: Peristerniinae). Scientia Marina, 79(1): 89-105.

DALL WH 1885 List of marine Mollusca comprising the Quaternary fossils and Recent forms from American localities between Cape Hatteras and Cape Roque including the Bermudas. Bulletin of the United States Geological Survey 24: 1-336.

DALL WH 1890 Contributions to the Tertiary fauna of Florida, with especial reference to the Miocene 
silex-beds of Tampa and the Pliocene beds of the Caloosahatchie River. Part I. Pulmonate, opisthobranchiate and orthodont gastropods. Transactions of the Wagner Free Institute of Science of Philadelphia 3: 1-200, 1-12pls.

Fedosov AE \& Kantor YI 2012 A new species and genus of enigmatic turriform Fasciolariidae from the Central Indo-Pacific (Gastropoda: Neogastropoda). Archiv für Molluskenkunde 141(2): 137-144.

FraUSSEN K, KANTOR Y \& HADORN R 2007 Amiantofusus gen. nov. for Fusus amiantus Dall, 1889 (Mollusca: Gastropoda: Fasciolariidae) with description of a new and extensive Indo-West Pacific radiation. Novapex 8(3-4): 79-101.

Gofas S \& BOUCHET P 2014 Tarantinaea lignaria (Linnaeus, 1758). Accessed through: World Register of Marine Species (WoRMS) on 201407-15 at http://www.marinespecies.org/aphia. php? $p=$ taxdetails\&id $=607879$.

GOFAS S 2014 Family Fasciolariidae Gray, 1853. Accessed through: World Register of Marine Species (WoRMS) on 2014-07-15 at http:/ / www.marinespecies.org/aphia.php? $\mathrm{p}=$ taxdetails\&id $=23038$.

JenSEN RH \& PEARCE TA 2009 Marine Mollusks of Bermuda: Checklist and Bibliography. Delaware Museum of Natural History: Wilmington, Delaware. 473p.

Kobelt W 1875 Catalog der Gattung Fasciolaria Lam. Jahrbücher der Deutschen Malakozoologischen Gesellschaft 2: 362-364.

Kosyan AR, Modica MV \& Oliverio M 2009 The anatomy and relationships of Troschelia (Neogastropoda, Buccinidae): new evidence for a closer fasciolariid-buccinid relationship? The Nautilus 123(3): 95-105.

KÜSTER HC \& KOBELT W 1844-1876 Die geschwäntzen unbewehrten Purpurschnecken. Erste Hälfte: Turbinella und Fasciolaria. - In: FHW Martini \& JH Chemnitz. Systematisches Conchylien-Cabinet, second edition (Küster HC) (3a): 1-164, 1-32pls, 9a, 9b, $13 b$.

LEAL JH 1991 Marine Prosobranch Gastropods from Oceanic Islands off Brazil. Backhuys/U.B.S. Oegstgeest, The Netherlands. 419p.

LINK DHF 1807 Beschreibung der naturalien-Sammlung der Universitar zu Rostock. Abtheilung 3: 101-165.

LINNAEUS C 1758 Systema Naturae per regna tria naturae, secundum classes, ordines, genera, species, cum characteribus, differentiis, synonymis, locis. Editio decima, reformata. Laurentius Salvius: Holmiae. ii, 824 p.

LYONS WG 1972 A New Fasciolaria from the Northeastern gulf of Mexico. The Nautilus 85(3): 96-99.

MALlaRd D \& Robin A 2005 Fasciolariidae. La Mother Achard, Les Sables-d'Olonne. 27p. 70pls.

Marcus E \& Marcus E 1962 On Leucozonia nassa. Boletim da faculdade de Filosofia Ciências e Letras da Universidade de São Paulo, Zoologaia 24: 1-30.

MattheWs-Cascon H, Matthews HR \& KotZian CB 1989 Os Gêneros Fasciolaria Lamarck, 1799 e Leucozonia Gray, 1847 no Nordeste Brasilieiro
(Mollusca: Gastropoda: Fasciolariidae). Memórias do Instituto Oswaldo Cruz 84, Supl. IV: 357-364.

Meirelles CAO \& Matthews-Cascon H 2005 Family Fasciolariidae Gray, 1853 Pleuroploca aurantiaca (Lamarck, 1816). 51-53, pl. 12 In: Matthews-Cascon $\mathrm{H}$, Rocha-Barreira CA \& Meirelles CAO. Egg Masses of Some Brazilian Mollusks. Expressão Gráfica e Editora, Fortaleza. 119p.

PONDER WF \& LindBERG DR 2008 Phylogeny and Evolution of the Mollusca. University of California Press, Berkeley. xi, 469p.

REDFERN C 2001 Bahamian Seashells: A Thousand Species from Abaco, Bahamas. Bahamian-seashells.com, Inc, Boca Raton, Florida. x, 280p, 124pls.

Rios EC 1970 Coastal Brazilian Seashells. Museu Oceanográfico de Rio Grande, Rio Grande. 255p. 60pls. 4 maps.

RIOS EC 1975 Brazilian Marine Mollusks Iconography. Museu Oceanográfico da FURG, Rio Grande, 331p. 91pls.

Rios EC 1985 Seashells of Brazil. Museu Oceanográfico, Fundação Univesidade do Rio Grande, Rio Grande, 328p.

Rios EC 1994 Seashells of Brazil. Museu Oceanográfico Prof. E. C. Rios, Fundação Universidade do Rio Grande, Rio Grande, 368p. 113pls.

RIOS EC 2009 Compendium of Brazilian Sea Shells. Museu Oceanográfico Prof. E. C. Rios, Fundação Universidade do Rio Grande, Rio Grande, 668p.

RöDING PF 1798 Museum Boltenianus sive Catalogus cimeliorum e tribus regnis naturae quae olim collegerat. Pars secunda continens Conchylia sive Testacea univalvia, bivalvia \& multivalvia. Hamburg, Johan Christi Trappii. viii, 199 p.

ROSENBERG G 2009 Malacolog 4.1.0: A Database of Western Atlantic Marine Mollusca [WWW database (version 4.1.0)] URL http:/ / www.malacolog.org/.

SIMONE LRL 2011 Phylogeny of the Caenogastropoda (Mollusca), Based on Comparative Morphology. Arquivos de Zoologia do Museu de Zoologia da Universidade de São Paulo, 42(2-4): 83-323.

SimONe LRL, CAVAlLaRi DC \& ABbate D 2013. Revision of the genus Teralatirus Coomans 1965in the Western Atlantic, with an anatomical description of T. roboreus (Reeve 1845) (Gastropoda: Neogastropoda: Fasciolariidae). Archiv für Molluskenkunde 142(2): 215-226.

SNYDER MA, VermeIJ GJ \& LYONS WG 2012 The genera and biogeography of Fasciolariinae (Gastropoda, Neogastropoda, Fasciolariidae). Basteria 76(1-3): 31-70.

SNYDER MA 2003 Catalogue of the marine gastropod family Fasciolariidae. Academy of Natural Sciences of Philadelphia Special Publications 21. Philadelphia. iv, 431p.

THIELE J 1929-1935 Handbuch der Systematischen Weichtierkunde. Gustav Fischer, Jena vol 1: vi, 778p. vol. 2: v, 779-1134p.

TRYON GW 1880 Manual of Conchology, Structural and Systematic, with Illustrations of the Species. Philiadelphia. 310p. 87pls. 
TunNEl JW, ANDrews J, BarRera NC \& MORETZSOHN F 2010 Encyclopedia of Texas Seashells - Identification, Ecology, Distribution \& History. Texas A\&M University Press. Corpus Christi. xi, 512p.

VALENCIENNES A 1832 Coquilles univalves marines de l'Amérique équinoxiale, recueillies pendant le voyage de MM de Humboldt et Bonpland: 262339. In Humboldt VA \& Bonplan A (eds) Recueil d'observations de zoologie et d'anatomie compar: faites dans l'ocn atlantique, dans l'intieur du nouveau continent et dans la mer du sud pendant les anns 1799, 1800,
1801, 1802 et 1803 , Deuxieme Volume, 352p pls $41-57$.

VOKES HE \& VOKES EH 1983 Distribution of ShallowWater Marine Mollusca, Yucatan Peninsula, Mexico. Middle American Research Institute, New Orleans 54: 183p. 50pls.

WARMKe GL \& Aввотt RT 1961 Caribbean Seashells: A Guide to Marine Mollusks of Puerto Rico and Other West Indian Islands. Bermuda and the Lower Florida Keys: Livingston Publishing Co., Narberth, Pennsylvania. xx, 348p. 44pls. 



\title{
A multilocus molecular phylogeny of Fasciolariidae (Neogastropoda: Buccinoidea)
}

\author{
Diogo R. Couto ${ }^{\mathrm{a}, \mathrm{b}, *}$, Philippe Bouchet ${ }^{\mathrm{c}}$, Yuri I. Kantor ${ }^{\mathrm{d}}$, Luiz R.L. Simone ${ }^{\mathrm{b}}$, Gonzalo Giribet ${ }^{\mathrm{a}}$ \\ ${ }^{a}$ Museum of Comparative Zoology, Department of Organismic and Evolutionary Biology, Harvard University, 26 Oxford Street, Cambridge, MA 02138, USA \\ ${ }^{\mathrm{b}}$ Laboratorio de Malacologia, Museu de Zoologia da Universidade de São Paulo, Avenida Nazaré 481, 04263-000 São Paulo, Brazil

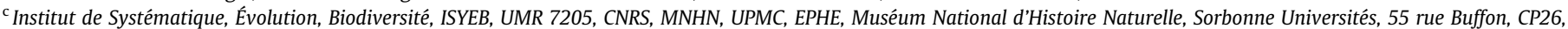 \\ F-75005 Paris, France \\ d 2A.N. Severtzov Institute of Ecology and Evolution, Russian Academy of Sciences, Leninski Prospect 33, Moscow 119071, Russia
}

\section{A R T I C L E I N F O}

\section{Article history:}

Received 5 November 2015

Revised 17 March 2016

Accepted 18 March 2016

Available online 23 March 2016

\section{Keywords:}

Fasciolariinae

Peristerniinae

Fusininae

Evolution

Dolicholatirus

Radula

\begin{abstract}
A B S T R A C T
The neogastropod family Fasciolariidae Gray, 1853 - tulips, horse-conchs, spindles, etc., comprises important representatives of tropical and subtropical molluscan assemblages, with over 500 species in the subfamilies Fasciolariinae Gray, 1853, Fusininae Wrigley, 1927 and Peristerniinae Tryon, 1880. Fasciolariids have had a rather complicated taxonomical history, with several genus names for a long time used as waste baskets to group many unrelated species; based on shell characters, recent taxonomic revisions have, however, began to set some order in its taxonomy. The present work is the first molecular approach to the phylogeny of Fasciolariidae based on a multigene dataset, which provides support for fasciolariids, an old group with a fossil record dating back to the Cretaceous. Molecular markers used were the mitochondrial genes $16 \mathrm{~S}$ rRNA and cytochrome $c$ oxidase subunit I, and the nuclear genes $18 \mathrm{~S}$ rRNA, 28S rRNA and histone H3, sequenced for up to 116 ingroup taxa and 17 outgroups. Phylogenetic analyses revealed monophyly of Dolicholatirus Bellardi, 1884 and Teralatirus Coomans, 1965, however it was not possible to discern if the group is the sister clade to the remaining fasciolariids; the latter, on the other hand, proved monophyletic and contained highly supported groups. A first split grouped fusinines and Pseudolatirus Bellardi, 1884; a second split grouped the peristerniine genera Peristernia Mörch, 1852 and Fusolatirus Kuroda and Habe, 1971, while the last group comprised fasciolariines and the remaining peristerniines. None of these clades correspond to the present-day accepted circumscription of the three recognized subfamilies.
\end{abstract}

(c) 2016 Elsevier Inc. All rights reserved.

\section{Introduction}

Neogastropoda, the most diverse caenogastropod mollusk clade, is supported by morphology-based phylogenetic analyses (Ponder and Lindberg, 1997; Strong, 2003) and by a Bayesian inference analysis of a combined morphological and molecular data (Ponder et al., 2008), but it has been challenged in several molecular studies (Harasewych et al., 1997; Colgan et al., 2000, 2003, 2007). In their complete mitochondrial genome and three nuclear-gene phylogeny, Osca et al. (2015) failed to recover Neogastropoda, and proposed the inclusion of Tonnoidea, or the exclusion of Cancellarioidea and possibly Volutidae from Neogastropoda. In the first case tonnoideans would have secondarily lost the traditional neogastropod synapomorphies, while in the latter

\footnotetext{
* Corresponding author at: Laboratorio de Malacologia, Museu de Zoologia da Universidade de São Paulo, Avenida Nazaré 481, 04263-000 São Paulo, Brazil.

E-mail address: diogoaut@gmail.com (D.R. Couto).
}

these synapomorphies would be considered homoplastic, in this sense agreeing with Kantor and Fedosov (2009). The superfamily Buccinoidea includes the families Buccinidae, Belomitridae, Busyconidae, Colubrariidae, Columbellidae, Nassariidae, Melongenidae and Fasciolariidae (Bouchet and Rocroi, 2005; WoRMS, 2016). They are considered highly derived in the Neogastropoda scheme due to the probable loss of the accessory salivary glands and the rectal glands.

Knowledge of the phylogenetic position of Fasciolariidae and of the families included in Buccinoidea is scant, and studies that deal specifically with the taxonomic position of these taxa are few. Hayashi (2005), utilizing sequences from the complete mitochondrial 16S rRNA gene, obtained a phylogeny based on 22 buccinoid species; Kosyan et al. (2009) used 20 species of buccinoids from partial 16S rRNA sequence data; finally, Oliverio and Modica (2010), analyzed 16S rRNA data from 30 buccinoids. All these analyses failed to recover Buccinidae as monophyletic due to the 
intercalation of Nassariidae and/or Fasciolariidae. There are no phylogenetic hypotheses that deal specifically with the family Fasciolariidae, based either on morphological or molecular characters, and the studies that do include some fasciolariid species (e.g., Hayashi, 2005; Kosyan et al., 2009; Zou et al., 2011) lack the resolution and coverage to clarify their relationships or to test their monophyly, as the family may potentially comprise multiple paraphyletic groups (Fedosov and Kantor, 2012).

Fasciolariidae, Melongenidae, Cancellariidae and Buccinidae date back to the early Cretaceous (Valanginian, 140 Mya) (Tracey et al., 1993), whereas other neogastropod families appeared between the late Cretaceous to early Paleogene, suggesting that the former families represent the first offshoots of Neogastropoda (Hayashi, 2005). While Fasciolariinae appeared during the Albian (Bandel, 1993), the fossil record indicates that the family - especially Fasciolariinae and Peristerniinae (Vermeij and Snyder, 2006) - diversified extensively during the early Neogene (Aquitanian, 24 Mya).

With 541 extant species in 51 genera worldwide (WoRMS, 2016), Fasciolariidae are a diverse element of the molluscan predatory fauna in shallow to deep coastal waters, especially on soft bottoms. Fasciolariids are gonochoristic with internal fertilization and, usually, direct development (Leal, 1991). They inhabit depths down to $1900 \mathrm{~m}$ (Callomon and Snyder, 2009) where they prey on sedentary polychaetes, bivalves, cirripedes and other gastropods (Taylor et al., 1980). The family is currently comprised of three subfamilies: Peristerniinae, which includes, among other genera, Peristernia and Latirus; Fusininae, the spindles; and Fasciolariinae with the conspicuous and well-known tulips and horse-conchs. For a long time, the name 'Fusus' has been used indiscriminately for numerous Cretaceous, Cenozoic and Recent spindle-shaped shells (Snyder, 2003), and likewise Latirus, Fasciolaria and Pleuroploca were also used for evidently heterogeneous assemblages. More recently, however, the group has undergone extensive taxonomical revision (e.g., Vermeij and Snyder, 2002, 2006; Snyder et al., 2012; Lyons and Snyder, 2013), elevating several subgenera to genus rank and establishing new genera.

Sampling of multiple independently evolving genes is recommended to produce a resolved and strongly supported phylogeny avoiding issues of incongruence among single gene analyses. The use of such a multi-gene molecular approach has helped resolve problems in different molluscan clades (e.g., Puillandre et al., 2011; Aktipis and Giribet, 2010; Tëmkin, 2010; Sharma et al., 2013). The present study aims to improve the phylogenetic understanding of the Fasciolariidae and investigate the diversification patterns of its members by conducting multi-gene phylogenetic analyses.

\section{Material and methods}

\subsection{Taxon sampling}

The present study is largely based on material vouchered in MNHN, collected during multiple expeditions conducted by MNHN and IRD, and other ad hoc fieldwork (see Acknowledgements). Before 2012, specimens were treated with an isotonic solution of magnesium chloride until relaxed (showing no response to touch), and then a tissue clip was cut. Starting from early 2012, specimens were processed using a microwave oven (Galindo et al., 2014), i.e., in most cases the entire body, or at least the last 1-1.5 whorls, were available for study. Tissue samples were preserved in $96 \%$ EtOH. Additional specimens were used from the following institutions: Academy of Natural Sciences of Philadelphia (ANSP); Florida Museum of Natural History (FMNH); Museum of Comparative Zoology, Harvard University, Cambridge, MA (MCZ); Museum of Zoology, University of São Paulo (MZSP); and Santa Barbara
Museum of Natural History (SBMNH). Some museum specimens were preserved in $70 \% \mathrm{EtOH}$. In total 116 specimens of Fasciolariidae were sequenced. The 116 ingroup taxa sampled consist of 10 Fasciolariinae, 67 Peristerniinae and 39 Fusininae. Outgroup taxa for the study consisted of 11 Buccinoidea, 2 Conoidea, 2 Muricoidea and 2 Cypraeoidea. The list of specimens, including collection voucher numbers, GenBank accession codes and collection details is found in Table 1.

\subsection{Molecular methods}

Total DNA was extracted from foot tissue using Qiagen's DNeasy tissue kit (Qiagen, Valencia, CA, USA). Molecular markers consisted of 2 nuclear ribosomal genes (18S rRNA and 28S rRNA), a mitochondrial ribosomal gene (16S rRNA), a mitochondrial proteinencoding gene (cytochrome $c$ oxidase subunit I [COI]) and one nuclear protein-encoding gene (histone H3) Primer sequences are listed in Table 2. Purified genomic DNA was used as a template for polymerase chain reaction (PCR) amplification.

Polymerase chain reactions (PCR) were performed on a Mastercycler Pro ${ }^{\circledR}$ Eppendorf (Hamburg, Germany) in a $25 \mu \mathrm{L}$ volume reaction, and consisted of $1 \mu \mathrm{L}$ of template DNA, $1 \mu \mathrm{M}$ of each primer, $200 \mu \mathrm{M}$ of deoxynucleotide triphosphates (dNTP's; Invitrogen, Carlsbad, CA, USA), 1X PCR buffer containing $1.5 \mathrm{mM} \mathrm{MgCl}$ (Promega, Madison, WI, USA) and 1.25 units of GoTaq DNA polymerase (Promega). The fragments were amplified under the following conditions: initial denaturing at $95^{\circ} \mathrm{C}$ for $15 \mathrm{~min}, 40$ cycles of $94{ }^{\circ} \mathrm{C}$ for $30 \mathrm{~s}, 43-64{ }^{\circ} \mathrm{C}$ (annealing temperatures, Table 2) for $70 \mathrm{~s}$ and $72{ }^{\circ} \mathrm{C}$ for $90 \mathrm{~s}$, and final extension step at $72{ }^{\circ} \mathrm{C}$ for $10 \mathrm{~min}$. Numerous PCR additives were utilized in order to optimize DNA amplification, including BSA (Bovine serum albumin) and DMSO (Dimethyl sulfoxide). BSA was utilized with different optimal concentrations per template $(0.8-5.6 \mu \mathrm{g} / \mathrm{mL})$. It exerts its effect through interacting with interfering substances and also stabilizing Taq DNA polymerase (Nagai et al., 1998). DMSO was used with a final concentration of $5 \%$ to reduce secondary structures that could inhibit the progress of the polymerase, being especially useful for GC-rich templates (Meyer et al., 2010).

Double-stranded PCR products were visualized by agarose gel electrophoresis (1\% agarose) and purified using $2 \mu \mathrm{L}$ of diluted (1:2) ExoSAP-IT (Affymetrix, Santa Clara, CA, USA) in a volume of $25 \mu \mathrm{L}$ PCR product and incubated at $37{ }^{\circ} \mathrm{C}$ for 20 min followed by enzyme inactivation at $80^{\circ} \mathrm{C}$ for $15 \mathrm{~min}$. Sequencing reactions were performed in a $10 \mu \mathrm{L}$ reaction volume with Big-Dye Terminator v.3.1 (Applied Biosystems, Foster City, CA, USA) following the manufacturer's instructions. using the thermal cycler described above, with an initial denaturation step for $3 \mathrm{~min}$ at $94{ }^{\circ} \mathrm{C}$ and 25 cycles of $94{ }^{\circ} \mathrm{C}$ for $10 \mathrm{~s}, 50^{\circ} \mathrm{C}$ for $5 \mathrm{~s}$ and $60^{\circ} \mathrm{C}$ for $4 \mathrm{~min}$.

Sequenced products were purified using Sephadex (Amersham Biosciences) and sequenced on an ABI Prism 3730 Genetic Analyzer (Applied Biosystems). Chromatograms obtained were visualized and edited in Geneious v.8.1.2 (http://www.geneious.com, Kearse et al., 2012). All new sequences have been deposited in GenBank under accession numbers KT753546-KT754145. The 5 genes were analyzed as follows:

18S rRNA: The complete gene was amplified with three overlapping markers $(a, b, c)$. In the present study we include 116 ingroup specimens plus 17 outgroups, for a total of $1777-1787$ bp per complete sequence. From the 116 ingroup sequences, all but 3 were complete.

28S rRNA: A $2.2 \mathrm{~Kb}$ fragment of the gene was amplified with three overlapping markers $(a, b, c)$, as described in Giribet and Shear (2010). The dataset includes 115 ingroup specimens plus 17 outgroups, for a total of 2085-2139 bp, showing considerable length variation in 28S rRNA. Fragment $a$ was sequenced for 115 
Table 1

List of species sampled and gene fragments included in phylogenetic analyses with GenBank accession numbers. Outgroup species appear in bold.

\begin{tabular}{|c|c|c|c|c|c|c|c|c|c|}
\hline Taxon & & & Voucher \# & Locality & 18S rRNA & 28S rRNA & 16S rRNA & $\mathrm{COI}$ & H3 \\
\hline Amiantofusus candoris & $\mathrm{Bu}$ & $\mathrm{f}$ & MNHN IM-2013-19759 & Bismarck Sea & KT753546 & KT753679 & KT753807 & KT753912 & KT754043 \\
\hline Amiantofusus pacificus & $\mathrm{Bu}$ & $\mathrm{f}$ & MNHN IM-2009-13533 & New Caledonia & KT753552 & KT753685 & KT753812 & KT753918 & KT754049 \\
\hline Amiantofusus pacificus & $\mathrm{Bu}$ & $\mathrm{f}$ & MNHN IM-2013-44400 & Taiwan & KT753581 & KT753714 & KT753837 & KT753947 & KT754078 \\
\hline Amiantofusus sebalis & $\mathrm{Bu}$ & $\mathrm{f}$ & MNHN IM-2007-32837 & Solomon Islands & KT753545 & KT753678 & - & KT753911 & KT754042 \\
\hline Amiantofusus sebalis & $\mathrm{Bu}$ & $\mathrm{f}$ & MNHN IM-2013-44196 & Taiwan & KT753592 & КT753725 & KT753846 & KT753958 & KT754089 \\
\hline Angulofusus nedae & $\mathrm{Bu}$ & $\mathrm{f}$ & MNHN IM-2007-32574 & Vanuatu & KT753618 & KT753751 & - & KT753984 & KT754114 \\
\hline Aurantilaria aurantiaca & $\mathrm{Bu}$ & $\mathrm{f}$ & MZSP 101904 & northeast Brazil & KT753649 & KT753782 & KT753888 & KT754013 & KT754143 \\
\hline Australaria australasia & $\mathrm{Bu}$ & $\mathrm{f}$ & MNHN IM-2013-42516 & Western Australia & KT753624 & KT753757 & KT753875 & KT753990 & KT754120 \\
\hline Benimakia fastigium & $\mathrm{Bu}$ & $\mathrm{f}$ & FMNH UF-369083 & Vanuatu & KT753645 & KT753778 & - & KT754010 & KT754139 \\
\hline Benimakia lanceolata & $\mathrm{Bu}$ & $\mathrm{f}$ & MNHN IM-2013-11873 & Papua New Guinea & KT753593 & KT753726 & KT753847 & KT753959 & KT754090 \\
\hline Chryseofusus acherusius & $\mathrm{Bu}$ & $\mathrm{f}$ & MNHN IM-2013-44302 & Taiwan & KT753590 & KT753723 & KT753844 & KT753956 & KT754087 \\
\hline Chryseofusus bradneri & $\mathrm{Bu}$ & $\mathrm{f}$ & MNHN IM-2007-32977 & New Caledonia & KT753577 & KT753710 & KT753833 & KT753943 & KT754074 \\
\hline Chryseofusus graciliformis & $\mathrm{Bu}$ & $\mathrm{f}$ & MNHN IM-2007-32797 & Solomon Islands & KT753582 & КT753715 & KT753838 & KT753948 & KT754079 \\
\hline Chryseofusus graciliformis & $\mathrm{Bu}$ & $\mathrm{f}$ & MNHN IM-2013-19938 & Solomon Sea & KT753597 & KT753730 & KT753851 & KT753963 & KT754094 \\
\hline Cinctura hunteria & $\mathrm{Bu}$ & $\mathrm{f}$ & MCZ 382637 & Florida & KT753646 & KT753779 & KT753887 & KT754011 & KT754140 \\
\hline Cyrtulus serotinus & $\mathrm{Bu}$ & $\mathrm{f}$ & MNHN IM-2013-42532 & Marchesas Islands & KT753603 & KT753736 & KT753857 & KT753969 & KT754099 \\
\hline Dolicholatirus aff. cayohuesonicus & $\mathrm{Bu}$ & $\mathrm{f}$ & MNHN IM-2013-7917 & Guadeloupe & KT753540 & KT753673 & KT753802 & KT753907 & KT754037 \\
\hline Dolicholatirus aff. cayohuesonicus & $\mathrm{Bu}$ & $\mathrm{f}$ & MNHN IM-2013-20291 & Guadeloupe & KT753550 & KT753683 & KT753810 & KT753916 & KT754047 \\
\hline Dolicholatirus aff. spiceri & $\mathrm{Bu}$ & $\mathrm{f}$ & MNHN IM-2013-42519 & Western Australia & KT753564 & KT753697 & - & KT753930 & KT754061 \\
\hline Dolicholatirus lancea & $\mathrm{Bu}$ & $\mathrm{f}$ & MNHN IM-2013-16640 & Papua New Guinea & KT753572 & KT753705 & KT753828 & KT753938 & KT754069 \\
\hline Dolicholatirus sp. & $\mathrm{Bu}$ & $\mathrm{f}$ & MNHN IM-2009-29739 & Western Australia & KT753541 & КT753674 & KT753803 & - & KT754038 \\
\hline Dolicholatirus spiceri & $\mathrm{Bu}$ & f & MNHN IM-2013-42515 & Western Australia & KT753570 & KT753703 & KT753826 & KT753936 & KT754067 \\
\hline Fasciolaria bullisi & $\mathrm{Bu}$ & $\mathrm{f}$ & FMNH UF-351146 & Florida & KT753622 & KT753755 & KT753874 & KT753988 & KT754118 \\
\hline Fasciolaria sp. & $\mathrm{Bu}$ & $\mathrm{f}$ & MNHN IM-2013-55965 & French Guyane & KT753626 & KT753759 & KT753876 & KT753992 & KT754122 \\
\hline Fasciolaria tulipa & $\mathrm{Bu}$ & $\mathrm{f}$ & MNHN IM-2013-19559 & Guadeloupe & KT753588 & КT753721 & KT753842 & KT753954 & KT754085 \\
\hline Filifusus filamentosus & $\mathrm{Bu}$ & $\mathrm{f}$ & MNHN IM-2013-13107 & Papua New Guinea & KT753543 & KT753676 & KT753805 & KT753909 & KT754040 \\
\hline Fusinus agatha & $\mathrm{Bu}$ & $\mathrm{f}$ & MZSP 53680 & northeast Brazil & KT753627 & КТ753760 & - & КT753993 & - \\
\hline Fusinus australis & $\mathrm{Bu}$ & $\mathrm{f}$ & MNHN IM-2013-42512 & Western Australia & KT753557 & KT753690 & KT753816 & KT753923 & KT754054 \\
\hline Fusinus brasiliensis & $\mathrm{Bu}$ & $\mathrm{f}$ & MZSP 117595 & southeast Brazil & KT753620 & КT753753 & KT753872 & KT753986 & KT754116 \\
\hline Fusinus brasiliensis & $\mathrm{Bu}$ & $\mathrm{f}$ & MZSP 108889 & southeast Brazil & KT753640 & KT753773 & KT753882 & KT754005 & KT754134 \\
\hline Fusinus colus & $\mathrm{Bu}$ & $\mathrm{f}$ & MNHN IM-2007-32560 & New Caledonia & KT753533 & KT753666 & KT753796 & KT753901 & KT754030 \\
\hline Fusinus crassiplicatus & $\mathrm{Bu}$ & $\mathrm{f}$ & MNHN IM-2007-34663 & New Caledonia & KT753551 & KT753684 & KT753811 & KT753917 & KT754048 \\
\hline Fusinus excavatus & $\mathrm{Bu}$ & $\mathrm{f}$ & ANSP A21957 & Barbados & KT753634 & KT753767 & KT753879 & KT754000 & KT754129 \\
\hline Fusinus filosus & $\mathrm{Bu}$ & $\mathrm{f}$ & MNHN IM-2013-42523 & Congo & KT753553 & KT753686 & - & KT753919 & KT754050 \\
\hline Fusinus forceps & $\mathrm{Bu}$ & $\mathrm{f}$ & MNHN IM-2007-38235 & Madagascar & KT753574 & KT753707 & KT753830 & KT753940 & KT754071 \\
\hline Fusinus gracillimus & $\mathrm{Bu}$ & $\mathrm{f}$ & MNHN IM-2013-42521 & Mozambique & KT753558 & KT753691 & KT753817 & KT753924 & KT754055 \\
\hline Fusinus longissimus & $\mathrm{Bu}$ & $\mathrm{f}$ & MNHN IM-2007-32535 & Philippines & KT753534 & KT753667 & - & - & KT754031 \\
\hline Fusinus mauiensis & $\mathrm{Bu}$ & $\mathrm{f}$ & FMNH 413989 & Hawaii & KT753621 & KT753754 & KT753873 & KT753987 & KT754117 \\
\hline Fusinus pulchellus & $\mathrm{Bu}$ & $\mathrm{f}$ & MCZ 378473 & France & KT753630 & KT753763 & - & KT753996 & KT754125 \\
\hline Fusinus salisburyi & $\mathrm{Bu}$ & $\mathrm{f}$ & MNHN IM-2007-32588 & New Caledonia & KT753609 & KT753742 & KT753863 & KT753975 & KT754105 \\
\hline Fusinus sandvichensis & $\mathrm{Bu}$ & $\mathrm{f}$ & FMNH UF-414048 & Hawaii & KT753637 & KT753770 & - & KT754002 & KT754131 \\
\hline Fusinus sandvichensis & $\mathrm{Bu}$ & $\mathrm{f}$ & FMNH 414020 & Hawaii & KT753644 & KT753777 & KT753886 & KT754009 & KT754138 \\
\hline Fusinus similis & $\mathrm{Bu}$ & $\mathrm{f}$ & ANSP A20012/411168 & Japan & KT753652 & KT753785 & KT753890 & KT754016 & KT754146 \\
\hline Fusinus syracusanus & $\mathrm{Bu}$ & $\mathrm{f}$ & MNHN IM-2013-32440 & Tunisia & KT753602 & КT753735 & KT753856 & КT753968 & KT754098 \\
\hline Fusinus virginiae & $\mathrm{Bu}$ & $\mathrm{f}$ & MNHN IM-2007-36654 & Madagascar & KT753578 & KT753711 & KT753834 & KT753944 & KT754075 \\
\hline Fusolatirus bruijnii & $\mathrm{Bu}$ & $\mathrm{f}$ & MNHN IM-2013-16671 & Papua New Guinea & KT753538 & KT753671 & KT753800 & KT753905 & KT754035 \\
\hline Fusolatirus bruijnii & $\mathrm{Bu}$ & $\mathrm{f}$ & MNHN IM-2013-18013 & Papua New Guinea & KT753613 & KT753746 & KT753867 & KT753979 & KT754109 \\
\hline Fusolatirus pachyus & $\mathrm{Bu}$ & $\mathrm{f}$ & MNHN IM-2007-35084 & New Caledonia & KT753595 & KT753728 & KT753849 & KT753961 & KT754092 \\
\hline Fusolatirus pearsoni & $\mathrm{Bu}$ & $\mathrm{f}$ & MNHN IM-2007-32495 & Vanuatu & KT753555 & KT753688 & KT753814 & KT753921 & KT754052 \\
\hline Fusolatirus rikae & $\mathrm{Bu}$ & $\mathrm{f}$ & MNHN IM-2007-32498 & Vanuatu & KT753610 & KT753743 & KT753864 & KT753976 & KT754106 \\
\hline Fusolatirus sp. & $\mathrm{Bu}$ & $\mathrm{f}$ & MNHN IM-2007-38359 & Madagascar & KT753573 & KT753706 & KT753829 & KT753939 & KT754070 \\
\hline Fusolatirus sp. & $\mathrm{Bu}$ & $\mathrm{f}$ & MNHN IM-2007-32508 & Vanuatu & KT753616 & KT753749 & KT753870 & KT753982 & KT754112 \\
\hline Granulifusus aff. kiranus & $\mathrm{Bu}$ & $\mathrm{f}$ & MNHN IM-2013-19037 & Bismarck Sea & KT753600 & KT753733 & KT753854 & KT753966 & KT754096 \\
\hline Granulifusus aff. niponicus & $\mathrm{Bu}$ & $\mathrm{f}$ & MNHN IM-2007-32823 & New Caledonia & KT753584 & KT753717 & - & KT753950 & KT754081 \\
\hline Granulifusus bacciballus & $\mathrm{Bu}$ & $\mathrm{f}$ & MNHN IM-2007-35089 & New Caledonia & KT753563 & KT753696 & KT753822 & KT753929 & KT754060 \\
\hline Granulifusus benjamini & $\mathrm{Bu}$ & $\mathrm{f}$ & MNHN IM-2007-32816 & New Caledonia & KT753566 & KT753699 & - & KT753932 & KT754063 \\
\hline Granulifusus hayashi & $\mathrm{Bu}$ & $\mathrm{f}$ & MNHN IM-2013-19210 & Bismarck Sea & KT753589 & KT753722 & KT753843 & KT753955 & KT754086 \\
\hline Granulifusus niponicus & $\mathrm{Bu}$ & $\mathrm{f}$ & MNHN IM-2013-19903 & Solomon Sea & KT753569 & KT753702 & - & KT753935 & KT754066 \\
\hline Granulifusus sp. & $\mathrm{Bu}$ & $\mathrm{f}$ & MNHN IM-2013-19724 & Bismarck Sea & KT753556 & KT753689 & KT753815 & KT753922 & KT754053 \\
\hline Granulifusus sp. & $\mathrm{Bu}$ & $\mathrm{f}$ & MNHN IM-2009-6658 & Solomon Islands & KT753561 & KT753694 & KT753820 & KT753927 & KT754058 \\
\hline Granulifusus staminatus & $\mathrm{Bu}$ & f & MNHN IM-2007-32750 & Philippines & KT753607 & KT753740 & KT753861 & KT753973 & KT754103 \\
\hline Hemipolygona armata & $\mathrm{Bu}$ & $\mathrm{f}$ & MNHN IM-2013-42511 & Senegal & KT753608 & КT753741 & KT753862 & КT753974 & KT754104 \\
\hline Hemipolygona mcgintyi & $\mathrm{Bu}$ & $\mathrm{f}$ & MZSP 36166 & Florida USA & KT753659 & KT753792 & - & KT754023 & KT754152 \\
\hline Lamellilatirus lamyi & $\mathrm{Bu}$ & $\mathrm{f}$ & MNHN IM-2013-56511 & French Guyane & KT753642 & KT753775 & KT753884 & KT754007 & KT754136 \\
\hline Latirolagena smaragdulus & $\mathrm{Bu}$ & $\mathrm{f}$ & MNHN IM-2007-32547 & Vanuatu & KT753598 & KT753731 & KT753852 & KT753964 & - \\
\hline Latirus amplustre & $\mathrm{Bu}$ & $\mathrm{f}$ & FMNH UF-410623 & Kiribati & KT753657 & KT753790 & KT753894 & KT754021 & KT754150 \\
\hline Latirus belcheri & $\mathrm{Bu}$ & $\mathrm{f}$ & MNHN IM-2007-32490 & Vanuatu & KT753587 & KT753720 & - & KT753953 & KT754084 \\
\hline Latirus gibbulus & $\mathrm{Bu}$ & f & MNHN IM-2007-32544 & Philippines & KT753542 & KT753675 & KT753804 & KT753908 & KT754039 \\
\hline Latirus pictus & $\mathrm{Bu}$ & $\mathrm{f}$ & MNHN IM-2013-10540 & Papua New Guinea & KT753601 & KT753734 & KT753855 & KT753967 & KT754097 \\
\hline Latirus polygonus & $\mathrm{Bu}$ & $\mathrm{f}$ & MZSP 99782 & Djibouti & KT753629 & KT753762 & KT753878 & KT753995 & KT754124 \\
\hline Latirus vischii & $\mathrm{Bu}$ & $\mathrm{f}$ & MNHN IM-2009-15038 & south Madagascar & KT753547 & KT753680 & KT753808 & KT753913 & KT754044 \\
\hline Leucozonia cerata & $\mathrm{Bu}$ & $\mathrm{f}$ & MZSP 63825 & Ecuador & KT753643 & KT753776 & KT753885 & KT754008 & KT754137 \\
\hline Leucozonia nassa brasiliana & $\mathrm{Bu}$ & $\mathrm{f}$ & MZSP 117596 & southeast Brazil & KT753628 & KT753761 & KT753877 & KT753994 & KT754123 \\
\hline Leucozonia nassa brasiliana & $\mathrm{Bu}$ & $\mathrm{f}$ & MZSP 103954 & southeast Brazil & KT753648 & KT753781 & - & KT754012 & KT754142 \\
\hline
\end{tabular}


Table 1 (continued)

\begin{tabular}{|c|c|c|c|c|c|c|c|c|c|}
\hline Taxon & & & Voucher \# & Locality & 18S rRNA & 28S rRNA & 16S rRNA & $\mathrm{COI}$ & H3 \\
\hline Leucozonia nassa cingulifera & $\mathrm{Bu}$ & $\mathrm{f}$ & MZSP 112955 & offshore northeast Brazil & KT753655 & KT753788 & KT753892 & KT754019 & KT754148 \\
\hline Leucozonia nassa nassa & $\mathrm{Bu}$ & $\mathrm{f}$ & MNHN IM-2013-20181 & Guadeloupe & КT753535 & KT753668 & KT753797 & KT753902 & KT754032 \\
\hline Leucozonia nassa nassa & $\mathrm{Bu}$ & $\mathrm{f}$ & MNHN IM-2007-9388 & Guadeloupe & KT753568 & KT753701 & KT753825 & KT753934 & KT754065 \\
\hline Leucozonia nassa nassa & $\mathrm{Bu}$ & $\mathrm{f}$ & MZSP 69365 & Dominican Republic & KT753636 & KT753769 & - & - & - \\
\hline Leucozonia ocellata & $\mathrm{Bu}$ & f & MNHN IM-2013-20444 & Guadeloupe & KT753612 & KT753745 & KT753866 & KT753978 & KT754108 \\
\hline Leucozonia ponderosa & $\mathrm{Bu}$ & $\mathrm{f}$ & MZSP 115436 & southeast Brazil & KT753654 & KT753787 & KT753891 & KT754018 & - \\
\hline Nodolatirus nodatus & $\mathrm{Bu}$ & $\mathrm{f}$ & MNHN IM-2013-42534 & Austral Islands & КT753539 & KT753672 & KT753801 & KT753906 & KT754036 \\
\hline Opeatostoma pseudodon & $\mathrm{Bu}$ & $\mathrm{f}$ & MZSP 68483 & Ecuador & KT753661 & - & KT753897 & KT754025 & - \\
\hline Peristernia forskalii & $\mathrm{Bu}$ & $\mathrm{f}$ & MNHN IM-2013-42522 & Mozambique & KT753537 & KT753670 & KT753799 & KT753904 & KT754034 \\
\hline Peristernia gemmata & $\mathrm{Bu}$ & $\mathrm{f}$ & MNHN IM-2013-42528 & Marchesas Islands & KT753614 & KT753747 & KT753868 & KT753980 & KT754110 \\
\hline Peristernia marquesana & $\mathrm{Bu}$ & $\mathrm{f}$ & MNHN IM-2013-15306 & Papua New Guinea & KT753548 & KT753681 & - & KT753914 & KT754045 \\
\hline Peristernia marquesana & $\mathrm{Bu}$ & $\mathrm{f}$ & MNHN IM-2007-32486 & Vanuatu & KT753567 & KT753700 & KT753824 & KT753933 & KT754064 \\
\hline Peristernia nassatula & $\mathrm{Bu}$ & f & MNHN IM-2007-32487 & Vanuatu & KT753579 & KT753712 & KT753835 & KT753945 & KT754076 \\
\hline Peristernia nassatula & $\mathrm{Bu}$ & $\mathrm{f}$ & MNHN IM-2013-18061 & Papua New Guinea & KT753591 & KT753724 & KT753845 & KT753957 & KT754088 \\
\hline Peristernia reincarnata & $\mathrm{Bu}$ & $\mathrm{f}$ & MNHN IM-2007-32482 & Vanuatu & KT753575 & KT753708 & KT753831 & KT753941 & KT754072 \\
\hline Peristernia sp. & $\mathrm{Bu}$ & $\mathrm{f}$ & MNHN IM-2013-17660 & Papua New Guinea & KT753560 & KT753693 & KT753819 & KT753926 & KT754057 \\
\hline Peristernia sp. & $\mathrm{Bu}$ & $\mathrm{f}$ & MNHN IM-2013-10337 & Papua New Guinea & KT753580 & KT753713 & KT753836 & KT753946 & KT754077 \\
\hline Peristernia sp. & $\mathrm{Bu}$ & $\mathrm{f}$ & MNHN IM-2013-10336 & Papua New Guinea & КT753599 & KT753732 & KT753853 & KT753965 & KT754095 \\
\hline Peristernia sp. & $\mathrm{Bu}$ & $\mathrm{f}$ & MNHN IM-2013-12522 & Papua New Guinea & KT753604 & KT753737 & KT753858 & KT753970 & KT754100 \\
\hline Peristernia sp. & $\mathrm{Bu}$ & $\mathrm{f}$ & MNHN IM-2013-13553 & Papua New Guinea & KT753611 & KT753744 & KT753865 & KT753977 & KT754107 \\
\hline Peristernia sp. & $\mathrm{Bu}$ & $\mathrm{f}$ & FMNH 457386 & Guam & KT753656 & KT753789 & КT753893 & KT754020 & KT754149 \\
\hline Pleuroploca trapezium & $\mathrm{Bu}$ & $\mathrm{f}$ & MNHN IM-2009-15358 & south Madagascar & KT753576 & KT753709 & KT753832 & KT753942 & KT754073 \\
\hline Pleuroploca trapezium & $\mathrm{Bu}$ & $\mathrm{f}$ & MNHN IM-2007-32591 & Vanuatu & KT753596 & KT753729 & KT753850 & KT753962 & KT754093 \\
\hline Polygona angulata & $\mathrm{Bu}$ & $\mathrm{f}$ & MZSP 112907 & northeast Brazil & KT753619 & KT753752 & KT753871 & KT753985 & KT754115 \\
\hline Polygona bernadensis & $\mathrm{Bu}$ & $\mathrm{f}$ & MNHN IM-2013-56077 & French Guyane & KT753635 & KT753768 & - & KT754001 & KT754130 \\
\hline Polygona infundibulum & $\mathrm{Bu}$ & $\mathrm{f}$ & MNHN IM-2013-19591 & Guadeloupe & KT753585 & KT753718 & KT753840 & KT753951 & KT754082 \\
\hline Pseudolatirus aff. pallidus & $\mathrm{Bu}$ & $\mathrm{f}$ & MNHN IM-2007-32913 & Philippines & KT753586 & KT753719 & KT753841 & KT753952 & KT754083 \\
\hline Pseudolatirus discrepans & $\mathrm{Bu}$ & $\mathrm{f}$ & MNHN IM-2007-34604 & Philippines & KT753562 & KT753695 & KT753821 & KT753928 & KT754059 \\
\hline Pseudolatirus discrepans & $\mathrm{Bu}$ & $\mathrm{f}$ & MNHN IM-2007-32791 & Solomon Islands & KT753594 & KT753727 & KT753848 & KT753960 & KT754091 \\
\hline Pseudolatirus kurodai & $\mathrm{Bu}$ & $\mathrm{f}$ & MNHN IM-2013-42520 & New Caledonia & KT753531 & KT753664 & - & KT753899 & KT754028 \\
\hline Pseudolatirus kuroseanus & $\mathrm{Bu}$ & $\mathrm{f}$ & MNHN IM-2013-14709 & Papua New Guinea & KT753571 & KT753704 & KT753827 & KT753937 & KT754068 \\
\hline Pseudolatirus pallidus & $\mathrm{Bu}$ & $\mathrm{f}$ & MNHN IM-2007-32537 & Solomon Islands & KT753544 & KT753677 & KT753806 & KT753910 & KT754041 \\
\hline Pseudolatirus sp. & $\mathrm{Bu}$ & $\mathrm{f}$ & MNHN IM-2007-32510 & New Caledonia & KT753565 & KT753698 & KT753823 & KT753931 & KT754062 \\
\hline Pustulatirus ogum & $\mathrm{Bu}$ & $\mathrm{f}$ & MZSP 69481 & southeast Brazil & КT753653 & KT753786 & - & KT754017 & KT754147 \\
\hline Pustulatirus praestantior & $\mathrm{Bu}$ & $\mathrm{f}$ & FMNH UF-359664 & west Panama & KT753650 & KT753783 & - & KT754014 & KT754144 \\
\hline Teralatirus noumeensis & $\mathrm{Bu}$ & $\mathrm{f}$ & MNHN IM-2013-42526 & Austral Islands & KT753549 & KT753682 & KT753809 & KT753915 & KT754046 \\
\hline Teralatirus noumeensis & $\mathrm{Bu}$ & $\mathrm{f}$ & MNHN IM-2013-4032 & Papua New Guinea & KT753632 & KT753765 & - & KT753998 & KT754127 \\
\hline Teralatirus roboreus & $\mathrm{Bu}$ & $\mathrm{f}$ & MZSP 108682 & Grenada & KT753660 & КT753793 & KT753896 & KT754024 & - \\
\hline Triplofusus giganteus & $\mathrm{Bu}$ & $\mathrm{f}$ & MCZ 382636 & Florida & KT753638 & KT753771 & KT753880 & KT754003 & KT754132 \\
\hline Turrilatirus craticulatus & $\mathrm{Bu}$ & $\mathrm{f}$ & MNHN IM-2007-32504 & Vanuatu & KT753554 & KT753687 & KT753813 & KT753920 & KT754051 \\
\hline Turrilatirus turritus & $\mathrm{Bu}$ & $\mathrm{f}$ & MNHN IM-2007-32516 & Vanuatu & KT753532 & KT753665 & - & KT753900 & KT754029 \\
\hline Turrilatirus turritus & $\mathrm{Bu}$ & $\mathrm{f}$ & MNHN IM-2013-17100 & Papua New Guinea & KT753615 & KT753748 & KT753869 & KT753981 & KT754111 \\
\hline Buccinum undatum & Bu & b & MCZ 378265 & Sweden & KT753631 & KT753764 & - & KT753997 & KT754126 \\
\hline Busycon africanus & Bu & b & MNHN IM-2013-42510 & Senegal & KT753536 & KT753669 & KT753798 & KT753903 & KT754033 \\
\hline Euthria cumulata & Bu & b & MNHN IM-2007-34931 & New Caledonia & KT753583 & KT753716 & KT753839 & KT753949 & KT754080 \\
\hline Euthria sp. & Bu & b & MNHN IM-2007-34934 & New Caledonia & KT753559 & KT753692 & KT753818 & KT753925 & KT754056 \\
\hline Manaria sp. & Bu & $\mathbf{b}$ & MNHN IM-2007-36855 & Madagascar & KT753605 & KT753738 & KT753859 & KT753971 & KT754101 \\
\hline Neptunea antiqua & Bu & b & MCZ 378610 & Sweden & KT753623 & KT753756 & - & KT753989 & KT754119 \\
\hline Prodotia sp. & Bu & $\mathbf{b}$ & MNHN IM-2007-34675 & New Caledonia & KT753606 & KT753739 & KT753860 & KT753972 & KT754102 \\
\hline Columbella aureomexicana & Bu & c & MCZ 378333 & Baja California, Mexico & KT753633 & KT753766 & - & KT753999 & KT754128 \\
\hline Mitrella scripta & Bu & c & MCZ 378586 & southeast France & KT753658 & KT753791 & KT753895 & KT754022 & KT754151 \\
\hline Nassarius glans & Bu & $\mathbf{n}$ & MCZ 378603 & east Australia & KT753641 & KT753774 & KT753883 & KT754006 & KT754135 \\
\hline Nassarius reticulatus & Bu & $\mathbf{n}$ & MCZ 378509 & Sweden & KT753617 & KT753750 & - & KT753983 & KT754113 \\
\hline Conus angasi & Co & c & MCZ 382632 & East Australia & KT753663 & KT753795 & KT753898 & KT754027 & KT754154 \\
\hline Phymorhynchus sp. & Co & $\mathbf{r}$ & MCZ 378670 & Unkown & KT753662 & KT753794 & - & KT754026 & KT754153 \\
\hline Thais nodosa & Mu & $\mathbf{m}$ & MCZ 378809 & Cameroon & KT753639 & KT753772 & KT753881 & KT754004 & KT754133 \\
\hline Thais speciosa & Mu & m & MCZ 378767 & Baja California, Mexico & KT753647 & KT753780 & - & - & KT754141 \\
\hline Erosaria erosa & Cy & c & MCZ 378355 & east Australia & KT753625 & KT753758 & - & KT753991 & KT754121 \\
\hline Monetaria annulus & Cy & c & MCZ 378587 & east Australia & KT753651 & KT753784 & KT753889 & KT754015 & KT754145 \\
\hline
\end{tabular}

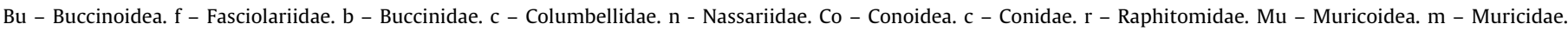
Cy - Cypraeoidea. c - Cypraeidae.

ingroup taxa and 16 outgroups, fragment $b$ for 116 and 17 , and fragment $c$ for 113 and 17.

16S rRNA: This gene was amplified for 94 ingroup and 10 outgroup terminals in a single amplicon between $505-520 \mathrm{bp}$.

COI: Amplified for 113 ingroup and 16 outgroup terminals in a single amplicon using a combination of different primer pairs. It showed no length variation among all sampled specimens (658 bp analyzed), being analyzed as a single fragment.

Histone H3: A single amplicon was amplified for 110 ingroup and 17 outgroup specimens. It was analyzed in a single fragment without variation in length among individuals sequenced (328 bp).

\subsection{Phylogenetic analyses}

Maximum likelihood (ML) and Bayesian inference (BI) analyses were conducted on static alignments using MUSCLE v.3.6 (Edgar, 2004) as implemented in the Geneious v.8.1.2 platform. In order to confirm codon position of protein encoding genes COI and histone $\mathrm{H} 3$, their sequences were translated into amino acids using the Geneious v.8.1.2 platform.

ML analysis was conducted using RAxML v.8.2.X (Stamatakis, 2014) on the complete dataset. For the ML searches, the General Time Reversible model with a discrete gamma distribution of 
Table 2

List of primer sequences utilized for amplification and sequencing with original references, indicating primer pairs and optimal annealing temperatures used.

\begin{tabular}{|c|c|c|c|c|c|c|}
\hline \multicolumn{2}{|c|}{ Primer } & \multicolumn{2}{|l|}{ Sequence } & \multirow{2}{*}{$\begin{array}{l}\text { Reference } \\
\text { Giribet et al. (1996) }\end{array}$} & \multirow{2}{*}{$\begin{array}{l}\text { Primer pairs } \\
1 F / 4 R\end{array}$} & \multirow{2}{*}{$\frac{\text { Annealing temp }}{43-45^{\circ} \mathrm{C}}$} \\
\hline $18 \mathrm{~S}$ & $1 \mathrm{~F}$ & 5'-TACCTGGTTGATCCTGCCAGTAG-3' & Forward & & & \\
\hline & $4 \mathrm{R}$ & 5'-GAATTACCGCGGCTGCTGG-3' & Reverse & Giribet et al. (1996) & & \\
\hline & $3 \mathrm{~F}$ & 5'-GTTCGATTCCGGAGAGGGA-3' & Forward & Giribet et al. (1996) & $3 \mathrm{~F} / \mathrm{bi}$ & $43-45^{\circ} \mathrm{C}$ \\
\hline & bi & 5'-GAGTCTCGTTCGTTATCGGA-3' & Reverse & Whiting et al. (1997) & & \\
\hline & $\mathrm{a} 2.0$ & 5'-ATGGTTGCAAAGCTGAAAC-3' & Forward & Whiting et al. (1997) & $\mathrm{a} 2.0 / 9 \mathrm{R}$ & $43-45^{\circ} \mathrm{C}$ \\
\hline & $9 \mathrm{R}$ & 5'-GATCCTTCCGCAGGTTCACCTAC-3' & Reverse & Giribet et al. (1996) & & \\
\hline \multirow[t]{7}{*}{$28 \mathrm{~S}$} & Rd1a & 5'-CCCSCGTAAYTTAGGCATAT-3' & Forward & Edgecombe and Giribet (2006) & $\operatorname{Rd} 1 a / R d 4 b$ & $47^{\circ} \mathrm{C}$ \\
\hline & $\mathrm{Rd} 4 \mathrm{~b}$ & 5'-CCTTGGTCCGTGTTTCAAGAC -3' & Reverse & Edgecombe and Giribet (2006) & $\mathrm{ZX} 1 \mathrm{f} / \mathrm{Rd} 4 \mathrm{~b}$ & $47-64^{\circ} \mathrm{C}$ \\
\hline & $\mathrm{ZX} 1 \mathrm{f}$ & 5'-ACCCGCTGAATTTAAGCATAT-3' & Forward & Auwera et al. (1994) & & $62-64{ }^{\circ} \mathrm{C}$ \\
\hline & A & 5'-GACCCGTCTTGAAGCACGGA-3' & Forward & Whiting et al. (1997) & $\mathrm{A} / \mathrm{Rd} 5 \mathrm{~b}$ & $44-45^{\circ} \mathrm{C}$ \\
\hline & Rd5b & 5'-CCACAGCGCCAGTTCTGCTTAC-3' & Reverse & Schwendinger and Giribet (2005) & & \\
\hline & $\mathrm{Rd} 4.8 \mathrm{a}$ & 5'-ACCTATTCTCAAACTTTAAATGG-3' & Forward & Schwendinger and Giribet (2005) & Rd 4.8a/Rd7b1 & $44-45^{\circ} \mathrm{C}$ \\
\hline & Rd7b1 & 5'-GACTTCCCTTACCTACAT-3' & Reverse & Schwendinger and Giribet (2005) & & \\
\hline \multirow[t]{2}{*}{$16 S$} & $\mathrm{a}$ & 5'-CGCCTGTTTATCAAAAACAT-3' & Forward & Palumbi (1996) & $\mathrm{a} / \mathrm{b}$ & $44-48^{\circ} \mathrm{C}$ \\
\hline & b & 5'-CTCCGGTTTGAACTCAGATCA-3' & Reverse & Palumbi (1996) & & \\
\hline \multirow[t]{5}{*}{$\mathrm{COI}$} & LCO1490 & 5'-GGTCAACAAATCATAAAGATATTGG-3' & Forward & Folmer et al. (1994) & LCO1490/HCO2198 & $45^{\circ} \mathrm{C}$ \\
\hline & HCO2198 & 5'-TAAACTTCAGGGTGACCAAAAAATCA-3' & Reverse & Folmer et al. (1994) & & \\
\hline & HCOout & 5'-CCAGGTAAAATTAAAATATAAACTTC-3' & Reverse & Carpenter and Wheeler (1999) & LCO1490/HCOout & $44-45^{\circ} \mathrm{C}$ \\
\hline & jgLCO1490 & 5'-TITCIACIAAYCAYAARGAYATTGG-3' & Forward & Geller et al. (2013) & jgLCO1490/jgHCO2198 & $47^{\circ} \mathrm{C}$ \\
\hline & jgHCO2198 & 5'-TAIACYTCIGGRTGICCRAARAAYCA-3' & Reverse & Geller et al. (2013) & & \\
\hline \multirow[t]{2}{*}{ H3 } & H3af & 5'-ATGGCTCGTACCAAGCAGACVGC-3' & Forward & Colgan et al. (1998) & H3af/H3ar & $47^{\circ} \mathrm{C}$ \\
\hline & H3ar & 5'-ATATCCTTRGGCATRATRGTGAC-3' & Reverse & Colgan et al. (1998) & & \\
\hline
\end{tabular}

site-rate heterogeneity $(\mathrm{GTR}+\Gamma)$ was specified for each individual gene. Nodal support was estimated via 1000 replicates of a rapid bootstrapping algorithm (Stamatakis et al., 2008) using the GTRGAMMA model, via the Cyber infrastructure for Phylogenetic Research (CIPRES) portal (Miller et al., 2010). Bootstrap resampling frequencies were thereafter mapped onto the optimal tree from the independent searches.

In order to assess the monophyly of Fasciolariidae, a constrained phylogeny was generated by RAxML, and site-wise loglikelihoods were calculated for the best tree topology and for the constrained tree with fasciolariid monophyly. These values were used in CONSEL v.0.1.j (Shimodaira and Hasegawa, 2001) to calculate the probabilities according to the approximately unbiased test (AU; Shimodaira, 2002), the Kishino-Hasegawa test (KH; Kishino and Hasegawa, 1989), and the Shimodaira-Hasegawa test (SH; Shimodaira and Hasegawa, 1999).

A Bayesian inference analysis was conducted using MrBayes v.3.2.5 (Ronquist et al., 2012) with a unique model of sequence evolution with corrections for a discrete gamma distribution and/ or a proportion of invariant sites $(\mathrm{GTR}+\Gamma+\mathrm{I})$ on each partition, as selected in jModelTest 2 v.2.1.7 (Guindon and Gascuel, 2003; Darriba et al., 2012) as implemented in the CIPRES gateway (Miller et al., 2010). Default priors were used starting with random trees and three runs, each with three hot and one cold Markov chains, were conducted until the average deviation of split frequencies reached $<0.01(7,000,000$ generations). Stationarity was checked using Tracer v.1.6 (Rambaut et al., 2014). After the burnin of $25 \%$ samples was discarded, a majority-rule consensus topology was generated from the sampled trees.

\section{Results}

The ML analysis of the concatenated genes (133 specimens in total) resulted in a tree topology with a $-\ln L=50219.14$ (Fig. 1). The BI analysis $(-\ln L=102047.8$ for run 1 ; $-\ln L=102507.2$ for run2) recovered a topology highly congruent with that of the ML analysis (Fig. 2).

Leaving aside Dolicholatirus/Teralatirus, both analyses recovered three major well-supported deep clades of Fasciolariidae, but none of these correspond to the traditional contents of the recognized subfamilies. A first split divides fasciolariids into a clade mostly corresponding to Fusininae, but also including the clearly nonmonophyletic genus Pseudolatirus (BS $=87 \%$; $\mathrm{PP}=1.00$ ) - traditionally classified in the Peristerniinae (BS=99\%; $\mathrm{PP}=1.00$ ). As it includes Fusinus colus (Linnaeus, 1758), the type species of Fusinus (type genus of Fusininae), we will refer to this clade as the Fusinus colus clade. Fasciolariinae, which appears monophyletic, is nested within a subclade of Fasciolariinae + Peristerniinae (BS $=99 \%$; $\mathrm{PP}=1.00$ ); as it includes Fasciolaria tulipa (Linnaeus, 1758), the type species of Fasciolaria (type genus of Fasciolariinae), we will refer to it as the Fasciolaria tulipa clade. Finally, its sister group is a clade containing various taxa of Peristerniinae (BS $=95 \%$; $\mathrm{PP}=1.00$ ); as it includes Peristernia nassatula (Lamarck, 1822), the type species of Peristernia (type genus of Peristerniinae), we will refer to it as the Peristernia nassatula clade.

A clade containing Dolicholatirus and Teralatirus was highly supported $(\mathrm{BS}=100 \%$; $\mathrm{PP}=1.00$ ). Its position varied in the $\mathrm{ML}$ and $\mathrm{BI}$ analyses, but in neither of them did it appear as a sister group to, or nested within, the remaining fasciolariids. The ML analysis for the constrained tree (fasciolariid monophyly) resulted in a tree topology with a $-\ln L=50257.70$, and the probability values (AU, $\mathrm{KH}$ and $\mathrm{SH}$ ) calculated in CONSEL showed no significant statistical difference between the relaxed ML tree and the constrained tree.

Single ML gene trees obtained from 16S rRNA (104 sequences) displayed the same overall topology but with less resolution in the internal nodes. Gene trees from 18S rRNA (133 sequences), $28 \mathrm{~S}$ rRNA (132 sequences) and COI (129 sequences) displayed rival topologies with many outgroup taxa nested within Fasciolariidae, and low nodal support as initially expected. Histone $\mathrm{H} 3$ is a conserved gene that generated a tree with short branch lengths for closely related species and low support for nodes. Individual ML trees are available in Supplementary Material Figs. S1-S5.

\section{Discussion}

This study presents the first comprehensive molecular phylogenetic analysis using combined sequences from nuclear and mitochondrial genes to infer the relationships of Fasciolariidae. None of the three traditionally recognized subfamilies (Fasciolariinae, Fusininae and Peristerniinae) was recovered with their currently accepted contents. The taxa currently included in Peristerniinae appeared among all three major lineages: the Peristernia nassatula 


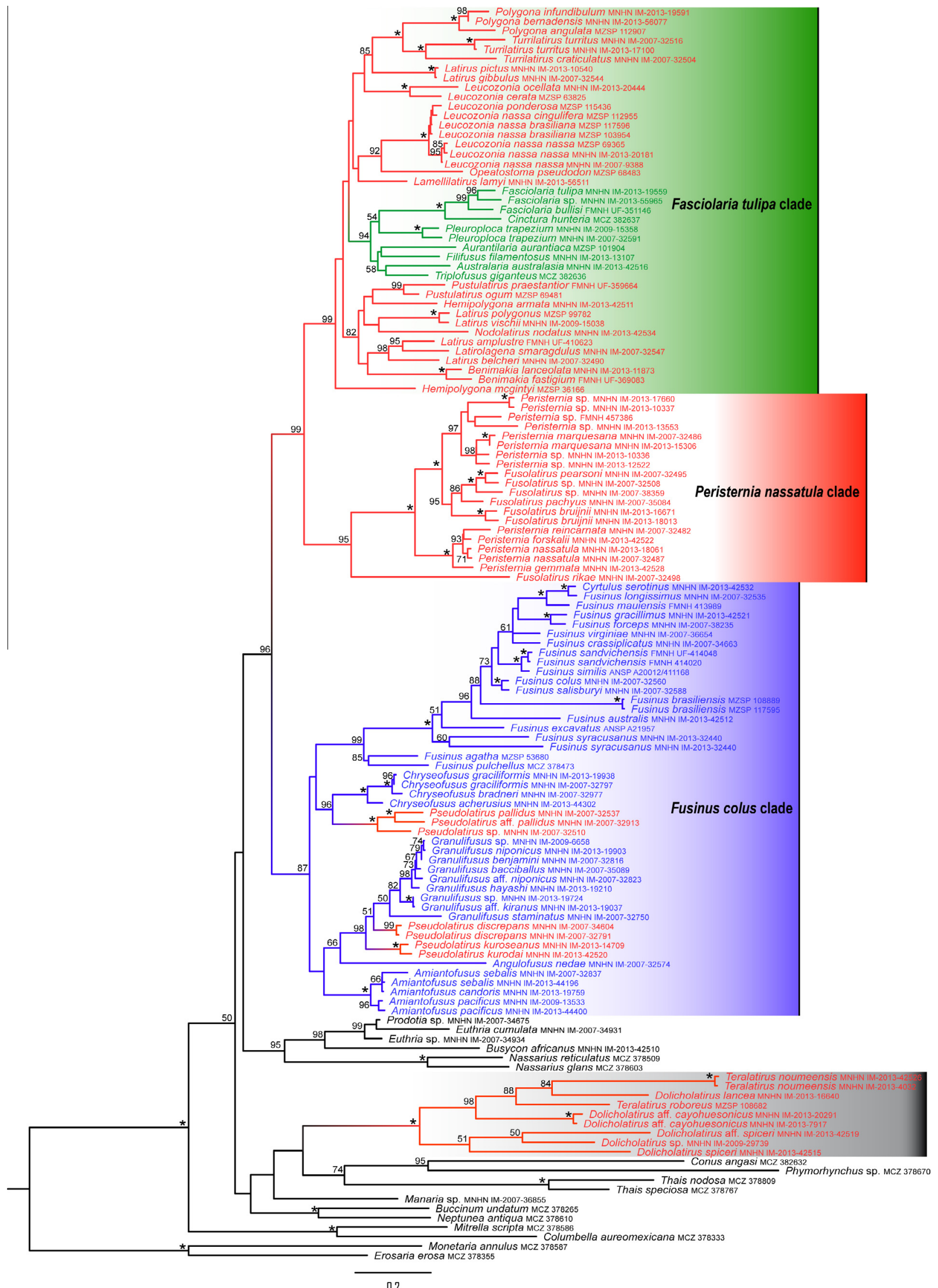

Fig. 1. Phylogenetic relationships of Fasciolariidae based on maximum likelihood analysis of five genes $(-\ln L=50219.139606)$. Numbers on nodes indicate bootstrap resampling, only bootstraps over 50 are shown, $*$ indicate $\mathrm{BS}=100 \%$. Color of taxon names indicates traditional subfamily placement (green: Fasciolariinae; blue: Fusininae; red: Peristerniinae). (For interpretation of the references to color in this figure legend, the reader is referred to the web version of this article.) 


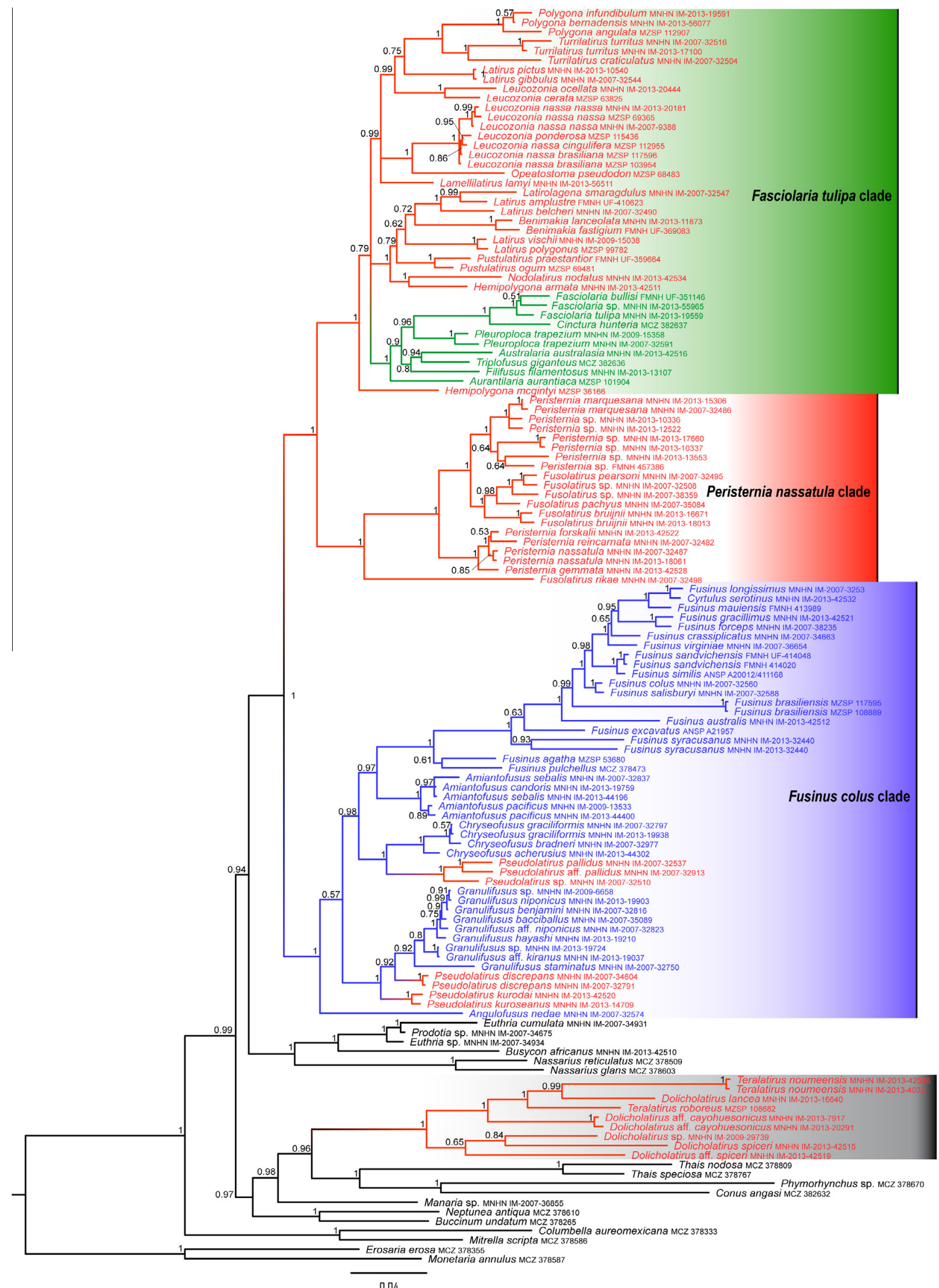

0.04

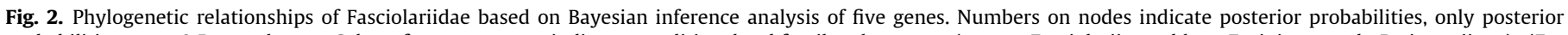

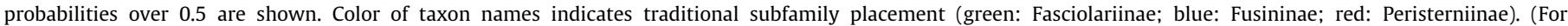
interpretation of the references to color in this figure legend, the reader is referred to the web version of this article.) 
clade (containing Peristernia and Fusolatirus); the Fusinus colus clade (containing Pseudolatirus); and a more derived Fasciolaria tulipa clade (containing Polygona, Turrilatirus, Leucozonia, Opeatostoma, Lamellilatirus, Pustulatirus, Hemipolygona, Nodolatirus, Benimakia, and the clearly polyphyletic Latirus).

Our study demonstrates the monophyly of a clade containing Dolicholatirus and Teralatirus ( $\mathrm{BS}=100 \%$; $\mathrm{PP}=1.00$ ) (Fig. 3). Its position as the sister group to the remaining fasciolariids remains uncertain, as the tests could not statistically discriminate between the constrained and unconstrained topologies. Dolicholatirus and Teralatirus are small buccinoids with distinctive shell characters, whose taxonomic position in Fasciolariidae is ambiguous, although currently generally accepted (e.g., Snyder, 2003). Originally established (Bellardi, 1884) as a section of Latirus for two fossil species, the genus Dolicholatirus was attributed to Fasciolariidae without any arguments or analysis, obviously on the basis of its fusiform shell superficially resembling many fasciolariids, although the presence of paired weak columellar plaits (uncommon in Fasciolariidae) was mentioned. Cossmann (1901) raised Dolicholatirus to full genus, designated the type species (Turbinella bronni Michelotti, 1847) and classified it in the family Fusidae [which Cossmann used in place of Fasciolariidae], subfamily Fusinae, also without providing supporting arguments. Subsequently, almost half of the genera included in Cossmann's Fusinae have since been transferred to other families of Neogastropoda (Columbarium, now Columbariinae, Turbinellidae; Exilia, now Ptychatractidae; Thersitea, now Thersiteidae; Euthriofusus, now Buccinidae). Thiele (1929) reverted to Dolicholatirus as a section of Latirus, still included in the family Fasciolariidae, a position followed by Wenz (1943) and finally by Snyder (2003; but see Vermeij and Snyder, 2006). Thus the current inclusion of Dolicholatirus in the Fasciolariidae goes back to Bellardi (1884) and is uncritically based on shell characters. Abbott (1958) was the first to examine the radula of $D$. cayohuesonicus (Sowerby II, 1878) and found it to be "the most highly modified of the Fasciolariidae radulae, and somewhat resembl[ing] those of Vasidae." Based on the shape of the egg capsules and differences in radula and shell morphology, Vermeij and Snyder (2006) argued that Dolicholatirus likely belongs to Turbinellidae, a view followed by Beu (2011). Simone et al. (2013) pointed out the similarities between Dolicholatirus and Teralatirus, and suggested that most likely these should be better placed together, a hypothesis confirmed here as Teralatirus nests within Dolicholatirus. Nevertheless Simone et al. (2013) followed a conservative approach with regard to the classification of Dolicholatirus/Teralatirus and no changes were made.

In our current phylogeny, the two Indo-Pacific $T$. noumeensis and $D$. lancea are the sister group to the Australian T. roboreus, and these are the sister group to D. cayohuesonicus, which in turn are the sister clade to the Caribbean D. spiceri. The genus Dolicholatirus is therefore paraphyletic with respect to Teralatirus, which is also non-monophyletic. The similarity of the radula of Crassicantharus norfolkensis illustrated by Ponder (1972: Fig. 14) suggests that Crassicantharus may belong in the same clade.

A Dolicholatirus sp. (Fig. 3C) from western Australia is nested in the same clade $(\mathrm{BS}=51 \%$; $\mathrm{PP}=0.65$ ). The radular morphology of another Dolicholatirus sp. (Fig. 3D) is virtually identical to that of $D$. cayohuesonicus (Fig. 3E) and T. roboreus figured by Simone et al. (2013: Figs. 31-34). This characteristic radula type likely occurs within all species in this clade (A radula of Dolicholatirus was supposedly figured by Bandel (1984), however we suspect a misidentification as this radula does not match our own observations [bicuspidate laterals, internal cusp hook-like], and we believe Bandel's specimen to have been a buccinid instead).

At least one species of Teralatirus, $T$. roboreus has conflicting characters in favor and against its inclusion in Fasciolariidae (Simone et al., 2013). It has salivary ducts attached to the anterior esophagus, the retractor muscle of the proboscis in a single beam,

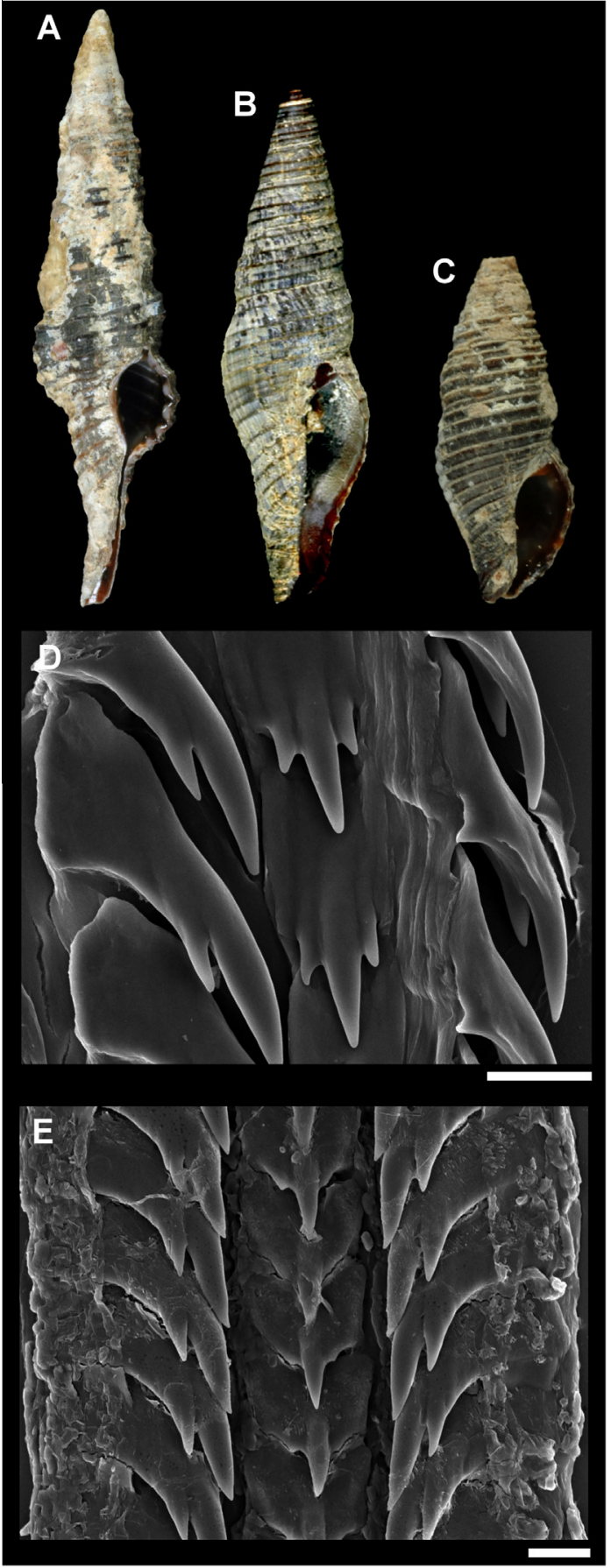

Fig. 3. Vouchers of sequenced non-Fasciolariidae specimens and radulae: A: Dolicholatirus lancea, MNHN IM-2013-16640, Papua New Guinea; B: Dolicholatirus spiceri, MNHN IM-2013-42515, Mozambique; C: Dolicholatirus sp., MNHN IM-200929739, Western Australia; D: radula of Dolicholatirus cayohuesonicus, MNHN IM2013-20291, Guadeloupe; E: radula of Dolicholatirus sp., MNHN IM-2009-29739, Western Australia. Scale bars $=10 \mu \mathrm{L}$.

and a simple stomach, which are fasciolariid-like characters; however, its radula, the lack of gland of Leiblein, and the huge esophageal gland are not. In conclusion, although the molecular results do not reliably establish their position outside the remaining fasciolariids, Dolicholatirus and Teralatirus form a monophyletic group and there is strong morphological evidence suggesting a nonfasciolariid position.

For the ML analysis, deep nodes were unresolved and/or weakly supported in all major outgroups sampled, resulting in conflicting 
topologies with the BI analysis. Perhaps phylogenomic analyses will be able to recover this part of the Neogastropoda tree with high support, as is usually the case with deep nodes in mollusks (Kocot et al., 2011; Smith et al., 2011; Zapata et al., 2014; Goodheart et al., 2015).

\subsection{The Fasciolaria tulipa clade}

Vermeij and Snyder (2006) considered Fasciolariinae as derived from early peristerniines and that the two groups are part of a single clade Fasciolariinae; Snyder et al. (2012) noted that the subfamilies are morphologically similar. Our analysis confirmed that fasciolariines (Fig. 4) are a clade derived from a group of Peristerniinae ( $\mathrm{BS}=94 \%$; $\mathrm{PP}=1.00$ ). Historically, most members of this clade have been assigned to the genera Fasciolaria or Pleuroploca. However, Snyder et al. (2012), after a thorough re-examination of their taxonomy, proposed several additional genera. Species with broad axial ribs and nodose spiral sculpture appear first as several lineages among members of this clade (Aurantilaria aurantiaca, Filifusus filamentosus, Australaria australasia, Triplofusus giganteus and Pleuroploca trapezium - all traditionally in the genus Pleuroploca); while Fasciolaria and Cinctura (BS $=100 \%$; $\mathrm{PP}=1.00$ ) represent a Caribbean lineage with obsolete axial sculpture and weakly convex spiral whorls (Fig. 4B). Vermeij and Snyder (2002, 2006) revised the taxonomy of many Latirus and related genera, elevated previous subgenera to genus rank (e.g., Polygona, Hemipolygona) and described new ones (e.g., Turrilatirus, Pustulatirus). Genus-level taxonomy and phylogenetic relationships of this group have been problematic, with names such as Latirus and Leucozonia applied indiscriminately. Fasciolariinae and Peristerniinae have a long history of divergence from the Cretaceous ( $\sim 140$ Mya) but diversifying extensively during the Neogene (24 Mya to the present) (Vermeij and Snyder, 2006). In our study, many deep relationships within this clade received little or no support and are incongruent between the ML and BI analyses. However, all genera, with the exception of Hemipolygona (represented by $H$. mcgintyi and H. armata), are monophyletic and have high support (Pustulatirus $[\mathrm{BS}=99 \% ; \mathrm{PP}=1.00]$, Benimakia $[\mathrm{BS}=100 \% ; \mathrm{PP}=1.00]$, Polygona $[\mathrm{BS}=100 \% ; \mathrm{PP}=1.00]$, Turrilatirus $[\mathrm{BS}=100 \% ; \mathrm{PP}=1.00]$ ).

A supported clade $(\mathrm{BS}=82 \% ; \mathrm{PP}=1.00$ ) grouped species that were historically associated to Latirus (Latirus, Benimakia, Pustulatirus, Hemipolygona, Nodolatirus) (Fig. 4C-F), including notably a clade with Latirus amplustre and Latirolagena smaragdula (BS $=95 \%$; PP $=0.99$ ). Latirolagena smaragdula and Latirus amplustre grouped with Latirus belcheri with high support (BS $=99 \%$; $\mathrm{PP}=1.00$ ).

The clade consisting of Leucozonia nassa and $L$. ponderosa was strongly supported $(\mathrm{BS}=100 \%$; $\mathrm{PP}=1.00$ ), but the genus was not monophyletic. Leucozonia nassa is a widely distributed species occurring from southeastern Brazil to North Carolina, including records from several locations in the Caribbean. Three distinct forms can be identified, which correspond to three subspecies sensu Abbott (1958) and Vermeij and Snyder (2002), or three species sensu Vermeij (1997): the typical L. nassa nassa which occurs in Caribbean islands and from North Carolina to Florida and the Gulf of Mexico; L. nassa cingulifera, found offshore in NE Brazilian waters, off Bahia and the islands of Fernando de Noronha and Atol das Rocas; and L. nassa brasiliana, from the SE to NE Brazilian coast.

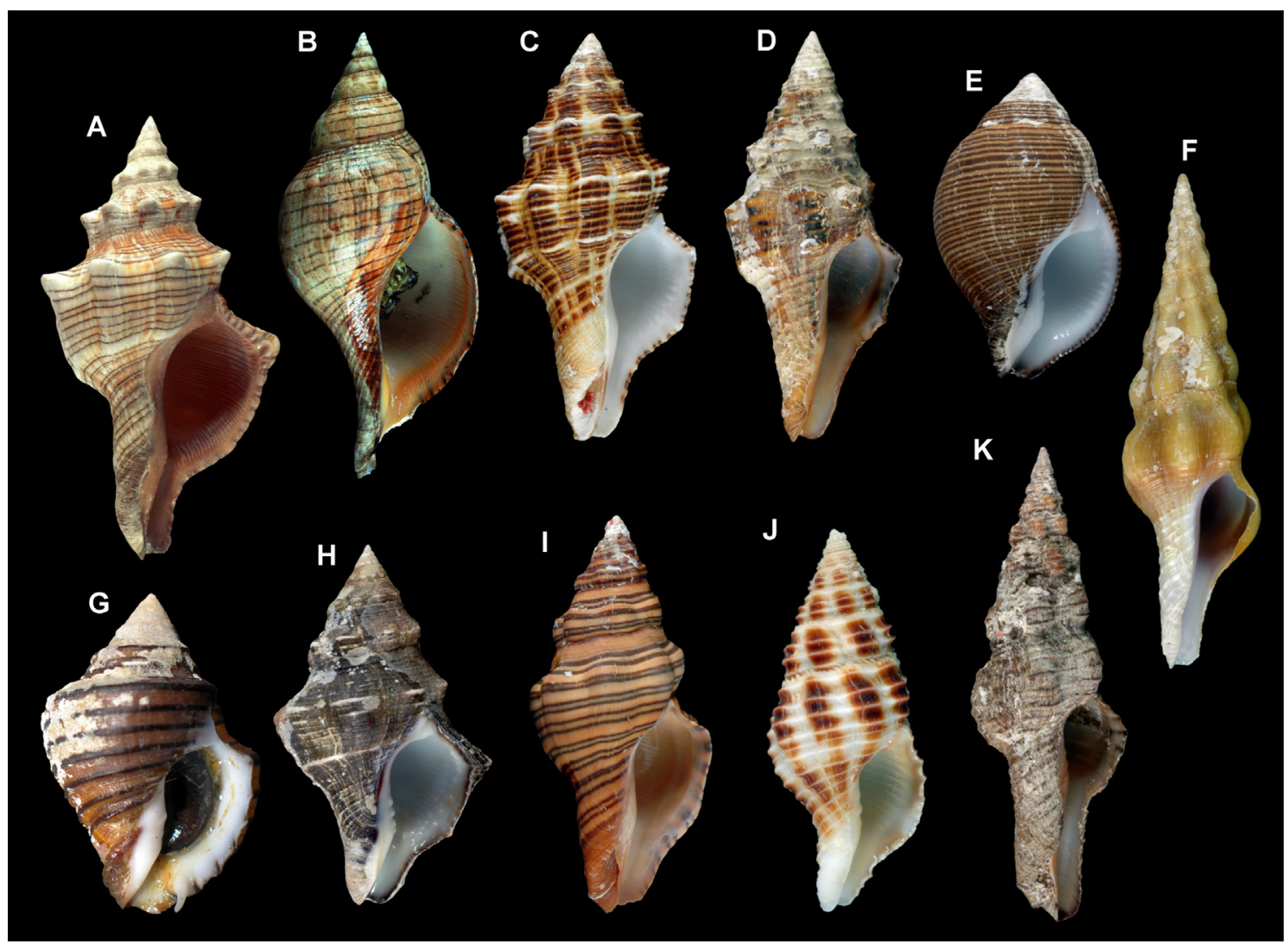

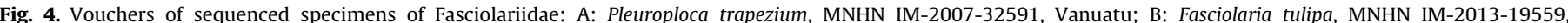

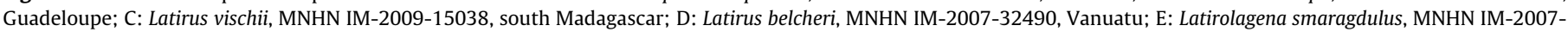

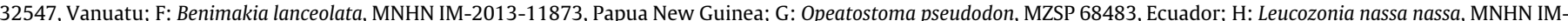

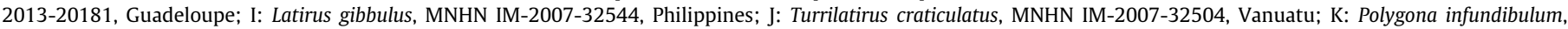
MNHN IM-2013-19591, Guadeloupe. 
Shell characters alone may be insufficient to allow unambiguous separation among the various forms (Vermeij and Snyder, 2002). Due to overlapping geographic ranges and the presence of intermediate forms, $L$. nassa is recognized as a single species (WoRMS, 2016). Leucozonia ponderosa was described by Vermeij and Snyder (1998) as endemic to Trindade Island, SE Brazil, while Vermeij and Snyder (2002) argued that it may be a local variant of the widespread $L$. nassa "with the hope that molecular investigations resolve this issue". Couto and Pimenta (2012) examined several specimens from both $L$. ponderosa and $L$. nassa and found no anatomical variation among them; however, they distinguished the species by their unique shell morphology.

In our study, we had representatives of all three geographical subspecies of Leucozonia nassa, and they grouped as a single well supported clade $(\mathrm{BS}=100 \% ; \mathrm{PP}=1.00)$. Leucozonia ponderosa appeared as sister to $L$. nassa cingulifera from the Fernando de Noronha Archipelago, NE Brazil. These insular species grouped with the coastal SE Brazilian L. nassa brasiliana, a clade that is sister group to the three Caribbean specimens corresponding to L. nassa. The Caribbean clade was highly supported in both ML and BI analysis ( $B S=95 \%$; $P P=1.00$ ), albeit the other nodes within this group received weak support and conflicting topologies among analyses.

Opeatostoma pseudodon is the sister group to the western Atlantic Leucozonia nassa complex clade with high support (BS $=92 \%$; $\mathrm{PP}=1.00$ ) (Fig. 4G and $\mathrm{H}$ ). The radula of Opeatostoma pseudodon has similar lateral tooth morphology to other Leucozonia species. Bullock (1974) called attention to the fact that the shell of the Indo-Pacific Latirus gibbulus, the type of the genus, has features notably its radula - that suggest affinity with species now classified in Leucozonia, rather than with the other species of Latirus. The radula of the species of Latirus and related genera (e.g., Polygona, Turrilatirus) has a small denticle on the inner side of the laterals, but this is reduced or absent in species of Leucozonia and Opeatostoma.

Latirus gibbulus (Fig. 4I) is grouped with L. pictus (BS $=100 \%$; $\mathrm{PP}=1.00$ ), and Leucozonia ocellata with $L$. cerata (BS $=100 \%$; $\mathrm{PP}=1.00$ ). However, deeper nodes are incongruent and have little support for their position among the other major lineages. Like the clade of Leucozonia + Opeatostoma, their radulae are similar because $L$. nassa and $O$. pseudodon lack the small denticle on the inner side of the lateral teeth.

Lyons (1991) suggested that, if L. gibbulus proves to be allied with Leucozonia, Leucozonia will become a junior synonym of Latirus and many species classified in Latirus will have to be re-classified. While L. gibbulus is in fact allied to Polygona and Turrilatirus ( $\mathrm{BS}=85 \%$; $\mathrm{PP}=0.75$ ), Leucozonia is not monophyletic so $L$. ocellata and $L$. cerata must be placed in a different genus. On the same note, Latirus proved to be polyphyletic, comprising three distinct lineages: (1): Latirus gibbulus + L. pictus, (2): L. amplustre + L. belcheri + Latirolagena smaragdulus $(\mathrm{BS}=98 \% ; \mathrm{PP}=1.00)$ and $(3)$ : Latirus polygonus + L. vischii $(\mathrm{BS}=100 \% ; \mathrm{PP}=1.00)$.

Latirus gibbulus + L. pictus received support with (Polygona + Turrilatirus) in the ML tree (BS $=85 \%$ ) (Fig. $4 \mathrm{~J}$ and $\mathrm{K}$ ). Several authors have recognized informal groups within Polygona (Lyons, 1991; Vermeij and Snyder, 2006); Vermeij and Snyder (2006) also grouped species of Polygona into two groups but opted against giving them formal status in view of the "absence of more definitive molecular evidence". The first group with Polygona infundibulum and the second with P. angulata. In our analyses, Polygona infundibulum grouped with $P$. bernadensis ( $B S=100 \%$; $P P=1.00$ ), while this clade is sister group to $P$. angulata; although a more thorough sampling of Polygona species is desirable, these groups concur with those recognized by Vermeij and Snyder (2006) and may indeed justify formal separation, possibly as subgenera.

\subsection{The Peristernia nassatula clade}

The genera Peristernia and Fusolatirus have strong support, both in the ML and $\mathrm{BI}$ analysis ( $\mathrm{BP}=95 \% ; \mathrm{PP}=1.00$ ) (Fig. 5) and in radular features, confirming the distinctiveness of the subfamily Peristerniinae.

Peristernia nassatula (type species of the genus) forms a wellsupported clade with $P$. forskalii, $P$. reincarnata and $P$. gemmata ( $\mathrm{BS}=100 \% ; \mathrm{PP}=1.00$ ) (Fig. 5A-C); Peristernia marquesana clustered with several related and possibly new species with high support ( $B S=97 \% ; P P=1.00$ ), and this clade is sister to some species of Fusolatirus ( $\mathrm{BS}=100 \%$; $\mathrm{PP}=1.00$ ). Because Peristernia is paraphyletic, the species in the clade of $P$. marquesana will have to be classified in a new genus. Vermeij (2001) assigned P. marquesana to the genus Benimakia; however B. fastigium and B. lanceolata cluster in the Fasciolaria tulipa clade.

The clade including Peristernia marquesana and its closest relatives is supported in both analysis (Fig. 5D-F), and it likely includes species related to $P$. ustulata (https://science.mnhn.fr/institution/ mnhn/collection/im/item/2000-6506) and P. lyrata (see Poppe (2008: 108-109) for the illustration of several forms). All four sequenced specimens in this clade have a dark spot in the siphonal canal and a pseudo-umbilicus, as well as varying degree of coloration of the spire. The genus Peristernia and its allies have not been the subject of taxonomical revisions, and several species (e.g., Fig. 5E and F) are most likely new to science.

The genus Fusolatirus (Fig. 5G and H) appeared diphyletic. Fusolatirus rikae is the sister taxon to Peristernia and all other Fusolatirus species ( $\mathrm{BS}=100 \% ; \mathrm{PP}=1.00$ ), and a clade nested within Peristernia comprises Fusolatirus pearsoni, F. pachyus and F. bruijnii (BP = 95\%; $\mathrm{PP}=1.00)$. Snyder and Bouchet (2006) considered Fusolatirus a valid genus of peristerniine fasciolariids with long siphonal canal, imbricated subsutural spiral ridge and Peristernia-like radula. In fact all radulae of Peristernia and Fusolatirus figured in the literature (e.g., Bandel, 1984; Taylor and Lewis, 1995; Kosyan et al., 2009 [Peristernia]; Snyder and Bouchet, 2006 [Fusolatirus]) have Peristernia-like radula, with the lateral teeth with alternating smaller and larger cusps, while in other Fasciolariidae the lateral teeth have regular cusp sizes.

\subsection{The Fusinus colus clade}

The clade containing all members of Fusininae is monophyletic and highly supported ( $\mathrm{BS}=87 \%$; $\mathrm{PP}=1.00$ ) (Fig. 6), with five major groups corresponding roughly to the five genera Fusinus (BS $=99 \%$; $\mathrm{PP}=1.00), \quad$ Amiantofusus $\quad(\mathrm{BS}=100 \% ; \quad \mathrm{PP}=1.00), \quad$ Granulifusus ( $\mathrm{BS}=50 \% ; \quad \mathrm{PP}=1.00)$, Chryseofusus $\quad(\mathrm{BS}=100 \% ; \quad \mathrm{PP}=1.00)$ and Angulofusus (monotypic). The genus Pseudolatirus, previously assigned to Peristerniinae, is polyphyletic and nested in two of these groups. However, due to the low support and incongruence of deeper nodes, the relationships among them are not well resolved. Vermeij and Snyder (2002) suggested that fusinines are a stem-group distinguished from the other subfamilies by the absence of columellar folds. Shells of fusinine generalized morphology extend back to the early Cretaceous and probably represent the plesiomorphic shell type of Neogastropoda (Harasewych, 1990; Riedel, 2000).

The central Pacific species Cyrtulus serotinus is endemic to the Marquesas Archipelago in French Polynesia, being the only species of the genus. The shape of its shell is unique within fusinines, with a last whorl embracing the earlier whorls, accompanied by a loss of ornamentation. Grabau (1907), in his article about ontogenetic variation, noted that "no one can distinguish the young of Cyrtulus serotinus from that of any member of the Fusus series (...). Nevertheless, it remains true that Cyrtulus serotinus is a derivation of 


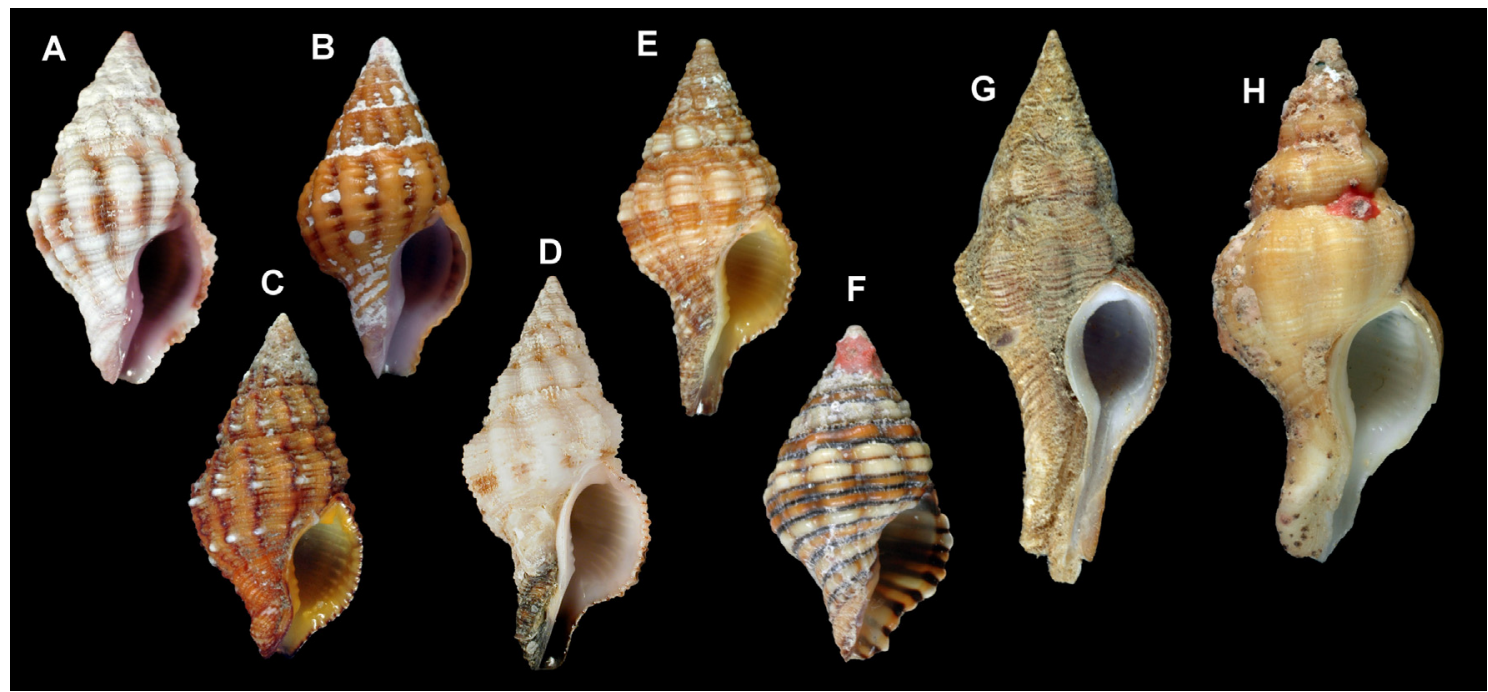

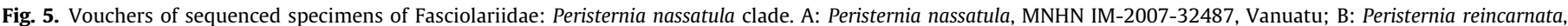

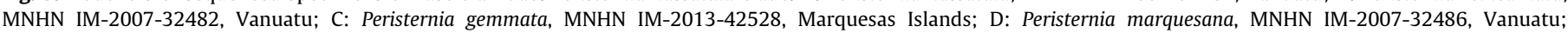

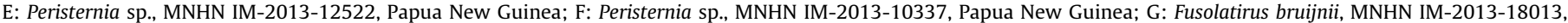
Papua New Guinea; H: Fusolatirus pachyus, MNHN IM-2007-35084, New Caledonia.

modern Fusus." It is clear that this species is a Fusinus (Fusus, sensu Grabau (1907)) if one takes a look at a growth series (Fig. 6A and B). This species, nested within Fusinus, is sister to the Philippine Fusinus longissimus ( $\mathrm{BS}=100 \%$; $\mathrm{PP}=1.00$ ). We thus agree with Grabau (1907) and consider Cyrtulus serotinus as part of the genus Fusinus, albeit highly derived.

Amiantofusus (Fig. 6E) was described to accommodate deep-water species that possess shells that are strikingly similar to Buccinidae, but with unique protoconch morphology and fasciolariid-like radula and soft-part morphology (Fraussen et al., 2007). In our analyses, the genus was strongly supported in both analyses ( $B S=100 \%$; $P P=1.00$ ), but the relationship with other Fusinininae proved controversial. In the BI analysis, Amiantofusus is sister group to Fusinus $(\mathrm{PP}=0.97)$ and this clade is in turn sister group to Chryseofusus + Pseudolatirus $(\mathrm{PP}=0.98)$; (Amiantofusus + Fusinus + Chryseofusus + Pseudolatirus) is sister group to Granulifusus + Pseudolatirus ( $\mathrm{PP}=0.57)$; and Angulofusus is a basal group to all the remaining fusinines ( $P P=0.57)$. In the $M L$ analysis, Amiantofusus is the sister genus to (Granulifusus + Pseudolatirus + Angulofusus), albeit unsupported (BS $=33 \%$ ), while this group is sister group to the remaining fusinines ( $\mathrm{BS}=44 \%$ ).

In our phylogeny, Chryseofusus (Fig. 6F), is monophyletic and highly supported $(\mathrm{BS}=100 \% ; \mathrm{PP}=1.00)$, forming a clade with the Pseudolatirus pallidus complex in both analyses ( $\mathrm{BS}=96 \%$; $\mathrm{PP}=1.00$ ).

The genus Pseudolatirus is currently classified in Peristerniinae (Snyder, 2003), however, Stahlschmidt and Fraussen (2012) noted that the type species is conchologically more similar to those of the subfamily Fusininae rather than to Peristerniinae, which is confirmed in the present study. Pseudolatirus proved nonmonophyletic in our analysis, as it forms two main clades nested within the Fusininae. The lineage of Pseudolatirus that is sister group to Chryseofusus comprises a species complex of Pseudolatirus pallidus (Fig. 6G-I); Callomon and Snyder (2009) pointed that many shells of this species differ somewhat among them (e.g., having finer and more broadly spaced axial sculpture, more slender profile), suggesting that this species, as well as others in the genus, require additional attention. Both $P$. pallidus and $P$. aff. pallidus have a different placement of the axial sculpture as noted by Callomon and Snyder (2009), and both appear together with an undescribed species (Fig. 6I). Since grouping with Chryseofusus seems an unlikely choice based on conchological characters alone, one must assume that the Pseudolatirus shell morphology is plesiomorphic, which is corroborated by the fact that this form is present in two independent clades (see below). Pseudolatirus also appears as a grade of two lineages that are basal to Granulifusus (BS $=98 \%$; $\mathrm{PP}=1.00)$ (Fig. 6J and K). Pseudolatirus discrepans is closest to Granulifusus, although this clade is poorly supported in the ML analysis ( $B S=51 \% ; P P=0.92$ ). This species has been considered a Granulifusus by several authors (e.g., Poppe, 2008), and based on our tree topology and on the sculpture of the initial whorls (which closely resembles that of many Granulifusus), we agree with the placement of Pseudolatirus discrepans in Granulifusus.

In the clade of Granulifusus + Pseudolatirus, a first split separates Pseudolatirus kuroseanus + P. kurodai from the rest, and while they share some similarities, there are very few resemblances between them and a Granulifusus-like shell. A more conservative approach is taken here, as taking any taxonomic actions herein requires additional research, including the investigation of type specimens and synonymies; however we consider Pseudolatirus to be a heterogeneous assemblage in the subfamily Fusininae.

Granulifusus is an Indo-Pacific genus, being one of the IndoPacific elements occurring in Japanese warm waters (Shuto, 1958). The genus was revised by Hadorn and Fraussen (2005), who described several new species (e.g., G. bacciballus, G. benjamini) and transferred several others to it. In our phylogeny, Granulifusus is monophyletic ( $\mathrm{BS}=51 \%$; $\mathrm{PP}=0.92$ ), a first split separates $G$. discrepans from of the remaining Granulifusus ( $B S=50 \%$; $\mathrm{PP}=0.92$ ). A second split separates Granulifusus staminatus from the rest $(\mathrm{BS}=82 \%$; $\mathrm{PP}=1.00$ ), including an undescribed species (Fig. 6L) with a canaliculated suture and reduced granulated surface; this new species is sister to G. kiranus ( $B S=100 \%$; $\mathrm{PP}=1.00$ ).

In the original description of Angulofusus nedae, the only representative of the genus Angulofusus, a superficial conchological resemblance to some Conoidea was noted by its authors (Fedosov and Kantor, 2012), notably the distinctive anal sinus. However its anatomy and radular structure placed it unambiguously in the family Fasciolariidae and Fedosov and Kantor (2012) noted that the radula, soft-part coloration and internal anatomy of Angulofusus nedae are very similar to those of species in the genus Amiantofusus; however, upon examination of its COI sequence through BLAST scores in the NCBI database, a closer relationship to Granulifusus was proposed. Indeed, in our multi-gene 


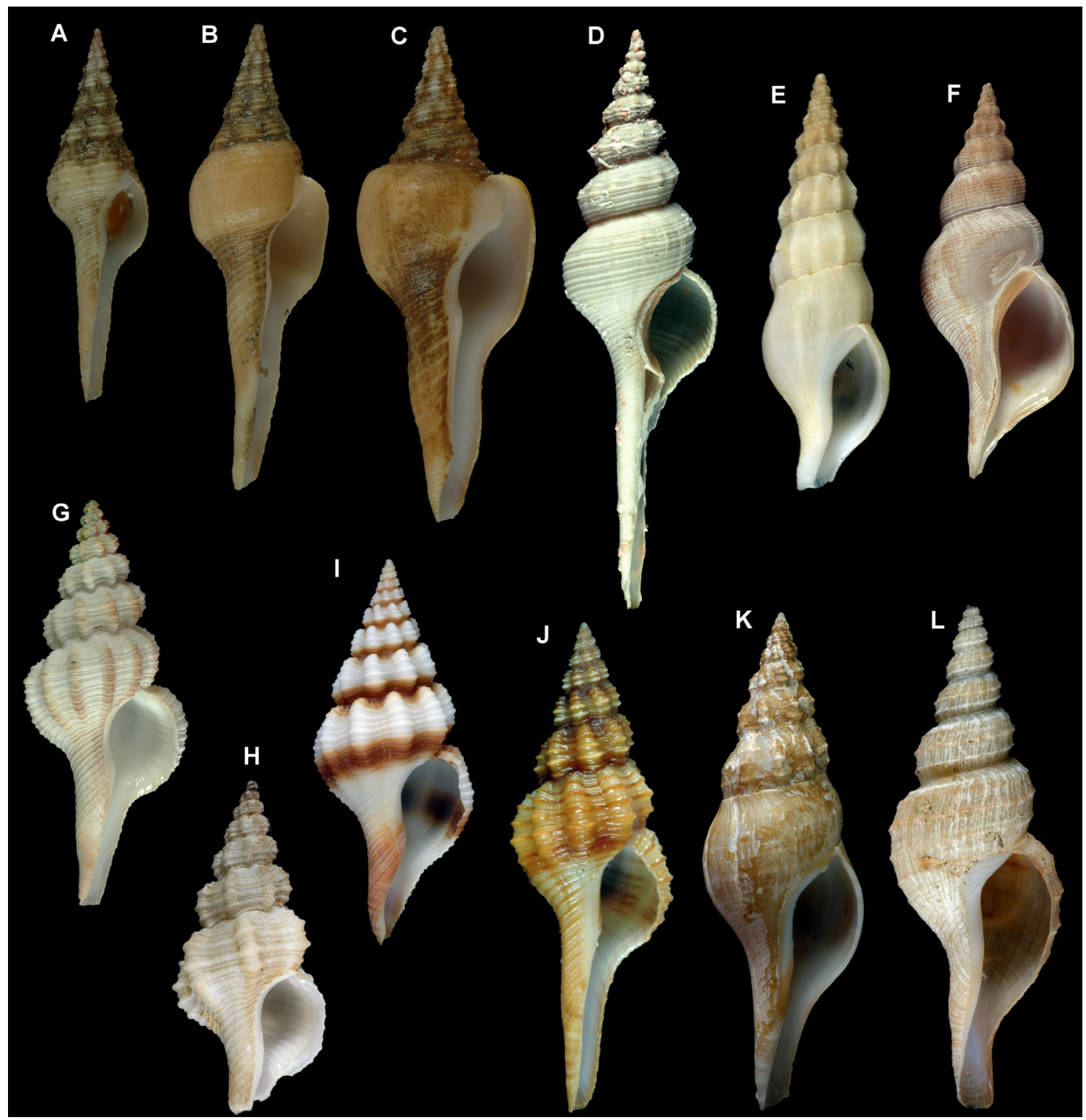

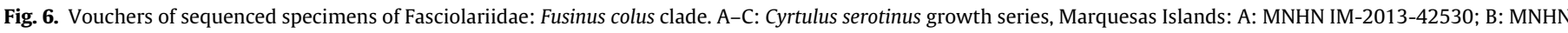

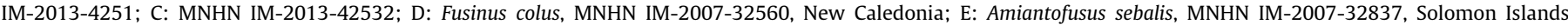

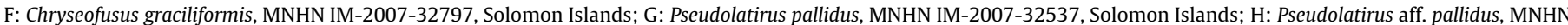

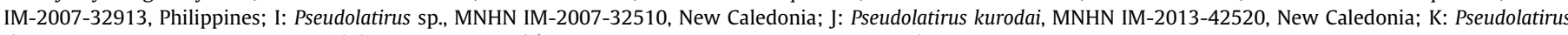
discrepans, MNHN IM-2007-34604, Philippines; L: Granulifusus sp., MNHN IM-2013-19724, Bismarck Sea.

ML analysis, Angulofusus nedae is grouped with the (Granulifusus + Pseudolatirus) clade, albeit weakly supported (BS = 66\%).

By using a dense taxon sampling and a multigene analysis of the putative members of the Fasciolariidae we were able to test the monophyly of the family and its main subclades. While the current molecular data are not able to conclude unambiguously whether the family includes or not the Dolicholatirus/Teralatirus clade, it showed reliable structure and three clades, each including the type species of the type genus of the three currently recognized subfamilies. These clades do not strictly correspond to the currently accepted taxonomy, as only Fasciolariinae is monophyletic but deeply nested within a clade of taxa hitherto classified as peristerniines. The type species of the type genus of Peristerniinae is present in another, Peristerniinae-only, clade. And, finally, Fusininae includes also members of the hitherto peristerniine genus Pseudolatirus. Our phylogenetic hypothesis thus provides a compelling new classification of the Fasciolariidae where the three current subfamilies are maintained, albeit with completely revised taxonomic extensions.

\section{Conclusions}

The clade consisting of Dolicholatirus/Teralatirus is monophyletic; however, topology tests do not reject its inclusion in Fasciolariidae or its relationship to the remaining fasciolariids. The remaining fasciolariids are monophyletic and strongly supported, and fall into three main clades that correspond to the three currently recognized subfamilies, but with their taxonomic extension considerably revised:

(1) Fusinus colus clade, containing all the Fusininae, consisting of five major lineages corresponding to the genera Amiantofusus, Angulofusus, Chryseofusus, Fusinus and Granulifusus, and also including the non-monophyletic Pseudolatirus. 
(2) Peristernia nassatula clade, consisting of the nonmonophyletic Peristernia and Fusolatirus; the name Peristerniinae can be retained for this clade.

(3) Fasciolaria tulipa clade, consisting of a monophyletic Fasciolaria-Pleuroploca clade and many other genera currently classified as peristerniines, among which the genera Latirus, Leucozonia, and Hemipolygona appeared non-monophyletic; deep nodes within this clade were unresolved or poorly supported. The taxonomic extension of the subfamily Fasciolariinae can be revised to encompass this third clade.

\section{Acknowledgements}

Most molecular material in this paper originates from numerous shore-based expeditions and deep-sea cruises, conducted respectively by MNHN and Pro-Natura International as part of the Our Planet Reviewed programme, and by MNHN and IRD as part of the Tropical Deep-Sea Benthos programme. Funders and sponsors include the French Ministry of Foreign Affairs, the Philippines Bureau of Fisheries and Aquatic Resources, the Total Foundation, Prince Albert II of Monaco Foundation, Stavros Niarchos Foundation, and Richard Lounsbery Foundation. We thank Gary Rosenberg (ANSP), Gustav Paulay (FMNH), Daniel Geiger (SBMNH), Gregory Herbert (USF) and Daniel Cavallari (MZSP) for loan of additional specimens and sending samples for this work; Virginie Héros, Philippe Maestrati, Pierre Lozouet, Barbara Buge, Laurent Charles (MNHN) and Ellen Strong (NMNH) for their role in specimen processing during the expeditions and curation; Lee Ann Galindo (MNHN) and Patricia Álvarez (UAM) provided helpful insights during the early stages of the lab work; Alexander Fedosov and Nicolas Puillandre (MNHN) for sending useful sequence information; Paul Callomon (ANSP) and William Lyons greatly helped in the identification of the sequenced specimens; Carlo Magenta (ANSP) for the valuable help during a visit to the Academy. Martin Snyder assisted with identifications and provided constructive insights to the manuscript. Rosa Fernández, Sarah Lemer, David Combosch, Erin McIntyre, Tauana Cunha, Ana Tourinho, Beka Buckham and Rafaela Jorge Trad (MCZ) helped with many aspects of bench work and analysis. Adam Baldinger (MCZ) for help in collection and management. John Slapcinsky (FMNH) sent photographic material. Two anonymous reviewers are acknowledged for their comments, which helped to improve this article. This work was funded in part by grant \#2012/14821-3, \#2013/27005-2 and \#2014/10951-5, Fundação de Amparo à Pesquisa do Estado de São Paulo (FAPESP), Brazil and by internal funds from the MCZ and the Faculty of Arts and Sciences, Harvard University.

\section{Appendix A. Supplementary material}

Supplementary data associated with this article can be found, in the online version, at http://dx.doi.org/10.1016/j.ympev.2016.03. 025 .

\section{References}

Abbott, R.T., 1958. The marine mollusks of Grand Cayman Island, British West Indies. Monogr. Acad. Nat. Sci. Philadelphia 11, 1-138.

Aktipis, S.W., Giribet, G., 2010. A phylogeny of Vetigastropoda and other "archaeogastropods": re-organizing old gastropod clades. Invertebr. Biol. 129, $220-240$.

Auwera, G.V., Chapelle, S., De Wächter, R., 1994. Structure of the large ribosomal subunit RNA of Phytophthora megasperma, and phylogeny of the Oomycetes. FEBS Lett. 338, 133-136.

Bandel, K., 1984. The radulae of Caribbean and other Mesogastropoda and Neogastropoda. Zool. Verh. 214, 1-188.

Bandel, K., 1993. Caenogastropoda during Mesozoic times. Scr. Geol. Special 2, 7-56.
Bellardi, L., 1884. I molluschi dei terreni terziarii del Piemonte e della Liguria. Parte IV. Fasciolariidae e Turbinellidae, Torino, pp. 62.

Beu, A., 2011. Marine Mollusca of isotope stages of the last 2 million years in New Zealand. Part 4. Gastropoda (Ptenoglossa, Neogastropoda, Heterobranchia). J. R. Soc. N.Z. 41, 11-53.

Bouchet, P., Rocroi, J.P., 2005. Classification and nomenclator of gastropod families. Malacologia 47, 1-397.

Bullock, R.C., 1974. A contribution to the systematics of some West Indian Latirus (Gastropoda: Fasciolariidae). Nautilus 88, 69-79.

Callomon, P., Snyder, M.A., 2009. On the genus Fusinus in Japan V: further species, an unnamed form and discussion. Venus 67 (3-4), 1-14.

Carpenter, J.M., Wheeler, W.C., 1999. Towards simultaneous analysis of morphological and molecular data in Hymenoptera. Zool. Scr. 28, 251-260.

Colgan, D., Ponder, W.F., Eggler, P.E., 2000. Gastropod evolutionary rates and phylogenetic relationships assessed using partial 28S rDNA and histone H3 sequences. Zool. Scr. 29, 29-63.

Colgan, D.J., McLauchlan, A., Wislon, G.D.F., Livingston, S., Edgecombe, G.D., Macaranas, J., Cassis, G., Gray, M.R., 1998. Molecular phylogenetics of the Arthropoda: relationships based on histone H3 and U2 snRNA DNA sequences. Aust. J. Zool. 46, 419-437.

Colgan, D.J., Ponder, W.F., Beacham, E., Macaranas, J.M., 2003. Molecular phylogenetic studies of Gastropoda based on six gene segments representing coding or non-coding and mitochondrial or nuclear DNA. Moll. Res. 23, 123-148.

Colgan, D.J., Ponder, W.F., Beacham, E., Macaranas, J., 2007. Molecular phylogenetics of Caenogastropoda (Gastropoda: Mollusca). Mol. Phylogenet. Evol. 42, 717 737.

Cossmann, M., 1901. Essais de paléoconchologie comparée, 4. The author and Société d'Éditions Scientifiques, Paris, pp. 293.

Couto, D.R., Pimenta, A.D., 2012. Comparative morphology of Leucozonia from Brazil (Neogastropoda: Buccinoidea: Fasciolariidae). Am. Malacol. Bul. 30, 103-116.

Darriba, D., Taboada, G.L., Doallo, R., Posada, D., 2012. JModelTest 2: more models, new heuristics and parallel computing. Nat. Meth. 9, 772.

Edgar, R.C., 2004. MUSCLE: multiple sequence alignment with high accuracy and high throughput. Nucl. Acids Res. 32, 1792-1797.

Edgecombe, G.D., Giribet, G., 2006. A century later - a total evidence re-evaluation of the phylogeny of scutigeromorph centipedes (Myriapoda: Chilopoda). Invertebr. Syst. 20, 503-525.

Fedosov, A.E., Kantor, Y.I., 2012. A new species and genus of enigmatic turriform Fasciolariidae from the Central Indo-Pacific (Gastropoda: Neogastropoda). Arch. Molluskenkunde 141, 137-144.

Folmer, O., Black, M., Hoeh, W., Lutz, R., Vrijenhoek, R., 1994. DNA primers for amplification of mitochondrial cytochrome $c$ oxidase subunit I from diverse metazoan invertebrates. Mol. Mar. Biol. Biotechnol. 3, 294-299.

Fraussen, K., Kantor, Y., Hadorn, R., 2007. Amiantofusus gen. nov. for Fusus amiantus Dall, 1889 (Mollusca: Gastropoda: Fasciolariidae) with description of a new and extensive Indo-West Pacific radiation. Novapex 8, 79-101.

Galindo, L.A., Puillandre, N., Strong, E.E., Bouchet, P., 2014. Using microwaves to prepare gastropod for DNA barcoding. Mol. Ecol. Res. 14, 700-705.

Geller, J., Meyer, C., Parker, M., Hawk, H., 2013. Redesign of PCR primers for mitochondrial cytochrome c oxidase subunit I for marine invertebrates and application in all-taxa biotic surveys. Mol. Ecol. Resour. 13, 851-861.

Giribet, G., Carranza, S., Baguñà, J., Riutort, M., Ribera, C., 1996. First molecular evidence for the existence of a Tardigrada + Arthropoda clade. Mol. Biol. Evol. $13,76-84$.

Giribet, G., Shear, W.A., 2010. The genus Siro Latreille, 1796 (Opiliones, Cyphophthalmi, Sironidae), in North America with a phylogenetic analysis based on molecular data and the description of four new species. Bull. Mus. Comp. Zool. 160, 1-33.

Goodheart, J., Camacho-García, Y., Padula, V., Schrödl, M., Cervera, J.L., Gosliner, T. M., Valdés, Á., 2015. Systematics and biogeography of Pleurobranchus Cuvier, 1804, sea slugs (Heterobranchia: Nudipleura: Pleurobranchidae). Zool. J. Linn. Soc. $174,322-362$.

Grabau, A.W., 1907. Studies of Gastropoda III. On orthogenetic variation in Gastropoda. Am. Nat., 607-651

Guindon, S., Gascuel, O., 2003. A simple, fast, and accurate algorithm to estimate large phylogenies by maximum likelihood. Syst. Biol. 52, 696-704.

Hadorn, R., Fraussen, K., 2005. Revision of the genus Granulifusus Kuroda \& Habe 1954, with description of some new species (Gastropoda: Prosobranchia: Fasciolariidae). Archiv für Molluskenkunde 134, 129-171.

Harasewych, M.G., 1990. Studies on bathyal and abyssal Buccinidae (Gastropoda: Neogastropoda): 1. Metula fusiformis Clench and Aguayo, 1941. Nautilus 104, $120-130$.

Harasewych, M.G., Adamkewicz, S.L., Blake, J.A., Saudek, D., Spriggs, T., Bult, C.J., 1997. Neogastropod phylogeny: a molecular perspective. J. Moll. Stud. 63, 327351.

Hayashi, S., 2005. The molecular phylogeny of the Buccinidae (Caenogastropoda: Neogastropoda) as inferred from the complete mitochondrial 16S rRNA gene sequences of selected representatives. Moll. Res. 25, 85-98.

Kantor, Y.I., Fedosov, A., 2009. Morphology and development of the valve of Leiblein: possible evidence for paraphyly of the Neogastropoda. Nautilus 123, $1-73$.

Kearse, M., Moir, R., Wilson, A., Stones-Havas, S., Cheung, M., Sturrock, S., Buxton, S., Cooper, A., Stones-Havas, S., Duran, C., Thierer, S., Ashton, B., Meintjes, P., Drummond, A., 2012. Geneious Basic: an integrated and extendable desktop software platform for the organization and analysis of sequence data. Bioinformatics 28, 1647-1649. 
Kishino, H., Hasegawa, M., 1989. Evaluation of the maximum likelihood estimate of the evolutionary tree topologies from DNA sequence data, and the branching order in Hominoidea. J. Mol. Evol. 29, 170-179.

Kocot, K.M., Cannon, J.T., Todt, C., Citarella, M.R., Kohn, A.B., Meyer, A., Santos, S.R., Schander, C., Moroz, L.L., Lieb, A., Halanych, K.M., 2011. Phylogenomics reveals deep molluscan relationships. Nature 477, 452-456.

Kosyan, A.R., Modica, M.V., Oliverio, M., 2009. The anatomy and relationships of Troschelia (Neogastropoda, Buccinidae): new evidence for a closer fasciolariidbuccinid relationship? Nautilus 123, 95-105.

Leal, J.H., 1991. Marine Prosobranch Gastropods from Oceanic Islands Off Brazil: Species Composition and Biogeography. Universal Book Services/W, Backhuys, pp. 418.

Lyons, W.G., 1991. Post-Miocene species of Latirus Montfort, 1810 (Mollusca: Fasciolariidae) of southern Florida, with a review of regional marine biostratigraphy. Bull. Fla. Mus. Nat. Hist. (Biol. Sci.) 34, 131-208.

Lyons, W.G., Snyder, M.A., 2013. The genus Pustulatirus Vermeij and Snyder, 2006 (Gastropoda: Fasciolariidae: Peristerniinae) in the western Atlantic, with descriptions of three new species. Zootaxa 3636, 35-58.

Meyer, A., Todt, C., Mikkelsen, N., Lieb, B., 2010. Fast evolving 18S rRNA sequences from Solenogastres (Mollusca) resist standard PCR amplification and give new insights into mollusk substitution rate heterogeneity. BMC Evol. Biol. 10, 70.

Miller, M.A., Pfeiffer, W., Schwartz, T., 2010. Creating the CIPRES Science Gateway for inference of large phylogenetic trees. Gateway Computing Environments Workshop (GCE), pp. 1-8.

Nagai, M., Yoshida, A., Sato, N., 1998. Additive effects of bovine serum albumin, dithiothreitol and glycerolon PCR. Int. Union Biochem. Mol. Biol. Life 44, 157163.

Oliverio, M., Modica, M.V., 2010. Relationships of the haematophagous marine snail Colubraria (Rachiglossa: Colubrariidae), within the neogastropod phylogenetic framework. Zool. J. Linn. Soc. 158, 779-800.

Osca, D., Templado, J., Zardoya, R., 2015. Caenogastropod mitogenomics. Mol. Phylogenet. Evol. 98, 118-128.

Palumbi, S.R., 1996. Nucleic acids II: the polymerase chain reaction. Mol. Syst. 2, 205-247.

Ponder, W.F., Colgan, D.J., Healy, J.M., Nützel, A., Simone, L.R.L., Strong, E.E., 2008. Caenogastropoda. In: Ponder, W.F., Lindberg, D.R. (Eds.), Phylogeny and evolution of the Mollusca. Univ. Calif. Press, pp. 331-383.

Ponder, W.F., 1972. Notes on some Australian species and genera of the family Buccinidae (Neogastropoda). J. Malacol. Soc. Aust. 2, 249-265.

Ponder, W.F., Lindberg, D.R., 1997. Towards a phylogeny of gastropod molluscs: an analysis using morphological characters. Zool. J. L. Soc. 119, 83-265.

Poppe, G.T., 2008. Philippine Marine Mollusks: Gastropoda, Pt. 2. ConchBooks, pp. 848.

Puillandre, N., Kantor, Y.I., Sysoev, A., Couloux, A., Meyer, C., Rawlings, T., Todd, J.A., Bouchet, P., 2011. The dragon tamed? A molecular phylogeny of the Conoidea (Gastropoda). J. Moll. Stud. 77, 259-272.

Rambaut, A., Suchard, M.A., Xie, D., Drummond, A.J., 2014. Tracer v1. 6. Computer Program and Documentation Distributed by the Author, website <http://beast. bio.ed.ac.uk/Tracer> (accessed 27 July 2014).

Riedel, F., 2000. Ursprung und evolution der "höheren" Caenogastropoda. Berl. Geowiss. Abhhandl. Reihe E Paläobiol. 32, 1-240.

Ronquist, F., Teslenko, M., van der Mark, P., Ayres, D., Darling, A., Höhna, S., Larget, B., Liu, L., Suchard, M.A., Huelsenbeck, J.P., 2012. MrBayes 3.2: efficient Bayesian phylogenetic inference and model choice across a large model space. Syst. Biol. 61, 539-542.

Schwendinger, P.J., Giribet, G., 2005. The systematics of the south-east Asian genus Fangensis Rambla (Opiliones: Cyphophthalmi: Stylocellidae). Inv. Syst. 19, $297-$ 323.

Sharma, P.P., Zardus, J.D., Boyle, E.E., González, V.L., Jennings, R.M., McIntyre, E., Wheeler, W.C., Etter, R.J., Giribet, G., 2013. Into the deep: a phylogenetic approach to the bivalve subclass Protobranchia. Mol. Phylogenet. Evol. 69, 188-204.

Shimodaira, H., 2002. An approximately unbiased test of phylogenetic tree selection. Syst. Biol. 51, 492-508.

Shimodaira, H., Hasegawa, M., 1999. Multiple comparisons of log-likelihoods with applications to phylogenetic inference. Mol. Biol. Evol. 16, 1114-1116.
Shimodaira, H., Hasegawa, M., 2001. CONSEL: for assessing the confidence of phylogenetic tree selection. Bioinformatics 17, 1246-1247.

Shuto, T., 1958. Granulifusus from the Miyazaki Group. Trans. Proc. Palaeont. Soc. Japan NS 31, 253-264.

Simone, L.R.L. Cavallari, D.C., Abbate, D. 2013. Revision of the genus Teralatirus Coomans 1965 in the Western Atlantic, with an anatomical description of $T$. roboreus (Reeve 1845) (Gastropoda: Neogastropoda: Fasciolariidae). Arch. Molluskenkunde 142, 215-226.

Smith, S.A., Wilson, N.G., Goetz, F.E., Feehery, C., Andrade, S.C., Rouse, G.W., Giribet G., Dunn, C.W., 2011. Resolving the evolutionary relationships of molluscs with phylogenomic tools. Nature 480, 364-367.

Snyder, M.A., 2003. Catalogue of the marine gastropod family Fasciolariidae. Acad. Nat. Sci. Philadelphia, 431.

Snyder, M.A., Bouchet, P., 2006. New species and new records of deep-water Fusolatirus (Neogastropoda: Fasciolariidae) from the West Pacific. J. Conchol. 39, $1-12$.

Snyder, M.A., Vermeij, G.J., Lyons, W.G., 2012. The genera and biogeography of Fasciolariinae (Gastropoda, Neogastropoda, Fasciolariidae). Basteria 76, 31-70.

Stahlschmidt, P., Fraussen, K., 2012. Crassibougia, a new genus for Fusus clausicaudatus Hinds, 1844, from South Africa, with description of a new species (Gastropoda: Fasciolariidae). Misc. Malacol. 5, 85-93.

Stamatakis, A., 2014. RAxML version 8: a tool for phylogenetic analysis and postanalysis of large phylogenies. Bioinformatics 31, 1-2.

Stamatakis, A., Hoover, P., Rougemont, J., 2008. A rapid bootstrap algorithm for the RAxML web servers. Syst. Biol. 57, 758-771.

Strong, E.E., 2003. Refining molluscan characters: morphology, character coding and a phylogeny of the Caenogastropoda. Zool. J. Linn. Soc. 137, 447-554.

Taylor, J.D., Morris, N.J., Taylor, C.N., 1980. Food specialization and the evolution of predatory prosobranch gastropods. Palaeontology 23, 375-409.

Taylor, J.D., Lewis, A., 1995. Diet and radular morphology of Peristernia and Latirolagena (Gastropoda: Fasciolariidae) from Indo-Pacific coral reefs. J. Nat. Hist. 29, 1143-1154.

Tëmkin, I., 2010. Molecular phylogeny of pearl oysters and their relatives (Mollusca, Bivalvia, Pterioidea). BMC Evol. Biol. 10, 342.

Thiele, J., 1929-1935. Handbuch der Systematischen Weichtierkunde. Gustav Fischer, Jena, pp. 1134.

Tracey, S., Todd, J.A., Erwin, D.H., 1993. Mollusca: gastropoda. In: Benton, M.J. (Ed.), The Fossil Record, vol. 2. Chapman \& Hall, London, pp. 845.

Vermeij, G.J., 1997. The genus Leucozonia (Gastropoda: Fasciolariidae) in the Neogene of tropical America. Tulane Stud. Geol. Paleont. 29, 129-134.

Vermeij, G.J., 2001. Innovation and evolution at the edge: origins and fates of gastropods with a labral tooth. Biol. J. Linn. Soc. 72, 461-508.

Vermeij, G.J., Snyder, M.A., 1998. Leucozonia ponderosa, a new fasciolariid gastropod from Brazil. Nautilus 112, 117-119.

Vermeij, G.J., Snyder, M.A., 2002. Leucozonia and related genera of fasciolariid gastropods: shell-based taxonomy and relationships. Proc. Acad. Nat. Sci. Philadelphia 152, 23-44.

Vermeij, G.J., Snyder, M.A., 2006. Shell characters and taxonomy of Latirus and related fasciolariid groups. J. Moll. Stud. 72, 413-424.

Wenz, W., 1938-1944. Teil 1: Allgemeiner Teil und Prosobranchia. In: Schindewolf, O.H. (Ed.), Handbuch der Paläozoologie, Band 6, Gastropoda. Borntraeger, Berlin, pp. 1639.

Whiting, M.F., Carpenter, J.C., Wheeler, Q.D., Wheeler, W.C., 1997. The Strepsiptera problem: phylogeny of the holometabolous insect orders inferred from $18 \mathrm{~S}$ and 28S ribosomal DNA sequences and morphology. Syst. Biol. 46, 1-68.

WoRMS, 2016. World Register of Marine Species. <http://www.marinespecies.org/> (accessed 17 February 2016).

Zapata, F., Wilson, N.G., Howison, M., Andrade, S.C., Jörger, K.M., Schrödl, M., Goetz, F.E., Giribet, G., Dunn, C.W., 2014. Phylogenomic analyses of deep gastropod relationships reject Orthogastropoda. Proc. R. Soc. Lond. B Biol. Sci. 281, 1-9.

Zou, S., Li, Q., Kong, L., 2011. Additional gene data and increased sampling give new insights into the phylogenetic relationships of Neogastropoda, within the caenogastropod phylogenetic framework. Mol. Phylogenet. Evol. 61, 425-435. 